\title{
Geology of the Sirius Group at Mount Feather and Table Mountain, South Victoria Land, Antarctica.
}

\author{
Nerida Lynn Bleakley
}

Submitted in fulfilment for the degree of Master of Science

Victoria University of Wellington

Wellington

New Zealand

1996 


\section{Frontispiece}

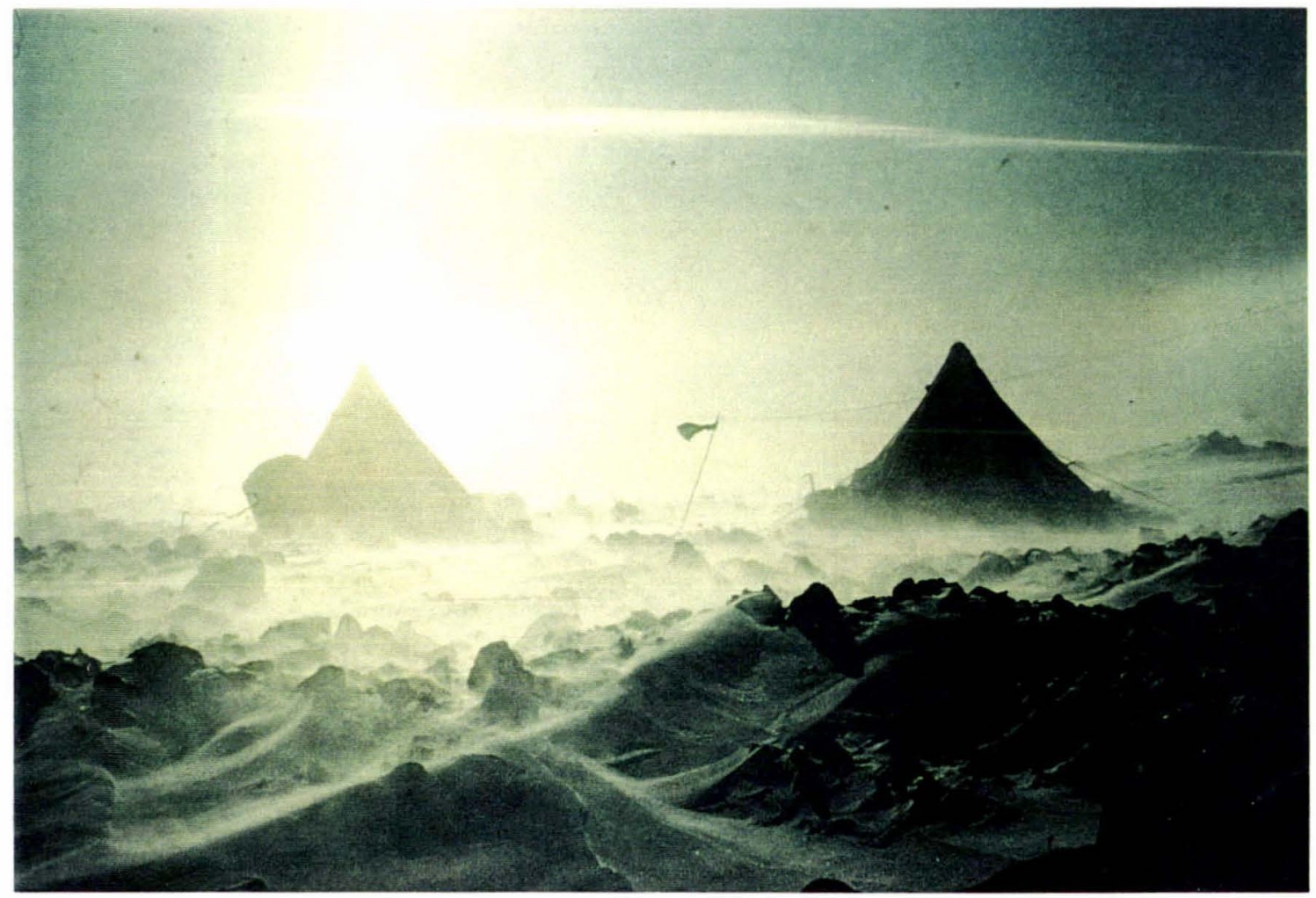

Our tents in an Antarctic storm on the platform at Mount Feather, wind gusts of $26 \mathrm{~m} / \mathrm{s}$ were recorded just before this photo was taken. At Mount Feather, when weather is nice, its very very nice, but when its bad......its horrible. Winds such as these could easily carry dried diatoms great distances in Antarctica. 


\section{Abstract}

The Sirius Group comprises of wet based glacial and related deposits found at high elevations throughout the Transantarctic Mountains. The discovery of marine Pliocene diatoms from within glacial till by Harwood (1983) led Webb et al. (1984) to propose that they were sourced from diatom bearing sediment eroded by glaciers from middle Pliocene marine basins inland of the Transantarctic Mountains. Others consider that temperatures during middle Pliocene times were not high enough to melt back the Antarctic ice sheet and expose these inland basins. They support the long held view of a stable Antarctic ice sheet since middle Miocene times, and insist that the Sirius Group is much older, explaining the diatoms as wind blown.

This study was undertaken in order to determine whether the diatoms were incorporated into Sirius Group tills during or after their deposition. Sites were sampled at Mount Feather and Table Mountain in South Victoria Land. The distribution of diatoms through the upper $37 \mathrm{~cm}$ of the till were documented. Samples were also taken in snow and from other non Sirius Group surfaces (regolith) for comparison purposes.

The geomorphic setting of the Sirius Group tills at Mt. Feather and Table Mountain suggests that their deposition predated the deep valleys that now run through the Transantarctic Mountains.

Diatom abundances from within the tills are low (averaging about 1 diatom diatom per gram) and highly variable from site to site. Initially 184 diatoms were recovered from 10 samples at Mt. Feather and less than 7 diatoms were found from 4 samples of till at Table Mountain. At Mount Feather diatoms are concentrated in the surface few centimetres of the till and numbers generally decrease with depth. The pore size within the tills is highly variable but is on average ten times the size of the average diatom (10-15 microns) from within the deposits, allowing at least some diatoms to work their way into the tills from the surface.

Diatoms from the snow and regolith from other rock surfaces have a similar diatom assemblage to the Sirius tills, containing many of the same common forms. Some non Sirius Group regolith samples have much larger 
concentrations of diatoms suggesting they have a much better trapping ability than the Sirius Group tills.

These data indicate that most diatoms from the Sirius Group tills have been introduced from the atmosphere and have worked their way into the till. Thus the Sirius diatoms record not Pliocene marine basins of the Antarctic interior and subsequent extensive over riding glaciation, but the atmospheric transport and collection of both modern and ancient diatom bearing dust from within and beyond the continent.

The Sirius Group tills do however have a phytolith (siliceous clasts from the cells of plant tissue) flora of glaciogenic origin, indicated by the lack of a vertical trend in abundance and very low levels of phytoliths in nearby snow and regolith samples. 


\section{Acknowledgements}

So much thanks to my supervisors Professor Peter Barrett and Dr. Mike Hannah for all their support and input into absolutely everything! Especially for helping me to take a step back and have a look at the whole picture when I was bogged down in the detail, the slides, the sediment, the data and......the lack of diatoms.

Also thanks to Dr. Margaret Harper all her suggestions, assistance and input throughout the time; Dr. David Harwood for his advice on processing methods, assistance in some diatom identification and thought provoking questions; And Dr. Lloyd Burckle for his processing methods and ideas.

Also thanks to the other two members of K045, Prof. David Christoffel and Adam Wooler; we were working on different areas of geology and they have learnt more than there fair share about the Sirius Group deposits and I have learnt more about paleomagnitism and the movement of the continents of Gondwana from the Devonian to the Triassic than I think I will ever need.

Thanks also to NZAP for there support in the field and to my field assistant on Mt. Feather, Rachel Brown; and the Ross Dependency Research Committee for making it all possible.

Also thanks to Dr. Warren Dickinson for his analysis of the petrography of the tills and the thought the provoking conversation; John Carter for the time he spent teaching me about phytoliths; Andrew Sutton for his space when there was really little to give and computer advise; John Rampton for his expertise with microsoft excel and inspiring conversation; Sally Rowe, Rhyl Singleton and Katrina Valentinen for their advise and assistance. And all the other members of the department who have put some input into the thesis and supported me throughout the time. Thanks to just about everyone in the Research School of Earth Sciences for their support assistance and enthusiasm.

A big thank you to my dear friends Ross Lauren and Katy Smales for proof reading the thesis and Aasha Pancha, Andrew Bridge, Katherine Lowe, Adam Wooler, Tamsin Smales, Bruce Anderson, Peter Stowell, Mathew Tetzlaf, Vanessa Bowmen, Dave Manning, Rob Christie, Steven Thornley, and the rest of the trouble makers for your friendship, advise and support, especially when it was needed the most. Also thanks to my parents, my brother Craig, Roderick Smith my boyfriend and all of my flatemates for their sense of humour, support, and their attempts to understand why we do soo much work for no income and a piece of paper. 


\section{Contents}

Frontispiece

Abstract

Acknowledgements

Contents

List of Figures

List of Tables

iv

$v$

xviii

xiiii

Chapter One: Introduction 1

1.1 Background

1.2 Aim of the study

1.3 Field work

1.4 Terminology

Chapter Two: The development of the controversy

2.1 Introduction

2.2 The Antarctic ice sheets

2.3 Pliocene warmth and high sea levels. 13

2.3.1 Global temperatures. 13

$\begin{array}{ll}2.3 .1 \text { Sea level. } & 15\end{array}$

2.4 The Sirius Group and a dynamic ice sheet. 17

2.4.1 The Sirius Formation sediments 17

2.4.2 Diatoms in the Sirius Group and the initiation of the dynamic ice sheet hypothesis.

2.4.3 Other fauna and flora from the Sirius Group.

2.4.4 High uplift rates in the Transantarctic Mountains during Pleistocene and Pliocene times?

2.4.5 Further evidence of a warm climate, high sea levels and open marine basins in East Antarctica during mid Pliocene times.

2.4.6 Evidence for a dynamic ice sheet before Late Pliocene times.

2.4.7 Discussion

2.5 Evidence for a stable Antarctic ice sheet.

2.5.1 Marine evidence

$\begin{array}{ll}2.5 .2 \text { Geomorphic evidence } & 27\end{array}$

$\begin{array}{ll}\text { 2.5.3 Sedimentology of the Sirius Group } & 29 \\ 2.5 .4 \text { Ice Sheet modelling and reconstruction } & 30\end{array}$

2.6 The wind blown diatom hypothesis 
3.1 Introduction

3.2 Sirius Group on Mount Feather 34

3.2.1 Bedrock beneath the Sirius Group tills 34

3.2.2 Distribution of the till 34

3.2.3 Lithology 41

3.2.4 Depositional environment 52

3.3 Sirius Group on Table Mountain 55

3.2.1 Bedrock beneath the Sirius Group tills 55

3.2.2 Distribution of the till 55

3.3.3 Lithology of the till $\quad 60$

3.3.4 Depositional environment 67

Chapter Four: Diatoms of the Sirius Group and adjacent material $\quad 70$

4.1 Introduction $\quad 70$

4.2 Method 71

4.2.1 Sampling method $\quad 71$

4.2.2 Diatom extraction technique 72

4.3 Diatoms from the Sirius Group till 76

4.3.1 Introduction $\quad 76$

4.3.2 Mt. Feather 77

4.3.3 Table Mountain $\quad 82$

4.4 Diatoms from the regolith 83

4.4.1 Mt. Feather 83

4.4.2 Table Mountain $\quad 84$

4.4.3 Mt. Crean 84

4.5 Diatoms from the snow 86

4.5.1 Mt. Feather 86

4.5.2 Table Mountain $\quad 86$

4.5.3 Mt. Crean 87

4.6 Diatoms in sea cliff tillites from the South Island, New Zealand. 88

4.7 Diatoms from cracks in Antarctic rocks from the rock store 89

4.8 Summary and conclusion 90

Chapter Five: The age of the Diatoms and the age of the Sirius Group 92

5.1 The original estimated age(s) of Sirius Group deposits using sedimentology and stratigraphy. 92

5.2 Diatoms of the Sirius Group and their age implications 93

5.3 Comparison of diatom species found in the Sirius Group and from other substrates.

5.3.1 Comparison of those species found in the regolith samples.

5.3.2 Comparison of species found in snow and ice cores $\quad 97$

5.4 Diatoms from the surface of the tills and diatoms found at depth. 
5.5 Discussion.

5.6 The age of the Sirius Group tills.

Chapter Six: Phytoliths and other microfossils in the Sirius Group and adjacent material.

6.1 Introduction.

6.2 Terrestrial microfossils in the Sirius Group. 101

6.2.1 Phytoliths. 101

6.2.2 Spores and pollen. $\quad 110$

6.2.3 Other plant material. $\quad 110$

6.2.3 Acritarchs. 110

6.3 Marine microfossils (other than diatoms) in the Sirius Group. 110

Chapter Seven: Summary and future work. 112

7.1 Summary. 112

7.1.1 Diatom distribution. 112

7.1.2 Phytolith distribution. 113

7.1.3 Sediment analysis of the Sirius Group tills at Mt.

Feather and Table Mountain. 113

7.2 The age of the Sirius group at Table mountain and Mt. Feather. 115

7.3 Source and origin of the diatoms in the Sirius Group tills. 115

7.3.1 Transport processes. 115

7.3.2 Diatom source. 116

7.4 Antarctica in the Pliocene. 118

7.5 Future analysis. 118

$\begin{array}{ll}\text { References } & 119\end{array}$

$\begin{array}{ll}\text { Appendix } & 140\end{array}$

Appendix One - List of samples. 141

Appendix Two - Grain size analysis. $\quad 145$

Appendix Three - Porosity and composition of gravel, sand, and clay. 165

Appendix Four - Measurements of clast shape and fabric and glacial striae.172

Appendix Five - Processing method for the concentration of biogenic silica.

Appendix Six - Diatom data and analysis. 200

Appendix Seven - Phytolith tables, diagrams and analysis. 256 


\section{List of Figures}

Chapter One

Figure 1.1 Location map of Antarctica showing the study region.

Figure 1.2 Regional map showing the mountain locations in this study.

Figure 1.3 Taking measurements on the till at Table Mountain.

Figure 1.4 Taking samples from Site Two at Mt. Feather.

Figure 1.5 Filtering melted snow from site two in the tent at Table Mountain.

Figure 1.6 Shows limited visibility on Table Mountain, we are standing on the ridge of Sirius Group sediments.

Chapter Two

Figure 2.1 The present-day Antarctic ice sheet.

Figure 2.2 Subglacial topography beneath the present day Antarctic ice sheet, without isostatic adjustments for the removal of the ice sheet.

Figure 2.2b Topography of Antarctica with the ice sheet removed and the bedrock surface isostatically adjusted.

Figure 2.3 Reconstruction of the Southern ocean 65, 53 and 21 million years ago and suggested bottom water circulation at these times.

Figure 2.4 Oxygen isotope and sea level curves from the Atlantic Ocean over the last $65 \mathrm{Ma}$.

Figure 2.5 Oxygen isotope curves for planktonic and benthic foraminifera from DSDP Sites 277,279 and 281.

Figure 2.6 Location of the Sirius Group outcrops in the Transantarctic Mountains. 
Figure 2.7A Antarctica showing the main Sirius Group sites in the Transantarctic Mountains. Ice thickness and flow lines are for the larger ice sheet required to deposit the Sirius Group debris, after Denton et al. (1991).

Figure 2.7B Cross section from the East Antarctic interior through the Transantarctic Mountains to the Ross Sea, showing the location of the Sirius Group deposits and their inferred source in the interior.

Figure 2.8 Sketch of the Antarctic ice sheet during an interval of extensive deglaciation based on sub glacial topography without isostatic adjustment.

Figure 2.9 Artist's impression of a low standing krummholz forest of Nothofagus aff. gunni.

Figure 2.10 Timing of significant events in the late Neogene glacial history of Antarctica as dated by the diatoms of the Sirius Group assuming the diatoms were incorporated at the same time as the tills were deposited.

Figure 2.11 Steady state ice sheet geometrics for temperature perturbations above present levels as indicated.

Chapter Three

Figure 3.1 Map of the Sirius Group deposits at Mount Feather

Figure 3.1a Map of the Sirius Group deposits at Mt. Feather, showing glacial flow directions and locations of photos in the thesis. 36

Figure 3.2 The Sirius Group deposits at Table Mountain

Figure 3.2a The Sirius Group deposits at Table Mountain, showing flow directions and locations of photos in the thesis.

Figure 3.3 Large clast of Feather Conglomerate and two boulders of Jurassic dolerite on the Sirius till deposited by post Sirius glacial activity.

Figure 3.4 Sirius Site Four, a patch of Sirius till on the slope of the North Ridge of Mt. Feather.

Figure 3.5 The platform at Mt. Feather over which the Sirius Group deposits drapes.

Figure 3.6 The $1000 \mathrm{~m}$ drop to the floor of Beacon Valley. 
Figure 3.7 Gravel moraine overlying and adjacent to Sirius group tills. 40

Figure 3.8 Hardness diagram of sites at Mt. Feather and Table Mountain, also showing depth of colour change and ice occurrence.

Figure 3.9 Large clast of coal in the Sirius Group till at Mt. Feather.

Figure 3.10 Plot of percent gravel, sand and mud at various depths at Site One, Mt. Feather.

Figure 3.11 Plot of the percent porosity in samples from the Sirius Group till, Mt. Feather.

Figure 3.12 Curves of (1) air dried, (2) ethylene glycol treated and (3) heated x-ray analysis of the clay fraction from Mt. Feather.

Figure 3.13 Strong fabric in the Sirus Group till at Mt. Feather.

Figure 3.14 Stereonet fabric plots from Sites One, Two and three at Mt. Feather. From measurements of the dip and dip direction of the long axis of clasts within the till. fabric shows a strong southerly paleo ice flow.

Figure 3.15 Diagrams from Boulton (1978) show the roundness and sphericity from different zones of transport in glaciers from Iceland and Spitsbergen. The location of the mean roundness vs. sphericity of the glaciers at Table Mountain and Mt. Feather are shown.

Figure 3.16 A. Topographic map of Mt. Feather showing the south east tranding glacial valley intersected by the present glacial drainage system. B. Cross section of the paleo glacial valley.

Figure 3.17 View of the Sirius Group till platform at Mt. Feather. Shows the paleoglacial valley and the flow direction of the glacier when it deposited the Sirius Group tills.

Figure 3.18 The contact between the Terra Cotta Siltstone and New Mountain Sandstone.

Figure 3.19 The largest of the patchy outcrops west of the ridge at Table Mountain. Shows the overlying gravely moraine material. 56 
Figure 3.20 Both pictures are Site Two at Table Mountain, showing the base of the till overlying the Terra Cotta Siltstone. This picture also shows the stratification of the till and the large size of some of the clasts within it.

Figure 3.21 Looking north west from Site Two at Table Mountain down the gently dipping platform to the Ferrar Glacier.

Figure 3.22 Looking north along the northern part of the ridge at table Mountain showing the snow filled hollows to the left of the ridge and the beginining of the platform dipping to the Ferrar Glacier to the right.

Figure 3.23 Sampling at Site One, Table Mountain.

Figure 3.24 Diagram of the ridge at Site One showing the location of the brown (upper) unit and the pink (lower) unit at Site One. 59

Figure 3.25 X-ray clay analysis plot from Site One on Table Mountain. 65

Figure 3.26 X-ray plot of clay analysis from Site Two at Table Mountain.65

Figure 3.27 Stereonet plots of fabric directions of the long axis of clasts in Sirius Group till at table Mountain.

Figure 3.28 Map showing paleoice flow directions at Mt. Feather and Table Mountain and at Mt. Fleming.

Chapter Four

Figure 4.1 Summary of processing method used.

Figure 4.2 a. Total number of diatoms per gram from Site One

b. Marine diatoms per gram from Site One.

c. Freshwater diatoms per gram from Site One

Figure 4.3 a. Total number of diatoms per gram from Site Two.

b. Marine diatoms per gram from Site Two.

c. Freshwater diatoms per gram from Site Two.

Figure 4.4 Total number of diatoms per gram from Site Three.

Figure 4.5 Combined distribution of diatoms with depth from all three Sirius Group sites at $M t$. Feather.
a. Total combined diatoms with depth.
b. Total marine diatoms with depth.
c. Total freshwater diatoms with depth. 
Figure 4.6 Total number of diatoms per gram from Table Mountain, Site One.

Figure 4.7 Total number of diatoms per gram from Table Mountain, Site Two.

Figure 4.8 a. Total number of diatoms per gram from the regolith at Mt. Feather, Table Mountain and Mt. Crean showing proportions of marine, freshwater and unidentified diatoms.

b. Number of marine diatoms per gram from regolith samples.

c. Number of freshwater diatoms per gram from regolith samples.

Figure 4.9 Total number of diatoms from the snow at Table Mountain, Mt. Feather and Mt. Crean.

Chapter Five

Figure 5.1 The time overlap of some of the major biostratigraphic diatom indicators found from the Sirius Group.

Chapter Six

Figure 6.1 Number of phytoliths per gram in the Sirius tills by site and depth, in regolith and from South Island till.

Figure 6.2 Percent of grass, tree and fern phytoliths from selected sites. 104

Figure 6.3 The "hole" form, one of the most common forms of phytoliths in the samples. It is nine microns. From Mt. Feather, Site One.

Figure 6.4 An elongate form of a phytolith derived from grass.

Length is $105 \mu \mathrm{m}$. From Mt. Feather, Site One.

Figure 6.5 A grass form from the Chionochloid class found in the Sirius Group till samples. Length is $22 \mu \mathrm{m}$. From Mt. Feather Site Two $0-2 \mathrm{~cm}$

Figure 6.6 Tree diagram from the Statistical Analysis System (SAS) using Ward's Minimum Variance Cluster Analysis

Figure 6.7 Staurastrum species, a freshwater acritarch, found in several samples from the Sirius Group till. Length is $110 \mu \mathrm{m}$. 


\section{List of Tables}

Chapter Three

Table 3.1 Geologic Units at Table Mountain and Mt. Feather

Table 3.2 Percent gravel, sand and mud in all the Sirius Group till samples at $\mathrm{Mt}$. Feather.

Table 3.3 Porosity and pore size in Sirius Group till samples from Mt. Feather.

Table 3.4 Clast lithology of the pebble size fraction from the Sirius Group tills at Mt. Feather and Table Mountain.

Table 3.5 Average point count percentages of the sand size fraction in thin section from the Sirius Group till at Mt. Feather and adjacent Beacon Supergroup Formations from Korsch (1974).

Table 3.6 Mean and standard deviation of the sphericity and roundness of clasts at $\mathrm{Mt}$. Feather and Table Mountain.

Table 3.7 Percent gravel, sand and mud from Sites One and Two, Table Mountain.

Table 3.8 Porosity of the Sirius Group samples from table Mountain. 63

Table 3.9 Average point count data for the sand fraction at each Sirius till site from thin section.

Chapter Four

Table 4.1 Average and maximum size of Diatoms and Phytoliths (intermediate axis) from the Sirius group at Mt. Feather.

Table 4.2 Hypothetical clast size at each level if the marine diatoms originated from diatomacous clasts at Sites One and Two, Mt. Feather.

Chapter Five

Table 5.1 Matrix comparing species in common between diatom assemblages from various workers and deposits. 
Table 5.2 Matrix comparing species in common between diatom assemblages from the regolith and surface and depth samples from the Sirius Group deposits at Mt. Feather and Mt. Fleming. 


\section{Chapter One}

\section{Introduction}

\subsection{Background}

Marine diatoms of Pliocene age have been identified from glacial debris termed the Sirius Group at several locations high in the Transantarctic Mountains. As a consequence Webb et al. (1983, 1984) and Harwood (1986) have proposed ice sheet collapse and seas in inland Antarctica during a MidPliocene warm interval. Others oppose the possibility suggesting that temperatures during the Pliocene were not high enough to reduce the size of the East Antarctic ice sheet and expose the inland basins currently beneath the ice sheet. They propose that the Sirius Group tills are much older and that the diatoms have most likely been introduced after the deposition of the tills.

\subsection{Aim of the study}

The main purpose of this study is to determine whether the diatoms found in the Sirius Group tills were carried in glacial debris from the East Antarctic interior or whether they were introduced from the atmosphere into the tills after their deposition, or whether both processes were operating. The discovery of diatoms in only surface layers of Sirius Group, on non-Sirius rock surfaces and in snow would indicate introduction after deposition, whereas occurrence of diatoms at depth and lack of diatoms on non-Sirius surfaces and in snow would indicate transport as glacial sediment.

In addition the the geology of the Sirius Group on Table Mountain and Mount Feather is briefly re-analysed and other non diatom microfossils found in the tills are documented. 


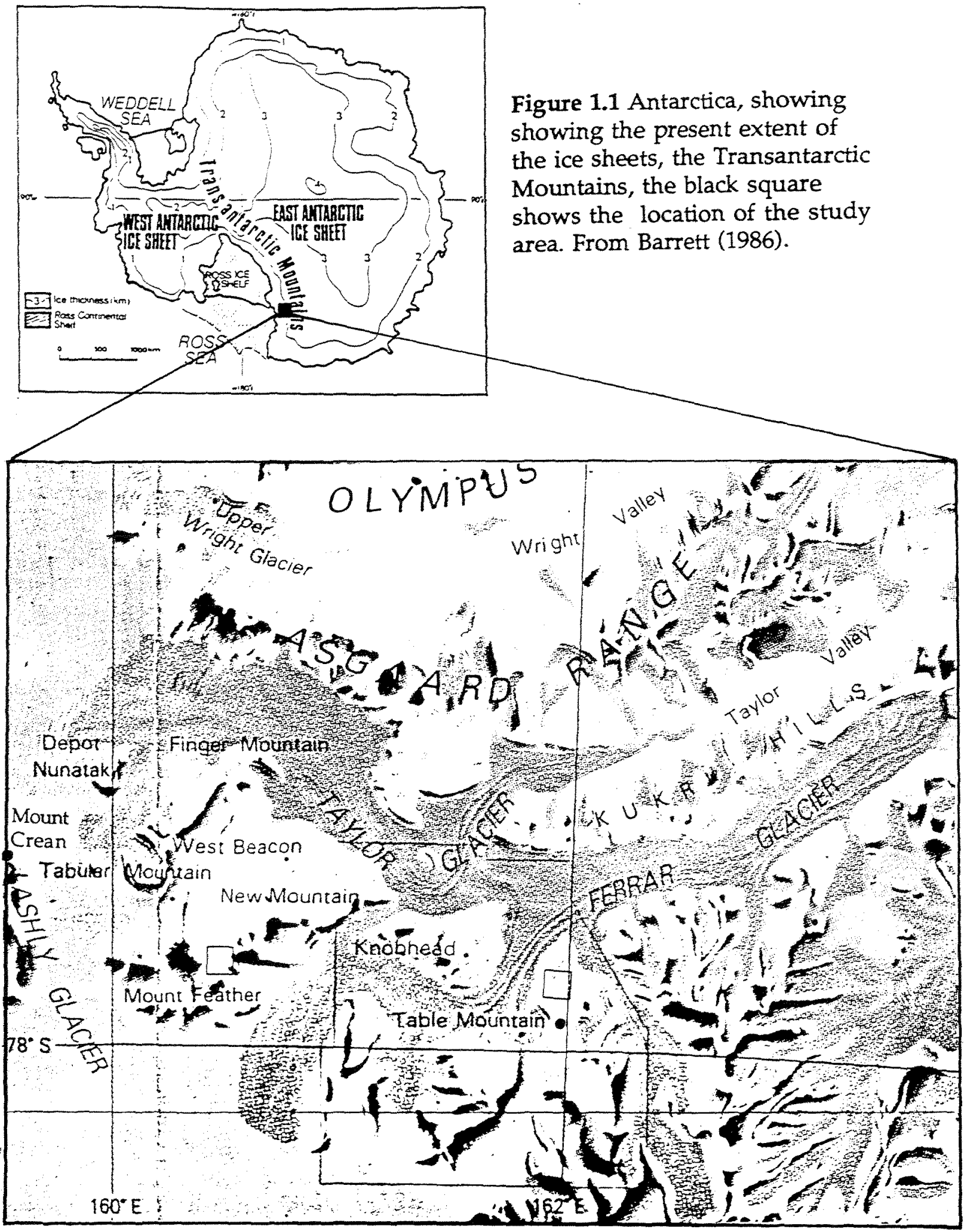

Figure 3.2 Regional map showing the mountain locations. The areas studied at Mount Feather and Table Mountain are marked with squares. 


\subsection{Field Work}

Field work was undertaken during November and December 1994 with members of the Department of Geophysics from Victoria University of Wellington who were sampling parts of the Beacon Supergroup which underlie Sirius Group sediments (fig. 3.5, table 3.1) at some locations.

Sirius Group tills at Mt. Feather and Table Mountain in South Victoria Land (figs 1.1 \& 1.2) were mapped. Clast fabric and striation measurements were taken on the tills in order to determine the flow direction of the glacier when the till was deposited (fig. 1.3). Roundness, sphericity and composition of the clasts were also noted.

Samples of Sirius Group sediment for diatom and petrographic analysis were taken at various depths into the till (fig. 1.4). Additional samples for microfossil analysis were taken of regolith from the Beacon Supergroup and from adjacent moraine sediments.

Finally snow samples were melted and filtered with a five micron sieve in the field for later analysis of diatom content in the laboratory (fig. 1.5).

\section{Table Mountain}

The camp was on the north western flank of Table Mountain on the eastern side of the Ferrar glacier at $1600 \mathrm{~m}$, grid reference $77^{\circ} 574^{\prime} \mathrm{S}, 162^{\circ} 015^{\prime} \mathrm{S}$. Temperatures were between $-22^{\circ}$ and $-27^{\circ} \mathrm{C}$. Snow and cloud limited visibility during three out of the four days of field work (fig. 1.6).

\section{Mount Feather}

Seven days were spent on an exposed platform $77^{\circ} 56^{\prime} \mathrm{S} 160^{\circ} 27^{\prime} \mathrm{E}$ at $2600 \mathrm{~m}$, on a platform north of the summit of Mt. Feather over looking the south western extent of Beacon Valley. Air temperature remained at between $-21^{\circ}$ and $-27^{\circ} \mathrm{C}$. Strong winds from the south (wind speeds of 52 knots were recorded) confined everyone to their tents for most of the first 1.5 days. 


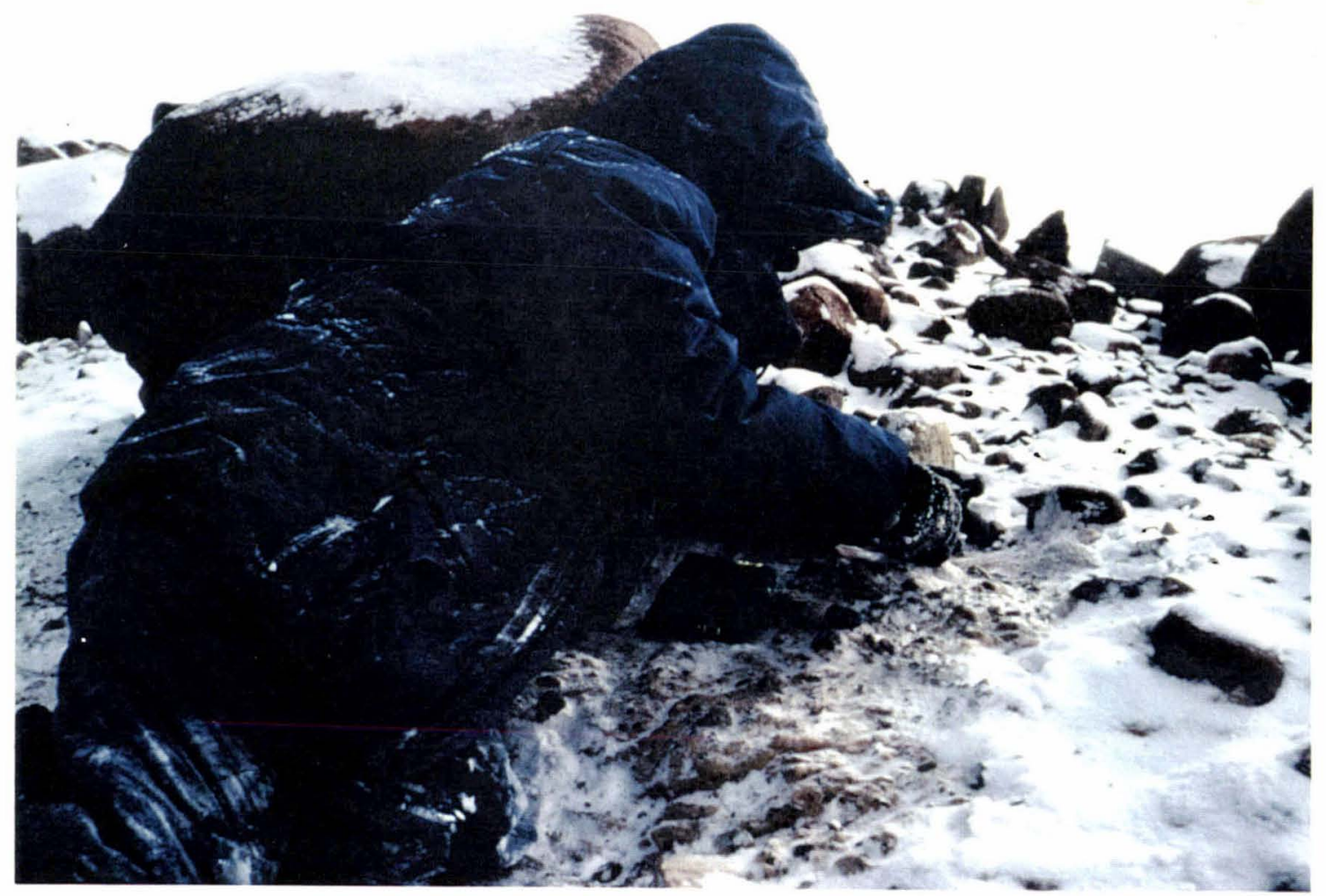

Figure 1.3 Taking fabric measurements on the snow covered till at Table Mountain. The paint brush to clear the snow was a very useful asset in the field.

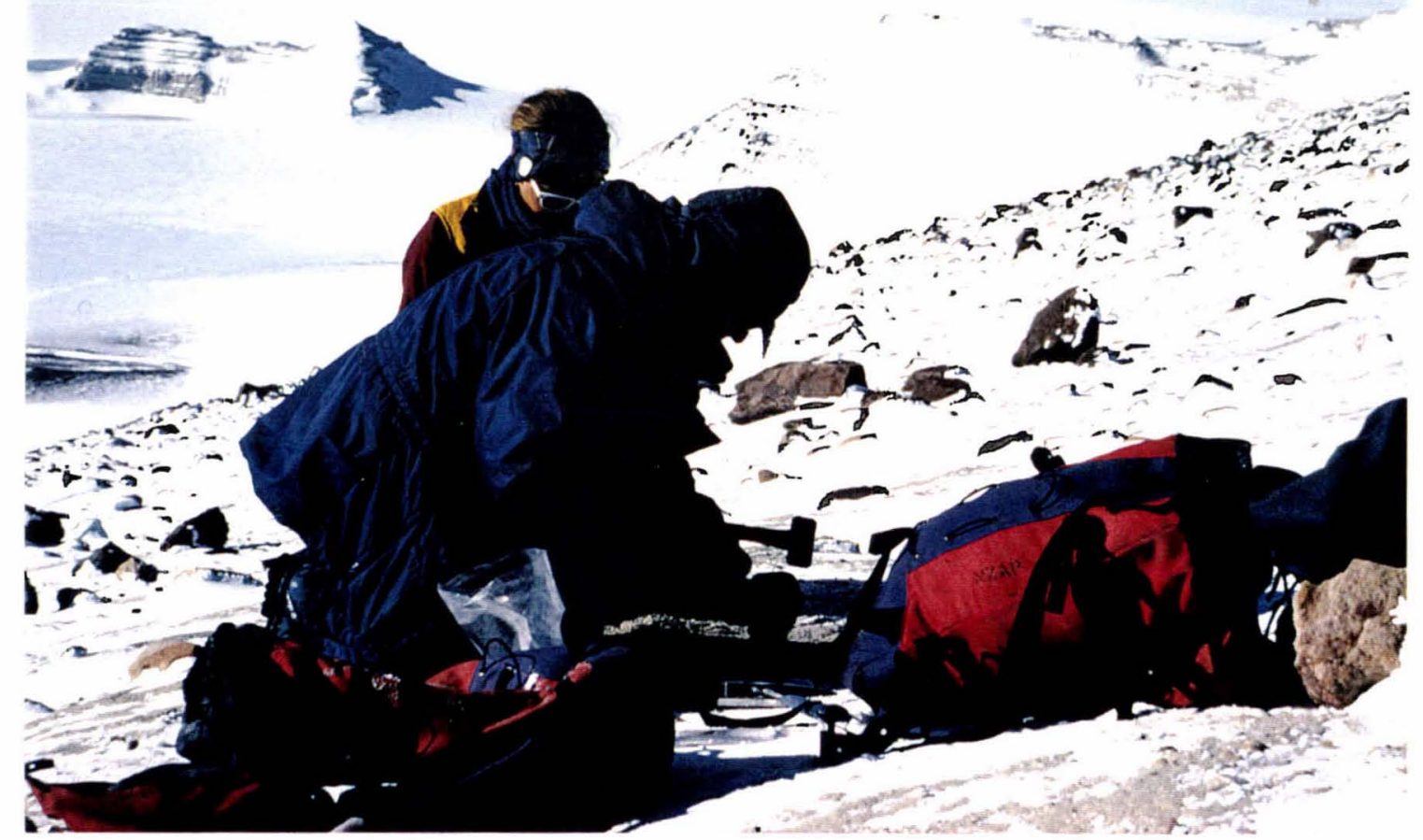

Figure 1.4 Taking samples from Site Two at Mt. Feather with a chisel and hammer. Photo looks south, Monastery Nunatak can be seen in the distance to the left of the photo. The flat platform begins $100 \mathrm{~m}$ to the right of the photo. 


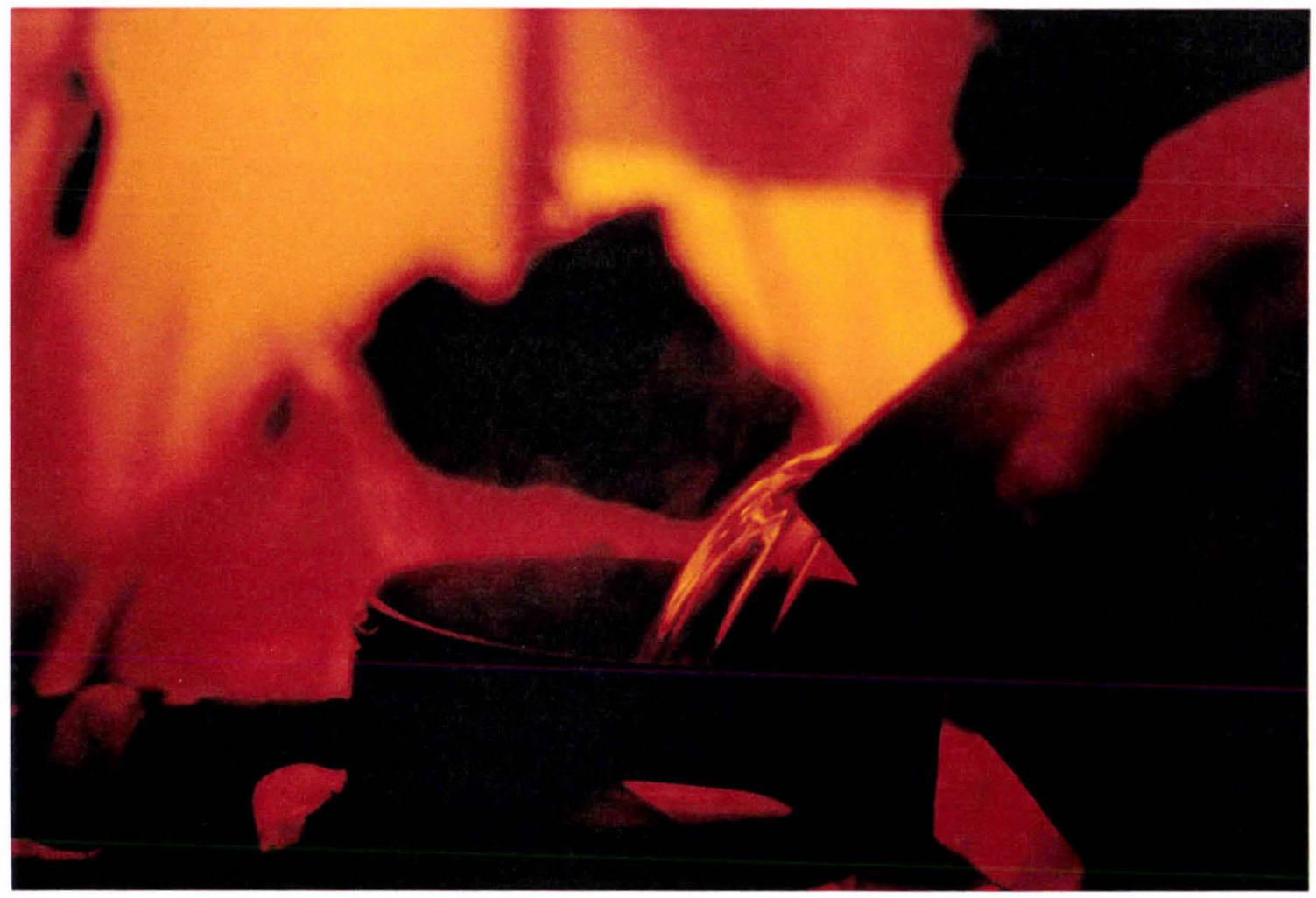

Figure 1.5 Filtering melted snow for diatoms in the tent at Table Mountain.

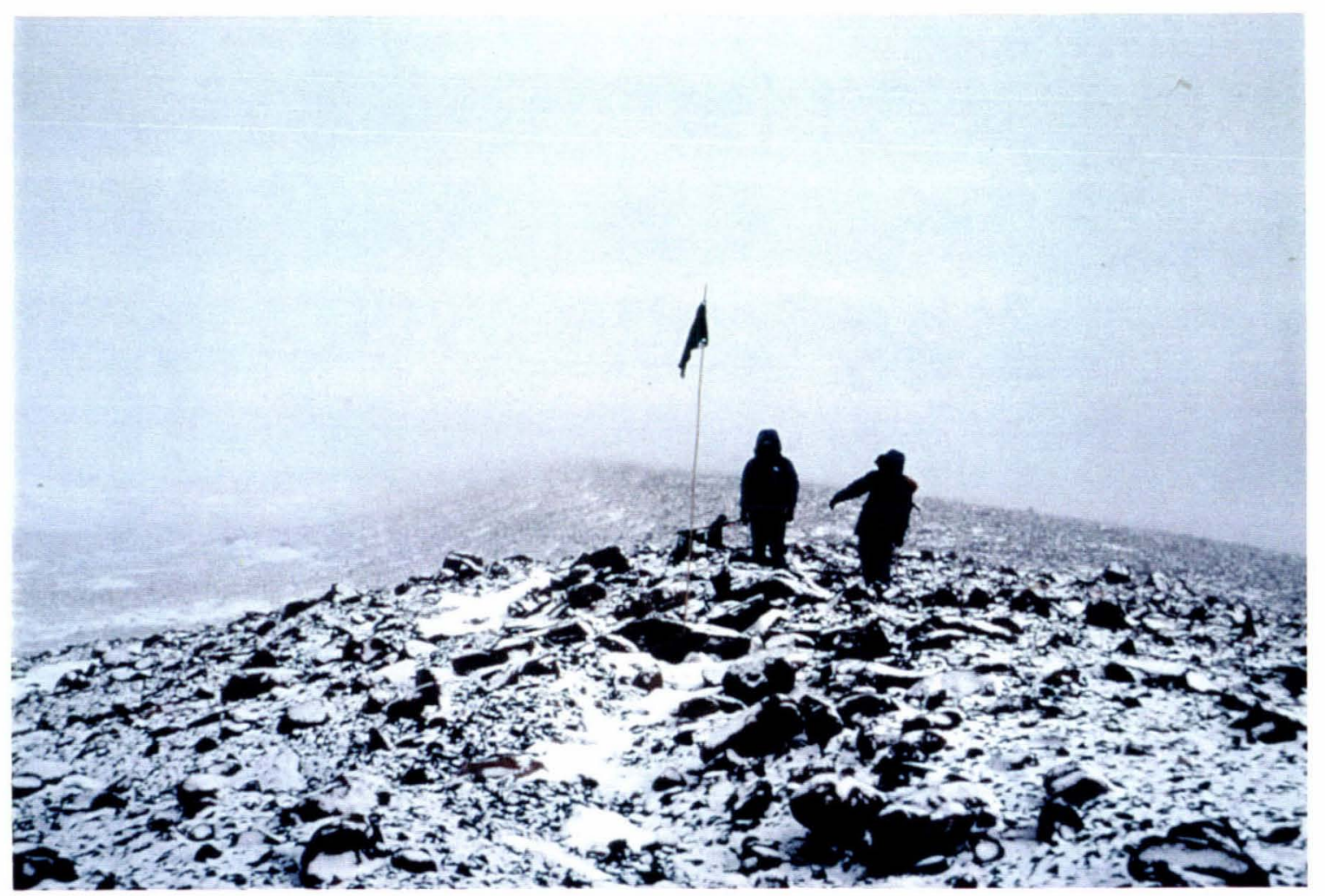

Figure 1.6 Another day of snow, another day of low visibility. Cloud lifted for this photo. Marker flags were used several times while in the field to help us relocate camp. Photo looks south along the ridge of Sirius Group till at Table Mountain. 
A further ten days were spent as a field assistant for the rest of the party on Mount Crean (fig 1.2), Portal Mountain and Mount Lashly. Further samples of regolith and snow were taken for this study at Mt. Crean.

\subsection{Terminology}

The Sirius Formation was first described by Mercer (1972) who defined it as a "compact glacial drift that unconformably covers pre-Tertiary rocks" but is older than the modern landscape. Its type section occurs at Mt. Sirius. The Sirius Formation was re-termed the Sirius Group by McKelvey et al. in 1991 with the formal recognition of two separate formations adjacent to Beadmore Glacier.

The Sirius Group at Mount Feather is non stratified material deposited directly by glacial ice, which defines a glacial till. At Table Mountain the Sirius Group occurs as a directly deposited till at some locations, but shows stratification and evidence of reworking at others. Generally it is a semilithified, unsorted mixture of muddy sandstone containing pebbles, cobbles and rare boulders which is termed a diamict (used by Barrett and Powell, 1982). The Sirius Group at both sites can be partially indurated, hence, it has also been referred to as a tillite and a diamictite in the past. In this thesis the term till is used throughout for the various lithified, unsaturated and unstratified matrix of slightly gravelly muddy sandstone that forms much of the Sirius Group. 


\section{Chapter Two}

\section{Development of the controversy}

\subsection{INTRODUCTION}

Over the last 20 years there has been increasing debate over the stability of the East Antarctic ice sheet. This debate has been further catalysed by the possibility of global warming over the next fifty to one hundred years and the effect this may have on the ice sheet (Houghton et al., 1990).

The traditional, or stabilist view has been of a stable Antarctic ice sheet that achieved its present size about fourteen million years ago (with a consequent lowering of sea level of about fifty metres), and which has varied little since that time (Kennett, 1982).

The alternative view is one of a 'dynamic' ice sheet which fluctuated in volume as it developed throughout the Neogene and in which the last major deglacial event occurred approximately three million years ago. The dynamic ice sheet hypothesis relies on the discovery of three million year old marine diatoms found in glacial deposits of the Sirius Group high in the Transantarctic Mountains. It has been argued the presence of these diatoms require the existence of marine basins inland of the Transantarctic Mountains at this time. Stabilists oppose the possibility and propose that the Sirius Group tills are much older and that the diatoms have most likely been introduced after the deposition of the tills.

\subsection{THE ANTARCTIC ICE SHEETS}

Today ice covers $97.6 \%$ of the continental Antarctic landmass (Keys, 1990). It is primarily in ice sheet form which consists of approximately $30 \times 10^{6} \mathrm{~km}^{3}$ of ice spread over an area of $13.6 \times 10^{6} \mathrm{~km}^{2}$ (Drewry et al. 1982; Drewry, 1983; Oerlemans and van der Veen, 1984 in Denton et al, 1993). In the winter the area of ice doubles with the formation of sea ice, which extends as far north as $53^{\circ} \mathrm{S}$ (Jacka, 1983 in Keys, 1990). During the spring and summer this ice reduces south, to the coast in several places. 


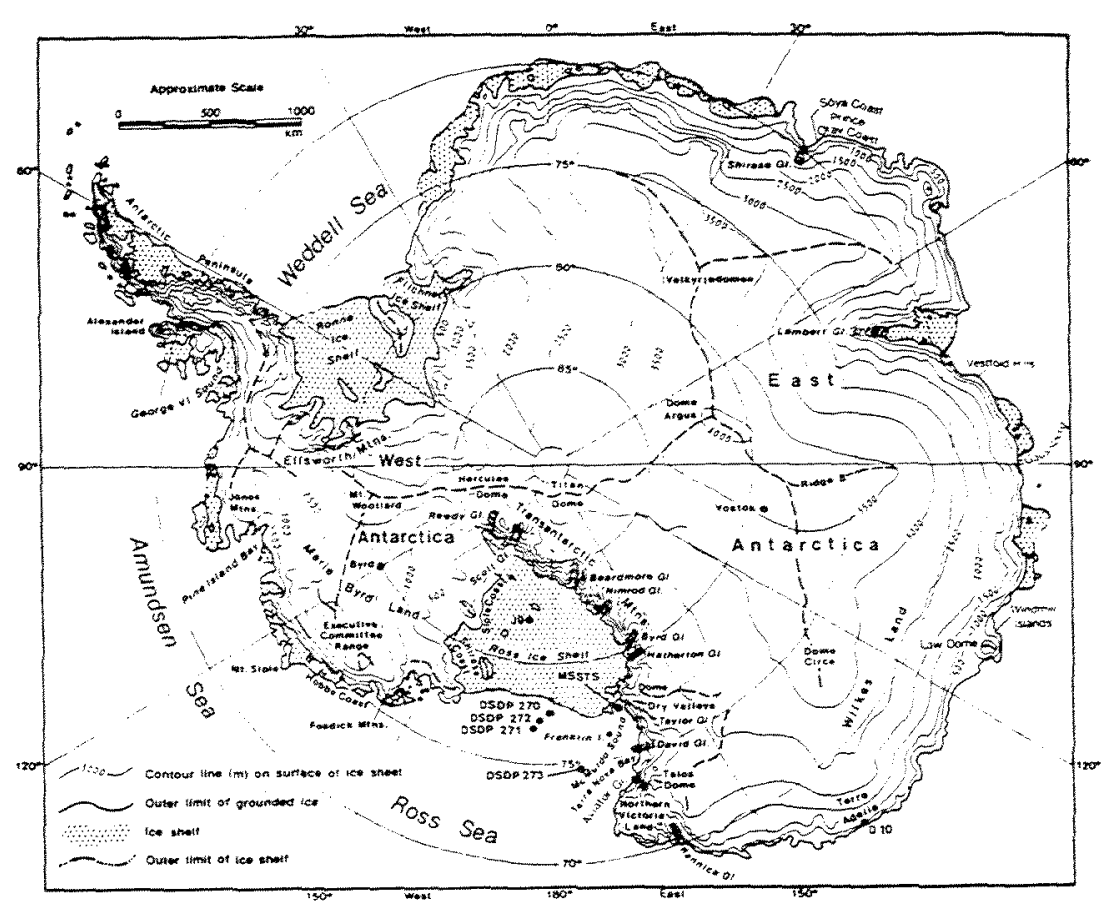

Figure 2.1 The present-day Antarctic ice sheet. From Denton et al. (1991)

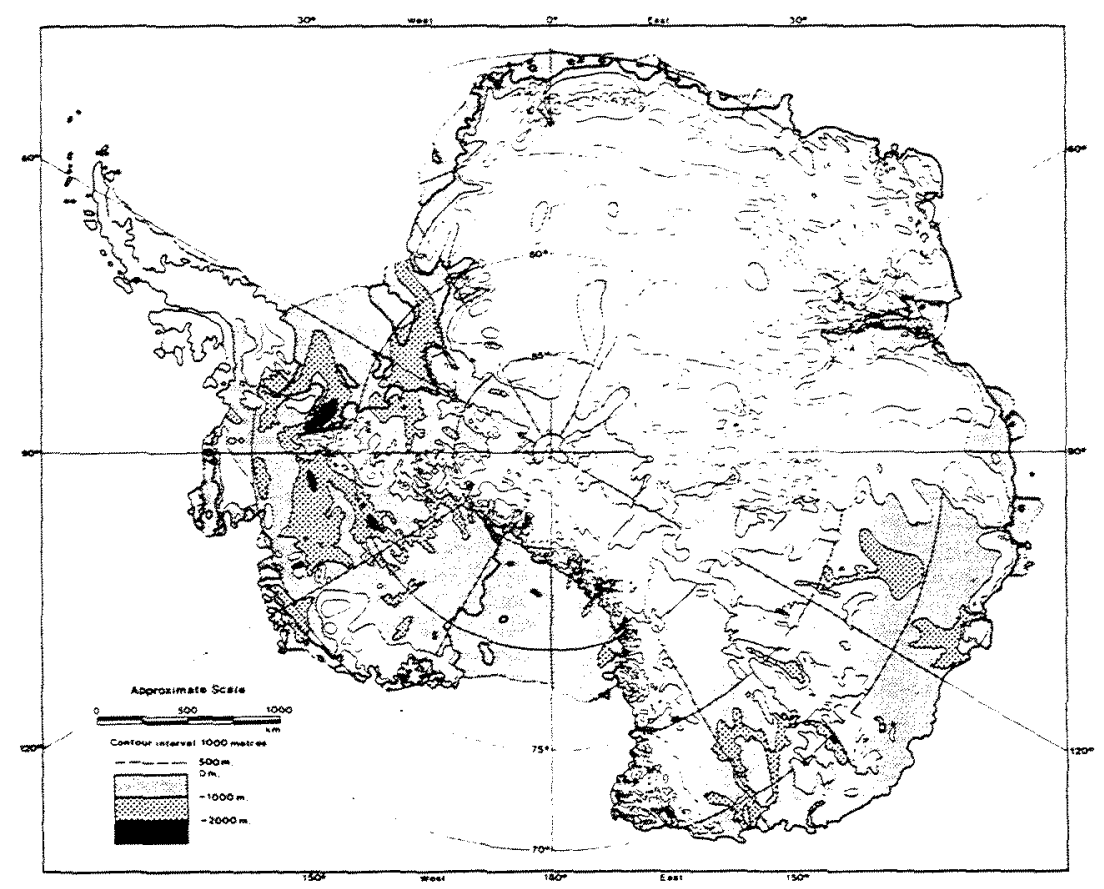

Figure 2.2 Map from Denton et al. (1993: 1991) based on Drewry (1983) of the subglacial topography beneath the present-day Antarctic ice sheet, without isostatic adjustments for the removal of the ice sheet. 


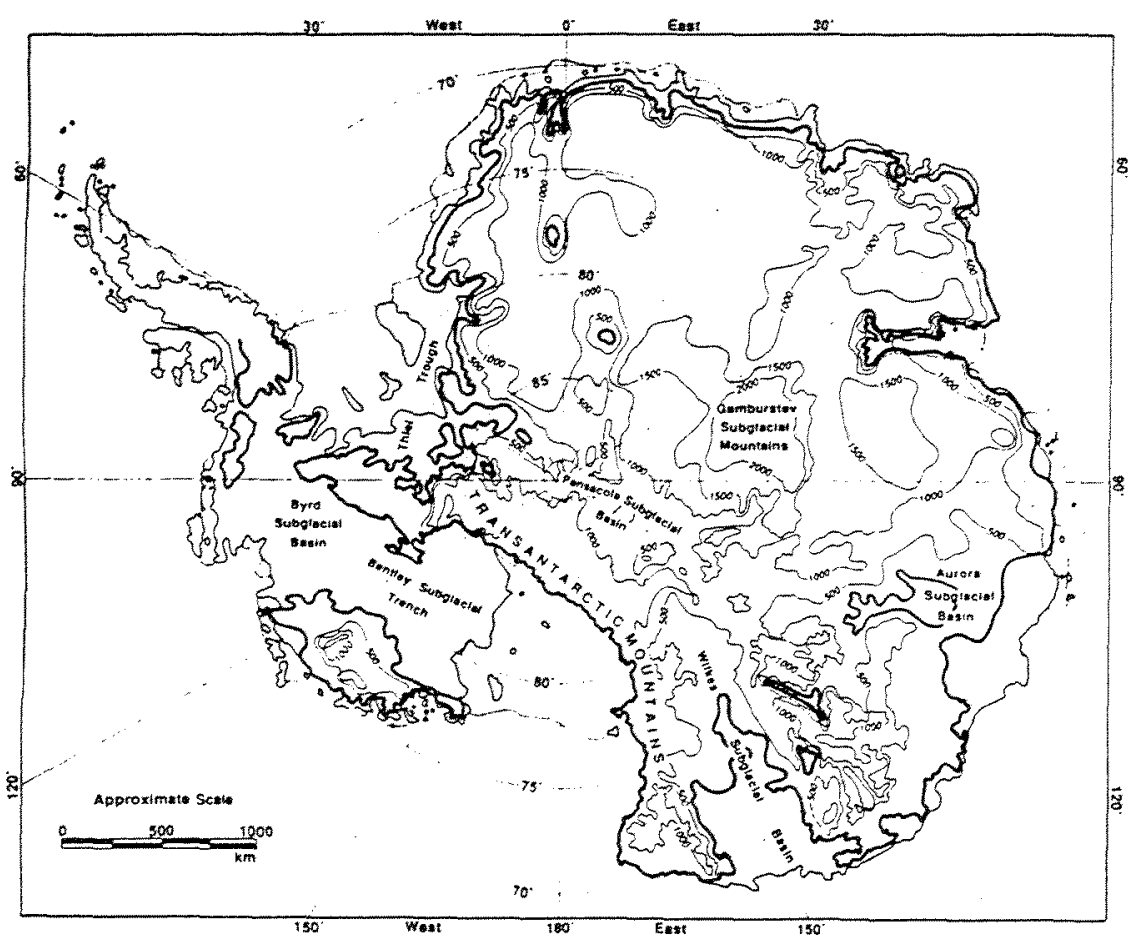

Figure 2.2b The topography of the Antarctic ice sheet removed and the bedrock surface isostatically adjusted (from Denton et al., 1993, after Drewry, 1983). Contour interval is $500 \mathrm{~m}$; bold line indicates $0 \mathrm{~m}$ contour.

Antarctica is divided by the Transantarctic Mountains into East and West Antarctica (fig. 2.1). The marine West Antarctic ice sheet is $3.3 \times 10^{6} \mathrm{~km}^{3}$ in size containing enough water to cause a sea level rise of 6 metres and is grounded below sea level. West Antarctica would most likely remain submerged if deglaciation occurred and isostatic rebound was completed (fig. 2.2b; Drewry, 1983).

The East Antarctic ice sheet is $26 \times 10^{6} \mathrm{~km}^{3}$ containing enough water to cause a sea-level rise of 60 metres is grounded above sea level (fig. 2.2, 2.2b; Denton et al. 1993). Some subglacial basins (including the Wilkes, Pensacola and Aurora basins) extend below sea level, although many would rise above sea level with isostatic adjustment if the ice sheet was removed.

Central domes of the East Antarctic ice sheet reach up to 3200-4000m (fig 2.1; Drewry, 1983). Flow of glacial ice from the central Antarctica discharges into the Filchner-Ronne ice shelf or into major outlet glaciers that pass through the Transantarctic Mountains (fig. 2.1). Coastal flow of glacial ice discharges locally by ice streams into fringing ice shelves or into the southern ocean. The two 
largest ice shelves are the Ross and the Filchner-Ronne (fig. 2.1) fed by glacial ice flowing from both the East and West Antarctic Ice Sheets (Denton et al, 1993).

Unlike the Greenland ice sheet, the Antarctic ice sheet does not now have large surface ablation zones (Denton et al., 1993). As a result it loses its mass almost entirely by basal melting beneath ice shelves and by carving of icebergs. Factors controlling area and volume of the Antarctic ice sheets are thought to include: eustatic sea level oscillations (causing grounding line advance and retreat, Denton and Hughes, 1981; Stuiver et al., 1981 in Denton et al., 1993); changes in interior accumulation (related to atmospheric temperature, Robin, 1977 in Denton et al, 1993); changes in ice shelves (related to back stress on grounded ice); and changes in ice dispersal into the surrounding ocean from ice streams (Bindshadler, 1991 in Denton et al, 1993).

When Antarctica tectonically separated from Australia the development of a circum-Antarctic current resulted in the thermal isolation of Antarctica and the development of the ice sheet (fig. 2.3, 2.4). The first evidence of glaciers reaching the sea is dated by a mid Eocene to early Oligocene microfossil assemblageas in sediments containing ice rafted detritus from the Kerguelen Plateau (Ehrmann et al., 1992). It has also been dated by a mid Eocene dinoflagellate assemblage in association with ice rafted detritus found in the CIROS-1 core from the Ross Ice Shelf (Hannah, 1994). Ehrmann et al. (1992) suggest "that it is unlikely that most of East Antarctica was glaciated at this time, and the coastal climate was probably temperate. From continental shelf and distal marine records, as well as the permanent increase in benthic foraminiferal $218 \mathrm{O}$, Erhmann et al. (1992) say that full-scale glaciation over a significant part of East Antarctica was under way by early Oligocene times (fig. $2.4,2.5)$.

Since this time the East Antarctic ice sheet is thought to have expanded gradually, reaching its present size in mid Miocene times, approximately 14 million years ago (fig. 2.4, 2.5; Shackleton and Kennett, 1975; Savin et al., 1975; Kennett, 1977; Kennett, 1982; Miller et al., 1987; Clapperton and Sugden, 1990; Sugden et al., 1993b). Whether it has stayed in roughly the same state since then and not receded at different times to the extent of exposing the inland basins to the sea is the issue of this controversy. 


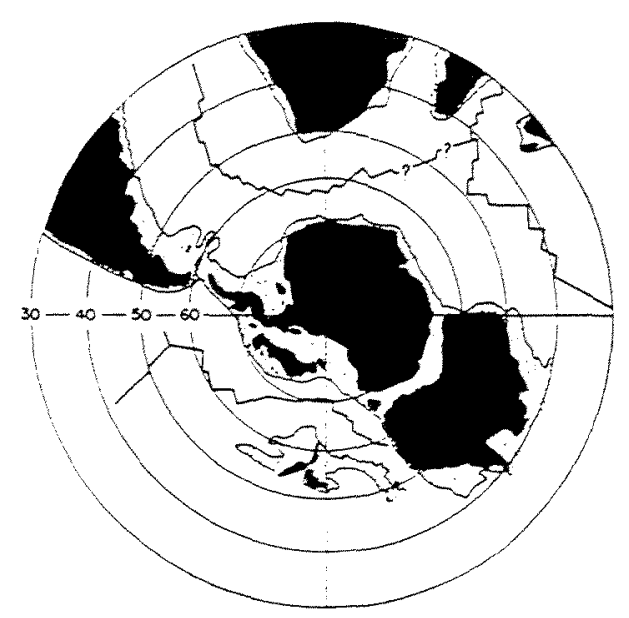

65 million years ago

Cretaceous-Tertiary boundary

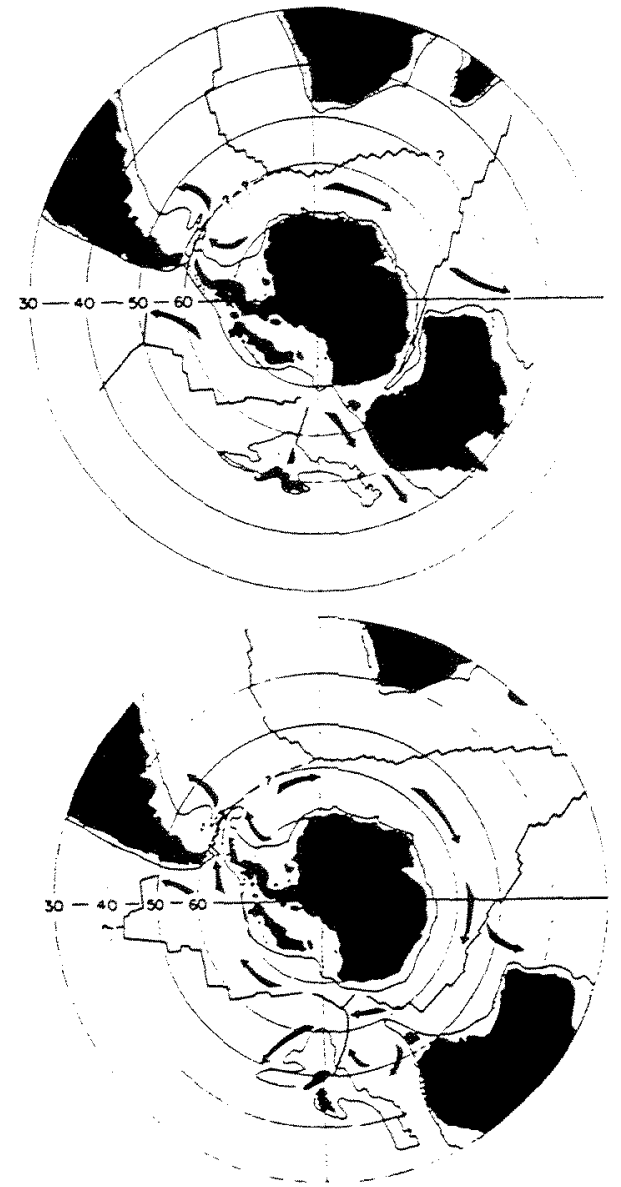

53 million years ago

Early Eocene

21 million years ago

Early Miocene

Figure 2.3 Reconstruction of the Southern Ocean 65, 53 and 21 million years ago and suggested bottom water circulation for these times as a result of the tectonic separation of the southern continents (from Kennett, 1982, after Kennett, 1978). 


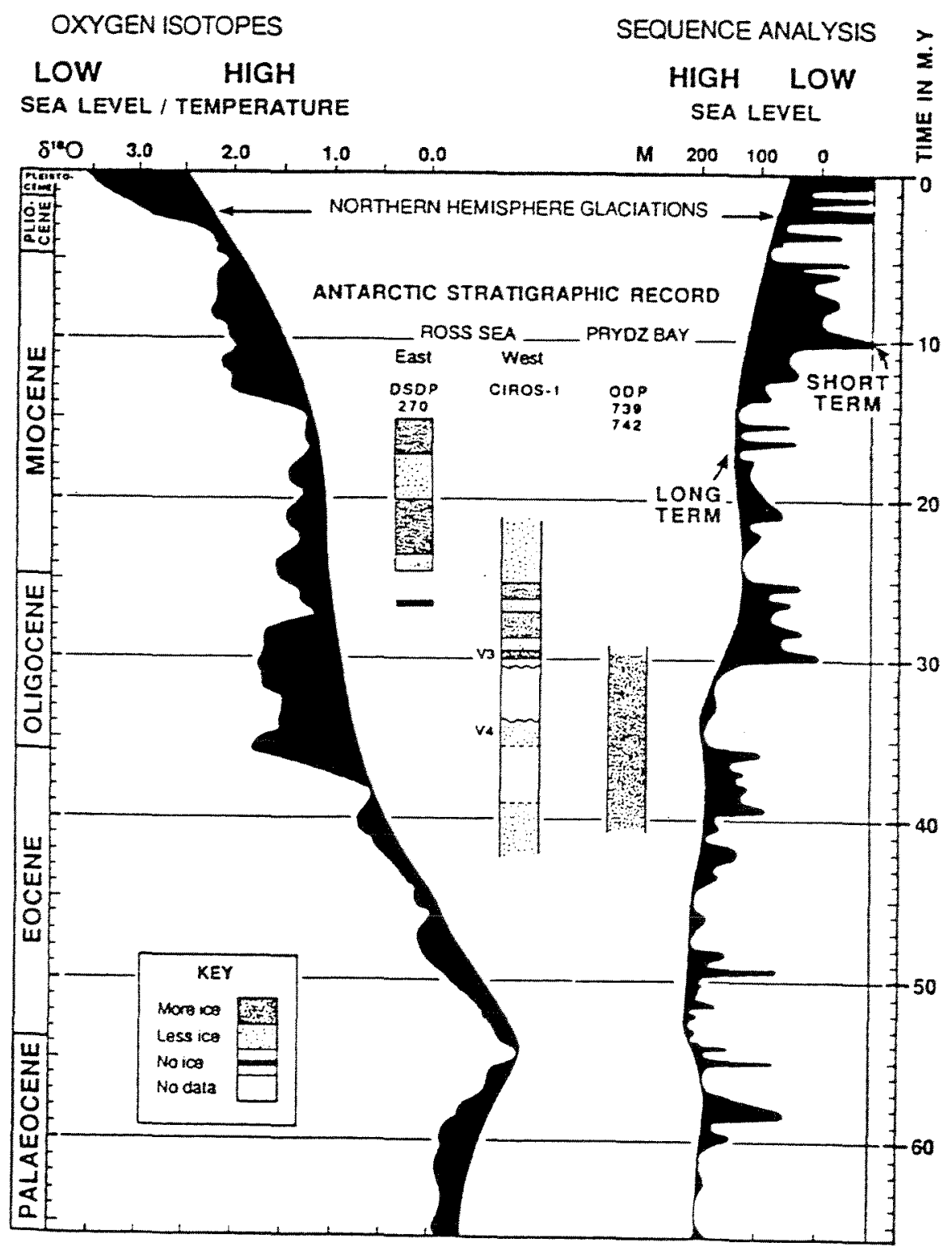

Figure 2.4 The curve on the left shows variation in the oxygen isotope ratio for deep sea benthic foraminifera from the Atlantic Ocean over the last $65 \mathrm{Ma}$ (Miller et al., 1984). Barrett (1994) says an increase of 1 per mil $\partial 18 \mathrm{O}$ is equivalent to a fall in sea level of $110 \mathrm{~m}$ in the Pleistocene or a fall in temperature of $4^{\circ} \mathrm{C}$. The curve shows major cooling/falls in sea level during latest Oligocene, Mid Miocene and late Pliocene times.

The curve on the right shows variation in global sea level from seismic sequence analysis (Haq et al., 1987), showing long term (10 7-8 years) lowering of sea level attributed to tectonism, and short term ( $10^{6}$ years) events attributed to ice volume changes. Times of high sea level can be identifed in early Oligocene, Mid Miocene and early Pliocene times.

The middle of the diagram shows time represented by strata cored on the Antarctic continental shelf. From Barrett (1994), after Barrett (1991). 


\section{OXYGEN ISOTOPES}

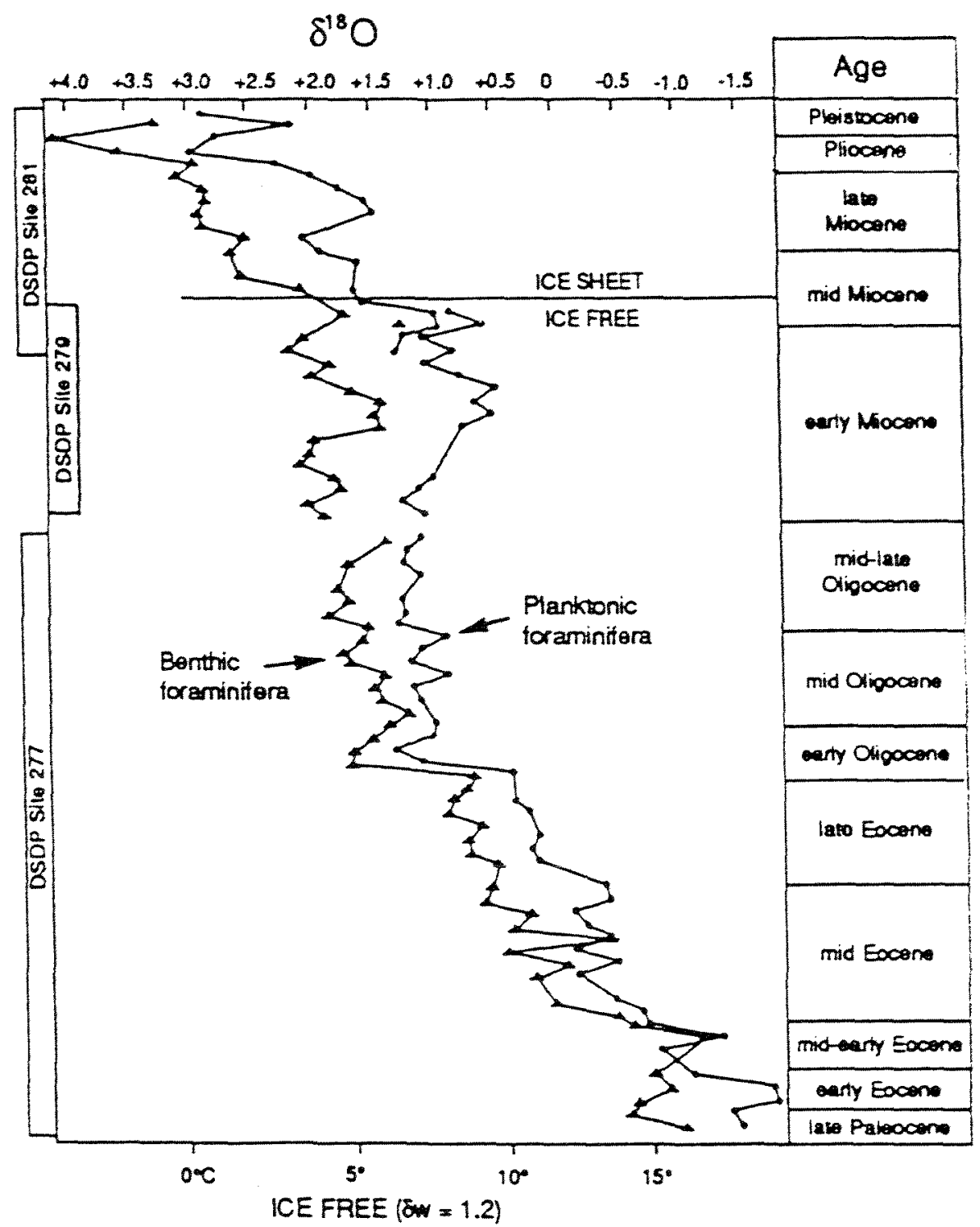

Figure 2.5 Oxygen isotope curves for planktonic and benthic foraminifera from deep sea drilling project sites 277, 279 and 281. From Wilson (1993) after Shackleton and Kennett (1975).

\subsection{PLIOCENE WARMTH AND HIGH SEA LEVELS}

\subsubsection{Global Temperatures}

Both global (oxygen isotope and paleontological evidence) and Antarctic (glacial geology and continental margin stratigraphy) evidence indicates an early-mid Pliocene warm climate (Dowsett et al., 1994). 
From oxygen isotope data Shackleton et al. (1993) shows a major shift in the climate system of the earth between 2.9 and 2.2 Ma. Before 2.9 Ma Shackleton (1993) shows in the oxygen isotope data that there were repeated intervals of warmer than present climate marking Pliocene times, when large ice sheets were thought only to exist in Antarctica (fig. 2.4). The most recent of these warm intervals occurred about $3 \mathrm{Ma}$. Paleontological evidence from this time also shows high-latitude air and sea surface temperatures in the Northern Hemisphere (Dowsett et al., 1994).

Pollen records suggest major vegetation changes in response to Pliocene warming. Data from Dowsett et al. (1994) show an increase in plant life in Greenland and surrounding regions and the northward expansion of conifer forests and savanna environments in the mid latitudes during Pliocene times.

\section{Warmer than present conditions inferred from Antarctica}

Data from fauna and flora in sediments collected along the Antarctic margin suggest early Pliocene Antarctic water surface temperatures must have ranged between 5 and $10^{\circ} \mathrm{C}$ (Harwood, 1996; Burckle et al., 1988; Quilty 1991; Ciesielski and Weaver, 1974; Abelmann et al., 1990). However other research suggests temperatures have remained consistently below $5^{\circ} \mathrm{C}$, Burckle and Pokras (1991) for example have found from diatom distribution studies that temperatures were most likely between 0 and $2^{\circ} \mathrm{C}$.

Diatom and radiolarian analysis of sediments from the Antarctic convergence zone suggest sea temperatures in mid Pliocene times were no more than $3-4^{\circ} \mathrm{C}$ warmer than present between latitudes $55^{\circ}$ and $60^{\circ}$ S (Barron, 1994; 1996).

Reduced numbers of sea ice related diatoms in Pliocene sediments (ie. Eucampia antarctica; Burckle et al., 1990; Abelmann et al., 1990) and the presence of diatomaceous sediments where they cannot occur today (because they are south of the limits of spring ice) indicate a greatly reduced extent of sea ice at that time (Kennett and Barker, 1990; Gersonde et al., 1990; Abelmann et al., 1990). Dowsett et al. (1994) has estimated winter sea ice limits in mid Pliocene times to be similar to the modern summer (February) conditions. A greater amount of ice free coast would lead to warmer conditions on terrestrial Antarctica. 
The discovery of fossil cetaceans unadapted to cold temperatures in $3.5 \mathrm{Ma}$ (from foraminiferal and diatom biostratigraphy) sediments in the Vestifold Hills (Harrison and Bryden, 1989; Fordyce, 1989) suggest that temperatures had to have been equivalent to those found in the Antarctic Convergence zone today (about $5^{\circ} \mathrm{C}$ ).

However the critical question is whether these conditions were warm enough to reduce the East Antarctic ice sheet to one third of its present size from the size it was in Late Miocene times as a dynamic ice sheet hypothesis suggests (section 2.4).

\subsubsection{Sea Level}

Kennett and Hoddell (1993) state that the melting of the Greenland ice sheet would raise sea level by $7.4 \mathrm{~m}$, the melting of the West Antarctic ice sheet would raise sea level by $5 \mathrm{~m}$ and that the melting of all Antarctic ice would raise sea level by about $70 \mathrm{~m}$.

Did the warm climate in early and middle Pliocene times melt the East Antarctic ice sheet to one third of it present size, exposing the Wilkes and Pensacola Basins as required by the dynamic ice sheet hypothesis? Such a deglaciation would result in a significant rise in sea level. Can this be seen in the sedimentary record?

Marine transgression during early Pliocene times has been recorded using oxygen isotope curve analysis and sequence stratigraphy from several ODP and DSDP sites (fig. 2.4, 2.5; Kennett, 1967; Berggren and Haq, 1976; Haq et al. 1988; Dowsett and Cronin, 1990).

The extent of glacioeustatic rise however is debated. Sea levels of up to $60 \mathrm{~m}$ higher than today have been predicted by Haq et al. (1987a \& b) based on sequence stratigraphy, but most studies consider this estimate too high. (Greenlee and Moore, 1988; Krantz, 1991; Wardlaw and Quinn, 1991)

By correlating Atlantic Coastal Plain sediments with oxygen isotope records from deep sea cores Krantz (1991) recorded sea levels of up to $30-35 \mathrm{~m}$ higher than today. Using the same method Wardlaw and Quinn (1991) estimate a mid Pliocene sea level maximum of between $29-36 \mathrm{~m}$ above the current sea level at 
Enewetak Atoll. Dowsett and Cronin (1990) record sea level of about $25 \mathrm{~m}$ above current sea level from the U.S. Middle Atlantic Coastal Plain. However, at Orangeburg scarp in the same area they found sea levels of up to $35 \mathrm{~m} \pm 18 \mathrm{~m}$ higher than today between 3.5 and $3 \mathrm{Ma}$. On the Virginia coastal plain Cronin et al. (in prep, in Cronin et al., 1995) have found micropaleontologic, stratigraphic and geomorphic evidence of maximum relative sea level approaching $50 \mathrm{~m}$ above present levels during Pliocene times .

In New Zealand Vella $(1953 ; 1963)$ recorded changes in sediments and fauna in Pliocene marine sequences from Eastern Wairarapa which indicate high sea levels and and warm climate in early and middle Pliocene times. Sediments and fauna inferring shallowing and deepening of seas were attributed to glacioeustatic changes in sea level (Vella, 1963). Wilson (1993) has identified several transgressive events in the Wanganui Basin of New Zealand over this time period, including sea levels reaching at least $40 \mathrm{~m}$ above present levels between 3.4 and $3.7 \mathrm{Ma}$ and sea levels reaching at least $20 \mathrm{~m}$ above the present between 2.8 and $3.2 \mathrm{Ma}$ and 2.5 and $2.6 \mathrm{Ma}$. This correlates well with transgressive events identified by Brigham-Grette (1995) in the Gubik Formation of Arctic Alaska.

Evidence from terrestrial Antarctica today, including: early-mid Pliocene benthic foraminifera in cores from DVDP Sites 10 and 11 in Eastern Taylor Valley (Ishman and Rieck, 1992); microfossils in raised marine deposits in the Vestfold Hills (Pickard et al., 1988) and data suggesting high sea levels in Wright Valley (Calkin et al., 1970 and Webb, 1972a\&b) all indicate Pliocene highstands of sea level.

By correlating the information from Ocean Drilling Program (ODP) and Deep Sae Drilling Project (DSDP) sites with information from coastal data Cronin et al. (1994) believed sea level between 3.5 Ma and 2.8 Ma was stable at about 30$40 \mathrm{~m}$ above present day sea level and that there were oscillations of between 40$60 \mathrm{~m}$ between 2.8 and $2.2 \mathrm{Ma}$ (Cronin et al, 1994; 1995).

Dowsett et al. (1994) suggest a middle Pliocene sea level at a more modest minimum of $25 \mathrm{~m}$ higher than present and presume this was largely due to a reduction of the size of the east Antarctic ice sheet. They also suggest that if sea levels were $25 \mathrm{~m}$ higher than present then an approximate $25 \%$ reduction in the East Antarctic Ice sheet is required, and a sea level rise to $46 \mathrm{~m}$ above 
present requires about a $60 \%$ reduction in the East Antarctic ice sheet. Records of sea levels greater than $50 \mathrm{~m}$ above the present are rare in the middle Pliocene, which suggests that if the East Antarctic ice sheet was $66 \%$ smaller than today's ice sheet, as the dynamic ice sheet hypothesis requires, it would only have been for very limited time intervals.

The mid Pliocene was clearly a time of high temperatures and sea level, which raises questions of how stable or dynamic the East Antarctic ice sheet was in response to these conditions and whether sea level purely controlled by reduction of the East Antarctic ice sheet?

\subsection{THE SIRIUS GROUP AND A DYNAMIC EAST ANTARCTIC ICE SHEET.}

The Sirius Group comprises all glacial sediments at high elevation throughout the Transantarctic Mountains. Locations of Sirius Group sediments are shown in Figure 2.6.

\subsubsection{The Sirius Formation sediments.}

The Sirius Formation was first described by Mercer (1972) from his studies on Mt. Sirius and in the Dominion Range as a "compact glacial drift that unconformably covers pre-Tertiary rocks". As a result of sedimentary and stratigtraphic analysis of the tills Mercer interpreted these deposits to occur as a result of deposition by temperate glaciers in the Transantarctic Mountains predating the formation of the Antarctic ice sheet.

Mayewski (1975) identified the Sirius Formation in 24 localities in the Transantarctic Mountains. He suggested that the similarities in location, directional data and size, texture and compositional analysis from the tills showed the Sirius Formation was deposited by one large ice sheet, over riding the Transantarctic Mountains, and post dating their glacial sculpturing.

Since the Sirius Formation was first recognised as a unit by Mercer (1968), it has been found in several locations by a number workers throughout the Transantarctic Mountains (fig. 2.6). It was re-termed as the Sirius Group by McKelvey et al. in 1991 with the formal recognition of two formations (Cloud maker and Meyer Desert Formations adjacent to Beadmore Glacier). 


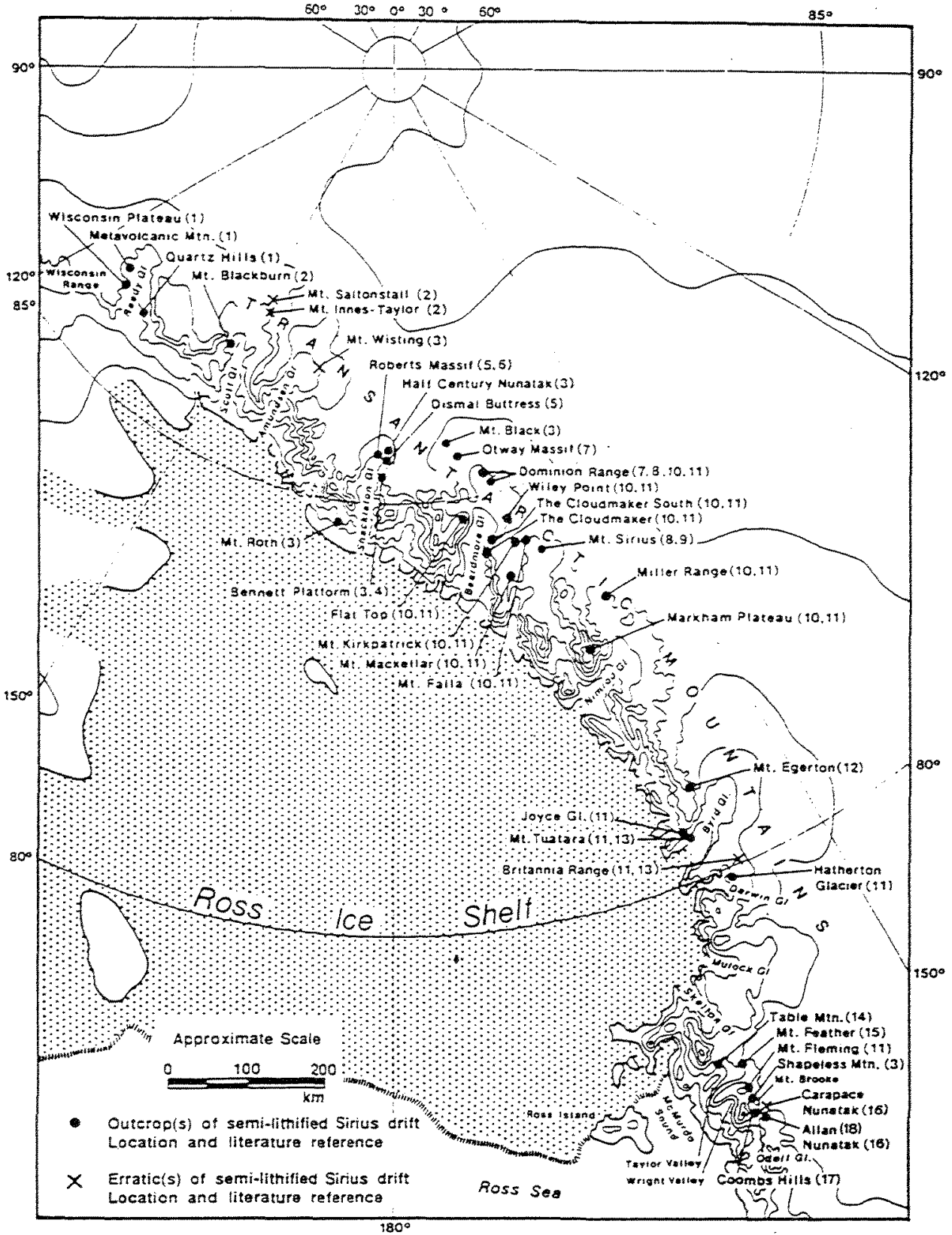

Figure 2.6 Location of the Sirius group outcrops in the Transantarctic Mountains (from Denton et al., 1993, with additional information from Wilson, 1993). References include: (1) Mercer (1968); (2) Doumani and Minshew (1965); (3) Mayewski (1975); (4) LaPrade (1984); (5) McGregor (1965); (6) Claridge and Campbell (1968); (7) Elliott et al. (1974); (8) Mercer (1972); (9) Barrett and Elliot (1973); (10) Prentice et al. (1986); (11) Denton et al. (1991); (12) Anderson J. unpublished; (13) Faure and Taylor (1981); (14) Barrett and Powell (1982); (15) Brady and McKelvey (1979); (16) Borns Jr. H.W. unpublished; (17)Brady and McKelvey (1983); (18) Faure and Harwood (1990). 


\subsubsection{Diatoms in the Sirius Group and the initiation of the dynamic ice sheet hypothesis.}

Harwood (1983) first recorded the presence of marine diatoms and diatomaceous microclasts in the Sirius Group at a number of sites along the Transantarctic Mountains. At several sites, including Mt. Feather, the youngest assemblages identified were reported as Mid Pliocene in age (Ch. 5). Assuming the diatoms were deposited with the tills the Sirius Group had to post-date the age of the youngest diatom assemblage. As a result it was proposed by Webb et al. in 1984 that the diatoms occurred in the Sirius Group as a consequence of marine deposition in the Antarctic interior between 3 and $2.5 \mathrm{Ma}$, followed by ice sheet growth and erosion of the marine sediments. Glaciers basally deposited the diatom bearing and other sediments at the present locations as the ice sheet over topped the Transantarctic Mountain sites (fig. 2.7, 2.8; Harwood, 1983, 1985, 1986a, b; Webb et al., 1984; Webb and Harwood 1987, 1991; Barrett, 1991, 1992; Barrett et al., 1992; in review).

This implies that the East Antarctic ice sheet was reduced by at least two thirds of its present size in the early-mid Pliocene warm period exposing the Wilkes and Pensacola subglacial basins to the sea. (fig. 2.8; Webb et al., 1984; Harwood, 1985, 1986; Pickard et al., 1988; McKelvey and Stevenson, 1990; Webb and Harwood, 1991). This was followed by a major change in global glaciation in the late Pliocene $(\sim 2.5 \mathrm{Ma})$ as a result of a major cooling (Prentice et al., 1987; Harwood and Webb, 1990; Webb and Harwood, 1991).

The 3.0 Ma age of the Pliocene diatom taxa found in the Sirius Group was confirmed in the Ross Sea area by Barrett et al. (1992) with the occurrence of the species found by Harwood $(1983,1986)$ in the Sirius Group deposits adjacent to a carefully dated $3 \mathrm{Ma}$ year old volcanic ash in the CIROS-2 core. 

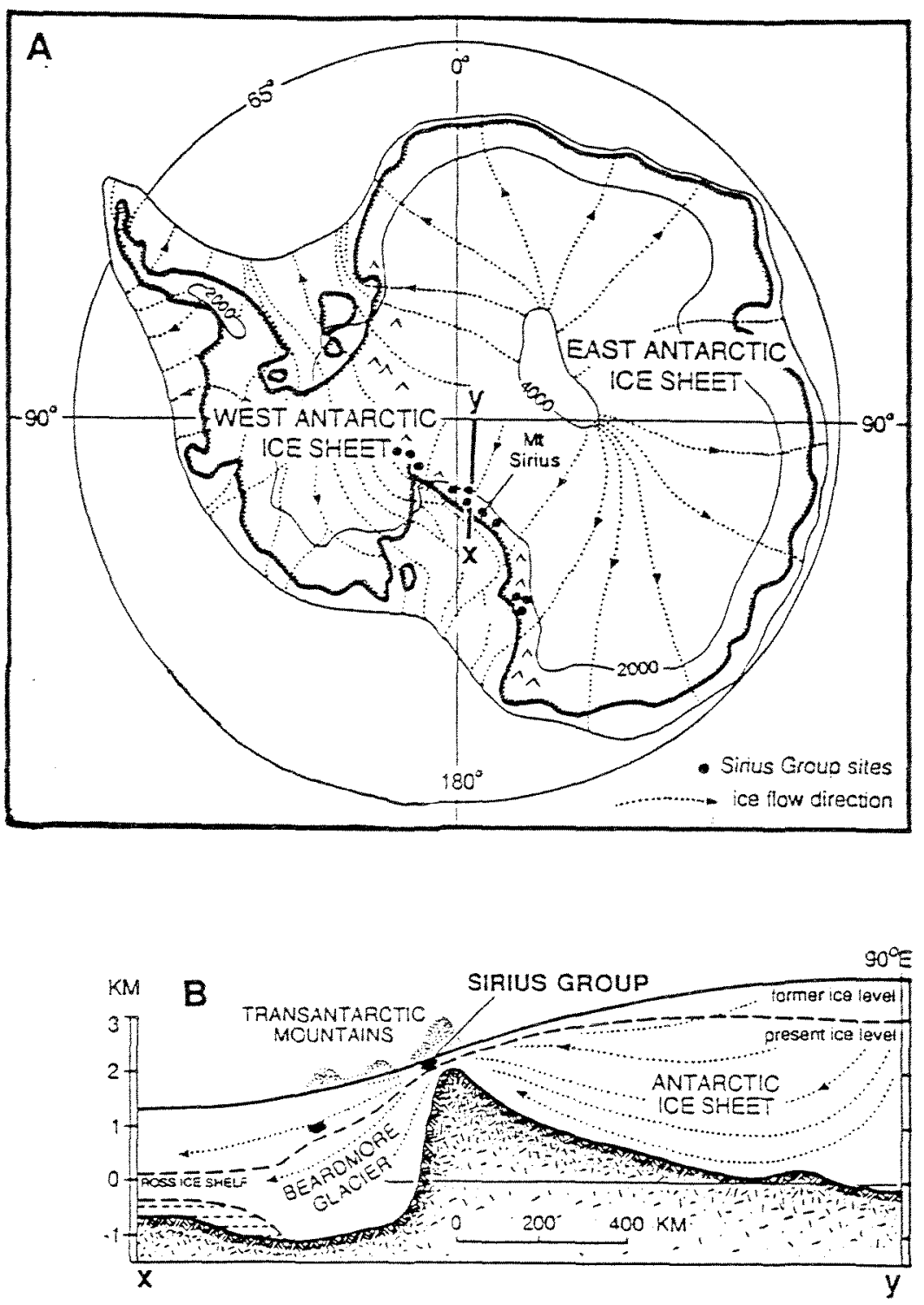

Figure 2.7 Figure 2.7A is a map of Antarctica showing the main Sirius Group sites in the Transantarctic Mountains. Ice thickness contours and flow lines are for the larger ice sheet required to deposit the Sirius Group debris after Denton et al. (1991). The flow pattern indicates an East Antarctic source for the diatoms if they were incorporated into the till at the same time it was deposited, an hence marine sedimentation there 3 million years ago. Figure $2.7 \mathrm{~B}$ is a cross section from the east Antarctic interior through the Transantarctic Mountains to the Ross Sea, showing the location of the Sirius Group deposits and there inferred source in the interior. In drawing this section Barrett et al. (1992) presume that the Transantarctic Mountains were at the present elevation during Sirius deposition, but they must have been much lower at the time to enable basal glacial deposition (Huybrechts, 1993). From Barrett et al. (1992). 


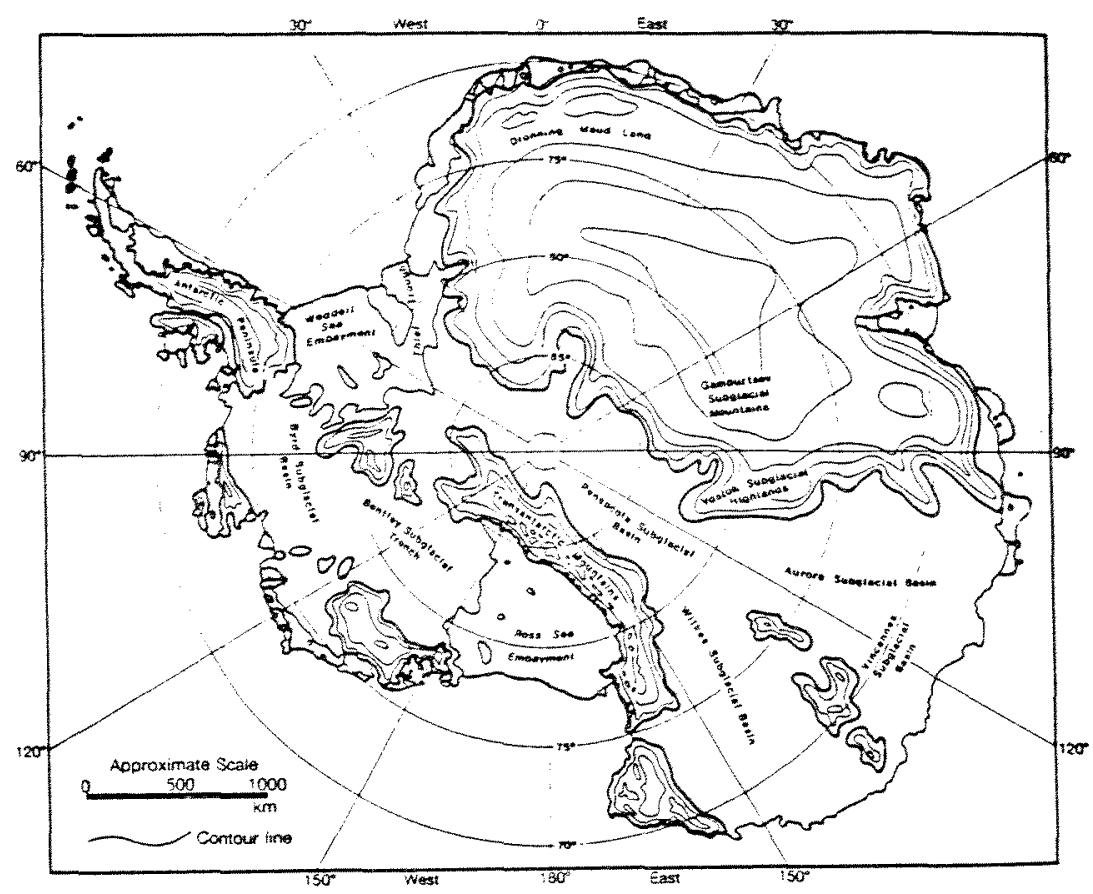

Figure 2.8 Sketch of the Antarctic ice sheet during an interval of extensive deglaciation based on sub glacial topography without isostatic adjustment. From Denton et al. (1991). A similar model is in Harwood (1986).

\subsubsection{Other fauna and flora from the Sirius Group.}

The occurrences of fragments of Nothofagus leaves and pollen and other plant material (Webb et al., 1994; Webb and Harwood, 1987, 1993) as well as vertebrate, arthropods in the Sirius Group in the Dominion Range (Ashworth et al., 1995) in association with a Pliocene marine diatom assemblage indicate temperatures must have been 17 to $20^{\circ} \mathrm{C}$ warmer in Pliocene times for at least scrubby Nothofagus and other fauna and flora to survive (fig. 2.9; Harwood and Webb, 1990; McKelvey et al., 1991). Because of the time scale and distances involved Burckle and Pokras (1991) conclude the recolonisation of beech on the Antarctic continent after the Miocene glaciation would be near impossible; hence Nothofagus must have survived in Antarctica in various refugia up until the inferred late Pliocene ice sheet over riding. This suggests a dynamic East Antarctic ice sheet until mid to late Pliocene times and that earlier Cenozoic glaciations did not develop ice sheets as large as the present one (fig. 2.10; Webb and Harwood, 1987; Carlquist, 1987; Barrett, 1992, Webb and Harwood, 1991). 


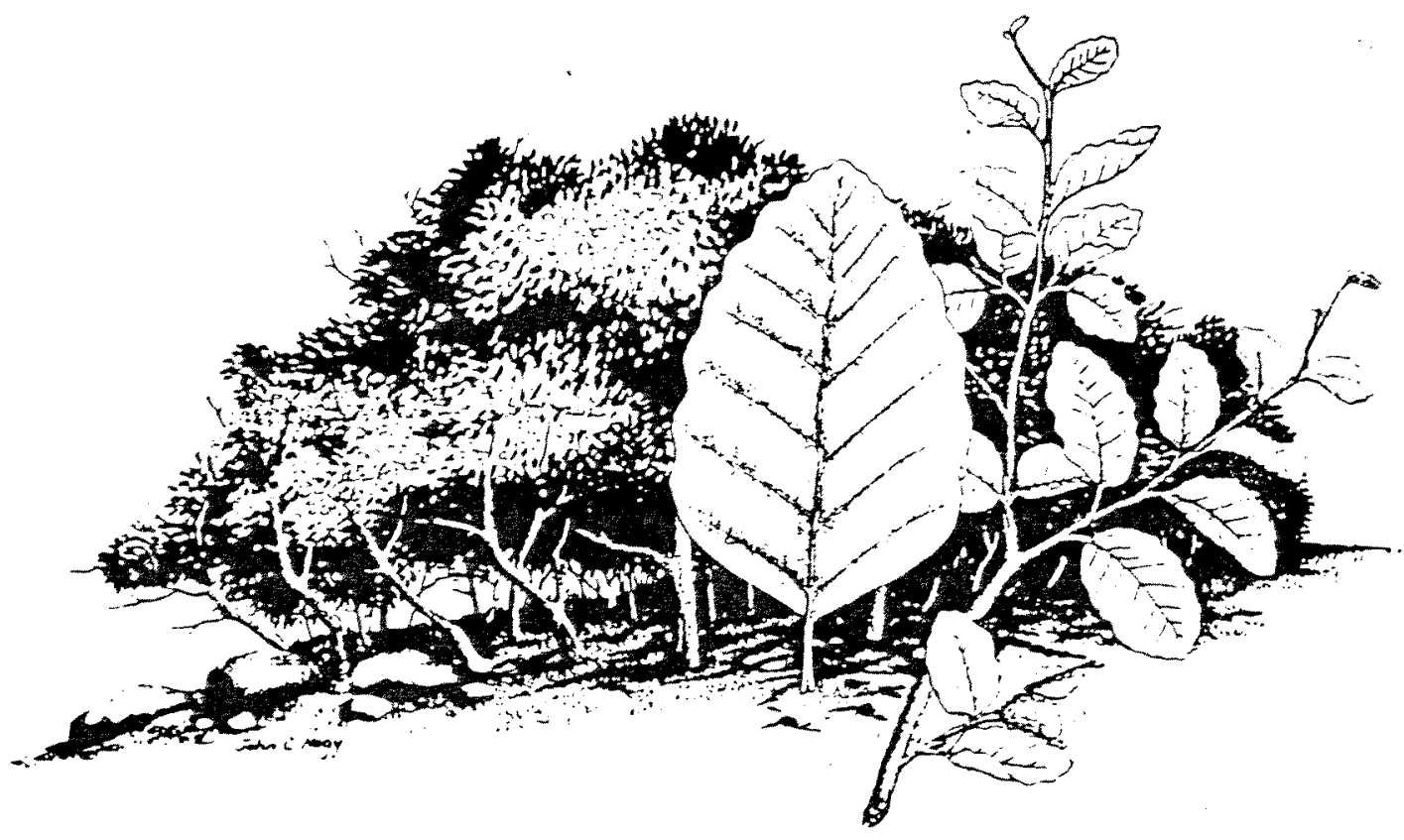

Figure 2.9 Artist's impression of a low-standing krummholz forest of Nothofagus aff. gunni, developed on a glacial rock debris terrain during Sirius Group times, and exposed on the southern slopes of the Beadmore valley system at a latitude of $85^{\circ} \mathrm{S}$. in the Transantarctic Mountains. Drawing by John Nagy, the Ohio State University. From Webb and Harwood (1993). However, Francis (1995) notes that offset tree rings suggest a more prostrate Nothofagus form.

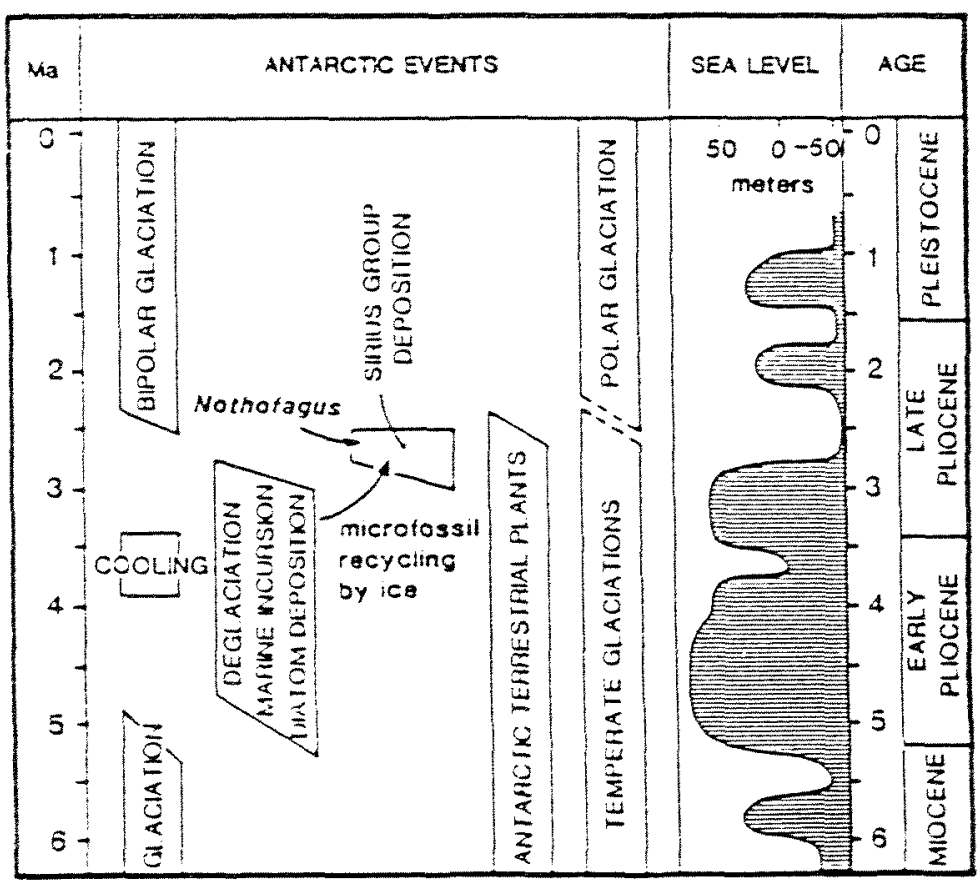

Figure 2.10 Timing of significant events in the Late Neogene glacial history of Antarctica as dated by the diatoms in the Sirius Group assuming the diatoms were incorporated at the same time as the tills were deposited. Sea level curve is after Haq et al. (1987). From Webb and Harwood (1991). 
The distribution of Nothofagus in the Sirius Group suggests they have been over run by glaciers advancing in the cool temperate conditions (Webb et al, 1987; Webb and Harwood, 1987; McKelvey et al. 1987, 1991; Carlquist, 1987; Webb and Harwood, 1991; Hill et al., 1991, 1994). Harwood and Webb (1995) suggest analogs for Antarctica in mid Pliocene times are the southern margins of Alaska and Southwest Greenland today.

\subsubsection{High uplift rates in the Transantarctic Mountains during the Pleistocene and Pliocene times?}

As a result of sedimentological analysis of the Sirius Group tills throughout the Transantarctic Mountains several workers (fig. 2.6) show they are dominantly basal or lodgement tills. For the Sirius Group to be deposited by an over riding ice sheet at there current locations in the Transantarctic Mountains, much lower elevations of their sites are required (Huybrechts, 1993). The present high elevation of insitu "Pliocene" marine and terrestrial strata and accompanying fossil material at Oliver Bluffs and The Cloudmaker formation localities requires a post Sirius Group uplift of between 350 and $550 \mathrm{~m} / \mathrm{Ma}$ (Webb et al., 1995).

Most groups analysing uplift rates from geomorphic evidence in the Dry Valleys, suggest an uplift rate of no more than $100 \mathrm{~m} / \mathrm{Ma}$ (Sugden et al., 1993, 1995, Denton et al., 1993, 1995). However Behrendt (1995) suggests differential and episodic uplift of separate crustal blocks along the Rift Shoulder Mountains may be comparable with possible variation between different blocks throughout the Transantarctic Mountains.

\subsubsection{Further evidence for a warm climate, high sea levels and open marine basins in East Antarctica during mid Pliocene times.}

The presence of diatoms in till clasts in blue-ice ablation areas of Elephant and Reckling moraines and in the Warren Range area argue for the presence of marine strata beneath the East Antarctic ice sheet being carried to the surface by glacial ice today (Faure and Harwood, 1990).

Also, Pliocene flora and fauna in the Pagodroma Group in the Northern Prince Charles Mountains (McKelvey et al. 1995) and in the Southern Prince Albert Mountains (Verbers, 1995) indicate warmer temperatures, high sea 
levels and a substantial decrease in ice volume (section 2.2) during mid Pliocene times.

If sea ice around Antarctica was replaced throughout the year by open water at $-1.9^{\circ} \mathrm{C}$ (all other boundary conditions are held the same) modeling shows an increase in precipitation and an increase in temperature over the Antarctic continent (Bromwich and Chen, 1995). This also shows substantial changes in the tropospheric westerlies confined to the southern hemisphere. This absence of the insulating effect of sea-ice, would result in the elevation of the mean annual atmospheric temperatures in Antarctica by more than $15^{\circ} \mathrm{C}$ (Webb and Harwood, 1995). The appearance of a sea ice diatom bioprovince in the late Pliocene provides an age control for the onset of significant sea-ice in the Southern Ocean in the late Pliocene (Harwood and Webb, 1995).

\subsubsection{Evidence for a dynamic ice sheet before Late Pliocene times}

High resolution seismic analysis beneath the Ross Sea by Bartek et al. (1995) shows units suggesting "a record of Cenozoic ice sheet waxing and waning events that correspond to many major climatic and eustatic events". Bartek et al. (1995) argue that from these data "Neogene ice sheet behaviour in Antarctica was anything but stable".

Further, Abelman et al. (1990) from microfissil evidence in the Weddell Sea and Ishmann and Rieck (1992) from Dry Valley Drilling Program (DVDP) Sites 10 and 11, have stated that the frequency of the marine oxygen isotope record represents glacio-eustatic sea level change giving further evedence for a dynamic behaviour of the ice sheet (fig. 2.4, 2.5) during Miocene and Pliocene times.

\subsubsection{Discussion}

High eustatic sea levels during mid Pliocene times from deep sea and coastal outcrop data globally average $25 \mathrm{~m}$ above present sea level (Dowsett et al, 1994 say this requires a $25 \%$ reduction of todays East Antarctic ice sheet) and up to $50 \mathrm{~m}$ above present sea level at some stages (Cronin et al, 1995, section 2.2; requiring over $60 \%$ reduction of todays East Antarctic ice sheet, Dowsett et al. 1994). There must have been some deglaciation of the East Antarctic ice sheet for sea levels to reach this height. However, was there enough declaciation to 
expose the Wilkes and Pensacola Basins required by the dynamic ice sheet hypothesis?

If the dynamic ice sheet hypothesis is correct it has been suggested that there is a "need to consider the stability of the Antarctic ice if global temperatures reach or exceed those of the Pliocene" (Barrett et al, 1992). Global temperatures today would have to exceed those of the middle Pliocene to reduce the East Antarctic ice sheet to the same extent today, because the East Antarctic ice sheet of Pliocene times assuming the dynamic ice sheet hypothesis was much smaller and less stable than today (Webb and Harwood, 1991).

\subsection{EVIDENCE FOR A STABLE EAST ANTARCTIC ICE SHEET}

Data opposing the notion a dynamic ice sheet until Late Pliocene times, and open marine basins in inland Antarctica in middle Pliocene times, comes from marine, geomorphological, sedimentological and ice sheet modelling evidence.

\subsubsection{Marine Evidence}

Isotope analysis and evidence of limited changes in ice sheets and temperature in the Pliocene.

Warnke (1995) and Hodell (1995) believe oxygen isotope records show the lowest $218 \mathrm{O}$ values in the mid Pliocene can either accommodate a $2.5^{\circ} \mathrm{C}$ warming of Antarctic surface waters and global deep waters or a sea level rise of 50-60m, but not both. Hence a major deglaciation of Antarctica could occur only in the absence of deep water temperature change and without warming of the Antarctic surface water, which is not possible. There is evidence of deep water temperature changes in the Pliocene from the Indian Ocean (Chen et al, 1995) and in the North Atlantic (Dwyer and Cronin, 1994). Hoddell (1995) claims that even if deep water temperature rose only $1^{\circ} \mathrm{C}$, this would leave little room for ice volume reduction (equivalent to $25 \mathrm{~m}$ sea level rise). Warnke (1995), suggest this oxygen isotope value probably results from some warming and a small reduction in global ice volume. Warnke (1995) also consider the greater than present warmth in the North Atlantic may have caused destablisation of the Greenland ice sheet, and some reduction of the 
Antarctic ice extent, resulting in a relatively minor (compared to the hypothesized $50 \mathrm{~m}$ ) sea level rise.

From their work on the subantarctic oxygen isotopic record Kennett and Hodell (1993) show an increase of average sea surface temperatures of no more than $3^{\circ} \mathrm{C}$ during the warmest interval of the Pliocene. Carbon isotopic analysis also lacks the large changes expected from major glacioeustatic changes (Kennett and Hoddell, 1993) during mid Pliocene times.

Significant ice rafted detritus, in the subantarctic continued relatively unchanged through the Pliocene (Warnke et al., 1992) indicating the continued presence of major ice sheets reaching the sea in Antarctica even during the warmest Pliocene intervals (Kennett and Hoddell, 1993).

Kennett and Hoddell (1993) point out that two thirds deglaciation of the East Antarctic ice sheet (described by Webb and Harwood, 1991 and Webb et al., 1984) would require a sea level rise of about $59 \mathrm{~m}$, although Dowsett et al. (1994) suggest a more modest $44 \mathrm{~m}$ (Oerlemans and Van der Veen, 1984), this is still a much greater rise than those levels estimated from sea level recorded globally at this time. Dowsett et al., (1994) show a 25-40\% reduction in the East Antarctic ice sheet is required to raise sea level to the $25-35 \mathrm{~m}$ sea level highs outlined earlier. This would not be sufficient to open the Pensacola and Wilkes basins to the sea.

\section{Limited evidence of biogenic change}

Kennett and Hoddell (1993) report that the low amount of biocalcareous sediment in Antarctic Waters and dominance of biosiliceous sediment suggests oceanographic conditions broadly similar to the present day. This would not be so if the temperature of the surface waters in the Antarctic had increased more than $5^{\circ} \mathrm{C}$. Kennett (1995) also points out that temperatures in the Pliocene did not influence the increasing endemism of Pliocene siliceous planktonic assemblages.

Diatom and Radiolarian assemblages from the mid Pliocene in deep sea cores around the Antarctic Polar front suggest the polar front was never greater than $6^{\circ}$ south of its present position (Barron, 1996 and Barron and Morley, 1995). Barron and Morley (1995) state "this provides constraints on maximum sea 
surface temperatures at the Antarctic Coast, but it does not preclude warmer (temperatures of $>15^{\circ} \mathrm{C}$ ) air surface temperatures in isolated places along the margin of East Antarctica that would theoretically result from the near absence of summer sea ice and a lowered East Antarctic Ice Sheet profile".

There is also little record of pollen and spores in late Neogene marine sediments from Antarctica or the Southern Ocean (Burckle and Pokras, 1991; Kennett and Hoddell, 1993). However, Nothofagus pollen has now been reported from Pliocene sediments from DSDP Site 274 (Fleming et al. 1996, Fleming and Barron, 1994) although the possibility of down hole reworking should not be eliminated. The only other spores and pollen to be found since Oligocene times in Antarctica (Truswell, 1986, 1991; Mohr, 1990; Mildenhall, 1989) are those of a Lower Miocene pollen assemblage from RISP site J/9, (Jiang and Harwood, 1992; 1995), which differs from the Sirius Group pollen assemblage (Harwood and Jiang, 1994).

\subsubsection{Geomorphic Evidence}

\section{Geomorphic evidence and uplift rates in the Dry Valleys}

Geomorphic evidence from the Antarctic Dry Valleys supports a stable East Antarctic ice sheet in mid Pliocene times by showing limited uplift of the Transantarctic Mountains, limited Late Pliocene glacial expansion and enduring polar desert climates since middle Miocene times (Denton et al, 1993; Marchant et al. 1993; Sugden et al. 1993).

Landform and erosional features such as weathering patterns suggest that significant slope evolution has not occurred since near the end of the middle Miocene (Denton et al, 1993). Marchant (1995) also show geomorphological evidence suggesting humidity in the far western regions of the Dry Valleys was never greater than levels of coastal and intermediate areas today.

The age of Miocene and Pliocene marine fauna and flora in the Dry Valleys Drilling Project sites 10 and 11 suggest an uplift rate of the Transantarctic Mountains of $100 \mathrm{~m} / \mathrm{Ma}$ (Ishman and Rieck, 1992), a much slower rate of uplift than the proposed 350 to $550 \mathrm{~m}$ per year required for the Dynamic ice sheet hypothesis. However these cores do suggest fluctuations in ice volume and 
subpolar paleoclimatic conditions in the late Neogene unlike today (Ishman, 1995).

\section{Limited slope evolution proposed from dated in situ ashes.}

Further evidence of limited slope evolution, and hence uplift and unchanged arid conditions since middle Miocene times in the Transantarctic Mountains, comes from 40Ar/39Ar and $\mathrm{K} / \mathrm{Ar}$ dates on in situ volcanic ashes. Some of these ashes occur on steep slopes while others in association with unconsolidated diamictons or basaltic lava flows interbedded with tills in the Dry Valleys and Quatermain Mts (Denton et al. 1993, Denton et al, 1995; Sugden et al, 1995; Potter, 1995). The dates of these in situ ashes range between 4 and 11.3 Ma suggesting little slope evolution or changes in the bedrock form since at least 11.3 Ma. (Denton et al, 1995; Sugden et al, 1995; Potter, 1995)

Sugden et al (1995) have found relict glacial ice covered by an $8 \mathrm{Ma}$ ash in Beacon Valley. Hall et al 1993, have also found alpine glacial moraines stratigraphically dated back to $>3.7 \mathrm{Ma}$ in Wright Valley.

It is argued that if glacial over riding had occurred, followed by the relatively rapid uplift required by the dynamic ice sheet hypothesis, none of these ashes or moraines would exist.

\section{The older age of surface rock exposure adjacent to the Sirius Group.}

$40 \mathrm{Ar} / 39 \mathrm{Ar}$, and cosmogenic $10 \mathrm{Be}$ and $26 \mathrm{Al}$ dating of surface rocks give minimum surface exposure dates greater in age than the ice sheet over riding required in the late Pliocene by the Webb and Harwood (1986) hypothesis; they also indicate uplift rates much less than hypothesized rate.

Numerous $40 \mathrm{Ar} / 39$ Ar whole rock ages of surface basaltic volcanic deposits on benches in Taylor Valley are reported to be essentially unmodified since at least early to mid Pliocene time (Wilch et al. 1993).

Wilch (1995) reports uplift rates using 40Ar/39Ar isotopic dating on olivine basalts which range in age from $3.7-1.8 \mathrm{Ma}$ on the North Wall of the Ferrar Valley which limit surface uplift to less than $341 \mathrm{~m}$ since $2.4 \mathrm{Ma}$. On the south wall of the Ferrar Valley surface uplift has been calculated to $277 \mathrm{~m}$ since $2.4 \mathrm{Ma}$ 
and at another site less than $640 \mathrm{~m}$ since $1.9 \mathrm{Ma}$. These rates are consistent with surface uplift rates reported in Taylor Valley by Wilch et al. (1993).

Cosmogenic dating using decay of $10 \mathrm{Be}$ and $26 \mathrm{Al}$ on surfaces in the Arena Valley and on material adjacent to the Sirius Group on Mt. Fleming and Table Mountain by Brook et al. (1995) and Ivy-Ochs et al. (1995a,b) suggest exposure ages much older than $3 \mathrm{Ma}$ and $5 \mathrm{Ma}$ respectively. This analysis also suggests a much slower rate of erosion hence a limited slope evolution supporting the slower rate of uplift of the Transantarctic Mountains in the last $3 \mathrm{Ma}$.

A similar analysis by Faure et al. (1995) suggests an exposure age of $2.3 \mathrm{Ma}$ from near the summit of Mt. Sirius to minimum exposure ages of between $5.5 \mathrm{Ma}$ (East Beacon) and 1.5 Ma (Mt. Fleming) from outcrops near the summits of various mountains along the edge of the East Antarctic Ice Sheet. There work suggests different rates of ice lobe recession depending on ice-removal rates of different outlet glaciers.

\section{Discussion}

Denton et al. (1995) argue for a stable East Antarctic ice sheet from evidence in Taylor and Wright Valleys suggesting Pliocene temperatures were 3-8 degrees higher than present, most recent ice sheet over riding in Miocene times $(>13.6$ Ma). limited late Pliocene glacial expansion and surface uplift of only 250$300 \mathrm{~m}$ " since the Pliocene.

However, after studying various areas in Antarctica, van der Wateren (1995) emphasises that no single regional geochronology can be universally applied to the entire continent. And that regional tectonic histories are sufficiently different to account for strongly contrasting landscape evolution histories, even in adjacent fault blocks. Assuming this, geomorphic evidence from the Dry Valleys cannot be used to argue against contrasting evidence at Beardmore Glacier.

\subsubsection{Sedimentology of the Sirius Group}

Stroeven and Prentice (1995) show the Sirius Group on Mt. Fleming was deposited subglacially by an alpine glacier system centred in the Transantarctic Mountains (Stroeven 1994; Stroeven et al. 1992, 1994). Mercer (1968) and Fuare 
et al. (1983) at Reedy Glacier, Mercer (1972) at Beardmore Glacier and Brady and McKelvey (1979) at Mt. Feather also concluded that the Sirius Group deposits at these sites were of local alpine origin. Barrett and Powell (1982) also estimate a much greater age for the Sirius Group at Table Mountain than the age of the diatoms from other Sirius group tills suggest.

\subsubsection{Ice Sheet Modelling and Reconstruction}

There is one further hypothesis for the Antarctic in the early Pliocene, and that is of ice sheet growth and development at this time referred to as the "snowgun hypothesis", proposed by Prentice and Matthews (1991). This is based on the idea that warming of the Southern Ocean would increase atmospheric moisture and continental precipitation, hence ice sheet growth causing instead a lowering of glacioeustatic sea level (Kennett and Hoddell, 1993) reducing the evidence of any change in the 2180 record.

Today a temperature increase of $17-20^{\circ} \mathrm{C}$ is required to create an ice free corridor over the Pensacola and Wilkes Subglacial Basins (fig. 2.11). For a temperature rise of less than $5^{\circ} \mathrm{C}$ modelling predicts a larger Antarctic ice sheet than today as a result of increased snowfall (fig. 2.11). The West Antarctic ice sheet was found not to survive temperatures of $8-10^{\circ} \mathrm{C}$ above present values (fig. 2.11). Difficulties also included raising the ice sheet base to the pressure melting point over the large areas necessary to consider the possibility of sliding instability (Huybrechts, 1993).

These reconstructions are based on how warmer than present temperatures would effect the current East Antarctic ice sheet, that has evolved into a more stable feature since the middle Pliocene times, not on the less stable fluctuating ice sheet of Miocene and Pliocene times that Webb and Harwood (1991) describe. This suggests much higher temperatures of over $17-20^{\circ} \mathrm{C}$ are required to make the East Antarctic ice sheet unstable under the conditions of today. 

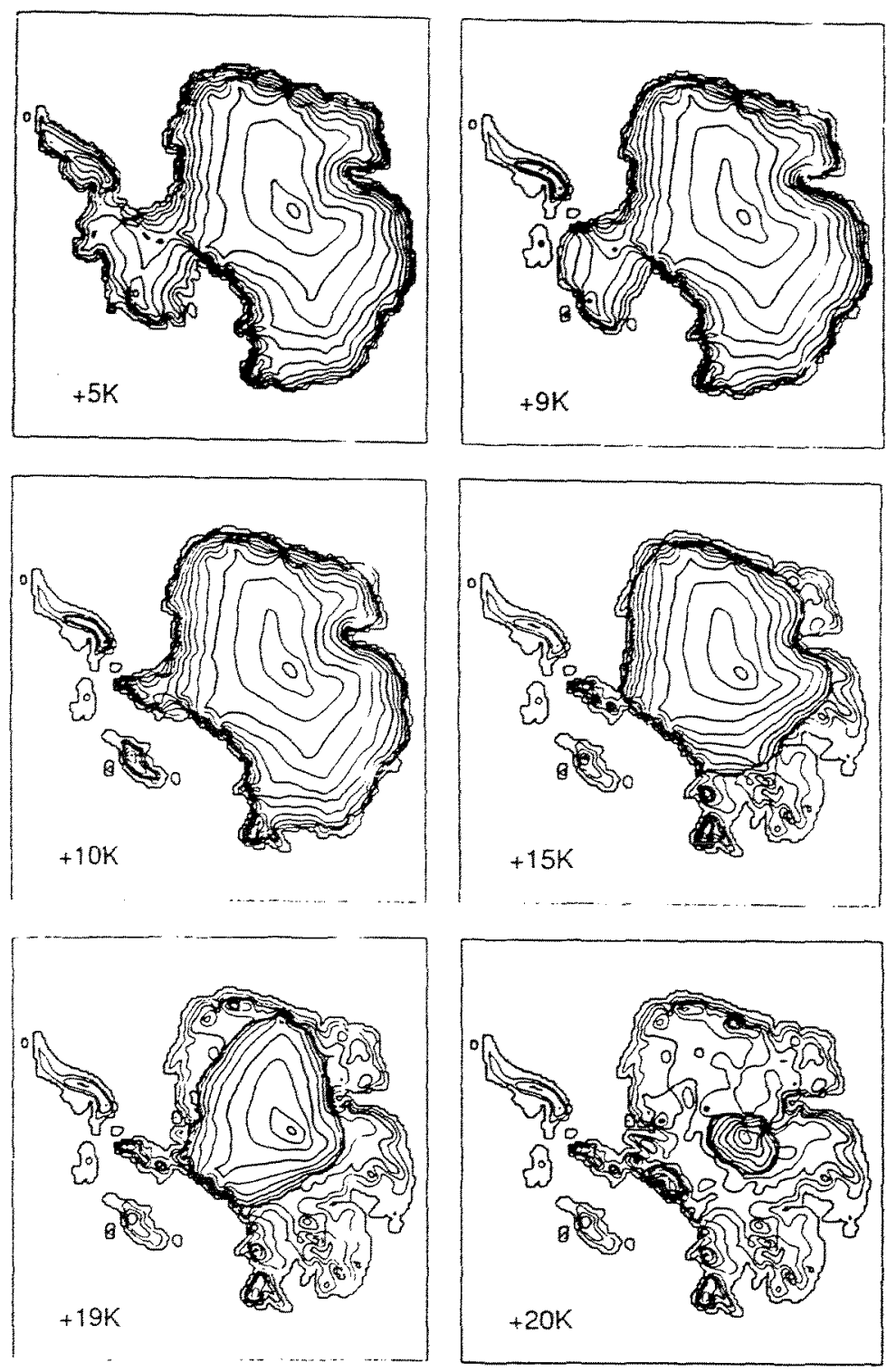

Figure 2.11 Steady state ice sheet geometrics for the temperature perturbations above present levels as indicated. Isoclines are for surface elevations. Contour interval is $333 \mathrm{~m}$, the thick lines are every $1000 \mathrm{~m}$. From Huybrechts (1993). 


\subsection{THE WIND BLOWN DIATOM HYPOTHESIS}

It was suggested that diatoms could have been introduced onto the surface of Sirius Group tills and worked into the sediment by Kellogg and Kellogg (1984) and later Denton et al. (1991). There were several reasons why this was not initially considered:

- That surface winds through out the Transantarctic Mountains are largely from the continental interior.

- Sparce diatom flora from the Dome C ice core, on the Antarctic Plateau was almost entirely terrestrial, with the exception of one small ice diatom (Burckle et al., 1988); and

- There was no evidence that marine diatoms could be transported much further than up to $2 \mathrm{~km}$ inland.

It has long been known that dried, lighter and more aerodynamic freshwater species of diatoms can be transported huge distances atmospherically. As long ago as the 1840's Darwin (1845 and 1846) identified freshwater species on the masthead of the Beagle hundreds of kilometres from nearest land. There are several reports of freshwater diatoms being picked up from dried freshwater sediments especially with a Sarahan Desert origin (Game, 1964, Håkansson and Nihlen, 1990, Kolbe 1955, 1957; Pokras and Mix, 1985; Pokras and Ruddiman, 1989).

There is very little evidence that marine diatoms can be carried far inland directly from the sea due to there larger size and greater specific gravity. However dried marine diatoms exposed to the wind (like the desiccated freshwater diatoms described above), could be carried some distance. There are reports of diatoms being carried in sea spray up to $2 \mathrm{~km}$ inland on Signy Island (Chalmers et al., 1996).

Data showing that diatoms are more concentrated in unconsolidated surface layers overlying the Sirius Group tills (Stroeven, 1994), the discovery of diatoms in cracks in older rocks in the Antarctic (Burckle, 1995) and the marine diatoms found to occur in the snow and ice at the south pole (Kellogg and Kellogg, 1996) has shifted the weight of evidence towards the possibility that diatoms in the Sirius Group have an atmospheric or wind blown origin once again. 


\section{Chapter Three}

\section{Sedimentology and Stratigraphy}

\subsection{Introduction}

The Sirius Group glacial deposits at Table Mountain and Mount Feather were plotted on maps constructed from 1: 50,000 topographic maps and air photos (fig. 3.1a and 3.2a). Geological units discussed at these locations are shown in Table One.

\subsection{Sirius Group on Mount Feather}

\subsubsection{Bedrock beneath the Sirius Group tills}

The Sirius Group till was deposited on a landscape cut in flat lying strata of the Beacon Supergroup intruded by sills of Ferrar Dolerite (Barrett, 1991b). The upper slopes of Mt. Feather comprise of 3 sedimentary formations, the Wellar Coal Measures (Permian), Feather Conglomerate (Permian to Early Triassic) and Lashly Formation (Triassic) and Ferrar Dolerite intrusions (Mid Jurassic, Table 3.1). The Feather Conglomerate with its lenses of quartz pebbles and the Ferrar Dolerite are the most obvious contributors to the Sirius Group tills (Fig. 3.3).

\subsubsection{Distribution of the till}

The Sirius Group till on Mount Feather occurs as a veneer disconformably overlying Beacon Supergroup sediments (above) on a bench $2500 \mathrm{~m}$ above sea level (fig 3.5), NNE of the summit of Mt. Feather (fig. 3.15). There are also several patches of Sirius till plastered on the steep slopes of the North Ridge of Mt. Feather (fig. 3.1 and 3.6). On either side of the bench the ground drops away, to the north $1000 \mathrm{~m}$ to the floor of the Beacon Valley (fig. 3.7a\&b) and to the south east $700 \mathrm{~m}$ to the Ferrar glacier (Brady and McKelvey, 1979). 
The extent of outcropping till was mapped and three sites were chosen for measurements and sampling (fig. 3.1).

Hummocky gravel moraines which were deposited by post-Sirius glacial deposition (fig. 3.8) overlie the till.

Table 3.1 Geologic Units at Table Mountain and Mt. Feather (from McElroy et al., 1987 and Woolfe et al., 1987).

\begin{tabular}{|l|l|l|}
\hline Unit & Age & Description \\
\hline Moraine & Unknown & $\begin{array}{l}\text { Loose clasts of gravel and larger } \\
\text { clasts dominated in composition } \\
\text { by Clasts of Ferrar Dolerite }\end{array}$ \\
\hline $\begin{array}{l}\text { Sirius Group } \\
\text { Tills }\end{array}$ & $\begin{array}{l}\text { Late Paleogene to } \\
\text { Neogene. } \\
\text { Ferrar Dolerite } \\
\text { greenish yellow dimictite. }\end{array}$ \\
\hline Lashly Formation & Liddle Jurassic & Dolerite sills and dikes \\
\hline $\begin{array}{l}\text { Feather } \\
\text { Conglomerate }\end{array}$ & Late Permian & $\begin{array}{l}\text { Green to yellowish grey lithic } \\
\text { sandstone and grey and black } \\
\text { shale. }\end{array}$ \\
\hline $\begin{array}{l}\text { Weller Coal } \\
\text { Measures } \\
\text { condstome with quartz } \\
\text { grey in colour. }\end{array}$ \\
\hline $\begin{array}{l}\text { New Mountain yellowish } \\
\text { Sandstone }\end{array}$ & Late Permian & $\begin{array}{l}\text { Silty grey sandstone, shaley } \\
\text { siltstone, coal and grey shale are } \\
\text { common, with coaly or } \\
\text { carbonaceous streaks and lenses. }\end{array}$ \\
\hline $\begin{array}{l}\text { Terra Cotta } \\
\text { Siltstone }\end{array}$ & Early Devonian & $\begin{array}{l}\text { Red, purple green and grey } \\
\text { siltstone, thin bedded. Thin } \\
\text { bedded. }\end{array}$ \\
\hline
\end{tabular}


Figure 3.1a Sirius Group Deposits, Mt. Feather

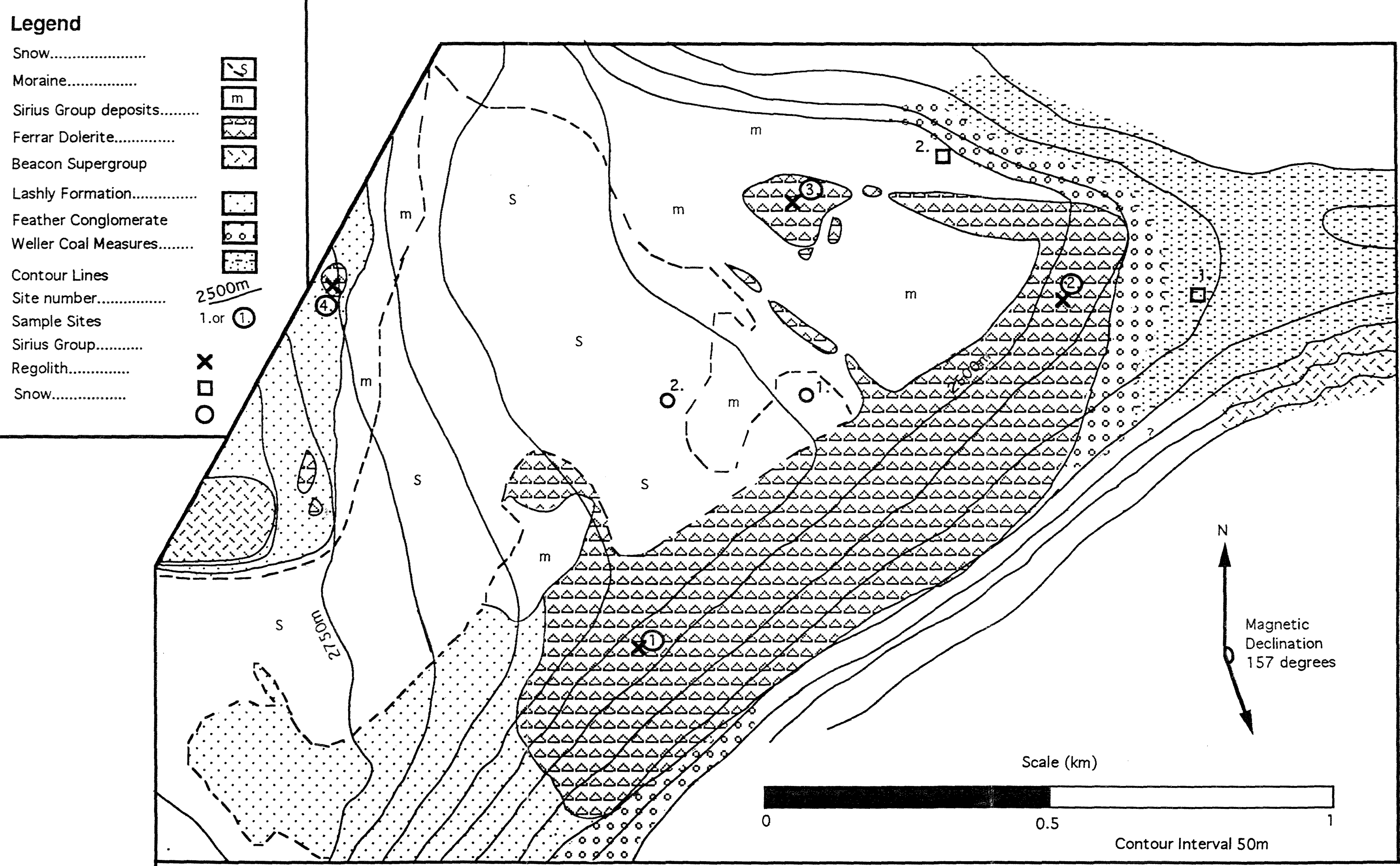




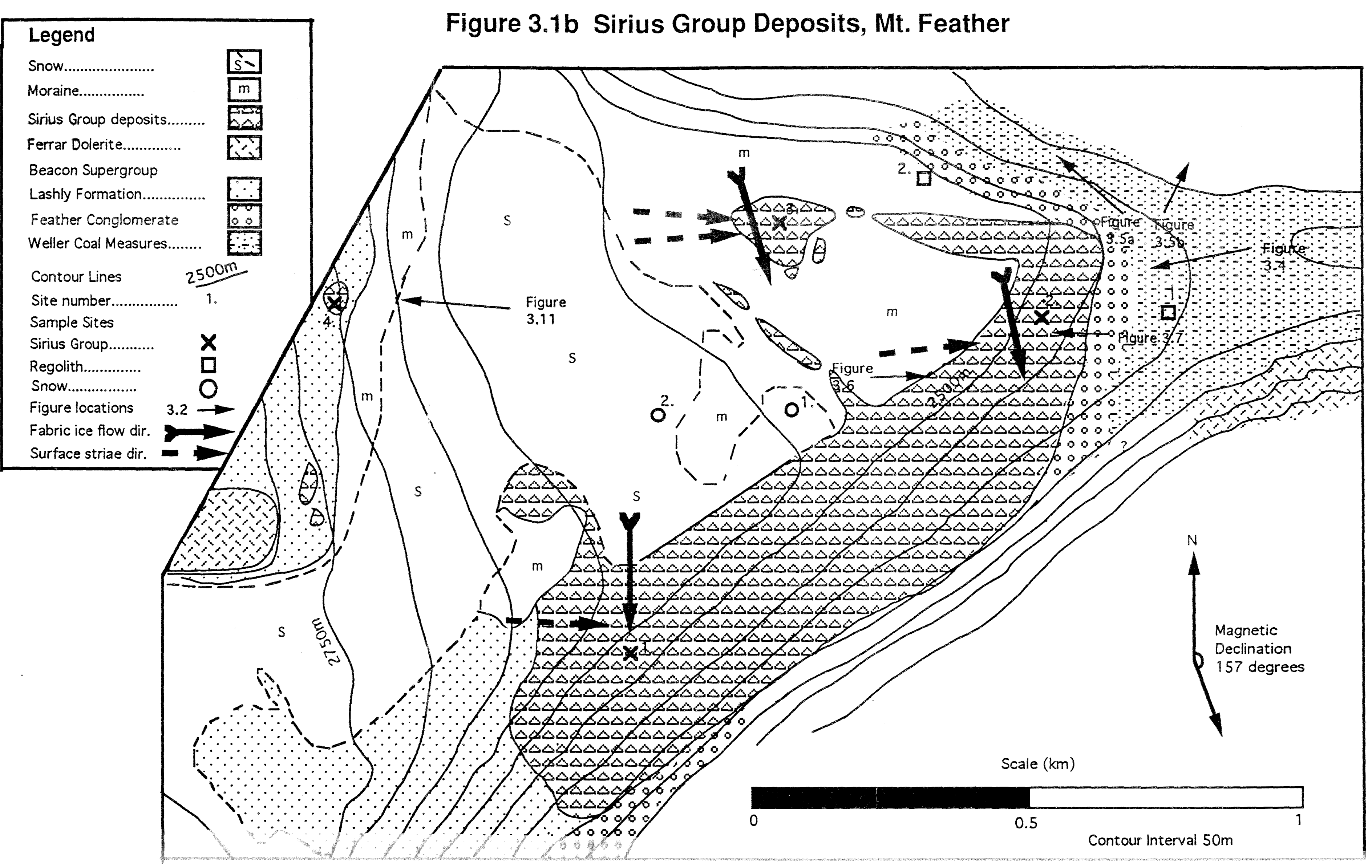


Figure 3.2a Sirius Group Deposits, Table Mountain

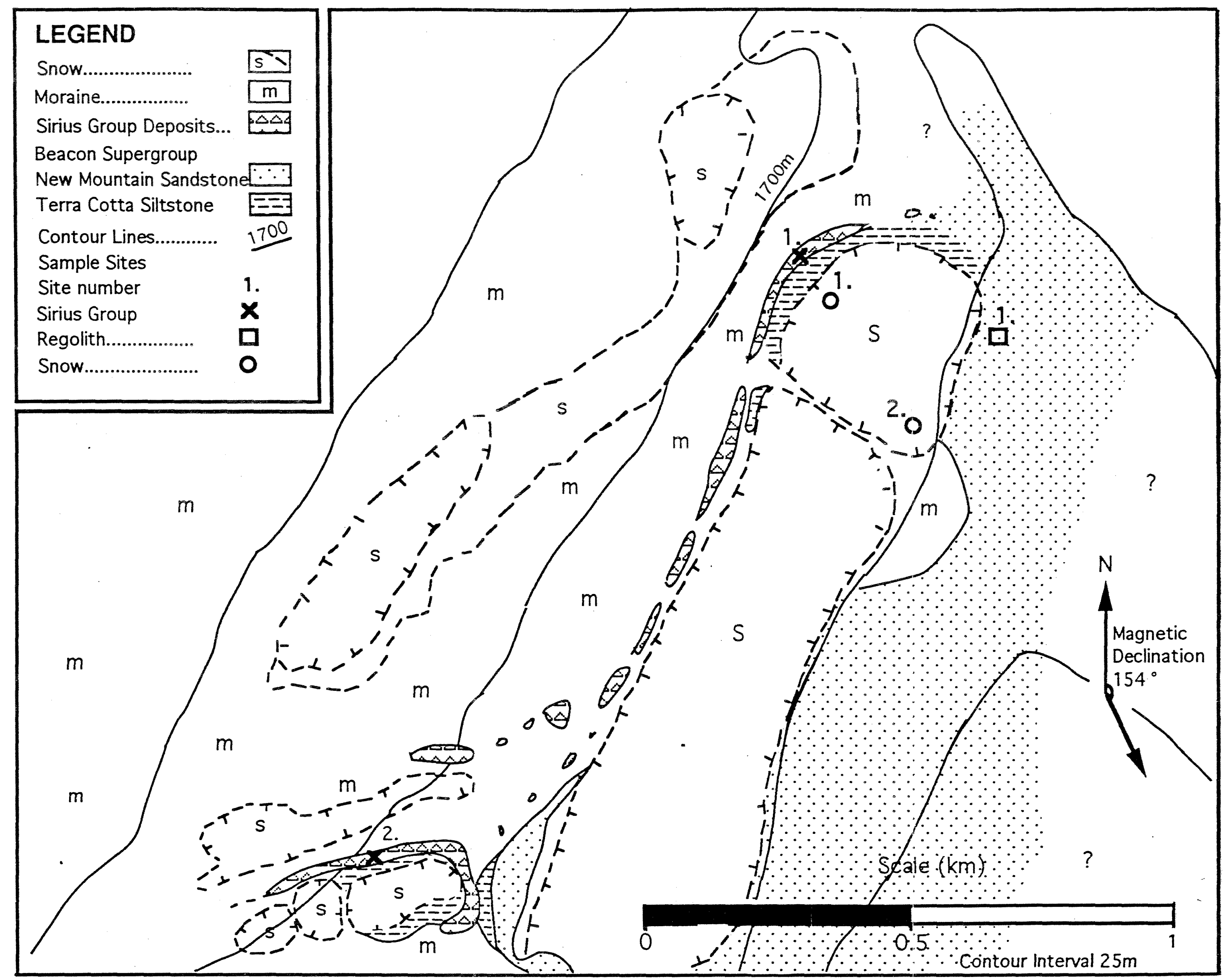


Figure 3.2b Sirius Group Deposits, Table Mountain

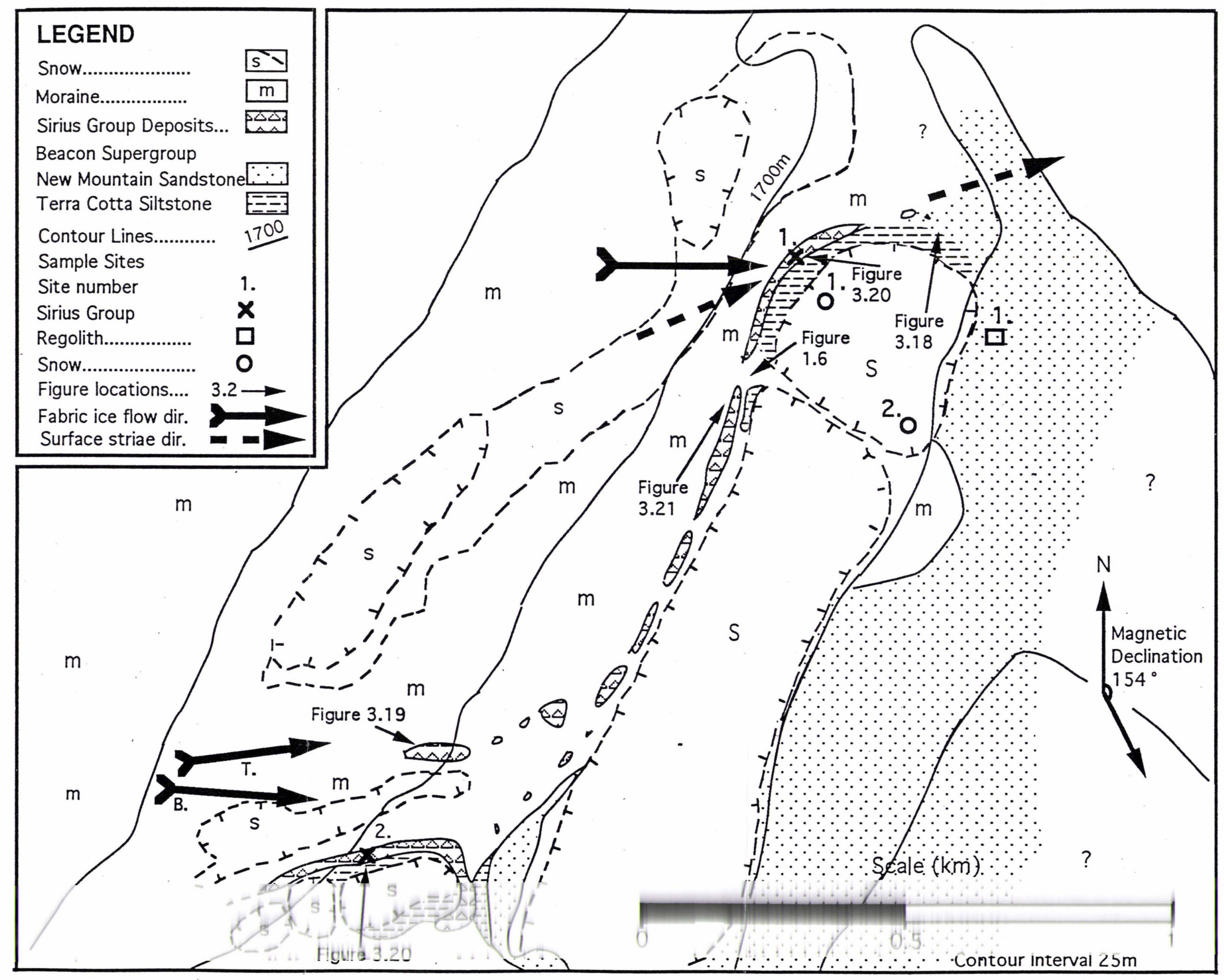




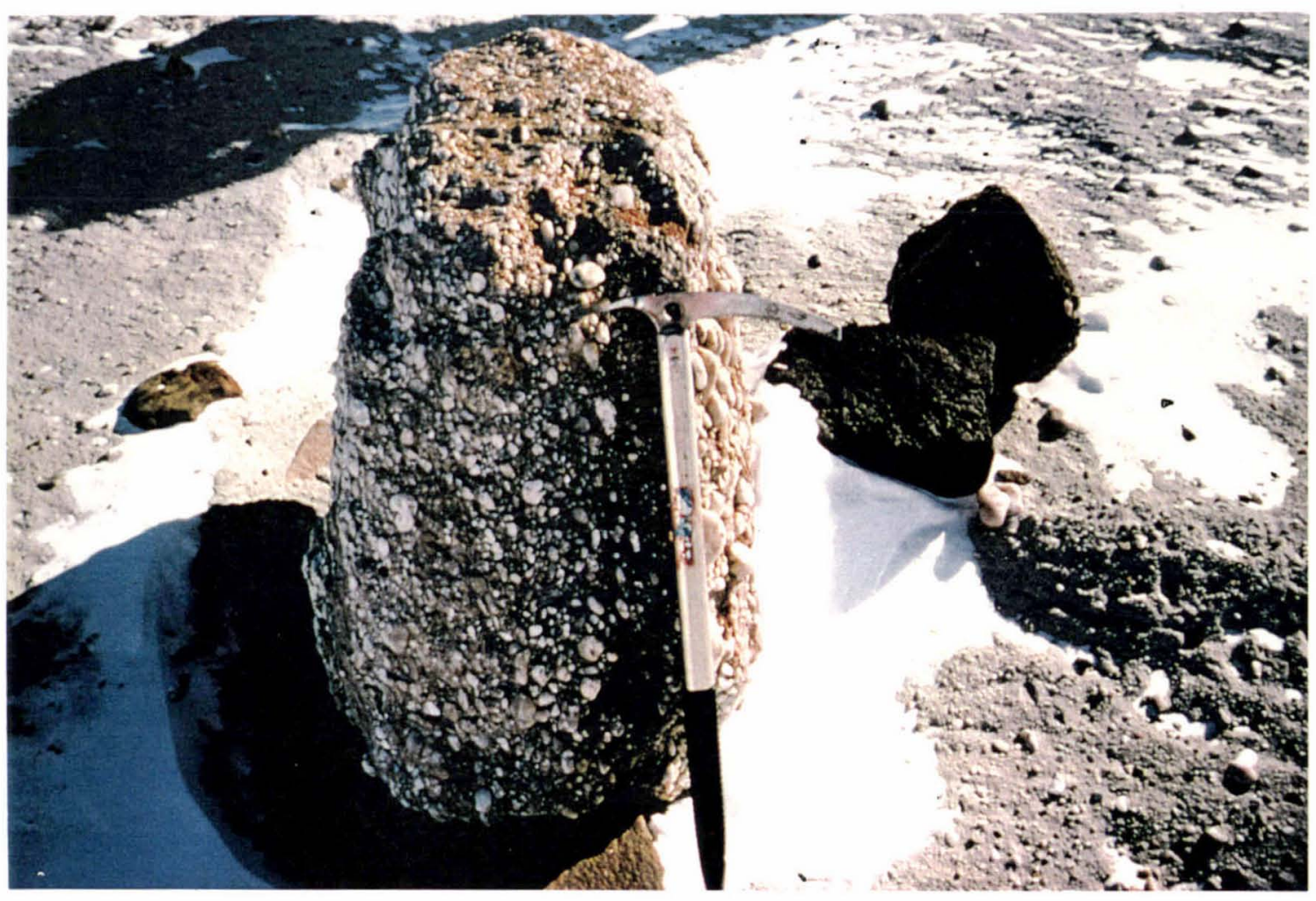

Figure 3.3 Large clast of Feather Conglomerate (Permian, left) and two boulders of Jurassic dolerite (right) on the Sirius till deposited by post Sirius glacial activity.

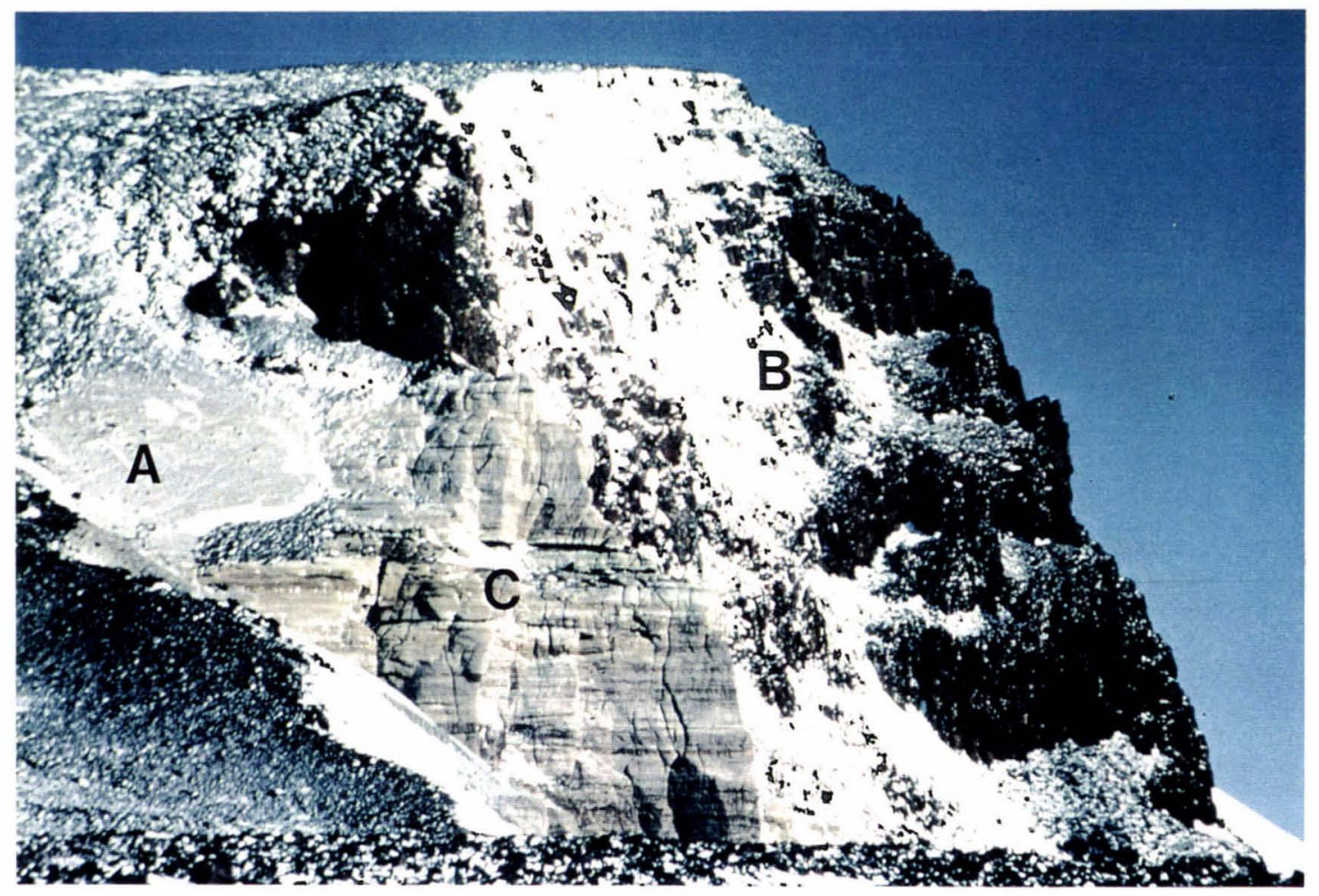

Figure 3.4 The letter A marks Sirius Site Four, a patch of Sirius till on the slope of the North Ridge of Mt. Feather. B marks the dark brown Ferrar Dolerite and $\mathrm{C}$ marks the striated fluvial beds of the Lashly Formation. 

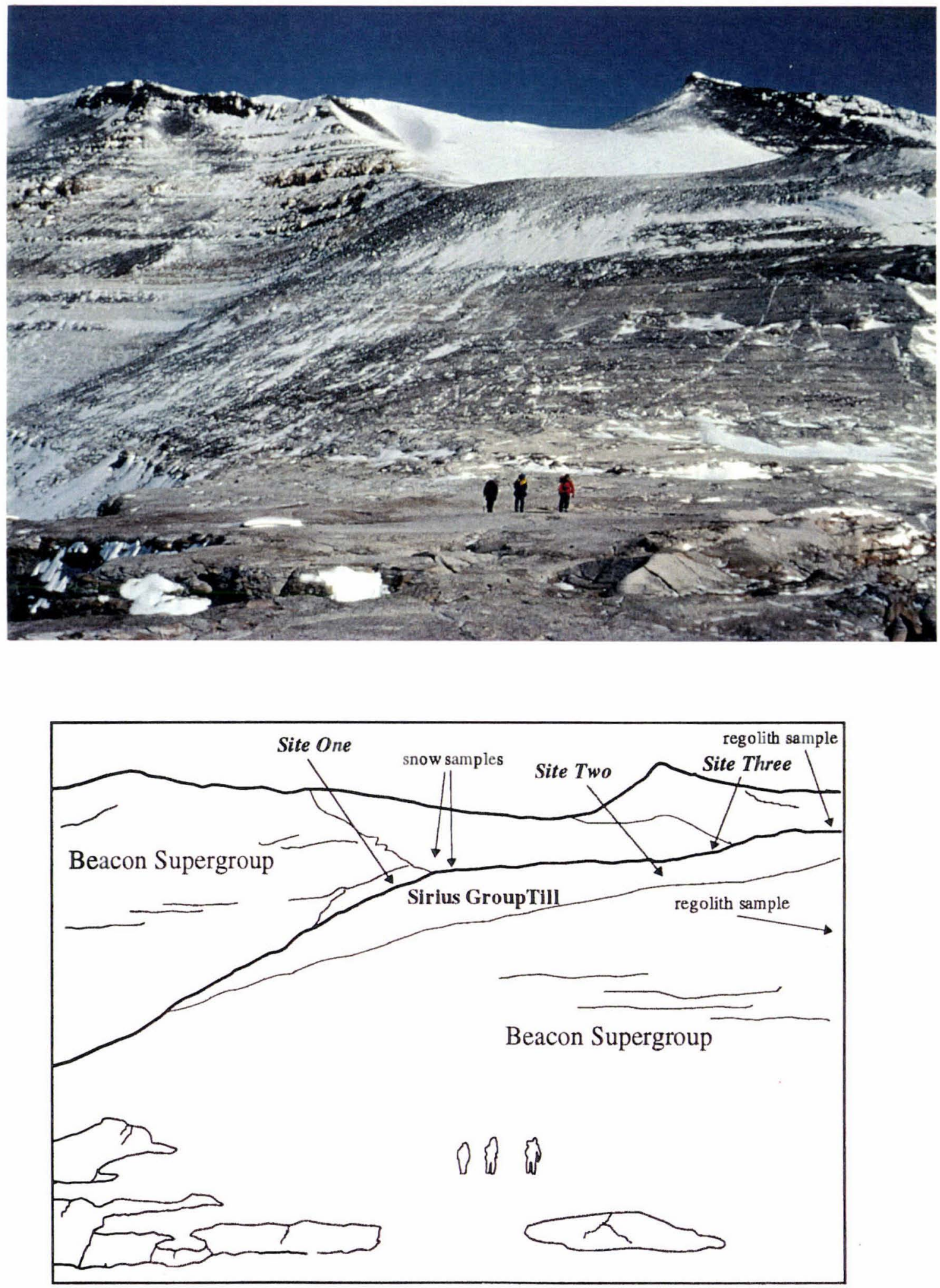

Figure 3.5 The platform at Mt. Feather over which the Sirius Group till drapes. The stencil outlines the important units and site locations. 


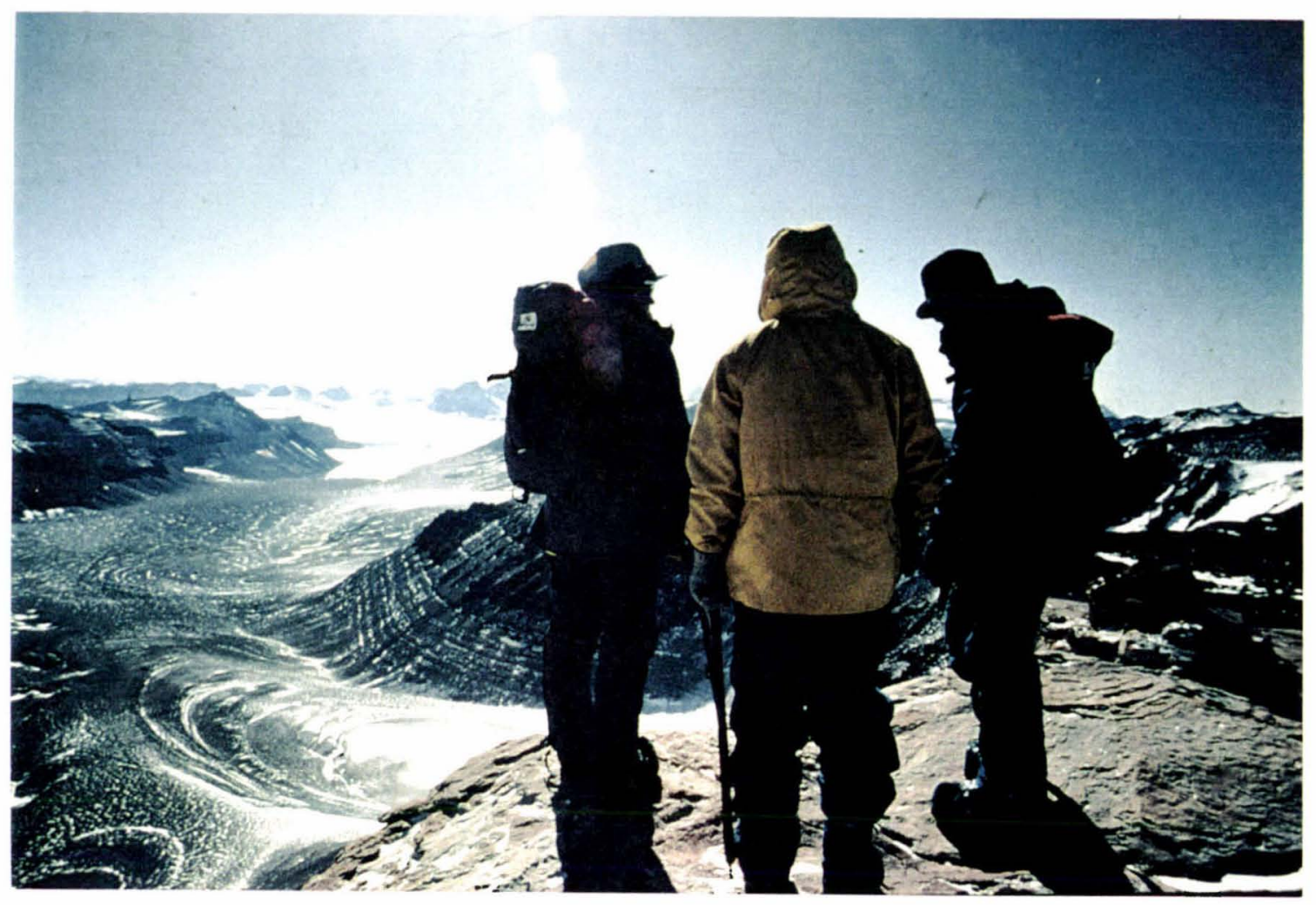

Figure 3.6 The 1000m drop to the floor of Beacon Valley. Photo looks north along Beacon Valley to Taylor Glacier in the distance.

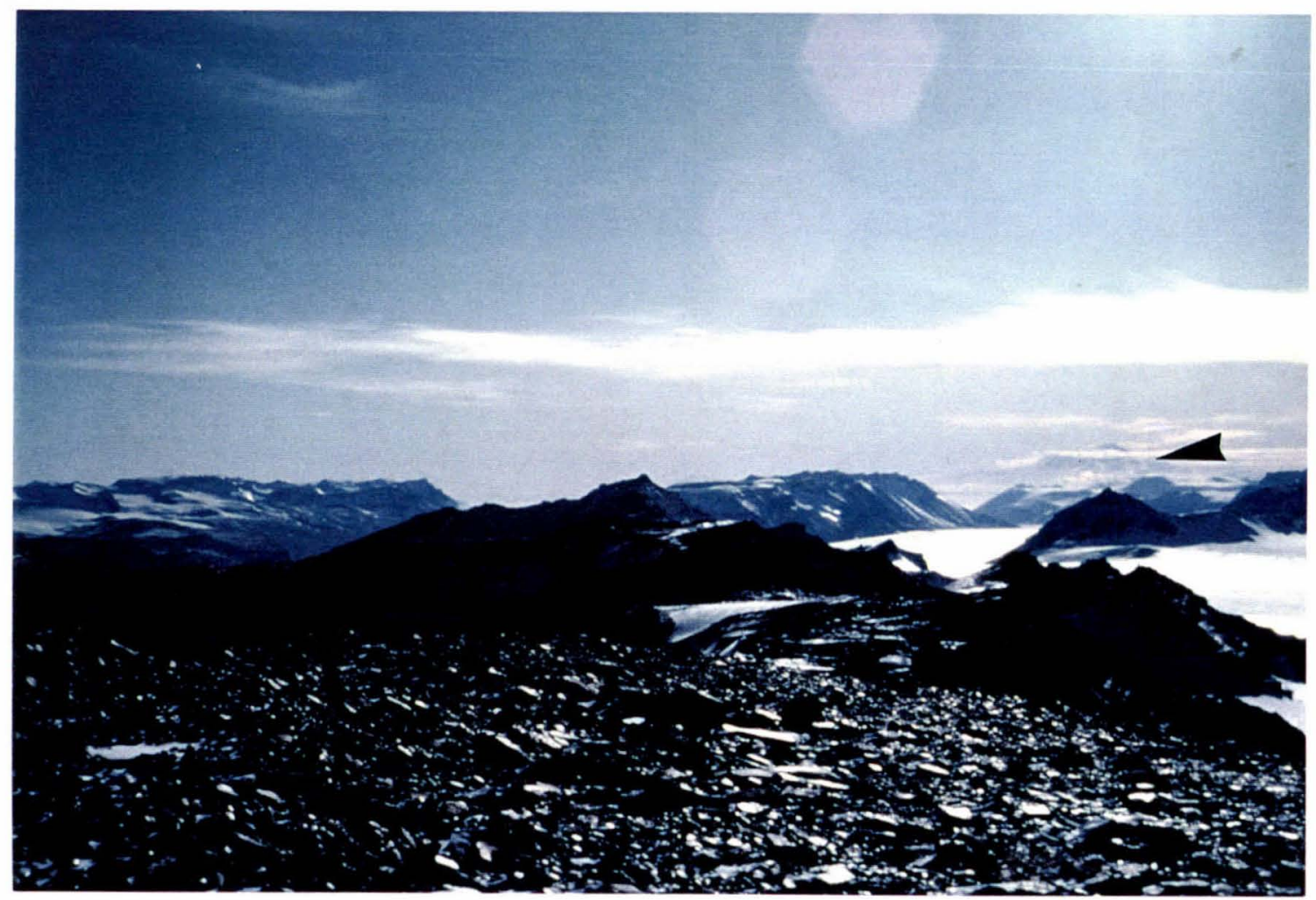

Figure 3.7 Gravel moraine overlying and adjacent to Sirius Group tills. Looks north east towards Ross Island (tip of arrow). 


\subsubsection{Lithology of the till}

\section{Hardness and Stratification}

Although the till at $\mathrm{Mt}$. Feather is similar in appearance, its compactness was highly variable. Figure 3.9 shows Site One was easier to penetrate to depth $(>17 \mathrm{~cm})$ using a chisel and hammer than the harder Site Two. The surface 15 $\mathrm{cm}$ at Site Three in the centre of the platform (fig. 3.1a) was a much softer sediment (fig. 3.9) but an extremely hard permafrost at $15 \mathrm{~cm}$ made further sampling with our equipment impossible.

No lithologic variation was seen in the till on Mt. Feather. However, there is a colour change with depth into the till from a light greenish grey to a darker grey as a result of surface weathering. The depth of change ranged from about $15 \mathrm{~cm}$ at Site One and Two, and $5 \mathrm{~cm}$ at Site Three (fig. 3.9).

The fresh darker grey colouring of the till most likely occurs from the influence of coal and carbonaceous shale originating from the Lashly Formation and Weller Coal Measures (fig. 3.10, table 3.1).

\section{Texture}

Grain size analysis was undertaken by both the author and Louisa Wolley using the sedimentology laboratory at Victoria University of Wellington. Results show there is very little variation in till texture at Mt. Feather (fig. 3.11, table 3.2). The tills comprise an average of $17.3 \%$ gravel, $58.9 \%$ sand and $23.8 \%$ mud. The material has a single well developed mode in the medium to coarse sand (1.00-1.50 phi) range (App. 2.2). This corresponds closely to the median size of sands in the upper part of the Beacon Supergroup of 1.5 phi (Weller Coal Measures) and $1.2 \mathrm{phi}$ (Feather Conglomerate). The overlying Lashly Formation is significantly lower in grainsize (2.15 phi, Korsch, 1974). 
Figure 3.8 Hardness diagram of sites at Mt. Feather and Table Mountain, also showing depth of colour change and ice occurrence.

\section{Mt. Feather}

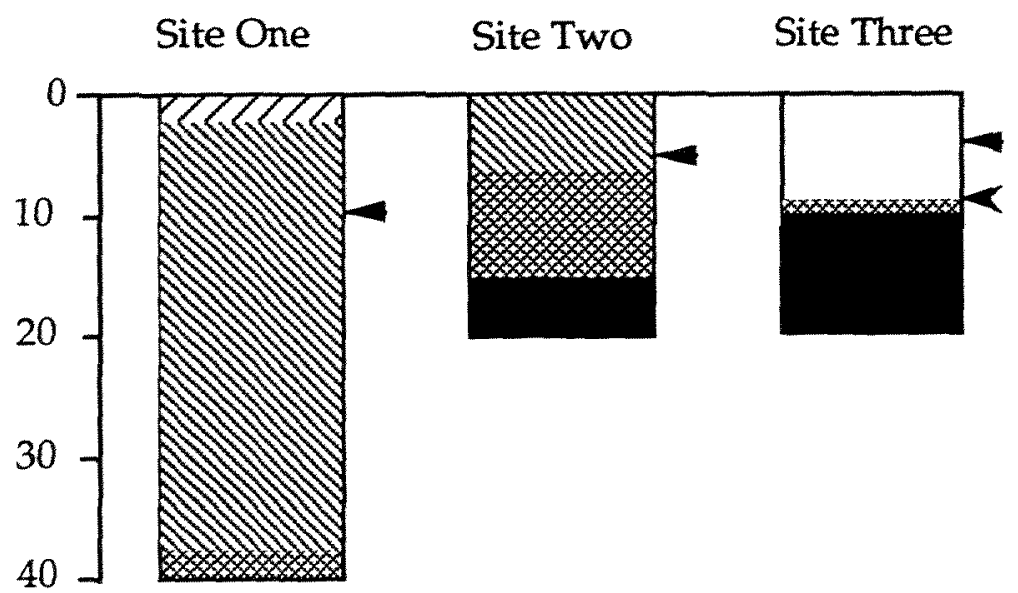

Table Mountain

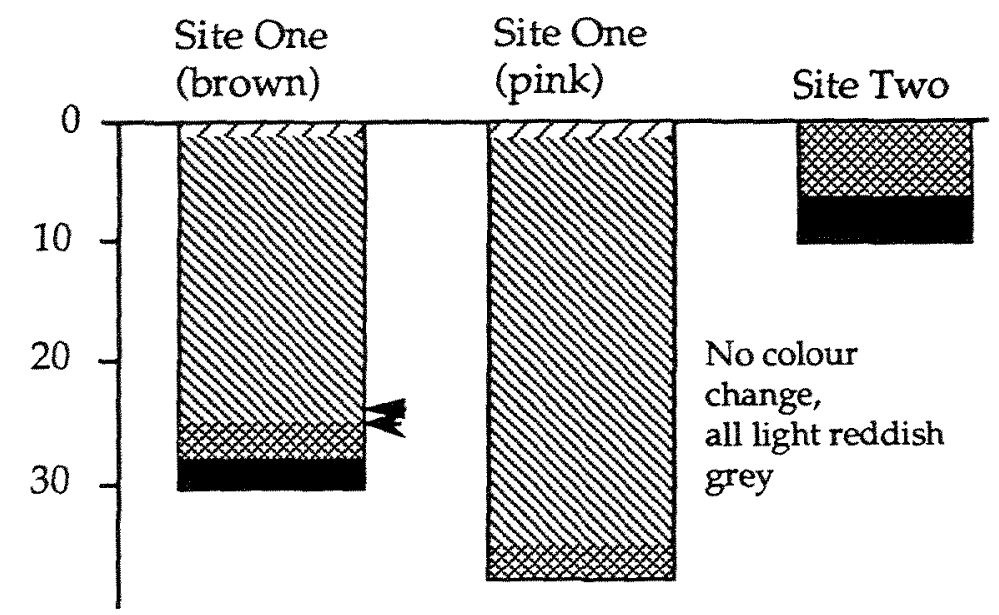

No colour change, all pale brown.

Key

Soft, crumbles in hands, easy to dig with a trowel

Firm, very difficult to dig with a trowel, easy to dig with a chisel and hammer.

Moderately hard, is penatrable with chisel and hammer

Hard, just penatrable with chisel and hammer

Very hard, not penetrable with chisel and hammer

- Depth of colour change.

Mt. Feather, from light greenish grey to a darker grey.

Table Mountain, from light grey (brown) to a light reddish grey (pink).

$<$ Ice begins 


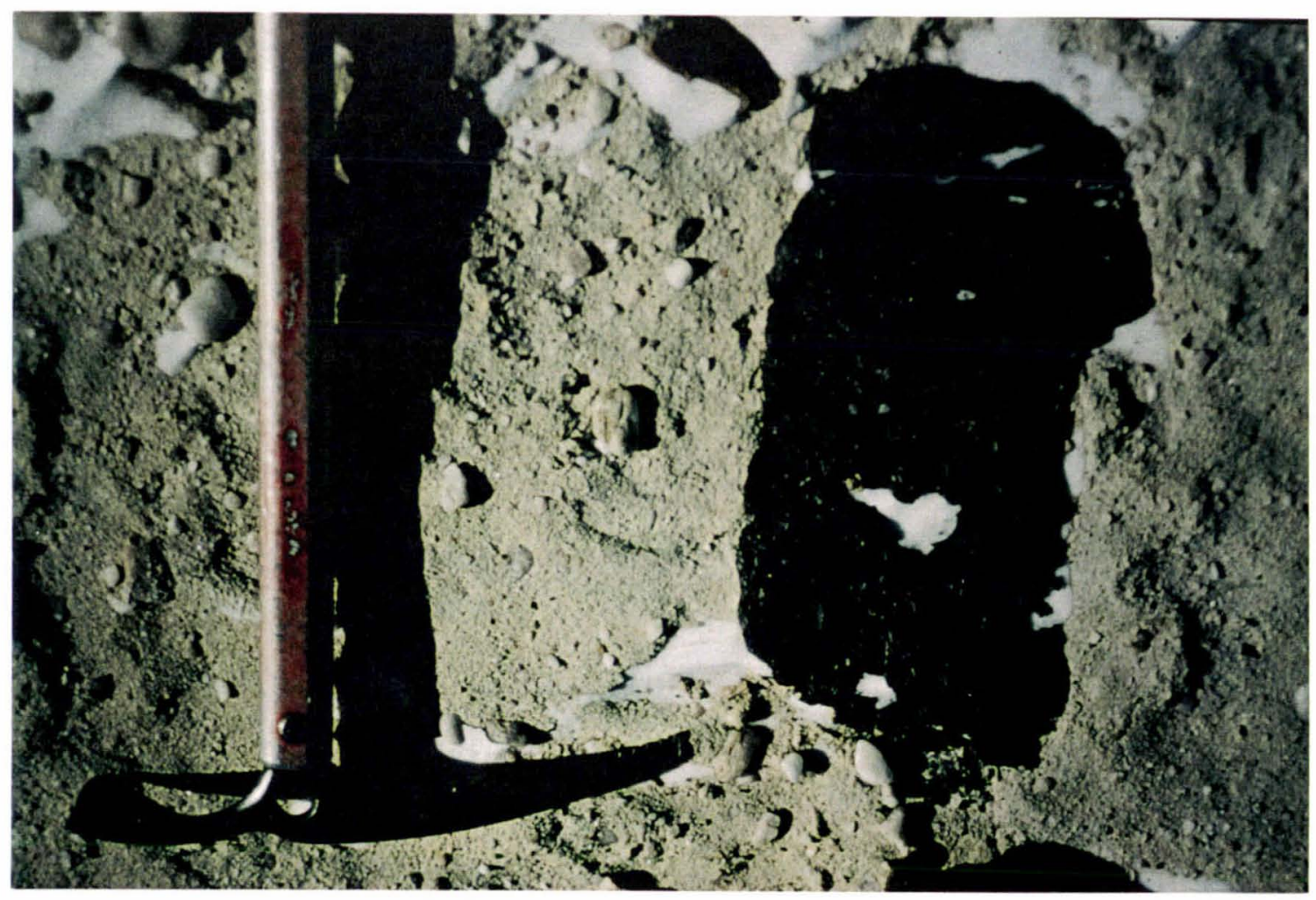

Figure 3.9 Large clast of coal in the Sirius Group till at Mt. Feather. Its origin may either be from Lashly Formation or Weller Coal Measures which lie adjacent to and below the Sirius Group till at Mt. Feather. There is a large amount of coal in the matrix of the Sirius Group material giving the fresh material its light grey colouring.

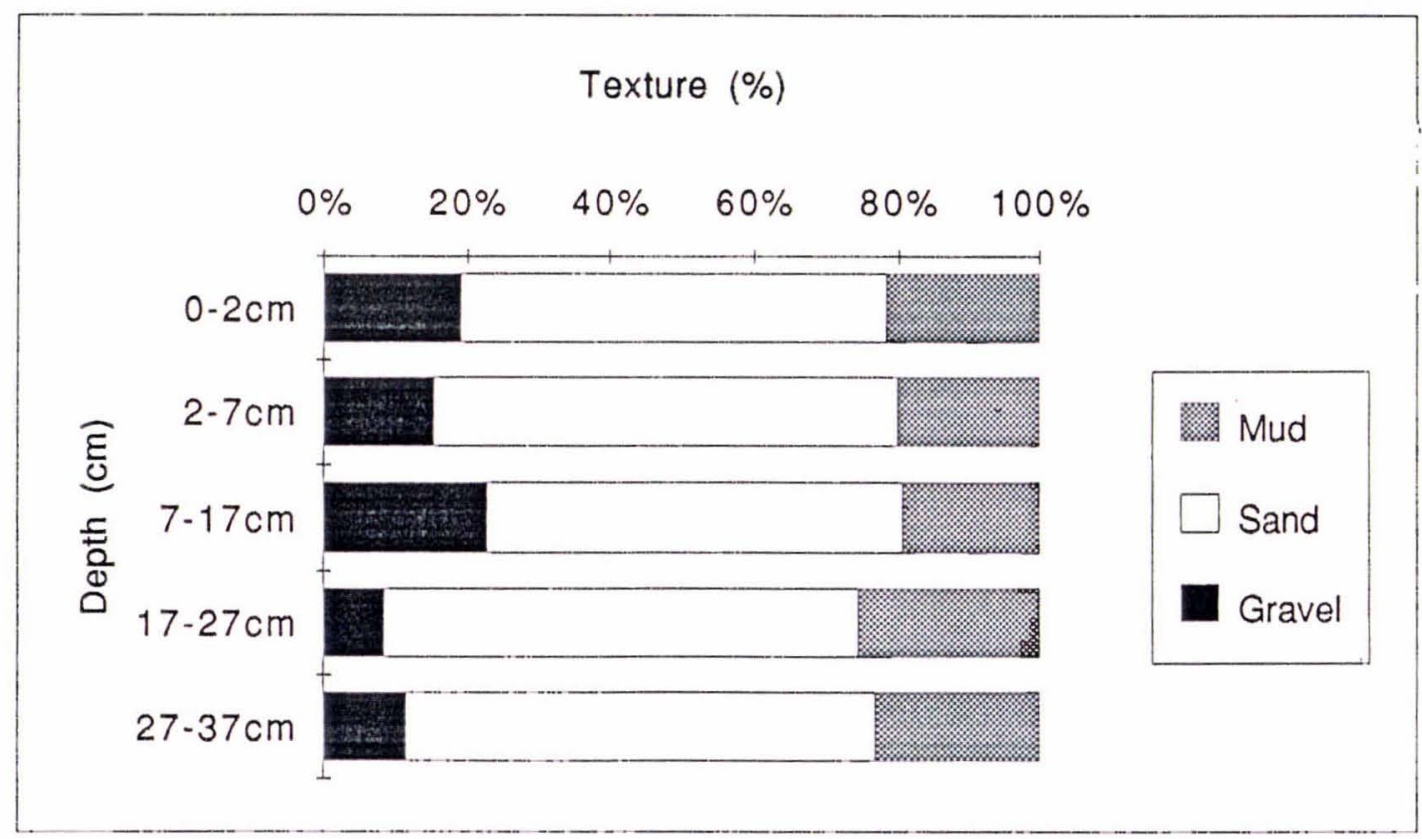

Figure 3.10 Plot of percent gravel, sand and mud at various depths at Site One, Mt. Feather. 
Table 3.2 Percent gravel, sand and mud in all Sirius till samples at Mt. Feather. Analyist: Dr. Warren Dickinson.

\begin{tabular}{|c|c|c|c|}
\hline & \multicolumn{3}{|c|}{ Percent $(\%)$} \\
\hline Sample & Gravel & Sand & Mud \\
\hline $\mathrm{F} 10-2 \mathrm{~cm}$ & 19.14 & 59.31 & 21.55 \\
\hline $\mathrm{F} 12-7 \mathrm{~cm}$ & 15.37 & 64.57 & 20.06 \\
\hline $\mathrm{F} 17-17 \mathrm{~cm}$ & 22.78 & 57.84 & 19.38 \\
\hline$F 1 \quad 17-27 \mathrm{~cm}$ & 8.50 & 66.08 & 25.42 \\
\hline$F 127-37 \mathrm{~cm}$ & 11.48 & 65.43 & 23.09 \\
\hline $\mathrm{F} 20-2 \mathrm{~cm}$ & 49.99 & 33.27 & 16.74 \\
\hline $\mathrm{F} 22-7 \mathrm{~cm}$ & 8.82 & 55.80 & 35.38 \\
\hline $\mathrm{F} 27-17 \mathrm{~cm}$ & 39.54 & 38.53 & 21.94 \\
\hline F3 $0-2 \mathrm{~cm}$ & 6.88 & 64.56 & 28.56 \\
\hline F3 $2-7 \mathrm{~cm}$ & 8.24 & 64.22 & 27.54 \\
\hline $\mathrm{F} 37-17 \mathrm{~cm}$ & 13.57 & 59.55 & 26.88 \\
\hline $\mathrm{F} 4 \quad 0-2 \mathrm{~cm}$ & 11.12 & 73.24 & 15.64 \\
\hline $\mathrm{F} 4 \quad 0-2 \mathrm{~cm}$ & 13.62 & 58.88 & 27.50 \\
\hline
\end{tabular}

\section{Porosity and matrix structures}

The porosity and matrix structures of the till from Mt. Feather were analysed by Dr. Warren Dickinson at Victoria University of Wellington. The till varies greatly in porosity with values ranging from $1 \%$ to $22 \%$ (table 3.3 ). The mean pore size varies between averages of $30 \mu \mathrm{m}$ (Site Two) and $360 \mu \mathrm{m}$ (Site Three). Generally samples with a larger porosity tend also to have a larger pore size (table 3.3). An aspect ratio averaging between 0.22 and 0.41 indicates pores of a slightly elongate form (App. 3.3). It should also be noted that porosity varies considerably even within a single thin section (Dr. Warren Dickinson, VUW, personal communication, 1995).

Site One shows a decrease in porosity at the $7-17 \mathrm{~cm}$ level, also a smaller overall pore size, and a slightly higher proportion of matrix than at the other levels (table 3.3, App.3.3).

Site Two has a lower porosity, smaller pores, a smaller standard deviation and a slightly higher proportion of matrix than Sites One and Three.

Site Three has a lower proportion of matrix than the other two sites. It shows a very high mean porosity and large pores on the surface and a very low porosity and small pores at depth (App. 3.3). 
Table 3.3 Porosity and pore size in Sirius Group till samples from Mt. Feather. Based on 300 points in thin section. Analyst: Dr Warren Dickinson.

\begin{tabular}{|l|c|c|c|c|c|c|}
\cline { 3 - 7 } \multicolumn{2}{c|}{} & \multicolumn{4}{c|}{ Pore size $(\mu \mathrm{m})$} \\
\hline F1 & Sample & Porosity $(\%)$ & Mean size & Std. dev. & $\times$ long axis & x short axis \\
F1 & $2-7 \mathrm{~cm}$ & 11 & 280 & 260 & 549 & 157 \\
F1 & $7-17 \mathrm{~cm}$ & 13 & - & - & - & - \\
F1 & $17-27 \mathrm{~cm}$ & 8 & 170 & 120 & 365 & 86 \\
F1 & $27-37 \mathrm{~cm}$ & 11 & - & - & - & - \\
\hline F2 & $0-2 \mathrm{~cm}$ & 14 & 230 & 180 & 428 & 127 \\
F2 & $2-7 \mathrm{~cm}$ & 4 & 40 & 20 & 77 & 21 \\
F2 & $7-17 \mathrm{~cm}$ & 1 & 30 & 20 & 95 & 12 \\
\hline F3 & $0-2 \mathrm{~cm}$ & 2 & 30 & 20 & 93 & 14 \\
F3 & $7-17 \mathrm{~cm}$ & 22 & 360 & 280 & 673 & 203 \\
\hline
\end{tabular}

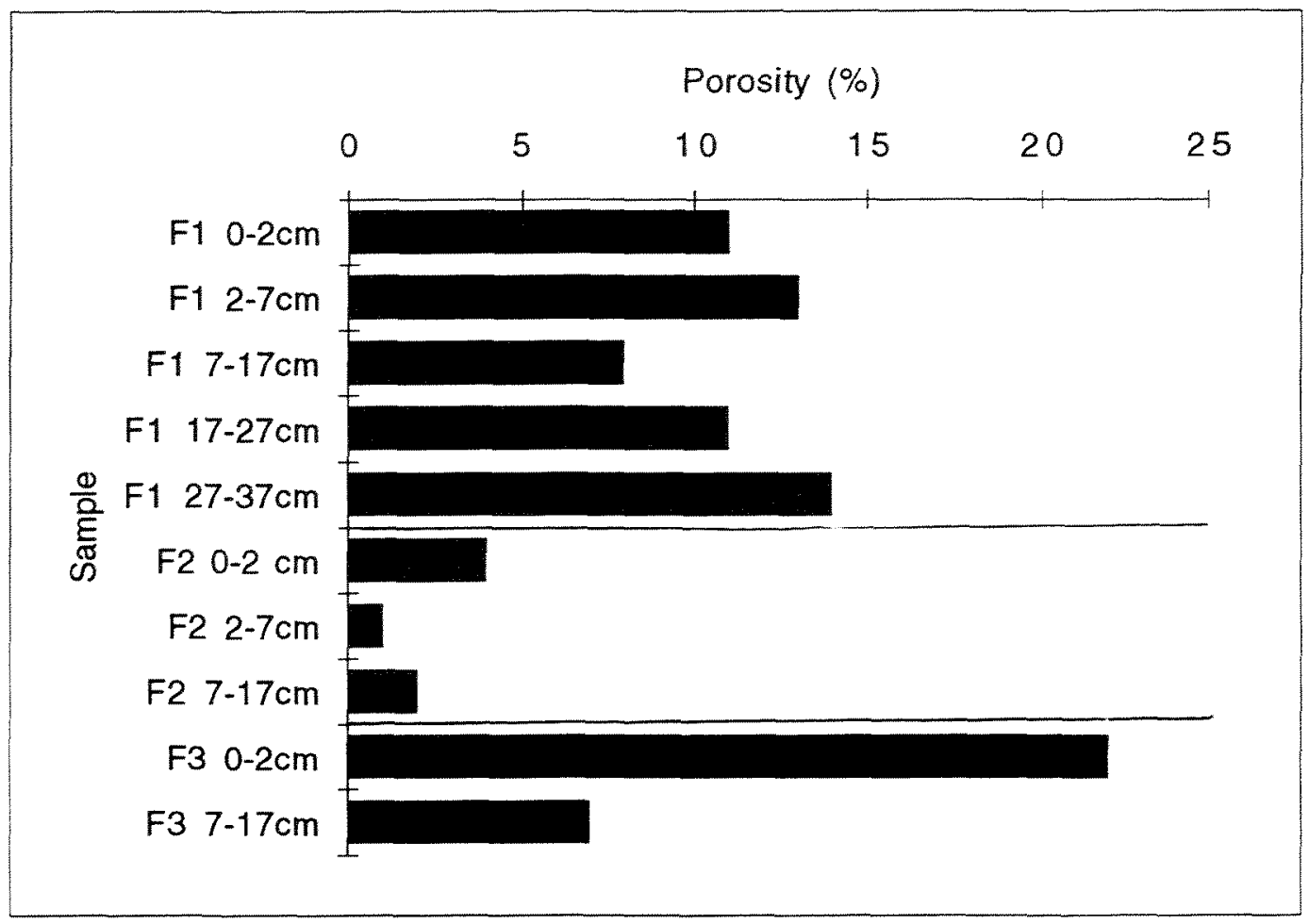

Figure 3.11 Plot of the percent porosity in samples from the Sirius Group till, Mt. Feather. 


\section{Composition}

\section{Clasts}

Quartz dominates the pebble clasts in the till at Mount Feather (table 3.4). This occurs as a result of glacial erosion of the Feather Conglomerate where clasts are almost entirely of quartz composition. Coal, the second most abundant clast in the Sirus Group tills at Mt. Feather most likely has its source from the Weller Coal Measures, which lie directly beneath the Feather Conglomerate.

Most of the boulder sized clasts identified were either of Ferrar Dolerite or Feather Conglomerate origin (fig. 3.4). Larger clasts of sandstone, siltstone and coal were also noted (fig. 3.10). These were most likely derived from the Lashly Formation, Feather Conglomerate, Weller Coal Measures and other local members of the Beacon Supergroup which lie adjacent to the Sirius Group till and for tens of kilometres surrounding Mt. Feather.

Table 3.4 Clast lithology of the pebble size fraction from the Sirius Group tills at Mt. Feather and Table Mountain.

\begin{tabular}{|l|c|c|c|c|c|c|c|c|c|}
\hline Clast & \multicolumn{3}{|c|}{ Mt. Feather, site } & \multicolumn{3}{|c|}{ Table Mountain, site } \\
\cline { 2 - 10 } \\
Lithology & 1 & 2 & 3 & Total & $\%$ & 1 & 2 & Total & $\%$ \\
\hline Quartz & 42 & 56 & 38 & 136 & 80 & 8 & 9 & 17 & 13 \\
Coal & 2 & 3 & 9 & 14 & 8 & & & & \\
Dolerite & 3 & & & 3 & 2 & 26 & 30 & 56 & 43 \\
Siltstone & 1 & & 2 & 3 & 2 & & & & \\
Sandstone & 2 & 2 & 4 & 8 & 5 & 17 & 14 & 31 & 23 \\
Coarse sandstone & 5 & & & 5 & 3 & 1 & 10 & 11 & 8 \\
Quartz conglom. & 1 & & & 1 & 0.5 & & & & \\
Shale & 1 & & & 1 & 0.5 & 4 & 13 & 17 & 13 \\
\hline Total & 57 & 61 & 53 & 171 & 101 & 56 & 76 & 132 & 100 \\
\hline
\end{tabular}

\section{Sand}

Table 3.5 (Table A3.4) shows the mineralogy of the sand size fraction which was microscopically point counted by Dr. Warren Dickinson, Geology Department, Victoria University of Wellington. Table 3.5 emphasises the high proportion of quartz in the sample most likely originating from the high proportion of quartz sand in the Beacon Supergroup. Matrix ranges from 26 and $35 \%$ of the slides (table 3.5 ). The igneous rock fragments reported are entirely of Ferrar Dolerite origin (table 3.5). 
Table 3.5 Average point count percentages of the sand size fraction in thin section from the Sirius Group till at Mt. Feather (based on 300 points in thin section; analyst: Dr Warren Dickinson) and adjacent Beacon Supergroup Formations from Korsch (1974).

\begin{tabular}{|l|c|c|c|c|c|c|c|c|}
\hline Sirius Sites & Quartz & Feldspar & SRF & IRF & MRF & Opaque & Clay Mtx & Other \\
\hline Site one & 37 & 5.2 & 7 & 7 & 2 & 2.5 & 22 & 1 \\
Site two & 26.6 & 11.6 & 6 & 10.6 & 3.3 & 6 & 32 & 1 \\
Site three & 35 & 5 & 8 & 7 & 4.5 & 4.5 & 25 & 0.5 \\
\hline Beacon Supergroup & & & & & & Mica & & \\
Lashly Fmn. & 48.4 & 12 & 8.1 & - & - & 0.6 & 30.6 & 0.22 \\
Feather Cong. & 70 & 9.7 & 1.3 & - & - & - & 19.1 & - \\
Weller Coal Mes. & 51 & 2.1 & 1.4 & - & - & 0.06 & 35.8 & 0.97 \\
\hline
\end{tabular}

* From Korsch (1974)

$\%$ porosity has not been included in the diagram. For full \% see Appendix 3.2

\section{Clay}

The samples were prepared by the author and run by Kerry Stevens in the xray defractometer in the Geology Department at Victoria University of Wellington. Samples analysed from Mt. Feather show a dominance of kaolinite (kaolin), with some mica and a small amount of chlorite (Fig. 3.12).

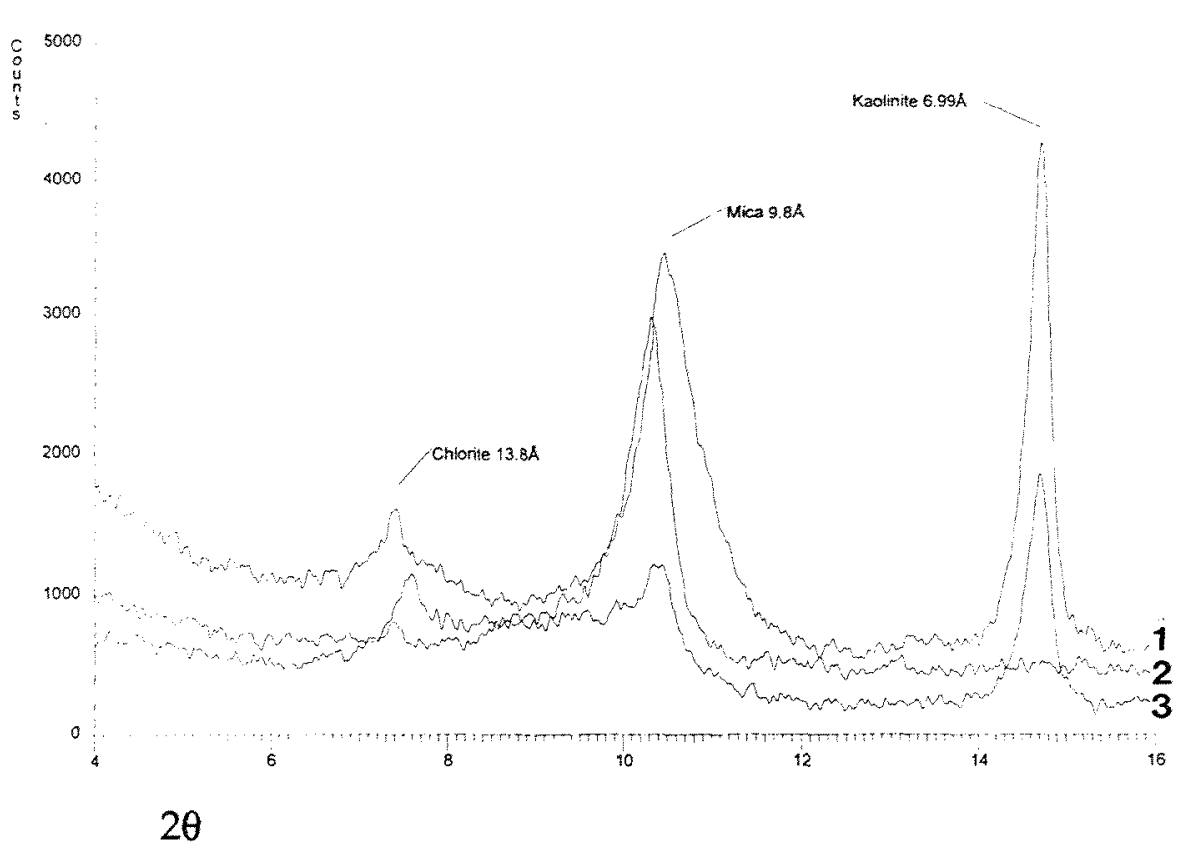

Figure 3.12 Curves of (1) air dried, (2) ethylene glycol treated and (3) heated xray analysis of the clay fraction from $\mathrm{Mt}$. Feather. 


\section{Discussion}

Kaolin forms as a consequence of long continued weathering in temperate to tropical climates, and does not occur in the unweathered Antarctic soils of today (Claridge and Campbell, 1986). Kaolin has been reported as common constituent of northern hemisphere polar desert soils, where the weathering environment is slightly warmer and more moist than the cold deserts of Antarctica (Bockheim, 1980). Kaolin occuring in polar regions may be derived from weathering of older kaolin bearing sediments, and erosion of paleosols (Ehrmann and Mackensen, 1992). Kaolin is thought not to survive the high temperature the Beacon Supergroup underwent (Warren Dickinsen, VUW per. comm. 1996). Hence warm enough conditions to create kaolin must have occurred in Antarctica at some time before the erosion and deposition of the till material which includes the detrital kaolin, but after the exposure of the Beacon Supergroup. There is little record of kaolin from Antarctica in the past, hence more clay analysis of the tills is being undertaken to further confirm these findings. About 1\% Kaolin has been identified from Eocene and Oligocene sediments at DSDP, site 323 (Zemmels and Cook, 1976).

\section{Clast Shape}

\section{Roundness}

Clast roundness using the visual roundness of Krumbein (1941) averaged at 0.49 (table 3.6, A4.2).

\section{Sphericity}

An average sphericity of 0.68 was calculated for the clasts at Mt. Feather. This is identical to the average sphericity calculated from the clasts in the Feather Conglomerate at Mt. Feather by Barrett and Fitzgerald (1985, table 3.6, A4.1).

Table 3.6 The mean and standard deviation of the sphericity and roundness of clasts at $\mathrm{Mt}$. Feather and Table Mountain from appendix 4.1 and 4.2 .

\begin{tabular}{|c|c|c|c|c|}
\hline Site & \multicolumn{2}{|l|}{ Sphericity } & \multicolumn{2}{c|}{ Roundness } \\
\hline Mount Feather & Mean & Std. Dev & Mean & Std.Dev \\
\cline { 2 - 6 } Site One & 0.68 & 0.13 & 0.48 & 0.14 \\
Site Two & 0.68 & 0.09 & 0.5 & 0.05 \\
Table Mountain & & & & \\
Site One & 0.59 & 0.15 & 0.44 & 0.07 \\
Site Two & 0.65 & 0.13 & 0.46 & 0.07 \\
\hline Feather Congl. & 0.68 & & 0.57 & \\
\hline
\end{tabular}




\section{Clast fabric and striae}

Clast fabrics in the Sirius Group tills on Mt. Feather are well developed (fig. $3.13,3.14)$. At Site One the azimuth and dip of the A axis of twenty two clasts from within the till were measured. The fabric from Site One suggests an average glacial flow direction at this site from $3^{\circ}$ (fig. 3.1b, 3.14). At Site Two (fig. 3.1b, 3.14) the fabric of fifty two clasts were measured suggesting an average glacial flow direction from $347^{\circ}$. Fifty clasts were measured from the till at Site Three also suggesting an average glacial flow direction from $347^{\circ}$ (fig. $3.1 \mathrm{~b}$, 3.14).

Measurements of rat-tail striations on the surface of the till give directions from $275^{\circ}$ at Site One, two directions of $285^{\circ}$ and $265^{\circ}$ at Site Two, and $266^{\circ}$ at Site Three, suggesting a more recent erosion of the till from these directions (fig. 3.1b, App 4.4).

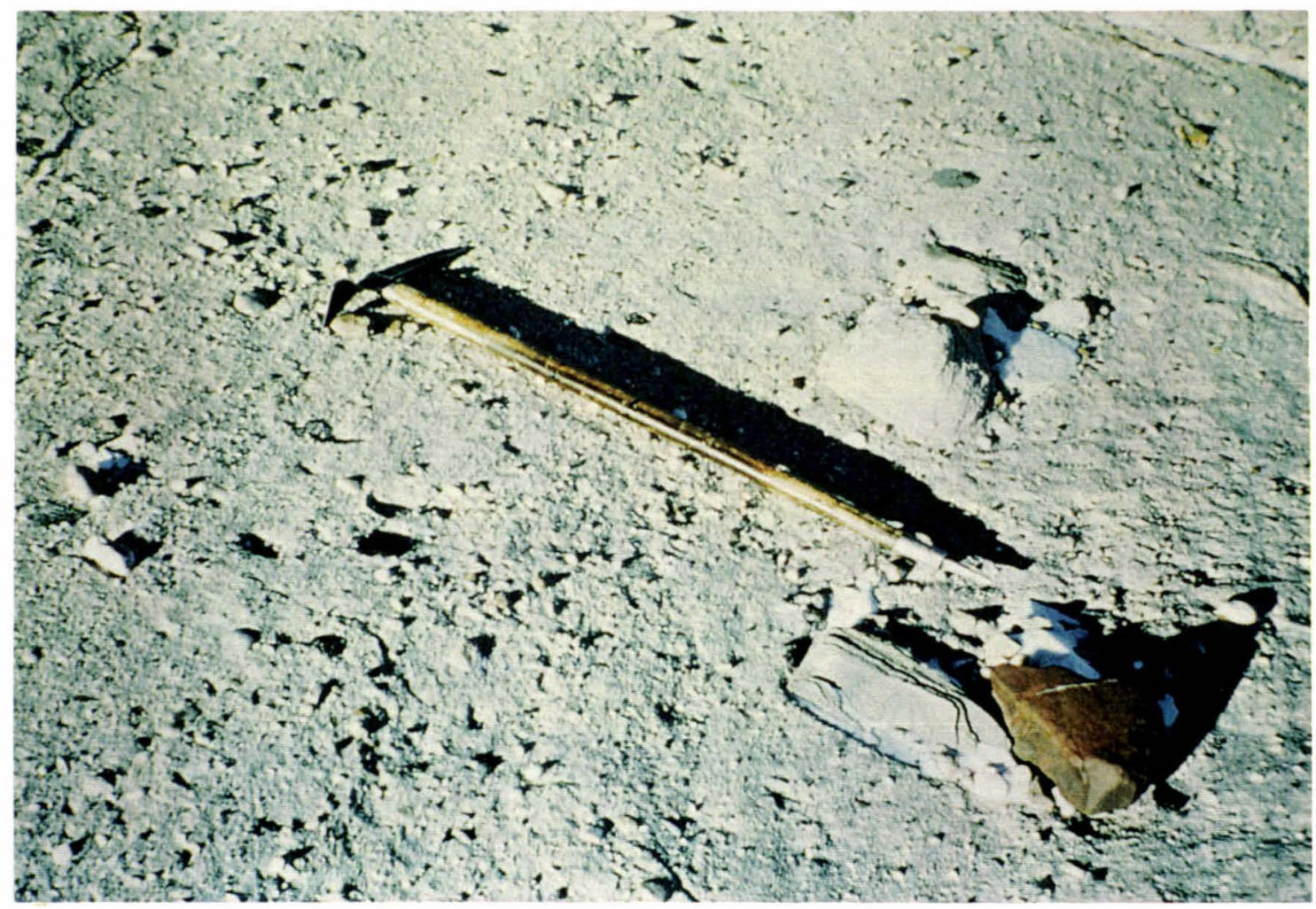

Figure 3.13 Strong fabric in the Sirius Group till at Mt. Feather (photo from Dave Harwood, University of Nebraska-Lincoln). 


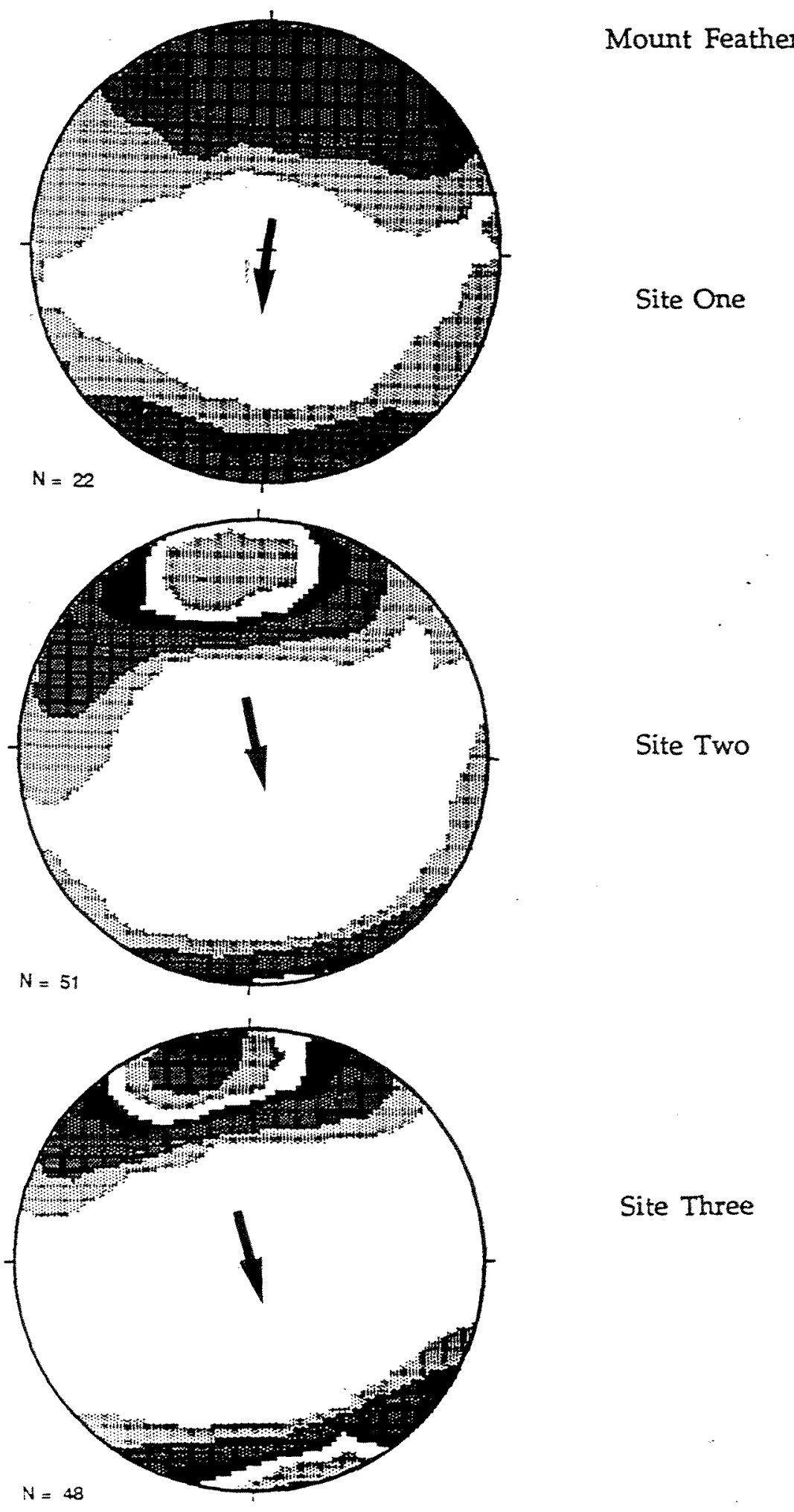

Figure 3.14 Stereonet fabric plots from Sites One, Two and Three at Mt. Feather. From measurements of the dip and dip direction of the long axis of clasts within the till. Fabric shows a strong southerly paleo ice flow. 

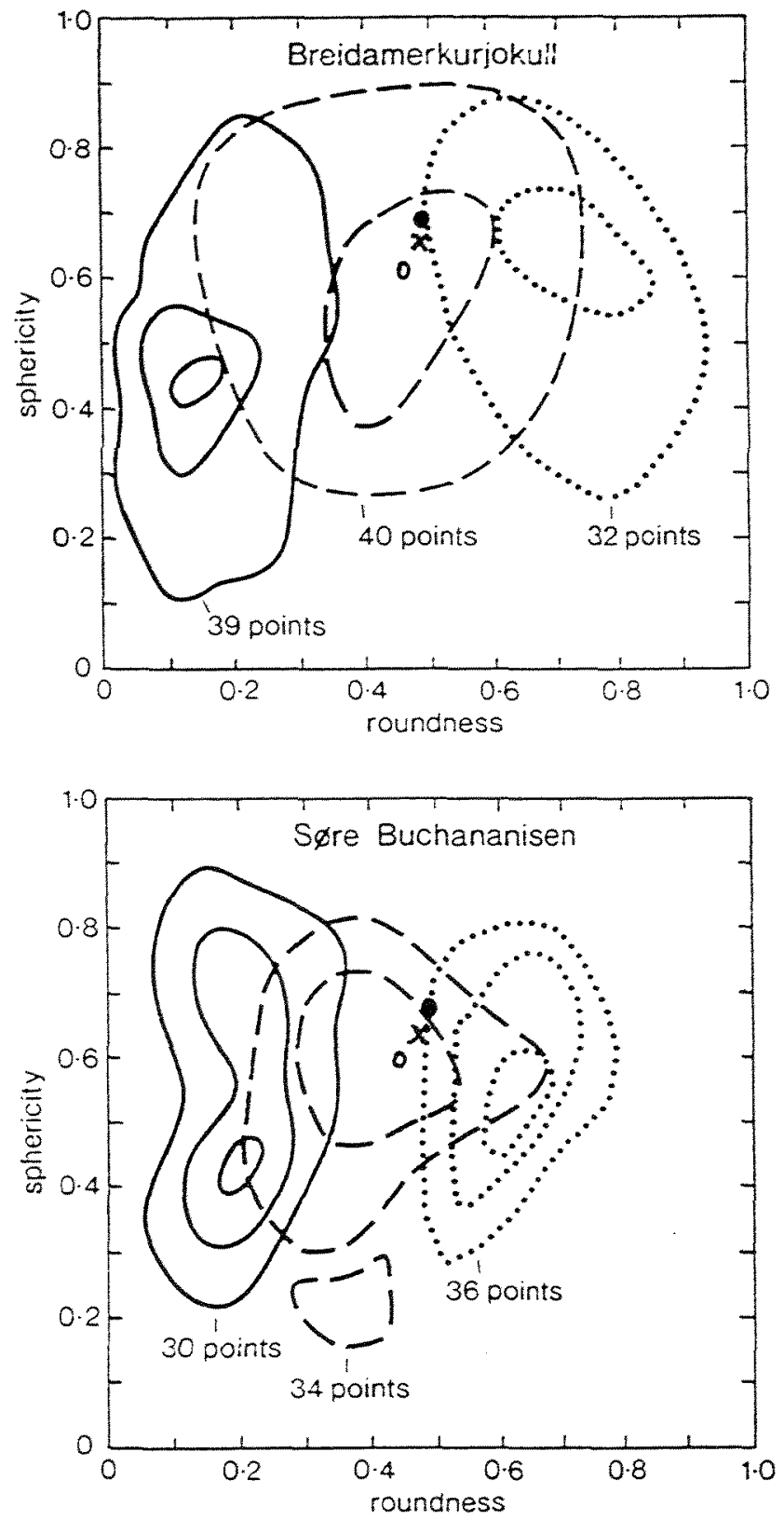

(D) Supiaglacially derivec boulders in high level iransport

E- Boulders trom the zone of traction

- Table Mountain, Site one

$\because \because$ Souiders embecded in lodgement till

$x$ Table Mountain, Site two

Contours at intervals of 2.4 .6 ponts per $1 \%$ of area

- Mount Feather

Figure 3.15 Diagrams from Boulton (1978) show the roundness and sphericity from different zones of transport in glaciers from Iceland and Spitsbergen. The location of the mean roundness vs. sphericity of the glaciers at Table Mountain and $\mathrm{Mt}$. Feather are shown. 


\subsubsection{Depositional environment}

The texture of the sediment is poorly sorted, typical of a glacial till. Fabric diagrams also show typical characteristics of a basal till (Hambrey, 1992). Clast shape for the Sirius till on Mt. Feather compares well to data from modern glacial basal debris (Boulton, 1978, fig 3.15).

Sand and clast composition suggests the sediment of the Sirius Group at Mt. Feather is similar to the formations over which it lies. All the material can be derived from within a few kilometres.

Chlorite in the clay fraction is a typical product of physical weathering and glacial scouring (Ehrmann and Mackensen, 1992). Mica detected in the clay fraction is most likely reworked from the upper local members of the Beacon Supergroup (table 3.5). The presence of kaolin suggests conditions warm enough to create this clay occurred in Antarctica at some time before the erosion and deposition of the till material, but after the exposure of the Beacon Supergroup.

Clast fabric indicates an average flow direction of the glacier depositing the till at Mt. Feather from $352^{\circ}$ (fig 3.27); this differs by $27^{\circ}$ from that measured by Brady and McKelvey (1979) who determined a glacial flow direction from $325^{\circ}$ (from both clast fabric and stration azimuths of 57 clasts). These two readings lie in a similar direction assuming some margin of error from human inconsistancies. However, this direction differs markedly from the glacial flow direction of Mayewski (1977, p49) whose fabric data (from 50 clasts) gave a glacial flow direction from the West South West. Striations on the till suggest a later event eroding the till from the west (fig 3.1b). The way the till is distributed on the platform at Mt. Feather suggests it mantles a South South East trending glacial valley that pre-dates the existence of the present glacial drainage system (fig. 3.16, 3.17). 


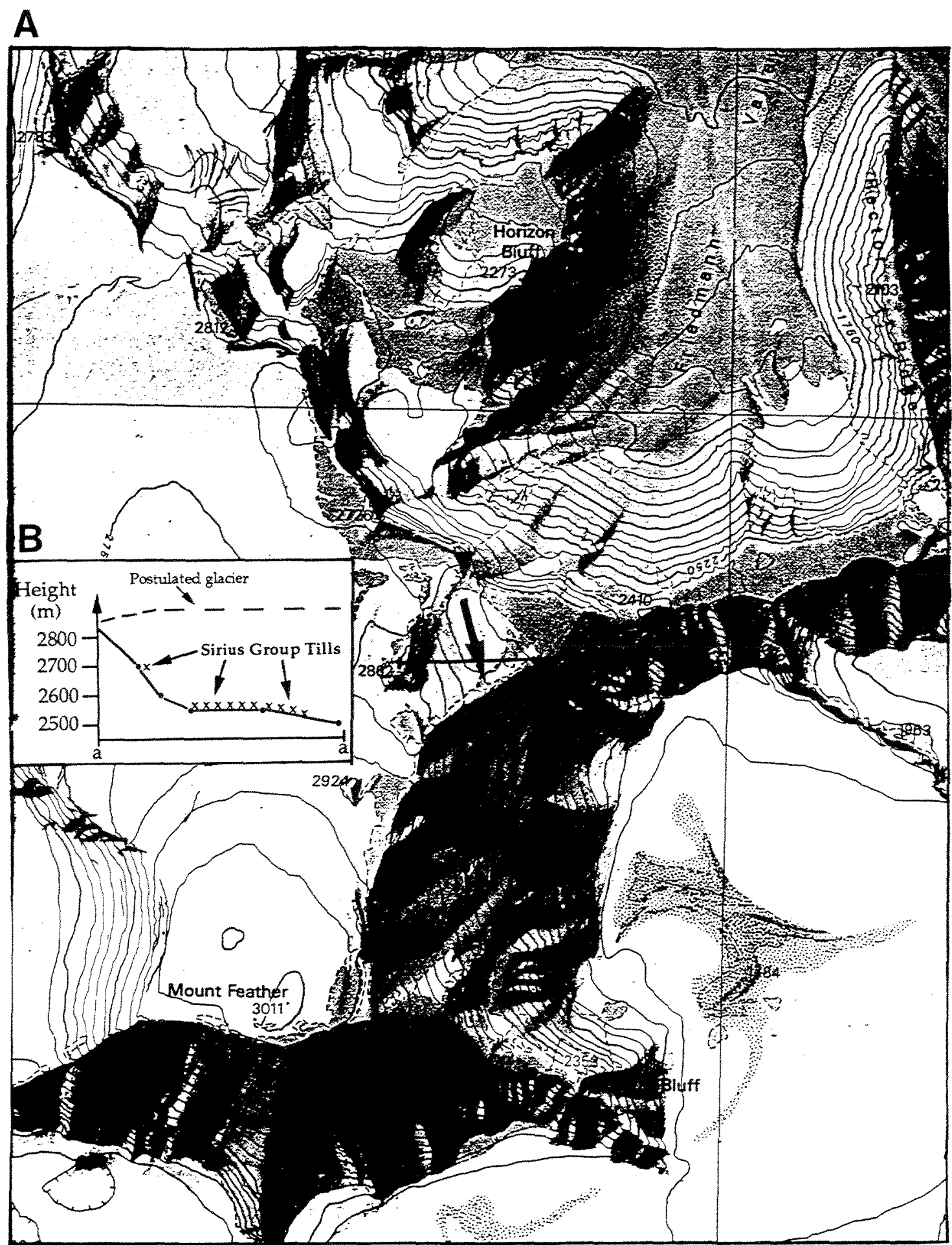

Figure 3.16 A is a topographic map of $\mathrm{Mt}$. Feather showing the south east south trending glacial valley (arrow shows direction of paleo glacial flow) intersected by the present glacial drainage system. $B$ is a cross section of the paleo glacial valley. 


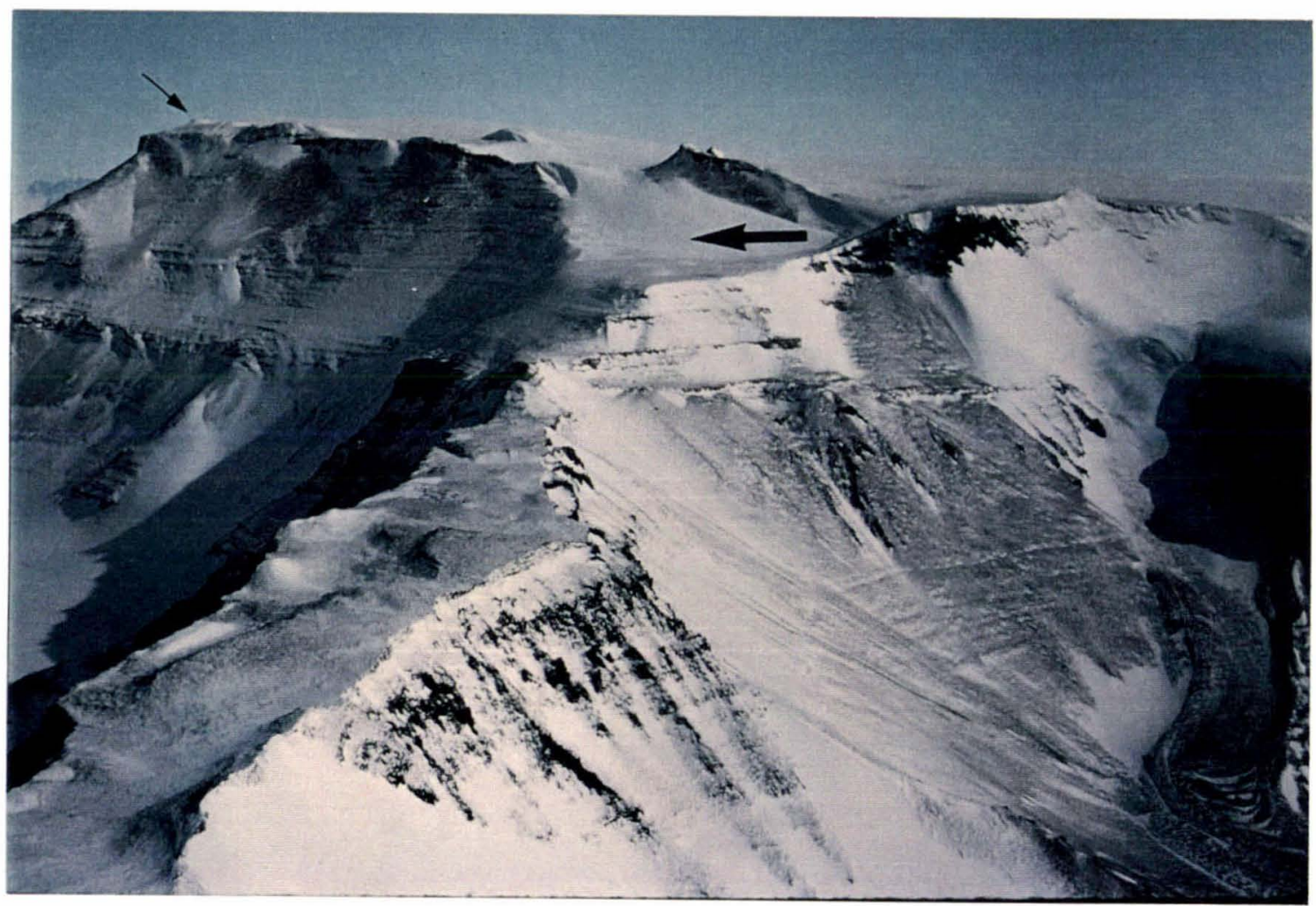

Figure 3.17 View of the Sirius Group till platform at Mt. Feather. Shows the paleoglacial valley and the flow direction of the glacier (arrow) when it deposited the Sirius Group tills. View is from above the south end of Rector Ridge (fig. 3.16) looking south west. The small arrow points to the summit of Mt. Feather. 


\subsection{Sirius Group on Table Mountain}

\subsubsection{Bedrock beneath the Sirius Group tills}

The Sirius Group till was deposited on a landscape cut in flat lying strata of the Beacon Supergroup intruded by sills of Ferrar Dolerite (Barrett, 1991b). The upper slopes of Table Mountain consist of 2 sedimentary formations, Terra Cotta Siltstone (Early Devonian) and New Mountain Sandstone (Early Devonian, fig. 3.18) and intrusions of Ferrar Dolerite (Mid Jurassic, table 3.1). All of these units are obvious contributions to the Sirius Group tills at Table Mountain (fig. 3.19).

\subsubsection{Distribution of the till}

The Sirius Group till at Table Mountain occurs as scattered exposures on a shallowly dipping bench between $1675 \mathrm{~m}$ and $1725 \mathrm{~m}$ above sea level and $700 \mathrm{~m}$ above the surface of the Ferrar glacier, NNW of the summit of Table Mountain (fig. 3.2, 3.21). It occurs almost entirely on the western slopes, although in a couple of places it is found on south or south west facing slopes.

In the north the till occurs as a long ridge, roughly $2 \mathrm{~m}$ high by $25 \mathrm{~m}$ wide along the north western side of a series of large snow filled hollows (fig. 3.2, 3.22). In the south it occurs in small patchy outcrops never more than $2 \mathrm{~m}$ high surrounded by gravel moraines (mostly of dolerite composition) on a shallowly dipping bench west of the southern end of the ridge described above (fig. 3.2, 3.20). Some outcrops identified by Barrett and Powell (1982) to the north west of Site Two were not reached in the field work for this study.

Once the mapping was completed, two sites were chosen for sampling and measurements of the tills (fig. 3.2, 3.23, 3.24). The Sirius till at both sites overlies the reddish gray to dark grey Terra Cotta Siltstone, of the Lower Beacon Supergroup formations of Early Devonian age (table 3.1, fig 3.23). 


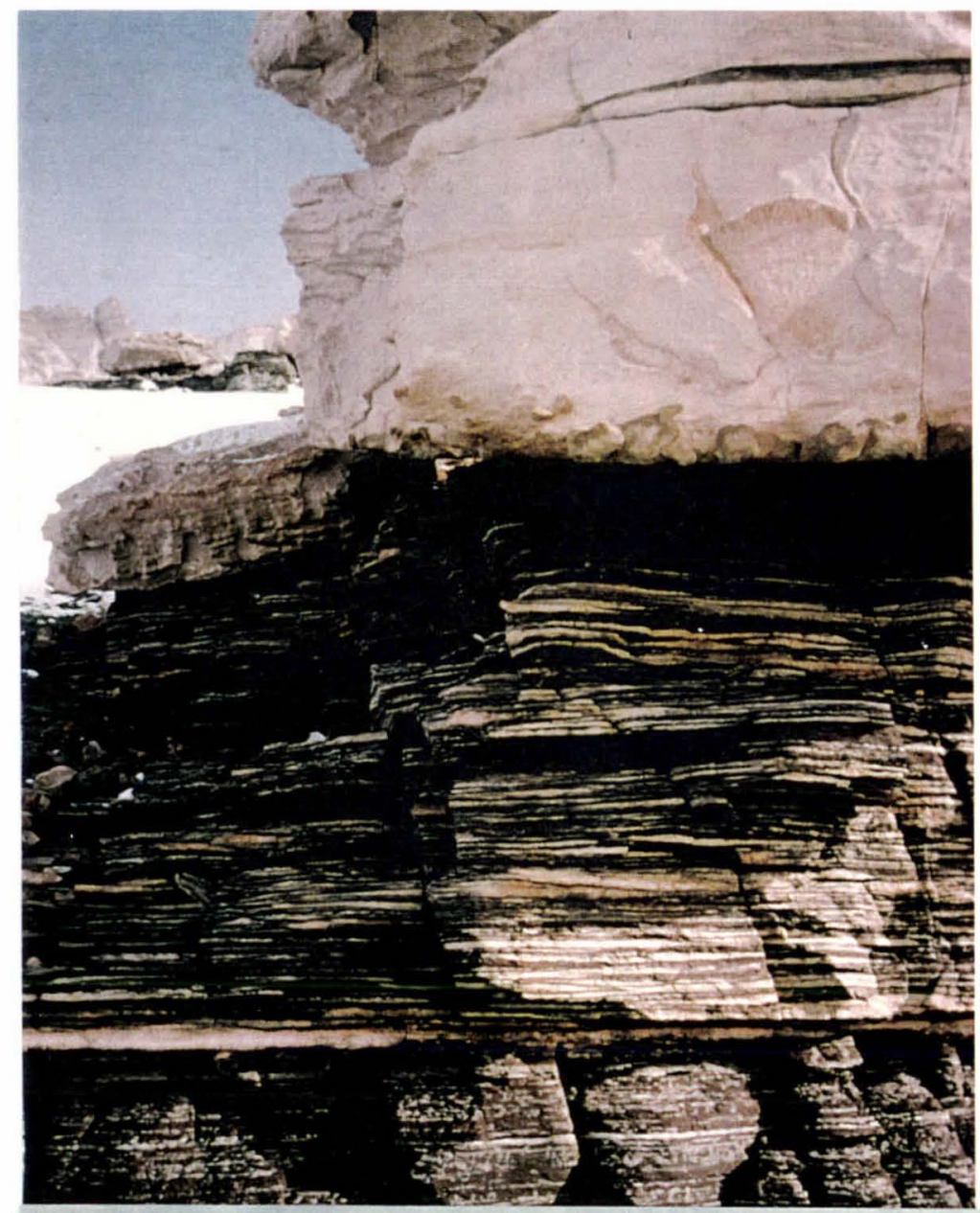

Figure 3.18

The contact

between Terra

Cotta Siltstone and

New Mountain

Sandstone(fig.

3.2b, table 3.1)

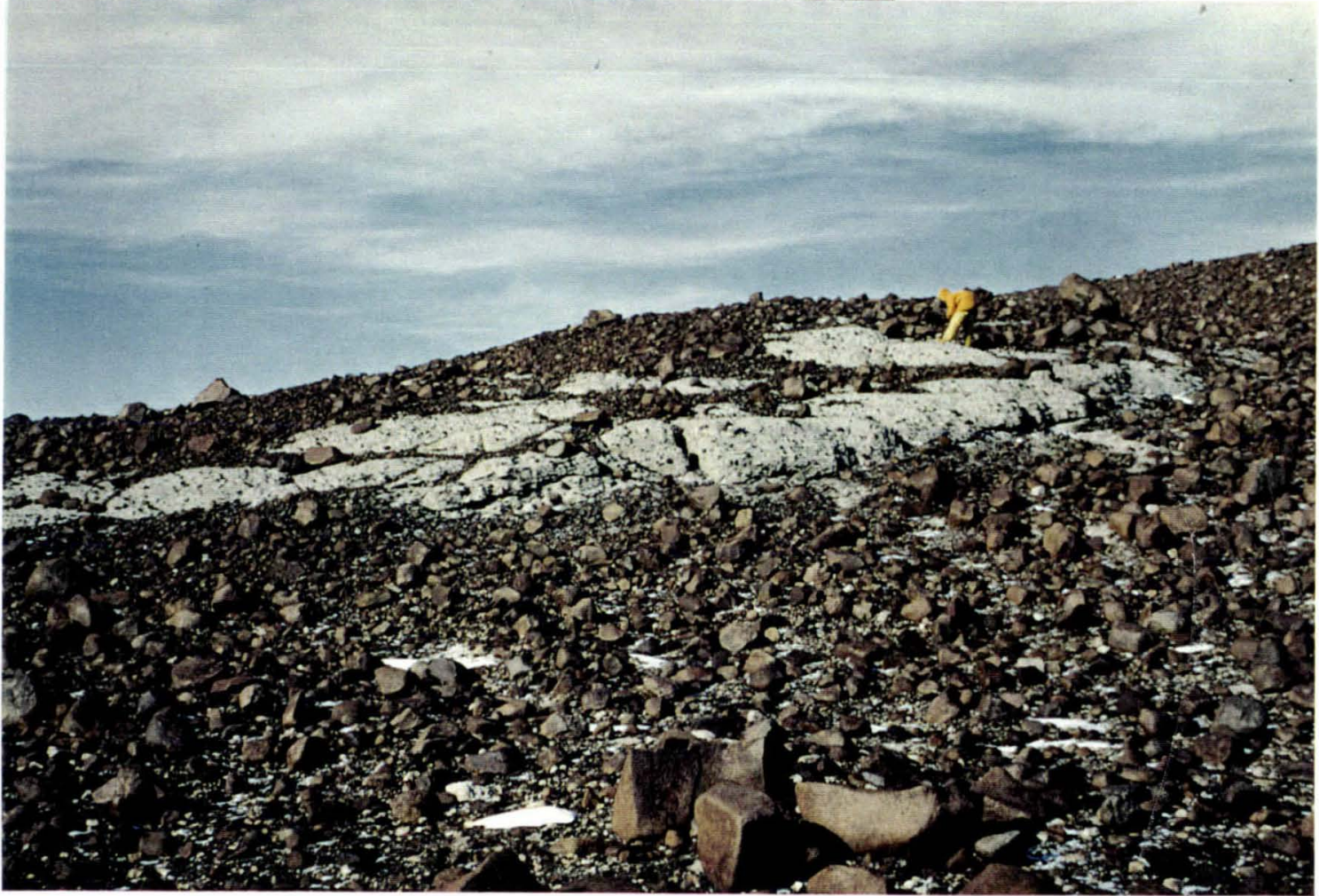

Figure 3.19 The largest of the patchy outcrops west of the ridge at Table Mountain (Fig 3.1b). Shows the over lying gravely moraine material (from Barrett and Powell, 1982). 

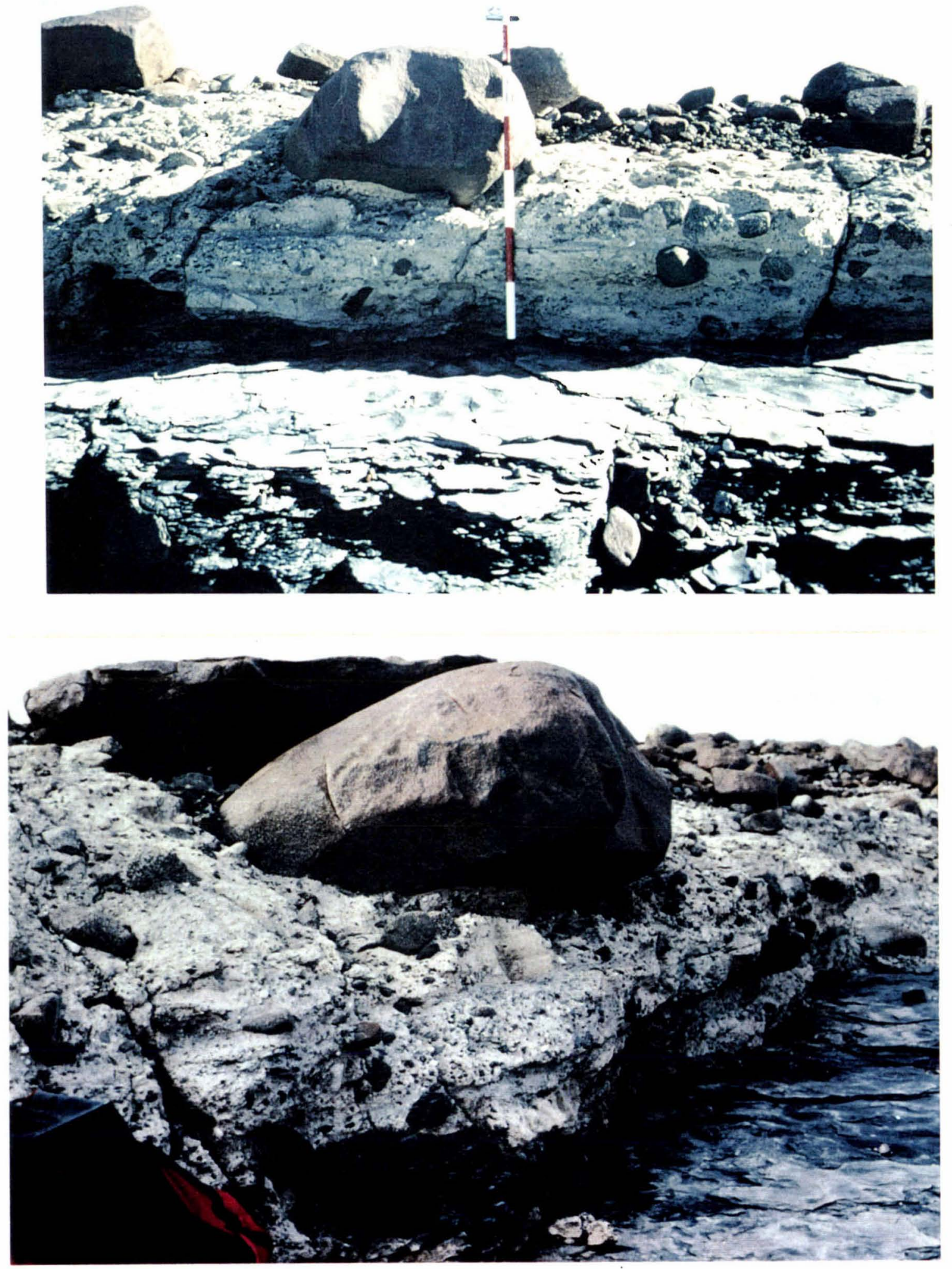

Figure 3.20 Both pictures are Site Two at Table Mountain, showing the base of the till overlying the Terra Cotta Siltstone. This picture also shows the stratification of the till and the large size of some of the clasts within it. The markings on the pole are $20 \mathrm{~cm}$ intervals (B. from Christian Schluchter, University of Bern). 


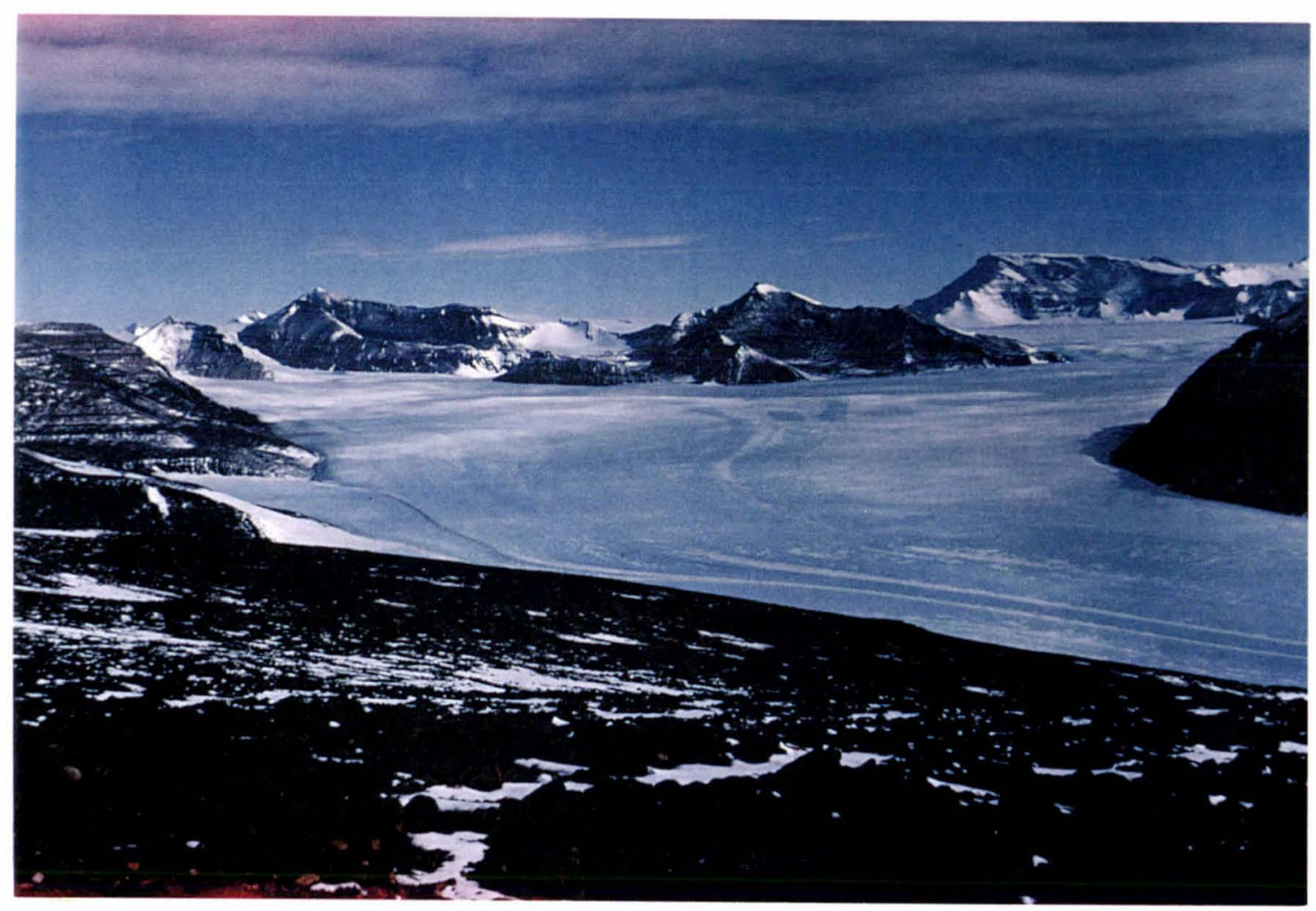

Figure 3.21 Looking north west from Site Two at Table Mountain down the gently dipping platform to the Ferrar Glacier.

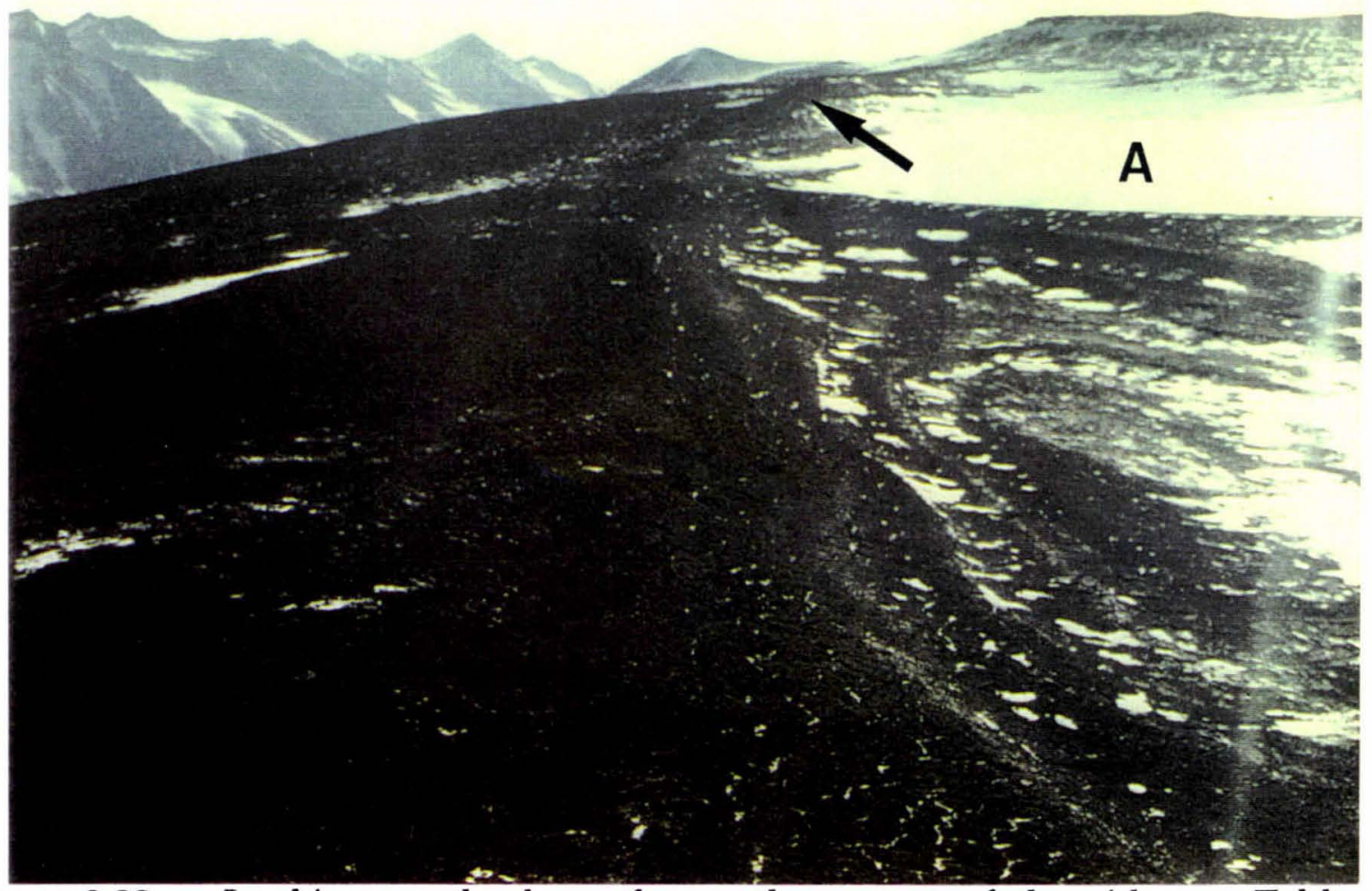

Figure 3.22 Looking north along the northern part of the ridge at Table Mountain showing the snow filled hollows to the left (east, labelled A) of the ridge and the beginning of the platform dipping to the Ferrar glacier to the right. The tip of the arrow marks Site One (from Christian Schluchter, University of Bern). 


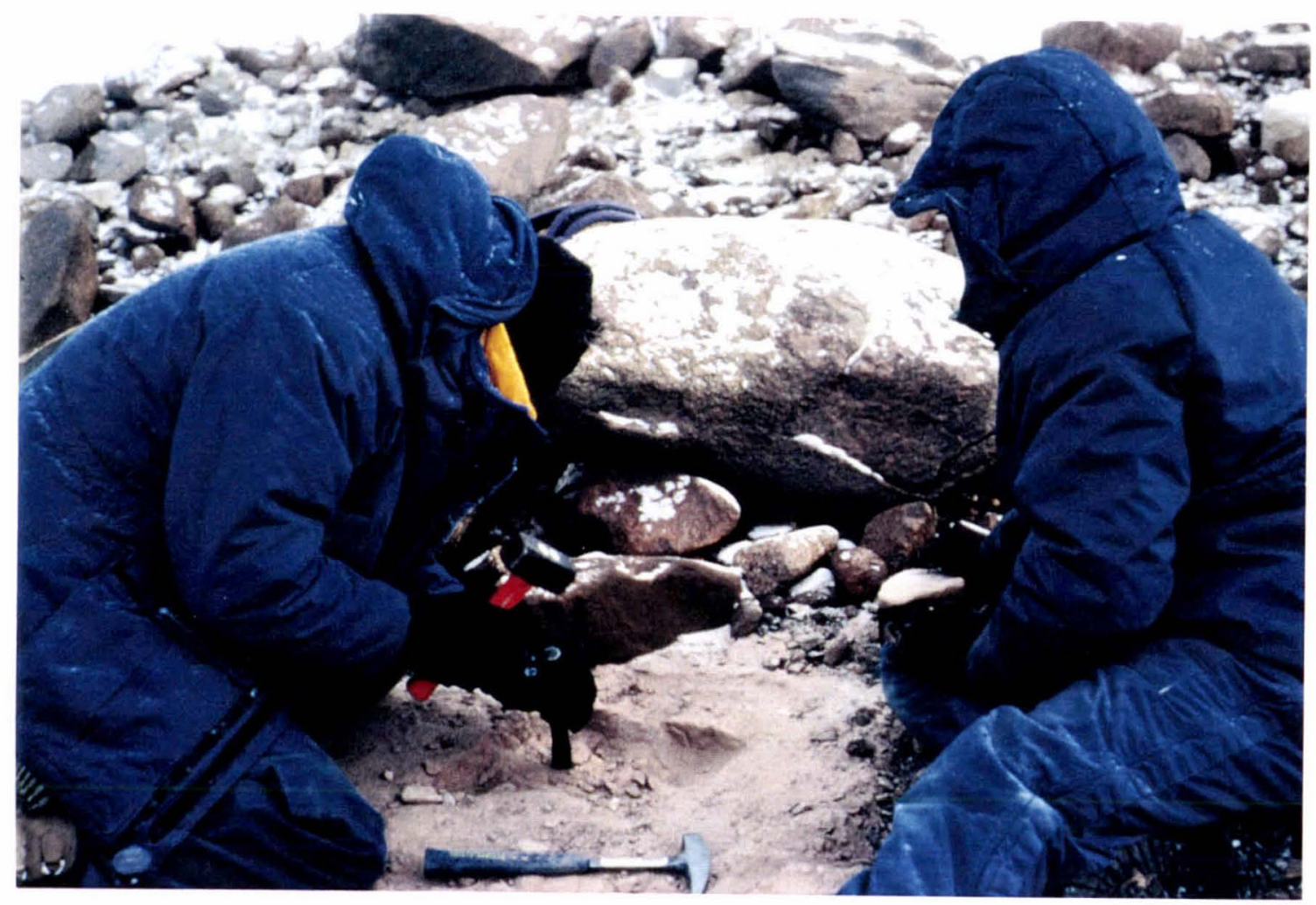

Figure 3.23 Sampling at Site One, Table Mountain. Note the pink colouring of the sediment and even the visual difference between this site and site two.

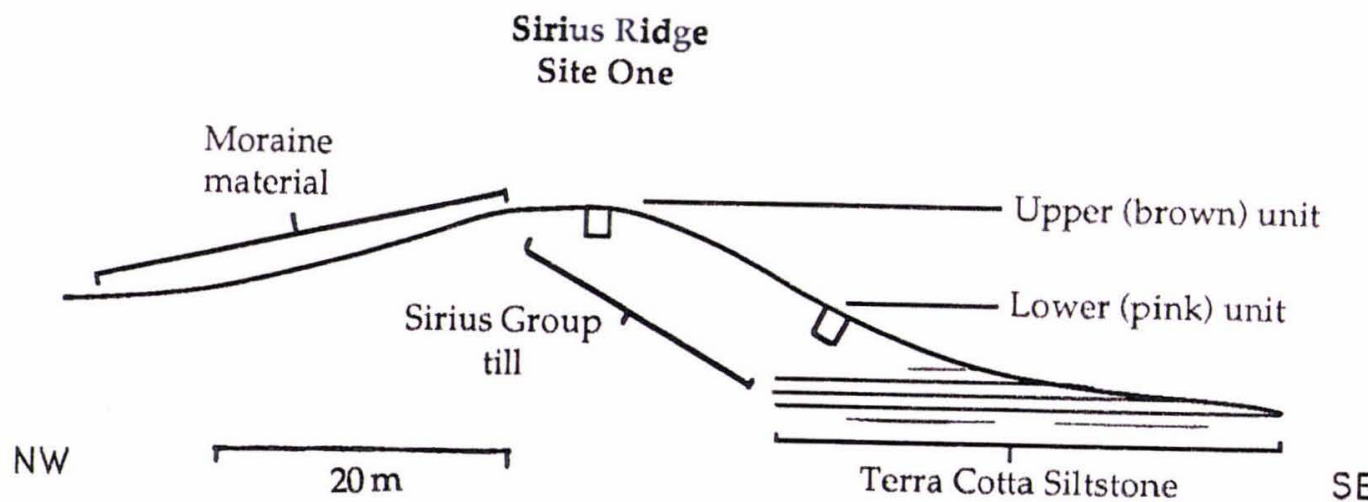

Figure 3.24 Diagram of the ridge at Site One showing the location of the brown (upper) unit and the pink (lower) unit at Site One. 
"Regolith" in this study is defined as unconsolidated silicate sediment weathered from adjacent rock. Regolith derived from the Sirius Group till occurs extensively on the south and south east facing slopes of ridges and on many flat surfaces at the western end adjacent to Sirius till outcrops. This loose material is up to $30 \mathrm{~cm}$ deep in places, no profile could be recognised. The occurrence of this regolith suggests that the till had once been much more extensive on Table Mountain and has since been weathered by later glacial action and/or buried by the more recent gravel moraines.

\subsubsection{Lithology of the till}

\section{Hardness and Stratification}

Site One and Two differed substantially in form and compactness. Figure 3.8 shows Site One could be penetrated with chisel and hammer, but Site Two was was impossible to penetrate to any more than a few centermetres.

\section{Sirius Group till, at the northern end (site one)}

Two parts, were identified in the till at Site One (fig. 3.8) indicated by a distinct colour change from light reddish grey $2.5 Y R 7 / 2$ (pink) at the base and eastern side of the ridge to a light grey $2.5 \mathrm{Y} 8 / 1$ (brown) in the upper part of the section closer to the crest of the ridge (fig. 3.24). At the upper site there was a sharp boundary at $28 \mathrm{~cm}$ with a change in colour to the light reddish grey sediment (fig. 3.24). This colour change in the sediment may be as a result of a different material occurring in the glacier with time. This may also occur, as a result of the weathering pattern of the sediments.

Clasts or concretions between 2 and $3 \mathrm{~cm}$ in length composed of till matrix could be removed from the till. These were not evident at any other sites. They could be interpreted as reworked till. 


\section{Sirius Group till at the southern end (site two).}

Figure 3.20 shows Site Two which is described below.

\section{Top}

$210-220 \mathrm{~cm}$ - Coarse sandstone with more quartz and feldspar toward the top. $160-210 \mathrm{~cm}$ - A light grey colouring with a yellow hue at the base, dominated by smaller $1-5 \mathrm{~cm}$ diameter clasts.

$60-160 \mathrm{~cm}$ - Smaller clast and grain size. Sediment becomes darker in colour changing from a pink to a yellow hue.

$30-60 \mathrm{~cm}$ - Decrease in volume of Terra Cotta clasts. Quartz and granodiorite become increasingly dominant. Average grain size of the matrix decreases.

$0-30 \mathrm{~cm}$ - Contains large clasts of grey Terra Cotta Siltstone, matrix, light grey with a pink hue, coarse sand texture.

Base - Sharp contact on Terra Cotta Siltstone.

The stratification of the sediment at this site suggests some current sorting of the sediment.

Sites to the north of Site Two (fig. 3.2) were not seen to directly overlie Terra Cotta siltstone. The deposits lie at a $5-8^{\circ}$ dip that coincides with the dip of the westward sloping bench.

\section{Texture}

Three till units were analysed at Table Mountain in this study, two at Site One and one at Site Two (fig. 3.22). Several other textural differences in grain size and sorting were observed from different parts of the till in the field.

Material from the lower pink unit at Site One has an average of $5.8 \%$ gravel, $85.5 \%$ sand and $8.6 \%$ mud and a mode which lies between the fine and coarse sand range. The material from the upper brown unit, higher on the rigde at Site One (fig. 3.22) contains $11.2 \%$ gravel, $77.3 \%$ sand and $11.5 \%$ mud. Unlike the lower site it has a well developed mode in the medium to coarse sand range (1-1.5 phi) and a slightly positive skewness suggesting some size sorting at this level. 
Site Two is comprised of $30 \%$ gravel, $65.6 \%$ sand and $4.4 \%$ mud and has a mode in the medium to coarse (1 and 1.5 phi) sand range, hence, less mud, less sand and more gravel than Site One.

The average medium to coarse sand texture is most likely a result of the provenance of the local sandstones of the Taylor Group, which have roughly the same grain size (Barrett and Powell, 1982). The mud component of the tills is also most likely derived from Terra Cotta Siltstone.

The material at Site One may be a result of glacial erosion and reworking of the harder basal till material such as that at Site Two and the incorporation of local Terra Cotta Siltstone, hence increasing the apparent mud content mud.

Clasts are dominantly of pebble size, but clasts of all sizes were identified up to $1.4 \mathrm{~m}$ in diameter (fig. 3.20). The large clasts commonly seen in the till at the southern end were not seen in the exposures at the northern end (figs. 3.20, 3.23).

Table 3.7 Percent gravel, sand and mud from Sites One and Two, Table Mountain.

\begin{tabular}{|l|c|c|c|}
\cline { 2 - 4 } \multicolumn{1}{c|}{} & \multicolumn{3}{c|}{ Percent (\%) } \\
\hline Sample & Gravel & Sand & Mud \\
\hline T1P 0-2cm & 6 & 86.4 & 7.6 \\
T1P 22-32cm & 5.6 & 84.7 & 9.7 \\
T1B $13-23 \mathrm{~cm}$ & 11.2 & 77.3 & 11.5 \\
T2 $2-5 \mathrm{~cm}$ & 30 & 65.6 & 4.4 \\
\hline
\end{tabular}

\section{Porosity and matrix structures}

Porosity on Table Mountain is much lower than at Mt. Feather, ranging from 0 to $5 \%$ at Site One and between 6 and $10 \%$ at Site Two (Table A3.1). However a secondary porosity of $1 \%$ occurs at Site Two as a result of the recrystallized zeolite Chabazite which now makes up between 14 and 15\% of the rock (table 3.9). Between 5 and 12\% chabasite also occurs at Site One (table 3.9). Chabazite has also been found in soils from the Dry Valleys by Gibson et al. (1983). Water must have moved through the till at one stage in order for chabazite to form from the elements of weathering pyroxene and feldspar minerals within the till. 
Table 3.8 Porosity of Sirius Group till samples from Table Mountain. Based on 300 points in thin section. Analyst: Dr Warren Dickinson.

\begin{tabular}{|ll|c|}
\hline \multicolumn{2}{|c|}{ Sample } & Porosity $(\%)$ \\
\hline $\mathrm{T} 1$ & $0-2 \mathrm{~cm}$ & 0 \\
$\mathrm{~T} 1$ & $2-7 \mathrm{~cm}$ & 1 \\
$\mathrm{~T} 1$ & $7-17 \mathrm{~cm}$ & 1 \\
$\mathrm{~T} 1$ & $17-27 \mathrm{~cm}$ & 5 \\
\hline $\mathrm{T} 2$ & $0-2 \mathrm{~cm}$ & 10 \\
$\mathrm{~T} 2$ & $7-17 \mathrm{~cm}$ & 5 \\
\hline
\end{tabular}

\section{Composition}

\section{Clasts}

From the clasts of the pebble size fraction in the till, fragments of Ferrar Dolerite dominate. Terra Cotta Siltstone and New Mountain Sandstone of the Beacon Supergroup also occur in large amounts (table 3.4). In northern exposures the pink colouring of the matrix suggests Terra Cotta Siltstone which the till directly overlies makes up a large component of the matrix. Large clasts of grey Terra Cotta Siltstone also occur at the base of outcrops at the southern end. At the western extent of the Sirius deposits on Table Mountain (fig. 3.2) a greater proportion of sub-rounded quartz clasts occurred in the till. Several clasts at Site Two within the till were striated in different directions.

\section{Sand (modal analysis)}

Quartz dominates the mineralogy of the Table Mountain slides followed by feldspar (table 3.7, A3.4). These are most likely reworked from local Beacon Supergroup sandstones. Igneous rock fragments originating from the Ferrar Dolerite are the next most abundant clasts in the sand size fraction (table 3.9).

Table 3.9 Average point count data for the sand fraction at each Sirius till site from thin section. Based on 300 points in thin section. Analyst: Dr Warren Dickinson.

\begin{tabular}{|c|c|c|c|c|c|c|c|c|}
\hline Sirius Sites & Quartz & Feldspar & SRF & IRF & MRF & Chabazite & Clay Mtx & Other \\
\hline Site One & 53.5 & 5.5 & 0.8 & 6 & 0.5 & 7 & 10.3 & 9.4 \\
Site Two & 39 & 13 & 5 & 6 & - & 14.5 & 6 & 8.5 \\
\hline
\end{tabular}

$\%$ porosity has not been included in this diagram. For full \% see Appendix 3.2 


\section{Clay}

$X$-ray diffraction analysis shows kaolinite (kaolin) to be the only clay mineral identified from both the upper and lower part of the till at Site One. The clay sample on the $x$-ray plot has a $2 \mathrm{D}$ spacing of $7.09 \AA$, the peak does not survive with heating of the sample (fig. 3.25), typical of kaolin. This clay has only been recorded in low abundancies from Antarctica and the Southern Ocean in the past (Zemmels and Cook, 1976).

Clay analysis from Site Two on Table Mountain shows large amounts of smectite, some mica and only a small proportion of kaolin (Fig. 3.26). This shows there is also a compositional difference in matrix between Site One and Two.

Detrital smectite was found in the lower part of the CIROS-1 core which has been dated Early Oligocene. From this, Claridge and Campbell (1989) suggest a cool or cold temperate climate in Oligocene times similar to that of Patagonia today. They suggest smectites were from soils derived from Ferrar Dolerite.

\section{Clast shape}

\section{Roundness}

From the visual roundness of chart of Krumbein (1941) clast shape from Site One averaged at 0.59 and at Site Two 0.65 (table 3.6, App. 4.2). Clasts are dominantly sub-rounded to rounded from Powers (1953) analysis (in Blatt et al, 1980).

\section{Sphericity}

Maximum Projection Sphericity of Sneed and Folk, 1941 (Blatt et al., 1980; Barrett, 1980) was calculated at 0.44 at Site One and 0.46 at Site Two (table 3.6, App. 4.1).

When comparing clast shape using roundness verses sphericity plots from glaciers today (of Boulton 1978), the material at Table Mountain plots in the area of the zone of traction (fig. 3.15). The material at Site Two lies closer to the criteria for a lodgement till. 


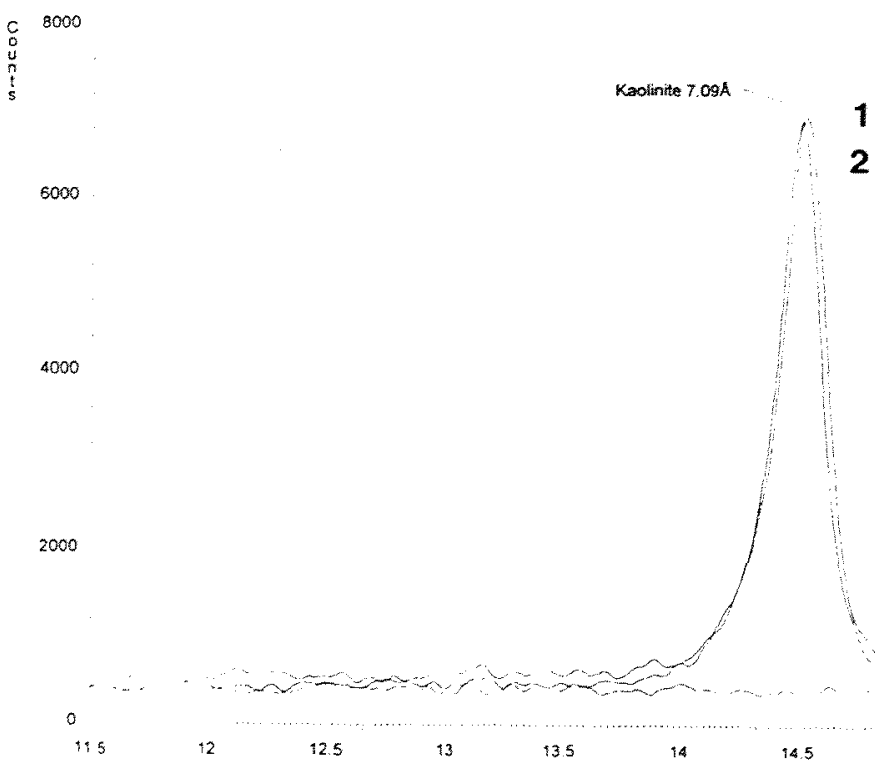

3

15516

Figure 3.25 X-ray clay analysis plot from Site One on Table Mountain. Shows a 2D spacing of $7.09 \AA$ with air dried (1) and glycolated (2) samples which vanishes with heating (3), suggesting the clay mineral kaolinite.

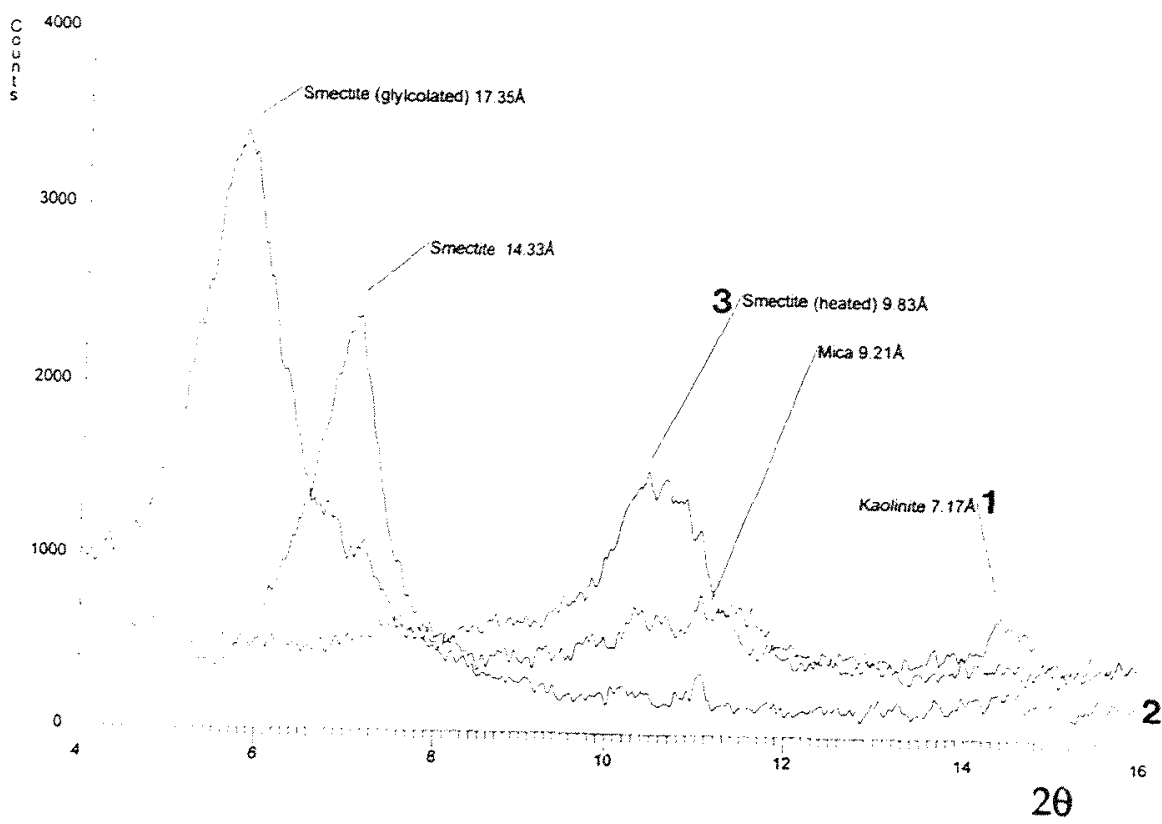

Figure 3.26 X-ray analysis plot of clay from Site Two at Table Mountain. The curves show the typical trends of smectite air dried (1) with heating (2) and glycolation (3), as do the smaller amounts of mica and kaolinite detected. 
Table Mountain

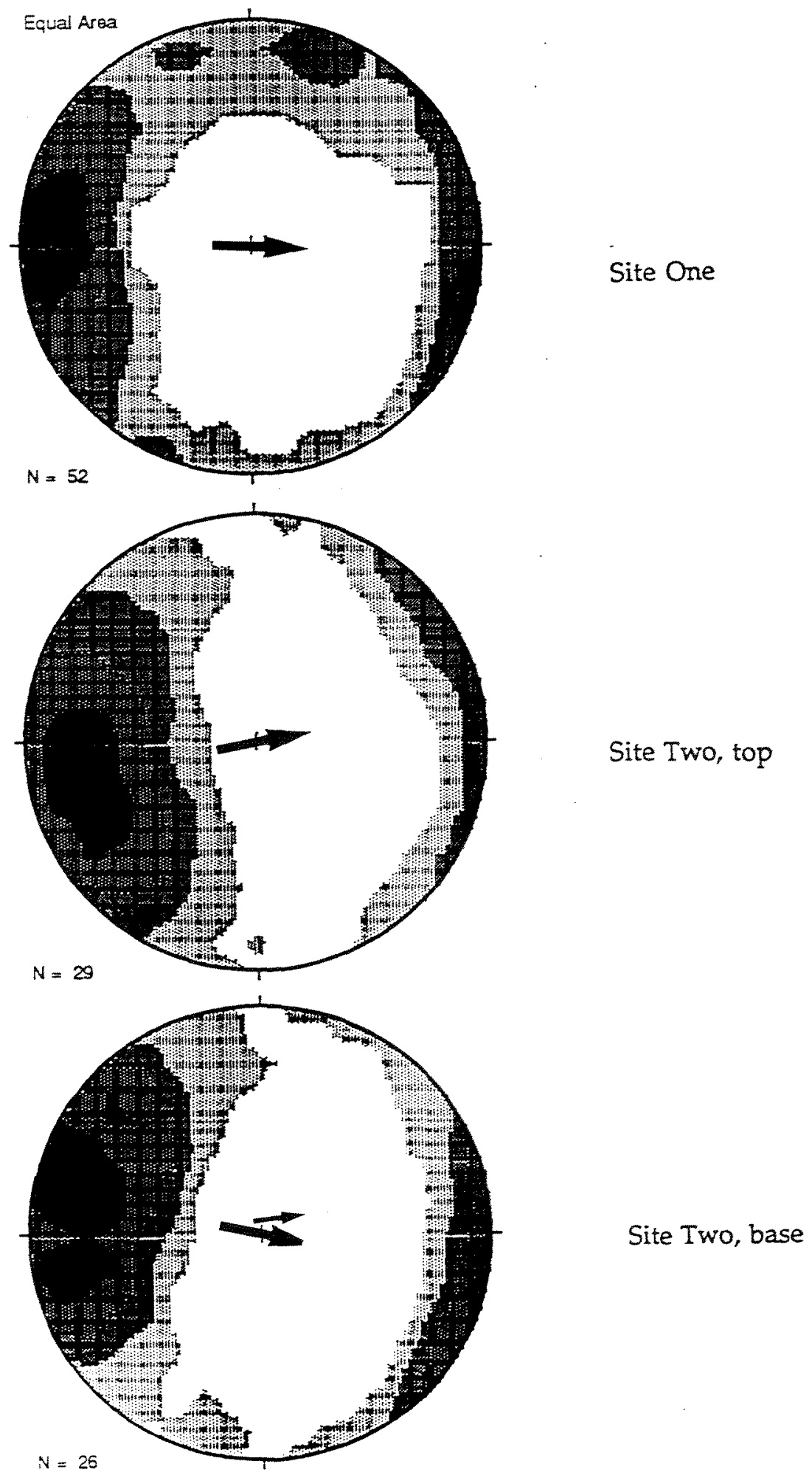

Figure 3.27 Stereonet plots of fabric directions of the long axis of clasts in Sirius Group till at Table Mountain. 


\section{Clast fabric and striae}

Clast fabric from the till at Table Mountain is very well developed (fig. 3.25). Fifty two clast fabric measurements collected at Site One suggest an average glacial flow direction from $270^{\circ}$ (fig. 3.1b, 3.25, App. 4.3). At Site Two, two groups of fabric readings were taken, one from the base, the other from the top of the till. This was done in order to determine whether any differences observed in the sediments were related changes in flow direction. The data from Site Two show some change in average glacial flow direction from $300^{\circ}$ at the base to from $250^{\circ}$ at the top of the till (fig. 3.25). This change in direction may also have occurred as a result of current reworking.

Striations on the New Mountain Sandstone suggest a flow to the north west (fig 3.1b). Rat-tail striations on the surface of the till suggest later erosion from between 230 and 260 degrees (figs. 3.1b, A4.2).

\subsubsection{Depositional environment}

Textural data show that generally sediment at most locations is poorly sorted, which is typical of a glacial till. However, a slight skewness in the grain size curves from Table Mountain (Figure A2.1) suggests some sediment sorting. The texture is most likely a product of the provenance of the Beacon Supergroup formations from which the material in the till was eroded.

Fabric data suggest glacial flow from the west $\left(270^{\circ}\right.$; fig 3.28). Fabric data taken from higher in the unit at Site Two suggest a slight movement of the flow direction through time from the southwest. The measurements from the orientation of the clasts in the moraines overlying the Sirius till, the striations on the surface of the till and on the New Mountain Sandstone suggest a later glacial flow direction from the southwest; this is similar to that of the Ferrar Glacier today.

When the sphericity and roundness data from the Sirius Group till at Table Mountain are compared to those denoting specific transport paths from other known glaciers (Boulton, 1978, fig. 3.15) they show that the Sirius till at Site Two is mostly made up of glacial basal debris while Site One has an origin completely from the zone of traction. 
The rounded clasts of matrix at Site One suggest reworking and redeposition of the glacial till (possibly of a till like Site Two) by some sort of later glacial action. The higher proportion of clay, fewer bolders and a skewness in grain size at Site One also presents this as a possibility.

Stratification at Site Two also suggests some current sorting of the material, suggesting, a climate much warmer than the present. Barrett and Powell (1982) point out that stream deposits like the current sorted beds they identified at Table Mountain are presently forming in the lowest parts of the Dry Valley region (Powell, 1976), where the temperature is roughly $15^{\circ} \mathrm{C}$ higher than at Table Mountain today. Barrett and Powell (1982) suggest this warmer climate "may have been due to either lower elevation or a warmer regional climate or both", at the time of the tills deposition.

Data on the sedimentology and stratigraphy of both Table Mountain and Mt. Feather suggest till deposition by ancient wet based glaciers which scoured the strata of the Beacon Supergroup before the deep cutting of the present glacial drainage system. This is further supported by a study of the Sirius Group tills at Mt. Fleming by Stroeven (1994). Using textural, lithological, clast shape and morphological analysis and ice flow indicators, Stroeven (1984) concluded the Sirius Group tills at Mt. Fleming were deposited by wet based alpine glaciers flowing from the north (upper Fleming till, fig. 3.28) and the south west (lower Fleming till). 


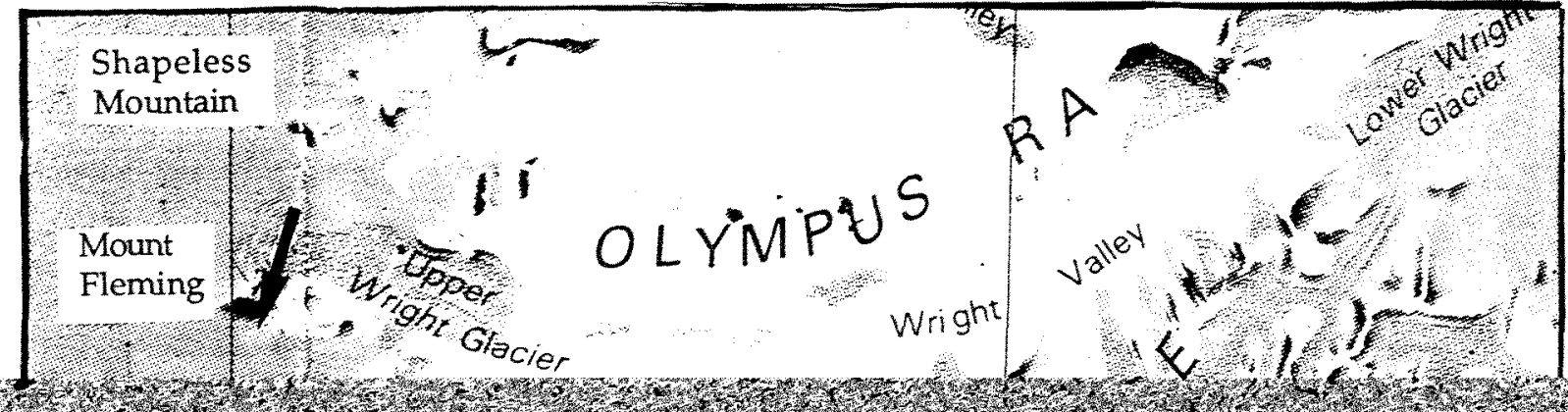

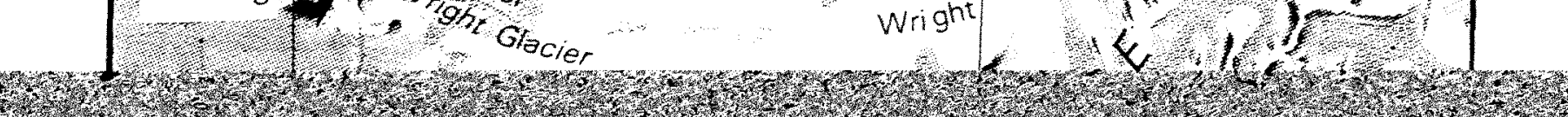

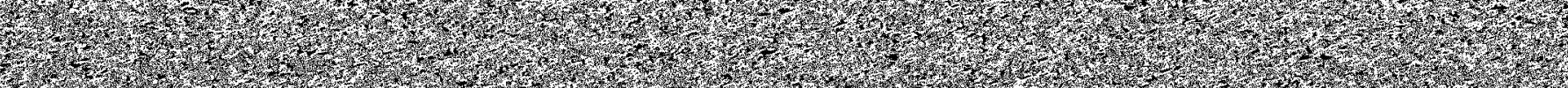




\section{Chapter Four}

\section{Diatoms of the Sirius Group and adjacent material}

\subsection{INTRODUCTION}

Diatoms are microscopic unicellular algae, which range in size from approximately $5 \mu \mathrm{m}$ to $500 \mu \mathrm{m}$. They live wherever there is moisture (Barber and Haworth, 1981). The cell wall or frustule is composed of silica, which when thick is highly resistant and remains long after the death of the cell and decay of its organic contents (in Barber and Harworth, 1981). Diatom taxonomy is largely based on the morphology of the silica frustule.

Diatom species are very sensitive to environmental conditions. Because of this their different assemblages are very good environmental indicators, and are often used for ecological and biostratigraphic reconstruction of past environment and climatic changes.

Diatoms can also be used as indicators of water quality: (eg. water $\mathrm{pH}$, pollution, eutrophication); coastal transition such as sea level change and isolation of bays from the sea (eg. freshwater, brackish and marine environments); and, changes to water catchments indicating lake, river or a wet soil environment (different assemblages live on stones, silt and water plants, with different tolerances to light and current).

Some species are cosmopolitan in their range while others can be endemic to an area. The main forms in this study are-

1. Freshwater planktonic, benthic and ice diatoms (occur in pools on the surface ice).

2. Marine benthic, planktonic and sea ice diatoms.

Many of these species are endemic to Antarctic and Sub-antarctic waters and can be good biostratigraphic indicators. 
Sea ice associated diatoms live a unique environment created by ice freezing over water. The ice reduces the solar input and the mixing of the upper layers of the water column by wind. The freezing and thawing of the ice and the affect the temperature and salinity structure has on the underlying sea water creates a unique environment (Horner, 1990).

\subsection{METHOD}

\subsubsection{SAMPLING METHOD}

Sample sites were chosen because of their orientation, slope or variation in the till. An ideal site showed no evidence of cracks where wind blown diatoms could work their way down from the surface.

On Mt. Feather pits were dug and samples were taken at the southern (Site One) and northern (Site Two) end of the Sirius till, on a $17^{\circ}$ slope with an easterly aspect (fig 3.1). A third pit (Site Three) was dug near the centre of the platform on a flat surface. Loose material was cleared from the surface at this site before the first sample $(0-2 \mathrm{~cm})$ was taken. Samples were taken from the surface of a fourth site (fig. 3.1) but were not processed due to time restrictions.

At Table Mountain two pits were dug, one at the northern end (Site One) and the other at the southern end (Site Two) of the ridge (fig. 3.2). Both sites had a southwest aspect.

Sirius till samples were taken at depths of $0-2 \mathrm{~cm}, 2-7 \mathrm{~cm}, 7-17 \mathrm{~cm}, 17-27 \mathrm{~cm}$ and $27-37 \mathrm{~cm}$. However, the depth to which samples could be taken was restricted by the increasing degree of induration with depth and/or ice cemented permafrost. Samples were taken with a chisel and hammer.

Regolith (loose weathered rock) samples were taken from cracks and under boulders in Beacon Supergroup sediment. Samples were also taken from moraines nearby.

Snow collected from the sites shown (fig 3.1, 3.2) was melted and filtered using with a $5 \mu \mathrm{m}$ sieve cloth in order to obtain any diatom material present.

All sample sites are shown in figs 3.1 and 3.2 . 


\section{Avoiding contamination in the field}

All the material was collected and sealed in clean new plastic bags and care was taken at all stages in subsequent handling to prevent any contamination. Filters and sieving equipment were soaked in a strong alkali solution to remove any possible diatom contaminants. They were then washed and placed in clean new plastic bags. Distilled water was taken to use as a control while sieving.

The large pot used for melting snow samples was the most likely source of contamination. This was cleaned to the best of our ability with alcohol and repeated boilings of distilled water. It became apparent later in the analysis that the first control and snow Site One from Table Mountain were contaminated with diatoms typical of those from the Canterbury Lakes in New Zealand (Flint, 1975; Table A6.8). This contamination did not continue into the following samples, which have a typical Antarctic assemblage (Håkansson and Jones, 1993).

\subsubsection{DIATOM EXTRACTION TECHNIQUE}

The concentration of diatoms in the Sirius till is extremely low (0-10 specimens per gram) and as a consequence special techniques and much work is required to recover them in significant numbers for useful study.

The methods used to extract and concentrate diatoms material include: disaggregation; removal of sand; removal of clay; heavy liquid separation; and, in some cases sieving (fig. 4.1). For further information on derivation of the method and decontamination experiments see Appendix Five.

\section{Disaggregation}

Two hundred grams of sample was placed in a 1 litre beaker of calgon and distilled water in order to disperse the clays. All samples broke down readily and there was no need for mechanical disaggregation. After 24 hours the liquid was siphoned and discarded. 


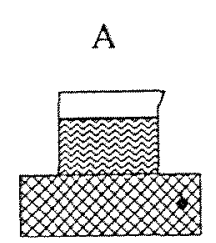

Disaggregation with Hydrogen Peroxide and Hydrochloric Acid.

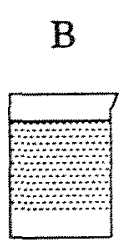

Removal of Sand.

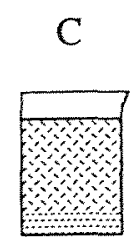

Removal of Clays.

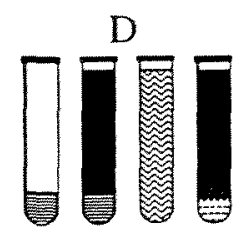

Removal of

Mineral Grains with Heavy Liquid.
E

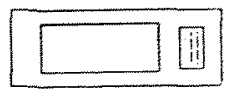

Slide preparation and analysis.

Figure 4.1 Summary of processing method used. The technique is derived from a combination of methods suggested by Dr. D. M. Harwood (University of Nebraska), Dr. L.H. Burckle (Columbia University) and Dr. M.A. Harper (Victoria University of Wellington).

Beakers containing the samples were placed in a water bath and $200 \mathrm{ml}$ of $10 \%$ hydrogen peroxide and $200 \mathrm{ml}$ of $10 \%$ hydrochloric acid was added to disperse any carbonate and organic cements. The water bath was maintained at a temperature of $50^{\circ} \mathrm{C}$ for five hours. After this time the samples were diluted with distilled water and left to settle over night. The supernatant was then siphoned off and discarded.

Complete dispersion of clay and silt from sand required a further step of addition of $200 \mathrm{mls}$ of $5 \%$ sodium hexametaphosphate and boiling for 10 minutes on a hot plate. This was then diluted with distilled water and the beaker containing the sample was placed in a DAWE ultrasonic tank at setting 60 for one minute. This completed the dissagregation process.

\section{Removal of the coarse fraction (sand and coarse silt)}

Beakers were filled with distilled water to a height of $12 \mathrm{~cm}$ and stirred vigorously. The sediment was allowed to settle for one minute and the supernatant was poured into a 21 beaker. This was repeated on the settled fraction and the remaining coarse fraction was discarded. This process was repeated again on the decanted fine fraction, any further settled material was discarded. 


\section{Removal of clay}

$200 \mathrm{mls}$ of $2 \%$ sodium hexametaphosphate (calgon) was added to the samples, which were boiled on a hot plate for 10 minutes. Beakers containing the sample were filled with distilled water to $12 \mathrm{~cm}$ above the base of the beaker, placed in a DAWE ultrasonic tank at setting 60 for one minute and left to settle for three hours. Clays remaining in suspension were siphoned off and discarded.

$400 \mathrm{mls}$ of Calgon was added, the sample stirred vigorously and left to settle for a further three hours.

This process was repeated up to six times, or until no clay remained in suspension after three hours. This was repeated with distilled water instead of calgon three more times to wash any residue of calgon from the sample.

If all the clay was not removed from the sample, the remaining sample was poured into $50 \mathrm{ml}$ centrifuge tubes. The tubes were filled with calgon, shaken vigorously and centrifuged at 1100 revolutions per minute (RPM) for three minutes. The supernatant was decanted and discarded. This was repeated until the supernatant was clear then repeated with distilled water a further three times, to wash the residual calgon from the sample.

\section{Heavy liquid separation}

Diatoms have a specific gravity of less than 2.25 . The heavy liquid sodium polytungstate (SPT) was made up to a specific gravity of 2.25 .

The samples were transferred to $50 \mathrm{ml}$ Falcon centrifuge tubes, and centrifuged at 2000 RPM for 5 minutes. All supernatant was decanted and $15 \mathrm{mls}$ of SPT was added to each sample. The tubes were shaken until all the sample was in suspension, then centrifuged at 1500 RPM for 15 minutes.

Material such as diatoms, palynomorphs and phytoliths with a specific gravity (SG) of less than 2.25 sat on the surface of the SPT. Mineral matter (and a few phytoliths) with a SG of greater than 2.25 dropped to the base of the tube beneath the SPT and was discarded. 
The lighter material (SG <2.25) was removed with cleaned disposable pippettes and transferred to $10 \mathrm{ml}$ centrifuge tubes. Distilled water was added to the centrifuge tubes. This was centrifuged at 2000 RPM for five minutes. The SPT in the centrifuge tubes now had a specific gravity of approximately 1.5. All the float material (e.g., coal and plant material, SG <1.5) was removed and discarded. The remaining SPT was decanted and filtered for reuse in the palynology lab.

The centrifuge tubes containing the samples were refilled with distilled water shaken vigorously and centrifuged at 2000 RPM for 5 minutes. The supernatant was decanted and discarded. This process of washing, centrifuging and decanting of the remaining sample was repeated up to ten times.

\section{Mechanical separation}

Some samples were separated and sieved at 5 and 20 microns in a cleaned Sartorius polycarbonate filter holder. This was done in order to further concentrate samples and determine the effect on the diatom assemblage of sieving which Harwood (1986) and Stroeven (1994) used in their processing.

\section{Slide preparation}

Distilled water was added to a desired height in the $10 \mathrm{ml}$ centrifuge tubes. Cover slips were placed on a hot plate. An estimated concentration of sample was placed on the cover slip, using an analytical pippette with disposable tips (concentration was first checked one slide and changed if unsuitable). Distilled water was added so the sample was evenly dispersed across the coverslip. The material was evaporated onto the coverslip. The slides were place on the hot plate and warmed. The mountant Naphrax (a high refractive index mountant) was placed on the slides and the dryed cover slips were turned sediment down onto the Naphrax. The slide was removed from the hot plate and bubbles beneath the slip were dispersed by rubbing a tooth pick over the slip. The slides were left to set for microscope analysis. 


\section{Microscope analysis}

Microscope analysis was undertaken on a Leitz Diaplan microscope, under partial phase and differential interference contrast. Diatom were searched for using an oil lens at $650 \times$ magnification. Diatom analysis and identification was undertaken at 1600 to $2000 x$.

\section{Avoiding contamination in the laboratory}

A laboratory was chosen which had previously been used for processing New Zealand soils but had never been used for micropaleontological processing before. The entire laboratory area was cleaned with alcohol before use. Distilled water was used at all stages of processing and all other water passing through the laboratory was filtered with 20 and 5 micron filters. Clean new gloves and a lab coat were also worn throughout processing to avoid any contamination from outside sources.

In order to check on possible contamination control samples (acid washed sand and beakers of distilled water) were processed for the extraction of diatoms with the rest of the samples. Other controls were added during slide preparation and sieving.

All equipment was soaked in either $1 \% \mathrm{HF}$ or $3 \mathrm{Molar} \mathrm{KOH}$ for 24 hours before use in the lab.

\subsection{DIATOMS FROM THE SIRIUS GROUP TILL}

\subsubsection{Introduction}

Diatom fragments were first identified from Sirius Group on Mt. Feather by H.T. Brady in the 1976 field season. He considered they could be due to laboratory contamination and not necessarily from the Sirius Formation (Harwood, 1986). In 1979 D. Kellogg identified a number of freshwater species and the marine species Coscinodiscus furcatus (730ka-present) from the Sirius Group tills on Mt. Feather (Kellogg and Kellogg, 1985, 1986). Coscinodiscus furcatus was suspected to be a contaminant. 
Harwood (1986) took 77 samples from 11 Sirius Group sites in the Transantarctic Mountains including Mt. Feather, Table Mountain and Mt. Fleming. From these Sirius Group samples some marine diatoms belonging to a 3.1 to $2.2 \mathrm{Ma}$ assemblage were identified based on the age ranges of Ciesielski (1983). The ages of these diatoms were confirmed by their occurrence with a 3 $\mathrm{Ma}$ radiometrically aged volcanic ash in the CIROS-2 drill hole (Barrett et al. 1992).

The purpose of this investigation is to determine whether diatoms could have been introduced into the Sirius Group till after its deposition. This can be done by determining whether diatoms are evenly distributed throughout the till or concentrated near the surface and determining whether similar diatoms also occur on rock types other than the Sirius Group tills and in snow.

\subsubsection{Mt. Feather}

\section{Site One}

Figure 4.2 and App. 6.1 show that the surface $2 \mathrm{~cm}$ of Site One has by far the greatest number of both freshwater and marine diatoms. Freshwater species are most abundant, dominated by various Aulacoseira species (App. 6.1 and 6.2). The deeper samples have significantly fewer diatoms of both freshwater and marine origin (fig. 4.2). Numbers increase at the $7-17 \mathrm{~cm}$ level (fig. 4.2), the depth at which the till changed from a brown to a grey colouring, where more gravel and less clay occurred. At the middle of this interval porosity decreases (Chapter 3.2). Actinocyclus actinochilius (0-3 Ma), one of the Harwood (1983, $1984,1986)$ age-constraining diatoms, was found in the top $2 \mathrm{~cm}$ at Site One (App 6.2).

\section{Site Two}

Site Two also shows a greater number of both freshwater and marine diatoms in the surface $2 \mathrm{~cm}$ (fig. 4.3). A slightly greater number of marine than freshwater diatoms occur in the surface sample (fig 4.3a).

\section{Site Three}

Both freshwater and marine diatoms occur in the surface $2 \mathrm{~cm}$ at Site Three, but significantly fewer than at the other two sites and none occur at $7-17 \mathrm{~cm}$ (fig. 4.4 ). The $2-7 \mathrm{~cm}$ depth was not processed due to time constraints. 
a.

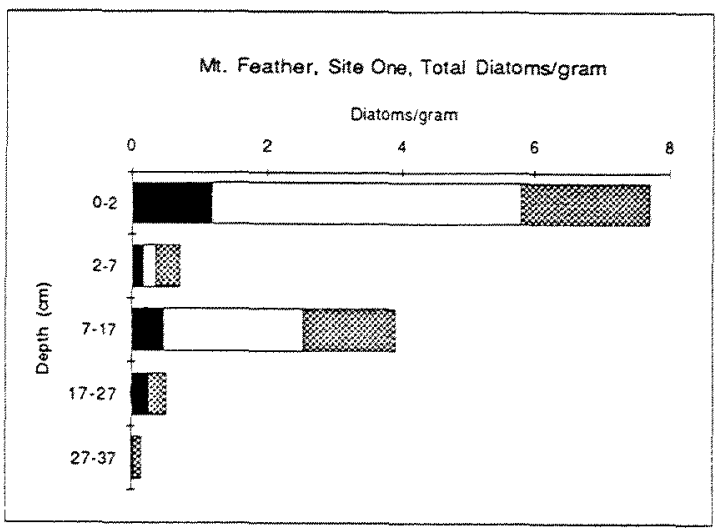

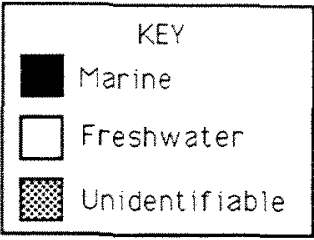

Mt. Feather, Site One, Freshwater Diatoms/gram

Diatorrsigram

c.

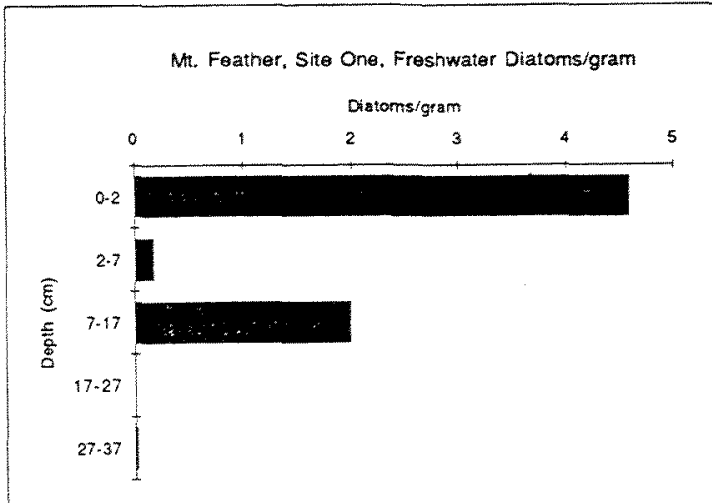

Figure 4.2 a. Total number of diatoms per gram from Site One. Showing proportions of marine, freshwater and unidentifiable diatoms. b. Marine diatoms per gram from Site One. c. Freshwater diatoms per gram from Site One.

a.
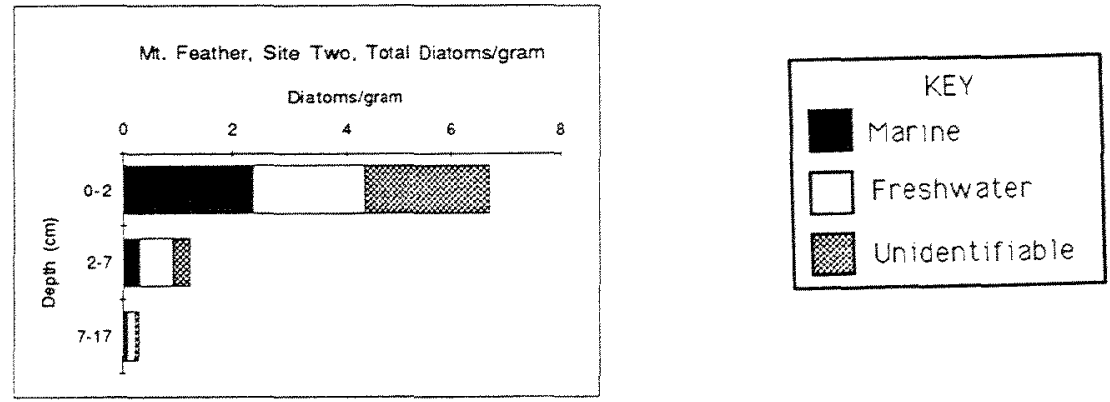

b.

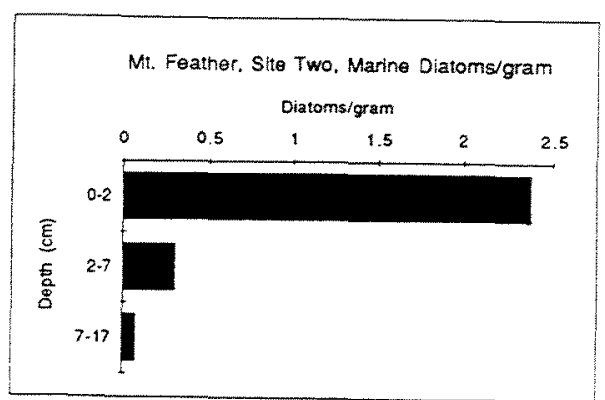

c.

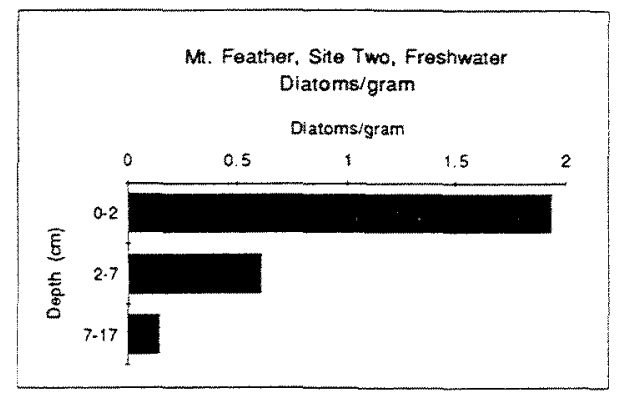

Figure 4.3 a. Total number of diatoms per gram from Site Two showing the proportions of marine, freshwater and unidentifiable diatoms. b. Marine diatoms per gram from Site Two. c. Freshwater diatoms per gram from Site Two. 

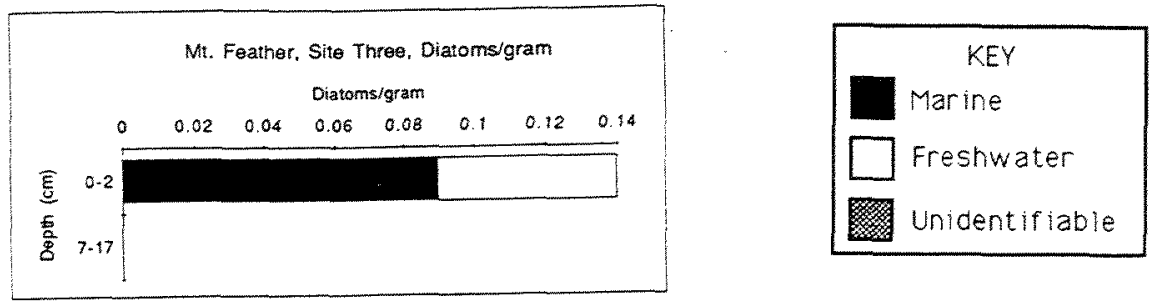

Figure 4.4 Total number of diatoms per gram from Site Three.

\section{General}

At all sites diatom populations are significantly greater in the surface $2 \mathrm{~cm}$ than in the deeper samples. For two of the three sites the decline in numbers with depth is progressive, but for Site One, where concentration is highest (8 diatoms per gram) there is a lack of diatoms at the 2-7 cm depth. Figure 4.5 shows the combined distribution of diatoms from all three Sirius Group sites at Mt. Feather showing the decrease with depth into the till. Table A6.1 also shows that phytoliths occur in a much greater abundance than the diatoms. Phytolith abundance varies considerably and if any trend it shows an aparent increase with depth (fig. 6.1).

a.
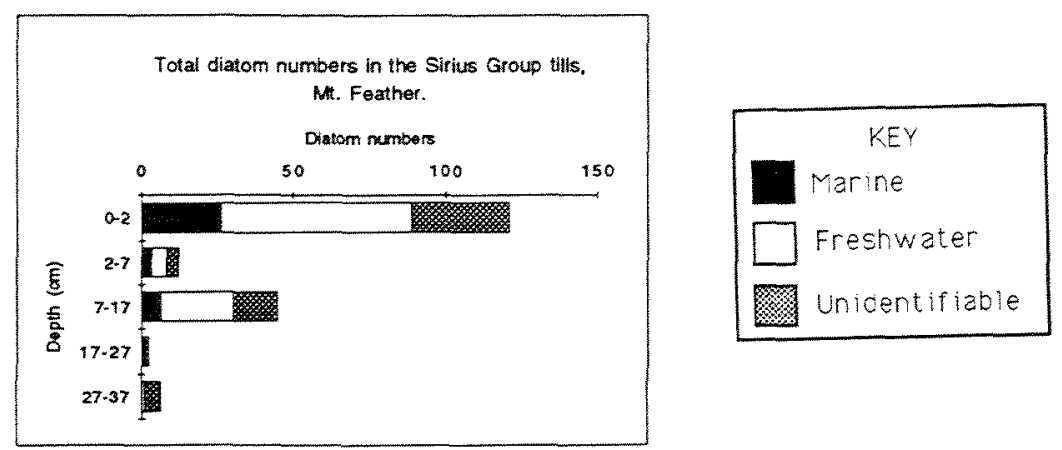

b.

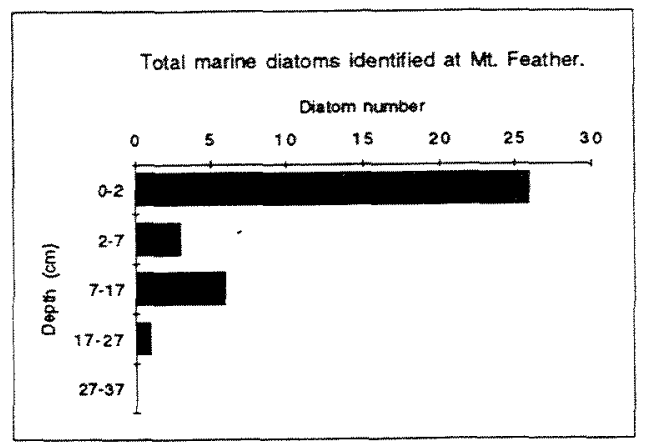

c.

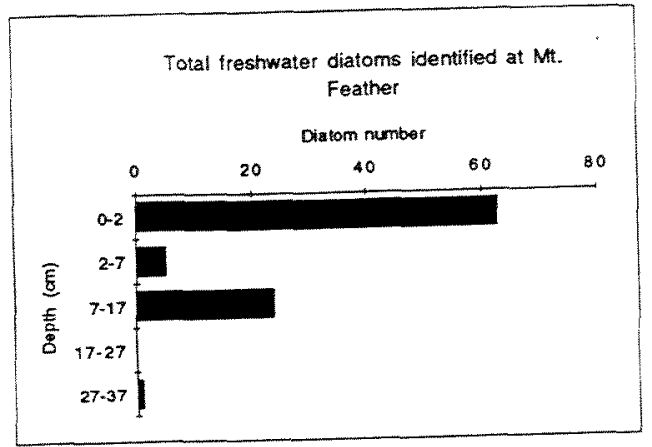

Figure 4.5 Combined distribution of diatoms with depth from all three Sirius Group sites at Mt. Feather. a shows the total combined diatoms with depth, $b$ shows the total marine diatoms with depth and $c$ shows the total freshwater diatoms with depth. 


\section{Diatom size}

Size is an important factor in deciding how diatoms might have been transported and incorporated with the till. Table 4.1 shows the size of the intermediate axis of diatoms identified from the Sirius Group at Mt. Feather is about $15 \mu \mathrm{m}$. The change in diatoms size with depth is given in Table A6.11.

The size of pore spaces in the Sirius till at Mt. Feather (App. 3.3) is roughly 10 times larger than the average diatom intermediate axis, producing ample oppotunity for diatoms to move down into the till from the surface. Porosity and permeability (App 3.3) are also strong controlling factors and porosity is low at Table Mountain.

Table 4.1 Average and maximum size of Diatoms and Phytoliths (intermediate axis) from the Sirius Group, Mt. Feather.

\begin{tabular}{|c|l|l|l|}
\hline & $\begin{array}{l}\text { Mean } \\
(\mu \mathrm{m})\end{array}$ & $\begin{array}{l}\text { Maximum } \\
(\mu \mathrm{m})\end{array}$ & $\begin{array}{l}\text { Number } \\
\text { counted }\end{array}$ \\
\hline Diatoms & & 20 & 24 \\
Marine & 15 & 63 & 168 \\
Freshwater & 16 & 51 & 2000 \\
Phytoliths & 13 & 5 \\
\hline
\end{tabular}

\section{Diatomacous clasts}

\section{Diatomaceous microclasts}

Like Harwood (1986) some diatom microclasts (clasts containing more than one diatom, often with clay matrix material) were identified in this study, most contained 1 to 3 diatoms or several broken pieces of diatom. Both marine and freshwater microclasts occurred. All microclasts were less than $100 \mu \mathrm{m}$ in diameter.

\section{Sedimentary clasts containing high concentrations of diatoms}

Harwood (1986) and Stroeven (1994) found a few single sedimentary clasts from their Sirius Group till samples contained greater numbers of diatoms than the surrounding matrix. Harwood (University of Nebraska, personal communication, 1995) suggests the concentration of diatoms on the surface of the till may be a result of these diatomacous sedimentary clasts breaking down at the surface. The processing method for the separation of diatoms used for 
this study completely breaks down all sedimentary material in the first stages, (App. 5) hence, no clasts containing larger concentrations of diatoms were identified. The separating methods of Stroeven and Harwood were not used because of time and financial restrictions. However, because all of the till sediment was broken down at all depths in the till, there was no bias for broken diatomacous clasts causing an apparent concentration of diatoms in the surface levels.

Table 4.2 gives rough sizes of potential diatomacous clasts at Sites One and Two at Mt. Feather if one clast was carrying all the marine diatoms found at each depth. Assuming this is true, much larger clasts would be required to occur on the surface of the till than at depth, rather than the expected even distribution with depth.

Table 4.2 Hypothetical clast size at each level if the marine diatoms originated from diatomacous clasts at Sites One and Two, Mt. Feather.

\begin{tabular}{|l|l|l|}
\hline Site & Sample & $\begin{array}{l}\text { Clast size (sum of } \\
\text { mean diatom size) }\end{array}$ \\
\hline One & $0-2 \mathrm{~cm}$ & $6.3 \mathrm{~mm}^{3}$ \\
& $2-7 \mathrm{~cm}$ & $0.5 \mathrm{~mm}^{3}$ \\
& $7-17 \mathrm{~cm}$ & $1.5 \mathrm{~mm}^{3}$ \\
& $17-27 \mathrm{~cm}$ & $0.2 \mathrm{~mm}^{3}$ \\
& $27-37 \mathrm{~cm}$ & $0 \mathrm{~mm}^{3}$ \\
Two & $0-2 \mathrm{~cm}$ & $6.8 \mathrm{~mm}^{3}$ \\
& $2-7 \mathrm{~cm}$ & $0.6 \mathrm{~mm}^{3}$ \\
& $7-17 \mathrm{~cm}$ & $0.2 \mathrm{~mm}^{3}$ \\
\hline
\end{tabular}

\section{Discussion}

The consistently high concentrations of both freshwater and marine diatoms on the surface of the till suggest they have been introduced onto the surface of the till and worked deeper into the sediment. The considerable porosity and large pore size of the Sirius Group till at Mt. Feather (10 times the size of the average diatom in the till) produces ample opportunity for at least some diatoms to migrate deep into the till. Much higher proportions of freshwater diatoms occur at Site One (App. 6.1, fig 4.2a), consistent with the findings of Kellogg and Kellogg (1984) who found much greater proportions of freshwater diatoms in the Sirius Group at Mt. Feather. However, at Site Two the proportions of fresh to marine diatoms are roughly the same (fig.4.3a). 
High proportions of the globally distributed freshwater genus Aulacoseira occur in the tills. Aulacoseira species occur on all other continents except for Antarctic and Sub-antarctic water bodies today (Håkansson and Jones, 1994; Wasell, 1993; Cragg, 1993), although Aulacoseira may have occured in Antarctica in Mid-Eocene - Oligocene times (Scherer, 1989, 1991). The concentration of Aulacoseira in the surface $2 \mathrm{~cm}$ of the till indicates they have been atmospherically transported.

The continuing high numbers of phytoliths at depth, and the lack of a trend in abundance with depth, suggests they were incorporated into the basal glacier ice then transported and deposited with the other glacial debris which formed the till.

\subsubsection{Table Mountain}

\section{Site One}

At Site One the 0-2 cm sample was barren but in the $27-37 \mathrm{~cm}$ sample six diatoms of the genus Aulacoseira were found (Table A6.1, Fig 4.6).

\section{Site Two}

The $0-2 \mathrm{~cm}$ sample from Site Two was also barren, and an unidentified diatom fragment was found in the $2-7 \mathrm{~cm}$ sample (fig. 4.7 ).

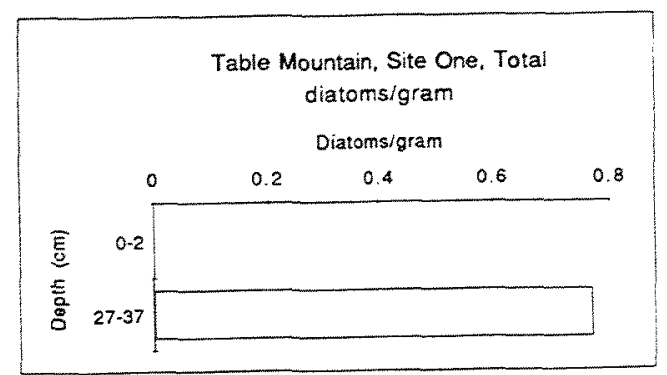

Figure 4.6 Total number of diatoms per gram from Table Mountain, Site One.
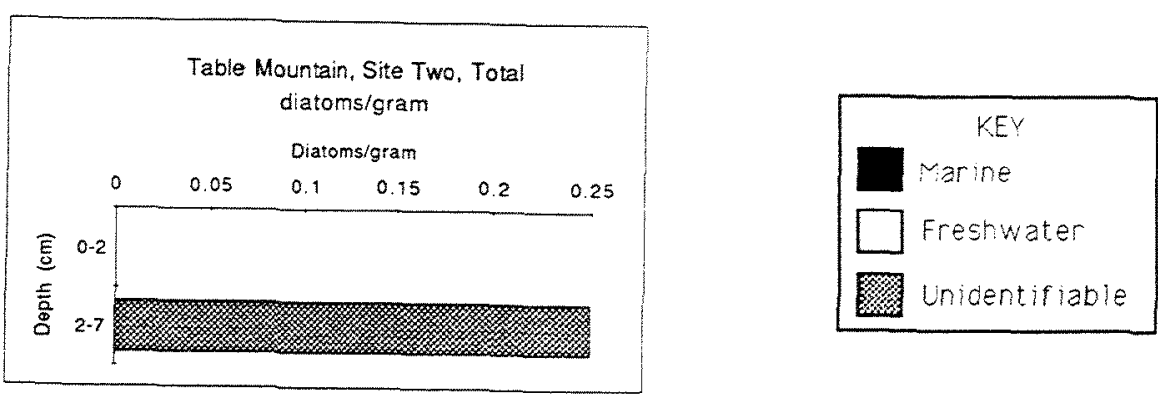

Figure 4.7 Total number of diatoms per gram from Table Mountain, Site Two. 


\section{Discussion}

Aulacoseira were the most common non-marine genus Sherer (1989, 1991) obtained in sediments cored from beneath the West Antarctic ice sheet at site Upstream B. Scherer (1989) shows their occurrence in large numbers along with chrysophyte cysts, pollen (Late Cretaceous to Paleogene forms), spores, plant tissue and amorphous organic matter with only small amounts of terrigenous clastic material, suggeting conditions indicative of a large coastal lake. Aulacoseira have also been recorded from Mid. Eocene lake sediments in North America (Bradbury and Krebs, 1995). The till at Table Mountain has a very low porosity and hence there is little possibility of diatom incorporation from the atmosphere at this depth $(27-37 \mathrm{~cm})$. The Aulacoseira species identified at Site One as well as the unidentified fragment found at Site Two may have been incorporated into the till when it was deposited.

\subsection{DLATOMS FROM THE REGOLITH}

If diatoms similar to those in the Sirius Group tills also occur on non-Sirius surfaces then at least some must have a atmospheric origin.

\subsubsection{Mt. Feather}

Table A6.7 and Figure 4.8 show the occurrence of diatoms from regolith at Site One. This sample is from a crevice in the Weller Coal Measures of the Beacon Supergroup $100 \mathrm{~m}$ in altitude lower and $300 \mathrm{~m}$ horizontally from the edge of the Sirius tills (fig 3.1). Only a few common freshwater diatom species were found in this sample.

The second sample was taken from a gravel moraine adjacent to the Sirius till at the northern edge of the platform over looking Beacon Valley (fig. 3.1). This sample contained relatively large numbers of diatoms, dominated by marine forms, including several diatom species that have been identified in the Sirius till from both Mt. Feather and Mt. Fleming previously (Stroeven, 1994; Harwood, 1986). The diatoms in this sample include the Sirius Group age indicators Actinocyclus actinochilus (3-0 Ma), Actinocyclus ingens (15-0.65 Ma) and Thalassiosira lentiginosa (3.9-0 Ma). 


\subsubsection{Table Mountain}

This regolith sample was taken in the lee of a large erratic on New Mountain Sandstone of the Beacon Supergroup. The sample was almost entirely sand in composition, which was processed out during separation concentrating the finer diatom fraction more to a greater extent than the other samples. The diatom assemblage contains large numbers of dominantly marine planktonic diatoms including the Sirius Group age indicators (Harwood, 1986). Actinocyclus ingens (15 - $0.65 \mathrm{Ma})$, Thalassiosira torokina (8 - $1.6 \mathrm{Ma})$,

Thalassiosira lentiginosa (3.9-0 Ma), Actinocyclus actinochilius (3-0 Ma), Nitzschia ritscheri (3.4 - 0 Ma) and Nitzschia kergulensis (3.1 - $0 \mathrm{Ma}$ ). It should also be noted that the marine diatoms from this site were in a better condition than those from the Sirius tills (more whole specimens occurred). Some of the species identified in the regolith also occurred in the snow at Table Mountain (Tables A6.8 and A6.7).

\subsubsection{Mt. Crean}

The regolith sample was taken from the eroded surface overlying the Aztec Siltstone. The sample was dominantly of sandstone origin. Only 0.4 diatoms per gram were calculated from Mt. Crean regolith samples. The marine to freshwater diatom ratio is more even than the assemblages in the regolith from Mt. Feather and Table Mountain (Table A6.1). Similar diatoms were identified from this sample to those in the Sirius Group tills (Table A6.7).

\section{Discussion}

The occurrence of several of the Sirius age indicators in the regolith at Table Mountain and Mt. Feather, plus the occurrence of several marine and freshwater diatoms on Mt. Crean (nowhere near any Sirius Group deposits) also points to diatoms in the Sirius Group tills being introduced from the atmosphere.

Two distinct assemblages appear to occur from the regolith. One in which diatoms occur in large numbers with an assemblage dominated by marine diatoms such at those at Table Mountain and Mt. Feather Site Two; and the other where there are fewer diatoms and proportionally more freshwater species (Table A6.1, fig 4.8) such as those at Mt. Feather Site One and Mt. Crean. The degree to which diatoms accumulate in the regolith may vary depending 
on how porous or sheltered the material is enabling a site to trap diatoms from the atmosphere. Some wind sorting of diatoms may occur, where lower wind speeds are able to re-entrain the smaller freshwater diatoms from some sites but not the heavier marine species.

This unusual patchiness and variation in assemblage also occurs in the Sirius Group till samples. Kellogg and Kellogg (1994) obtained an almost entirely freshwater assemblage from the Sirius Group at Mt. Feather while Harwood (1996,although biasing his sample by sieving at $25 \mu \mathrm{m}$ to concentrate the larger marine diatom age indicators) obtained a dominantly marine flora. Some sites contain no diatoms at all, while others contain large numbers.

a.

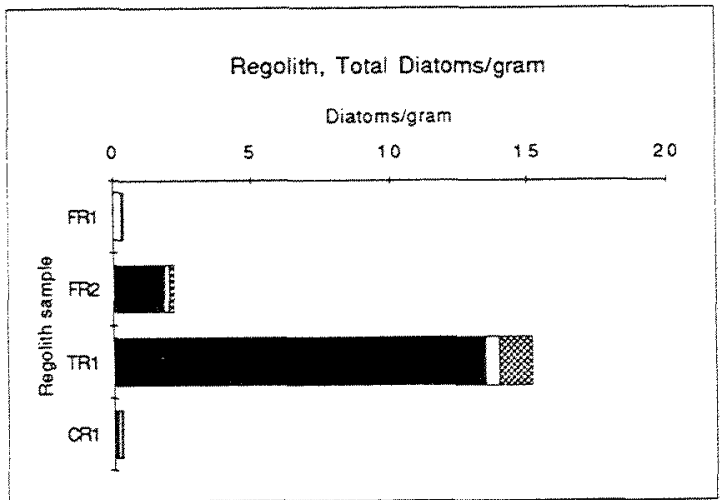

b.

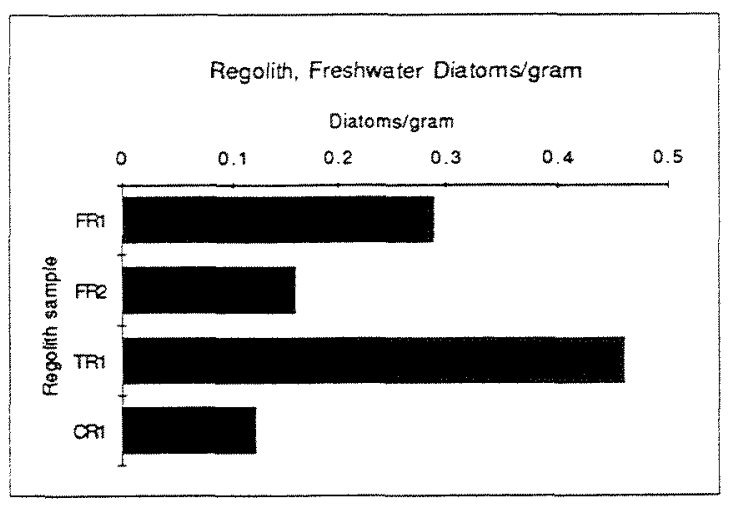

c.

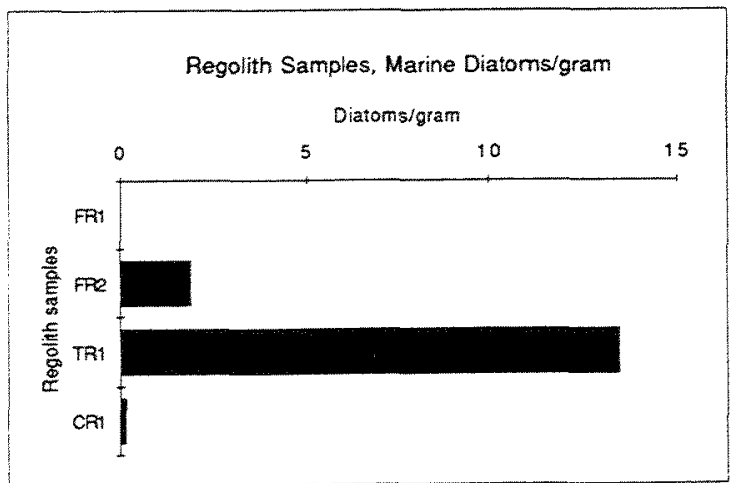

Figure 4.8 a. Total number of diatoms per gram from the regolith at $\mathrm{Mt}$. Feather, Table Mountain and Mt. Crean showing the proportions of marine, freshwater and unidentifiable diatoms. $b$. Number of marine diatoms per gram from regolith samples. c. Number of freshwater diatoms per gram from regolith samples.

Some questions remain. If the marine diatoms from the regolith at Site Two at Mt. Feather are eroded Sirius Group material, or have dropped into it after being entrained by high winds from the surface of the Sirius Group, why are 
there so many more marine diatoms in the regolith than on the surface of the till (figs 4.2, 4.3 and 4.8); and why are there almost all marine species in the regolith at Site Two when freshwater species dominate in the surface samples from the Sirius Group (figs. 4.8 and 4.2)?

Harwood (personal communication, 1996) has suggested that diatoms in the regolith and snow may have been blown off the Sirius Group outcrops. However the regolith at Table Mountain yielded a similar species assemblage to the material on Mt. Feather but at a much larger concentration (Tables A6.7, A6.2). Further, more diatoms are rare in the Sirius Group on Table Mountain and marine diatoms are totally absent. Hence, the diatoms from regolith Site One at Table Mountain cannot have originated from the adjacent Sirius Group till. The nearest diatom bearing Sirius Group tills to the Table Mountain and Mt. Crean regoliths are those on Mt. Feather.

\subsection{DIATOMS FROM THE SNOW}

\subsubsection{Mt. Feather}

A few small pieces of marine diatom were found in the snow from Mt. Feather (Table A6.8). Large numbers of Freshwater diatoms, specifically of various Aulacoseira species were identified (Table A6.8).

\subsubsection{Table Mountain}

The snow from Site One was the first to be melted after the control, it yielded only five freshwater diatoms; one of which is the same as one of the species identified in the contaminants from the control sample, another species Asterionella formosa occurs in Antarctic Lakes (Cragg, 1995) as well as some South Island lakes (Flint, 1975) and is suspect (Table A6.8).

There are higher numbers of marine diatoms found from the snow at Site Two at Table Mountain (fig. 4.9, Table A6.1, A6.8). Most of the marine species identified including Nitzschia curta, Nitzschia obliquecostata and Nitzschia sublineata are Antarctic sea ice diatoms (App. 6.6, Table A6.8). The freshwater species identified are typical Antarctic lake species (Håkasson and Jones, 1993, App. 6.6, Table A6.8 ). 


\section{Discussion}

It is uncertain where and when the sea ice diatoms identified from the snow came. They may have been derived directly from the sea ice and been incorporated from the air into the snow as it formed and then been deposited or it may have been blown onto the snow from the regolith nearby. Sea ice diatoms are dominant in many collections of air borne diatoms on Signy Island (Dr. M. Harper, VUW, personal communication, 1996). The species Nitzschia curta occurs in wind traps at Signey Island up to two $\mathrm{km}$ from the sea (Harper and Chalmers, in press). Nitzschia curta has also been identified in the snow from Site Two at Table Mountain, from ice cores from inland Antarctica (Kellogg and Kellogg, 1996) and from the Sirius Group tills (Harwood, 1986).
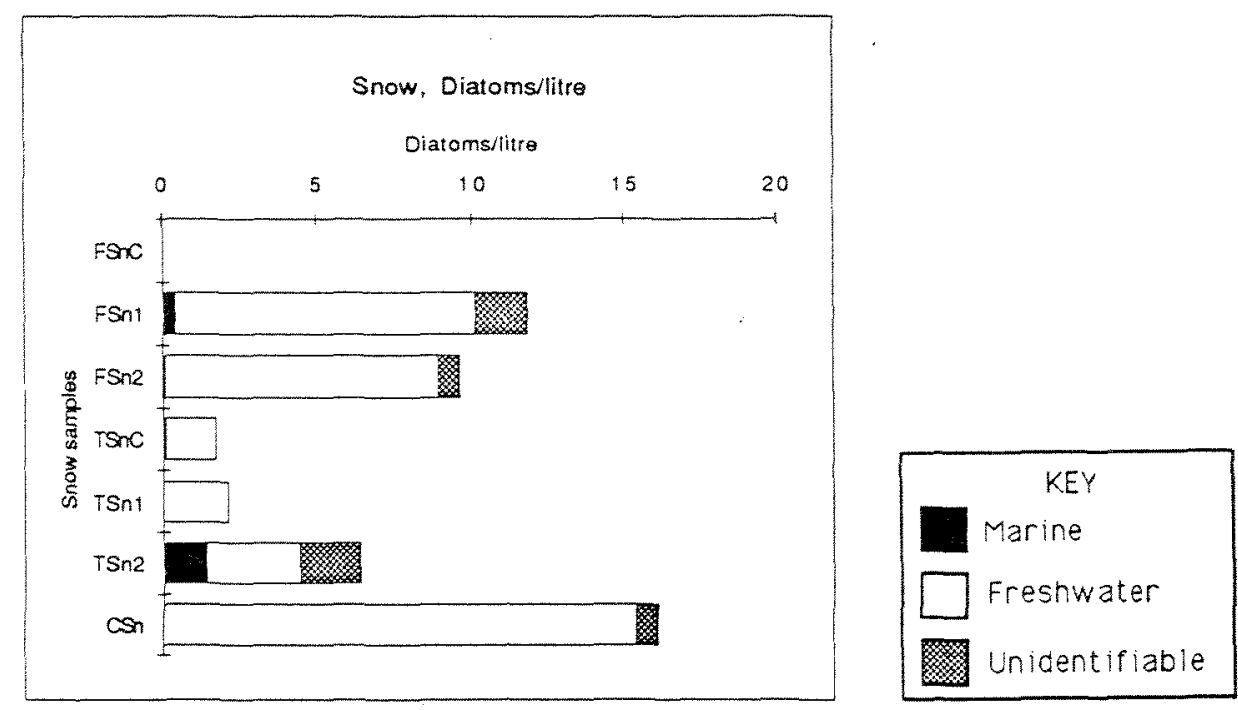

Figure 4.9 Total number of diatoms from the snow at Table Mountain, Mt. Feather or Mt. Crean. F, T or C donates the Mountain location, Sn refers to snow, 1 or referrs to site one or two, $C$ at the end of the sample abbreviation refers to the control sample.

\subsubsection{Mt. Crean}

The diatom assemblage from the snow at Mt. Crean is entirely freshwater in origin, containing dominantly Aulacoseira species, but also a single Cocconeis species (Table A6.6). This is a similar assemblage found in the Sirius Group deposits from Mt. Feather by Kellogg and Kellogg (1984). 


\section{Discussion}

The few small marine fragments identified in the snow at Mt. Feather may have been derived from the surface of the Sirius till or the adjacent regolith deposits. The large numbers of the genus Aulacoseira (which does not occur in Antarctica today) identified in the snow at both Mt. Feather and Mt. Crean suggests they have been introduced from the atmosphere. Aulacoseira are very resistant to dissolution occurring frequently in dried material blown from the Sarahan desert (Kolbe 1955, 1957; Pokras and Mix, 1985; Prokras and Ruddimann, 1989). Dr. M.A. Harper (VUW, personal communication, 1996) suggests Aulacoseira may also be frequent in material from dried lakes in Patagonia and adjacent regions, hence regularly blown into Antarctica.

Although Aulacoseira does not occur in Antarctic lakes today, Scherer (1991) also found large numbers in Upstream B which suggests diatoms were present in Antarctica in least in Late Eocene-Oligocene times. However, because Aulacoseira occurs only in the surface $2 \mathrm{~cm}$ of the till at Mt. Feather it must have been introduced from the atmosphere rather than being incorporated with the tills when they were deposited.

\subsection{DIATOMS IN SEA CLIFF TILLITES FROM THE SOUTH ISLAND, NEW ZEALAND.}

Two samples were collected from tills from Okarito on the West Coast of the

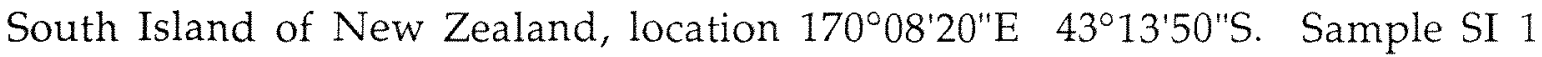
was from a lower unit at the base of the coastal bluffs, $500 \mathrm{~m}$ southwest of the car park at the south end of the village. This was identified as a lodgement till with a silty matrix (Dr. Goff, VUW, personal communication, 1995). Sample SI 2 was from an upper unit, in the middle of the coastal bluffs, $475 \mathrm{~m}$ southwest of the car park at the south end of the village. This upper unit was massive with a silty matrix and identified as a meltout till (Hicock et al. in press).

Both sites lie approximately 50 metres from the sea. The surface $4 \mathrm{~cm}$ of the till were cleared and both samples were taken and put in clean plastic bags. These tillites are approximately 20,000 years old (Dr. Goff, VUW, personal comminication, 1995).

The samples were processed for the extraction of diatoms using the same methods as the Sirius Group samples (App. 5.1). 
Sample SI 2 was dominated by Rhophalodia rupestis, a benthic freshwater diatom (Table A6.9). One brackish coastal species (Hendy, 1964) Amphora coffeaeformis was present. There was no evidence of any other partially marine or fully marine diatom species in the samples, even though they were only $50 \mathrm{~m}$ from the sea.

\subsection{DLATOMS FROM CRACKS IN ANTARCTIC ROCKS FROM THE ROCK STORE.}

Dr. Burckle (Lamont-Doherty Earth Observatory, personal communication, 1995) obtained samples of non-Sirius group material from storage areas of several Antarctic scientists originating from a number of sites in the Transantarctic Mountains (Burckle, 1995; Burckle and Potter, 1996). Fine silty material was removed from cracks in these rocks and processed for diatoms, from which a number of species were identified.

This experiment was repeated with some Antarctic rocks in storage from Victoria University of Wellington rock storage room. Two samples of dust from the rock storage room was taken as controls. A few diatoms, both freshwater and marine were identified in the silt from the cracks in some of these rocks. The most successful assemblage was from silt in a crack in petrified wood from Wellar Coal Measures from Allen Hills. None were found from cracks in our own samples.

Analysis of the controls showed large numbers of both freshwater and marine diatoms present in dust from the rock store (Table A6.11). This suggests there is a possibility of diatom contamination of material that has been stored in rock stores. Although the diatoms found in the cracks of rocks from the Transantarctic Mountains may not be contamination, the possibility that they could be contaminated was considered too great to continue this analysis.

The possible contaminants that these rocks may have been exposed to from the time they were collected, until they were received for processing, is not known. 


\subsection{SUMMARY AND CONCLUSION}

1. Diatoms were found in greatest concentration in the surface samples from the Sirius Group Tills at Mt. Feather and the numbers of diatoms decreased with depth, though the distribution of diatoms is patchy areally and vertically.

2. Mean pore size in the Sirius till is roughly ten times larger than the mean size of the intermediate axis of the diatoms at Mt. Feather, allowing the penetration (diffusion) of diatoms down from the surface.

3. Equivalent and larger numbers of diatoms were found in regolith from the Beacon Supergroup and in the adjacent moraines than in the Sirius Group tills themselves.

4. Many of the diatoms identified also occur in the Sirius Group tills including some of the biostratigraphic indicators for the age of the Sirius Group. Extinct age indicating diatoms occur in the regolith in this study but are not found in the Sirius Group sediment samples or in the snow. Material in the moraine sample at Mt. Feather may be reworked from the Sirius Group till, but this does not explain the high numbers of diatoms and an almost entirely marine assemblage similar to that from the regolith at Table Mountain.

5. Diatoms similar to some of those in the Sirius tills also occur in snow samples from Table Mountain, Mt. Feather and Mt. Crean. There is no Sirius Group at Mt. Crean to act as a source for diatoms.

6. Diatoms from tills on the West Coast of the South Island of New Zealand, that occur not $50 \mathrm{~m}$ from the high tide mark, show a dominantly freshwater assemblage with only a couple of brackish coastal diatoms present.

Points 1, 2, 3, 4 and 5 above indicate that diatoms in the Sirius Group at Mt. Feather have been introduced after the deposition of the tills from an external source. Point 6 suggests that in New Zealand conditions marine diatoms cannot be easily picked up from the sea and transported far. However, Antarctic sea ice diatoms were found in wind traps at Signey Island suggesting sea ice diatoms can be transported at least two kilometres inland (Harper and Chalmers, in press), possibly from the surface of overturned ice bergs. It is also known that fresh water diatoms in dried sediments exposed to the wind can be 
picked up and carried great distances (section 2.6). This may also occur for marine diatoms, especially in extreme Antarctic conditions. 


\section{Chapter Five}

\section{The age and distribution of Sirius diatoms and the age of the Sirius Group.}

\subsection{The original estimated age(s) of Sirius Group deposits using sedimentology and stratigraphy.}

From the sedimentology of the Sirius Formation on Mt. Sirius and in the Dominion Range Mercer (1972) interpreted the Sirius Group to be a result of deposition by temperate ice cover situated on the Transantarctic Mountains, pre-dating the formation of the Antarctic ice sheet. However, Mayewski (1972, 1975), also analysed the sedimentology of several Sirius Group sites and concluded that it was all deposited at one time by ice over riding the Transantarctic Mountains "post-dating the glacial sculpturing of the Transantarctic Mountains by the Antarctic ice sheet" (in Brady and McKelvey, 1979). Hence, even in 1972 there was some disagreement as to the age of the Sirius Group deposits.

The deposition of the Sirius Group at Table Mountain was estimated by Barrett and Powell (1982) to be "late Oligocene to Early Miocene in age before the outlet glaciers had cut deeply into the Transantarctic Mountains", which coincided with glacial deposition and high sedimentation rates at Deep Sea Drilling Program Site 270, indicating extensive, wet-based, glacial erosion around the Ross Embayment (Barrett, 1975).

From the sedimentology of the Sirius Group of Mt. Feather Brady and McKelvey (1979) also thought that Sirius Formation pre-dated cutting of the existing glacial drainage system in Southern Victoria Land including Wright Valley. Because the oldest diatom floras from Lake Vanda in the Wright Valley are between 7 and $10 \mathrm{Ma}$, glacial cutting must pre date this age (in Brady and McKelvey, 1979) and post date the first ice rafting in the Ross Sea (at that time thought to be $25 \mathrm{Ma}$ or latest Oligocene, Hayes et al., 1975). Hence, Brady and McKelvey (1979) estimated the age of the Sirius Group deposition at Mt. Feather to be in early or middle Miocene times. 


\subsection{Diatoms in the Sirius Group and their age implications}

Harwood was not the first to extract diatoms from the Sirius Group but he was the first to use them to provide an age for the unit (Harwood, 1983). He identified diatoms from nine localities scattered along the length of the Transantarctic Mountains and found that he could identify the Cosmidiscus insignus Zone through the Nitzschia interfrigidaria-Coscinodiscus Zone (3.1 to $3.5 \mathrm{Ma}$ ) of Ciesielski (1983). The youngest assemblage included Coscinodiscus vulnificus (now Thalassiosira vulnifica) which ranges in age from 3.1 to 2.2 ma (fig. 5.1). Harwood thought the diatoms were deposited at the same time as the tills and hence deposition of the tills had to post date the age of this youngest diatom assemblage present.

On Mt. Feather Harwood initially took nine samples, a further three were collected by Peter Webb and one sample was obtained from John Mercer who collected it from Mt. Feather 1964. Of these 13 samples, 6 were barren and a total of 133 diatoms were identified. The diatoms constraining the age of the Sirius Group on Mt. Feather were "the Upper Neogene diatoms: Hemidiscus karstenii, Coscinodiscus lentiginosus, C. lentiginosus f. obovatus, Nitzschia kerguelensis, Rouxia antarctica, and others" (Harwood, 1983). These species were only found in the one Mercer sample, which had been in storage for 20 years. In fact 88 of the 133 diatoms identified from Mt. Feather were identified from this one sample.

Weaver and Gambos (1981) and DeFelice (1979) show "C. lentiginosus $f$. obovatus is restricted to middle Pliocene through to lowest Pliocene times in the Southern Ocean" (in Harwood, 1983), again assuming the species to be insitu, this implies that the deposition of the Sirius Group must be younger than early Pliocene.

Harwood (1986) noted that Thalassiosira lentiginosa and Nitzschia kerguelensis are are two of the most abundant diatoms in the southern oceans siliceous ooze belt but are now not commonly found south of the Antarctic Divergence Zone. He considered the presence of these two slightly warmer climate planktonic diatoms in the Sirius Group suggests marine waters with temperatures between 2 and $6^{\circ} \mathrm{C}$ in the late Neogene in the Wilkes and Pensacola Seas. Palmisano and Garrison (1993) and Pichon (1984) both report Nitszchia kerguelensis in Antarctic Seas and at the ice edge today (no more 
than $20 \%$ of the total assemblage), especially in the summer months. However, it is still most dominant in the Antarctic Divergence Zone and Antarctic open oceans (60-80\%, Pichon 1984).

On Mt. Fleming, Stroeven (1994) found the youngest identifiable marine diatom assemblage is constrained in age by the first appearance datum of Actinocyclus actinochilus ( $3 \mathrm{Ma}$ ) and the last appearance datum of Thalassiosira torokina (1.8 Ma).

The only age constraining diatom species identified in the Sirius Group at Mt. Feather in this study was Actinocyclus actinochilus which first appeared three million years ago and exists today.

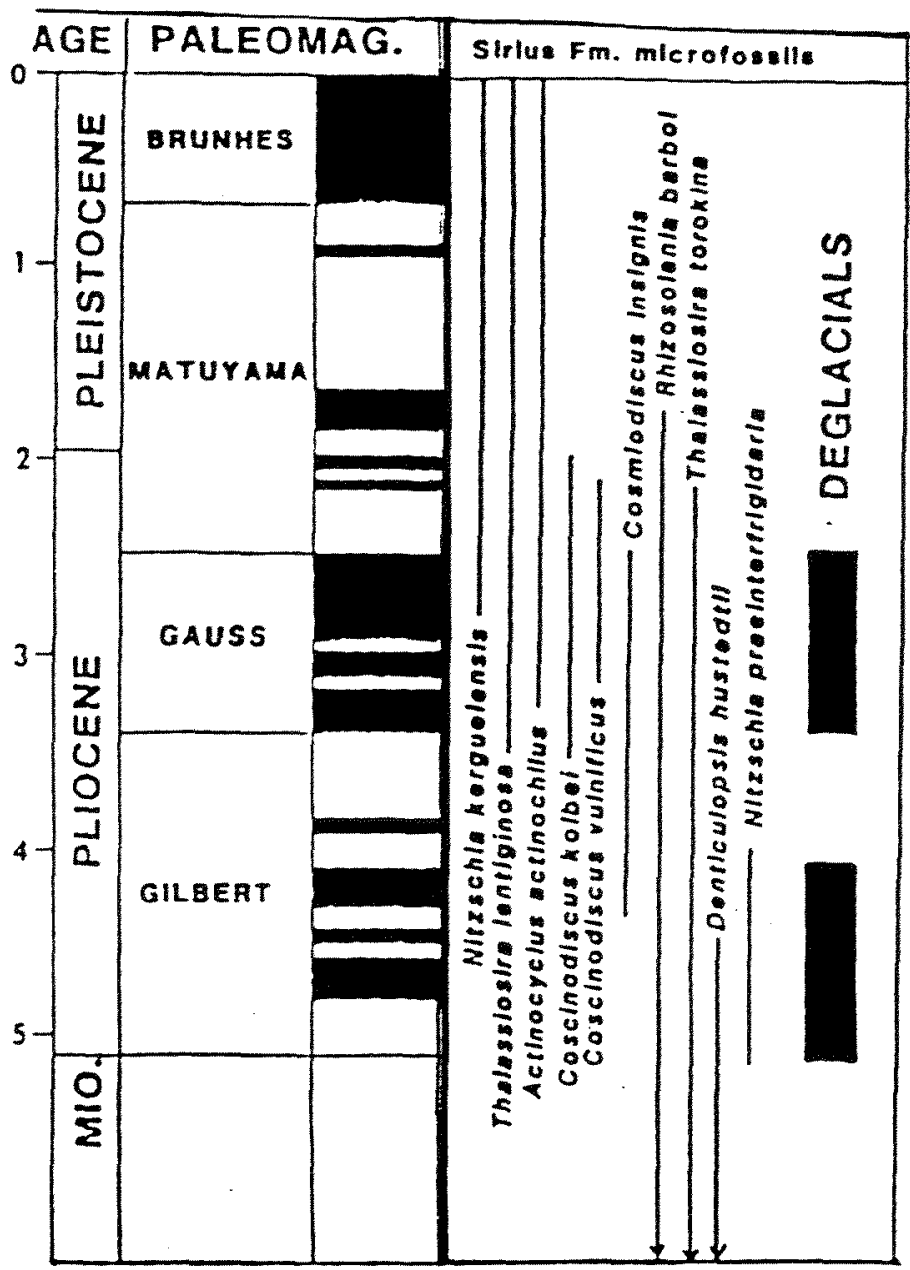

Figure 5.1 The time overlap of some of the major biostratigraphic diatom indicators found from the Sirius Group, from Harwood (1986). As a result of these two distinct assemblages, Harwood proposed two distinct times of deglaciation in central Antarctica. Nitzschia kergulensis now first appears at 3.1 $\mathrm{Ma}$, and Thalassiosira lentiginosa now first appears at 3.9 Ma. 


\subsection{Comparison of diatom species found in the Sirius Group and from other substrates.}

A comparison needs to be drawn between the diatom assemblages found from the Sirius Group tills and other Antarctic substrates by various workers (even though their processing methods may be slightly different). If some species that occur regolith and snow samples also occur in Sirius tills, then the diatoms from the Sirius till are more likely to be introduced from the atmosphere. Table 5.1 is a matrix comparing the numbers of species in common from the assemblages found by various people on different Antarctic substrates. The data associated with this matrix is shown in Table A6.14.

Of the 12 marine species identified from the Sirius Group in this study four were also identified by Harwood in the Sirius Group at Mt. Fleming and Mt. Feather. Three of the 12 also occurred from the Sirius Group from Mt. Fleming in Stroeven's work.

\subsubsection{Comparison of those species found in regolith samples.}

Although few age constraining species were identified in the tills from $\mathrm{Mt}$. Feather some age constraining species were identified from regolith samples. At Table Mountain Actinocyclus actinochilus (3-0 Ma) and Thalassiosira torokina (8-1.8 Ma) give a constraining age of between 3 and $1.8 \mathrm{Ma}$ (fig. 5.1). These are two of the species that that Harwood $(1983,1986)$ uses to constrain the age of the Sirius Group tills (Fig. 5.1)

The greatest similarities in species are between the regolith samples from $\mathrm{Mt}$. Feather and Table Mountain and the diatoms of the Sirius Group from Harwood (1986), Stroeven (1994) and from this study. Eight of the 12 marine species identified in the Sirius Group at Mt. Feather in this study also occurred in the regolith samples; also 10 of the 12 marine species identified in the regolith also occurred in the Sirius Group from Mt. Fleming (Stroeven, 1994); 11 of the 12 marine species identified from the regolith also occurred in the assemblage of thirty one marine species identified by Harwood (1986, table 5.1). The regolith samples had more species in common with the individual Sirius tills than did the three Sirius Group species assemblages themselves. The clear implication of these observations is that the diatoms in the Sirius tills and the regolith have a similar source. 
Table 5.1 Matrix comparing species in common between diatom assemblages from various workers and deposits.

MARINE

\begin{tabular}{|c|c|c|c|c|c|c|c|c|c|c|}
\hline & $\operatorname{Sir}(B \mid)$ & $\operatorname{Sir}(S)$ & $\operatorname{Sir}(H)$ & $\operatorname{Sir}(K)$ & $\operatorname{Reg}(\mathrm{Bl})$ & Reg(Bu) & $\operatorname{Sn}(B \mid)$ & $\operatorname{Sn}(K)$ & $S n(B u)$ & Tot. Mar \\
\hline $\operatorname{Sir}(B)$ & & 3 & 4 & 0 & 8 & 1 & 1 & 2 & 0 & 12 \\
\hline $\operatorname{Sir}(S)$ & $?$ & 8 & 9 & 0 & 10 & 7 & 1 & 4 & 0 & 24 \\
\hline $\operatorname{Sir}(H)$ & 2 & $?$ & & 0 & 11 & 6 & 3 & 8 & 1 & 31 \\
\hline $\operatorname{Sir}(K)$ & 2 & $?$ & 0 & & 0 & 0 & 0 & 0 & 0 & 1 \\
\hline Reg(B) & 4 & $?$ & 2 & 0 & & 9 & 1 & 4 & 1 & 25 \\
\hline $\operatorname{Reg}(\mathrm{Bu})$ & 0 & 0 & 0 & 0 & 0 & & 0 & 1 & 1 & 13 \\
\hline $\operatorname{Sn}(B \mid)$ & 5 & $?$ & 2 & 2 & 4 & 0 & & 6 & 0 & 6 \\
\hline $\operatorname{Sn}(K)$ & 7 & $?$ & 1 & 1 & 3 & 0 & 5 & & 0 & 28 \\
\hline $\mathrm{Sn}(\mathrm{Bu})$ & 2 & $?$ & 0 & 0 & 1 & 0 & 1 & 1 & & 13 \\
\hline Tot. FW & 14 & - & 2 & 11 & 5 & 0 & 15 & 11 & 6 & \\
\hline
\end{tabular}

FRESHWATER

Key-

Freshwater species are compared below the diagonal and marine species are compared above the diagonal.

Sir(Bl) -Diatoms found in the Sirius Group at Mt. Feather by Bleakley, this study

Sir(S) -Diatoms found from the Sirius Group by Stroeven (1994) from Mt. Fleming.

$\operatorname{Sir}(\mathrm{H})$-Diatoms found from the Sirius Group by Harwood (1986) from Mt. Feather and Mt. Fleming.

$\operatorname{Sir}(\mathrm{K})$-Diatoms found in the Sirius Group at Mt. Feather by Kellogg and Kellogg (1984).

Reg(Bl)-Diatoms found from regolith at Mt. Feather, Table Mountain and Mt. Crean, by Bleakley, this study, excluding those found from Site Two on Mt. Feather due to the possibility of reworking and concentration from the Sirius Group material nearby.

$\operatorname{Reg}(\mathrm{Bu})$-Diatom assemblage found in cracks from much older Antarctic rocks from Burckle (1996).

$\mathrm{Sn}(\mathrm{Bl})$-Diatoms found from the snow, by Bleakley, this study.

$\mathrm{Sn}(\mathrm{K})$-Diatom species in common with other groups in the matrix found in ice cores from 18 sites, around Antarctica from Kellogg and Kellogg (1996).

$\mathrm{Sn}(\mathrm{Bu})$-Diatoms assemblage found from the Dome $\mathrm{C}$ ice core by Burckle et al. (1988).

Tot. Mar. -Total number of marine species identified from each study.

Tot. FW. -Total number of freshwater species identified from each study. 
Burckle and Potter (1996) have investigated the diatom assemblages found in sediment from cracks in rocks from Paleozoic and Mesozoic Beacon Supergroup sediments and basalts from the Dry Valleys. These rocks were from the rock stores and that were collected by other Antarctic scientists over the last 30 years. Over $50 \%$ of their assemblages contained Nitzschia kerguelensis and Thalassiosira lentiginosa that, as described above from Harwood's work, are most common in the Antarctic Divergence Zone. Of the 13 marine species Burckle and Potter (1996) identified 9 were also identified in the regolith samples in this study. Seven of Burckle and Potter's species were also in common with Stroeven's assemblage from Mt. Fleming (table 5.1).

\subsubsection{Comparison of species in snow and ice cores}

Burckle et al. (1988) analysed diatom species from an ice core at Dome C, in this they obtained a $98 \%$ freshwater diatom assemblage and a piece of the marine ice diatom Nitzschia kerguelensis. Because few of these diatom species correlated with the assemblage found by Harwood (1986) in the Sirius Group tills the possibility of eolian transport of diatoms onto the Sirius tills was discounted (Barrett et al, 1992). However Kellogg and Kellogg (1996), have since shown that diatom assemblages from other ice cores from 18 locations throughout Antarctica do contain some of the marine diatom species identified by Harwood (1986) in the Sirius Group (table 5.1, App. 6.10).

Eight of the Kellogg and Kellogg (1996) 28 marine species from the ice cores also occur in Harwood's Sirius Group samples from Mt. Feather and Mt. Fleming. Four and two marine species respectively from the ice cores were also found in Sirius Group till by Stroeven and in this study .

All 6 marine species that occurred in the snow samples from this study also occurred in the ice core assemblages, while only 5 of the 15 freshwater species identified in the snow were also identified in the ice cores (table 5.1).

Of the 28 marine species identified in the ice cores 4 also occurred in the regolith samples from this study, fewer in proportion than those in common with Harwood's Sirius Group samples (table 5.1). 


\subsection{Diatoms from the surface of the tills and diatoms found at depth}

If the diatoms from the Sirius tills are introduced from the atmosphere, then similar species shold be shared by the regolith and surface samples from the till. Also if the diatoms are work into the till from the surface, then the species found at depth in the till shold also occur in the surface samples. Table 5.2 compares the species found in the regolith with those from the surface and those from depth in the tills at Mt. Feather (this study) and Mt. Fleming (Stroeven, 1994), the numbers of each diatom can be seen in Appendix 6.11.

Table 5.2 Matrix comparing species in common between diatom assemblages from the regolith and surface and depth samples from Sirius Group deposits at Mt. Feather and Mt. Fleming.

\begin{tabular}{|c|c|c|c|c|c|c|}
\hline & Reg(BI) & Si.B $<7 \mathrm{~cm}$ & Si.S $<10 \mathrm{~cm}$ & Si.B $>7 \mathrm{~cm}$ & Si.S $>10 \mathrm{~cm}$ & Tot. Mar. \\
\hline Reg(BI) & & 8 & 11 & 2 & 3 & 26 \\
\hline Si.B $<7 \mathrm{~cm}$ & 4 & & 3 & 2 & 2 & 11 \\
\hline Si.S $<10 \mathrm{~cm}$ & $?$ & $?$ & 3 & 2 & 6 & 23 \\
\hline Si.B $>7 \mathrm{~cm}$ & 2 & 3 & $?$ & & 2 & 3 \\
\hline Si.S $>10 \mathrm{~cm}$ & 0 & 0 & 0 & 0 & & 6 \\
\hline Tot. FW & 5 & 15 & $?$ & 3 & 0 & \\
\hline
\end{tabular}

FRESHWATER

Key -

Marine species are compared above the diagonal and freshwater species are compared below the diagonal.

Groups

$\operatorname{Reg}(\mathrm{Bl})$ - Diatoms from regolith at Table Mountain, Mt. Feather and Mt. Crean, excluding those from site two at Mt. Feather, which could be reworked from the Sirius Group.

$\mathrm{SiBl}<7 \mathrm{~cm}$-Diatoms from the surface $7 \mathrm{~cm}$ of the Sirius Group tills at Mt.

Feather in this study

SiS $<10 \mathrm{~cm}$-Diatoms from the surface $10 \mathrm{~cm}$ from the tills at $\mathrm{Mt}$. Fleming from Stroeven (1994)

$\mathrm{SiBl}>7 \mathrm{~cm}$-Diatoms from greater than $7 \mathrm{~cm}$ in depth from the tills at $\mathrm{Mt}$.

Feather in the study.

SiS $>10 \mathrm{~cm}$-Diatoms from $>10 \mathrm{~cm}$ in depth from the tills at $\mathrm{mt}$. Fleming from

Stroeven (1994)

Tot.Mar. - The total number of Marine species identified from each study.

Tot. FW - The total number of Freshwater species identified from each study. 
All six species that occur at $>10 \mathrm{~cm}$ depth in the Sirius tills at Mt. Fleming in the work of Stroeven (1994) also occur at the surface of the deposit (App. 6.11).

All the freshwater species that occur at depth in the till in this study also occur on the surface. There are two marine species that do not occur on the surface but do at depth (table 5.2).

\subsection{Discussion}

Assemblages from both the Sirius Group deposits and the regolith are patchy and variable. The results from the regolith show the diatoms have several species in common with the diatoms from the tills, which further supports an atmospheric origin for the diatoms in the tills. Interestingly samples from the ice and snow tend to have fewer species in common with the Sirius Group than the regolith.

Of the biostratigraphic assemblages Harwood (1986) recognised from the Mt. Feather sample collected by Mercer, all the biostratigraphic indicators have now been recognised in snow or regolith from his Upper Miocene to Lower Pliocene assemblage. Also, all but Rouxia antarctica and Hemidiscus karstenii from his Upper Miocene through Pliocene assemblage, and all but Thalassiosira lentiginosa $f$. obovatus from his Mid. to Upper Pliocene assemblage have been recognised in the snow and regolith where there mode of emplacement can only have been from the atmosphere.

\subsection{The age of the Sirius Group tills}

The data clearly points to the introduction of most diatoms into Sirius Group tills from the atmosphere. If this is the case then the age of the Sirius Group tills is more likely late Oligocene to Mid. Miocene closer to that suggested by the original studies of the tills.

Since those papers were produced, the earliest evidence of temperate glaciers reaching the sea in the Ross Sea region is from a Late Eocene dinoflagellate assemblage in association with ice rafted detritus at the base of the CIROS-1 core, drilled from the Ross Ice Shelf (Hannah et al, in prep). Further, high rates of glacial deposition in the south and central Ross Sea by late Oligocene and 
Miocene times $(41 \mathrm{~m} / \mathrm{Ma})$ is an indication of more extensive wet based glacial erosion around the Ross embayment (Barrett, 1975).

The age of the Sirius Group at Table Mountain and Mt. Fleming can also be constrained by a minimum age from cosmogenic ${ }^{10}$ Be surface exposure dating of the rocks. At Table Mountain minimum ages of exposure are 2.6-2.9 Ma surrounding the Sirius Group and $5 \mathrm{Ma}$ on the New Mountain Sandstone (Ivy-Ochs et al., 1995). The deposition of the Sirius Group at Table Mountain must pre dated these ages. Ivy Ochs et al. (1995) also have a minimum exposure age from Mt. Fleming of $4.8 \mathrm{Ma}$. Hence age of deposition of the Sirius Group from the Dry Valley region has occurred at during Miocene times at the earliest.

Also the last period of major glacial erosion in the Dry Valleys region which the Sirius Group at Mt. Feather and Table Mountain must pre-date comes from late Miocene paleontologic ages from sediment fill in lower Taylor Valley (Webb and Wrenn, 1982) and a Mid. Miocene diatom assemblage from sediments beneath lake Vanda which Dry Valley erosion must pre-date. This agrees with the estimated age of greater than $13 \mathrm{Ma}$ for the last evidence of glacial over riding of the Transantarctic Mountains by Sugden et al. (1993).

Hence the deposition of the Sirius Group tills must be no older than the first evidence of wet based glaciation in the Ross Sea (Mid Eocene) and be no younger than the last period of major glacial erosion that deeply disected the Transantarctic Mountains and the Dry Valleys area (mid Miocene)

If the diatoms in the Sirius Group are wind blown then the different assemblages of diatoms may have collected in the the Sirius tills at different times, (Late Miocene-Lower Pliocene assemblages and Middle to Late Pliocene assemblages, fig. 5.1, Harwood, 1986) from various sources (the sea and lakes) in times of till exposure or of different weather conditions in the Ross Sea area. They may have come from fossil material of this age exposed elsewhere in Antarctica either today or during late Pliocene times. 


\section{Chapter Six}

\section{Phytoliths and other microfossils in the Sirius Group and adjacent material}

\subsection{Introduction}

Although the primary focus of this study was the occurrence of diatoms the preparations were found to contain phytoliths (siliceous particles from the cells of plants) in abundances $10 \mathrm{x}$ as great. These are the main subject of this chapter, though fragments of sponge spicules, silicoflagellates, coccoliths, radiolarians and whole acritarchs and palynomorphs were also recovered (App. 5.1 - 5.7).

Previous workers have also found remains of other microfossils in the Sirius till, but this is the first record of phytoliths.

Harwood (1986) reported a number of microfossils other than diatoms in the Sirius Group material including silicoflagellates, radiolarians, sponge spicules and foraminifera of marine origin; and a terrestrial component of palynomorphs, woody tissue and fungal fragments. Calcareous nannoplankton and an ostracod were also identified at some sites.

Leaves, pollen and twigs of fossil Nothofagus have also been identified from Sirius Group deposits at Oliver Bluffs (Askin and Markgraf, 1986; Burckle and Pokras, 1991; Hill and Truswell, 1993) along with seeds of other vascular plants and various beetle parts (Ashworth et al. 1995).

\subsection{Terrestrial Microfossils in the Sirius Group}

\subsubsection{Phytoliths}

\section{Introduction}

Phytoliths are particles of opaline silica (amorphous hydrated silica) that develop in the tissue cells of plants. Kondo et al. (1994) says "they form mostly 
in stems and leaves and accumulate in the upper layers of soils when plants decay".

Phytoliths have been used in paleoenvironmental reconstruction in studies of soils, tephra deposits, deep sea, lake sediments and peat bogs (Kondo et al, 1994, Piperno $1988 \mathrm{a} \& \mathrm{~b}$, Kondo and Sase, 1986). The phytoliths are described here in terms of a broad classification system based on form, from Kondo (1984; App. 7.1).

\section{General overview}

Phytoliths are 10 s to 1000 s of times more abundant in the Sirius Group tills than diatoms (fig. 4.1). The mean diameter of the intermediate axis of phytoliths from the Sirius Group tills is $13 \mu \mathrm{m}$ (table 4.2). Although phytoliths are commonly carried in wind blown dust there is no decrease in numbers with depth into the till, but rather an increase (fig 6.1). Phytoliths of grass origin dominate the assemblage (approximately $80 \%$ ), those of tree and shrub origin form about $15 \%$ of the assemblage, with very few fern phytoliths present except in one sample from the lowest depth at Site One from Mt. Feather (fig. 6.2, Table Appendix (A7.3).

Percentages of phytoliths from trees and woody plants are slightly higher in the upper samples (above $7 \mathrm{~cm}$ ) while grass tends show the reverse trend (fig 6.2). This suggests that trees are the origin of a small atmospherically introduced component or that tree phytoliths do not weather out of the till as easily as the smaller generally more spherical grass phytoliths.

The dominant phytolith in most of the assemblages was a smooth, spherical to triangular form which is mostly hollow on the inside. These have been placed as a grass class (fig 6.3). Similar forms have been identified as silicified epidermis from DSDP Site 590 in the south west Pacific, from Upper Miocene samples (Locker and Martini, 1985). 


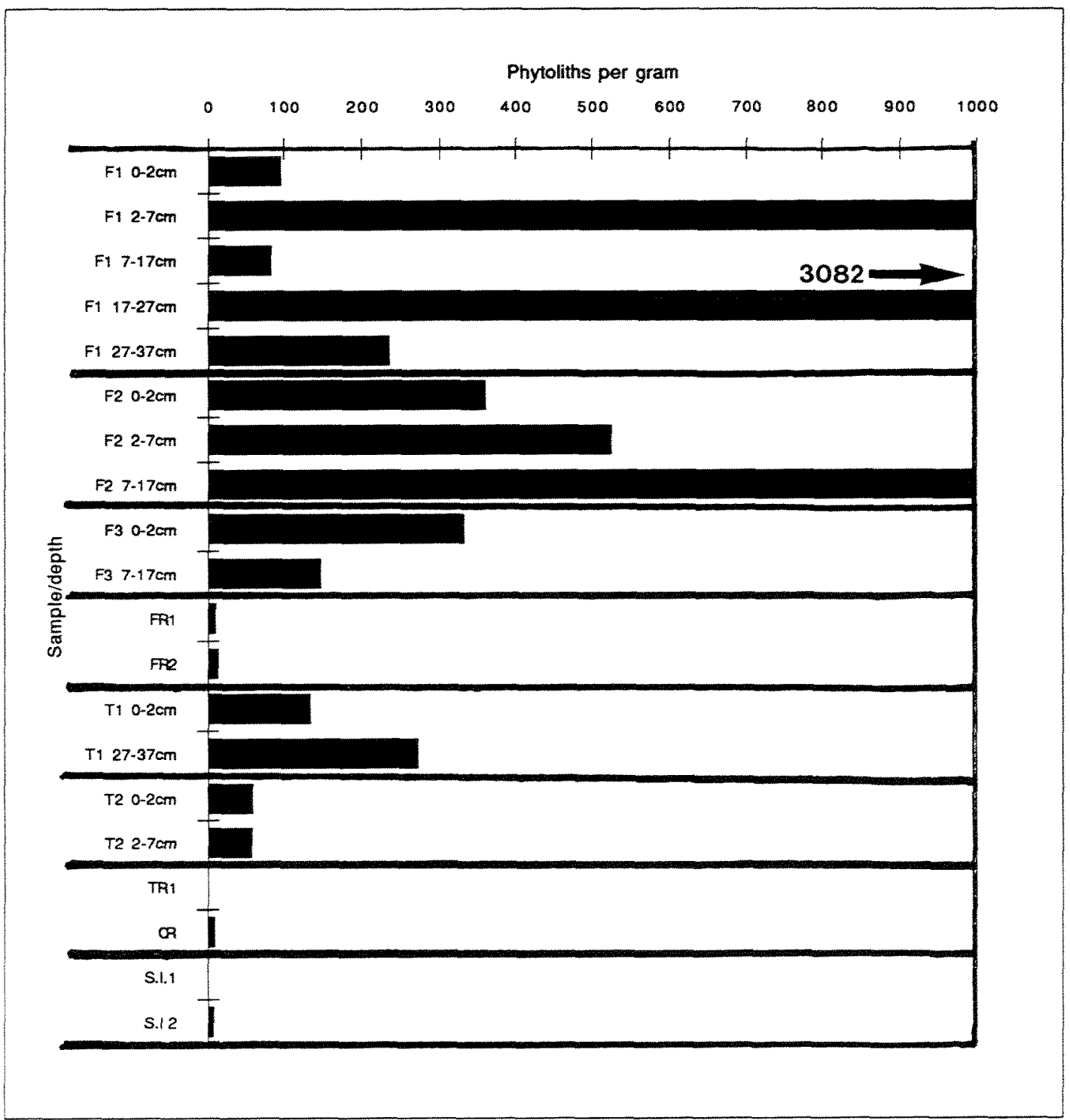

Key -

F1, F2, F3

Mount Feather sites.

$\mathrm{T} 1, \mathrm{~T} 2$ Table Mountain sites.

FR1, FR2, TR1, CR Regolith sites.

SI. 1, SI. 2 South Island samples.

Note - Phytoliths were also found in all snow samples.

Figure 6.1 Number of phytoliths per gram in the Sirius tills by site and depth, in regolith and from South Island till. No consistent trend with depth is evident. The lack of phytoliths in regolith snow samples is in contrast to their abundance in the till plainly indicates their glaciogenic origin. 


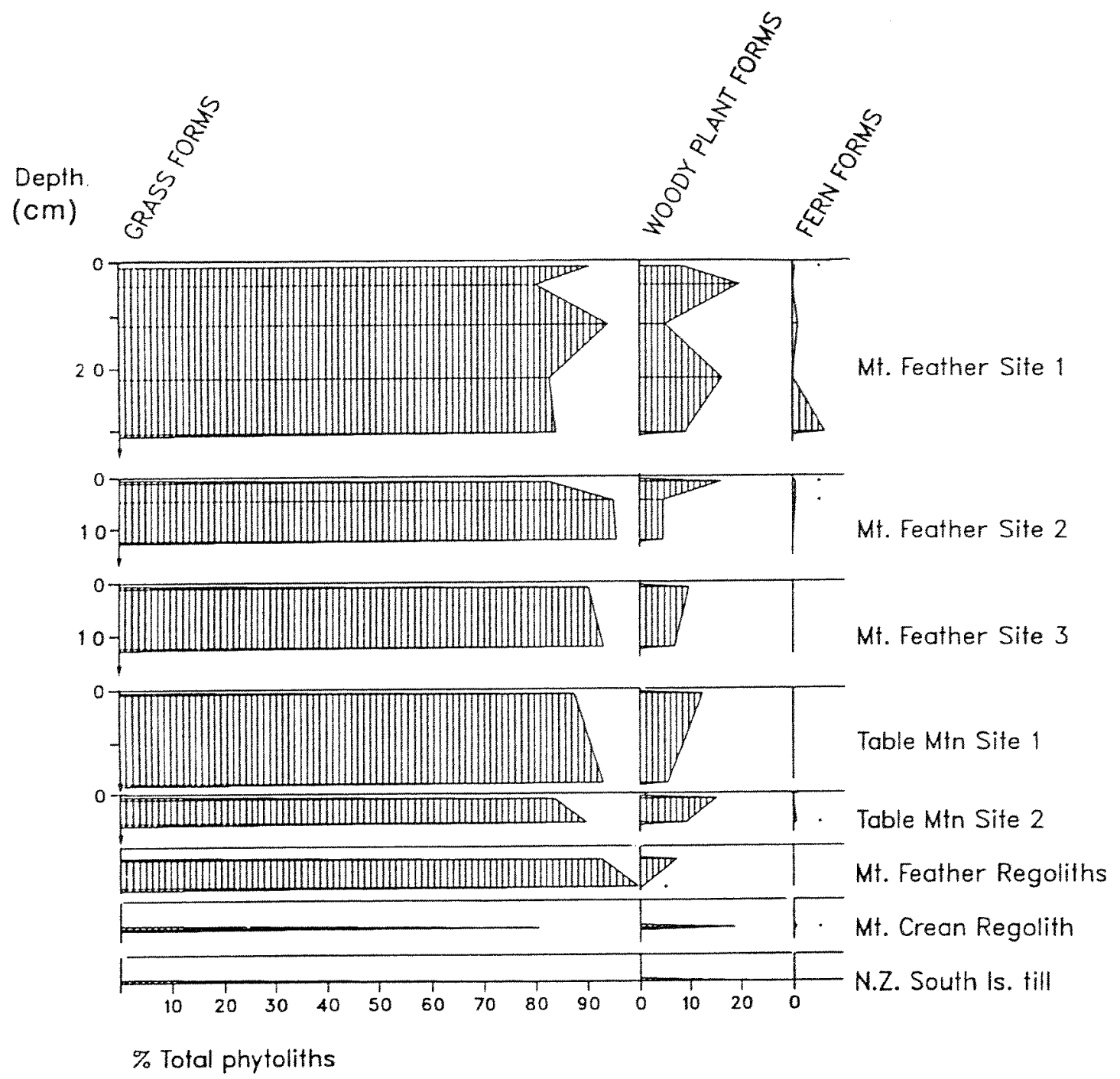

Figure 6.2 Percent of grass, tree and fern phytoliths from selected sites. 


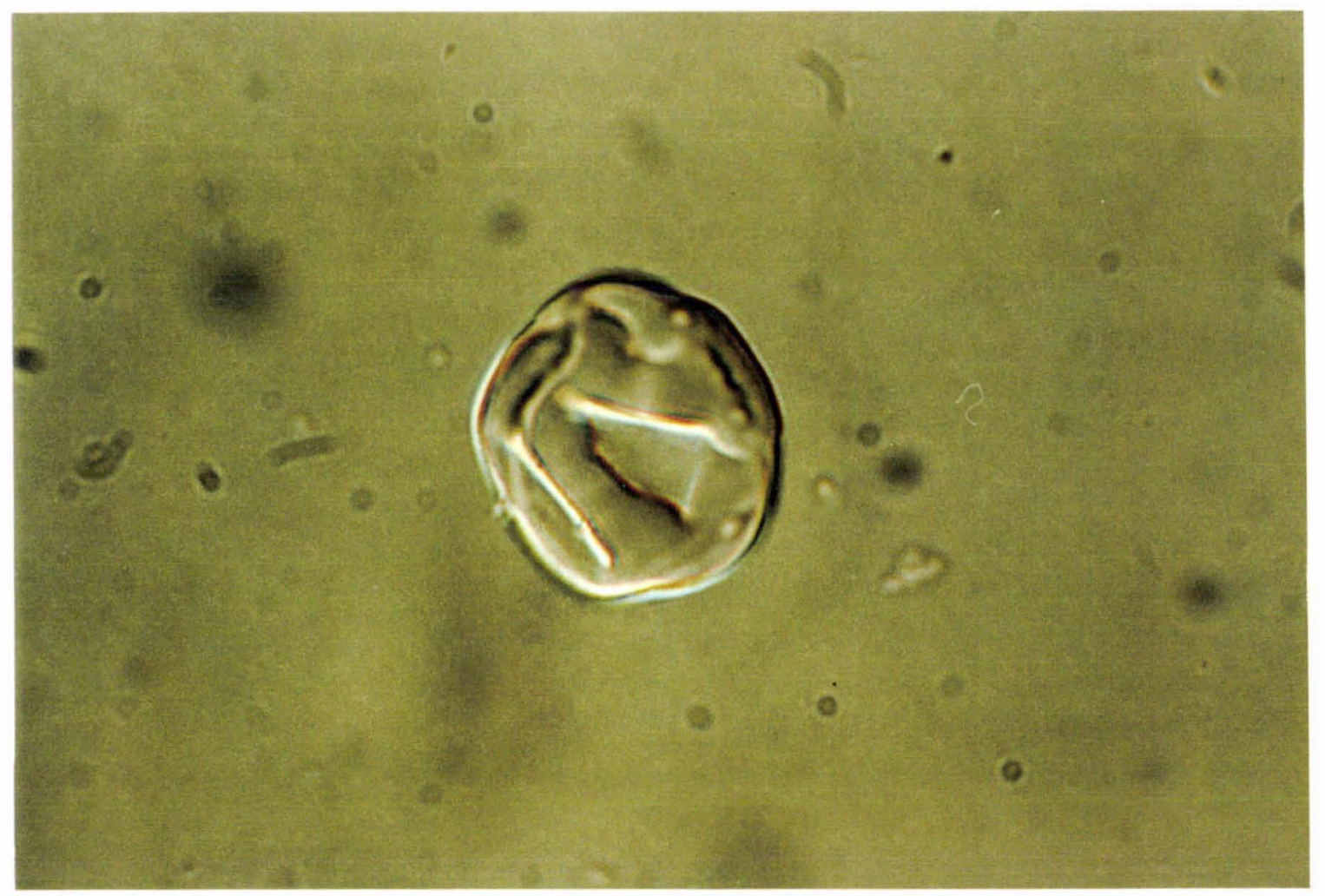

Figure 6.3 One of the most common forms of phytolith in the samples. From Mt. Feather, Site One $27-32 \mathrm{~cm}$. Diameter is $9 \mu \mathrm{m}$.

Elongate phytoliths, suggestive of a grass origin, were also common but are not good environmental indicators (fig. 6.5). Festucoid forms, which come from both the Pooideae and some Arundinoideae grass groups (fig 6.4, App. 7.1) are common in both exotic pasture and native grasses (e.g. genus Poa and Festuca) in New Zealand (Kondo et al. 1994). Chionochloid forms occur in leaves of the genus Chionochloa and Cortaderia in New Zealand (fig 6.5, App. 7.1).

Grass first appeared in Australia in the Eocene (White, 1986) and was the dominant form in central Australia from Mid. Miocene times.

Material from the Beacon Supergroup was processed for phytoliths by John Carter at Victoria University of Wellington in order to determine whether the the Sirius Group phytoliths have a Beacon Supergroup source. Only a few phytoliths from the Sirius Group sediments occurred in the processed Beacon Supergroup samples. 


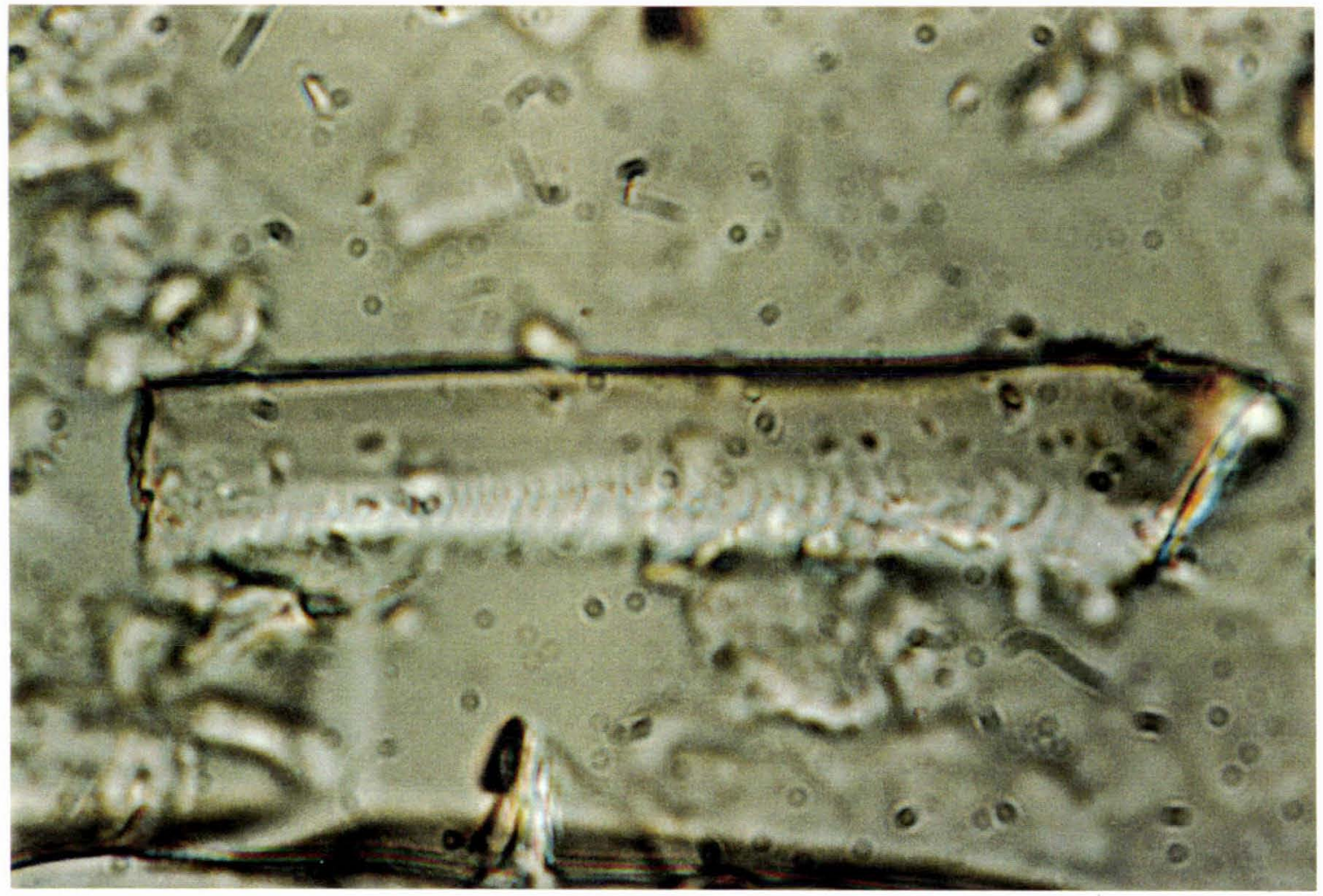

Figure 6.4 An elongate form of a phytolith derived from grasses. Length is $105 \mu \mathrm{m}$. From Mt. Feather Site One 0-2 cm.

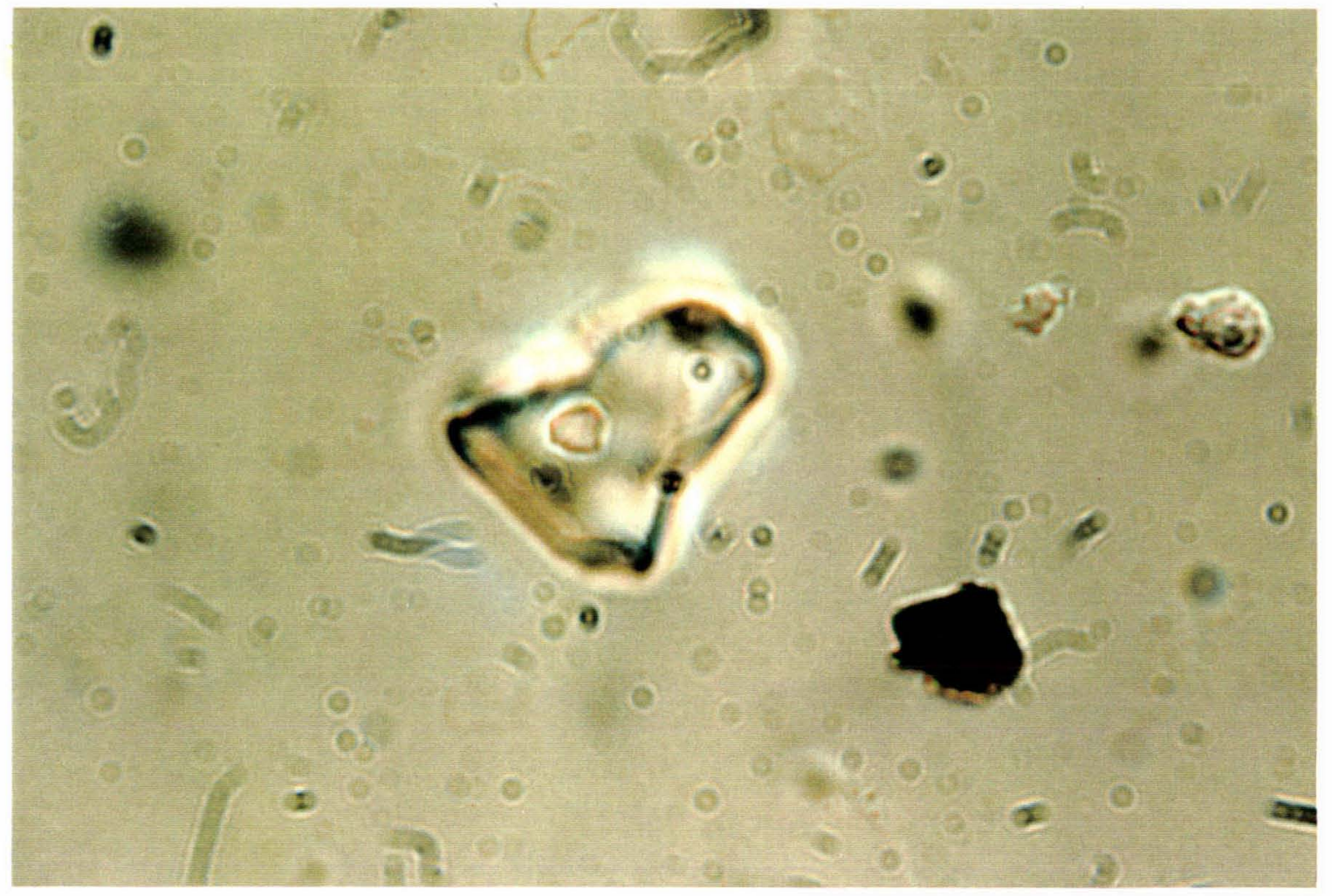

Figure 6.5 A grass form from the Chionochloid class found in the Sirius Group till samples. Length is $22 \mu \mathrm{m}$. From Mt. Feather Site Two $0-2 \mathrm{~cm}$. 


\section{Cluster analysis of Phytolith samples using SAS}

Ward's Minimum Variance Cluster Analysis was carried out on phytolith data using a SAS (Statistical Analysis System, 1979) by Dr. Harper (Victoria University of Wellington). The analysis compares similarities in phytolith numbers from each class and each sample. The results of the analysis shown in Appendix Seven (Table A7.4 and Fig. 6.6). Major points and trends found at each location are discussed below with descriptions for each locality.

\section{Mt. Feather}

Site One shows varying concentrations of phytoliths with depth while Site Two shows an increase in the numbers with depth. Site Three shows a decrease with depth but has lower numbers overall, as is also the case for diatoms at the site. The 7-17 cm level at Site Three is where an ice permafrost occurs. The occurrence of permafrost suggests that water was ponded at this site at some stage in the past and that there may have been some dissolution of silica from diatoms and phytoliths by the water at this site (Dr. M. Harper, VUW, personal communication, 1996).

The closest similarity in phytolith assemblage is between the $7-17 \mathrm{~cm}$ levels at Site One and Two at Mt. Feather (Table A7.4, Fig. A7.2). The surface samples from Sites One and Two at Mt. Feather also show a close similarity assemblage (Table A7.4, Fig. 6.6). Most of the samples from Mt. Feather contain similar phytolith classes, the $0-2 \mathrm{~cm}$ sample at Site One for example, has a close association with most of the other samples from Mt. Feather (Table A7.4).

Regolith samples contain about $1 / 100$ th of the numbers found in the till samples. However, the assemblages show a close similarity (fig. 6.6). The phytoliths in the regolith most likely have an atmospheric origin, but it is also probable, given there abundance in the Sirius till, that they could have come from there also. 


\section{Table Mountain}

There are smaller concentrations of phytoliths in the tills from Table Mountain than there are at Mt. Feather. The occurrence of relatively large amounts of chabazite in the tills at Table Mountain suggests water was moving through the system at some stage promoting silica dissolution.

Phytoliths from Table Mountain differ from those at Mt. Feather, in that they have more of the grass class Chionchloid and Fan Shaped phytoliths (App. 7.1). This suggests differences in source vegetation in either space or time.

The samples at depth from Table Mountain at Site One and Site Two show a close similarity in assemblage, as do the samples from the surfaces of these two sites. This suggests either some input from outside sources or similarities occurring as a function of weathering (Fig. 6.6, Table A7.4)

The phytolith assemblage in the Mt. Crean regolith sample is different from most of the other samples analysed (Fig. 6.6).

\section{South Island Samples}

The sample from tills of the last glacial maximum in New Zealand show a closer similarity in assemblage to the those from Mt. Feather (Fig. 6.6).

There could well be similarities between the vegetation in Antarctica before the deposition of the Sirius Group till at Mt. Feather and the vegetation from the west coast of New Zealand prior to the last glacial maximum.

\section{Discussion}

Phytoliths are known to be wind transported in continental dust (Folger, 1970; Folger et al, 1967), and they do occur in regolith, and in snow in this study (App. 6.1). However, thier numbers are two orders of magnitude less than numbers from the Sirius Group samples (fig. 6.1), indicating that most phytolith material from the Sirius tills is glaciogenic in origin. Phytoliths in the Sirius Group tills at Mt. Feather and Table Mountain suggest erosion from grassland, in which some cold tolerant trees and/or shrubs (including Nothofagus) existed (possibly in sheltered refugia). 


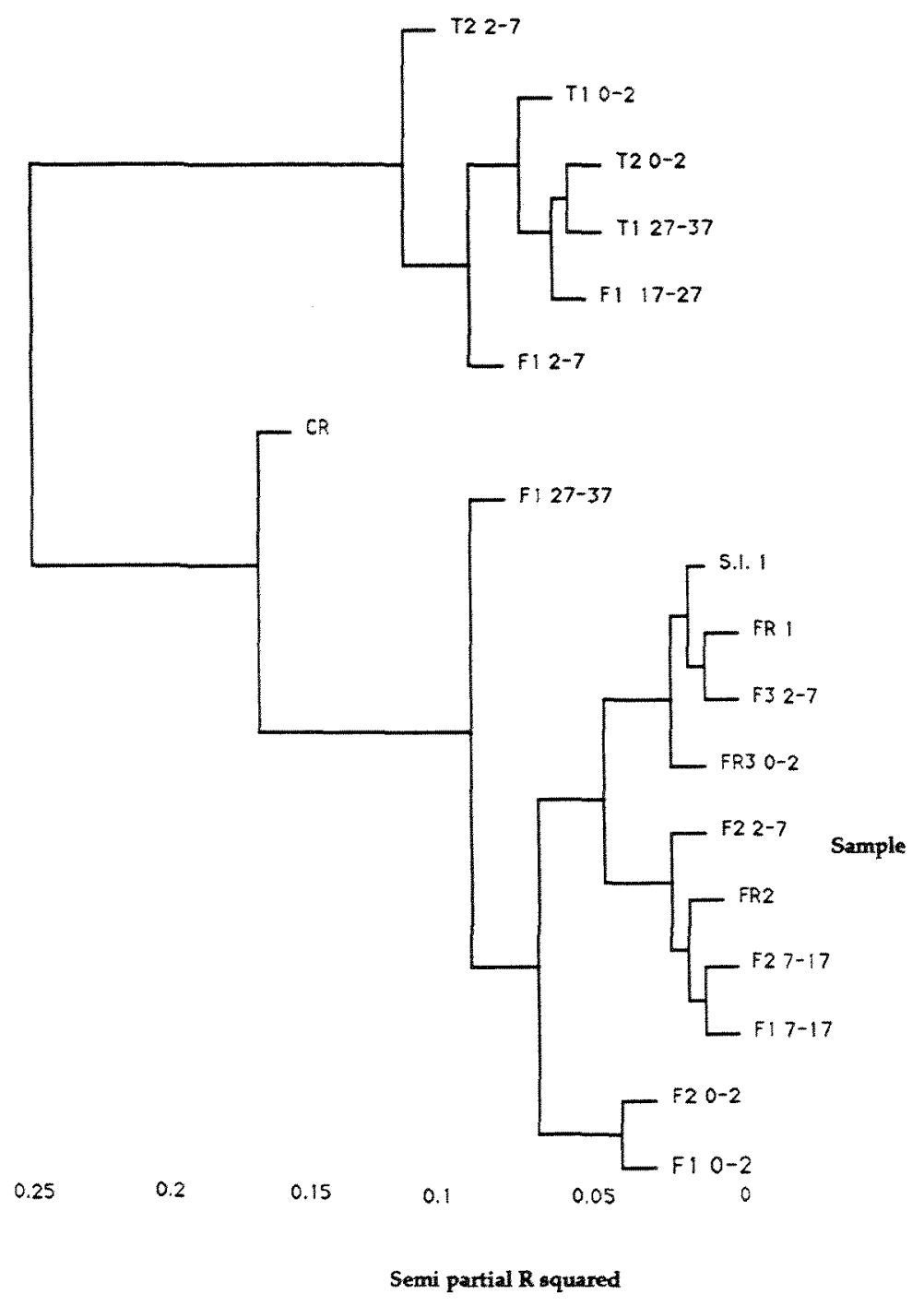

\section{Figure 6.6}

Tree diagram from the Statistical Analysis System (SAS) using Ward's Minimum Variance Cluster Analysis. This compares the proportion of phytoliths in each class from each sample as shown in Table A7.4 and clusters them in the tree according to their assemblage similarities. Note that no Table Mountain samples occur on the side of the tree where most of the Mount Feather samples cluster, suggesting a difference in the source vegetation. The Mount Crean regolith assemblage is least like any of the other samples. The South island sample is most similar to the phytolith assemblages from Mount Feather, perhaps indicating similar types of vegetation as source material. 


\subsubsection{Spores and Pollen}

No Nothofagus pollen was seen in the samples processed for this study, though it may have been lost during processing stages. Other pollen and spores were identified in the samples, but their very dark colouring clearly showed they were reworked from Beacon Supergroup sediments, such as the Weller Coal Measures which outcrop beneath the tills on Mt. Feather.

The two podocarp pollen spores found in samples are most likely laboratory contamination.

\subsubsection{Other Plant Material}

Some other pieces of plant material and woody tissue were also identified from the tills.

\subsubsection{Acritarchs}

One form of acritarch occurred in the Sirius Group sample at Mt. Feather. This was identified by Dr. Grenfell from Auckland Museum as a Staurastrum species, an algae which occurs in freshwater bodies (fig. 6.7). This was found at various depths in the Sirius Group till at Mt. Feather (App 6.2-10).

\subsection{Marine microfossils (other than diatoms) in the Sirius Group}

Other marine fossils identified included: pieces of sponge spicule; silicoflagellate; radiolaria; and a coccolith (numbers shown in Table A6.2-6.7). Remains of sponge spicules were the most abundant of these four groups. Sponge spicule and silicoflagellate fragments occurred in greatest numbers in surface till samples and occurred in equivalent numbers in the regolith from Mt. Crean, Table Mountain and Mt. Feather, suggesting that they too have a wind blown origin. Radiolarian pieces and coccolith numbers were too low to identify any trends. 


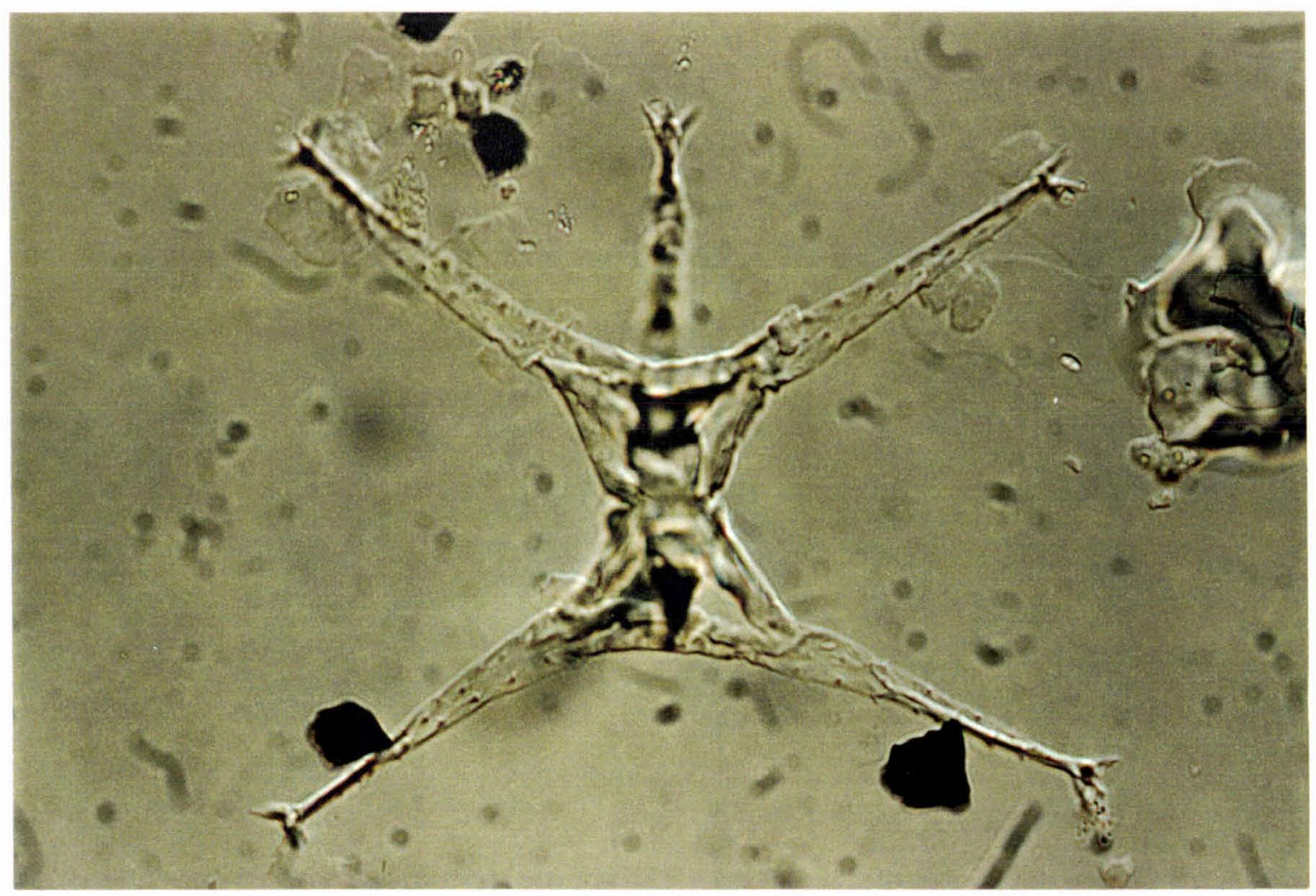

Figure 6.7 Staurastrum species a freshwater acritarch, found in several samples from the Sirius Group till. Length is $110 \mu \mathrm{m}$. 


\section{Chapter Seven}

\section{Summary, discussion and future work}

\subsection{SUMMARY}

\subsubsection{Diatom distribution}

Both marine and freshwater diatoms from all Sirius Group till sites at $\mathrm{Mt}$. Feather tend to be concentrated in the upper $2 \mathrm{~cm}$. At Table Mountain only rare freshwater species at levels deeper than $2 \mathrm{~cm}$ were found. The distribution of diatoms is very patchy both areally and vertically at both locations.

It is difficult to think of an origin for diatoms from regolith on old rock surfaces at Mt. Feather, Table Mountain and Mt. Crean other than the atmosphere. They occur either in large numbers with their assemblage dominated by marine diatoms, or in smaller numbers with a larger freshwater diatom component. Distribution in the regolith is also very patchy ( 0.4 to 16 diatoms per gram). This may relate to the trapping abilities of the sediment, including the porosity of the sediment, aspect of the location and how sheltered or exposed the site is (Ch. 4, App.6). The assemblage from regolith samples is similar to that from Sirius Group tills.

Diatoms have been found to occur in local snow indicating without any doubt their transport via the atmosphere. The distribution again is very patchy (2-16 diatoms per litre, Ch. 4, App. 6). Most taxa are also found in regolith and Sirius Group till.

Other marine microfossils (eg. fragments of sponge spicules and silicoflagellates) from within the tills also occur in much higher concentrations on the surface (Ch. 6, App 6) and are found in the regolith and snow samples.

The high porosity of the till at Mt Feather (2-22\%), and pore sizes up to 100 times greater than the average size of the diatoms within them, shows how easily diatoms could work their way into the tills (Ch. 3, Ch. 4). 
The absence of marine diatoms from a $20 \mathrm{Ka}$ year old tills approximately $50 \mathrm{~m}$ from the sea on the west coast of New Zealand suggest marine diatoms can only be transported and incorporated into tills in special circumstances, ie. in very dry conditions with high winds and porous exposed sediments (Chpt 4, App. 6).

From these findings it is difficult to conceive an origin for the majority of diatoms in the Sirius Group till at Mt. Feather being other than being wind blown or atmospheric.

\subsubsection{Phytolith distribution}

Phytoliths are tens to hundreds of times greater in proportion in the Sirius Group tills than diatoms. Although they are known to be transported by the wind (Folger, 1970) there is no notable decrease in numbers with depth into the till. They occur in much smaller numbers from regolith and snow than from the Sirius Group till. The phytolith forms from the tills are dominated by shape classes of grass origin, but there are also some tree phytoliths and a few fern phytolith forms. The phytoliths most likely occurred from phytolith rich sediment that was scraped up and incorporated into the glacial sediment (Ch. 6).

\subsubsection{Sediment Analysis of the Sirius Group tills at Mt. Feather and Table Mountain.}

\section{Till composition and origin}

\section{Mount Feather}

The fabric direction at Mt. Feather suggests ice flow from the NNW when the Sirius Group tills at this site were deposited. Striae on the surface of the till suggest a later erosional event from the west (fig. 3.1b). Composition and texture of the tills show evidence of local Beacon Supergroup and Ferrar Dolerite origin (Ch. 3). Roundness and sphericity of clasts within the sediment suggest they originated from between the basal zone and the zone of traction of the glacier, although the high roundness is most likely attributed to reworking of rounded clasts from the Feather Conglomerate (Ch. 3). The occurrence of the detrital clay kaolinite suggests the glacier eroded and 
incorporated an older paleosol from a much warmer climate into the till. This coincides with the occurrence of large numbers of phytoliths distributed through the Sirius Group tills described above (Ch. 3, Ch. 6).

\section{Table Mountain}

Fabric directions at Table Mountain suggest an ice flow direction largely from the west when the Sirius Group tills here were deposited (fig. 3.2b). There is a direction change closer to the WSW at the top of the unit at Site Two along with clast size sorting, which may be a result of the influence of a small amount of flowing water at some stage after or during till deposition (Ch.3). The occurrence of water in the tills suggests conditions much warmer and/or at a lower altitude than today when the tills at Table Mountain were deposited. Striation measurements from the surface of the till and the New Mountain sandstone also suggest erosion from the WSW (fig. 3.2b). The roundness and sphericity of the clasts in the till suggest the base of Site Two falls into the zone of basal glacial sediment, while the surface of Site Two lies closer to the zone of traction. The clasts at Site One also plot into the zone of glacial traction (Ch. 3, fig. 3.12).

The composition of the till suggests a local Beacon Supergroup and Ferrar Dolerite origin (Ch. 3). Clasts of till matrix at Site One suggest the till has been deposited and reworked by glaciers from another location. The occurrence of the clays kaolinite and smectite, and phytoliths in this till also suggest some glacial erosion of warmer climate paleosols at that time ( $\mathrm{Ch}$. 3, Chpt 6). The low porosity of the till at both sites from Table Mountain suggest wind blown diatoms could not penetrate the tills very easily.

The occurrence of the zeolite chabazite and an ice permafrost at Table Mountain and to a slightly lesser extent at Mt. Feather suggest some sort of dissolution and chemical exchange by moisture at some stage(s) in the past; chabazite also occurs in pore space further limiting the ability of diatoms to penetrate the tills at Table Mountain. 


\subsection{THE AGE OF THE SIRIUS GROUP AT MT. FEATHER AND TABLE MOUNTAIN}

Chapter six suggests the deposition of the Sirius Group till most likely predates mid Miocene deposition in Lake Vanda and is no older than the first evidence of wet based glaciation in the Ross Sea, now dated to at least Late Eocene to Early Oligocene (Hannah et al. in prep). Perhaps the Pliocene diatom ages reported by Harwood (1986) represent the exposure of Sirius Group surfaces for the introduction of wind blown diatoms (fig. 5.1).

\subsection{SOURCE AND ORIGIN OF THE DLATOMS IN THE SIRIUS GROUP TILLS}

The above evidence suggests diatoms have been introduced into the Sirius Group tills and adjacent material from an external source after the deposition of the tills.

\subsubsection{Transport processes}

In the past Kellogg and Kellogg (1984) and Denton et al. (1991) have also suggested a wind blown origin for the diatoms in the Sirius Group. However, there were concerns that winds may not be able to pick up and carry marine diatoms such great distances (up to $200 \mathrm{~km}$ inland). There is no evidence that wet marine diatoms containing cytoplasm can be picked up from the surface of the sea other than in sea spray. However, marine diatoms that have been dried on exposed surfaces could be picked up and carried such distances in Antarctica, especially considering Selby et al. (1974) show from ripples in sediment from the Dry Valleys that high winds and high density cold air in Antarctica appear capable of moving pebbles of up to $19 \mathrm{~mm}$ in diameter.

Also, while field work was being undertaken for this study on Mt. Feather, a skua was seen resting on the Sirius Group till. It must be considered that skuas and nesting snow petrels that normally feed adjacent to the coast could also have introduced some marine diatoms from guano, feet and feathers over time (Schlichting et al. 1977; Croll and Holmes 1982; Holmes and Croll, 1984). 
The knowledge that both freshwater and marine diatoms that can be transported by wind when they are dried and that diatoms can be contributed at rare occasions from birds suggests the external introduction of diatoms to the Sirius Group and other surfaces is possible. Although these mechanisms of introduction of diatoms onto these surfaces could be rare, their current occurance is still plausable because of the long time over which these surfaces my have been exposed, and the extremely low abundancies of microfossils.

\subsubsection{Diatom Source}

\section{A dominantly local and Ross sea origin.}

Selby et al. (1974) also point out that "both up valley and down valley winds blow through the Dry Valleys with easterly winds from the Ross Sea dominating the eastern ends of the valleys and westerly winds from the polar plateau dominating the western ends. Central parts of the Dry Valleys experience the alternating winds most fully".

This suggests that dried exposed diatoms could easily have been picked up by high winds and carried up valley to their current locations from the Ross Sea area several times since the surfaces sampled were deposited.

The freshwater diatoms could have been introduced to the tills from the atmosphere from local sources because most (but not all) of the freshwater assemblage are Antarctic species.

\section{An origin from great distances away}

The isotopic signature in dust from Dome $\mathrm{C}$, dated at around $18 \mathrm{Ka}$, suggests an origin from Argentina rather than from local Antarctic material (Grousset et al, 1992). This Argentinian origin could be the same for the diatom material identified from the Dome C ice core (Burckle et al. , 1988) and possibly diatom material in other ice cores (Kellogg and Kellogg, 1996). Some of the freshwater species in the Sirius Group tills and regolith and snow samples including the genus Aulacosiera (that does not occur in Antarctica today), are more common in Argentina than Antarctica today (Izaguirre, 1990). 


\section{Further possibilities and a question of time.}

There are several other possibilities for the source of the Sirius Group, regolith, and snow diatoms. Nitzschia kergulensis and Thalassiosira lentigenosa occur in regolith from cracks from the Beacon Supergroup and Devonian to Cretaceous igneous rocks (Burckle et al, 1996), in regolith (this study) and in the Sirius Group (Harwood, 1986, Stroeven, 1994). There are several possibilities for their origin alone; they could originate from the coast, sea ice or from sea birds today (where the occur in numbers of less the $20 \%$ in Antarctic waters); they could be carried great distances from dried material in the Antarctic divergence zone (where the occur as about $80 \%$ of the assemblage); or they could have been transported to these sites during the warmer Pliocene times. These diatoms could be coming to the surface and edges of the ice sheet long after they have been introduced to the surface of the ice, or, as Webb and Harwood postulate, from erosion of marine sediments in the inland basins today.

Winds could be carrying diatoms from a source of dried exposed $3 \mathrm{Ma}$ sediments in the Dry Valleys, or exceptional wind conditions during Late Pliocene times could have carried these diatoms from exposed, dry diatomacous sediments and sea ice.

The exposure of dry diatomaceous sediment after the fall in sea level in Late Pliocene times is a possible diatom source for the assemblages found in regolith and in the tills. However, most marine diatoms from the Sirius Group are planktonic and not benthic, which would be expected to also occur in the assemblage if diatoms were exposed and dried with a fall in sea level (Dr. Harwood personal communication, 1996). However, this depends on other environmental conditions from where the diatoms came. Planktonic forms must have been (or be) more available as dried material, than benthic forms.

Evidence from this thesis, problems with uplift rates and other evidence such as that described in Chapter Two, suggest the Sirius Group material at Mt. Feather, Table Mountain and Mt. Fleming is much older than the hypothesized post 2.2 to $3.1 \mathrm{Ma}$. Harwood (personal communication, 1996) suggests the diatoms in the Sirius Group at Mt. Feather could still be derived 
from strong winds from the south picking up material from the dry sediment and ice from inland seas during Pliocene times.

\subsection{ANTARCTICA IN THE PLIOCENE ?}

Evidence in favour of a dynamic ice sheet presented in Chapter Two suggests there were still warm conditions and high sea levels in the Pliocene, this evidence also suggests that the East Antarctic ice sheet was affected to some degree, but not to the extent of the exposure of the inland basins required by Webb and Harwood (1984, 1991).

\subsection{FUTURE ANALYSIS}

Analysis of diatoms in the Sirius Group has shown that there is a decrease in diatoms with depth into the till suggesting a wind blown or atmospheric origin. Could there be a wind blown diatom component and an original diatom component, which are in fact a part of the original till? This can only be determined by further analysis of samples from greater than $1 \mathrm{~m}$ into the tills (where wind blown diatoms are unable to penetrate) at Sirius Group locations where diatoms are most common.

If no Pliocene diatoms are found at these depths (away from the influence of the wind blown assemblages) then there is no reason to believe that the Pensacola and Wilkes basins were ever ice-free in Pliocene times and a source for diatoms in the Sirius Group tills. If Pliocene diatoms are found at depth in the tills, then the existance of inland basins during Pliocene times and the dynamic ice sheet hypothesis would have to be accepted. 


\section{REFERENCES}

Abelmann, A., Gersonde, R. and Speiss, V., 1990. Pliocene- Pleistocene paleoceanography in the Weddel Sea - siliceous microfossil evidence. In: Bleil, U. and Thiede, J. (eds), Geological History of the Polar Oceans: Arctic Verses Antarctic. Kluwer Academic Publ., The Nederlands: 729759.

Andrews, G.W., 1986. Evolutionary trends in the marine diatom Genus Dephineis. Proceedings of the 9th diatom symposium. Biopress Ltd. Bristol :197-206.

Armstrong, R.L., 1978. K-Ar dating: Late Cenozoic McMurdo Volcanic Group and Dry Valley glacial history, Victoria Land, Antarctica. New Zealand Journal of Geology and Geophysics, 21: 685-698.

Ashworth, A.C., Harwood, D.M. and Webb, P.N., 1994. Beetle and seed fossils from the Meyer Desert Formation, Sirius Group: New Records for Antarctica. In Ishman, S.E. (Ed), Pliocene High-Latitude Climate Records. Abstracts from a USGS workshop, Herndon, Virginia, July 25-27, 1994. USGS Open-File report 94-0603:3

Ashworth, A., 1995. Vertebrate, Arthropod, and plant fossils from the Meyer Desert Formation, Sirius Group, Dominion Range, Antarctica. Abstracts. Pliocene Antarctic Glaciation Workshop, 19-21 April, 1995, Woods Hole MA. Woods Hole Oceanographic Institution.

Askin, R.A. and Markgraf, V., 1986. Palynomorphs from the Sirius Formation, Dominion Range, Antarctica. Antarctic Journal of the United States, 21(5): 34-35.

Baldauf, J.G. and Barron, J.A., 1980. Actinocyclus ingens var. nodus: a new stratigraphically useful diatom of the circum - North Pacific. Micropaleontology, 26: 103 - 110.

Barber, H.G. and Harworth E.Y., 1981. A Guide to the Morphology of the Diatom Frustule. Freshwater Biological Association, Scientific Publication, 44.

Barrett, P.J., 1975. Textural characteristics of Cenozoic pre glacial and glacial sediments at Site 270, Ross Sea, Antarctica. In, Hayes, D.E., Frakes, L.A., and others. Initial Reports of the Deep Sea Drilling Project, 28: 757-767. Washington, US Govt. Printing Office.

Barrett, P.J., 1980. The shape of rock particles, a critical view. Sedimentology, 27: 291-303. 
Barrett, P.J. (ed.), 1986. Antarctic Cenozoic history from the MSSTS-1 drillhole, McMurdo Sound. DSIR Bulletin, 237: 174pp.

Barrett, P.J. (ed.), 1989. Antarctic Cenozoic history from the CIROS -1 drillhole, McMurdo Sound. DSIR Bulletin, 245: 154pp.

Barrett, P.J., 1991. Antarctica and global climate change: a geological perspective. In: Harris, C. and Stonehouse, B. (eds): Antarctica and Global Climate Change, Cambridge, Scott Polar Institute and Belhaven Press: 35-50.

Barrett, P.J., 1991. The Devonian to Jurassic Beacon supergroup of the Transantarctic Mountains and correlatives in other parts of Antarctica: in Tingey, R.J., (ed.), The Geology of Antarctica. Oxford University Press: 120-152.

Barrett, P.J., 1992. Debate: Antarctic ice sheets and global warming, a new view. Antarctic , 12/10: 330-332.

Barrett, P.J., 1994. Progress towards a Cenozoic Antarctic glacial history. Terra Antarctica Special Issue 1(2): 247-248.

Barrett, P.J., Adams, C.J., McIntosh, W.C., Swisher III, C.C. and Wilson, G.S., 1992. Geochronological evidence supporting Antarctic glaciation three million yearsago. Nature, 359: 816-818.

Barrett, P., Bleakley, N., Dickinson, W.W., Hannah, M.J., 1995. Occurrence of Diatoms in Sirius Diamictite on Mt. Feather, Antarctica. Abstracts. Pliocene Antarctic Glaciation Workshop, 19-21 April 1995, Woods Hole MA. Woods Hole Oceanographic Institution.

Barrett, P.J., Bleakley, N.L., Dickinson, W.W., Hannah, M.J. and Harper, M.A., in review. Distribution of siliceous microfossils on Mt. Feather, Antarctica, and the age of the Sirius Group. Proceedings Volume of the VIIth Antarctic Earth Science Symposium.

Barrett, P.J. and Elliot, D.H., 1973. Reconnaissance geologic map of the Buckley Island quadrangle, Transantarctic Mountains, Antarctica. Antarctic geologic map A-3, U.S. Geological Servey, Washington D.C.

Barrett, P.J. and Fitzgerald, P.G., 1985. Deposition of the Lower Feather Conglomerate, a Permian braided river peposits in Southern Victoria Land, Antarctica, with notes on regional paleogeography. Sedimentary Geology, 45: 189-208.

Barrett, P.J. and Powell, R.D., 1982. Middle Cenozoic glacial beds at Table Mountain, South Victoria Land. In: Craddock, C. (ed.): Antarctic Geoscience, : 1029-1067. Madison, University of Winconsin Press. 
Barron, J.A., 1994. PRISM reconstructions of SST and sea ice in the Southern Ocean. In Ishman, S.E. (Ed), Pliocene High-Latitude Climate Records. Abstracts from a USGS workshop, Herndon, Virginia, July 25-27, 1994. USGS Open-File report 94-0603: 4.

Barron, J. and Morley, 1995. Diatom and Radiolarian evidence for the position of the Antarctic Polar Front in the middle part of the Pliocene: Constraints on sea surface temperatures. Abstracts. Pliocene Antarctic Glaciation Workshop, 19-21 April 1995, Woods Hole MA, Woods Hole Oceanographic Institution.

Barron, J.A., 1996. Diatom constraints on the position of the Antarctic Polar Front in the middle part of the Pliocene. Marine Micropaleontology. 27: 195-213.

Bartek, L., Anderson, J., Oneacre,T., and Henrys, S., 1995. Results of recent marine geologic and geophysical serveys of the Ross Sea, Antarctica and their implications for understanding of the nature of dynamic Neogene Antarctic ice sheet behavior.

Bates, C.D., Coxon, P. and Gibbard, P.L., 1978. A new method for the preparation of clay-rich sediment samples for palynological investigation. New Phytologist, 81: 459-463.

Behrendt, J., 1995. Differential, episodic uplift of separate crustal blocks along the Rift Shoulder Mountains of the West Antarctic rift system in Neogene times. Abstracts. Pliocene Antarctic Glaciation Workshop 19-21 April 1995 Woods Hole MA. Woods Hole Oceanographic Institution.

Behrendt, C.J. and Cooper A., 1991. Evidence of rapid Cenozic uplift of the shoulder escarpment of the Cenozoic west Antarctic rift system and a speculation on possible climate forcing, Geology, 19(4):315-319.

Berggren, W.A. and Haq, B.U., 1976. The Andalusian Stage (Late Miocene): Biostratigraphy, biochronology and paleoecology. Palaeogeography, Palaeoclimatology, Palaeoecology, 20: 67-91.

Berggren, W.A., Kent, D.V., and Van Couvering, J.A., 1985. The Neogene: Part 2. Neogene geochronology and chronostratigraphy. In: Snelling, N,J.(ed). The chronology of the geological record, Memiors Geological Society., London, 10: 211-260.

Blatt, H., Middleton, G., and Murray, R., 1980. Origin of sedimentary rocks. Prentice-Hall Inc., New Jersey.

Bockheim, J.G., 1990. Properties and classification of some desert soils in coarse textured glacial drift of the Arctic and Antarctic. Geoderma 24:45-69. 
Boulton, G.S. 1978. Boulder shapes and grain-size distributions of debris as indicators of transport paths through a glacier and till genesis. Sedimentology, 25: 6-21.

Bradbury and Krebs, 1995. In, Babcock, L.E. and Ausich, J. (eds) Siliceous Microfossils. Short coarses in paleontology, No. 8. A publication of the Paleontological Society.

Brady, H.T., 1977. Extraction of diatoms from glacial sediments. Antarctic Joumal of the United States, 12(4): 123-124.

Brady, H.T., 1982. Late Cenozoic history of Taylor and Wright Vallys and McMurdo Sound inferred from diatoms in Dry Valley drilling Project Cores, In, Craddock, C. (ed), Antarctic Geoscience : 1123-1131. Madison: University of Wisconsin Press.

Brady, H.T.and McKelvey, B.C., 1979. The interpretation of a Tertiary tillite at Mount Feather, Southern Victoria Land, Antarctica, Journal of Glaciology, 22(86): 189-193.

Brady, H.T., and McKelvey, B.C., 1983. Some aspects of the Cenozoic glaciation of southern Victoria Land. Journal of Glaciology, 29(102): 343-349.

Brigham-Grette, J., 1995. Warm Pliocene high sea level records from Arctic Alaska: Regional tectonics or Antarctic ice volume? Abstracts. Pliocene Antarctic Glaciation Workshop 19-21 April 1995 Woods Hole MA. Woods Hole Oceanographic Institution.

Brigham-Grette, J., Carter, L.D., Marincovich, L., Brouwers, E. and Hopkins, D.M., 1994. Warm Pliocene high sea-level records from Arctic Alaska and possible inplications for Antarctic ice volume 2.8-2.2 Ma. In, Ishman, S.E. (ed), Pliocene High-Latitude Climate Records. Abstracts from a USGS workshop, Herndon, Virginia, July 25-27, 1994. USGS Open-File report 94-0603: 5-6.

Bromwich, D. and Chen, B., 1995. Simulated global atmospheric changes associated with year-round open water adjacent to Antarctica. Abstracts. Pliocene Antarctic Glaciation Workshop ,19-21 April 1995, Woods Hole MA. Woods Hole Oceanographic Institution.

Brook, E., Brown, E., Kurz, M., Ackert, R., Raisbeck, G., Yiou, F., 1995.

Constraints on age, erosion and uplift of Neogene glacial deposits in the Transantarctic Mountains using in situ cosmoggenic 10Be and $26 \mathrm{Al}$. Abstracts. Pliocene Antarctic Glaciation Workshop, 19-21 April 1995, Woods Hole MA. Woods Hole Oceanographic Institution. 
Bruno, L.A., Baur, H., Ivy, S.D., Schuchter, C., Signer, P. and Wieler, R., 1994. Dating of geomorphic surfaces in the Antarctic Dry Valleys with in situ produced cosmogenic $3 \mathrm{He}$ and $21 \mathrm{Ne}$. U.S. Geological Survey Circular, 1107: 42.

Burckle, L., 1995. Upper Neogene diatoms in the Beacon Supergroup (Devonian to Jurassic) sedimentary rocks: the collapse of the collapse hypothesis. Abstracts. Pliocene Antarctic Glaciation Workshop 19-21 April 1995 Woods Hole MA. Woods Hole Oceanographic Institution.

Burckle, L.H., Gayley, R.I., Ram, M., and Petit, J.-R., 1988. Diatoms in Antarctic ice cores: some implications for the glacial history of Antarctica, Geology, 16(4): 326-329.

Burckle, L.H., Gersonde, R. and Abrams, N., 1990. Late Pliocene-Pleistocene paleoclimate in the Jane Basin region: ODP Site 697. In: Barker, P.F., Kennett, J.P., et. al., Proceedings Ocean Drilling Program, Scientific Results, 113: 803-809, College Station, Texas.

Burckle, L.H., and Pokras, E.M., 1991. Implications of a Pliocene stand of Nothofagos (southern Beech) within 500 kilometres of the South Pole, Antarctic Science, 3: 389-403.

Burckle, L.H., and Potter, Jr. N., 1996. Pliocene-Pleistocene diatoms in Paleozoic and Mesozoic sedimentry and igneous rocks from Antarctica: A Sirius problem solved. Geology 24(3):235-238.

Burckle, L.H., Gayley, R.I., Ram, M. and Petit, J-R, 1988. Diatoms in Antarctic ice cores: some implications for the glacial history of Antarctica: Geology, 16: 326-329.

Burckle, L.H., and Pokras, E.M., 1991. Implications of a Pliocene stand of Nothofagos (southern Beech) within 500 kilometres of the South Pole, Antarctic Science, 3: 389-403.

Burckle, L.H., Prentice, M.L., and Denton, G.H., 1986. Neogene Antarctic glacial history: New evidance from marine diatoms in continental deposits, EOS,Transactions, American Geophysical Union, 67 (16): 295.

Calkin, P.E., Behling, R.E. and Bull, C., 1970. Glacial history of the Wright Valley, southern Victoria Land, Antarctica. Antarctic Journal of the United States, 5: 22-27.

Campbell, I.B., and Claridge, G.G.C., 1987. Antarctica: Soils, Weathering Processes and Environment, Amsterdam, Elsevier.

Carlquist, S., 1987. Pliocene- lower Pleistocene Nothofagus wood from the Transantarctic Mountains, Aliso, 11(4):571-583. 
Carter, J., 1994. Phytolith Analysis in Paleoenvironmental Reconstruction. Research Monograph No. 5. ISSN 0113-1753, Department of Geography, Victoria University of Wellington. 38pp.

Chalmers, M.O., Harper, M.A., Marshell, W.A., 1996. An illistrated catalog of air borne micro biotas of the maritime Antarctic. British Antarctic Servey.

Chen, J., Farrell, J. W., Murray, D. W. and Prell, W. L., 1995. Timescale and paleoceanographic implications of a 3.6 m.y. oxygen isotope record from the northeast Indian Ocean (Ocean Drilling Program Site 758) Paleoceanography, 10(1): 21-47.

Ciesielski, P.F., and Weaver, F.M., 1974. Early Pliocene temperature changes in the Antarctic seas, Geology, 2: 511-515.

Ciesielski, P.F., 1983. The Neogene and Quaternary Diatom Biostratigraphy of Subantarctic sediments, Deep Sea Drilling Project Leg 71. In: Ludwig, W.J., Krasheninnikov, V.A., and others. Initial reports of the Deep Sea Drilling Project LXXI: 635-665. U.S. Govt. Printing office, Washington, D.C.

Ciesielski, P.F. and Grinstead, G.P., 1986. Pliocene variations in the position of the Antarctic Convergence in the Southwest Atlantic. Paleoceanography, 1(2):197-232.

Ciesielski, P.F., and Weaver, F.M., 1974. Early Pliocene temperature changs in the Antarctic seas. Geology, 2: 511-515.

Clapperton, C.M., and Sugden, D.E., 1990. Late Cenozoic glacial history of the Ross Embayment Antarctica: Quarernary Science Reviews, 9:252-272.

Claridge, G.G.C. and Campbell, I.B., 1968. Soils of the Shackleton Glacier region, Queen Maud Range, Antarctica. New Zealand Journal of Science, 1: 1115.

Claridge, G.G.C. and Campbell, I.B., 1986. Clay mineralogy in Antarctic. In, Barrett, P.J. (ed). Cenozoic history of the MSSTS-1 drillhole McMurdo Sound, DSIR Bulletin: 153-157.

Cook, H.E., Zemmels, I. and Matti, J.C., 1975. X-ray clay mineralogy data, Austral-Antarctic region, Leg 28, Deep Sea Drilling project. Initial Reports of the Deep Sea Drilling Project, 28: 981-998. U.S. Govt. Printing office, Washington, D.C. 
Cragg, D., 1993. Sedimentary Diatom assemblages from saline lakes of the Vestfold Hills Princess Elizabeth Land, Antarctica. Project for the Diploma of Antarctic and Southern Ocean Studies with Honours, Institute of Antarctic and Southern Ocean Studies, University of Tasmania.

Croll, D.A. and Holmes, R.W., 1982. A note on the occurrence of Diatoms in the feathers of sea birds. Auk, 99(4):765-766.

Cronin, T.M. and Dowsett, H.J. (eds) 1991. Pliocene Climates. Quaternary Science Reviews, 10 (2/3).

Cronin, T., Dwyer, P., Barker, B., Kamiya, T., Ikeya, N., Kitamura, A., 1995. Late Pliocenne sea level history. Abstracts. Pliocene Antarctic Glaciation Workshop 19-21 April 1995 Woods Hole MA. Woods Hole Oceanographic Institution.

Cronin, T.M., Kitamura, A., Ikeya, N., Kamiya, T., 1994. Mid Pliocene paleoceanography of the Sea of Japan. Paleogeography, paleoclimatology, Paleoecology. 108 (3/4), 437-456.

Darwin, C. E., 1845. The Voyage of the Beagle.

Darwin, C. E., 1846. An account of the fine dust which falls onvessels in the Atlantic Ocean. Quarterly Journal of the Geological Society (London) 2: 26.

DeFelice, D.R., 1979. Morphological comparison of Coscinodiscus lentiginosus Janish and Coscinodiscus obovatus Castracane. Antarctic Journal of the United States, 14: 127-129.

Denton, G.H. and Hughes, T.J. (eds), 1981. The Last Great Ice Sheets. New York: Wiley-Interscience.

Denton, G.H., Prentice, M.L. and Burkle, L.M., 1991. Cainozoic history of the Antarctic Ice Sheet. In, Tingey, R.J. (ed), The Geology of Antarctica, Oxford monographs on Geology and Geophysics, 17. Oxford: Clarendon Press: $365-433$.

Denton, G.H., Sugden, D.E., Marchant, D.R., Hall, B.L., and Wilch, T.I., 1993. East Antarctic Ice Sheet sensitivity to Pliocene climatic change from a Dry Valley perspective, Geografiska Annaler, 75A(4): 155-204.

Denton G., Sugden, D., Marchant, D., Hall, B., and Wilch, T., 1995. East Antarctic ice sheet sensitivity to Pliocene climatic change from a Dry Valley perspective. Abstracts. Pliocene Antarctic Glaciation Workshop 19-21 April 1995 Woods Hole MA. Woods Hole Oceanographic Institution. 
Desikachary, T.V. and Sreelatha, P.M., 1989. Omaru Diatoms. Bibl. Diatomologica 19: 1-330 145 Taf.

Doumani, G.A. and Minshew, V.H., 1965. General geology of the Mt. Weaver area, Queen Maud Mountains, Antarctica. In, Hadley J.B. (ed.). Geology and paleontology of the Antarctic, Antarctic Research Series 6: 127-139. American Geophysical Union, Washington, D.C..

Dowsett, H., Thompson, R., Barron, J., Cronin, T., Fleming, F., Ishman, S., Poore, R., Willard D. and Holtz Jr. T., 1994. Joint investigations of the Middle Pliocene climate I : PRISM paleoenvironmental reconstructions. Global and Planetary Change 9: 169-195.

Dowsett, H.J. and Cronin, T.M., 1990. High eustatic sea level during the middle Pliocene: evidence from the Southeastern U.S. Atlantic coastal plain. Geology 18: 435-438.

Drewry, D.J., Jordan, S.R. and Jankowski, E., 1982. Measured properties of the Antarctic ice sheet: Surface configuration, ice thickness, volume, and bedrock characteristics. Annals of Glaciology, 3, 83-91.

Drewry, D.J., 1983: Ice flow, bedrock, and geothermal studies from radio-echo sounding inland of McMurdo Sound, Antarctica. In: C. Craddock (ed.) Antarctic Geoscience: 977-983. University of Wisconsin Press, Madison.

Dwyer, G.S. and Cronin, T.M., 1994. North Atlantic deep water temperature change during Late Pliocene and Quaternary climatic cycles. In Ishman, S.E. (Ed), Pliocene High-Latitude Climate Records. Abstracts from a USGS workshop, Herndon, Virginia, July 25-27, 1994. USGS Open-File report 94-603: 11-12.

Elliot, D.H., Barrett, P.J. and Mayewaki, P.A., 1974. Reconnaissance geologic map of the Plunket Point Quadrangle, Transantarctic Mountains, Antarctica. U.S. Geological Servey Antarctic Map No. 4.

Elliot, D.H. , Bromwich, D.H., Tzeng Ren-Yow, Harwood, D.M. and Webb, P. N., 1991: The Sirius Group: a possible test of climate modeling results for Antarctica. In, International Conference on the Role of the Southern Ocean and Antarctica in Global Climate Change: An Ocean Drilling Perspective, abs

Ehrmann, W.U. , Hambrey, M.J., Baldauf, J.G., Barron,J., Larson, B., Mackensen, A., Wise, Jr., S.W., and Zachos, 1992. History of Antarctic Glaciation: An Indian Ocean perspective. In, Synthesis of Results from Scientific Drilling in the Indian Ocean. AGU Geophysical Monograph, 70: 423-445.

Ehrmann, W.U. and Mackensen, A., 1992. Sedimentological evidence for the formation of a East Antarctic Ice sheet in Eocene/Oligocene time. Paleogeography, Paleoclimatology, Paleoecology, 93: 85-112. 
Faure, G., and Harwood D.M., 1990. Marine microfossils in till clasts of the Elephant Moraine on the East Antarctic ice sheet. Antarctic Journal of the United States, 25(5): 23-24.

Faure, G., Nishiizumi, K., Finkel, R., Kohl. C. 1995. Cosmic-ray exposure dating of quartz by means of cosmogenic 10Be and $26 \mathrm{Al}$ on Mt. Sirius and in Southern Victoria Land.Abstracts. Pliocene Antarctic Glaciation Workshop 19-21 April 1995 Woods Hole MA. Woods Hole Oceanographic Institution.

Faure, G. and Taylor, K.S., 1981. Provenance of some glacial deposits in the Transantarctic Mountains based on Rb-Sr dating of Feldspars. Chemical Geology, 32(3/4): 271-290.

Faure, G., Taylor, K. S. and Mercer, J. H., 1983. Rb-Sr provenance dates of feldspar in glacial deposits of the Wisconsin Range, Transantarctic Mountains. Geological Society of America Bulletin 94(110): 1275-1280.

Fleming, R.F. and Barron, J.A., 1994 Evidence of Pliocene Nothofagus in Antarctica from DSDP/ODP cores. In, Ishman, S.E. (Ed), Pliocene HighLatitude Climate Records. Abstracts from a USGS workshop, Herndon, Virginia, July 25-27, 1994. USGS Open-File report 94-0603: 13.

Fleming, R.F., Farley and Barron, J.A., 1996. Evidence of Pliocene Nothofagus in Antarctica from Pliocene marine sedimentary deposits (DSDP Site 274) Marine Micropaleontology. 27: 227-263.

Flint, E.A., 1975. Phytoplankton in some New Zealand lakes. In, Lolly, V.H. and Brown J.M.A. (eds), New Zealand Lakes. Auckland University Press, New Zealand: 163-192.

Folger, D. W., 1970. Wind Transport of land-derived mineral, biogenic and ind ustrial matter over the North Atlantic. Deep Sea Research, 17: 337352.

Folger, D. W., Burckle, L.H. \& Heezen, L.H., 1967. Opal phytoliths in a North Atlantic dust fall. Science, 155: 1234-1244.

Fordyce, R.E., 1989. Origins and Evolution of Antarctic marine mammals. Origins and Evolution of the Antarctic Biota, Special Publication Geological Society of London, 47: 269-281.

Francis, J.E., 1995. Abstracts of the VII International Symposium on Antarctic Earth Sciences 10-15 September 1995, Siena (Italy): 142.

Fryxell, G.A., 1990. Family Hemidiscaceae, Chapter 14.. In Medlin, L.K. and Priddle, J. (eds). Polar Marine Diatoms: 111-114.British Antarctic Servey. Cambridge. 
Fryxell, G.A. and Johansen, F.R., 1990. Family Thalassiosiraceae, Section 2. Chapter 11. In Medlin, L.K. and Priddle, J. (eds). Polar Marine Diatoms: 111-104. British Antarctic Servey. Cambridge.

Game, P. M. 1964. Observations on a dustfall in the Eastern Atlantic, Febuary, 1962. Journal of Sedimentary Petrology , 34: 355-359.

Geis, J.W., 1973. Biogenic silica in selected species of deciduous angiosperms. Soil Science, 116: 113-130.

Germain, H., 1981. Flore des diatomees eux doces et saumatres. Societe Nouvelle des Editions Boubee, Paris. 444pp.

Gersonode, R., Alelmann, A., Burckle, L.H., Hamilton, N., Lazarus, D., McCartney, K., O'Brien, P., Speiss, V., and Wise, S.W., 1990.

Biostratigraphy of Neogene siliceous microfossils from the Atlantic ocean, ODP Leg 113 (Weddell Sea). Proceedings of the Ocean Drilling Program Scienyific Res.ults, 113: 915-936. U.S. Govt. Printing office, Washington, D.C.

Gibson, E.K., Wentworth, S.J. and McKay, D.S., 1983. Chemical weathering and Diagenesis of a cold desert soil from the Wright Valley, Antarctica: An analog of martian weathering processes. Proceedings of the thirteenth lunar and planetary science conference, Part 2. Journal of Geophysical Research, 88, supplement: A912-A928.

Greenlee, S.M. and Moore, T.C., 1988. Recognition and interpretation of depositional sequences and calculation of sea- level changes from stratigraphic data off shore New Jersey and Alabama Tertiary. In: Wilgus, D.K. and Hastings, B.S. et al. (eds). Sea-level changes-an integrated approach, Society of Economic Paleontologists and Mineralogists, Special publication , 42: 329-353.

Grousset, F.E., Biscaye, P.E.,Revel, M., Petit ,J.-R., Pye, K.,Joussaume, S. and Jouzel, J., 1992. Antarctic (Dome C) ice-core dust at 18 k.y. B.P: Isotopic constraints on origins. Earth and Planetary Science Letters, 111: 175-182.

Håkansson, H. and Nihlen, T. 1990. Diatoms of eolian deposits in the Mediterranean. Arch. Protistenkd., 138: 313-322.

Håkansson, H. and Jones, 1993. The compiled freshwater Antarctic diatom taxonomic list to the maritime Antarctic region of South Shetland and South Orkney Islands. In, Hawk, P.B. (ed.). Proceedings of the 4th ArcticAntarctic Diatom Symposium (Workshop). Canada, September 18-21, 1993. 
Hall, B.L., Denton, G.H, Lux, D.R. and Bockheim, J.G., 1993. Late Tertiary Antarctic paleoclimate and ice-sheet dynamics inferred from surface deposits in Wright Valley, Geografiska Annaler, 75A (4):239-267.

Hambrey, M.J. 1994. Glacial environments. UCL Press, London.

Hannah, M.J., 1994. Eocene Dinoflagellates from CIROS-1 Drill-Hole, McMurdo Sound, Antarctica. Terra Antartica, 1(2), 371.

Hannah, M.J., in prep. Redating the base of CIROS I.

Haq, B.H., Hardenbol, J. and Vail, P.R.,, 1987a. Chronology of fluctuating sea levels since the Triassic. Science, 235: 1156-1167.

Haq, B.U., Hardenbol, J. and Vail, P.R., 1987b. The new chronostratigraphic basis of Cenozoic and Mesozoic sea level cycles. Foraminiferal Research Special Publication, 24: 7-13. Cushman Found.

Haq, B.U., Hardenbol, J. and Vail, P.R., 1988. Mesozoic and Cenozoic Chronostratigraphy and Cycles of sea-level change. In, Wilgus, C.K. et al. (eds.), Sea level changes: an integrated approach, Society of Economic Paleontologists and Mineralogists, Special Publication, 42: 71-108.

Harper, M.A., 1995. Marine diatoms blown inland compared with inland Antarctic Diatoms. Abstracts. Pliocene Antarctic Glaciation Workshop 19-21 April 1995 Woods Hole MA. Woods Hole Oceanographic Institution.

Harrison, R., and Bryden, M. M., 1989. Whales, Dolphins and Porpoises. Weldon Owen, Sydney, Australia.

Harwood, D.M., 1983. Diatoms from the Sirius Formation, Transantarctic Mountains. Antarctic Journal of the United States, 18:98-100.

Harwood, D.M., 1985. Late Neogene climatic fluctuations in the southern high latitudes: Implications of a warm Pliocene and deglaciated Antarctic continent. South African Journal of Science, 81: 5, 239-241.

Harwood, D.M., 1986a. Diatom biostratigraphy and palaecology with a Cenozoic history of Antarctic Ice Sheets. Doctoral dissertation, Ohio State University, Columbus, Ohio: 510pp.

Harwood, D.M., 1986b. Recycled siliceous microfossils from the Sirius

Formation. Antarctic Joumal of the United States, Review 21(5): 101-103.

Harwood, D.M., Grant, M.W. and Karrer, M.H., 1986. Techniques to improve diatom recovery from glacial sediments. Antarctic Journal of the United States, Review, 21(5): 107-108. 
Harwood, D.M. and Jiang, X., 1994. The palynological record of Antarctic Neogene vegetation. In, Ishman, S.E. (ed.), Pliocene High-Latitude Climate Records. Abstracts from a USGS workshop, Herndon, Virginia, July 25-27, 1994. USGS Open-File report 94-0603: 16.

Harwood, D.M. and Maruyama, T., 1992. Middle Eocene to Pliestocene diatom biostratigraphy of Southern Ocean sediments from the Kerguelen Plateau, Leg 120. In, Wise Jr., S.W., Schlich, R. and others (eds.) Proceedings of the Ocean Drilling Program, Scientific Results, (Part 2), 120: 683-734. College Station, Ocean Drilling Program, Texas.

Harwood, D.M., Srivastav, A. and Winter, D.M., 1994. Sea-ice absence and $30^{\circ} \mathrm{C}$ marine seas - Is this all it takes? In Ishman, S.E. (ed), Pliocene HighLatitude Climate Records. Abstracts from a USGS workshop, Herndon, Virginia, July 25-27, 1994. USGS Open-File report 94-0603: 15

Harwood, D.M. and Webb P.-N., 1986. Recycled marine fossils from basal debris-ice in ice-free valleys of southern Victoria Land. Antarctic Journal of the United States, 21(5): 87-88.

Harwood, D.M., and Webb P.-N., 1990. Early Pliocene deglaciation of the Antarctic ice sheet and late Pliocene onset of bipolar glaciation. EOS, Transactions, American Geophysical Union, 71(17): 538-539.

Harwood, D.M., and Webb, P-N., 1995. A case for Dynamic Cenozoic Ice Sheets in Antarctica. Abstracts. Pliocene Antarctic Glaciation Workshop, 19-21 April 1995. Woods Hole Oceanographic Institution.

Hasle G.R., 1990. Family Diatomaceae, Chapter 17. In, Medlin, L.K. and Priddle, J. (eds). Polar Marine Diatoms: 133-150. British Antarctic Servey. Cambridge.

Hasle G.R. and Medlin, L.K., 1990. Family Bacillariaceae: Genus Nitzschia, Section Fragilariopsis, Chapter 24. In, Medlin, L.K. and Priddle, J. (eds.). Polar Marine Dintoms: 181-196. British Antarctic Servey. Cambridge.

Hasle G.R. and Syvertsen E.E., 1990. Family Biddulphiaceaem, Chapter 16. In, Medlin, L.K. and Priddle, J. (eds.). Polar Marine Diatoms.: 129-132. British Antarctic Servey, Cambridge.

Hendey, N.I., 1964. An Introductoty Account of the Smaller Algae of the British Coastal Waters. Fisheries Investigations Series IV, part $V$ Bracillariophyceae (Diatoms). Her Majesty's Stationary Office, London.

Hill, R.S., Harwood D.M., and Webb, P.-N., 1991. Last remnant of Antarctica's Cenozoic flora: Nothofagus of the Sirius Group, Transantarctic Mountains. In, Eighth International Symposium on Gondwana, Hobart, Tasmania: $43-48$ 
Hill, R.S. and Trustwell, E.M., 1993.Nothofagus Fossils inthe Sirius Group, Transantarctic Mountains: Leaves and Pollen and their climatic implications. In, Kennett and Warnke (eds), The Antarctic Paleoenvironment: A perspective on global change. AGU, Antarctic research series, 60: 67-73.

Hill, R.S., 1994. Pliocene Nothofagus of the Sirius Gropup, Transantarctic Mountains. In, Ishman, S.E. (Ed), Pliocene High-Latitude Climate Records. Abstracts from a USGS workshop, Herndon, Virginia, July 2527, 1994. USGS Open-File report 94-0603: 18-19.

Hill, R.S., Harwood, D.M., Webb, P.N., Francis, J. and Pillans, B., 1995. Last remnant of Antarctica's Cenozoic Flora: Nothofagus of the Sirius Group, Transantarctic Mountains. Abstracts. Pliocene Antarctic Glaciation Workshop, 19-21 April 1995, Woods Hole MA. Woods Hole Oceanographic Institution.

Hinchey, J.V. and Green, O.R., 1994. A guide to the extraction of fossil diatoms from lithified or partly consolidated sediments. Micropaleontology, 40 (4): 368-372.

Hodell, D., 1995. Oxygen isotopic constraints on the magnitude of teemperature and ice volume variation during the Pliocene. Abstracts. Pliocene Antarctic Glaciation Workshop 19-21 April 1995 Woods Hole MA. Woods Hole Oceanographic Institution.

Horner, R., 1990. Ice- Related Ecosystems, Chapter 2. In, Medlin, L.K. and Priddle, J. (eds.). Polar Marine Diatoms: 19-24. British Antarctic Servey. Cambridge.

Holmes, R.W. and Croll, D.A., 1984: Initial observations on the composition of dense diatom growth on the body feathers of three species of diving birds. Proceedings of the 7th Diatom Symposium. Philadelphia 1982: 265278.

Hustedt, F., 1962. Die Kieselalgen. New York Johnson Reprint Corporation, Weinheim Verlag Von J. Cramer, Germany: 920pp.

Hustedt, Trans. in Jensen, 1985. The Pennate Diatoms. Strauss and Cramer, Hirschberg: 918pp.

Houghton, J.T. , Jenkins, G.J., Ephraums, J.J. (eds), 1990. Climate Change: the IPCC scientific assesment. Report prepared for IPCC by Working Group 1. Cambridge University Press.

Huybrechts, Ph., 1993. Glaciological modelling of the Late Cenozoic East Antarctic ice sheet, stability or dynamism?Geografiska Annaler, $75 \mathrm{~A}(4): 221-238$. 
Ishman, S., 1995. A late Neogene ice proximal record of paleoenvironmental change: Victoria Land margin, Antarctica. Abstracts. Pliocene Antarctic Glaciation Workshop, 19-21 April 1995, Woods Hole MA. Woods Hole Oceanographic Institution.

Ishman, S.E. and Rieck, H.J., 1992. Late Neogene Antarctic Glacio-eustatic Record, Victoria Land Basin Margin Antarctica. In Kennett, J.P. and Warnke (eds.) The Antarctic Paleoenvironment: A perspective in Global Change, Part One., American Geophysical Union, Antarctic Research Series, 56: 327-347. Washington D.C.

Ivy-Ochs, S., Schluchter, C., Kubik, P.W., Dittrich-Hannen, B. and Beer, J., 1995. Minimum ${ }^{10}$ Be exposure ages of early Pliocene for the Table Mountain plateau and the Sirius Group at Mount Fleming, Dry Valleys, Antarctica. Geology 23(11): 1007-1010.

Izaguirre, I., 1990. Comparative analysis of the phytoplankton of six bentic environments from the province of Chubut (Argentina). Physis (Buenos Aires), Secc. B, 48(114-115): 7-23

Jiang, X. and Harwood, D.M., 1992. A glimpse of early Miocene Antarctic forests: Palynomorphs from RISP diatomite, Antarctic Journal of the United States, 27(5): 3-6.

Jiang, X. and Harwood D, 1995. Neogene palynology of Antarctica.Abstracts. Pliocene Antarctic GlaciationWorkshop 19-21, April 1995, Woods Hole MA. Woods Hole Oceanographic Institution.

Kellogg, T.B. and Kellogg, D.E., 1984. Non-marine diatoms in the Sirius Formation. Antarctic Journal of the United States 19(5): 44-45.

Kellogg, T.B. and Kellogg, D.E., 1985. Evidence bearing on the former existance of grounded ice sheets in the Ross Sea, Antarctica. South African Journal of Science. 81: 237-238.

Kellogg, D.E. and Kellogg, T.B., 1996. Diatoms in South Pole ice: Implications for eolian contamination of Sirius Group deposits. Geology 24(2): 115118.

Kennett, J.P., 1967. Recognition and correlation of the Kapitean Stage (Upper Miocene, New Zealand), New Zealand Journal of Geology and Geophysics 10: 1051- 1063.

Kennett, J.P., 1977. Cenozoic evolution of Antarctic glaciation, the CircumAntarctic Ocean, and their Impact on Global Palaeoceanography. Journal of Geophysical Research, 82: 3843-3859.

Kennett, J.P., 1982. Marine Geology. Prentice-Hall, Englewood Cliffs, New Jersey: 813pp. 
Kennett, J. P., 1995. Modern Shallow marine Faunas of the Antarctic: Long term evolutionary consequences of a relatively stable isolated, colsd water ecosystem. Abstracts, Pliocene Antarctic Glaciation Workshop. 19 21, April 1995, Woods Hole MA. National Science Foundation.

Kennett, J.P. and Hodell, D.A., 1993. Evidence for the relative climatic stability of Antarctica during the early Pliocene: A marine perspective. Geografisca Annaler, 75A: 205-220.

Kennett, J.P., and Barker P.F., 1990. Latest Cretaceous to Cenozoic climate and oceanographic developments in the Weddell Sea, Antarctica: An ocean drilling perspective, In Baker, P.F. and Kennett, J.P. (ed.): Proceedings of the Ocean Drilling Program, Scientific Results : 113: 937-960. College Station, Ocean Drilling Program, Texas.

Kennett, J.P. and Hodell, D.A., 1995. Stability or instability of Antarctic ice sheets during warm climates of the Pliocene? GSA Today, 5(1): 1-22.

Keys, J.R., 1990. Ice, Chapter 4. In, Glasby, G.P (ed), Antarctic Sector of the Pacific: 95-123. Elsevier oceanography series

Kolbe, R. W., 1955. Diatoms from equatorial Atlantic cores. Rep. Swed. Deep Sea Exped. Goteberg, 9: 1-49.

Kolbe, R. W., 1957. Freshwater diatoms from Atlantic deep-sea sediments. Science, 126: 1053-1056.

Korsch, R.J., 1974. Petrographic comparison of the Taylor and Victoria Groups (Devonian to Triassic) in Southern Victoria Land, Antarctica. New Zealand Joumal of Geology and Geophysics, 17(3): 523-541.

Ko-bayashi, T., 1963. Variation in some Pennate Diatoms from Antarctica 1. Polar section, National Science Museam, Tokyo. Japanese Antarctic research Expedition 1956 - 1962, Scientific Reports Series E181-20.: 1-20.

Kondo, R., Childs, C. and Atkinson, I., 1994. Opal Phytoliths of New Zealand. Manaaki Whenua Press, Canterbuty, New Zealand: 85pp.

Kondo, R., and Pearson, T., 1981. Opal phytoliths in leaves (part 2): Opal phytoliths in disotyledonous angiosperm trees. Research bulletin of Obihiro University, 12: 217-230.

Kondo, R. and Sase, T., 1986. Opal Phytoliths, their nature and application. The Quaternary 25: 31-63. [in Japanese]

Krammer, K. and Lange-Bertalot, H., 1986. Süßwasserflora von Mitteleuropa. Bacillariophyceae 1. Teil: Naviculaceae. VEB Gustav Fischer Verlag Jena, BRD: 876pp. 
Krammer, K. and Lange-Bertalot, H., 1988. Süßwasserflora von Mitteleuropa. Bacillariophyceae 2. Teil: Bacillariaceae, Epithemiaceae, Surirellaceae. Gustav Fischer Verlag Stuttgart, New York, Germany: 596pp.

Krammer, K. and Lange-Bertalot, H., 1991a. Süßzuasserflora von Mitteleuropa. Bacillariophyceae 3. Centrales, Fragilariaceae, Eunotiaceae. Gustav Fischer Verlag Stuttgart, New York, Germany: 576pp.

Krammer, K. and Lange-Bertalot, H., 1991b. Süßwasserflora von Mitteleuropa. Bacillariophycene 4. Teil: Achnanthaceae. Gustav Fischer Verlag Stuttgart, New York, Germany: 437pp.

Krantz, D.E., 1991. A chronology of Pliocene sea-level fluctuations: The U.S. Middle Atlantic Coastal Plain record. Quaternary Science Reviews, 10: 163-174.

Krebs, W., Brodbury, J.P. and Theriot, E., 1987. Neogene and Quaternary lacustrine diatom biochronology, Western USA. Palaios 2: 505-513.

Krumbein, 1941. Measurement and Geological significance of shape and roundness of sedimentary particles. Journal of Sedimentary Petrology, 11: $64-72$.

LaParade, K.E., 1984. Climate, geomorphology and glaciology of the Shackleton Glacier Area, Queen Maud Mountains, Antarctica. In, Turner, M.D. and Splettstoesser. Antarctic Research Series 36: 163-196. American Geophysical Union, Washington D.C.

Locker, S. and Martini, E., 1985. Phytoliths of the South West Pacific, Site 591. In, Kennett (ed). Initial reports of the Deep Sea Drilling Project, 90(2), 1079-1084. U.S. Govt. Printing office, Washington, D.C.

Lohman, K.E. and Andrews, G.W., 1968. Late Eocene non-marine diatoms from the Beaver Divide Area, Fremont Country, Wyoming, United States. U.S. Geological Survey Publication, 593-E: 1-24.

Mabin, M.C.G., 1986. Sirius Formation basal contacts in the Beardmore glacier region. Antarctic Journal of the United States, 21(5): 32-33.

Marchant, D.R., Denton, G.H. and Swisher III, C.C., 1993. East Antarctic Ice Sheet sensitivity to Pliocene climatic change from a Dry Valley perspective, Geografiska Annaler, 75A(4): 269-302.

Marchant, D., 1995. Miocene and Pliocene paleoclimate of the Dry Valleys region, Southern Victoria Land: A geomorphological approach. Abstracts. Pliocene Antarctic Glaciation Workshop, 19-21 April 1995, Woods Hole MA. Woods Hole Oceanographic Institution. 
Mayewski, P.A., 1975. Glacial geology and late Cenozoic history of the Transantarctic Mountains, Antarctica. Columbus: Institute of Polar Studies report 56. The Ohio State University. 168pp.

McCollum, D.W., 1975. Diatom stratigraphy of the Southern Ocean. Initial Reports of the Deep Sea Drilling Project. 28: 515-571. U.S. Govt. Printing office, Washington, D.C.

McElroy, C.T. and Rose, G., 1987. Geology of the Beacon Heights Area, Southern Victoria Land, Antarctica, 1:50 000, Miscellaneous Series Map 15. New Zealand Geological Servey, Department of Scientific and I ndustrial Research.

McGregor, V.R., 1965. Notes on the geology of the area between the heads of the Beardmore and Shackleton Glaciers, Antarctica. New Zealand Journal of Geology and Geophysics 8: 278-291.

McIntosh, W. and Wilch, T., 1995. Applications of ${ }^{40} \mathrm{Ar} /{ }^{39} \mathrm{Ar}$ dating of volcanic ash to Antarctic Neogene climate and glacial history - a review of some published and on going studies. Abstracts. Pliocene Antarctic Glaciation Workshop, 19-21, April 1995, Woods Hole MA. Woods Hole Oceanographic Institution.

McKelvey, B., Hambrey, M. and Mablin, M., 1995. The Neogene Pagodroma Group in the Northern Prince Charles Mountains, Eastern Antarctica. Abstracts. Pliocene Antarctic Glaciation Workshop, 19-21 April 1995, Woods Hole MA., Woods Hole Oceanographic Institution.

McKelvey, B.C., Mercer, J.H., Harwood, D.M. and Stott, L.D., 1985. The Sirius Formation: Further considerations. Antarctic Journal of the United States, 19(5): 42-43.

McKelvey, B.C., Webb, P.-N., Harwood, D.M. and Mabin, M.C.G., 1987. The Dominion Range Sirius Group: A late Pliocene-early Pleistocene record of the ancestral Beardmore Glacier. Fifth International Symposium on Antarctic Earth Sciences, Cambridge, August, 1987.

McKelvey, B.C., Webb, P.-N., Harwood, D.M. and Mabin, M.C.G., 1991. The Dominion Range Sirius Group: A record of the late Pliocene - early Pleistocene Beardmore glacier. In, Thomson, M.R.A., Crame, J.A. and Thomson, J.W. (eds.), Geological Evolution of Antarctica, : 675-682. Cambridge, Cambridge University Press.

Medlin, L.K. and Priddle, J. (eds). Polar Marine Diatoms. British Antarctic Servey. Cambridge

Mercer, J.H., 1968. Glacial geology of the Reedy glacier area, Antarctica. Geological Society of America Bulletin, 79: 217-225. 
Mercer, J.H., 1972. Some obseravations on the glacial geology of the Beardmore Glacier area. In, Adie, R.J. (ed.). Antarctic Geology and Geophysics : 427433. Oslo, Universitetsforlarget.

Mildenhall, D.C., 1989. Terrestrial palynology. In, Barrett, P.J. (ed.). Antarctic Cenozioc history from the CIROS-1 drillhole, McMurdo Sound. DSIR bulletin 245: 119-127.

Miller, K.G., Fairbanks, R.G. and Mountain, G.S., 1987. Tertiary oxygen isotope synthesis, sea level history and continental margin erosion.

Palaeoceanography, 2: 1-19.

Mohr, B.A.R., 1990. Eocene and Oligocene Sporomorphs and Dinoflagellate Cysts from Leg 113 Drill Sites, Weddell Sea, Antarctica. In, Baker, P.F., Kennett, J.P., O'Connnell, S. and Pisias, N.G. (eds). Proceedings of the Ocean Drilling Program, Scientific Results, 113: 595-612. College Station, Texas.

Oerlemans, J. and Van der Veen, C.J., 1984. Ice Sheets and Climate. Reidel, Dordrecht. 217pp.

Palmisano, A.C. and Garrison, D.L., 1993. Microorganisms in Antarctic Science. In, Friedmann, E.I. (ed.) Antarctic Microbiology. Wikey-Liss. New York: $167-217$.

Patrick, R. and Reimer, C.W., 1966. The Diatoms of the United States. Monograph Series of the Academy of Natural Sciences of Philadelphia No. 3, Pennsylvania.

Pearsall, D.M., 1989. Phytolith analysis. In, Paleoethnobotany: a handbook of procedures. San Diego, Academic Press: 311-470.

Pearsall, D.M. and Trimble, M.K., 1983. Phytolith analysis of soil samples. In, Clark, J.T. and Kirch, P.V. (eds). Archeological investigations of the Mudlane-Waimea-Kawaihae Road Corridor, Island of hawait:an interdisciplinary study of an environmental transect. Bernice P. Bishop Museum departmental report, Series 83-1: 472-497.

Pickard, J., Adamson, D.A., Harwood, D.M., Miller, G.H., Quilty P.G. and Dell , R.K., 1988. Early Pliocene marine sediments, coastline and climate of East Antarctica, Geology, 16 (2): 158-161.

Piperno, D.R., 1988. Phytolith analysis: an archaeological and geological perspective. San Diego, Academic press. 280pp.

Pokras, E.M. and Mix, A.C., 1985. Eolian evidence for spatial variability of late Quaternary climates in tropical Africa. Quaternary Research, 24: 137-149. 
Pokras, E.M and Ruddiman, W.F., 1989. Evolution of the South Saharan/Sahelian aridity based on Freshwater Diatoms (Genus Melosira) and opal phytoliths: sites 662 and 664 . Initial Reports of the Deep Sea Drilling Project 108: 143. U.S. Govt. Printing office, Washington, D.C.

Potter, N., 1995. Glacial history of Beacon Valley, Quartermain Mts., Antarctica. Abstracts. Pliocene Antarctic Glaciation Workshop, 19-21 April 1995, Woods Hole MA. Woods Hole Oceanographic Institution.

Powell, R.D., 1976. Textural Characteristics of some glacial sediments in Taylor Valley, Antarctica. Master's thesis, Victoria University of Wellington, New Zealand. 316pp.

Prat, H., 1936. La systematique des Gramminees. Annales des sciences naturelles, Botanique series II, 18: 165-258.

Prat, H., 1948. General features of the epidermis in Zea mays. Annals of the Missouri Botanical Garden, 35: 341-351.

Prentice, M.L., Berkman, P. and van Bloem, S., 1995. Sirius Group deposits in the McMurdo Sound Region: Geomorphic and lithostratigraphic considerations. Abstracts. Pliocene Antarctic Glaciation Workshop, 19-21 April 1995, Woods Hole MA. Woods Hole Oceanographic Institution.

Prentice, M.L., Denton, G.H., Lowell, T.V., Conway, H. and Heusser, I.E., 1986. Pre-late Quaternary glaciation of the Beardmore Glacier region, Antarctica. Antarctic Journal of the United States 21(5): 95-98.

Prentice, M.L., Denton G.H., Burckle, L.H., and Hodell, D.A., 1987. Evidence from the Wright Valley for the responce of the Antarctic ice sheet to climate warming. Antarctic Joumal of the United States, 22(5): 56-58.

Prentice, M.L., and Matthews R.K., 1991. Tertiary ice sheet dynamics: The snow gun hypothesis. Journal of Geophysical Research, 96 (B4): 6811-6827.

Quilty, P.G., 1991. The geology of Marine Plain, Vestfold Hills, East Antarctica, in Thomson, M.R.A., Crame, J.A. and Thomson, J.W. (eds) The Geological Evolution of Antarctica : 683-686, Cambridge University Press, New York.

Richter, H.G., 1980. Occurrence, morphology, and taxonomic implications of crystalline and siliceous inclusions in the secondary xylem of Lauraceae and related families. Wood science technology, 14: 35-44.

Round, F.E., Crawford, R.M., and Mann, D.G., 1990. The Diatom biology and Morphology of the Genera. Cambridge University Press, Cambridge. 
Savin, S.M., Douglas, R.G. and Stetehli, E.G., 1975. Tertiary marine paleotemperatures. Geological Society of America Bulliten, 86: 1499-1510

Scherer, R.P., 1987. Paleoenvironmental studies of non-marine diatoms in Quaternary Antarctic sediments. Antarctic Journal of the United States, 22: $35-37$

Scherer, R.P., 1989. Paleoenvironments of the west antarctic interior: Microfossil study of sediments below Upstream B. Antarctic Journal of the United States, 24(5): 56-58.

Scherer, R.P., 1991. Quaternary and Tertiary microfossils from beneath Ice Stream B: Evidence for a dynamic West Antarctic Ice Sheet history. Palaeogeography, Palaeoclimatology, Palaeoecology, 90: 395-412.

Schlichting, Jr, H.E., Speziale, B.J. and Zink, R.M., 1977. Dispersal of algae and Protozoa by antarctic flying birds. Antarctic Journal of the United States, 122(1\&2): 14-21.

Schrader, H.J., 1969. Die pennaten diatomeen, aus demo Obereozän von Omaru, Neuseeland, Nova Hedwegia. Beih 28: 1-124.

Shackleton, N.J. and Kennett, P.J., 1975. Late Cenozoic oxygen and carbon isotopic changes at the DSDP Site 284: Implications for glacial history of the Northern Hemisphere and Antarctica. In, Kennett, J.P., Houtz, R.E., et al. Initial reports of the Deep Sea Drilling Project $29: 801$ 807.Washington, D.C., U.S. Government Printing Office.

Shemesh, A., Mortlock, R.A., Smith, R.J. and Froelich, P.N., 1988.

Determination of Ge/Si in marine siliceous microfossils: Separation, cleaning and dissolution of Diatoms and Radiolaria. Marine Chemistry, 25: 305-323.

Selby, M.J., Rains, R.B. and Palmer, R.W., 1974. Eolian deposits of the ice-free Victoria Valley, Southern Victoria Land, Antarctica. New Zealand Journal of Geology and Geophysics, 17: 543-562.

Stroeven, A.P., Prentice, M.J. and Borns Jr., H.W., 1992. Mt. Fleming Upper Valley Drift: Evidence for neogene glacial history of Antarctica. Antarctic Journal of the United States, 27(5): 51-54.

Stroeven, A.P. and Prentice, M.L., 1994. Do marine diatoms in Sirius Group tills indicate ice sheet disintegration? Abstracts, Geological Society of America Abstracts With Programs, 26(7): A-143.

Stroeven, A.P., 1994. Semi-consolidated glacial deposits on Mt. Fleming, South Victoria Land, Antarctica: A test of the late Neogene East Antarctic Ice Sheet collapse hypothesis. MSc thesis, University of Maine. 183pp. 
Stroeven, A. and Prentice, M., 1995. Marine Diatoms in Antarctic Tertiary tills: A new dataset from Mt. Fleming, South Victoria Land indicates possible transport. Abstracts. Pliocene Antarctic Glaciation Workshop, 19-21 April, 1995 Woods Hole MA. Woods Hole Oceanographic Institution.

Sugden, D.E., Marchant D.R., Denton, G.H., 1993a. The case for a stable East Antarctic Ice Sheet. Geografiska Annaler. 75A: 151- 353.

Sugden, D.E., Marchant D.R., Denton, G.H., 1993b. The case for a stable East Antarctic Ice Sheet: The background. Geografiska Annaler. 75A: 151-154.

Sugden, D.E., Denton, G. and Marchant D., 1995. Landscape evolution of the Dry Valleys Transantarctic Mountains: Tectonic implications. Abstracts. Pliocene Antarctic Glaciation Workshop, 19-21, April 1995, Woods Hole MA. Woods Hole Oceanographic Institution.

Temnsiskova-Topalova, D., Valeva, M. and Ognjanova-Rumenova, N., 1990. Non marine biostratigraphy of some Genera of the Class Centyrophyceae from Southern Bulgaria. In, Simola, A.(ed). Proceedings of the 10th diatom symposium: Joensuu, Finland, August 28 - September 2, 1988: 357-364. Koeltz Scientific Books.

Truswell, E.M., 1986. Palynology. In, Barrett, P.J. (ed.). Antarctic Cenozoic history from MSSTS-1 drillhole McMurdo Sound. DSIR bulletin 237: 131-134.

Truswell, E.M., 1991. Antarctica: a history of terresrtial vegetation. In,Tingy, R.J. (ed.). The Geology of Antarctica. Oxford Monographs on Geology and Geophysics 17: 499-537.

Twiss, P.C., Suess, E. and Smith, R.M., 1969. Morphological classification of grass phytoliths. Soil Science Society of America proceedings, 33:109-115.

Van Heurick, H, 1896. A treatise on the Diatomaceae. William Westley and Son, Strand. 556pp.

Van der Wateren, F.M., 1995. Differential tectonic movement controlling landscape evolution of different blocks in the West Antarctic rift system. Abstracts. Pliocene Antarctic Glaciation Workshop, 19-21 April 1995, Woods Hole MA. Woods Hole Oceanographic Institution.

Vella, P., 1953. The Genus Pelicaria in the Tertiary of East Wairarapa. Transactions of the Royal Society of New Zealand, 81: 35-48.

Vella, P., 1963. Plio-Pleistocene Cyclothems, Wairarapa, New Zealand. Transactions of the Royal Society of New Zealand, 2(2).

Verbers, A., 1995. Microfossil content of glacial deposits from the Southern Prince Albert Mountains, Antarctica, and its implication for landscape 
evolution. Abstracts. Pliocene Antarctic Glaciation Workshop, 19-21 April 1995, Woods Hole MA. Woods Hole Oceanographic Institution.

Wardlaw, B.R. and Quinn, T.M., 1991. The record of Pliocene sea- level chance at Enewetak Atoll. Quaternary Science Review. 10: 247-258.

Warnke, D., 1995. Major deglaciation of east Antartica during the Gauss Chron? Unlikely from marine perspective. Abstracts. Pliocene Antarctic Glaciation Workshop, 19-21 April 1995, Woods Hole MA. Woods Hole Oceanographic Institution.

Warnke, D.A., Allen, C.P., Miller, D.W., Hoddell, D.A. and Brunner, C.A., 1992. Miocene-Pliocene Antarctic glacial evolution: A synthesis of ice-rafted debris, stable isotope, and planktonic foraminiferal indicators, ODP Leg 114. In, Kennett, J.P. and Warnke, D.A., (eds). The Antarctic Paleoenvironment : A perspective on Global Change 1., Antarctic Research Series 56: 311-325.

Wasell, A., 1993. Diatom stratigraphy and evidence of Holocene environmental changes in selected lake basins in the Antarctic and South Georgia. PhD. thesis. Stockholm University. 87pp.

Wasell, A. and Håkansson, H., 1992. Diatom stratigraphy in a lake on Horseshoe island, Antarctica: A marine-brackish-freshwater transition, with comments on the systematics and ecology of the most common diatoms. Diatom Research, 7(1): 157 - 194.

Weatherhead, A.V., 1988. The occurrence of plant opal in New Zealand soils. New Zealand Soil Bureau record, 108.

Weaver, F.M., and Gombos Jr., A.M. 1981. Southern high-latitude diatom biostratigraphy. In, Warme, J.E., Douglas, R.G. and Winterer (eds.), DSDP: A dacade of progress. Society of Economic Paleontologists and Mineralogists Special Publication, 32: 445-470.

Webb, P.-N., 1972a. Paleontology of late Tertiary- Quaternary sediments, Wright Valley, Antarctica. Antarctic Journal of the United States, 7(4): 96-97.

Webb, P.-N., 1972b. Wright Fjord, Pliocene marine invasion of an Antarctic Dry Valley, Antarctic Journal of the United States, 7(6): 227-234.

Webb, P.-N., 1991. A review of the Cenozoic stratigraphy and palaeontology of Antarctica. In, Thomson, M.R.A., Crame, J.A. and Thompson, J.W. (eds), Geological evolution of Antarctica, Cambridge University Press: 599-608. 
Webb, P.N., Harwood, D.M. and McKelvey, B.C., 1994. Recent progress in the investigation of Late Neogene records adjacent to the East Antarctic rift system lithosphere boundry. In, Ishman, S.E. (ed), Pliocene HighLatitude Climate Records. Abstracts from a USGS workshop, Herndon, Virginia, July 25-27, 1994. USGS Open-File report 94-0603: 27-29.

Webb, P.-N., Harwood, D.M., McKelvey, B.C., Mercer, J.H. and Stott, L.D., 1983. Late Neogene and older Cenozoic microfossils in high elevation deposits of the Transantarctic Mountains: Evidence of marine sedimentation and ice volume variation on the East Antarctic craton, Antarctic Journal of the United States, 18(5): 96-97.

Webb, P.-N., Harwood, D.M., McKelvey, B.C., Mercer, J.H. and Stott, L.D., 1984. Cenozoic marine sedimentation and ice-volume variation on the East Antarctic craton. Geology, 12: 287-291.

Webb, P.-N.,McKelvey, B.C., Harwood, D.M., Mabin, M.C.G. and Mercer, J.H., 1987. Sirius formation of the Beardmore glacier region, Antarctic Journal of the United States, 22: 8-13.

Webb, P.-N. and Harwood, D.M., 1987. Terrestrial flora of the Sirius Formation: It's significance for late Cenozoic glacial history, Antarctic Joumal of the United States 22: 7-11.

Webb, P.-N., and Harwood, D.M., 1986. Late Cenozoic tectonic and glacial history of the Transantarctic Mountains. Antarctic Journal of the United States, 22: 7-11.

Webb, P.-N., and Harwood, D.M., 1991. Late Cenozoic glacial history of the Ross Embayment, Antarctica. Quaternary Science Reviews 10: 215-224.

Webb, P.-N., Harwood, D.M., McKelvey, B.C., Mercer, J.H. and Stott, L.D., 1984. Cenozoic marine sedimentation and ice-volume variation on the East Antarctic craton. Geology, 12: 287-291.

Webb, P.N., Harwood, D., Ashworth, A., Hill, R., Mablin, M. and McKelvey, B., 1995. Late Cenozoic Beardmore Valley and Paleofjord. Abstracts. Pliocene Antarctic Glaciation Workshop, 19-21 April 1995, Woods Hole MA., Woods Hole Oceanographic Institution.

Webb, P.-N and Wrenn, J., 1982. Upper Cenozoic Micropaleontology and Biostratigraphy of Eastern Taylor Valley, Antarctica. In, Craddock, C. (ed).Antarctic Geoscience: 1117-1122. Madison, University of Wisconsin Press.

West, W. and West, G.S., 1911. Freshwater Algae. British Antarctic Expedition, 1907 - 1909. Scientific Reports, Biology I., 7:263 - 298.

White, M.E., 1988. The greening of Gondwana. Reed, Sydney, Australia: 256pp. 
Wilch, T., 1995. Volcanic limits on surface uplift in South Victoria Land, Antarctica - New date from Ferrar Valley. Abstracts. Pliocene Antarctic Glaciation Workshop, 19-21 April 1995, Woods Hole MA., Woods Hole Oceanographic Institution.

Wilch, T.I., Lux, D.R., Denton, G.H. and McIntosh, W.C., 1993a. Limited Pliocene glacier extent and surface uplift in middle Taylor Valley, Antarctica, Geografiska Annaler, 75 A: 331-351.

Wilding, L.P. and Drees, L.R., 1973. Scanning electron microscopy of opaline forms isolated from forest soils in Ohio. Soil Science Society of America proceedings, 37: 647-650.

Wilson, G.S., 1993. Ice Induced Sea level Change in the Late Neogene. PhD thesis. Victoria University of Wellington, New Zealand. 510pp.

Wise, S.W., Breza, J., Harwood, D.M. and Wei, W., 1991, Paleogene glacial history of Antarctica. In Muller, D.W., McKenzie, J.A. and Weissert, H. (eds), Controversies in modern Geology: 133-171.London, Academic Press.

Woolfe, K.J., Kirk, P.A., Sherwood, A.M. 1987. Geology of the Knobhead Area, Southern Victoria Land, Antarctica. 1: 50000 Miscellaneous Series Map. New Zealand Geological Servey, Department of Scientific and Industrial Research.

Wright, I.C. and Vella, P.P., 1988. A New Zealand Late Miocene magnetostratigraphy: glacioeustatic and biostratigraphic correlations. Earth and Planetary Science Letters, 87, 193-204.

Zotov, V.D., 1963. Synopsis of the grass subfamily Arundinoideae in New Zealand. New Zealand journal of botany., 1: 78-136.

Zemmels, I. and Cook, H.E., 1976. X-ray mineralogy data from the Southeast Pacific Basin - Leg 35 Deep Sea Drilling Project. In, Worstell P. (ed). Initial reports of the Decp Sea Drilling Project XXXV: 747-756. U.S. Govt. Printing office, Washington, D.C. 


\section{APPENDIX}

APPENDIX ONE

List of samples

APPENDIX TWO

Grain size analysis

APPENDIX THREE

Porosity and composition of gravel, sand, and clay.

APPENDIX FOUR

Measurements of clast shape and fabric and glacial striae.

APPENDIX FIVE

Processing method for the concentration of biogenic slilca.

APPENDIX SIX

Diatom data and analysis

APPENDIX SEVEN

Phytolith tables, diagrams and analysis. 


\section{APPENDIX ONE \\ List of samples}

Appendix 1.1 Samples from Mount Feather.

Appendix 1.2 Samples from Table Mountain.

Appendix 1.3 Samples from Mount Crean.

Appendix 1.4 Samples from New Zealand, South Island till (from Okarito) 


\section{List of Samples}

Samples were taken for petrographical and diatom/microfossil analysis in the laboratory.

\subsection{Mount Feather}

Sirius Group till deposits

$\begin{array}{ll}\text { Site One } & \text { Site Two } \\ \text { F1 } 0-2 \mathrm{~cm} & \text { F2 } 0-2 \mathrm{~cm} \\ \text { F1 } 2-7 \mathrm{~cm} & \text { F2 } 2-7 \mathrm{~cm} \\ \text { F1 } 7-17 \mathrm{~cm} & \text { F2 } 7-17 \mathrm{~cm} \\ \text { F1 } 17-27 \mathrm{~cm} & \text { Harder } \\ \text { F1 } 27-37 \mathrm{~cm} & \end{array}$

Regolith

Site One

Site Two

Snow

Site One

Site Two Measures

Site Three
F3 $0-2 \mathrm{~cm}$
F3 $2-7 \mathrm{~cm}$
F3 $7-17 \mathrm{~cm}$
Soft surface
Very hard ice

Site Three

Site Four

F4 0-2cm (Top)

F4 $0-2 \mathrm{~cm}$ (Base)

Sirius till on the slopes of the slope of the North Ridge of Mt. Feather.

From sandy moraine material adjacent to the tills.

Loose broken material from cracks in the Weller Coal

The surface $25 \mathrm{~cm}$ of surface snow was cleared away, snow was sampled at between $25 \mathrm{~cm}$ and and $75 \mathrm{~cm}$ into the snow and melted to produce 101 of water.

The surface $40 \mathrm{~cm}$ was cleared away, samples were taken at depths between $40 \mathrm{~cm}$ and $90 \mathrm{~cm}$ and melted to 101 of water.

Locations, figure 3.1 . 


\subsection{Table Mountain}

Sirius Group Tills

$\begin{array}{lll}\text { Site One (P) } & \text { Site One (B) } & \text { Site Two } \\ 0-2 \mathrm{~cm} & 0-2 \mathrm{~cm} & 0-2 \mathrm{~cm} \\ 2-7 \mathrm{~cm} & 2-7 \mathrm{~cm} & 2-7 \mathrm{~cm} \\ 7-27 \mathrm{~cm} & 7-17 \mathrm{~cm} & 7-10 \mathrm{~cm} \\ 27-33 \mathrm{~cm} & 17-27 \mathrm{~cm} & \text { Very } \\ & 27-37 \mathrm{~cm} & \text { hard. }\end{array}$

Regolith

Site One

In the lee of a bolder in New Mountain Sandstone.

Site Two In "soil" derived from Sirius Group Deposits.

Site Three

From overlying moraine material a. $0-5 \mathrm{~cm}$ b $5-20 \mathrm{~cm}$.

Snow

Site One The surface $25 \mathrm{~cm}$ was cleared. Sample was taken between $25 \mathrm{~cm}$ and $70 \mathrm{~cm}$ and melted to 101 of snow.

Site Two The surface $30 \mathrm{~cm}$ was cleared away. Sample was taken between $30 \mathrm{~cm}$ and $90 \mathrm{~cm}$ into the snow and melted to produce 101 of water.

Locations, figure 3.2

\subsection{Mt. Crean}

Regolith

Site One One sample was taken from loose sandy material from the in the Weller Coal measures.

\section{Snow}

Site One The surface $20 \mathrm{~cm}$ was cleared. Sample was taken between 20 and $50 \mathrm{~cm}$ depth and melted to produce 101 of water.

Location of Mt. Crean, figure 1.1, Grid Reference $77^{\circ} 55^{\prime} \mathrm{S} 159^{\circ} 32^{\prime} \mathrm{E}$ 


\subsection{New Zealand, South Island till (from Okarito)}

Samples collected by Dr. James Goff, Victoria University of Wellington, 1995.

Till

Site One Lower unit. Base of coastal cliffs, $500 \mathrm{~m}$ SW of car park at south end of Village. Lodgement till, silty matrix, light olive brown on colour. SI B(1).

Site Two Upper unit. Middle of coastal bluffs, $475 \mathrm{~m}$ SW of car park at south end of village. Meltout till massive silty matrix - light brown in colour. SI G(2).

Location Okarito, coastal cliffs, west coast of the South Island New Zealand. Grid reference $170^{\circ} 08^{\prime} 20^{\prime \prime} \mathrm{E} 43^{\circ} 13^{\prime} 50^{\prime \prime} \mathrm{S}$. 


\section{APPENDLX TWO}

\section{Grain size analysis}

Aids in determining the source and mode of deposition of the sediments.

APPENDIX 2.1 Grain size data summary tables and graphs.

Table A2.1 Percent gravel, sand, silt and clay from the Sirius Group tills at Mt. Feather and table Mountain.

Figure A2.1 Grain size distribution histograms for some mt. Feather and Table Mountain samples.

APPENDIX 2.2 Initial grain size analysis data sheets, for samples from Mt. Feather and Table mountain. 


\section{APPENDIX 2.1 Grain size data summary tables and graphs.}

Table A2.1

A. Initial grain size data (frequency percent gravel, sand and clay) for samples. from Mt. Feather and Table Mountain. Site locations are shown in Chapter Three, figures 3.1 and 3.2. Analist: N. Bleakley.

\begin{tabular}{|l|c|c|c|}
\cline { 2 - 4 } \multicolumn{1}{c|}{} & \multicolumn{3}{c|}{ Percent $(\%)$} \\
\hline Sample & Gravel & Sand & Mud \\
\hline MF1 0-2cm & 26.5 & 57.85 & 15.64 \\
MF1 2-7cm & 18.79 & 68.68 & 12.53 \\
MF1 7-17cm & 18.57 & 67.94 & 13.49 \\
MF1 27-37cm & 17.2 & 68.37 & 14.43 \\
\hline TM1P 0-2cm & 6.03 & 86.39 & 7.58 \\
TM1P 22-32cr & 5.58 & 84.69 & 9.73 \\
TM1B 13-23cr & 11.17 & 77.34 & 11.5 \\
TM2 2-5cm & 30.06 & 65.61 & 4.33 \\
\hline
\end{tabular}

B. Percent gravel sand, silt and clay, and summary statistics of the matrix (samples less gravel) for the Sirius Group tills from Mt. Feather. Analyst: L.Wolley (VUW).

\begin{tabular}{|l|c|c|c|c|c|c|c|c|c|c|}
\cline { 2 - 9 } \multicolumn{1}{c|}{} & \multicolumn{3}{c|}{ Percent $\%$ ) } & \multicolumn{3}{c|}{ Weight } & \multicolumn{3}{c|}{ Matrix only (\%) } \\
\hline Sample & Gravel & Sand & Mud & Gravel & Sand & Mud & Sand & Silt & Clay \\
\hline F1 $0-2 \mathrm{~cm}$ & 19.14 & 59.31 & 21.55 & 9.99 & 30.96 & 11.35 & 73.30 & 7.30 & 19.30 \\
F1 2-7cm & 15.37 & 64.57 & 20.06 & 5.25 & 22.05 & 6.85 & 76.30 & 7.90 & 15.80 \\
F1 $7-17 \mathrm{~cm}$ & 22.78 & 57.84 & 19.38 & 12.47 & 31.66 & 10.61 & 73.20 & 8.90 & 17.90 \\
F1 $17-27 \mathrm{~cm}$ & 8.50 & 66.08 & 25.42 & 5.13 & 39.88 & 15.34 & 72.20 & 9.10 & 18.70 \\
F1 $27-37 \mathrm{cmA}$ & 11.48 & 65.43 & 23.09 & 4.64 & 26.44 & 9.33 & 74.00 & 7.20 & 18.90 \\
F1 $27-37 \mathrm{cmB}$ & 13.56 & 62.53 & 23.91 & 5.03 & 23.20 & 8.87 & 72.30 & 8.40 & 19.30 \\
& & & & & & & & & \\
F2 $0-2 \mathrm{~cm}$ & 49.99 & 33.27 & 16.74 & 22.39 & 14.90 & 7.50 & 66.50 & 13.50 & 20.00 \\
F2 $2-7 \mathrm{~cm}$ & 8.82 & 55.80 & 35.38 & 3.27 & 20.68 & 13.11 & 61.20 & 14.70 & 24.10 \\
F2 $7-17 \mathrm{~cm}$ & 39.54 & 38.53 & 21.94 & 17.61 & 17.16 & 9.77 & 63.70 & 12.80 & 23.50 \\
& & & & & & & & & \\
F3 $0-2 \mathrm{~cm}$ & 6.88 & 64.56 & 28.56 & 2.85 & 26.78 & 11.83 & 69.30 & 8.30 & 22.40 \\
F3 $2-7 \mathrm{~cm}$ & 8.24 & 64.22 & 27.54 & 2.56 & 19.94 & 8.55 & 70.00 & 9.10 & 20.90 \\
F3 $7-17 \mathrm{~cm}$ & 13.57 & 59.55 & 26.88 & 5.68 & 24.92 & 11.25 & 68.90 & 9.50 & 21.60 \\
& & & & & & & & & \\
F4-1 & 11.12 & 73.24 & 15.64 & 6.10 & 40.18 & 8.58 & 71.20 & 9.20 & 19.60 \\
F4-2 & 13.62 & 58.88 & 27.50 & 5.82 & 25.16 & 11.75 & 68.20 & 11.60 & 20.30 \\
\hline
\end{tabular}


Figure A2.1 Grain Size Distribution Histograms for some Mt. Feather and Table Mountain samples.
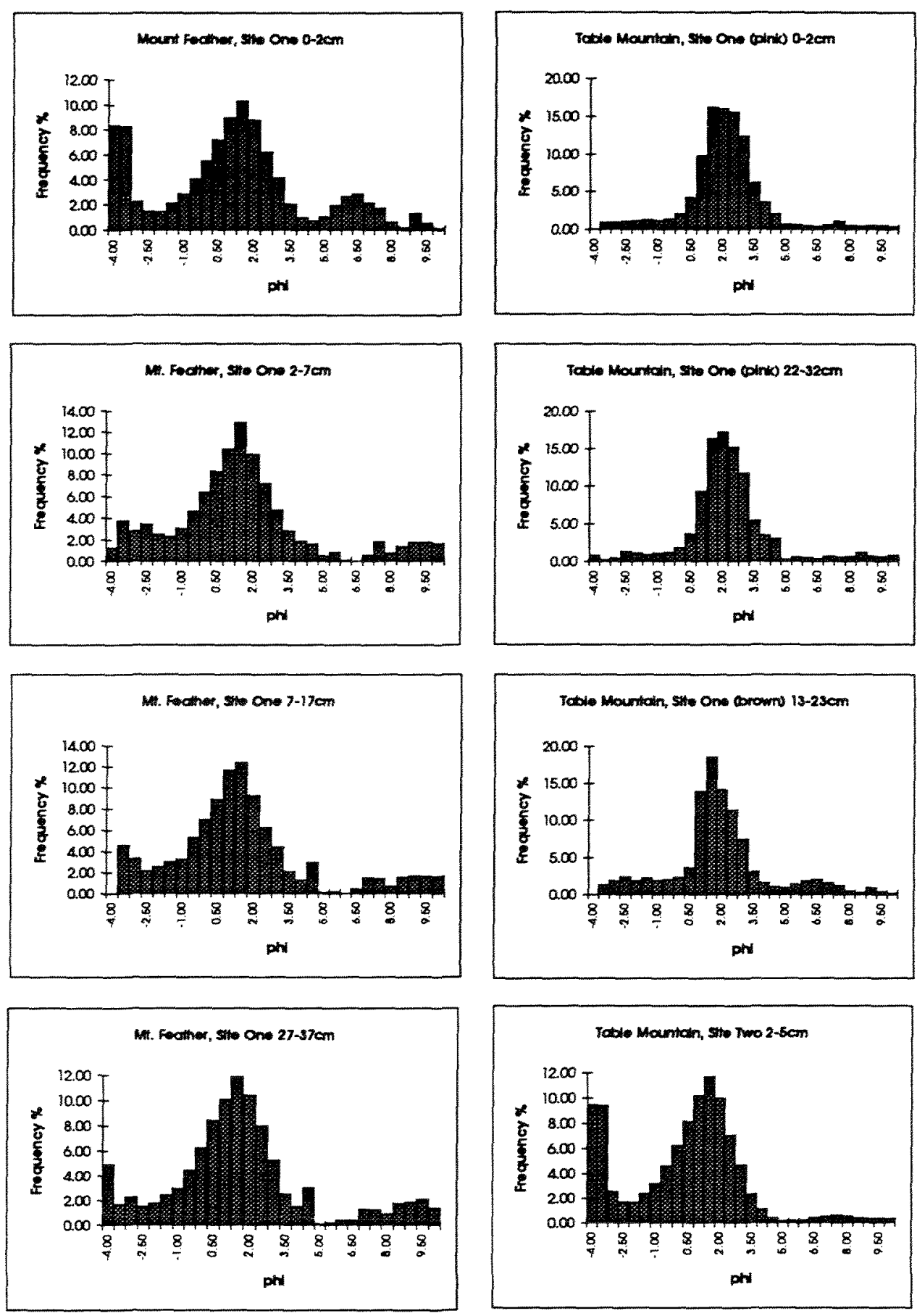
APPENDIX 2.2

Initial grain size analysis data sheets, for samples from Mt. Feather and Table Mountain. 
SAMPLENO: FI O-2cm ANALYST: N.L.Bleakley DATE: 10/10/95

BEAKER WGT: $\quad 167.40 \quad$ SAMPLE WEIGHT $\quad 700.60$

WET SIEVE DIAMETER: $\quad$ Goum

SIZE DISTRIBUTION HISTOGRAM:

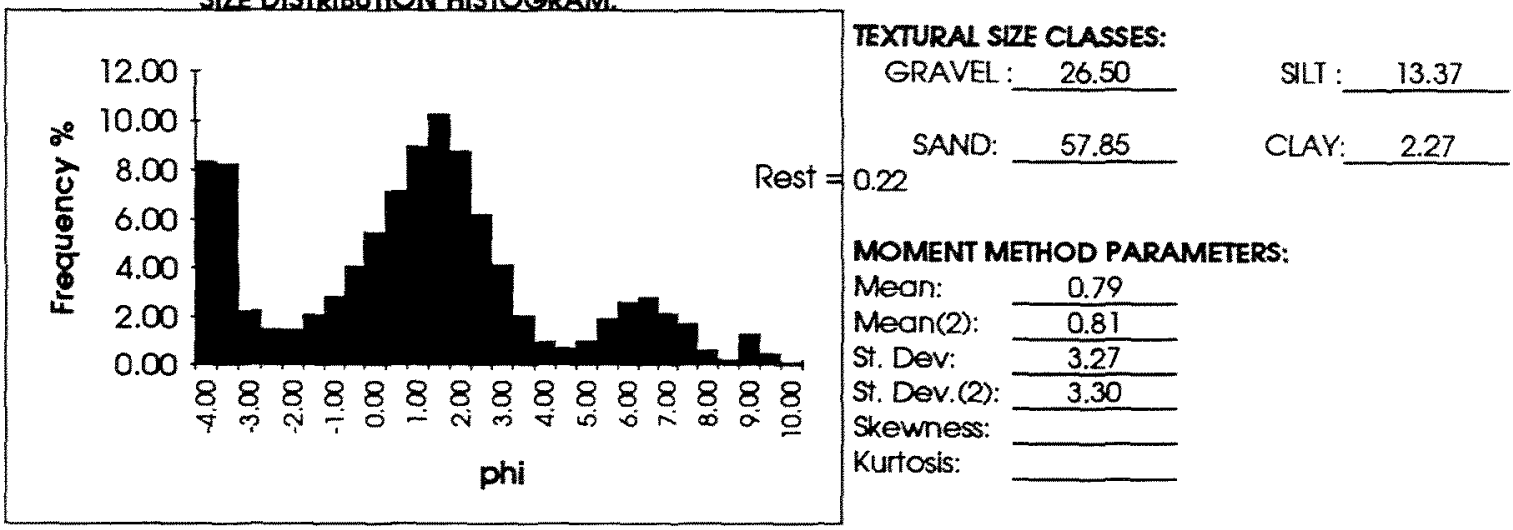

ERRORS:

$\%$ lost in centrifuging and wet sievinu

\% lost in dry sieving:

1.50

DATA:

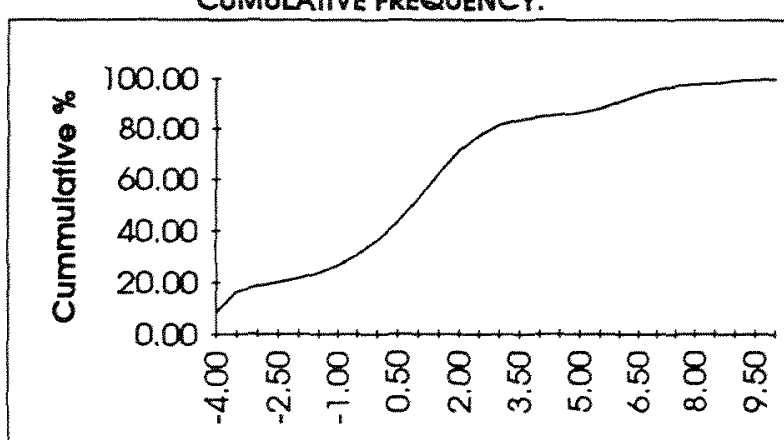

phi

\begin{tabular}{|c|c|c|c|}
\hline Class Limits & Dato & Freq. $\%$ & Fumulative \\
\hline $\mathbf{- 4 . 0 0}$ & 51.30 & 8.33 & 8.33 \\
$\mathbf{- 3 . 5 0}$ & 50.70 & 8.23 & 16.56 \\
$\mathbf{- 3 . 0 0}$ & 13.60 & 2.21 & 18.77 \\
$\mathbf{- 2 . 5 0}$ & 9.00 & 1.46 & 20.23 \\
$\mathbf{- 2 . 0 0}$ & 8.83 & 1.43 & 21.66 \\
$\mathbf{- 1 . 5 0}$ & 12.60 & 2.05 & 23.71 \\
$\mathbf{- 1 . 0 0}$ & 17.21 & 2.79 & 26.50 \\
$\mathbf{- 0 . 5 0}$ & 24.74 & 4.02 & 30.52 \\
$\mathbf{0 . 0 0}$ & 33.53 & 5.44 & 35.96 \\
$\mathbf{0 . 5 0}$ & 43.96 & 7.14 & 43.10 \\
1.00 & 55.11 & 8.95 & 52.05 \\
1.50 & 63.14 & 10.25 & 62.30 \\
$\mathbf{2 . 0 0}$ & 53.97 & 8.76 & 71.06 \\
$\mathbf{2 . 5 0}$ & 38.22 & 6.21 & 77.27 \\
$\mathbf{3 . 0 0}$ & 25.30 & 4.11 & 81.37 \\
$\mathbf{3 . 5 0}$ & 12.49 & 2.03 & 83.40 \\
$\mathbf{4 . 0 0}$ & 5.85 & 0.95 & 84.35 \\
$\mathbf{4 . 5 0}$ & 4.37 & 0.71 & 85.06 \\
$\mathbf{5 . 0 0}$ & 6.11 & 0.99 & 86.05 \\
$\mathbf{5 . 5 0}$ & 11.74 & 1.91 & 87.96 \\
$\mathbf{6 . 0 0}$ & 15.97 & 2.59 & 90.55 \\
$\mathbf{6 . 5 0}$ & 17.10 & 2.78 & 93.33 \\
7.00 & 12.98 & 2.11 & 95.43 \\
$\mathbf{7 . 5 0}$ & 10.51 & 1.71 & 97.14 \\
$\mathbf{8 . 0 0}$ & 3.61 & 0.59 & 97.73 \\
$\mathbf{8 . 5 0}$ & 1.24 & 0.20 & 97.93 \\
$\mathbf{9 . 0 0}$ & 7.93 & 1.29 & 99.21 \\
$\mathbf{9 . 5 0}$ & 2.99 & 0.48 & 99.70 \\
$\mathbf{1 0 . 0 0}$ & 0.52 & 0.08 & 99.78 \\
$\mathbf{2 1 0}$ & 1.34 & 0.22 & 100.00 \\
\hline
\end{tabular}


SAMPLE NO: Fl0-2cm ANALYST: N.L.BleakleY DATE: 10/10/95

BEAKER WGT

SAMPLE WEIGHT

700.60

FINE FRACTION

COARSE FRACTION

BEAK. WGI 167.40 COARSE FRAC + BEAKER: $-\frac{691.05}{523.60}$

WET SIEVE DIAMETER:

60um

FINE FRACION WG

103

TOTAL SAMPLE WEIGHT

\% LOST IN WET SIEVING, CENTRIFUGING: 1.50

\begin{tabular}{|c|c|c|c|c|c|c|}
\hline & \multirow{3}{*}{$\begin{array}{c}\text { SIEVE } \\
\text { WEIGHT }\end{array}$} & & & \\
\hline \multirow{2}{*}{\begin{tabular}{|l|} 
SIZE \\
(phi) \\
-400 \\
\end{tabular}} & & \multirow{2}{*}{\multicolumn{3}{|c|}{ SIEVE ANALYSIS }} & & \\
\hline & & & & & SIZE (phi) & WEIGHT \\
\hline & 51.30 & \multicolumn{3}{|c|}{ SHAKING TIME $18 \mathrm{mlns}$} & -4.00 & 51.30 \\
\hline-3.50 & 50.70 & \multicolumn{3}{|c|}{ INTENSITY $\quad 6$} & -3.50 & 50.70 \\
\hline-3.00 & 13.60 & \multicolumn{3}{|c|}{ Inter/micro } & -3.00 & 13.60 \\
\hline-2.50 & 9.00 & \multirow{2}{*}{\multicolumn{3}{|c|}{ SEDIGRAPH ANALYSIS }} & -2.50 & 9.00 \\
\hline-2.00 & 8.83 & & & & -2.00 & 8.83 \\
\hline-1.50 & 12.60 & \multicolumn{3}{|c|}{ Wt. of fine fraction } & -1.50 & 12.60 \\
\hline-1.00 & 17.21 & & & 103.00 & -1.00 & 17.21 \\
\hline-0.50 & 24.74 & & & & -0.50 & 24.74 \\
\hline 0.00 & 33.53 & & & & 0.00 & 33.53 \\
\hline \multirow{3}{*}{$\begin{array}{l}1.00 \\
1.50\end{array}$} & \multirow{2}{*}{$\begin{array}{l}43.96 \\
55.11\end{array}$} & \multirow[b]{2}{*}{ 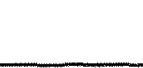 } & & & 0.50 & 43.96 \\
\hline & & & \multirow[b]{2}{*}{$\%$} & \multirow[b]{2}{*}{ WEIGHT } & 1.00 & 55.11 \\
\hline & 63.14 & SIZE $(\mathrm{phl})$ & & & 1.50 & 63.14 \\
\hline 2.00 & 53.97 & 2.00 & & 0.00 & 2.00 & 53.97 \\
\hline 2.50 & 38.22 & 2.50 & & 0.00 & 2.50 & 38.22 \\
\hline 3.00 & 25.30 & 3.00 & & 0.00 & 3.00 & 25.30 \\
\hline 3.50 & 12.49 & 3.50 & & 0.00 & 3.50 & 12.49 \\
\hline 4.00 & 5,85 & 4.00 & 0.00 & 0.00 & 4.00 & 5.85 \\
\hline 4.50 & 2.10 & 4.50 & 2.20 & 2.27 & 4.50 & 4.37 \\
\hline 5.00 & 0.34 & 5.00 & 5.60 & 5.77 & 5.00 & 6.11 \\
\hline PAN & 0.03 & 5.50 & 11.40 & 11.74 & 5.50 & 11.74 \\
\hline \multirow{2}{*}{$\begin{array}{c}\text { TOTAL } \\
\% \text { ERROR }\end{array}$} & 522.02 & 6.00 & 15.50 & 15.97 & 6.00 & 15.97 \\
\hline & \multirow[t]{2}{*}{0.30} & 6.50 & 16.60 & 17.10 & 6.50 & 17.10 \\
\hline & & 7.00 & 12.60 & 12.98 & 7.00 & 12.98 \\
\hline \multirow{9}{*}{$\vec{b}$} & & 7.50 & 10.20 & 10.51 & 7.50 & 10.51 \\
\hline & & 8.00 & 3.50 & 3.61 & 8.00 & 3.61 \\
\hline & & 8.50 & 1.20 & 1.24 & 8.50 & 1.24 \\
\hline & & 9.00 & 7.70 & 7.93 & 9.00 & 7.93 \\
\hline & & 9.50 & 2.90 & 2.99 & 9.50 & 2.99 \\
\hline & & 10.00 & 0.50 & 0.52 & 10.00 & 0.52 \\
\hline & & REST & 1.30 & 1.34 & REST & 1.34 \\
\hline & & \multirow{2}{*}{$\begin{array}{c}\text { TOTAL } \\
\times \text { ERROR } \\
\end{array}$} & 91.20 & \multirow{2}{*}{$\begin{array}{c}93.94 \\
8.80 \\
\end{array}$} & TOTAL & 615.93 \\
\hline & & & 8.80 & & & \\
\hline
\end{tabular}

\begin{tabular}{|c|c|c|c|}
\hline Class LImlts & Data & Frequency $\%$ & Cumulative $\%$ \\
\hline$-4,00$ & 51.30 & 8.33 & 8.33 \\
\hline-3.50 & 50.70 & 8.23 & 16.56 \\
\hline$-3,00$ & 13.60 & 2.21 & 18.77 \\
\hline-2.50 & 9.00 & 1.46 & 20.23 \\
\hline-2.00 & 8.83 & 1.43 & 21.66 \\
\hline-1.50 & 12.60 & 2.05 & 23.71 \\
\hline-1.00 & 17.21 & 2.79 & 26,50 \\
\hline-0.50 & 24.74 & 4.02 & 30.52 \\
\hline 0.00 & 33.53 & 5.44 & 35,96 \\
\hline 0.50 & 43.96 & 7.14 & 43,10 \\
\hline 1,00 & 55.11 & 8.95 & 52.05 \\
\hline 1.50 & 63.14 & 10.25 & 62.30 \\
\hline 2.00 & 53.97 & 8.76 & 71.06 \\
\hline 2.50 & 38.22 & 6.21 & 77.27 \\
\hline 3.00 & 25.30 & 4.11 & 81.37 \\
\hline 3.50 & 12,49 & 2.03 & 83.40 \\
\hline 4.00 & 5.85 & 0.95 & 84.35 \\
\hline 4.50 & 4.37 & 0.71 & 85.06 \\
\hline 5.00 & 6.11 & 0.99 & 86.05 \\
\hline 5.50 & 11.74 & 1.91 & 87.96 \\
\hline 6.00 & 15.97 & 2.59 & 90.55 \\
\hline 6.50 & 17.10 & 2.78 & 93.33 \\
\hline 7.00 & 12.98 & 2.11 & 95.43 \\
\hline 7.50 & 10.51 & 1.71 & 97.14 \\
\hline 8.00 & 3.61 & 0.59 & 97.73 \\
\hline 8.50 & 1.24 & 0.20 & 97.93 \\
\hline 9.00 & 7.93 & 1.29 & 99.21 \\
\hline 9,50 & 2.99 & 0,48 & 99.70 \\
\hline 10.00 & 0.52 & 0.08 & 99.78 \\
\hline$>10$ & 1.34 & 0.22 & 100.00 \\
\hline GRAVEL & 26.50 & SILT: & 13.37 \\
\hline SAND & 57.85 & CLAY & 2.27 \\
\hline
\end{tabular}


SAMPLENO: F1 2-7cm ANALYST: N.L.Bleakley DATE: $10 / 10 / 95$ DETAILS:

SIZE DISTRIBUTION HISTOGRAM:

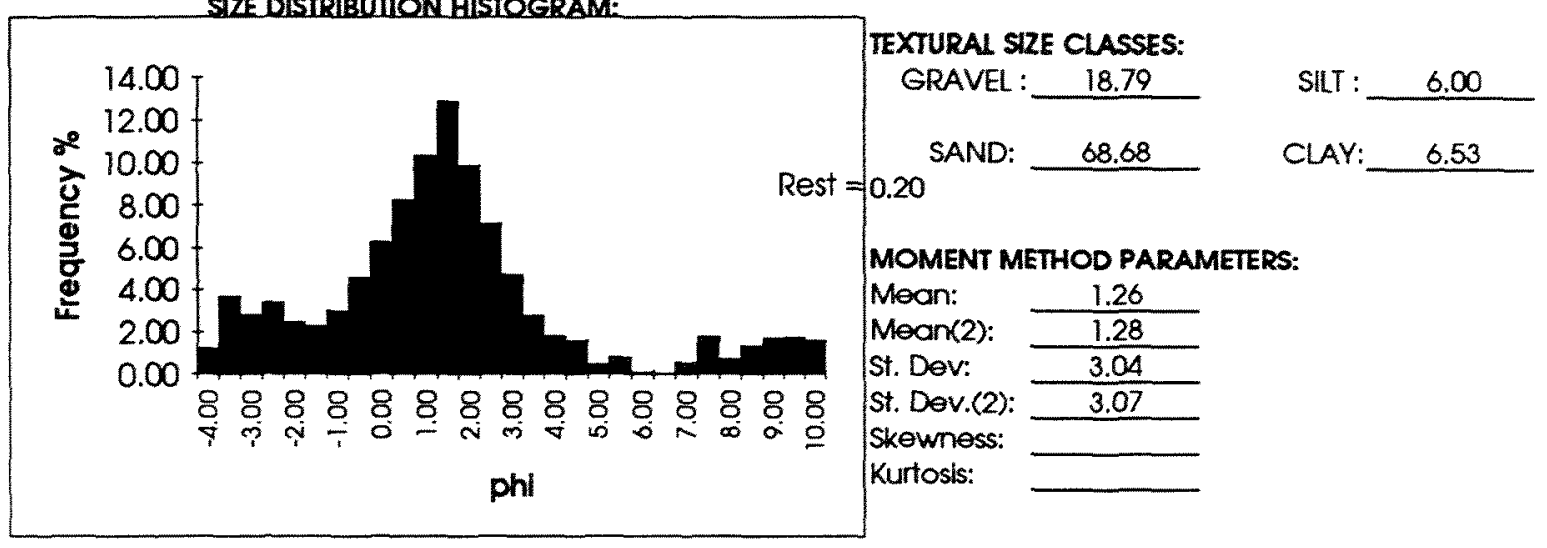

ERRORS:

\% lost in centrifuging and wet sieving \% lost in dry steving:

CUMULATVE FREQUENCY:

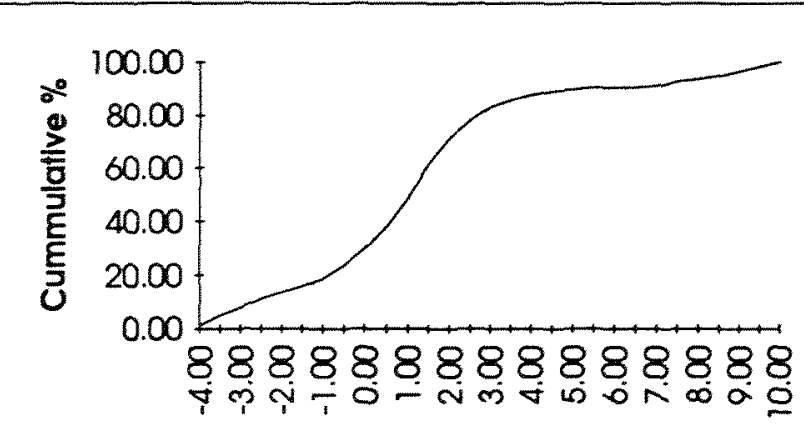

phi

DATA:

\begin{tabular}{|c|c|c|c|}
\hline Class Limits & Data & Freg. $\%$ & fumulative \\
\hline-4.00 & 8.15 & 1.22 & 1.22 \\
\hline-3.50 & 24.61 & 3.67 & 4.89 \\
\hline-3.00 & 18.70 & 2.79 & 7.68 \\
\hline-250 & 22.70 & 3.39 & 11.07 \\
\hline-200 & 16.52 & 2.47 & 13.54 \\
\hline-1.50 & 15.18 & 2.27 & 15.81 \\
\hline-1.00 & 19.97 & 2.98 & 18.79 \\
\hline-0.50 & 30.70 & 4.58 & 23.37 \\
\hline 0.00 & 42.12 & 6.29 & 29.66 \\
\hline 0.50 & 55.37 & 8.27 & 37.93 \\
\hline 1.00 & 69.36 & 10.36 & 48.29 \\
\hline 1.50 & 86.32 & 12.89 & 61.18 \\
\hline 200 & 66.06 & 9.86 & 71.04 \\
\hline 2.50 & 47.78 & 7.13 & 78.18 \\
\hline 3.00 & 31.59 & 4.72 & 82.89 \\
\hline 3.50 & 18.53 & 2.77 & 85.66 \\
\hline 4.00 & 12.12 & 1.81 & 87.47 \\
\hline 4.50 & 10.53 & 1.57 & 89.04 \\
\hline 5.00 & 3.29 & 0.49 & 89.53 \\
\hline 5.50 & 5.40 & 0.81 & 90.34 \\
\hline 6.00 & 0.48 & 0.07 & 90.41 \\
\hline 6.50 & 0.00 & 0.00 & 90.41 \\
\hline 7.00 & 3.65 & 0.55 & 90.95 \\
\hline 7.50 & 11.91 & 1.78 & 92.73 \\
\hline 8.00 & 4.92 & 0.74 & 93.47 \\
\hline 8.50 & 8.89 & 1.33 & 94.80 \\
\hline 9.00 & 11.28 & 1.68 & 96.48 \\
\hline 9.50 & 11.59 & 1.73 & 98.21 \\
\hline 10.00 & 10.64 & 1.59 & 99.80 \\
\hline$>10$ & 1.34 & 0.20 & 100.00 \\
\hline
\end{tabular}


GRAIN SIZE ANALYSIS DATA SHEET

SAMPLE NO: F12-7cm ANALYST: N.LBleakleY DATE: $10 / 10 / 95$ DETAILS:

BEAKER WGT $\quad 167.40$

SAMPLE WEIGHT

784.90

WET SIEVE DIAMETER:

6oum

\% LOST IN WET SIEVING, CENIRIFUGING: $\quad 4.60$

FINE FRACIION

COARSE FRACTION

BEAK. WGT 167.45 COARSE FRAC + BEAKER

DRY WG 326.26 COARSE WEIGH 589.4

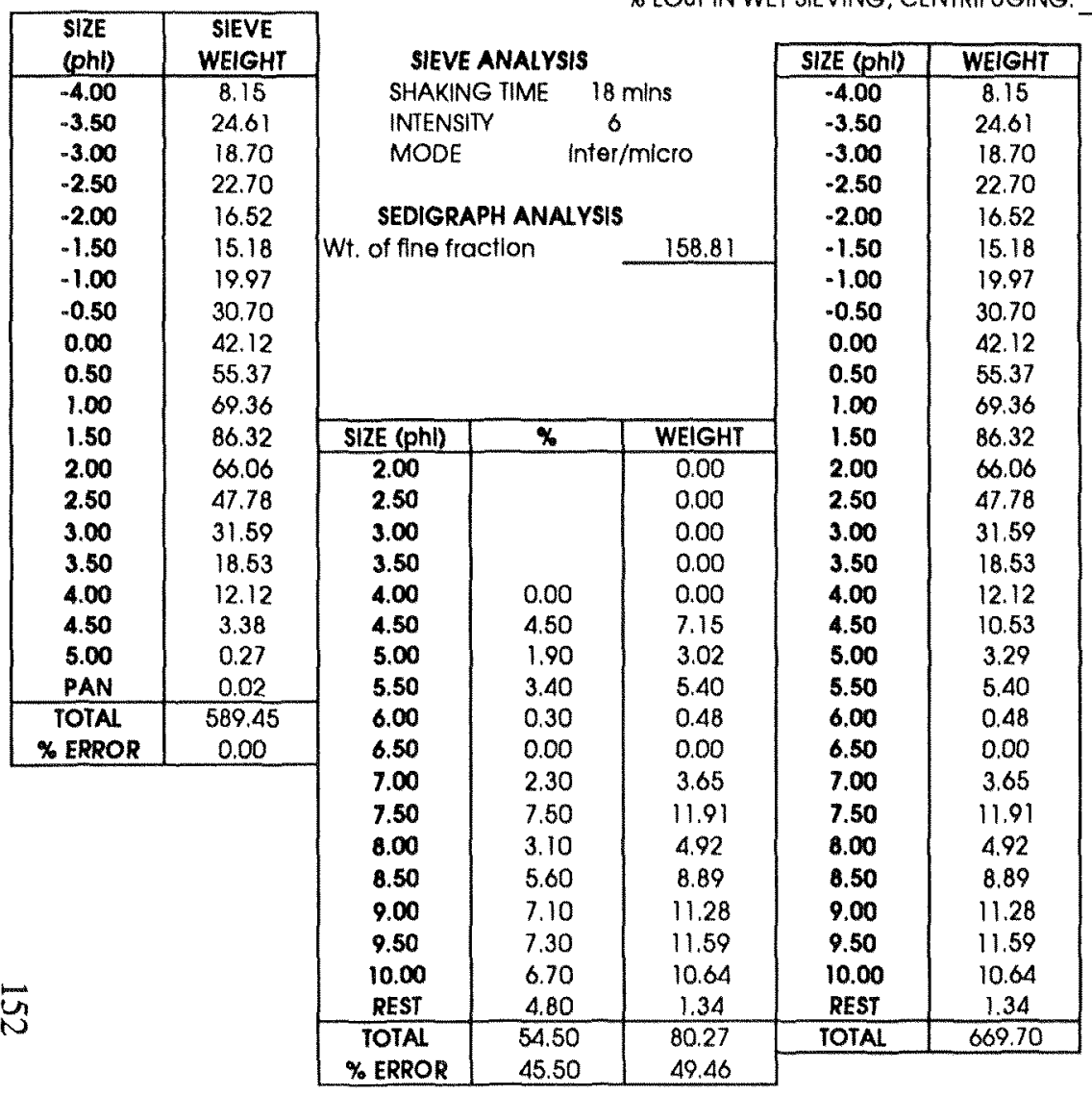

\begin{tabular}{|c|c|c|c|}
\hline Class LImits & & & \\
\hline-4.00 & Data & Frequency $\%$ & Cumulative $\%$ \\
\hline-3.50 & 8.15 & 1.22 & 1.22 \\
\hline-3.00 & 24.61 & 3.67 & 4.89 \\
\hline-2.50 & 18.70 & 2.79 & 7,68 \\
\hline-2.00 & 22.70 & 3.39 & 11.07 \\
\hline-1.50 & 16.52 & 2.47 & 13.54 \\
\hline$-1,00$ & 15.18 & 2.27 & 15.81 \\
\hline-0.50 & 19.97 & 2.98 & 18.79 \\
\hline 0.00 & 30.70 & 4.58 & 23.37 \\
\hline 0.50 & 42.12 & 6.29 & 29.66 \\
\hline 1.00 & 55,37 & 8.27 & 37,93 \\
\hline 1.50 & 69.36 & 10.36 & 48.29 \\
\hline 2.00 & 86.32 & 12.89 & 61.18 \\
\hline 2.50 & 66.06 & 9.86 & 71.04 \\
\hline 3.00 & 47.78 & 7.13 & 78.18 \\
\hline 3.50 & 31.59 & 4.72 & 82.89 \\
\hline 4.00 & 18.53 & 2.77 & 85.66 \\
\hline 4.50 & 12.12 & 1.81 & 87.47 \\
\hline 5.00 & 10.53 & 1.57 & 89.04 \\
\hline 5.50 & 3.29 & 0.49 & 89.53 \\
\hline 6.00 & 5.40 & 0.81 & 90.34 \\
\hline 6.50 & 0.48 & 0.07 & 90.41 \\
\hline 7.00 & 0.00 & 0.00 & 90.41 \\
\hline 7.50 & 3.65 & 0.55 & 90.95 \\
\hline 8.00 & 11.91 & 1.78 & 92.73 \\
\hline 8.50 & 4.92 & 0.74 & 93.47 \\
\hline 9.00 & 8.89 & 1.33 & 94.80 \\
\hline 9.50 & 11.28 & 1.68 & 96.48 \\
\hline 10.00 & 11.59 & 1.73 & 98.21 \\
\hline$>10$ & 10.64 & 1.59 & 99.80 \\
\hline \multirow{2}{*}{\multicolumn{4}{|c|}{100.00}} \\
\hline & & SILT : & 6.00 \\
\hline SAND: & 68,68 & CLAY: & 6.53 \\
\hline
\end{tabular}


SAMPLENO: FI $7-17 \mathrm{~cm}$ ANALYST: N.L.Bleakley DATE: $7 / 7 / 95$

WET SIEVE DIAMETER:

SIZE DISTRIBUTION HISTOGRAM

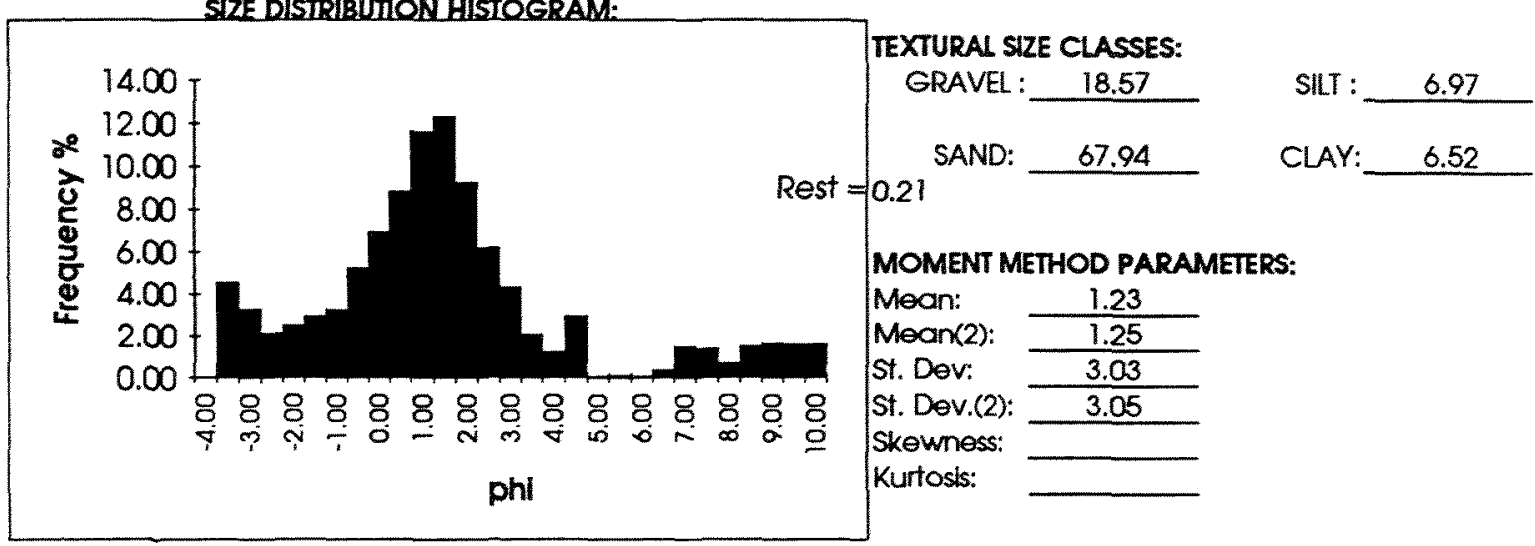

ERRORS:

\% lost in centrifuging and wet sieving

$\%$ lost in dry sieving:

CUMULATIVE FREQUENCY:

DATA:

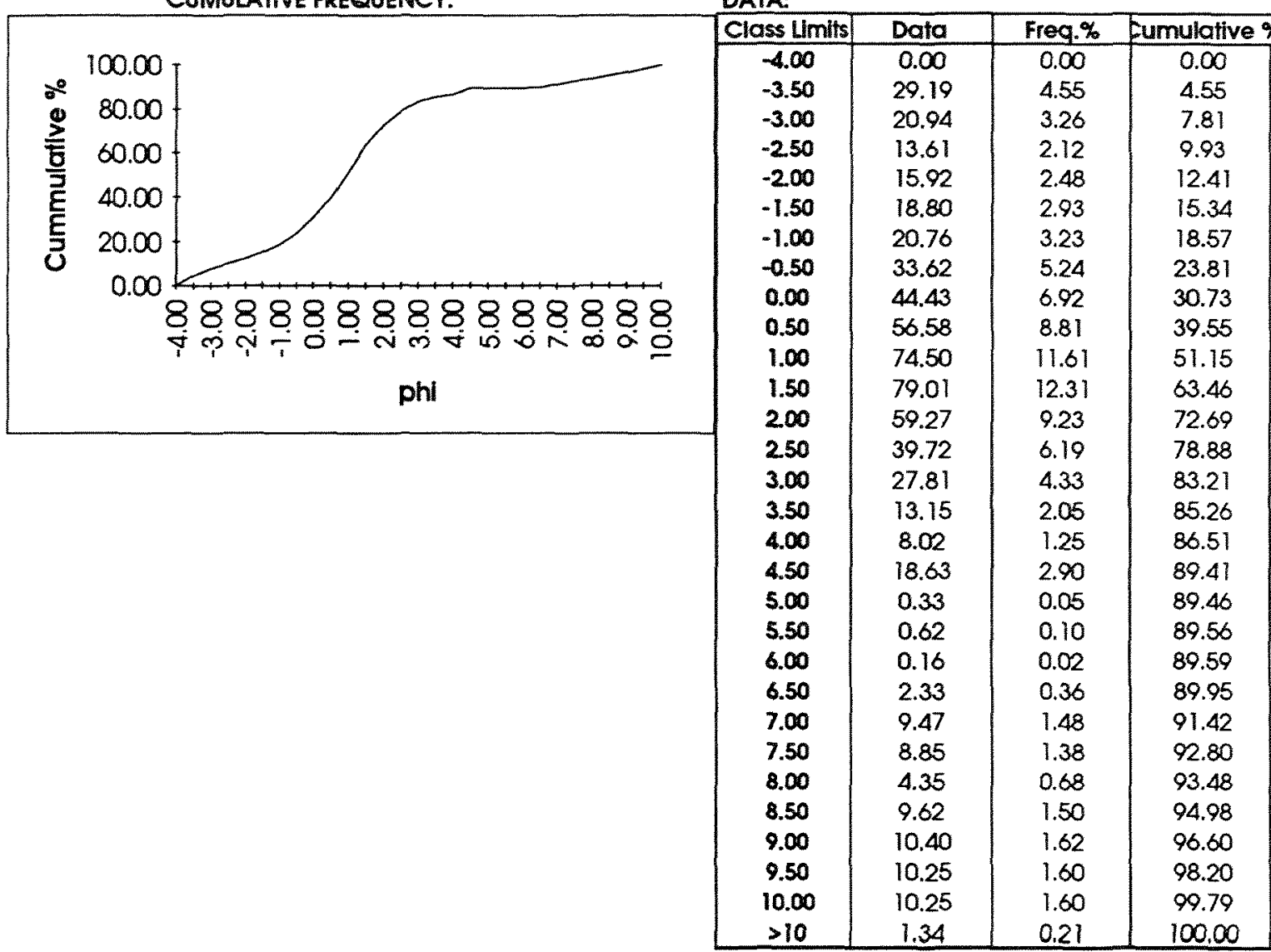


SAMPLE NO: $117-17 \mathrm{~cm}$ ANALYSI: N.L.BleakleY DATE: $10 / 10 / 95$

BEAKER WGT 252.78

SAMPLE WEIGHT 769.96

FINE FRACTION

COARSE FRACTION

BEAK. WGT 167.40 COARSE FRAC + BEAKER : $\quad 899.77$

WET SIEVE DIAMETER:

60um

FINE FRACIION WG $\frac{270.48}{155.24}$

TOTAL SAMPLE WEIGH

\% LOST IN WET SIEVING CENTRIFUGING: 700

\begin{tabular}{|c|c|c|c|c|c|c|}
\hline \multirow{2}{*}{$\begin{array}{l}\text { SIZE } \\
\text { (phI) }\end{array}$} & \multirow{2}{*}{$\begin{array}{c}\text { SIEVE } \\
\text { WEIGHT }\end{array}$} & \multirow{2}{*}{\multicolumn{2}{|c|}{ SIEVE ANALYSIS }} & & & \\
\hline & & & & & SIZE (phi) & WEIGHT \\
\hline-4.00 & 0.00 & \multicolumn{3}{|c|}{ SHAKING TIME $18 \mathrm{mins}$} & $-4,00$ & 0.00 \\
\hline-3.50 & 29.19 & \multicolumn{3}{|c|}{ INTENSITV 6} & -3.50 & 29.19 \\
\hline .3 .00 & 20.94 & \multicolumn{3}{|c|}{ MODE Inter/micro } & -3.00 & 20.94 \\
\hline .2 .50 & 13.61 & & & & -2.50 & 13.61 \\
\hline-2.00 & 15.92 & \multicolumn{3}{|c|}{ SEDIGRAPH ANALYSIS } & -2.00 & 15.92 \\
\hline-1.50 & 18.80 & \multicolumn{2}{|c|}{ Wt. of fine fraction } & 155.24 & -1.50 & 18.80 \\
\hline .1 .00 & 20.76 & & & & -1.00 & 20.76 \\
\hline-0.50 & 33.62 & & & & -0.50 & 33.62 \\
\hline 0.00 & 44.43 & & & & 0.00 & 44.43 \\
\hline 0.50 & 58.58 & & & & 0.50 & 56.58 \\
\hline 1.00 & 74.50 & & & & 1.00 & 74.50 \\
\hline 1.50 & 79.01 & SIZE (phi) & $x_{0}$ & WEIGHT & 1.50 & 79.01 \\
\hline 2.00 & 59.27 & 2.00 & & 0.00 & 2.00 & 59.27 \\
\hline 2.50 & 39.72 & 2.50 & & 0.00 & 2.50 & 39.72 \\
\hline 3.00 & 27.81 & 3.00 & & 0.00 & 3.00 & 27.81 \\
\hline 3.50 & 13.15 & 3.50 & & 0.00 & 3.50 & 13.15 \\
\hline 4.00 & 8.02 & 4.00 & 0.00 & 0.00 & 4.00 & 8.02 \\
\hline 4.50 & 3.26 & 4.50 & 9.90 & 15.37 & 4.50 & 18.63 \\
\hline 5.00 & 0.33 & 5.00 & 0.00 & 0.00 & 5.00 & 0.33 \\
\hline PAN & 0.08 & 5.50 & 0.40 & 0.62 & 5.50 & 0.62 \\
\hline TOTAL & 559,00 & 6.00 & 0.10 & 0.16 & 6.00 & 0.16 \\
\hline \multirow{2}{*}{\multicolumn{2}{|c|}{ * ERROR }} & 6.50 & 1.50 & 2.33 & 6.50 & 2.33 \\
\hline & & 7.00 & 6.10 & 9,47 & 7.00 & 9.47 \\
\hline & & 7.50 & 5.70 & 8.85 & 7.50 & 8.85 \\
\hline & & 8.00 & 2.80 & 4.35 & 8.00 & 4.35 \\
\hline & & 8.50 & 6.20 & 9.62 & 8.50 & 9.62 \\
\hline & & 9.00 & 6.70 & 10.40 & 9.00 & 10.40 \\
\hline & & 9.50 & 6.60 & 10.25 & 9.50 & 10.25 \\
\hline & & 10.00 & 6.60 & 10.25 & 10.00 & 10.25 \\
\hline & & REST & 6.80 & 1.34 & REST & 1.34 \\
\hline & & TOTAL & 59.40 & 83.00 & TOTAL & 641.92 \\
\hline & & $\%$ ERROR & 40.60 & 46.54 & & \\
\hline
\end{tabular}

\begin{tabular}{|c|c|c|c|}
\hline Class Limits & & & \\
\hline$-4,00$ & Data & Frequency $\%$ & Cumulative $\%$ \\
\hline-3.50 & 0.00 & 0.00 & 0.00 \\
\hline-3.00 & 29.19 & 4.55 & 4.55 \\
\hline-2.50 & 20.94 & 3.26 & 7.81 \\
\hline-2.00 & 13.61 & 2.12 & 9.93 \\
\hline-1.50 & 15.92 & 2.48 & 12.41 \\
\hline-1.00 & 18.80 & 2.93 & 15.34 \\
\hline-0.50 & 20.76 & 3.23 & 18.57 \\
\hline 0.00 & 33.62 & 5.24 & 23.81 \\
\hline 0.50 & 44.43 & 6.92 & 30.73 \\
\hline 1.00 & 56.58 & 8.81 & 39.55 \\
\hline 1.50 & 74.50 & 11.61 & 51.15 \\
\hline 2.00 & 79.01 & 12.31 & 63.46 \\
\hline 2.50 & 59.27 & 9.23 & 72,69 \\
\hline 3.00 & 39.72 & 6.19 & 78.88 \\
\hline 3.50 & 27.81 & 4.33 & 83.21 \\
\hline 4.00 & 13.15 & 2.05 & 85.26 \\
\hline 4.50 & 8.02 & 1.25 & 86.51 \\
\hline 5.00 & 18.63 & 2.90 & 89.41 \\
\hline 5.50 & 0.33 & 0.05 & 89.46 \\
\hline 6.00 & 0.62 & 0.10 & 89.56 \\
\hline 6.50 & 0.16 & 0.02 & 89.59 \\
\hline 7.00 & 2.33 & 0.36 & 89.95 \\
\hline 7.50 & 9.47 & 1.48 & 91.42 \\
\hline 8.00 & 8.85 & 1.38 & 92.80 \\
\hline 8.50 & 4.35 & 0.68 & 93.48 \\
\hline 9.00 & 9,62 & 1.50 & 94.98 \\
\hline 9.50 & 10.40 & 1.62 & 96.80 \\
\hline 10.00 & 10.25 & 1.60 & 98,20 \\
\hline$>10$ & 10.25 & 1.60 & 99.79 \\
\hline \multirow{2}{*}{ GRAVEL } & 1.34 & 0.21 & 100.00 \\
\hline & 18.57 & SILT: & 6.97 \\
\hline SAND: & 67.94 & CLAY: & 6.52 \\
\hline
\end{tabular}


SAMPLENO: F1 27-37 ANALYST: N.LBleakley DATE: 10/10/95

WET SIEVE DIAMETER: $\quad$ Goum

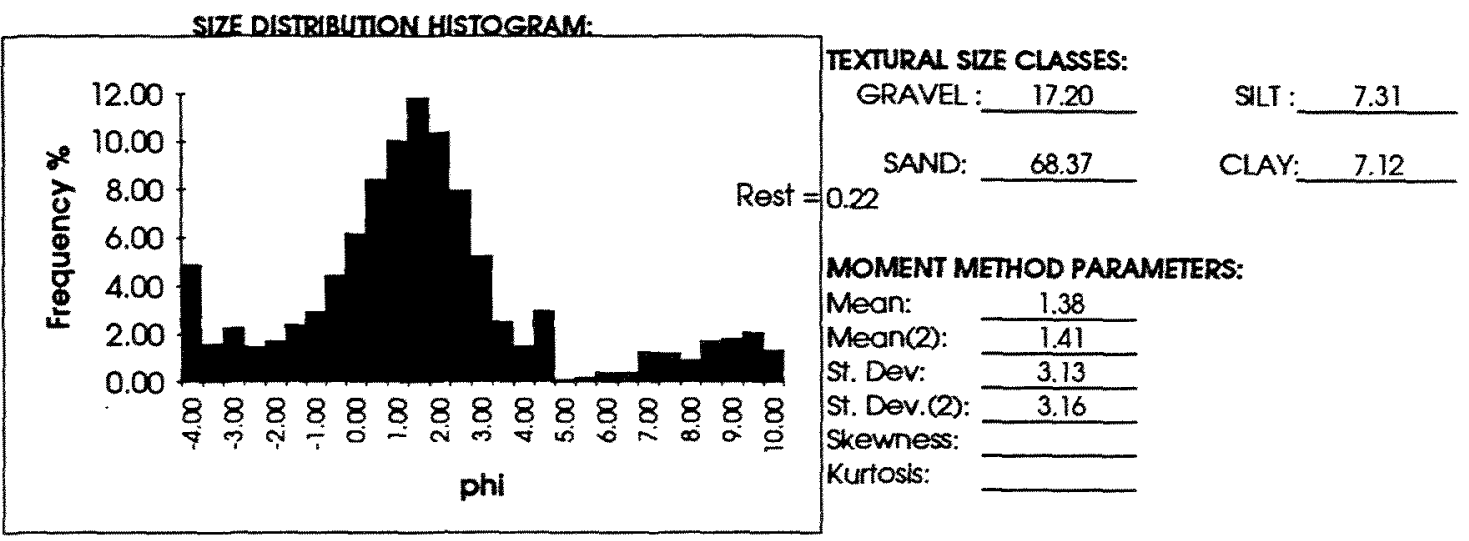

ERRORS:

\% lost in centrifuging and wet sievin \% lost in dry sieving:

CUMULATIVE FREQUENCY:

\begin{tabular}{|c|c|c|c|c|}
\hline \multirow{31}{*}{ 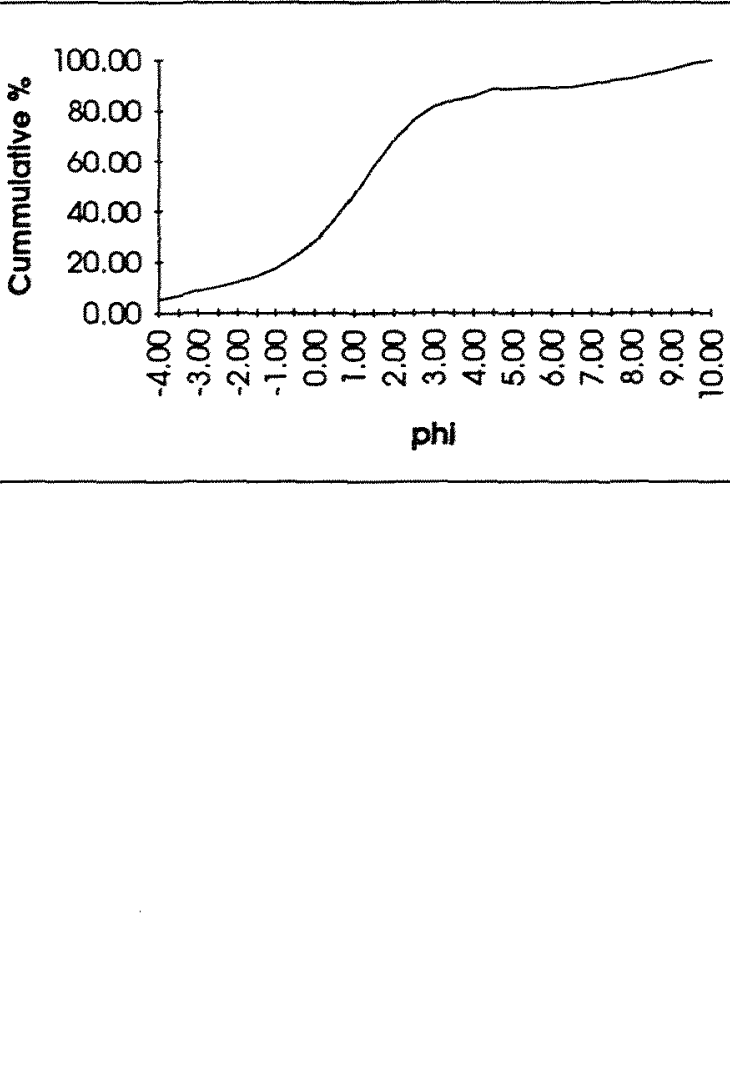 } & Class IImits & Data & Frog \% & Eumulotive: \\
\hline & $-4 \mathrm{~m}$ & 2000 & 4.47 & 487 \\
\hline & $\begin{array}{r}-3,00 \\
-3,50\end{array}$ & $\begin{array}{c}29.04 \\
960\end{array}$ & 4.81 & $\begin{array}{l}4.01 \\
6.48\end{array}$ \\
\hline & -3.00 & 13.46 & 2.25 & 8.73 \\
\hline & -2.50 & 8.76 & 1.47 & 10.19 \\
\hline & -2.00 & 10.21 & 1.71 & 11.90 \\
\hline & -1.50 & 14.28 & 2.39 & 14.29 \\
\hline & -1.00 & 17.38 & 2.91 & 17.20 \\
\hline & -0.50 & 26.54 & 4.44 & 21.63 \\
\hline & 0.00 & 36.85 & 6.16 & 27.80 \\
\hline & 0.50 & 50.19 & 8.40 & 36.19 \\
\hline & 1.00 & 60.04 & 10.04 & 46.24 \\
\hline & 1.50 & 70.59 & 11.81 & 58.04 \\
\hline & 2.00 & 61.89 & 10.35 & 68.40 \\
\hline & 2.50 & 47.60 & 7.96 & 76.36 \\
\hline & 3.00 & 31.18 & 5.22 & 81.57 \\
\hline & 3.50 & 14.89 & 2.49 & 84.06 \\
\hline & 4.00 & 8.99 & 1.50 & 85.57 \\
\hline & 4.50 & 17.81 & 2.98 & 88.55 \\
\hline & 5.00 & 0.40 & 0.07 & 88.61 \\
\hline & 5.50 & 0.92 & 0.15 & 88.77 \\
\hline & 6.00 & 229 & 0.38 & 89.15 \\
\hline & 6.50 & 2.29 & 0.38 & 89.53 \\
\hline & 7.00 & 7.48 & 1.25 & 90.79 \\
\hline & 7.50 & 7.18 & 1.20 & 91.99 \\
\hline & 8.00 & 5.34 & 0.89 & 92.88 \\
\hline & 8.50 & 10.23 & 1.71 & 94.59 \\
\hline & 9.00 & 10.84 & 1.81 & 96.40 \\
\hline & 9.50 & 12.22 & 2.04 & 98.45 \\
\hline & 10.00 & 7.94 & 1.33 & 99.78 \\
\hline & $>10$ & 1.34 & 0.22 & 100.00 \\
\hline
\end{tabular}


SAMPLE NO: F1 27-37 ANALYST: N.L.Bleakley DATE: 10/10/95

BEAKER WGT $\quad \$ 07.40$

SAMPLE WEIGH

706.40

DIAMETER: 60um

\% lost In dissagragation, wet sleveing and centrlfugh 5.20

FINE FRACTION

COARSE FRACIION

COARSE FRAC + BEAKER :

COC + BEAKER: $\frac{770.07}{51720}$

$\frac{5.47}{152.69}$ COARSE WEIGH $\quad 517.20$ FINE FRACIION WG

\begin{tabular}{|c|c|}
\hline $\begin{array}{c}\text { SIZE } \\
\text { (Phi) }\end{array}$ & $\begin{array}{c}\text { SIEVE } \\
\text { WEIGHT }\end{array}$ \\
\hline $\mathbf{- 4 . 0 0}$ & 29.09 \\
$\mathbf{- 3 . 5 0}$ & 9.62 \\
$\mathbf{- 3 . 0 0}$ & 13.46 \\
$\mathbf{- 2 . 5 0}$ & 8.76 \\
$\mathbf{- 2 . 0 0}$ & 10.21 \\
$\mathbf{- 1 . 5 0}$ & 14.28 \\
$\mathbf{- 1 . 0 0}$ & 17.38 \\
$\mathbf{- 0 . 5 0}$ & 26.54 \\
$\mathbf{0 . 0 0}$ & 36.85 \\
$\mathbf{0 . 5 0}$ & 50.19 \\
1.00 & 60.04 \\
$\mathbf{1 . 5 0}$ & 70.59 \\
$\mathbf{2 . 0 0}$ & 61.89 \\
$\mathbf{2 . 5 0}$ & 47.60 \\
$\mathbf{3 . 0 0}$ & 31.18 \\
$\mathbf{3 . 5 0}$ & 14.89 \\
$\mathbf{4 . 0 0}$ & 8.99 \\
$\mathbf{4 . 5 0}$ & 3.00 \\
$\mathbf{5 . 0 0}$ & 0.40 \\
PAN & 0.14 \\
\hline TOTAL & 515.10 \\
$\mathbf{\%}$ ERROR & 11.28 \\
\hline
\end{tabular}

$\breve{n}$

SIEVE ANALYSIS

SHAKING TIME $18 \mathrm{mins}$

INTENSITY 6

MODE

6

\begin{tabular}{|c|c|}
\hline SIZE (phi) & WEIGHT \\
\hline-4.00 & 29.09 \\
-3.50 & 9.62 \\
-3.00 & 13.46 \\
\hline
\end{tabular}

$\begin{array}{ll}-3.50 & 9.62\end{array}$

$-3.00 \quad 13.46$

$\begin{array}{ll}-2.50 & 8.76\end{array}$

SEDIGRAPH ANALYSIS

Wt. of fline fraction $\quad 152.69$

\begin{tabular}{l|l}
-2.00 & 10.21 \\
-1.50 & 14.28
\end{tabular}

$-1.00$

$-0.50$

$0.00 \quad 36.85$

$0.50 \quad 50.19$
1.00

1.00

$1.50 \quad 70.59$

\begin{tabular}{|c|c|c|c|}
\hline SIZE (phi) & $\bar{x}_{0}$ & WEIGHT & 1.50 \\
\hline 2.00 & & 0.00 & 2.00 \\
\hline
\end{tabular}

2.50

3.00

3.50

4.00

4.00

4.50

5.50

\begin{tabular}{l|l}
0.70 & 14.81 \\
0.00 & 0.00
\end{tabular}

$\begin{array}{ll}0.60 & 0.92 \\ 1.50\end{array}$

\begin{tabular}{l|l|l}
6.00 & 1.50 & 2.29
\end{tabular}

6.50

7.00

7.50

8.00
8.50

8.50
9.00

9.50

10.00

\begin{tabular}{l|l}
1.50 & 2.29
\end{tabular}

\begin{tabular}{l|l}
4.90 & 7.48 \\
4.70 & 7.18
\end{tabular}

\begin{tabular}{l|l}
4.70 & 7.18 \\
3.50 & 5.34
\end{tabular}

\begin{tabular}{l|l}
3.50 & 5.34 \\
6.70 & 10.23 \\
7.10 & 10.84
\end{tabular}

$7.10 \quad 10.84$

8.00

$\begin{array}{ll}5.20 & 7.94\end{array}$

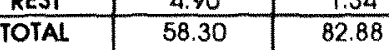

TOTAL

4170

\begin{tabular}{|c|c|c|c|}
\hline Closs LImits & & & \\
\hline-4.00 & Data & Frequency $\%$ & Cumulative $x$ \\
\hline-3.50 & 29,09 & 4.87 & 4.87 \\
\hline-3.00 & 9.62 & 1.61 & 6.48 \\
\hline-2.50 & 13.46 & 2.25 & 8.73 \\
\hline-2.00 & 8.76 & 1.47 & 10.19 \\
\hline-1.50 & 10.21 & 1.71 & 11.90 \\
\hline-1.00 & 14.28 & 2.39 & 14.29 \\
\hline-0.50 & 17.38 & 2.91 & 17.20 \\
\hline 0.00 & 26.54 & 4.44 & 21.63 \\
\hline 0.50 & 36.85 & 6.16 & 27.80 \\
\hline 1.00 & 50.19 & 8.40 & 36.19 \\
\hline 1.50 & 60.04 & 10.04 & 46.24 \\
\hline 2.00 & 70.59 & 11.81 & 58.04 \\
\hline 2.50 & 61.89 & 10.35 & 68.40 \\
\hline 3.00 & 47,60 & 7.96 & 76.36 \\
\hline 3.50 & 31.18 & 5.22 & 81.57 \\
\hline 4.00 & 14.89 & 2.49 & 84.06 \\
\hline 4.50 & 8.99 & 1.50 & 85.57 \\
\hline 5.00 & 17.81 & 2.98 & 88.55 \\
\hline 5.50 & 0.40 & 0.07 & 88.61 \\
\hline 6.00 & 0.92 & 0.15 & 88.77 \\
\hline 6.50 & 2.29 & 0.38 & 89.15 \\
\hline 7.00 & 2.29 & 0.38 & 89.53 \\
\hline 7.50 & 7.48 & 1.25 & 90.79 \\
\hline 8.00 & 7.18 & 1.20 & 91.99 \\
\hline 8.50 & 5.34 & 0.89 & 92.88 \\
\hline 9.00 & 10.23 & 1.71 & 94.59 \\
\hline 9.50 & 10.84 & 1.81 & 96.40 \\
\hline 10.00 & 12.22 & 2.04 & 98.45 \\
\hline$>10$ & 7.94 & 1.33 & 99.78 \\
\hline \multirow[b]{2}{*}{ GRAVEL: } & 1.34 & 0.22 & 100,00 \\
\hline & 17.20 & SILT: & 7.31 \\
\hline SAND: & 68.37 & CLAY & 7.12 \\
\hline
\end{tabular}


SAMPLENO: II B 13-23cr ANALYST: N.L.Bleakley DATE: 10/10/95

BEAKER WGT: $338.61 \quad$ SAMPLE WGI: $\quad 784.10$

WET SEVE DIAMETER: $\quad$ GOUM

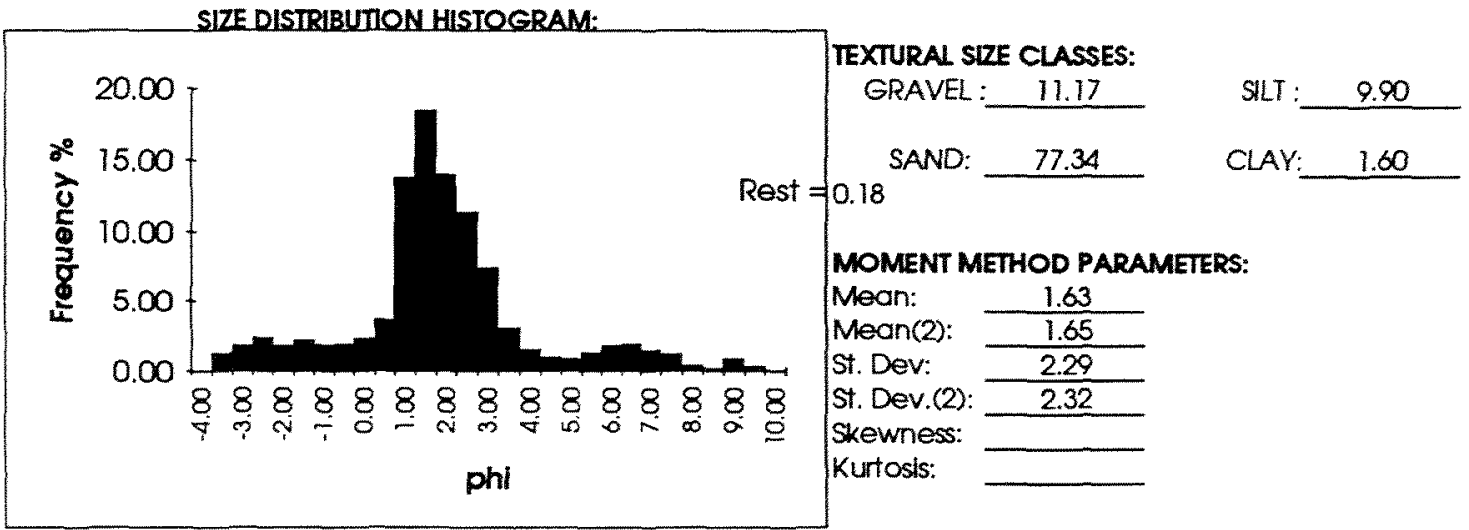

$\%$ lost in centrifuging and wet sevin

$\%$ lost in dry seving:

6.40

DATA:

\begin{tabular}{|c|c|c|c|c|}
\hline & Class Limits & Dafa & Freq\% & Eumulative" \\
\hline 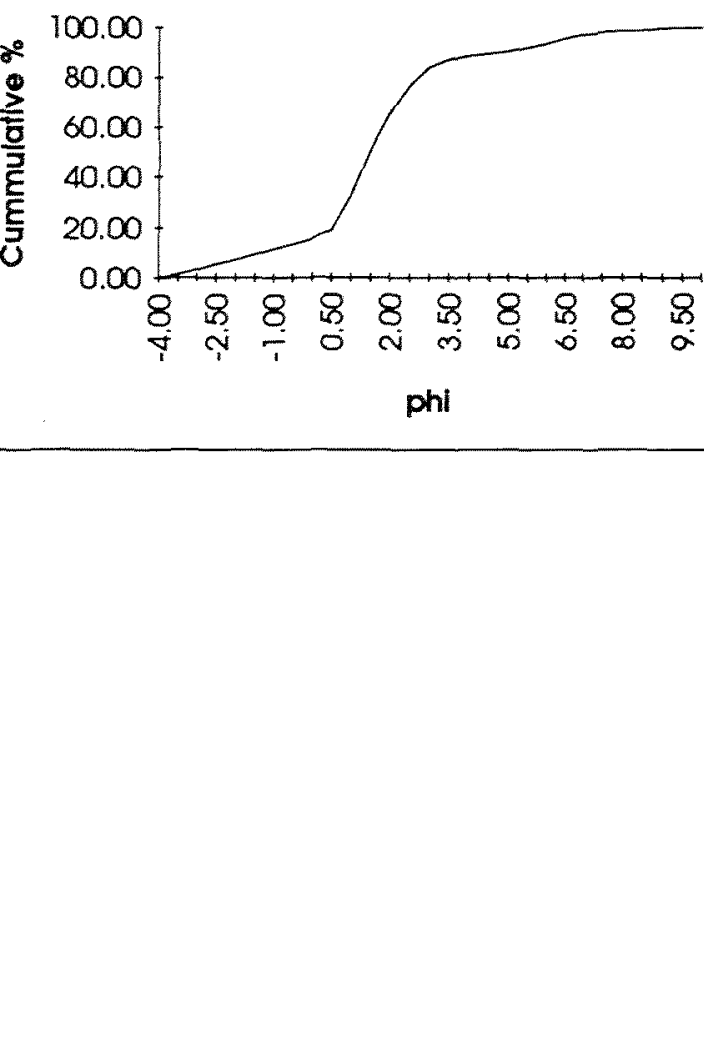 & \begin{tabular}{|c|}
-4.00 \\
-3.50 \\
-3.00 \\
-2.50 \\
-2.00 \\
-1.50 \\
-1.00 \\
-0.50 \\
0.00 \\
0.50 \\
1.00 \\
1.50 \\
2.00 \\
2.50 \\
3.00 \\
3.50 \\
4.00 \\
4.50 \\
5.00 \\
5.50 \\
6.00 \\
6.50 \\
7.00 \\
7.50 \\
8.00 \\
8.50 \\
9.00 \\
9.50 \\
10.00 \\
$>10$ \\
\end{tabular} & $\begin{array}{l}0.00 \\
8.90 \\
12.80 \\
16.90 \\
13.13 \\
15.81 \\
13.56 \\
13.95 \\
16.42 \\
26.15 \\
99.97 \\
134.23 \\
101.71 \\
82.37 \\
53.70 \\
22.09 \\
11.14 \\
7.22 \\
6.40 \\
9.52 \\
12.94 \\
13.86 \\
10.52 \\
8.51 \\
2.92 \\
1.00 \\
6.43 \\
2.42 \\
0.42 \\
1.34\end{array}$ & $\begin{array}{l}0.00 \\
1.23 \\
1.76 \\
2.33 \\
1.81 \\
2.18 \\
1.87 \\
1.92 \\
2.26 \\
3.60 \\
13.76 \\
18.48 \\
14.00 \\
11.34 \\
7.39 \\
3.04 \\
1.53 \\
0.99 \\
0.88 \\
1.31 \\
1.78 \\
1.91 \\
1.45 \\
1.17 \\
0.40 \\
0.14 \\
0.88 \\
0.33 \\
0.06 \\
0.18\end{array}$ & \begin{tabular}{|c|}
0.00 \\
1.23 \\
2.99 \\
5.31 \\
7.12 \\
9.30 \\
11.17 \\
13.09 \\
15.35 \\
18.95 \\
32.71 \\
51.19 \\
65.20 \\
76.54 \\
83.93 \\
86.97 \\
88.51 \\
89.50 \\
90.38 \\
91.69 \\
93.47 \\
95.38 \\
96.83 \\
98.00 \\
98.40 \\
98.54 \\
99.42 \\
99.76 \\
99.82 \\
100.00 \\
\end{tabular} \\
\hline
\end{tabular}


SAMPLE NO:T] B $13-23 \mathrm{~cm}$ ANALYST: N.L.Bleqkley DATE: $10 / 10 / 95$

BEAKER WGT

SAMPLE WEIGHT $\quad 784.10$

FINE FRACTION

COARSE FRACTION

BEAK. WGT 338.61 COARSE FRAC + BEAKER: 988.94

DRY WGT 270.48 COARSE WEIGH 651.85

WET SIEVE DIAMETER:

boum

FINE FRACTIONWG

83.47

TOIAL SAMPLE WEIGHT 735.32

\% LOST IN WET SIEVING, CENTRIFUGING: $\quad 6.40$

\begin{tabular}{|c|c|c|c|c|c|c|}
\hline SIZE & SIEVE & & & & & \\
\hline (phl) & WEIGHT & SIEVE & IALYSIS & & SIZE (phi) & WEIGHT \\
\hline-4.00 & 0.00 & SHAKIN & IME & & -4.00 & 0.00 \\
\hline-3.50 & 8.90 & INTENS & & & -3.50 & 8.90 \\
\hline-3.00 & 12.80 & MODE & & hicro & -3.00 & 12.80 \\
\hline-2.50 & 16.90 & & & & -2.50 & 16.90 \\
\hline-2.00 & 13.13 & SEDIGR/ & ANAL' & & -2.00 & 13.13 \\
\hline-1.50 & 15.81 & Wt. of fine fro & & 83.47 & -1.50 & 15.81 \\
\hline-1.00 & 13.56 & & & & -1.00 & 13.56 \\
\hline-0.50 & 13.95 & & & & -0.50 & 13.85 \\
\hline 0.00 & 16.42 & & & & 0.00 & 16.42 \\
\hline 0.50 & 26.15 & & & & 0.50 & 26.15 \\
\hline 1,00 & 99.97 & & & & 1.00 & 99.97 \\
\hline 1.50 & 134.23 & SIZE (phi) & $x_{0}$ & WEIGHT & 1.50 & 134.23 \\
\hline 2.00 & 101.71 & 2.00 & & 0.00 & 2.00 & 101.71 \\
\hline 2.50 & 82.37 & 2.50 & & 0.00 & 2.50 & 82.37 \\
\hline 3.00 & 53.70 & 3.00 & & 0.00 & 3.00 & 53.70 \\
\hline 3.50 & 22.09 & 3.50 & & 0.00 & 3.50 & 22.09 \\
\hline 4.00 & 11.14 & 4.00 & 0.00 & 0.00 & 4.00 & 11.14 \\
\hline 4.50 & 5.38 & 4.50 & 2.20 & 1.84 & 4.50 & 7.22 \\
\hline 5.00 & 1.73 & 5.00 & 5.60 & 4.67 & 5.00 & 6.40 \\
\hline PAN & 0.39 & 5.50 & 11.40 & 9.52 & 5.50 & 9.52 \\
\hline TOTAL & 650.33 & 6.00 & 15.50 & 12.94 & 6.00 & 12.94 \\
\hline$\%$ ERROR & 13.00 & 6.50 & 16.60 & 13.86 & 6.50 & 13.86 \\
\hline & & 7.00 & 12.60 & 10.52 & 7.00 & 10.52 \\
\hline & & 7.50 & 10.20 & 8.51 & 7.50 & 8.51 \\
\hline & & B.00 & 3.50 & 2.92 & 8.00 & 2.92 \\
\hline & & 8.50 & 1.20 & 1.00 & 8.50 & 1.00 \\
\hline & & 9.00 & 7.70 & 6.43 & 9.00 & 6.43 \\
\hline & & 9.50 & 2.90 & 2,42 & 9.50 & 2.42 \\
\hline & & 10.00 & 0.50 & 0.42 & 10.00 & 0.42 \\
\hline & & REST & 1.30 & 1,34 & REST & 1.34 \\
\hline & & TOTAL & 91.20 & 76.38 & TOTAL & 726.32 \\
\hline & & $\%$ ERROR & 8.80 & 8.49 & & \\
\hline
\end{tabular}

\begin{tabular}{|c|c|c|c|}
\hline Class Umits & Data & Frequency $\%_{0}$ & Cumulative $\%$ \\
\hline$-4,00$ & 0.00 & 0.00 & 0.00 \\
\hline-3.50 & 8.90 & 1.23 & 1.23 \\
\hline-3.00 & 12,80 & 1.76 & 2.99 \\
\hline-2.50 & 16.90 & 2.33 & 5.31 \\
\hline-2.00 & 13.13 & 1.81 & 7.12 \\
\hline-1.50 & 15.81 & 2.18 & 9,30 \\
\hline-1.00 & 13.56 & 1.87 & 11.17 \\
\hline-0.50 & 13.95 & 1.92 & 13.09 \\
\hline 0.00 & 16.42 & 2.26 & 15.35 \\
\hline 0.50 & 26.15 & 3.60 & 18.95 \\
\hline 1.00 & 99.97 & 13.76 & 32.71 \\
\hline 1.50 & 134.23 & 18.48 & 51.19 \\
\hline 2,00 & 101.71 & 14.00 & 65.20 \\
\hline 2.50 & 82.37 & 11.34 & 76.54 \\
\hline 3.00 & 53.70 & 7.39 & 83.93 \\
\hline 3.50 & 22.09 & 3.04 & 86.97 \\
\hline 4.00 & 11,14 & 1.53 & 88.51 \\
\hline 4.50 & 7.22 & 0.99 & 89.50 \\
\hline 5.00 & 6.40 & 0.88 & 90.38 \\
\hline 5.50 & 9.52 & 1.31 & 91.69 \\
\hline 0.00 & 12,94 & 1.78 & 93.47 \\
\hline 6.50 & 13.86 & 1.91 & 95.38 \\
\hline 7.00 & 10.52 & 1.45 & 96.83 \\
\hline 7.50 & 8.51 & 1.17 & 98.00 \\
\hline 8.00 & 2.92 & 0.40 & 98.40 \\
\hline 8.50 & 1.00 & 0.14 & 98.54 \\
\hline 9,00 & 0,43 & 0.88 & 99,42 \\
\hline 9.50 & 2.42 & 0.33 & 99.76 \\
\hline 10.00 & 0.42 & 0.06 & 99.82 \\
\hline$>10$ & 1.34 & 0.18 & 100.00 \\
\hline GRAVEL & 11.17 & SILT : & 9.90 \\
\hline SAND & 77.34 & CLAY & 1.60 \\
\hline
\end{tabular}


WET SIEVE DIAMETER: $\quad$ GOUM

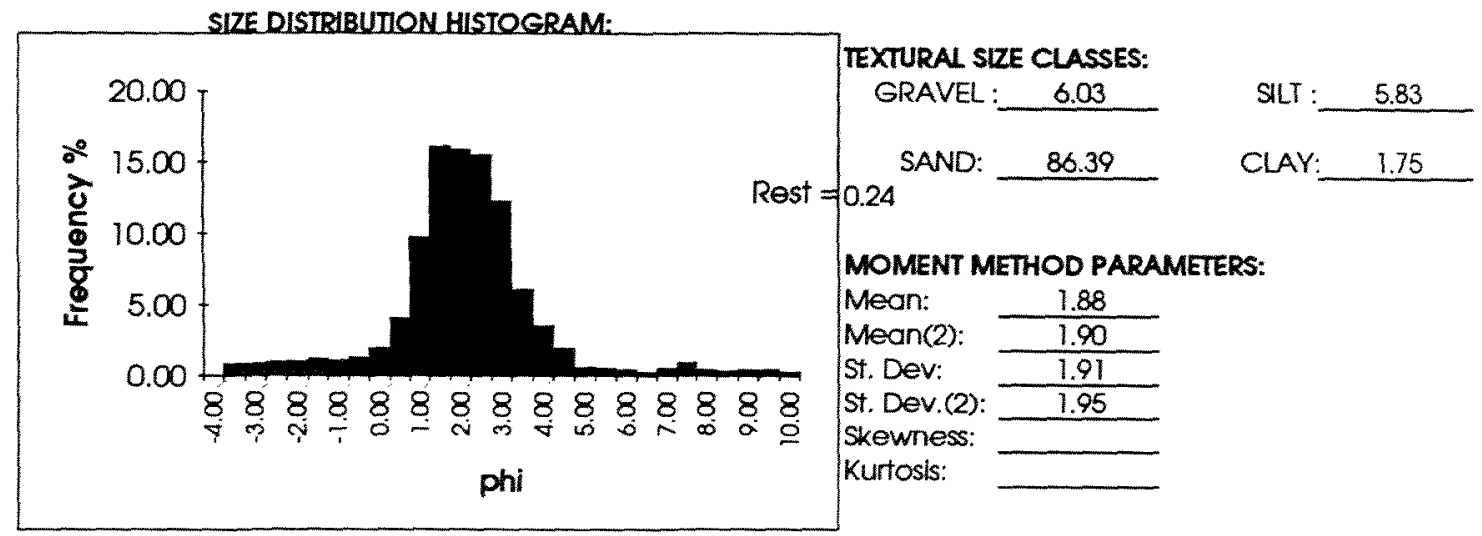

ERRORS:

\% lost in centrfuging and wet slevin:

$\%$ lost in ary sleving:

9.50

DATA:

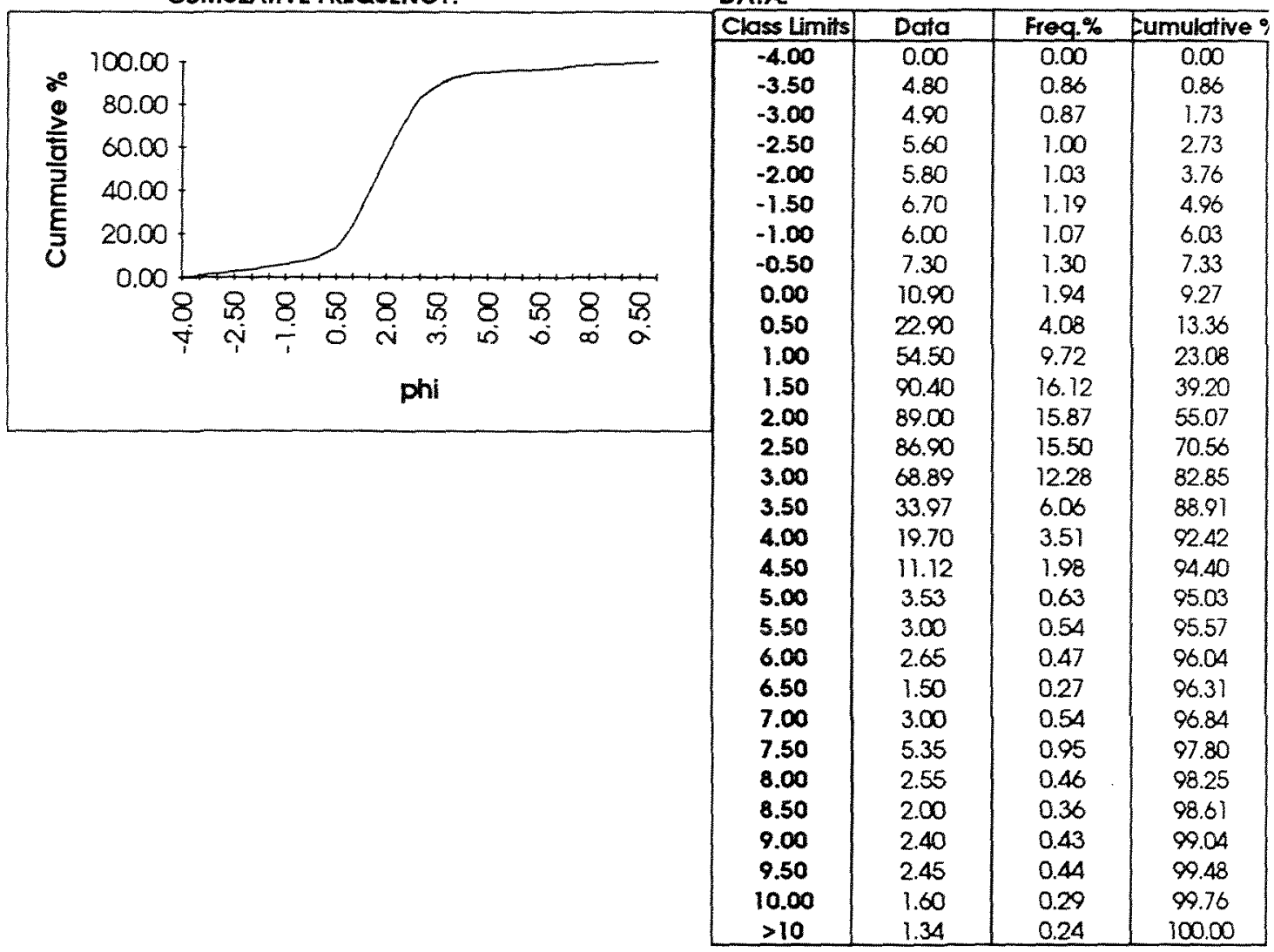


SAMPLE NO: II P0-2 ANALYST: N.LBleakley DATE: 10/10/95

BEAKER WGT 252.78

SAMPLE WEIGHT

642.20

WET SIEVE DIAMETER: 6oum

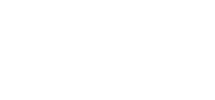

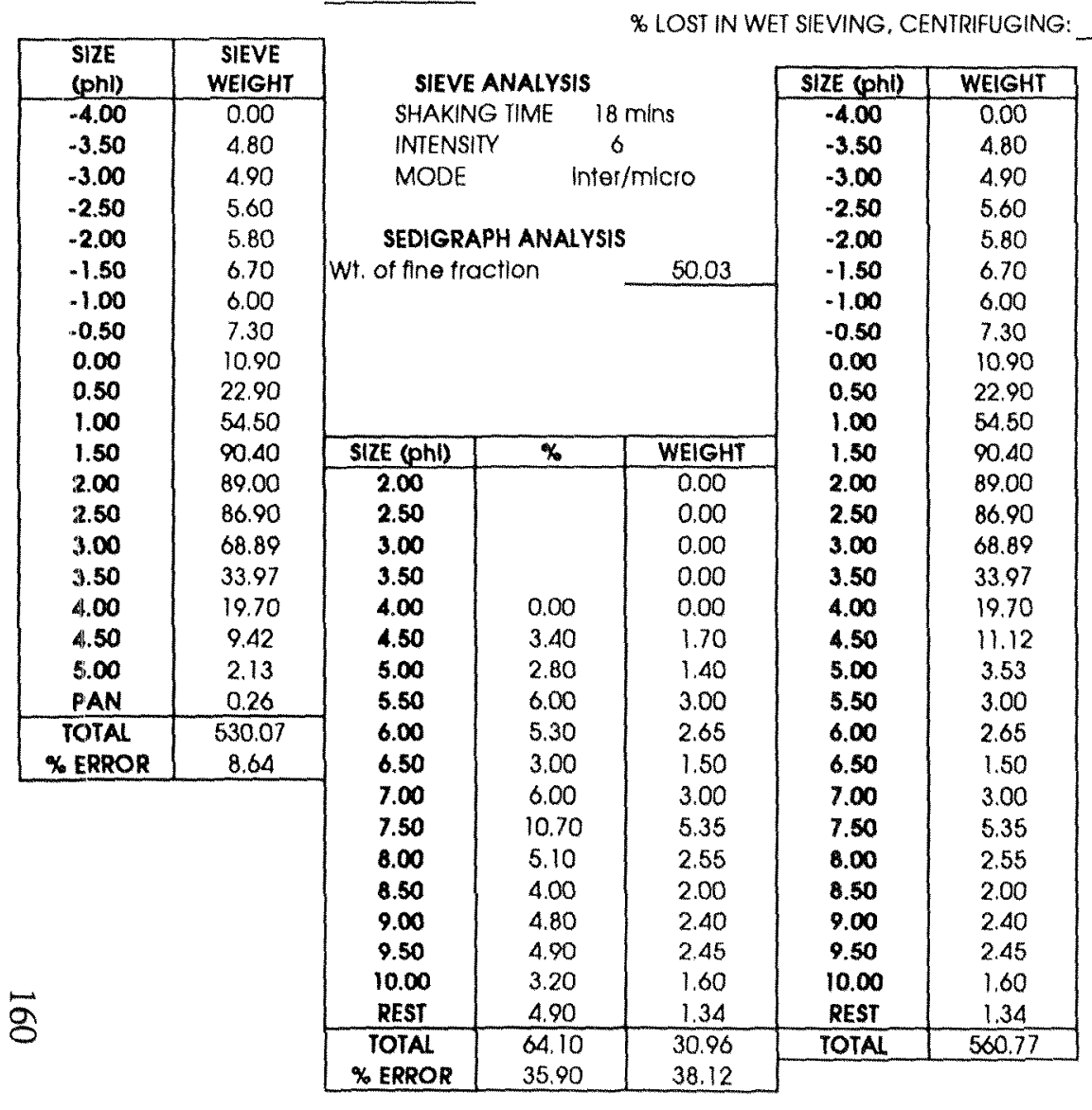

FINE FRACTION

COARSE FRACIION

BEAK. WGT 252.78 COARSE FRAC + BEAKER: 784.48 DRYWGT 303.08 COARSE WEIGH 531.70 FINE FRACTION WG 50.03 TOTAL SAMPLE WEIGHT

1.73

$$
9.50
$$

\begin{tabular}{|c|c|c|c|}
\hline Class Limits & Data & Frequency $\%_{0}$ & Cumulative $\%$ \\
\hline-4.00 & 0.00 & 0.00 & 0.00 \\
\hline-3.50 & 4.80 & 0.86 & 0.86 \\
\hline$-3,00$ & 4.90 & 0.87 & 1.73 \\
\hline-2.50 & 5.60 & 1.00 & 2.73 \\
\hline$-2,00$ & 5.80 & 1.03 & 3.76 \\
\hline-1.50 & 6.70 & 1.19 & 4.96 \\
\hline$-1,00$ & 0.00 & 1.07 & 0.03 \\
\hline-0.50 & 7.30 & 1.30 & 7.33 \\
\hline 0,00 & 10.90 & 1.94 & 9.27 \\
\hline 0.50 & 22.90 & 4.08 & 13.36 \\
\hline 1.00 & 54.50 & 9.72 & 23.08 \\
\hline 1.50 & 90.40 & 16.12 & 39.20 \\
\hline 2.00 & 89,00 & 15.87 & 55.07 \\
\hline 2.50 & 86.90 & 15.50 & 70.56 \\
\hline 3.00 & 68.89 & 12.28 & 82,85 \\
\hline 3.50 & 33.97 & 6.06 & 88.91 \\
\hline 4.00 & 19.70 & 3.51 & 92.42 \\
\hline 4.50 & 11.12 & 1.98 & 94.40 \\
\hline 5.00 & 3.53 & 0.83 & 95.03 \\
\hline 5.50 & 3.00 & 0.54 & 95.57 \\
\hline 6.00 & 2.65 & 0.47 & 96.04 \\
\hline 6.50 & 1.50 & 0.27 & 96.31 \\
\hline 7.00 & 3.00 & 0.54 & 96,84 \\
\hline 7.50 & 5.35 & 0.95 & 97,80 \\
\hline 8.00 & 2.55 & 0.46 & 98.25 \\
\hline 8,50 & 2.00 & 0.36 & 98.61 \\
\hline 9.00 & 2.40 & 0.43 & 99.04 \\
\hline 9.50 & 2.45 & 0.44 & 99.48 \\
\hline 10.00 & 1.60 & 0.29 & 99.76 \\
\hline$>10$ & 1.34 & 0.24 & 100.00 \\
\hline GRAVEL & 6.03 & SILT & 5.83 \\
\hline SAND & 86.39 & CLAY & 1.75 \\
\hline
\end{tabular}


SAMPLE NO: 11 P 22-32 ANALYST: $\underline{\text { N.L.Bleakley }}$ DATE: $10 / 10 / 95$

BEAKER WGT: $\quad 167.40$

SAMPLE WGT:

579.60

WET SIEVE DIAMETER: $\quad$ GOUM

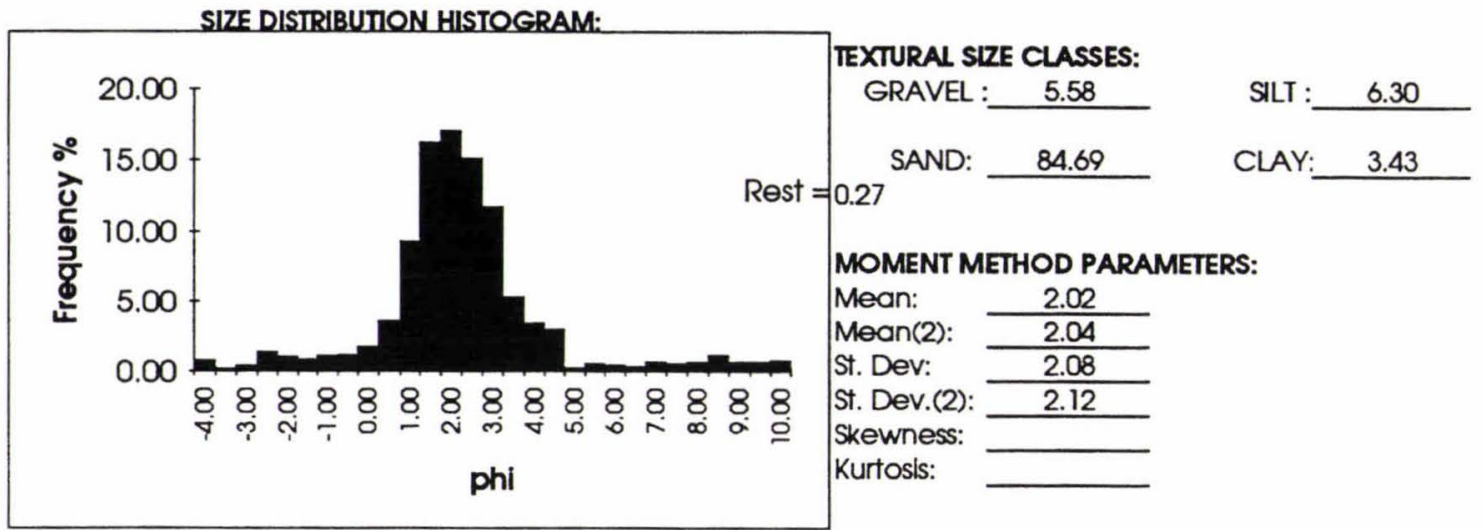

ERRORS:

\% lost in centrifuging and wet sievin

$\%$ lost in dry sleving:

7.30

CUMULATIVE FREQUENCY:

DATA:

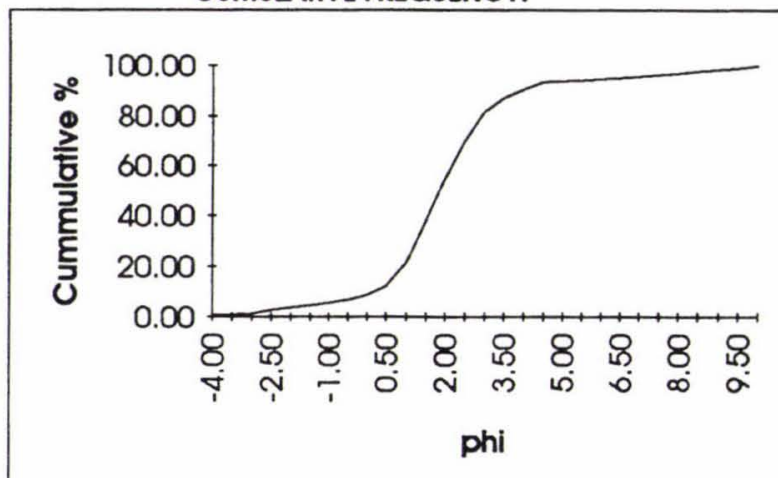

Class L

\begin{tabular}{|c|c|c|c|}
\hline Class Umits & Data & Freq.\% & Fumulative \\
\hline $\mathbf{- 4 . 0 0}$ & 3.90 & 0.78 & 0.78 \\
$\mathbf{- 3 . 5 0}$ & 0.88 & 0.18 & 0.96 \\
$\mathbf{- 3 . 0 0}$ & 1.80 & 0.36 & 1.32 \\
$\mathbf{- 2 . 5 0}$ & 6.60 & 1.32 & 2.64 \\
$\mathbf{- 2 . 0 0}$ & 5.23 & 1.05 & 3.68 \\
$\mathbf{- 1 . 5 0}$ & 4.04 & 0.81 & 4.49 \\
$\mathbf{- 1 . 0 0}$ & 5.44 & 1.09 & 5.58 \\
$\mathbf{- 0 . 5 0}$ & 5.78 & 1.16 & 6.73 \\
$\mathbf{0 . 0 0}$ & 8.59 & 1.72 & 8.45 \\
$\mathbf{0 . 5 0}$ & 18.11 & 3.62 & 12.07 \\
$\mathbf{1 . 0 0}$ & $\mathbf{4 6 . 3 5}$ & 9.27 & 21.35 \\
$\mathbf{1 . 5 0}$ & 81.17 & 16.23 & 37.58 \\
$\mathbf{2 . 0 0}$ & 85.36 & 17.07 & 54.65 \\
$\mathbf{2 . 5 0}$ & 75.62 & 15.12 & 69.78 \\
$\mathbf{3 . 0 0}$ & 58.51 & 11.70 & 81.48 \\
$\mathbf{3 . 5 0}$ & 26.62 & 5.32 & 86.80 \\
$\mathbf{4 . 0 0}$ & 17.32 & 3.46 & 90.27 \\
$\mathbf{4 . 5 0}$ & 15.07 & 3.01 & 93.28 \\
$\mathbf{5 . 0 0}$ & 1.16 & 0.23 & 93.51 \\
$\mathbf{5 . 5 0}$ & 2.60 & 0.52 & 94.03 \\
$\mathbf{6 . 0 0}$ & 2.15 & 0.43 & 94.46 \\
$\mathbf{6 . 5 0}$ & 1.63 & 0.33 & 94.79 \\
$\mathbf{7 . 0 0}$ & 3.12 & 0.62 & 95.41 \\
$\mathbf{7 . 5 0}$ & 2.67 & 0.53 & 95.95 \\
$\mathbf{8 . 0 0}$ & 3.12 & 0.62 & 96.57 \\
$\mathbf{8 . 5 0}$ & 5.57 & 1.11 & 97.68 \\
$\mathbf{9 . 0 0}$ & 3.26 & 0.65 & 98.34 \\
$\mathbf{9 . 5 0}$ & 3.19 & 0.64 & 98.98 \\
$\mathbf{1 0 . 0 0}$ & 3.78 & 0.76 & 99.73 \\
$\mathbf{> 1 0}$ & 1.34 & 0.27 & 100.00 \\
& & &
\end{tabular}


SAMPLE NO: II P22-32 ANALYST: N.L.Bleakley DATE: $10 / 10 / 95$

BEAKER WGT $\quad 167.40$

SAMPLE WEIGHT

579.60

WET SIEVE DIAMETER:

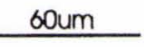

$$
\text { Q LOSTINWETSEVING, CENTR }
$$
\% LOST IN WET SIEVING, CENTRIFUGING:

FINE FRACTION

BEAK. WGT 167.40 $\begin{array}{r}630.08 \\ \hline\end{array}$ \begin{tabular}{rr} 
DRY WGT $\frac{241.65}{74.2}$ & COARSE WEIGH \\
FINE FRACTION WG & 462.68 \\
\hline
\end{tabular}

\begin{tabular}{|c|c|c|c|c|c|c|}
\hline SIZE & SIEVE & \multirow{2}{*}{\multicolumn{3}{|c|}{ SIEVE ANALYSIS }} & & \\
\hline (phl) & WEIGHT & & & & SIZE (phl) & WEIGHT \\
\hline-4.00 & 3.90 & \multicolumn{3}{|c|}{ SHAKING TIME $18 \mathrm{mins}$} & -4.00 & 3.90 \\
\hline-3.50 & 0.88 & \multicolumn{3}{|c|}{ INTENSITY $\quad 6$} & -3.50 & 0.88 \\
\hline-3.00 & 1.80 & \multicolumn{3}{|c|}{ Inter/mlcro } & -3.00 & 1.80 \\
\hline-2.50 & 6.60 & & & & -2.50 & 6.60 \\
\hline-2.00 & 5.23 & \multicolumn{3}{|c|}{ SEDIGRAPH ANALYSIS } & -2.00 & 5.23 \\
\hline-1.50 & 4.04 & \multicolumn{3}{|c|}{ Wt. of fine fractlon } & -1.50 & 4.04 \\
\hline-1.00 & 5.44 & & & & -1.00 & 5.44 \\
\hline-0.50 & 5.78 & & & & -0.50 & 5.78 \\
\hline 0.00 & 8.59 & & & & 0.00 & 8.59 \\
\hline 0.50 & 18.11 & & & & 0.50 & 18.11 \\
\hline 1.00 & 46.35 & & & & 1.00 & 46.35 \\
\hline 1.50 & 81.17 & SIZE (phi) & $\%$ & WEIGHT & 1.50 & 81.17 \\
\hline 2.00 & 85.36 & 2.00 & & 0.00 & 2.00 & 85.36 \\
\hline 2.50 & 75.62 & 2.50 & & 0.00 & 2.50 & 75.62 \\
\hline 3.00 & 58.51 & 3.00 & & 0.00 & 3.00 & 58.51 \\
\hline 3.50 & 26.62 & 3.50 & & 0.00 & 3.50 & 26.62 \\
\hline 4.00 & 17.32 & 4.00 & 0.00 & 0.00 & 4.00 & 17.32 \\
\hline 4.50 & 10.99 & 4.50 & 5.50 & 4.08 & 4.50 & 15.07 \\
\hline 5.00 & 0.71 & 5.00 & 0.60 & 0.45 & 5.00 & 1.16 \\
\hline PAN & 0.03 & 5.50 & 3.50 & 2.60 & 5.50 & 2.60 \\
\hline TOTAL & 463.05 & 6.00 & 2.90 & 2.15 & 6.00 & 2.15 \\
\hline \% ERROR & -0.08 & 6.50 & 2.20 & 1.63 & 6.50 & 1.63 \\
\hline \multirow{10}{*}{$\vec{s}$} & & 7.00 & 4.20 & 3.12 & 7.00 & 3.12 \\
\hline & & 7.50 & 3.60 & 2.67 & 7.50 & 2.67 \\
\hline & & 8.00 & 4.20 & 3.12 & 8.00 & 3.12 \\
\hline & & 8.50 & 7.50 & 5.57 & 8.50 & 5.57 \\
\hline & & 9.00 & 4.40 & 3.26 & 9.00 & 3.26 \\
\hline & & 9.50 & 4.30 & 3.19 & 9.50 & 3.19 \\
\hline & & 10.00 & 5.10 & 3.78 & 10.00 & 3.78 \\
\hline & & REST & 4.10 & 1.34 & REST & 1.34 \\
\hline & & \multirow{2}{*}{$\begin{array}{c}\text { TOTAL } \\
\% \text { ERROR }\end{array}$} & \multirow{2}{*}{$\begin{array}{l}42.10 \\
47.90 \\
\end{array}$} & \multirow{2}{*}{$\begin{array}{l}36.96 \\
50.19 \\
\end{array}$} & TOTAL & 499.98 \\
\hline & & & & & & \\
\hline
\end{tabular}

\begin{tabular}{|c|c|c|c|}
\hline Class LImils & Data & Frequency \% & Cumulative \% \\
\hline-4.00 & 3.90 & 0.78 & 0.78 \\
-3.50 & 0.88 & 0.18 & 0.96 \\
-3.00 & 1.80 & 0.36 & 1.32 \\
-2.50 & 6.60 & 1.32 & 2.64 \\
-2.00 & 5.23 & 1.05 & 3.68 \\
-1.50 & 4.04 & 0.81 & 4.49 \\
-1.00 & 5.44 & 1.09 & 5.58 \\
-0.50 & 5.78 & 1.16 & 6.73 \\
0.00 & 8.59 & 1.72 & 8.45 \\
0.50 & 18.11 & 3.62 & 12.07 \\
1.00 & 46.35 & 9.27 & 21.35 \\
1.50 & 81.17 & 16.23 & 37.58 \\
2.00 & 85.36 & 17.07 & 54.65 \\
2.50 & 75.62 & 15.12 & 69.78 \\
3.00 & 58.51 & 11.70 & 81.48 \\
3.50 & 26.62 & 5.32 & 86.80 \\
4.00 & 17.32 & 3.46 & 90.27 \\
4.50 & 15.07 & 3.01 & 93.28 \\
5.00 & 1.16 & 0.23 & 93.51 \\
5.50 & 2.60 & 0.52 & 94.03 \\
6.00 & 2.15 & 0.43 & 94.46 \\
6.50 & 1.63 & 0.33 & 94.79 \\
7.00 & 3.12 & 0.62 & 95.41 \\
7.50 & 2.67 & 0.53 & 95.95 \\
8.00 & 3.12 & 0.62 & 96.57 \\
8.50 & 5.57 & 1.11 & 97.68 \\
9.00 & 3.26 & 0.65 & 98.34 \\
9.50 & 3.19 & 0.64 & 98.98 \\
10.00 & 3.78 & 0.76 & 99.73 \\
$>10$ & 1.34 & 0.27 & 100.00 \\
\hline & & & \\
\end{tabular}

GRAVEL: $\quad 5.58$ SILT : $\quad 6.30$

SAND : $\quad 84.69$

CLAY 3.43 
SAMPLENO: T22-5cm ANALYST: N.L. Bleakle) DATE: $10 / 10 / 95$

BEAKER WGT: $\quad 167.40$ SAMPLE WEIGHT $\quad 451.02$

WET SIEVE DIAMETER: $\quad$ GOum

SIZE DISIRIBUTION HISTOGRAM:

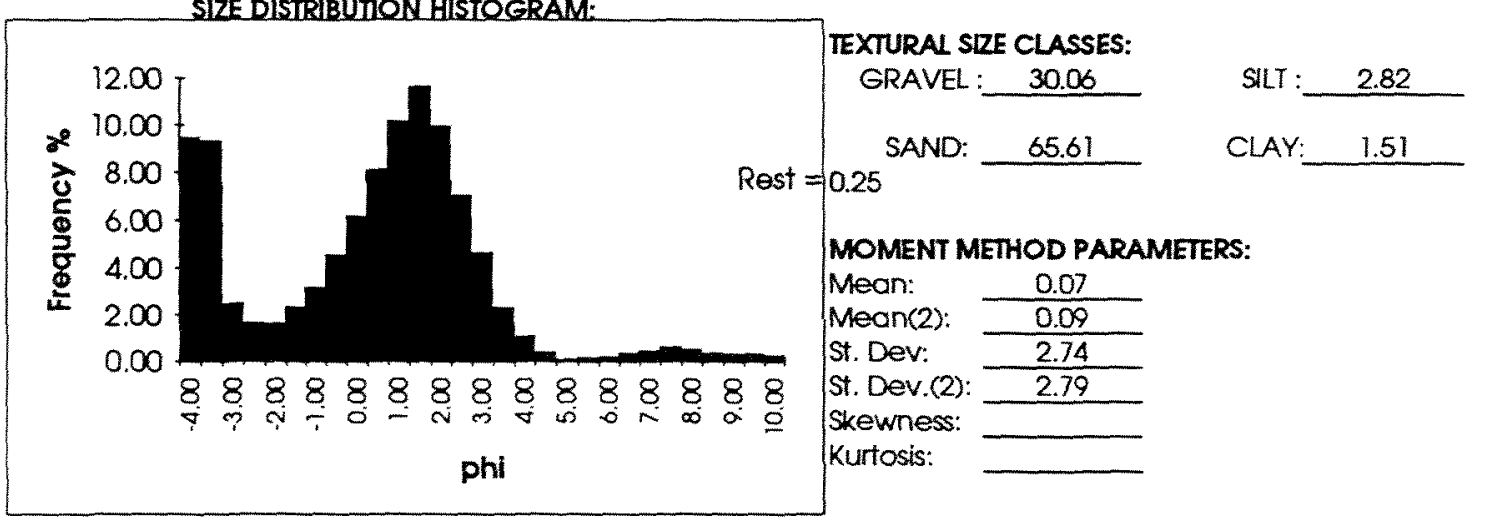

ERRORS:

$\%$ lost in centrifuging and wet sievin

$\%$ lost in ary sieving:

CUMULATIVE FREQUENCY:

DATA:

\begin{tabular}{|c|c|c|c|c|c|}
\hline \multirow{30}{*}{ 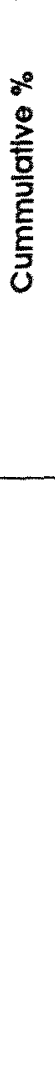 } & & Class Umits & Dafa & Freq. \% & Eumulative \\
\hline & 100.00 & -3.50 & 50.70 & 9.34 & $\begin{array}{c}9.45 \\
18.78\end{array}$ \\
\hline & 80.00 & -3.00 & 13.60 & 2.50 & 21.29 \\
\hline & 60.00 & -2.50 & 9.00 & 1.66 & 22.94 \\
\hline & $\mathrm{mm}$ & -2.00 & 8.83 & 1.63 & 24.57 \\
\hline & 40.00 & -1.50 & 12.60 & 2.32 & 26.89 \\
\hline & 20.00 & -1.00 & 17.21 & 3.17 & 30.06 \\
\hline & $n m$ & -0.50 & 24.74 & 4.56 & 34.62 \\
\hline & 888888888888888 & 0.00 & 33.53 & 6.17 & 40.79 \\
\hline & 的 di & 0.50 & 43.96 & 8.09 & 48.88 \\
\hline & 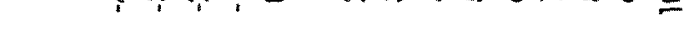 & 1.00 & 55.11 & 10.15 & 59.03 \\
\hline & phi & 1.50 & 63.14 & 11.63 & 70.66 \\
\hline & & 2.00 & 53.97 & 9.94 & 80.60 \\
\hline & & 2.50 & 38.22 & 7.04 & 87.64 \\
\hline & & 3.00 & 25.30 & 4.66 & 92.29 \\
\hline & & 3.50 & 12.49 & 2.30 & 94.59 \\
\hline & & 4.00 & 5.85 & 1.08 & 95.67 \\
\hline & & 4.50 & 2.10 & 0.39 & 96.06 \\
\hline & & 5.00 & 0.55 & 0.10 & 96.16 \\
\hline & & 5.50 & 0.87 & 0.16 & 96.32 \\
\hline & & 6.00 & 1.08 & 0.20 & 96.52 \\
\hline & & 6.50 & 1.92 & 0.35 & 96.87 \\
\hline & & 7.00 & 2.52 & 0.46 & 97.34 \\
\hline & & 7.50 & 3.38 & 0.62 & 97.96 \\
\hline & & 8.00 & 2.88 & 0.53 & 98.49 \\
\hline & & 8.50 & 1.99 & 0.37 & 98.85 \\
\hline & & 9.00 & 1.71 & 0.32 & 99.17 \\
\hline & & 9.50 & 1.69 & 0.31 & 99.48 \\
\hline & & 10.00 & 1.48 & 0.27 & 99.75 \\
\hline & & $>10$ & 1.34 & 0.25 & 100.00 \\
\hline
\end{tabular}


SAMPLE NO: $122-5 \mathrm{~cm}$ ANALYST: N.L.Bleakley DATE: $10 / 10 / 95$

BEAKER WGT

SAMPLE WEIGHT $\quad 451.02$

167.40

FINE FRACTION

COARSE FRACTION

DRY WGI $\frac{188.54}{21.14}$ COARSE WEIGH

$\begin{array}{r}\text { COARSE WEIGH } \quad 407.31 \\ \text { TOTAL SAMPLE WEIGHT } \\ \hline\end{array}$

WET SIEVE DIAMETER: $\quad$ GOUM

\% LOST IN WET SIEVING, CENTRIFUGING:

CTION WG

\begin{tabular}{|c|c|}
\hline SIZE & $\begin{array}{c}\text { SIEVE } \\
\text { (Phi) }\end{array}$ \\
WEIGHT \\
\hline-4.00 & 51.30 \\
$\mathbf{- 3 . 5 0}$ & 50.70 \\
$\mathbf{- 3 . 0 0}$ & 13.60 \\
$\mathbf{2 . 5 0}$ & 9.00 \\
$\mathbf{2 . 0 0}$ & 8.83 \\
-1.50 & 12.60 \\
-1.00 & 17.21 \\
$\mathbf{0 . 5 0}$ & 24.74 \\
0.00 & 33.53 \\
0.50 & 43.96 \\
1.00 & 55.11 \\
1.50 & 63.14 \\
$\mathbf{2 . 0 0}$ & 53.97 \\
$\mathbf{2 . 5 0}$ & 38.22 \\
$\mathbf{3 . 0 0}$ & 25.30 \\
$\mathbf{3 . 5 0}$ & 12.49 \\
$\mathbf{4 . 0 0}$ & 5.85 \\
$\mathbf{4 . 5 0}$ & 2.10 \\
5.00 & 0.34 \\
PAN & 0.03 \\
\hline TOTAL & 522.02 \\
\% ERROR & -28.16 \\
\hline
\end{tabular}

弯

SIEVE ANALYSIS

SHAKING TIME $18 \mathrm{mlns}$

INTENSITY 6

MODE

6

SEDIGRAPH ANALYSIS

Wt. of fine fraction

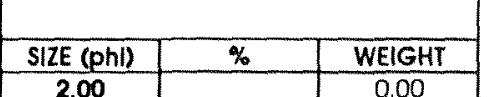

\begin{tabular}{c|c|c}
\hline SIZE (phl) & $\%$ & WEIGHT \\
\hline 2.00 & & 0.00 \\
2.50 & & 0.00
\end{tabular}

2.50

3.00

3.50

4.00

4.50

5.00

5.50

5.50
6.00

6.00
8.50

6.50
7.00

7.50

8.00

8.50

9.00

9.50

10.00
REST

0.00
0.00
0.00

0.00

$0.00 \quad 0.00$

$\begin{array}{ll}4.10 & 0.87\end{array}$

$5.10 \quad 1.08$

9.10

\begin{tabular}{l|l}
11.90 & 2.52
\end{tabular}

$16.00 \quad 3.38$

$\begin{array}{ll}13.60 & 2.88\end{array}$

9.40

\begin{tabular}{l|l}
9.40 & 1.99 \\
8.10 & 1.71
\end{tabular}

8.10

\begin{tabular}{l|l}
8.00 & 1.69
\end{tabular}

\begin{tabular}{c|c|c} 
REST & 6.00 & 1.34 \\
\hline TOTAL & 99.30 & 21.06
\end{tabular}

$\%$ ERROR

\begin{tabular}{|c|c|}
\hline SIZE (phi) & WEIGHT \\
\hline $\mathbf{- 4 . 0 0}$ & 51.30 \\
$\mathbf{- 3 . 5 0}$ & 50.70 \\
$\mathbf{- 3 . 0 0}$ & 13.60 \\
$\mathbf{- 2 . 5 0}$ & 9.00 \\
$\mathbf{- 2 . 0 0}$ & 8.83 \\
-1.50 & 12.60 \\
-1.00 & 17.21 \\
$\mathbf{- 0 . 5 0}$ & 24.74 \\
$\mathbf{0 . 0 0}$ & 33.53 \\
$\mathbf{0 . 5 0}$ & 43.96 \\
1.00 & 55.11 \\
$\mathbf{1 . 5 0}$ & 63.14 \\
$\mathbf{2 . 0 0}$ & 53.97 \\
$\mathbf{2 . 5 0}$ & 38.22 \\
$\mathbf{3 . 0 0}$ & 25.30 \\
$\mathbf{3 . 5 0}$ & 12.49 \\
$\mathbf{4 . 0 0}$ & 5.85 \\
$\mathbf{4 . 5 0}$ & 2.10 \\
$\mathbf{5 . 0 0}$ & 0.55 \\
$\mathbf{5 . 5 0}$ & 0.87 \\
$\mathbf{6 . 0 0}$ & 1.08 \\
$\mathbf{6 . 5 0}$ & 1.92 \\
$\mathbf{7 . 0 0}$ & 2.52 \\
$\mathbf{7 . 5 0}$ & 3.38 \\
$\mathbf{8 . 0 0}$ & 2.88 \\
$\mathbf{8 . 5 0}$ & 1.99 \\
$\mathbf{9 . 0 0}$ & 1.71 \\
$\mathbf{9 . 5 0}$ & 1.69 \\
$\mathbf{1 0 . 0 0}$ & 1.48 \\
$\mathbf{R E S T}$ & 1.34 \\
\hline TOTAL & 543.05 \\
\hline & \\
&
\end{tabular}

\begin{tabular}{|c|c|c|c|}
\hline Class LImiths & Data & Frequency $\%$ & Cumulative $\%$ \\
\hline-4.00 & 51.30 & 9.45 & 9.45 \\
\hline-3.50 & 50.70 & 9.34 & 18.78 \\
\hline-3.00 & 13.60 & 2.50 & 21.29 \\
\hline$-2,50$ & 9.00 & 1.66 & 22.94 \\
\hline-2.00 & 8.83 & 1.63 & 24.57 \\
\hline-1.50 & 12.60 & 2.32 & 26.89 \\
\hline-1.00 & 17.21 & 3.17 & 30.06 \\
\hline-0.50 & 24.74 & 4.56 & 34.62 \\
\hline 0.00 & 33.53 & 0.17 & 40.79 \\
\hline 0.50 & 43.96 & 8.09 & 48.88 \\
\hline 1.00 & 55.11 & 10.15 & 59.03 \\
\hline 1.50 & 63.14 & 11.63 & 70.60 \\
\hline 2.00 & 53.97 & 9,94 & 80.60 \\
\hline 2.50 & 38.22 & 7.04 & 87.64 \\
\hline 3.00 & 25.30 & 4.66 & 92.29 \\
\hline 3.50 & 12.49 & 2.30 & 94.59 \\
\hline 4.00 & 5.85 & 1.08 & 95.67 \\
\hline 4.50 & 2.10 & 0.39 & 96.06 \\
\hline 5.00 & 0.55 & 0.10 & 96.16 \\
\hline 5.50 & 0.87 & 0.16 & 96.32 \\
\hline 6.00 & 1.08 & 0.20 & 96.52 \\
\hline 0.50 & 1.92 & 0.35 & 96.87 \\
\hline 7.00 & 2.52 & 0.46 & 97.34 \\
\hline 7.50 & 3.38 & 0.62 & 97.96 \\
\hline 8.00 & 2.88 & 0.53 & 98.49 \\
\hline 8.50 & 1.99 & 0.37 & 98.85 \\
\hline 9.00 & 1.71 & 0.32 & 99.17 \\
\hline 9.50 & 1.69 & 0.31 & 99.48 \\
\hline 10.00 & 1.48 & 0.27 & 99.75 \\
\hline$>10$ & 1.34 & 0.25 & 100.00 \\
\hline GRAVEL & 30.06 & SILT: & 2.82 \\
\hline SAND & 65.61 & CLAY & 1.51 \\
\hline
\end{tabular}




\section{APPENDIX THREE}

\section{Porosity and composition of gravel, sand and clay}

Aids in determining the source of the sediment, its post depositional modifications and tells wheather diatoms can get into the surface layers of the of the till.

Table A3.1 Percent porosity and pore size from thin section of the Sirius Group from Mt. Feather.

Table A3.2 Composition of clasts of the pebble size fraction from Mt. Feather and table mountain.

Table A3.3 Counts of the composition of the 30 to 300 micron size fraction from $\mathrm{Mt}$. Feather and table mountain.

Table A3.4 Percent composition of the 30 to 300 micron size fraction for samples from Mt. Feather and Table Mountain.

Figure A3.1 X-ray diffractograms from the clay fraction of the Sirius group till at Mt. Feather and Table Mountain. 
Table A3.1 Percent porosity and pore size measured from thin sections of the Sirius Group at Mt. Feather. Analyst: Dr. Warren Dickinson, Geology department, Victoria University of Wellington.

\begin{tabular}{|c|c|c|c|c|c|c|c|c|c|c|c|}
\hline \multirow[b]{2}{*}{ Sample } & \multirow[b]{2}{*}{ Clay $\mathrm{Mtx}$} & \multirow[b]{2}{*}{ Pore $\%$} & \multicolumn{2}{|c|}{ Long axis $(\mu \mathrm{m})$} & \multicolumn{2}{|c|}{ Short Axis $(\mu \mathrm{m})$} & \multicolumn{3}{|c|}{ Size $(\mu \mathrm{m})$} & \multirow[b]{2}{*}{$\times A . R}$. & \multirow[b]{2}{*}{ A.R.S.D } \\
\hline & & & Mean & Max. & Mean & Max. & $x \operatorname{siz} \theta$ & Std. Dev & Max. size & & \\
\hline MF1 $0-2 \mathrm{~cm}$ & 87 & 11 & 549 & 2300 & 157 & 157 & 280 & 260 & 1030 & 0.31 & 0.23 \\
\hline MF1 $7-17 \mathrm{~cm}$ & 76 & 8 & 365 & 1610 & 86 & 86 & 170 & 120 & 520 & 0.29 & 0.22 \\
\hline MF1 $27-37 \mathrm{~cm}$ & 85 & 14 & 428 & 1840 & 127 & 127 & 230 & 180 & 920 & 0.38 & 0.29 \\
\hline MF2 $\quad 0-2 \mathrm{~cm}$ & 99 & 4 & 77 & 351 & 21 & 21 & 40 & 20 & 150 & 0.41 & 0.31 \\
\hline MF2 $2-7 \mathrm{~cm}$ & 88 & 1 & 95 & 805 & 12 & 12 & 30 & 20 & 170 & 0.22 & 0.19 \\
\hline MF2 $7-17 \mathrm{~cm}$ & 103 & 2 & 93 & 409 & 14 & 14 & 30 & 20 & 180 & 0.23 & 0.24 \\
\hline MF3 $\quad 0-2 \mathrm{~cm}$ & 71 & 22 & 673 & 2530 & 203 & 203 & 360 & 280 & 1380 & 0.35 & 0.22 \\
\hline MF3 $7-17 \mathrm{~cm}$ & 77 & 7 & 116 & 518 & 38 & 38 & 60 & 60 & 483 & 0.36 & 0.27 \\
\hline
\end{tabular}


Table A3.2

Composition of clasts of the pebble size fraction from the Sirius Group till at Table Mountain and Mount Feather. Site locations are on figures 3.1 and 3.2 in Chapter Three of the main body of the thesis.

\begin{tabular}{|l|c|c|c|c|c|c|c|c|c|}
\hline Clast & \multicolumn{9}{|l|}{ Mt. Feather, site } \\
\cline { 2 - 10 } Lithology & 1 & 2 & 3 & Total & $\%$ & 1 & 2 & Total & $\%$ \\
\hline Quartz & 42 & 56 & 38 & 136 & 80 & 8 & 9 & 17 & 13 \\
Coal & 2 & 3 & 9 & 14 & 8 & & & & \\
Dolerite & 3 & & & 3 & 2 & 26 & 30 & 56 & 43 \\
Siltstone & 1 & & 2 & 3 & 2 & & & & \\
Sandstone & 2 & 2 & 4 & 8 & 5 & 17 & 14 & 31 & 23 \\
Coarse sandstone & 5 & & & 5 & 3 & 1 & 10 & 11 & 8 \\
Quartz conglom. & 1 & & & 1 & 0.5 & & & & \\
Shale & 1 & & & 1 & 0.5 & 4 & 13 & 17 & 13 \\
\hline Total & 57 & 61 & 53 & 171 & 101 & 56 & 76 & 132 & 100 \\
\hline
\end{tabular}




\section{Table A3.3}

Composition of the 30 to 300 micron size fraction for samples from Mt. Feather and Table Mountain, based on 300 counts per sample. Site locations are shown in Figures 3.1 and 3.2 in Chapter Three of the mainbody of the thesis.

Analyist: Dr. Warren Dickinson, Geology Department, Victoria University of Wellington.

\begin{tabular}{|c|c|c|c|c|c|c|c|c|c|c|c|c|c|}
\hline Sample & Quartz & Feldspar & IRF & SAF & MPF & $H M$ & Opaque & Clay Mtx & Calcite & Ehabazite & Porosity & Other & Total \\
\hline $\mathrm{F} 1 \quad 0-2 \mathrm{~cm}$ & 118 & 13 & 9 & 28 & 10 & 1 & 2 & 87 & 0 & 0 & 32 & 0 & 300 \\
\hline $\mathrm{F} 1 \quad 2-7 \mathrm{~cm}$ & 37 & 7 & 13 & 2 & 0 & 0 & 5 & 19 & 0 & 0 & 13 & 4 & 100 \\
\hline F1 $7-17 \mathrm{~cm}$ & 118 & 18 & 19 & 27 & 14 & 0 & 3 & 76 & 0 & 0 & 25 & 0 & 300 \\
\hline $\mathrm{F} 1 \quad 17-27 \mathrm{~cm}$ & 37 & 4 & 5 & 6 & 0 & 0 & 2 & 35 & 0 & 0 & 11 & 0 & 100 \\
\hline $\mathrm{F} 1 \quad 27-37 \mathrm{~cm}$ & 100 & 16 & 22 & 23 & 2 & 0 & 9 & 85 & 1 & 0 & 42 & 0 & 300 \\
\hline $\mathrm{F} 2 \quad 0.2 \mathrm{~cm}$ & 83 & 30 & 28 & 21 & 3 & 4 & 19 & 99 & 0 & 0 & 13 & 0 & 300 \\
\hline $\mathrm{F} 2 \quad 2-7 \mathrm{~cm}$ & 80 & 35 & 42 & 24 & 7 & 1 & 17 & 88 & 0 & 0 & 4 & 2 & 300 \\
\hline $\mathrm{F} 2 \quad 7-17 \mathrm{~cm}$ & 75 & 38 & 26 & 10 & 21 & 3 & 18 & 103 & 0 & 0 & 6 & 0 & 300 \\
\hline $\mathrm{F} 3 \quad 0-2 \mathrm{~cm}$ & 70 & 18 & 20 & 28 & 13 & 4 & 9 & 71 & 0 & 0 & 67 & 0 & 300 \\
\hline $\mathrm{F} 3 \quad 7-17 \mathrm{~cm}$ & 112 & 12 & 22 & 22 & 15 & 1 & 17 & 77 & 0 & 0 & 22 & 0 & 300 \\
\hline T1 $0-2 \mathrm{~cm}$ & 176 & 10 & 13 & 1 & 4 & 4 & 1 & 26 & 26 & 13 & 1 & 25 & 300 \\
\hline $\mathrm{T} 12.7 \mathrm{~cm}$ & 176 & 19 & 12 & 0 & 4 & 4 & 2 & 26 & 0 & 12 & 4 & 41 & 300 \\
\hline $\mathrm{T} 1 \quad 7-17 \mathrm{~cm}$ & 48 & 8 & 9 & 2 & 0 & 2 & 1 & 11 & 0 & 8 & 1 & 10 & 100 \\
\hline $\mathrm{T} 117-27 \mathrm{~cm}$ & 48 & 5 & 7 & 1 & 0 & 6 & 0 & 12 & 0 & 12 & 5 & 4 & 100 \\
\hline T2 $0-2 \mathrm{~cm}$ & 44 & 12 & 5 & 3 & 0 & 7 & 0 & 4 & 0 & 14 & 10 & $1(2 P)$ & 100 \\
\hline T2 $7.17 \mathrm{~cm}$ & 34 & 14 & 7 & 7 & 0 & 4 & 0 & 8 & 0 & 15 & 6 & 5 & 100 \\
\hline
\end{tabular}


Table A3.4

Percent composition of the 30 to 300 micron size fraction for samples from Mt. Feather and Table Mountain, based on counts per sample. Site locations are shown in Figures 3.1 and 3.2 in Chapter Three of the mainbody of the thesis.

Analyist: Dr. Warren Dickinson, Geology Department, Victoria University of Wellington.

\begin{tabular}{|c|c|c|c|c|c|c|c|c|c|c|c|c|c|}
\hline Sample & Quartz & Feldspan & IRF & SRF & MRF & $H M$ & Opaque & Clay Mtx & Calcite & Ehabazit & Porosity & Other & Total \\
\hline $\mathrm{F} 1 \quad 0-2 \mathrm{~cm}$ & 39 & 4 & 3 & 9 & 3 & 0 & 1 & 29 & 0 & 0 & 11 & 0 & 100 \\
\hline $\mathrm{F} 1 \quad 7-17 \mathrm{~cm}$ & 39 & 6 & 6 & 9 & 5 & 0 & 1 & 25 & 0 & 0 & 8 & 0 & 100 \\
\hline $\mathrm{F} 1 \quad 27-37 \mathrm{~cm}$ & 33 & 5 & 7 & 8 & 1 & 0 & 3 & 28 & 0 & 0 & 14 & 0 & 100 \\
\hline $\mathrm{F} 2 \quad 0-2 \mathrm{~cm}$ & 28 & 10 & 9 & 7 & 1 & 1 & 6 & 33 & 0 & 0 & 4 & 0 & 100 \\
\hline F2 $2-7 \mathrm{~cm}$ & 27 & 12 & 14 & 8 & 2 & 0 & 6 & 29 & 0 & 0 & 1 & 1 & 100 \\
\hline $\mathrm{F} 3 \quad 7-17 \mathrm{~cm}$ & 37 & 4 & 7 & 7 & 5 & 0 & 6 & 26 & 0 & 0 & 7 & 0 & 100 \\
\hline T1 $0-2 \mathrm{~cm}$ & 59 & 3 & 4 & 0 & 1 & 1 & 0 & 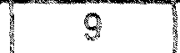 & 9 & 4 & 0 & 8 & 100 \\
\hline $\mathrm{T} 1 \quad 2-7 \mathrm{~cm}$ & 59 & 6 & 4 & 0 & i & 1 & 8 & 9 & 0 & 4 & 1 & 14 & 100 \\
\hline $\mathrm{T} 1 \quad 7-17 \mathrm{~cm}$ & 48 & 8 & 9 & 2 & 0 & 2 & 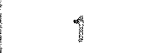 & 4 & 0 & 8 & 1 & 10 & 100 \\
\hline T1 $17-27 \mathrm{~cm}$ & 48 & 5 & 7 & 1 & 0 & 6 & 0 & 12 & 0 & 12 & 5 & 4 & 100 \\
\hline T2 $0-2 \mathrm{~cm}$ & 44 & 12 & 5 & 3 & 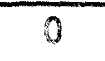 & 7 & 7 & 4 & 0 & 14 & 10 & $1(2 P)$ & 100 \\
\hline
\end{tabular}

IRF - Igneous Rock fragments dominantly of dolerite origin.

SRF - Sedimentary rock fragments of sandstone, shale, coal, heavy minerals etc. dominantly of Beacon Supergroup origin.

MRF - Metamorphic rock fragments.

Matrix - Clay and silt sized particles that are either partially obscured by clay or were too small to identify.

。․ HM - Heavy minerals 
Figure A3.1

X-ray diffractograms and their interpretation from the clay fraction of samples from Sirius Group tills from Mt. Feather and Table Mountain. samples were prepared by the author and run in the XRF analyser by Mr. K. Stevens, Geology Department, Victoria University of Wellington. On all graphs 1. labels the output of the air dried sample, 2. labels the output of the glycolated sample and 3. labels the output of the heated sample.

A. Mt. Feather, Site Two, $2-7 \mathrm{~cm}$.

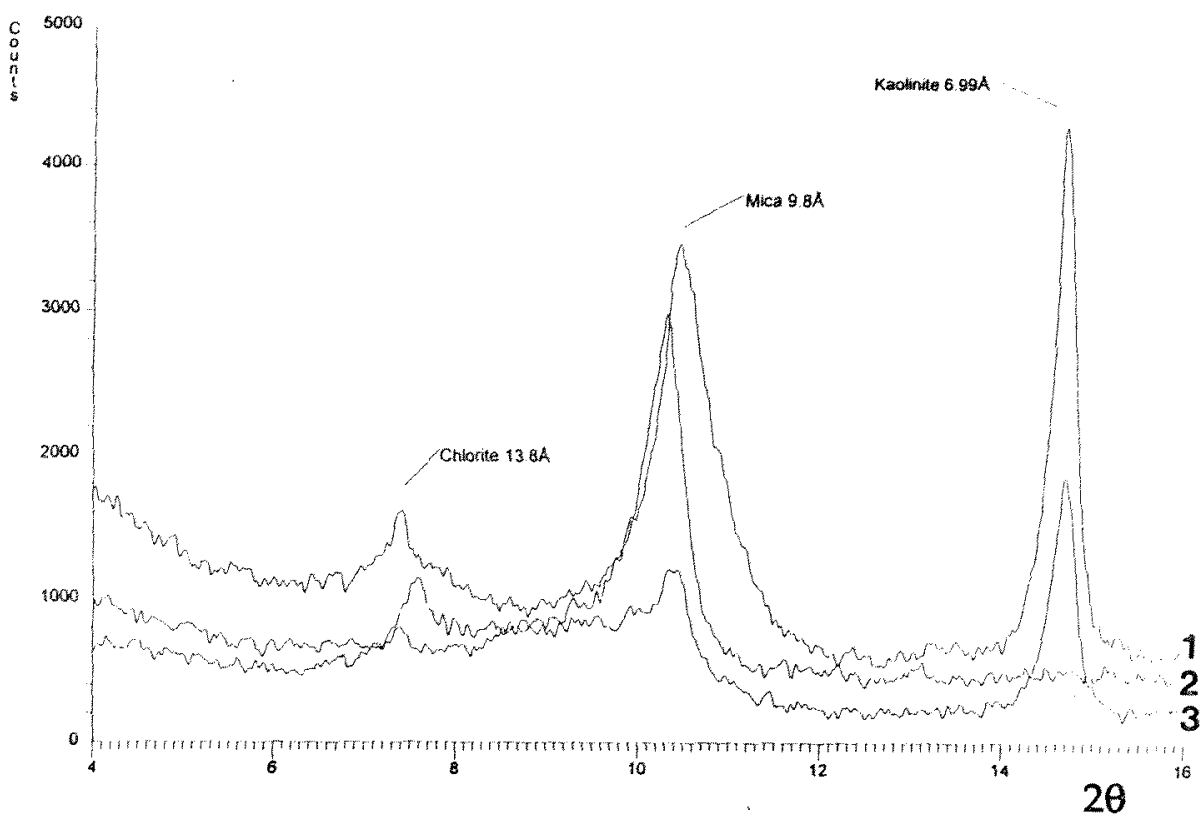

B. Table Mountain, Site Two, $2-5 \mathrm{~cm}$.

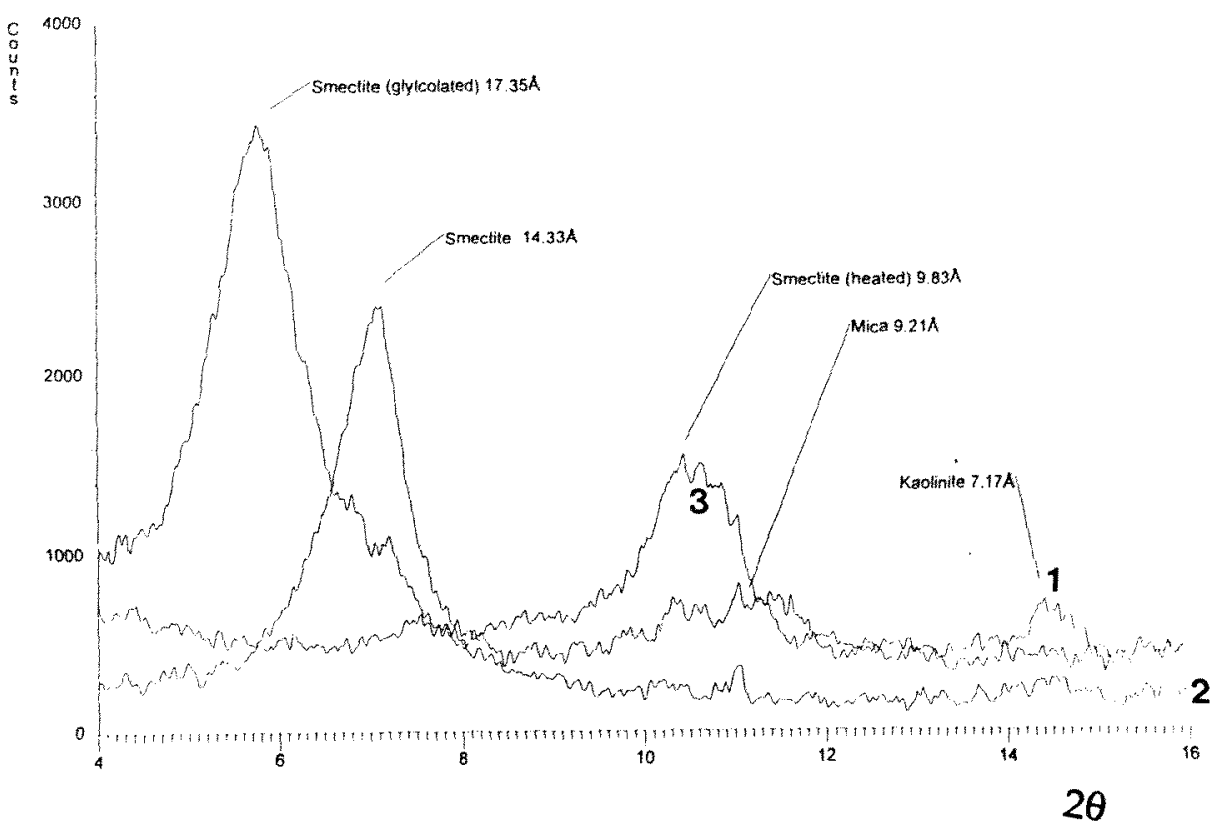


C. Table Mountain, Site One, Top (Brown) $17-27 \mathrm{~cm}$.

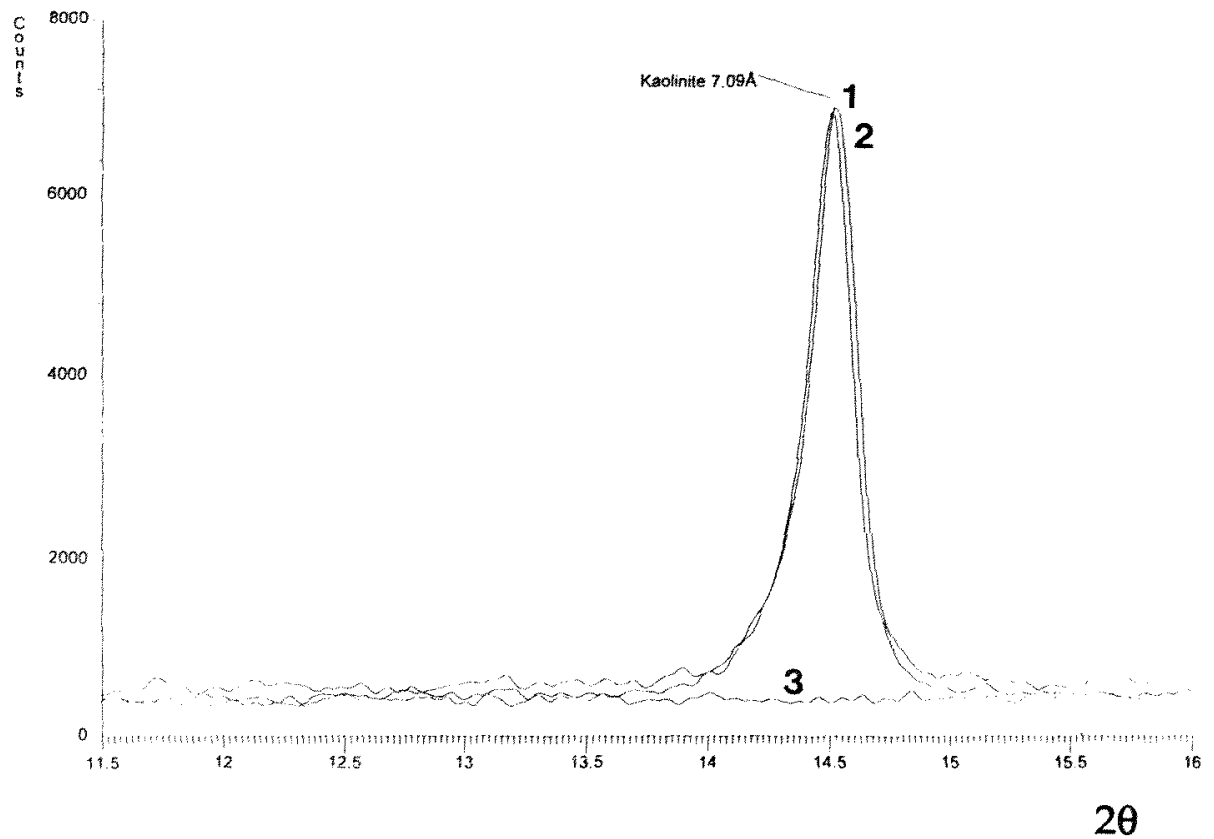

D. Table Mountain, Site One, Base (Pink) $27-37 \mathrm{~cm}$.

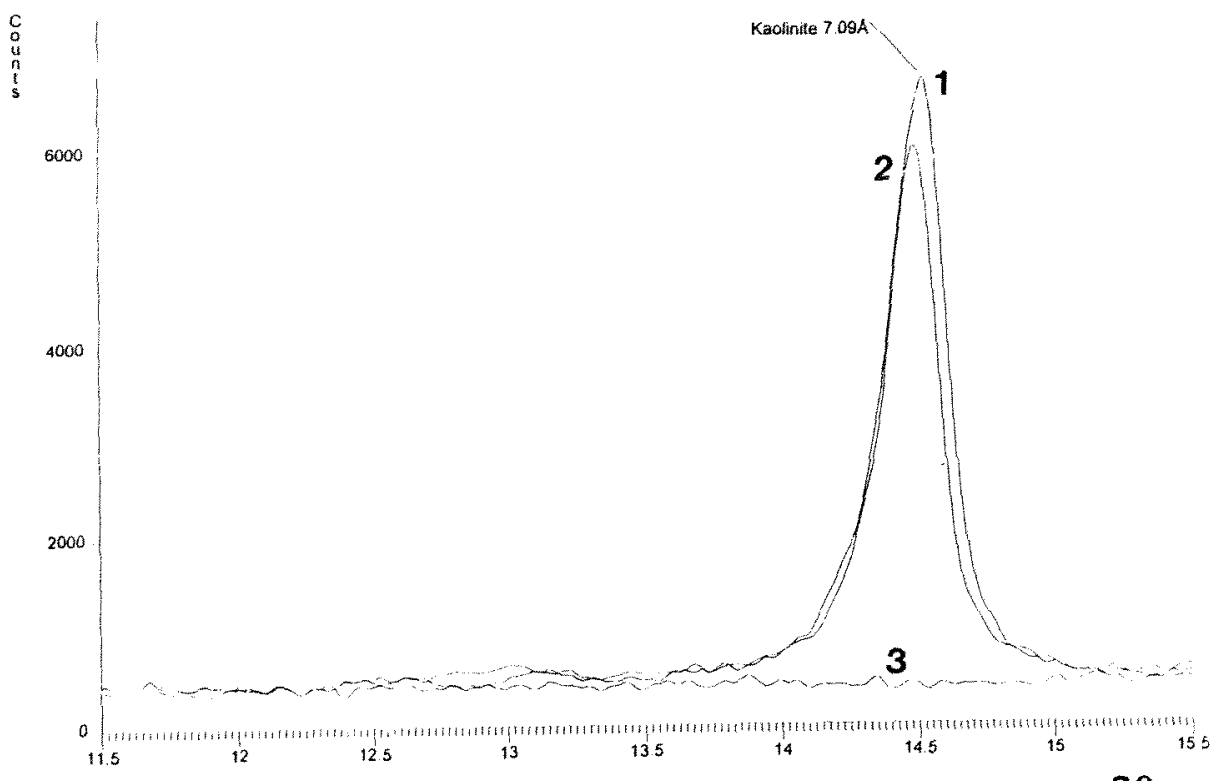




\section{APPENDIX FOUR}

\section{Measurements of clast shape and fabric and glacial striae}

Aids in determining the part of the glacier in which the tills were transported and the glacial flow direction when the tills were deposited.

Table A4.1 Sphericity measurements from Sites One and Two at both Mt. Feather andTable Mountain.

Table A4.2 Roundness measurements from Sites One and Two at Mt. Feather and Table Mountain.

Table A4.3 Mean and standard deviation of roundness and sphericity at Mt. Feather and Table Mountain, Sites One and Two.

Table A4.4 Fabric Data from Sites One, Two and Three at Mt. Feather and One and Two at Table Mountain.

Table A4.5 Striation measurements from the surface of the till at Mt. Feather, Sites One, Two and Three and some surface rock orientations from the overlying moraine material.

Figure A4.1 Plots of fabric data from Mt. Feather, from Table A4.4.

Figure A4.2 Plots of striation measurements and surface rock orientations at Mt. Feather, from Table A4.5

Figure A4.3 Plots of fabric measurements from Table Mountain, from Table A4.4. 
Table A4.1

Sphericity measurements from Site One and Two at Mt. Feather and Site One and Two at Table Mountain.

Mt. Feather

A. Site One
$\left.\begin{array}{|ccc|c|}\hline \text { A-axis } & \text { B-axis } & \text { C-axis } & \text { Sphericity } \\ \hline 31 & 20 & 10 & 0.54 \\ 20 & 19 & 18 & 0.95 \\ 26 & 20 & 13 & 0.69 \\ 35 & 29 & 15 & 0.61 \\ 28 & 26 & 13 & 0.61 \\ 28 & 26 & 9 & 0.48 \\ 23 & 18 & 9 & 0.58 \\ 27 & 22 & 12 & 0.62 \\ 24 & 15 & 13 & 0.78 \\ 17 & 16 & 9 & 0.67 \\ 24 & 13 & 13 & 0.82 \\ 20 & 13 & 8 & 0.63 \\ 22 & 16 & 7 & 0.52 \\ 29 & 28 & 9 & 0.46 \\ 22 & 13 & 9 & 0.66 \\ 16 & 10 & 9 & 0.80 \\ 18 & 16 & 10 & 0.70 \\ 21 & 16 & 12 & 0.75 \\ 20 & 13 & 11 & 0.77 \\ 18 & 12 & 10 & 0.77 \\ 18 & 11 & 8 & 0.69 \\ 18 & 13 & 10 & 0.75 \\ 21 & 15 & 9 & 0.64 \\ 16 & 14 & 8 & 0.66 \\ 19 & 11 & 7 & 0.62 \\ 25 & 17 & 10 & 0.62 \\ 22 & 16 & 4 & 0.36 \\ 48 & 29 & 20 & 0.66 \\ 30 & 22 & 20 & 0.85 \\ 35 & 23 & 18 & 0.74 \\ 24 & 17 & 12 & 0.71 \\ 20 & 13 & 12 & 0.82 \\ 21 & 15 & 13 & 0.81 \\ 18 & 15 & 13 & 0.86 \\ 19 & 15 & 14 & 0.88 \\ 21 & 14 & 11 & 0.74 \\ 36 & 20 & 13 & 0.62 \\ 21 & 22 & 10 & 0.60 \\ 25 & 22 & 6 & 0.40 \\ 16 & 16 & 7 & 0.58 \\ \hline\end{array}\right]$

continued over 
A. Mt. Feather Site One, continued....

\begin{tabular}{|ccc|c|}
\hline 22 & 15 & 14 & 0.84 \\
23 & 12 & 11 & 0.76 \\
17 & 16 & 8 & 0.62 \\
17 & 12 & 11 & 0.84 \\
14 & 12 & 8 & 0.72 \\
23 & 13 & 8 & 0.60 \\
19 & 10 & 7 & 0.64 \\
17 & 14 & 10 & 0.75 \\
16 & 14 & 12 & 0.86 \\
16 & 14 & 5 & 0.48 \\
\hline Mean & & & 0.68 \\
\hline Standard Deviation & & 0.13 \\
\hline
\end{tabular}

B. Site Two

\begin{tabular}{|ccc|c|}
\hline A-axis & B-axis & C-axis & Sphericity \\
\hline 26 & 20 & 15 & 0.76 \\
27 & 15 & 12 & 0.71 \\
22 & 14 & 7 & 0.54 \\
21 & 15 & 12 & 0.77 \\
20 & 15 & 9 & 0.65 \\
\hline Mean & & 0.68 \\
\hline Standard & Deviation & 0.09 \\
\hline
\end{tabular}

\section{Table Mountain}

C. Site One

\begin{tabular}{|ccc|c|}
\hline A-axis & B-axis & C-axis & Sphericity \\
\hline 24 & 11 & 6 & 0.51 \\
24 & 19 & 9 & 0.56 \\
20 & 12 & 12 & 0.84 \\
27 & 20 & 9 & 0.53 \\
17 & 10 & 6 & 0.60 \\
49 & 46 & 24 & 0.63 \\
43 & 30 & 21 & 0.70 \\
25 & 14 & 3 & 0.30 \\
15 & 15 & 8 & 0.66 \\
\hline Mean & & & 0.59 \\
\hline Standard Deviation & & 0.15 \\
\hline
\end{tabular}


D. Table Mountain Site Two

\begin{tabular}{|ccc|c|}
\hline A-axis & B-axis & C-axis & Sphericity \\
\hline 19 & 13 & 7 & 0.58 \\
16 & 6 & 5 & 0.64 \\
33 & 19 & 16 & 0.74 \\
24 & 16 & 10 & 0.64 \\
23 & 21 & 13 & 0.70 \\
19 & 16 & 8 & 0.59 \\
22 & 21 & 12 & 0.68 \\
19 & 12 & 10 & 0.76 \\
18 & 15 & 10 & 0.72 \\
23 & 10 & 8 & 0.65 \\
16 & 12 & 10 & 0.80 \\
5 & 10 & 7 & 0.99 \\
17 & 14 & 6 & 0.53 \\
18 & 12 & 6 & 0.55 \\
14 & 11 & 4 & 0.47 \\
16 & 11 & 9 & 0.77 \\
15 & 13 & 11 & 0.85 \\
13 & 10 & 10 & 0.92 \\
15 & 10 & 9 & 0.81 \\
15 & 12 & 9 & 0.77 \\
13 & 12 & 6 & 0.61 \\
33 & 22 & 17 & 0.74 \\
16 & 13 & 7 & 0.62 \\
15 & 9 & 4 & 0.49 \\
14 & 11 & 9 & 0.81 \\
13 & 11 & 7 & 0.70 \\
14 & 8 & 7 & 0.76 \\
16 & 11 & 6 & 0.59 \\
30 & 22 & 10 & 0.53 \\
26 & 19 & 10 & 0.59 \\
23 & 32 & 12 & 0.58 \\
28 & 18 & 10 & 0.58 \\
24 & 13 & 9 & 0.64 \\
17 & 16 & 7 & 0.56 \\
20 & 17 & 10 & 0.67 \\
18 & 15 & 5 & 0.45 \\
18 & 12 & 6 & 0.55 \\
18 & 9 & 5 & 0.54 \\
19 & 12 & 11 & 0.81 \\
18 & 12 & 7 & 0.61 \\
13 & 13 & 4 & 0.46 \\
15 & 12 & 7 & 0.65 \\
17 & 9 & 3 & 0.39 \\
16 & 12 & 8 & 0.69 \\
17 & 16 & 8 & 0.62 \\
16 & 13 & 9 & 0.73 \\
16 & 13 & 7 & 0.62 \\
13 & 9 & 2 & 0.32 \\
14 & 8 & 7 & 0.76 \\
15 & 9 & 6 & 0.64 \\
12 & 9 & 8 & 0.84 \\
\hline Mean & & & 0.65 \\
Standard & Deviation & & 0.13 \\
\hline & & & \\
\hline
\end{tabular}




\section{Table A4.2}

Roundness measurements from Sites One and Two at Mt. Feather and Table Mountain. Locations are shown in Figures 3.1 and 3.2 in the main body of the thesis.

\begin{tabular}{|c|c|cc|c|c|}
\hline Krumbein & \multicolumn{3}{|c|}{ Table Mountain } & \multicolumn{3}{c|}{ Mount Feather } \\
\cline { 2 - 7 } Roundness & Site One & \multicolumn{2}{|c|}{ Site Two } & Site One & Site Two \\
\hline & & Top & Base & & \\
0.1 & - & - & - & 4 & - \\
0.2 & - & 1 & - & 3 & - \\
0.3 & 3 & 1 & - & 2 & - \\
0.4 & 15 & 2 & 4 & 12 & 4 \\
0.5 & 40 & 21 & 17 & 24 & 6 \\
0.6 & 5 & 5 & 9 & 6 & - \\
0.7 & - & - & - & 2 & - \\
0.8 & - & - & - & 1 & - \\
\hline Mean & & 0.49 & 0.51 & & \\
& 0.48 & 0.5 & & 0.44 & 0.46 \\
\hline Std. Dev. & 0.07 & 0.07 & & 0.14 & 1.41 \\
\hline
\end{tabular}

\section{Table A4.3}

Mean and Standard Deviation of roundness and sphericity data at Mt. Feather and Table Mountain, Sites One and Two.

\begin{tabular}{|c|c|c|c|c|}
\hline Site & \multicolumn{2}{|l|}{ Sphericity } & \multicolumn{2}{|c|}{ Roundness } \\
\hline Mount Feather & Mean & Std. Dev. & Mean & Std.Dev \\
Site One & 0.68 & 0.13 & 0.48 & 0.14 \\
Site Two & 0.68 & 0.09 & 0.5 & 0.05 \\
Table Mountain & & & & \\
Site One & 0.59 & 0.15 & 0.44 & 0.07 \\
Site Two & 0.65 & 0.13 & 0.46 & 0.07 \\
Feather Congl.* & 0.68 & & 0.57 & \\
\hline
\end{tabular}

${ }^{\wedge}$ From the Visual Roundness of Krumbein (1941)

*Barrett and Fitzgerald,(1985) 


\section{Table A4.4}

Fabric Data from Sites One and Two at Table Mountain and One, Two and Three at Mt. Feather. Locations are shown in Figures 3.1 and 3.2 in Chapter Three in the main body of the thesis.

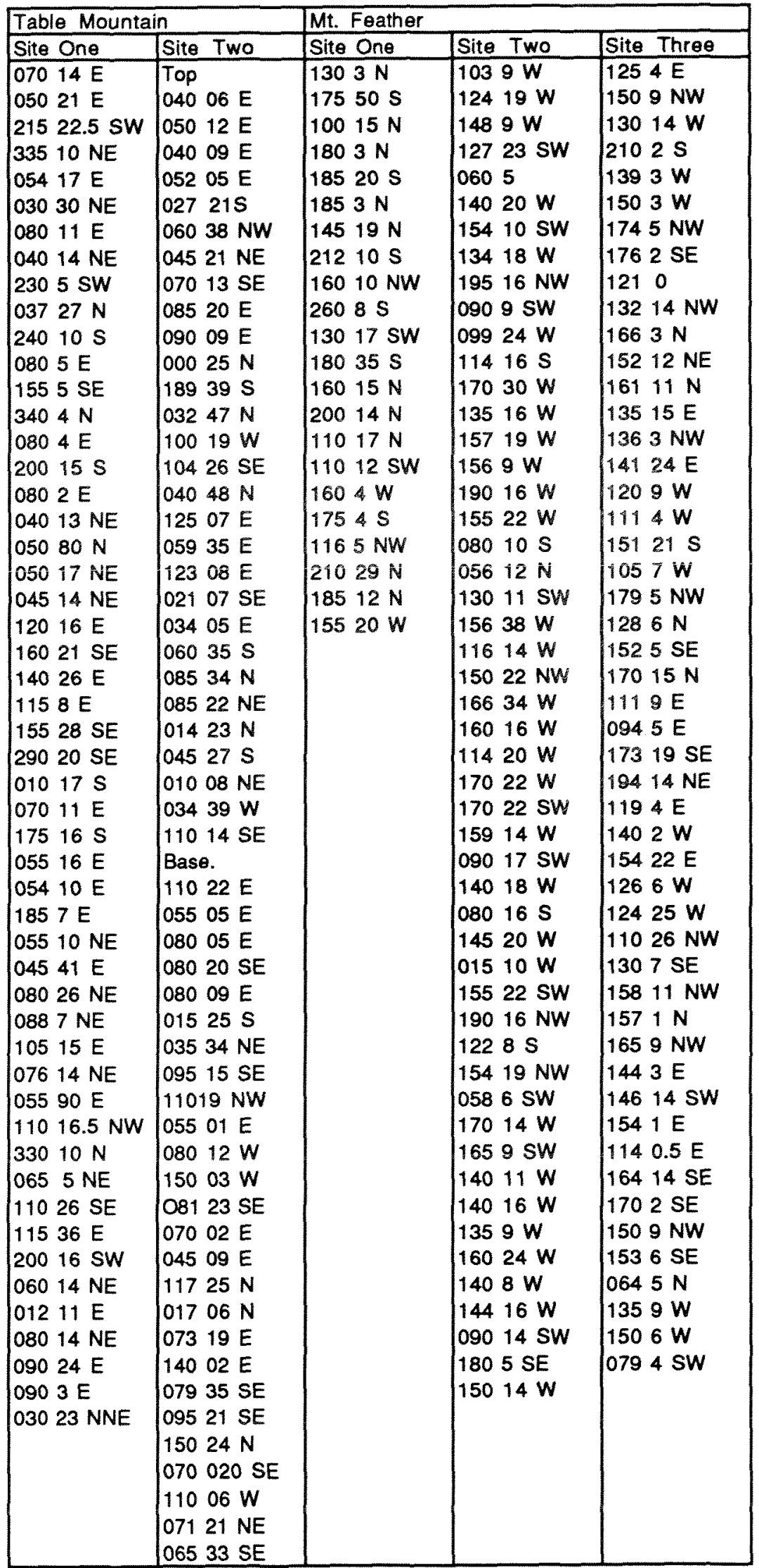




\section{Table A4.5}

Striation measurements from the surface of the till at Mt. Feather at Sites One, Two and Three and some surface rock orientations from the overlying moraine material.

\begin{tabular}{|c|c|c|c|}
\hline Site One & Site Two & Site Three & S.R.O. \\
\hline $93 \mathrm{E}$ & $97 E$ & $83 E$ & 278 \\
\hline $98 \mathrm{E}$ & $138 \mathrm{~S}$ & $102 \mathrm{E}$ & 283 \\
\hline $84 E$ & $101 \mathrm{SE}$ & $88 \mathrm{E}$ & 193 \\
\hline $93 \mathrm{E}$ & 113 SE & $70 \mathrm{E}$ & 173 \\
\hline $85 E$ & $108 \mathrm{SE}$ & $86 \mathrm{E}$ & 213 \\
\hline $93 \mathrm{E}$ & $82 E$ & $96 \mathrm{E}$ & 173 \\
\hline $93 \mathrm{E}$ & $107 \mathrm{E}$ & $96 \mathrm{E}$ & 223 \\
\hline $78 \mathrm{E}$ & $105 \mathrm{E}$ & $83 E$ & 253 \\
\hline $92 \mathrm{E}$ & $110 \mathrm{E}$ & $87 \mathrm{E}$ & 213 \\
\hline $103 \mathrm{SE}$ & $93 \mathrm{E}$ & $72 \mathrm{E}$ & 303 \\
\hline $98 \mathrm{E}$ & $108 \mathrm{E}$ & $69 E$ & 203 \\
\hline $107 \mathrm{SE}$ & $87 \mathrm{E}$ & $69 \mathrm{E}$ & 223 \\
\hline $83 \mathrm{E}$ & $78 \mathrm{E}$ & $66 \mathrm{E}$ & 223 \\
\hline $93 \mathrm{E}$ & $103 \mathrm{E}$ & $93 \mathrm{E}$ & 143 \\
\hline $85 \mathrm{E}$ & $84 \mathrm{E}$ & $87 \mathrm{E}$ & 303 \\
\hline $105 \mathrm{SE}$ & $113 \mathrm{E}$ & $79 E$ & 193 \\
\hline $93 E$ & $87 E$ & $111 \mathrm{SE}$ & 273 \\
\hline $83 E$ & $95 \mathrm{E}$ & $65 \mathrm{E}$ & 213 \\
\hline $103 \mathrm{E}$ & $78 \mathrm{E}$ & $82 \mathrm{E}$ & 198 \\
\hline $103 \mathrm{E}$ & $103 E$ & $89 \mathrm{E}$ & 163 \\
\hline \multirow[t]{37}{*}{$93 \mathrm{E}$} & $89 E$ & $54 \mathrm{E}$ & 203 \\
\hline & $95 \mathrm{E}$ & $63 \mathrm{E}$ & 223 \\
\hline & $126 \mathrm{SE}$ & $87 \mathrm{E}$ & 273 \\
\hline & $82 \mathrm{E}$ & $81 \mathrm{E}$ & 198 \\
\hline & $78 \mathrm{E}$ & $73 \mathrm{E}$ & 248 \\
\hline & $107 \mathrm{E}$ & $91 \mathrm{E}$ & 193 \\
\hline & $106 \mathrm{E}$ & $94 \mathrm{E}$ & $223 \mathrm{~N}$ \\
\hline & $83 \mathrm{E}$ & $94 \mathrm{E}$ & 288 \\
\hline & $122 \mathrm{E}$ & $77 \mathrm{E}$ & 253 \\
\hline & $98 \mathrm{E}$ & $89 \mathrm{E}$ & 193 \\
\hline & $83 \mathrm{E}$ & $87 \mathrm{E}$ & 183 \\
\hline & $118 \mathrm{SE}$ & $74 E$ & 173 \\
\hline & $77 \mathrm{E}$ & $69 \mathrm{E}$ & 163 \\
\hline & $77 \mathrm{E}$ & $68 \mathrm{E}$ & 243 \\
\hline & $78 \mathrm{E}$ & $84 E$ & 278 \\
\hline & & $105 \mathrm{E}$ & 243 \\
\hline & & $104 E$ & 203 \\
\hline & & $96 \mathrm{E}$ & 278 \\
\hline & & $124 \mathrm{SE}$ & 233 \\
\hline & & $84 \mathrm{E}$ & 223 \\
\hline & & $75 \mathrm{E}$ & 243 \\
\hline & & $71 \mathrm{E}$ & 243 \\
\hline & & $97 E$ & 263 \\
\hline & & $94 \mathrm{E}$ & 193 \\
\hline & & $84 \mathrm{E}$ & 303 \\
\hline & & $102 \mathrm{E}$ & 183 \\
\hline & & $92 \mathrm{E}$ & 223 \\
\hline & & $98 \mathrm{E}$ & 243 \\
\hline & & $89 \mathrm{E}$ & 233 \\
\hline & & $99 \mathrm{E}$ & 193 \\
\hline & & & 143 \\
\hline & & & 293 \\
\hline & & & 233 \\
\hline & & & 153 \\
\hline & & & 188 \\
\hline & & & $\begin{array}{l}233 \\
173\end{array}$ \\
\hline & & & \\
\hline
\end{tabular}

S.R.O = surface rock orientation 
Figure A4.1 Plots of fabric data from Mt. Feather from Table A4.4

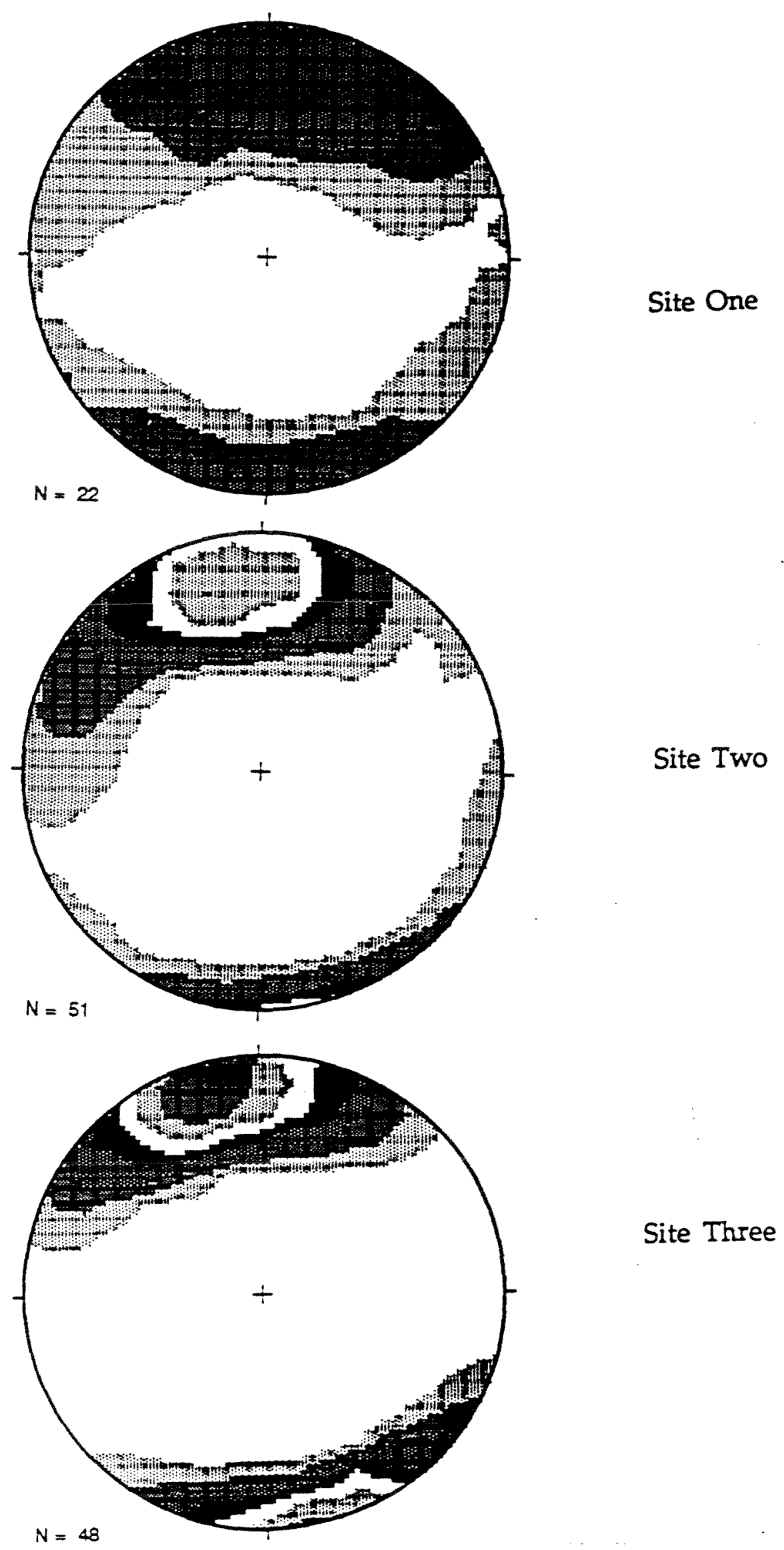


Figure A4.2 Plots of striation measurements and surface rock orientations at Mt. Feather from Table A4.5.

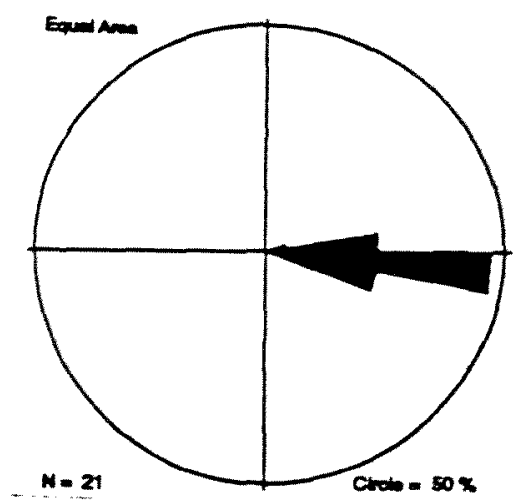

A. Surface striation measurements from Site One

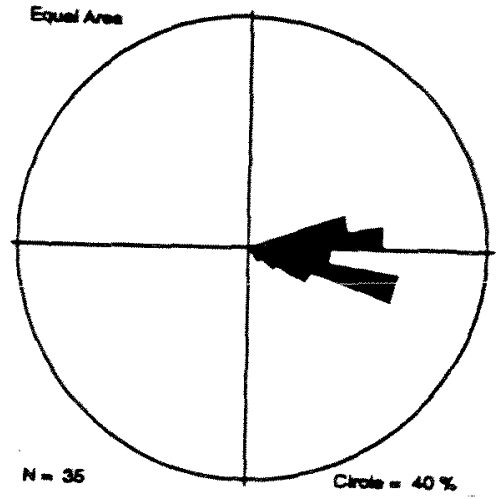

B. Surface striation measurements from Site Two.

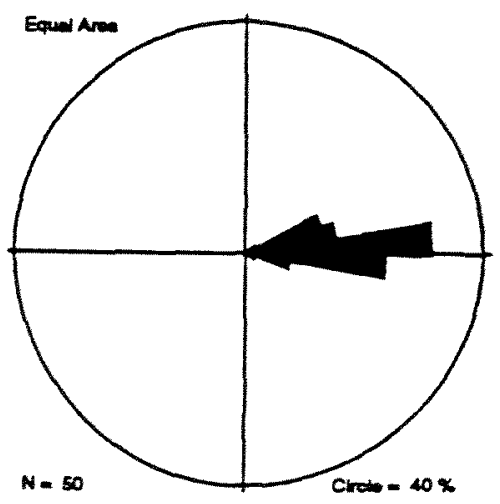

C. Surface striation measurements from Site Three

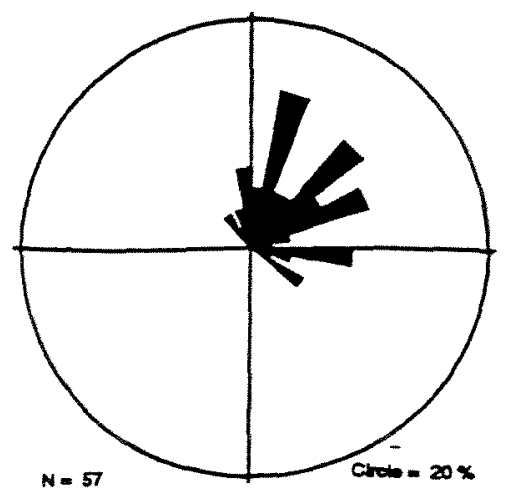

D. Surface rock orientation measurements on the platform between Sites One and Two 
Figure 4.3 Plots of fabric measurements from Table Mountain from Table A4.4.

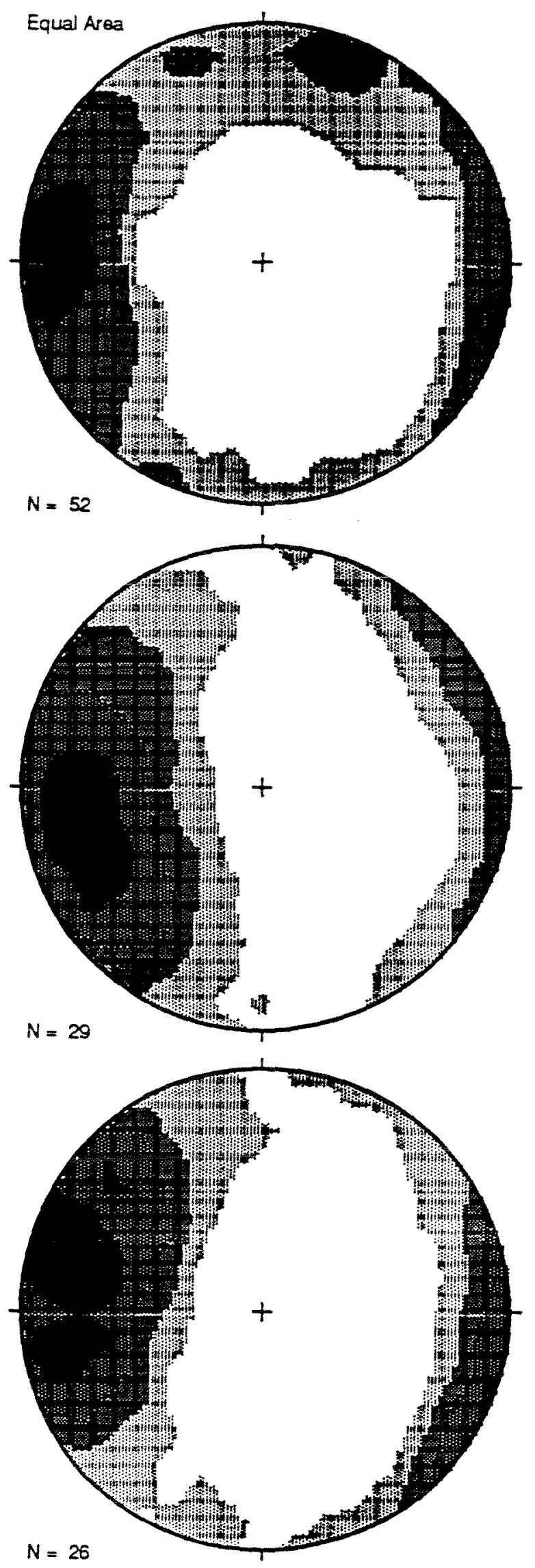

\section{Site One}

Site Two, top

Site Two, base 


\section{APPENDIX FIVE}

\section{Processing method for the concentration of biogenic silica}

Diatoms are rare in the Sirius Group tills (about one diatom per gram) hence a lot of careful processing is required to concentrate them to amounts in which we can find them.

APPENDIX 5.1 Table of methods used for diatom extraction. Table A5.1 The two main methods used to concentrate diatoms from the Sirius Group tills by other diatomists and the method used for this thesis.

APPENDIX 5.2 Slide preparation

APPENDIX 5.3 Microscope analysis.

APPENDIX 5.4 Comparison of methods used by Burckle and Harwood.

APPENDIX 5.5 Separating diatioms in snow samples.

APPENDIX 5.6 Contamination and decontamination Table A5.2 Results of decontamination test.

APPENDIX 5.7 Problems with processing and separating sediment.

APPENDIX 5.8 Initial processing method.

Figure A5.1 Initial method and equipment for this study for the concentration of diatoms.

Table A5.3 Concentration calculations for diatoms and phytoliths counted.

APPENDIX 5.9 Method used for determining number of diatoms and phytoliths per gram. 


\section{APPENDIX 5.1 Table of methods used for diatom extraction}

Table A5.1 The two main methods used to concentrate diatoms from the Sirius Group tills, used by two diatomists involved in this debate, Lloyd Burckle (Columbia University) and David Harwood (Universityof Nebraska). Here the two methods are outlined, and discussed, along with the method used for this thesis, which was modified from a number of sources and experiments done in the lab. Notes on modifications and references are marked (1) and discussed in the text following the table.

\begin{tabular}{|c|c|c|}
\hline Burckle method & Harwood method & Method used for thesis \\
\hline $\begin{array}{l}\text { (I) Disaggregation } \\
250 \mathrm{ml} \text { of } 10 \% \mathrm{H}_{2} \mathrm{O}_{2} \text { and } \\
250 \mathrm{ml} \text { of } 1 \mathrm{~mol} \mathrm{HCL} \text { or } 1 \mathrm{pt} \\
36 \% \mathrm{HCL} \text { and } 9 \mathrm{pts} \text { water. } \\
\text { Place in water bath for } 5 \mathrm{hrs} \\
\text { at } 50^{\circ} \mathrm{C} \text {. } \\
\text { Let cool and settle over } \\
\text { night. Decant and discard } \\
\text { supernatant. } \\
\text { Refill with distilled water, } \\
\text { and settle again for } 8 \mathrm{hrs} \text {. } \\
\text { Decant and discard } \\
\text { supernatant. } \\
\text { Add } 200 \text { ml of } 5 \mathrm{~g} / 1 \text { of } \\
\text { Sodium hexametaphosphate }\end{array}$ & $\begin{array}{l}\text { Sample placed in a beaker of } \\
\text { distilled water and calgon and left } \\
\text { to soak for } 48 \mathrm{hrs}\end{array}$ & $\begin{array}{l}200 \mathrm{~g} \text { of sample is placed in a } 11 \text { beaker of calgon and distilled } \\
\text { water, stirred and left for } 24 \mathrm{hrs} \text {. } \\
\text { Calgon siphoned off. } \\
200 \mathrm{ml} \text { of } 10 \% \mathrm{H}_{2} \mathrm{O}_{2} \text { and } 200 \mathrm{ml} \text { of } 11 \% \mathrm{HCl} \text { is added. The } \\
\text { samples are placed in a water bath for five hours at } 50^{\circ} \mathrm{C} \text { (1). } \\
\text { Samples are then diluted and left to settle overnight. } \\
\text { Supernatant is decanted and discarded. This is sufficient to } \\
\text { disaggregate the samples. Much higher concentrations are } \\
\text { usually used to remove organic matter and calcarious } \\
\text { material. } \\
\text { Disaggregation is continued with the addition of } 200 \mathrm{ml} \text { of } \\
5 \mathrm{~g} / \mathrm{l} \text { Sodium hexametaphosphate. The beaker is placed on a } \\
\text { hot plate and brought to boil for } 15 \text { minutes, then diluted to } \\
500 \text { ml with distilled water. The beaker is then placed in a } \\
\text { DAWE ultrasonic cleaning tank at setting } 60 \text { for one } \\
\text { minute (2). Sample is left to settle overnight and } \\
\text { supernatent is siphoned and discarded. }\end{array}$ \\
\hline
\end{tabular}


Table A5.1 continued

Burckle method, contd.

(II) Removal of sand

Sand is separated throughout the various stages of processing using settling time techniques.

\section{(III) Removal of Clays}

The sample is transferred to an $800 \mathrm{ml}$ beaker. $200 \mathrm{ml}$ of $1 \%$ sodium hexametaphosphate is added. This is boiled for 15 minutes and diluted with distilled water. The beaker is placed in a sonication bath for two minutes and allowed to settle for 1-2 hours.

The supernatant is siphoned off and discarded.
Harwood method,. contd.

Method used for thesis,..contd.

It was calculated by (in Stroevan 1994) that a water column with an upward water velocity of 0.40 $\mathrm{cm} / \mathrm{sec}$ will float diatoms and fine material and leave behind siliclastic material of the same size and larger. This replaces the method of useing bubbles to float the diatoms from the sediment, which Harwood used in 1986.

The suspended material is siphoned off near the top of the tube (fig 6.1) and sieved at 25 microns .

The fraction less than $25 \mu \mathrm{m}$ is collected in 191 buckets. An over flow mechanism then diverts the excess water into a bigger basin which in turn is collected into a bigger basin which in turn is connected through an over flow mechanism to the sewage system.

When the upper part of the column remained clear after stirring all suspended material is siphoned off.
Beakers are filled with distilled water to a $12 \mathrm{~cm}$ height and stirred vigorously. Sediment is settled for one minute and the supernatant pored into a 21 beaker (3).

The above is repeated on the settled fraction, then the remaining coarse fraction is discarded.

The above process is repeated on all the remaining decanted fine fraction. The settled coarse material is discarded.

All sediment is left to settle overnight. Supernatant is siphoned and discarded.

Samples are added to a 1 or 21 beakers with $200 \mathrm{mls}$ of $2 \%$ Sodium Hexametaphosphate (Calgon), these are boiled vigorously on a hot plate for 15 minutes.

Samples are topped up to $12 \mathrm{~cm}$ above the base of the beaker with distilled water, and placed in a DAWE ultrasonic cleaning tank at setting 60 for one minute and left to settle for three hours (4).

Clays remaining in suspension are siphoned off and discarded. 
Table A5.1 continued.

Burckle method, contd.

This process of boiling, sonicatrion settling and decantation was repeated up to six times, using Calgon ( $2 \%$ solution) until the settled material is white. This is also repeated three times using distilled and deionized water to remove any residual hexametaphosphate and clays.

\section{(IV) Heavy liquid separation.}

Uses sodium potytungstate with a specific gravity of 2.2 in a similar manner to that used by Harwood (next column).
Harwood method, contd.

Residual material in the base of the tube is sieved in a sieve stack of $500,250,125$ and $63 \mu \mathrm{m}$ and dried. Any sedimentary clasts found are processed for diatoms using $\mathrm{H}_{2} \mathrm{O}_{2}$ and $\mathrm{HCl}$ to disaggregate them then clays and sand are removed removed by usual diatom processing methods (Harwood 1984, Brady 1977).

The separation is done in $15 \mathrm{ml}$ vials, using SPT with a specific gravity of 2.2. The vials are filled with $3.5 \mathrm{ml}$ SPT. Bottles containing the $>25 \mu \mathrm{m}$ fraction are shaken, and allowed to settle for 2 minutes before pippetting.
Method used for thesis, contd

$400 \mathrm{ml}$ of $2 \%$ Calgon is added. The sample is stirred vigorously and left to settle for a further three hours (5).

This process is repeated up to six times or until no clay remains in suspension after three hours. The same method with distilled water instead of calgon is repeated three more times to wash any residue of calgon from the sample.

If after this process most of the clay is not removed, the material is transferred to $50 \mathrm{ml}$ centrifuge tubes. The tubes are filled with calgon, shaken vigorously and centrifuged at 1100 RPM for 3 minutes, the supernantant is decanted and discarded. This is repeated until the supernataint is clear. The final three times are repeated with distilled water only, to wash residual calgon from the sample (6).

Diatoms have a specific gravity of less than 2.25. The heavy liquid, sodium polytungstate (SPT) is made up to a specific gravity of $2.25(7)$.

The samples are transferred to $50 \mathrm{ml}$ centrifuge tubes, and centrifuged at $2000 \mathrm{rpm}$ for 5 minutes. All supernatant is removed and $15 \mathrm{mls}$ of SPT is added. This is shaken until all the sample is in suspension. It is then placed in a centrifuge at 1500 RPM for 15 minutes (8). 
Table A5.1 continued.

\begin{tabular}{|c|c|c|}
\hline Burckle method, contd. & Harwood method, contd. & Method used for thesis, contd \\
\hline Pers Comm Burckle (1994) & $\begin{array}{l}\text { Sediment is taken from different } \\
\text { areas above and below the } \\
\text { sediment water interface and } \\
\text { added on top of the SPT in the } \\
\text { vials. They are centrifuged for } 5 \\
\text { minutes at } 500 \text { RPM. } \\
\text { After centrifuging, sediment with } \\
\text { a SG }>2.2 \text { sits on the bottom, then } \\
\text { SPT lies above this followed by } \\
\text { material < } 2.2 \text { and on the top } \\
\text { water. The < } 2.2 \text { material is } \\
\text { removed and added to a new vial } \\
\text { which is filled to } 15 \text { mls with } \\
\text { distilled water while shaken in a } \\
\text { vortex mixer. } \\
\text { The vials are centriguged at } 2000 \\
\text { RPM for } 3 \text { minutes. This washing, } \\
\text { shaking and centrifuging is } \\
\text { repeated } 4 \text { times to remove the } \\
\text { SPT, before permanent slides of } \\
\text { the SG }<2.2 \text { are prepared. } \\
\text { From Stroeven (1994) }\end{array}$ & $\begin{array}{l}\text { Material such as diatoms, palynomorphs and most } \\
\text { phytoliths with a specific gravity (SG) of less than } 2.25 \text { sit on } \\
\text { the surface of the SPT while the mineral matter with an SG } \\
\text { of greater that } 2.25 \text { will be at the base of the tube beneath the } \\
\text { SPT, this is discarded. } \\
\text { The }<2.25 \text { material is removed with cleaned disposable } \\
\text { pipettes and is transferred into } 10 \mathrm{ml} \text { centrifuged tubes. The } \\
10 \mathrm{ml} \text { test tubes are half filled with the }<2.25 \text { material. } \\
\text { Distilled water is added to } 10 \mathrm{ml} \text { and the test tube is shaken } \\
\text { to mix the SPT and distilled water giving the SPT in the test } \\
\text { tube a SG of } 1.5 \text {. The test tubes are centrifuged at } 2000 \text { RPM } \\
\text { for } 5 \text { minutes and the float material (organic matter, coal } \\
\text { and wood SG <1.5) is removed and discarded (9). Distilled } \\
\text { water is added, the test tube is shaken and centrifuged at } \\
2000 \text { RPM for } 5 \text { minutes. Most of the water, further } \\
\text { remaining SPT above the sample is removed. This process } \\
\text { of washing, centrifuging and decanting of the remaining } \\
\text { sample in the test tube is repeated up to } 10 \text { times (10). } \\
\text { (V) Mechanical Separation } \\
\text { Some samples were separated and sieved at } 20 \mu \mathrm{m} \text { and } 5 \mu \mathrm{m} \\
\text { in a Saetorius polycarbonate filter holder and mounted as } 5- \\
20 \mu m \text { and }>20 \mu m \text { separations (11) }\end{array}$ \\
\hline
\end{tabular}


Derivation of the method used from references marked (1) in Table A5.1.

(1) This was sufficient to disaggregate the samples. Much higher concentrations are usually used to remove organic matter and calcarious material. These lower concentrations did not appear to remove that much, hence some plant matter, and palynomorphs were still identified at analysis stage.

(2) Too long under ultrasound or sonication conditions on too higher setting can break apart most diatom valves, long pennate diatoms are most susceptible to such breakage (Dr. E. Harworth, FBA, pers. comm., 1991, Krammer and Lange Bertalot, $1986 \mathrm{p} \mathrm{68)}$ ). Only very small amounts of sonication at low setting can be used.

(3) The settling time for the removal of sand is either 45 seconds or 1 minute depending in the concentration and height of fall. Quarts spheres fall much faster than diatoms of the same volume because if their hydrodynamic properties and their lower specific gravity. Margaret Harper (VUW, pers comm, 1994) uses 45 seconds for an $8 \mathrm{~cm}$ fall. Krammer and Lange-Bertalot (1986) recommend a 1-2 minute settling time.

(4) The settling time for the removal of clay was derived from Krammer and Lange-Bertalot (1986) say large diatoms from 30 to $60 \mu \mathrm{m}$ long take $10 \mathrm{mins}$ per $1 \mathrm{~cm}$ to settle out of suspension, and diatoms less than $10 \mu \mathrm{m}$ take about two hours per $\mathrm{cm}$. A three hours settling time or 20 minutes $/ \mathrm{cm}$ for material greater than $10 \mu \mathrm{m}$ was found to be sufficient.

(5) The sample is stirred rather than boiled after the first time to reduce the time required for processing. It was found that vigorous stirring had a sufficient effect of dispersal and suspension with calgon.

(6) For the removal of clays in the centrifuge Hinchey and Green (1995) recommend 1000 RPM for three minutes with modification depending on the centrifuge. In order to prevent any possible loss of smaller material, $1100 \mathrm{RPM}$ for 3 minutes is used. 
(7) Harwood et al. 1986, describe diatoms to have a SG of between 2 and 2.25. A specific gravity (SG) of 2.2 is most often used for diatom separation. A SG of 2.25 was used instead of 2.2 used by Stroeven (1994) and others because phytoliths are obtained using an SG of 2.3, (John Carter, VUW, pers. comm.) this obtained most of the phytoliths and all of the diatoms in suspension.

(8) John Carter, VUW, pers comm. 1995.

(9) Material with a SG of between 1.5 and 2.25 (including some palynomorphs, phytoliths and diatoms) sit on the bottom. The remaining residual SPT was removed and filtered for reuse in the palanology lab.

(10) The first samples were washed six times and residual SPT still occurred on the slides after mounting.

(11) This was done in order to further concentrate the samples and determine the sampling bias (introduced by Harwood and Stroeven) created in favour of concentrating the large marine diatom age indicators if samples were sieved at 20-25 $\mu \mathrm{m}$. Table 6.3 suggests some smaller diatoms (mostly broken material, smaller freshwater diatoms and a few elongate marine species) would have been missed.

Most of the diatoms and diatom material found was $10 \mu \mathrm{m}$ or greater. Therefore from this work I recommend sieving at $10 \mu \mathrm{m}$ to remove most of the smaller material without biasing the diatom assemblage.

\section{APPENDIX 5.2 Slide preparation}

Distilled water is added to a desired height in the $10 \mathrm{ml}$ test tubes. Cover slips are placed on a hot plate. An estimated concentration of sample is placed on the coverslip, using an analytical pipette with disposable tips (concentration was checked on an initial slide and material was mounted at a different concentration if unsuitable). Distilled water is added so the sample is evenly dispersed across the coverslip. The material is evaporated onto the coverslip. The slides are place on the hot plate and warmed. The mountant Naphrax (a high refractive index mountant) is placed on the slides and the dryed cover slips are turned sediment down onto the Naphrax. The slide was removed 
from the hot plate and bubbles beneath the slip were dispersed by rubbing a tooth pick over the slip. The slides were left to set for microscope analysis. Numbers of slides produced and concentrations are shown in Table 6.3.

Harwood et al. uses glycerol as the diatom mountant (D. Harwood, pers. comm.) Both Glycerol (Refractive index 1.43), and Naphrax (refractive index of 1.69) were initially used as a comparison. Naphrax was preferred for this study as it increased the optical contrast of the diatom frustules.

\section{APPENDIX 5.3 Microscope analysis}

Microscope analysis is undertaken on a Leitz Diaplan microscope, under partial phase with differential interference contrast in the paleontology microscope laboratory (Geology Department at Victoria University of Wellington). Ten to twenty slides of each sample are examined using an oil lens at $650 \times$ magnification. Diatom analysis and identification is undertaken at 1600 to $2000 x$.

\section{APPENDIX 5.4 Comparison of Methods by Burckle and Harwood}

A large settling cylinder and tank system similar to that used in the processing method by Harwood (Fig. 6.1, pers. comm. 1994) and Stroeven (1994) was constructed at VUW in order to compare the processing methods used by Dr. Burckle and Dr. Harwood. Unfortunately cracks developed in the cylinder as a result of the poor quality of the cylinder material supplied. Obtaining a new stronger cylinder would have taken too long to transport from overseas at a much larger cost, hence this processing stage and experiment was abandoned.

Using this method Harwood managed to separate sedimentary clasts which could contain more diatoms than the surrounding matrix. Very few sedimentary clasts (other than those from the Beacon Supergroup) were identified in this study, and no diatoms were identified in those that were processesed

Using Burckle's method, all sedimentary clasts were broken down in the first disaggregation stages. Because Harwood's method could not be used we could not repeat his findings on remaining sedimentary clasts. 
Another distinction between the two methods is that the Harwood method sieves the material at $25 \mu \mathrm{m}$, hence anything less than 25 microns, that is not attached to other material, is removed from out of the main material for analysis, the purpose for this is to concentrate the larger marine diatoms, that are age indicators. An analysis of this sieving bias is discussed in the mechanical separation section (11) on the method used above.

\section{APPENDIX 5.5 Separating diatoms in snow samples.}

The surface of the sieves from the melted smow samples were washed into $500 \mathrm{ml}$ beakers using distilled water and left to settle overnight. The water was siphoned off and discarded. Samples were then transferred to $50 \mathrm{ml}$ centrifuge tubes, and processed for the removal of coarse material. They were then again left to settle overnight. Any material left in suspension after this time was siphoned off and discarded. They were then centrifuged at 2000 RPM for 5 minutes, and the excess distilled water was poured off. The remaining $5 \mathrm{mls}$ was shaken into an even suspension and mounted onto slides, using Glycerol Jelly (two drops of Glycerol to four drops of sample) as the mountant for the first 3 slides and using Naphrax (as for sediment samples above) for the rest.

\section{APPENDIX 5.6 Contamination and Decontamination}

\section{Avoiding contamination in the laboratory}

A laboratory was chosen which had previously been used for processing New Zealand soils (which rarely contain diatoms). It had never been used for micropaleontological processing before.

The entire laboratory area was cleaned with alcohol before use.

Distilled water was used at all stages of processing and all other water passing through the laboratory was filtered with 20 and 5 micron filters. Clean new gloves and a lab coat were also worn throughout processing to avoid any contamination from outside sources.

In order to determine or discover any contamination control samples (acid washed sand and beakers of distilled water) were processed for the extraction of diatoms with the rest of the samples. Other controls were added during slide preparation and sieving. 


\section{Decontamination Experiment.}

Aim: to determine the most effective chemical and chemical concentration for the decontamination and removal of diatoms from processing equipment.

Initially soaking in $1 \% \mathrm{HF}$ for $24 \mathrm{hrs}$ was used on all equipment. However this becomes expensive and appears over careful; also after repeated treatments it etches and weakens any glassware used, creating the risk of losing a sample part way through processing.

Strong alkalis are also recommended for the dissolution and breakdown of Diatoms. Three of the most recommended alkalis including $\mathrm{NaCO} 3, \mathrm{NaOH}$ and $\mathrm{KOH}$ were tested, for effective breakdown of diatoms.

Concentrations and times used.

2 and 4 molar concentrations, of $\mathrm{NaCO}_{3}$ and $\mathrm{NaOH}$ and 2 molar concentration of $\mathrm{KOH}$ the different concentrations including a distilled water control were added to a diatomaceous sample for 4, 8 and $24 \mathrm{hrs}$.

The sample used for this experiment was processed diatomaceous material from Lake Rotohama. The diatomaceous material was shaken into an even suspension and $5 \mu \mathrm{mls}$ of the sample were placed in test tubes containing alkalis of the different concentration.

At the end of the trial time, the sample was diluted with distilled water, shaken and centrifuged up to six times. They were then mounted for analysis, using the same method as for the Antarctic samples.

About three hundred diatoms were counted from each sample.

Diatoms are ranked from 1 to 5 according to their degree of breakdown. 5 - entire clean diatom without any sigh of breakage and/or dissolution.

4 - whole diatom with dissolution and/or some breakage, $3 / 4$ to a whole diatom.

$3-1 / 2$ to $3 / 4$ of a diatom

$2-1 / 4-1 / 2$ of the diatom.

1 - less than $1 / 4$ of a diatom. 
Notes were also made on dissolution features and the degree of dissolution.

Table A5.2 Results of decontamination test.

Breakage class - counts

Breakage classes - weighted no.

\begin{tabular}{|l|l|l|l|l|l|l|l|l|l|l|l|l|}
\hline Sample & 5 & 4 & 3 & 2 & 1 & Tot & 5 & 4 & 3 & 2 & 1 & Tot \\
\hline NaOH & & & & & & & & & & & & \\
\hline 4 M 4hrs & 8 & 40 & 97 & 64 & 68 & 277 & 40 & 160 & 291 & 128 & 68 & 687 \\
\hline $4 \mathrm{M} 8 \mathrm{hrs}$ & 9 & 34 & 57 & 88 & 121 & 309 & 45 & 136 & 171 & 176 & 121 & 649 \\
\hline $\begin{array}{l}\text { 4M } \\
\text { 24hrs }\end{array}$ & 28 & 53 & 42 & 49 & 128 & 300 & 140 & 212 & 126 & 98 & 28 & 604 \\
\hline 2M 4hrs & 71 & 52 & 36 & 72 & 69 & 300 & 355 & 208 & 108 & 144 & 69 & 884 \\
\hline 2M 8hrs & 31 & 70 & 44 & 65 & 91 & 301 & 155 & 280 & 132 & 130 & 91 & 788 \\
\hline $\begin{array}{l}\text { 2M } \\
\text { 24hrs }\end{array}$ & 5 & 39 & 130 & 61 & 166 & 401 & 25 & 153 & 390 & 122 & 166 & 856 \\
\hline KOH & & & & & & & & & & & & \\
\hline 2M 4hrs & 14 & 51 & 40 & 85 & 109 & 299 & 70 & 201 & 120 & 170 & 109 & 670 \\
\hline 2M 8hrs & 14 & 46 & 37 & 66 & 137 & 300 & 70 & 187 & 111 & 132 & 137 & 637 \\
\hline $\begin{array}{l}2 \mathrm{M} \\
\text { 24hrs }\end{array}$ & 1 & 40 & 136 & 96 & 27 & 320 & 5 & 160 & 408 & 192 & 27 & 792 \\
\hline NaCO3 & & & & & & & & & & & & \\
\hline 2M 4hrs & 49 & 95 & 24 & 47 & 83 & 298 & 245 & 380 & 72 & 94 & 83 & 874 \\
\hline 2M 8hrs & 29 & 76 & 20 & 41 & 134 & 300 & 145 & 304 & 60 & 82 & 134 & 725 \\
\hline $\begin{array}{l}\text { 2M } \\
\text { 24hrs }\end{array}$ & 25 & 22 & 24 & 90 & 159 & 320 & 25 & 88 & 72 & 180 & 69 & 434 \\
\hline $\begin{array}{l}\text { Control } \\
\text { 24hrs }\end{array}$ & 33 & 35 & 32 & 73 & 127 & 300 & 165 & 140 & 96 & 146 & 127 & 674 \\
\hline
\end{tabular}

The second part of the table was calculated by multiplying each of the totals by the number they represented $5,4,3,2$, or 1 . These were then totalled. Roughly the totals should show a decrease with increasing concentration ie. more diatoms in category ' 5 ' (whole diatoms) and fewer in ' 1 ' will produce a high number, more diatoms in ' 1 ' and very few in ' 5 ' will produce a lower number. This assumes the chemicals simply break the bonds holding the diatoms together. However it appears dissolution over 24 hrs has completely broken down the smaller pieces of diatom, while many of the whole diatoms show a strong dissolution but still remained whole simply causing a change from category ' 5 ' to ' 4 '. It was not convienent to determine whether there was any change in the concentration of the diatoms present at the volume of diatoms was to great. 
Because the sample did not initially contain $100 \%$ whole diatoms a comparison of diatoms to the control is necessary. Unfortunately with the high $\mathrm{NaCO}_{3}$ in 2 and 4 molar concentrations the chemical precipitated on the slide and proper results could not be obtained. $\mathrm{NaOH}$ and $\mathrm{KOH}$ gave good results.

The decided concentration for decontamination was 3 Molar $\mathrm{KOH}$ for $24 \mathrm{hrs}$. Small parts of diatoms would have dissolved away under higher concentrations for longer periods. Hence the number of smaller parts of the frustule decrease, leaving a relative increase in number of the stronger whole tests with large amounts of dissolution, referred to breakage class 4 in this experiment. All diatoms showed large amounts of dissolution that could easily be identified under the microscope.

\section{APPENDIX 5.7 Problems with processing and separating sediment}

A gelatinous orange compound dominated the Table Mountain samples after the removal of other material obscuring any diatoms present. This mineral appeared to be a result of secondary mineralisation and made up about $15 \%$ of the till in thin section at Table Mountain. At first it was thought to be some sort of iron compound, created from the samples during processing. However, processing the samples for the removal of iron turned the material from a pink to a white colour but did not remove it. The mineral was further analysed using $x$-ray diffaction, which produced only a small hump on the read out suggesting an aqueous mineral (Warren Dickinson, VUW, pers comm., 1995).

Electron micro-probe analysis in the Geology Department at Victoria University of Wellington and microscope analysis by Dr. Warren Dickinson (Victoria University of Wellington), first indicated the mineral was the zeolite analcite. It was advised by Dr. Johnson (VUW, Pers. Comm., 1995) that $\mathrm{NaOH}$ with $\mathrm{PH} 11$ should remove analcite from the sample. As a result of the decontamination experiment above it was considered that the diatoms would not be at risk. $\mathrm{NaOH}$ with a $\mathrm{PH}$ of 11 was added to half of a sample from Table Mountain in a beaker, and the solution was warmed on a hot plate. The samples were then removed from the hot plate and shaken into suspension every 15 minutes for $6 \mathrm{hrs}$. Little if any of the 'analcite' material broke down. 
Other methods investigated would also break down diatom valves, so were not an option for processing.

Finally Ray Soong from Institute of Nuclear and Geological Sciences (IGNS) identified the zeolite as Chabazite, with further analysis under the microscope and using the electron micro-probe. This could not easly be separated from the material without effecting the diatoms. 


\section{APPENDIX 5.8 Initial processing method}

The apparatus that was originally constructed to concentrate microfossil material from the sediment. The processes was derived from a combination of processing methods used by Stroeven (1994), Harwood et al. (1986), Harwood (pers. comm. 1984), Shemesh et al. (1988), Bates (1978) and Burckle (Pers. Comm. 1994). This method was not used as a result of poor tube quality, causing it to split. The cost of replacement with a better quality cylinder was too high and would have taken too long to replace to continue with this method for the thesis.

Figure A5.1 Initial method and equipment for this study for the concentration of diatoms. The diagram of the next page shows the plumbing system for this method constructed in early 1995.

1. Disaggregation of samples in calgon and distilled water for 48 hours.

2. Dissection and removal of any sedimentary clasts for closer analysis.

3. Hydrodynamic extraction using the below apparatus (Stroeven, 1994). The upward velocity of the water at $0.4 \mathrm{~cm} / \mathrm{sec}$ is enough to separate diatoms based on their hydrodynamic properties.

4. The larger clasts that are not carried by the water will then be removed and sieved in different size fractions for further analysis.

5. Material that is separated in 3 will be sieved to concentrate the larger marine diatoms.

6. Material that passes through the sieve is washed into a 201 container, allowing smaller diatoms to settle to the bottom while the finer clays are washed into a larger container and the settling processes is repeated. The remaining sediment in suspension is washed into the sewer. The settled material is then chemically treated to any remove clay that has settled out with the diatoms.

7. All the sediment collected is separated from the micro fossil material using sodiumpolytungstate which has a controlled specific gravity. Diatoms have a specific gravity of less than 2.2. hence they float up in the sodiumpolytungstate while the sediment falls to the bottom of the tube. The diatom mixture is then cleaned and mounted on slides for microscope analysis. 


\section{Figure A5.1}

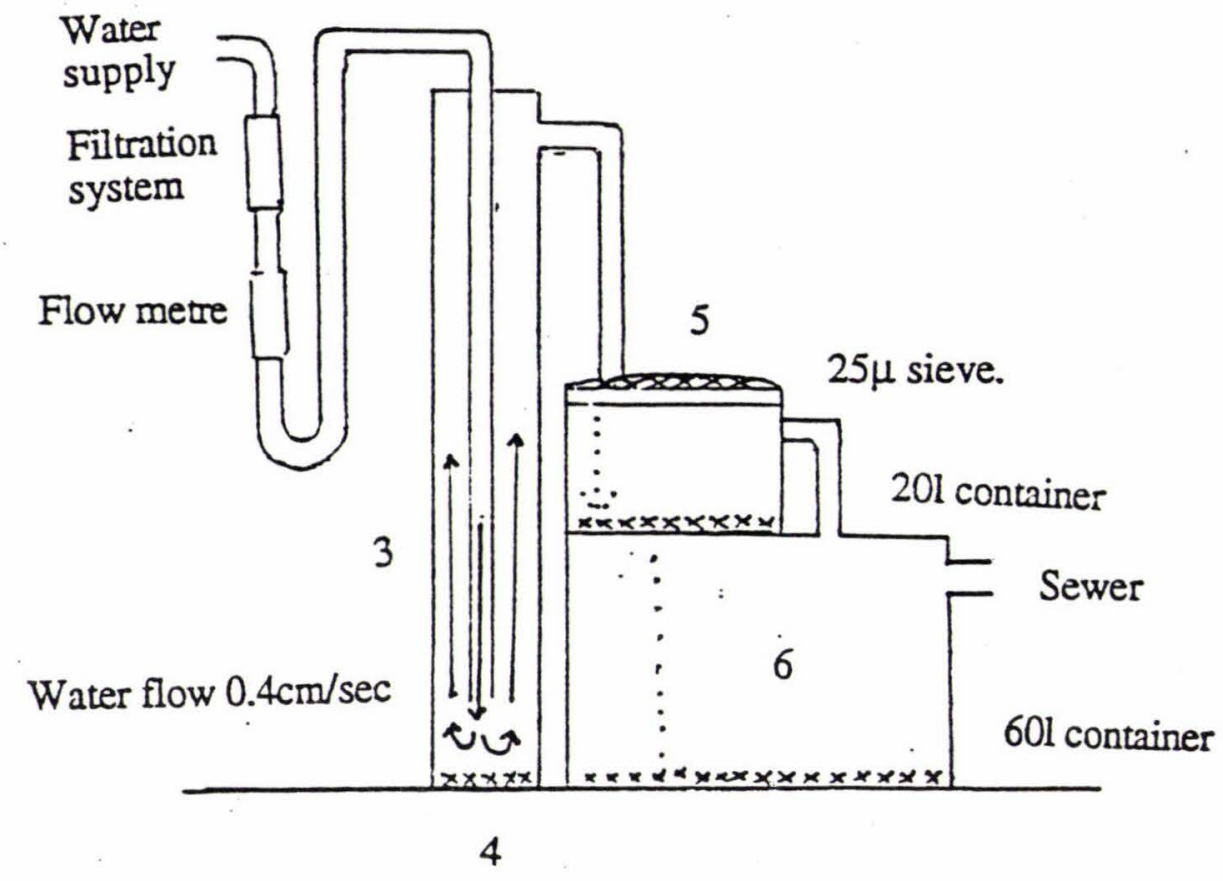




\section{APPENDIX 5.9 Method used for determining weights of diatoms and phytoliths per gram.}

Table A5.3 Concentration calculations for diatoms and phytoliths counted. A written explaination follows the table.

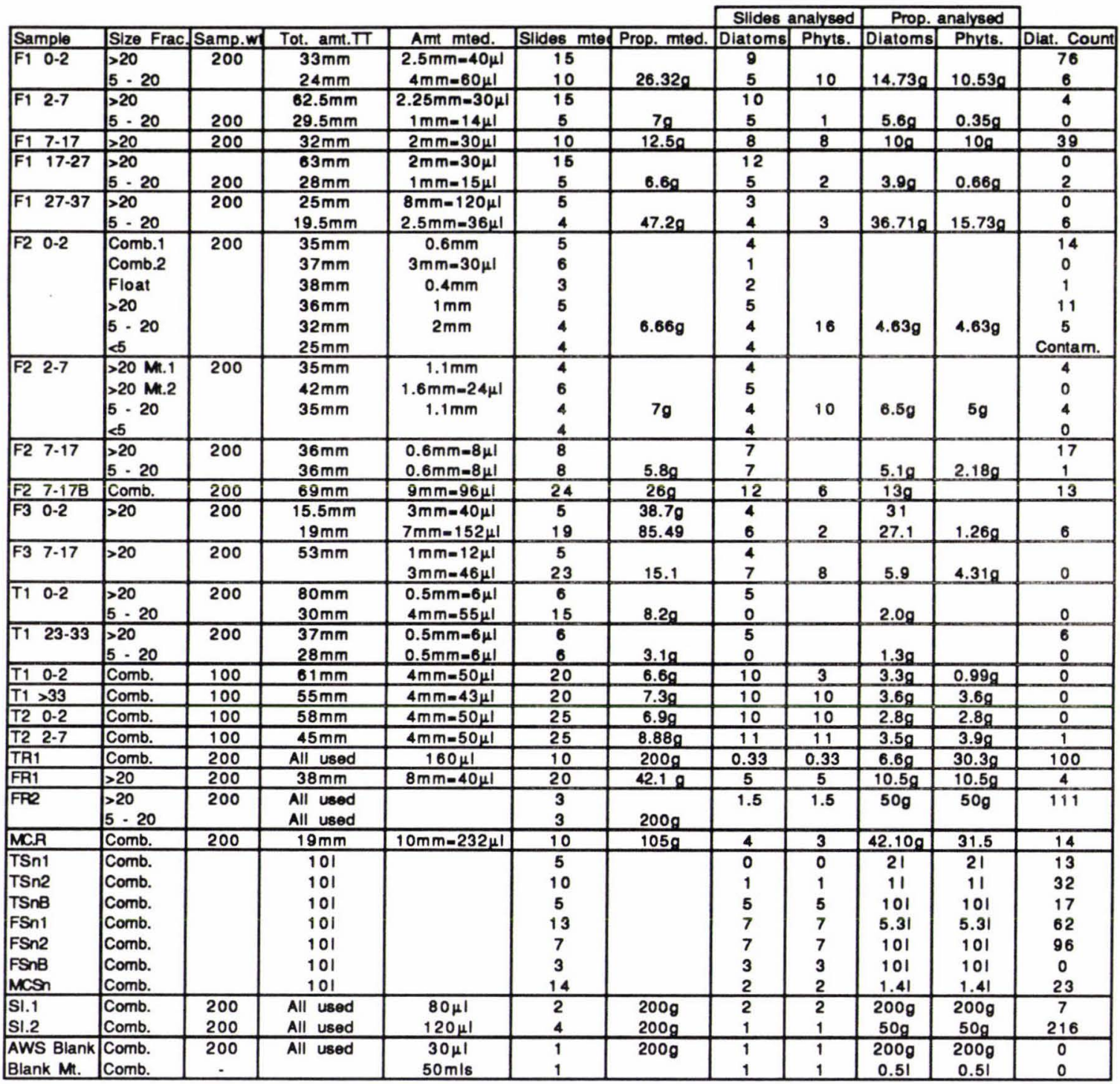

\section{Table Explanation}

Column One- Sample- First letter' $=$ location $T=$ Table Mountair $F=$ Mt. Feather $\quad M C=$ Mt. Crean Second figure' $=$ site number

Third numbers' $=$ depth $(\mathrm{cm})$

$\mathrm{R}^{\prime}=$ regolith

$\mathrm{Sn}^{\prime}=$ snow

S.I = South Island, New Zealand, Tillite

AWS $=$ Acid washed sand control

Blank Mt. = Distilled water control 
Table Explanation Continued

Column Two - Size Fraction

Several of the samples were divided into different size fractions during processing.

$>20=$ greater than 20 micron fraction

5-20 $\quad$ 5-20 micron fraction

Comb. = Combined. The sample was not separated.

Comb. 1 included some material with a specific gravity less than 1.8

Comb. 2 = included no float, specific gravity greater than 1.8 .

Float $=$ material floated from the sample using Sodium

Polytungstate at a Specific Gravity of 1.8. This was mounted and analysed for diatoms.

Mt.1 and 2 = Because of the large amount of sample Sample F2 2-7 was split before it was processed with heavy liquids. Mt.1 is the first separation, Mt.2 is the second.

Column Three - Sample Weight

Total sample weight before processing.

Column Four - Total amount in the test tube

Total height in mm, of material left after all stages of processing and distilled water in the test tube. Distilled water is added to a preferred dilution for mounting.

Column Five - Amount mounted

Total amount of processed sample (mm down test tube) removed and mounted onto slides for analysis. This is also measured in $\mu$ l using an analytical pipette. The number of $\mu \mathrm{ls} / \mathrm{mm}$ varies as a result of diameter variation in the test tubes which ranges from $11 \mu \mathrm{l} / \mathrm{mm}$ to $15 \mu \mathrm{l} / \mathrm{mm}$.

Column Six - Slides mounted

Total number of slides mounted of the processed material.

Column Seven - Relative proportion mounted.

Relative proportion of the processed material from the original sample weight mounted.

Amount mounted

Total amount in test tube $\quad X$ Sample Weight 
Column Eight - Slides Analysed

Number of slides analysed for: first column, diatoms; second column, phytoliths.

Column Nine - Relative proportion analysed.

Relative proportion of the processed material from the original sample analysed for: first column, diatoms; second column, phytoliths.

Slides analysed

Slides mounted X Relative Proportion Mounted

To obtain the number of diatoms or phytoliths per gram of sample, the number of diatoms or phytoliths from each sample is divided by the proportion analysed. With the exception of the regolith samples, no major changes were made to the appearances of the graphs, or the comparative proportions of diatoms with depth.

Column Ten - Diatoms counted

Total number of diatoms counted from each sample and sample separation. 


\section{APPENDIX SIX}

\section{Diatom data and analysis}

Diatom occurrence, tables and assemblages from all sites sampled. Information on the ecology of the diatoms found and a comparison of diatoms found from other studies and this one.

\section{APPENDIX 6.1}

Table A6.1 Results table, showing diatoms and phytoliths counted, the percet of each sample counted and the proportion of diatoms and phytoliths calculated per gram of sediment

APPENDIX 6.2 Species tables with numbers counted from all samples processed.

Table A6.2 Mount Feather, Sirius till, Site One.

Table A6.3 Mount Feather, Sirius till, Site Two.

Table A6.4 Mount Feather, Sirius till, Site Three

Table A6.5 Table Mountain, Site One

Table A6.6 Table Mountain, Sirius till, Site Two

Table A6.7 Regolith samples from Table Mountain, Mt. Crean and Mt. Feather.

Table A6.8 Snow samples from Table Mountain, Mt. Feather and Mt. Crean.

Table A6.9 New Zealand, South Island till.

Table A6.10 Controls

APPENDIX 6.3 Analysis for the posibility of diatoms in cracks in other rocks in Antarctica, not collected for this study, and for the possibility of contamination. 
Table A6.11 Diatoms, phytoliths and sponge spicules from cracks in rocks from various sites in Antarctica and the VUW rock store.

APPENDIX 6.4 The size of phytoliths and diatoms (whole and fragments) from Mt. Feather.

Table A6.12 Average and maximum size of diatoms and phytoliths (intermediate axis) from the Sirius group at Mt. Feather.

Table A6.13 The size of the intermediate axis, of diatoms and phytoliths from Sirius Sites One and Two and from snow and regolith at Mt. Feather.

APPENDIX 6.5 Species lists of diatom assemblages found by various people from within Sirius group sediments, regolith and snow.

Table A6.14 Comparison of diatoms found by various authors significant to the debate.

Table A6.15 Comparison of diatom abundance in regolith with surface and depth Sirius Group data from Bleakley and Stroeven.

APPENDIX 6.6 Species lists and other important information on all diatoms found.

APPENDIX 6.6a

Table A6.16 Species list. and summary information on ages, environment, and the samples in which they were found.

APPENDIX 6.6b Comments, Systematics and Ecology of taxa.

A. Species from the Sirius Group till, snow and regolith samples.

B. Species from South Island samples and South island contaminants from the control at table Mountain.

APPENDIX 6.7 Diatom plates. 
APPENDIX 6.1

Table A6.1 Results table, showing diatoms and phytoliths counted, the percent of each sample counted and the proportion of diatoms and phytoliths calculated per gram of sediment.

\begin{tabular}{|c|c|c|c|c|c|c|c|c|c|c|c|c|}
\hline \multirow[t]{2}{*}{ Location/Sample } & \multicolumn{4}{|c|}{ Counts } & \multirow[t]{2}{*}{ Phyt. } & \multicolumn{2}{|c|}{$\begin{array}{l}\% \text { of sample } \\
\text { analysed for:- }\end{array}$} & \multicolumn{4}{|c|}{ Number per gram } & \multirow{2}{*}{ Phyt. } \\
\hline & Marine & Fresh & Unid & Total & & Diatoms & Phyts & Marine & Fresh & Unid. & Total & \\
\hline Mt. Feather Site One $0-2 \mathrm{~cm}$ & 13 & 49 & 20 & 82 & 1014 & 7.4 & 5.3 & 1.2 & 4.6 & 1.9 & 5.6 & 96 \\
\hline Mt. Feather Site One $2-7 \mathrm{~cm}$ & 1 & 1 & 2 & 4 & 350 & 2.8 & 0.2 & 0.2 & 0.2 & 0.4 & 0.7 & 1000 \\
\hline Mt. Feather Site One $7-17 \mathrm{~cm}$ & 5 & 20 & 14 & 39 & 835 & 5 & 5 & 0.5 & 2 & 1.4 & 3.9 & 84 \\
\hline Mt. Feather Site One $17-27 \mathrm{~cm}$ & 1 & 0 & 1 & 2 & 2034 & 2 & 0.3 & 0.3 & 0 & 0.3 & 0.5 & 3082 \\
\hline Mt. Feather Site One $27-37 \mathrm{~cm}$ & 0 & 1 & 5 & 6 & 3700 & 18.4 & 7.9 & 0 & 0.1 & 0.1 & 0.2 & 235 \\
\hline Mt. Feather Site Two $0-2 \mathrm{~cm}$ & 11 & 9 & 11 & 31 & 1676 & 2.3 & 2.3 & 2.4 & 1.9 & 2.4 & 6.7 & 362 \\
\hline Mt. Feather Site Two $2-7 \mathrm{~cm}$ & 2 & 4 & 2 & 8 & 2624 & 3.3 & 2.5 & 0.3 & 0.6 & 0.3 & 1.2 & 525 \\
\hline Mt. Feather Site Two $7-17 \mathrm{~cm}$ & 1 & 2 & 1 & 4 & 2186 & 6.5 & 1.1 & 0.1 & 0.2 & 0.1 & 0.8 & 1001 \\
\hline Mt. Feather Site Three $0-2$ & 5 & 3 & 0 & 8 & 419 & 15.5 & 0.6 & 0.1 & 0.1 & 0 & 0.2 & 333 \\
\hline Mt. Feather Site Three 7-17 & 0 & 0 & 0 & 0 & 640 & 3 & 2.2 & 0 & 0 & 0 & 0 & 148 \\
\hline Mt. Feather Regolith Site One & 0 & 3 & 1 & 4 & 105 & 5.3 & 5.3 & 0 & 0.3 & 0.1 & 0.4 & 10 \\
\hline Mt. Feather Regolith Site Two & 95 & 8 & 8 & 111 & 708 & 25 & 25 & 2 & 0.2 & 0.2 & 2.2 & 14 \\
\hline Table Mt. Site One $0-2 \mathrm{~cm}$ & 0 & 0 & 0 & 0 & 270 & 1.7 & 0.5 & 0 & 0 & 0 & 0 & 135 \\
\hline Table Mt. Site One $27-37 \mathrm{~cm}$ & 0 & 6 & 0 & 6 & 355 & 1.8 & 1.8 & 0 & 0.8 & 0 & 0.8 & 273 \\
\hline Table Mt. Site Two $0-2 \mathrm{~cm}$ & 0 & 0 & 0 & 0 & 171 & 1.4 & 1.4 & 0 & 0 & 0 & 0 & 61 \\
\hline Table Mt. Site Two $2-7 \mathrm{~cm}$ & 0 & 0 & 1 & 1 & 228 & 2 & 2 & 0 & 0 & 0.3 & 0.3 & 59 \\
\hline Table Mt. Regolith Site One & 89 & 3 & 8 & 100 & 10 & 3.3 & 3.3 & 13.5 & 0.5 & 1.2 & 15.2 & 0.3 \\
\hline Mt. Crean Regolith & 6 & 5 & 3 & 14 & 297 & 21.1 & 15.8 & 0.2 & 0.1 & 0.1 & 0.4 & 9 \\
\hline South Island Brown & 0 & 7 & 0 & 7 & 65 & 100 & 100 & 0 & 0.1 & 0 & 0.1 & 0.3 \\
\hline South Island Grey & 0 & 214 & 2 & 216 & 400 & 25 & 25 & 0 & 4.3 & 0.1 & 4.4 & 8 \\
\hline
\end{tabular}

\begin{tabular}{|c|c|c|c|c|c|c|c|c|c|c|c|c|}
\hline Snow Samples & Counts & & & & & $\%$ sam & analys & Diat & ns/lit & & & \\
\hline Mt. Feather Snow Blank & 0 & 0 & 0 & 0 & 35 & 100 & 100 & 0 & 0 & 0 & 0 & 3.5 \\
\hline Mt. Feather Snow Site One & 2 & 51 & 9 & 62 & 342 & 20 & 20 & 0.4 & 9.7 & 1.7 & 11.8 & 65 \\
\hline Mt. Feather Snow Site Two & 1 & 88 & 7 & 96 & 58 & 10 & 10 & 0.1 & 8.8 & 0.7 & 9.6 & 5.8 \\
\hline Table Mt. Snow Blank & 1 & 16 & 0 & 17 & 43 & 100 & 100 & 0.1 & 1.6 & 0 & 1.7 & 4.3 \\
\hline Table Mt. Snow Site One & 0 & 13 & 0 & 13 & 7 & 53 & 53 & 0 & 2.1 & 0 & 2.1 & 1.1 \\
\hline Table Mt. Snow Site Two & 7 & 15 & 10 & 32 & 525 & 100 & 100 & 1.4 & 3 & 2 & 6.4 & 105 \\
\hline At Crone Crave & 0 & 22 & & 23 & 12 & 14 & 14 & 0 & 15.4 & 0.7 & 16.1 & 3.4 \\
\hline
\end{tabular}




\section{APPENDIX 6.2}

Species tables with numbers counted from all samples processed.

Table A6.2 Mount Feather, Sirius till, Site One

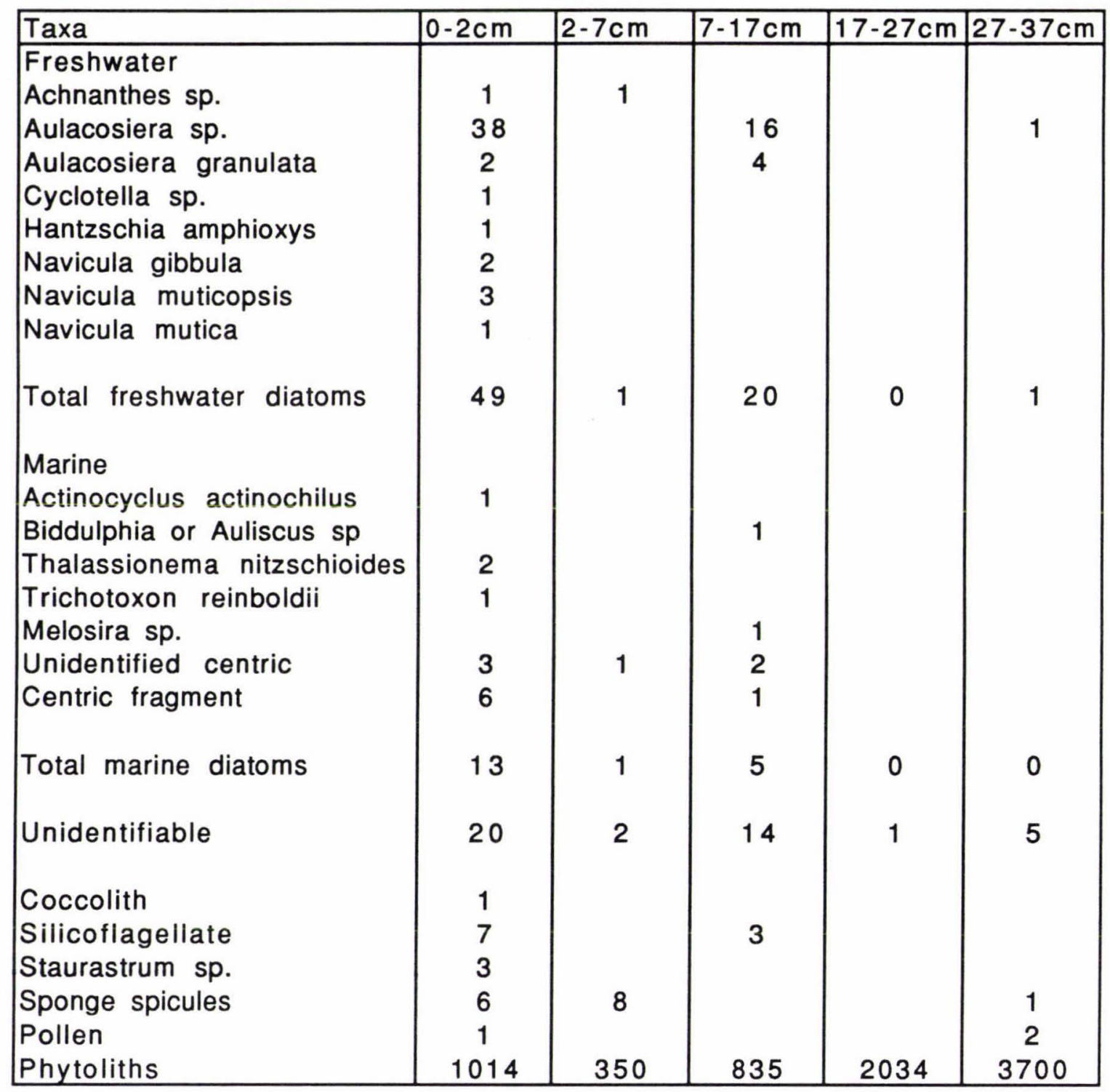


Table A6.3 Mount Feather, Sirius till, Site Two.

\begin{tabular}{|c|c|c|c|}
\hline Taxa & $0-2 \mathrm{~cm}$ & $2-7 \mathrm{~cm}$ & $7-17 \mathrm{~cm}$ \\
\hline $\begin{array}{l}\text { Freshwater } \\
\text { Aulacosiera ambigua } \\
\text { Aulacosiera sp. } \\
\text { Cyclotella sp. } \\
\text { Fragilaria aff. berolinensis } \\
\text { Fragilaria ulna var. acus } \\
\text { Fragilaria sp. } \\
\text { Gomphonema angustatum. } \\
\text { Navicula muticopsis } \\
\text { Pinnularia c.f. maior } \\
\text { Unidentified }\end{array}$ & $\begin{array}{l}1 \\
2 \\
1 \\
1 \\
1 \\
1 \\
1 \\
1\end{array}$ & 1 & 1 \\
\hline $\begin{array}{l}\text { Total freshwater diatoms } \\
\text { Marine } \\
\text { Actinoptychus sp. } \\
\text { Thalassionema nitzschioides } \\
\text { Centric fragments }\end{array}$ & $\begin{array}{l}1 \\
2 \\
8\end{array}$ & 4 & 1 \\
\hline Total marine diatoms & 11 & 2 & 1 \\
\hline $\begin{array}{l}\text { Total unidentifiable diatoms } \\
\text { Coccolith } \\
\text { Radiolarian sp. } \\
\text { Sponge spicules } \\
\text { Staurastrum sp. } \\
\text { Phytoliths }\end{array}$ & $\begin{array}{c}1 \\
14 \\
1676\end{array}$ & $\begin{array}{c}1 \\
2624\end{array}$ & $\begin{array}{c}1 \\
2186\end{array}$ \\
\hline
\end{tabular}


Table A6.4 Mt. Feather, Sirius till, Site Three

\begin{tabular}{|l|c|c|}
\hline Taxa & $0-2 \mathrm{~cm}$ & $7-17 \mathrm{~cm}$ \\
\hline Freshwater & 1 & \\
Navicula sp. & 2 & \\
Nitzschia sp. & 3 & 0 \\
Total Freshwater & & \\
Marine & 1 & \\
Melosira aff. charcotii & 1 & \\
Pleurosigma sp. & 1 & \\
Podosira sp. & 2 & \\
Unidentified centric & 5 & 0 \\
Total marine diatoms & 1 & \\
Pollen grain & 419 & 640 \\
Phytoliths & & \\
\hline
\end{tabular}

Table A6.5 Table Mountain, Site One

\begin{tabular}{|l|c|c|}
\hline Taxa & $0-2 \mathrm{~cm}$ & $27-37 \mathrm{~cm}$ \\
\hline $\begin{array}{l}\text { Freshwater } \\
\text { Aulacosiera sp. } \\
\text { (three species) } \\
\text { Total Freshwater }\end{array}$ & 0 & 6 \\
Phytoliths & 270 & 355 \\
\hline
\end{tabular}

Table A6.6 Table Mountain, Sirius till, Site Two

\begin{tabular}{|l|c|c|}
\hline Taxa & $0-2 \mathrm{~cm}$ & $2-7 \mathrm{~cm}$ \\
\hline Marine & & \\
Unidentifiable & 1 & \\
Total Marine Diatoms & 1 & \\
Unidentified Diatoms & & 1 \\
Phytoliths & & 228 \\
\hline
\end{tabular}


Table A6.7 Regolith samples from Table Mountain, Mt. Crean and Mt. Feather.

\begin{tabular}{|c|c|c|c|c|}
\hline & Table Mt. & Mt. Crean & Mt. Feathe & \\
\hline Taxa & & & Site One & Site Two \\
\hline $\begin{array}{l}\text { Freshwater } \\
\text { Aulacosiera sp. }\end{array}$ & & & 3 & \\
\hline Caloneis cf. tenuis & & 2 & & \\
\hline Cyclotella cf. ocellata & 1 & 1 & 3 & $\begin{array}{l}1 \\
2\end{array}$ \\
\hline Navicula cf. laevissma & & & & 1 \\
\hline Navicula muticopsis & 1 & 1 & & \\
\hline Navicula sp. & 1 & & & 1 \\
\hline Total freshwater diatoms & 3 & 4 & 3 & 5 \\
\hline Marine & & & & \\
\hline Actinocyclus actinochilus & 2 & & & 1 \\
\hline Actinocyclus aff. ingens & 1 & & & \\
\hline Actinocyclus sp. & 2 & & & \\
\hline Coscinodoscus aff. lineatus & 1 & & & 1 \\
\hline $\begin{array}{l}\text { Coscinodiscus c.f. marginatus } \\
\text { Coscinodiscus perforatus }\end{array}$ & & & & $\begin{array}{l}1 \\
1\end{array}$ \\
\hline Coscinodiscus aff. radiatus & 1 & & & \\
\hline $\begin{array}{l}\text { Coscinodiscus aff. sublineatus } \\
\text { Coscinodiscus sp. }\end{array}$ & 2 & & & 3 \\
\hline $\begin{array}{l}\text { Eucampia antarctica } \\
\text { Melosira aff. charcotii }\end{array}$ & 1 & & & 3 \\
\hline Nitzschia cf. grunowii & & 1 & & \\
\hline Nitzschia kergulensis & 1 & & & \\
\hline Nitzschia ritscheri & 1 & & & \\
\hline Nitzschia seperanda & & & & 3 \\
\hline Nitzschia sp. & & & & 2 \\
\hline Pleurosigma sp. & 5 & & & \\
\hline Podosira type & 7 & & & \\
\hline Stephanopyxis aff. grunowii & 3 & & & \\
\hline Thalassionema nitzchioidies & 17 & 2 & & 6 \\
\hline Thalassiosira sp. & 2 & & & 1 \\
\hline Thalassiosira cf. frenquelliopsis & & & & 1 \\
\hline Thalassiosira aff lentigenosa & 1 & & & 1 \\
\hline Thalassiosira cf. oestrupii & 3 & & & \\
\hline Thalassiosira oliverina & 1 & & & \\
\hline Thalassiosira torokina & 11 & & & \\
\hline Thalassiosira aff. trifulta & & & & 1 \\
\hline Thalassiosira c.f. tumida & & & & 1 \\
\hline Thalassiothrix antarctica & 3 & 1 & & \\
\hline Trichotoxon reinboldii & 1 & & & 2 \\
\hline Centric fragment & 20 & 1 & & 56 \\
\hline Unidentifiable Centric & 4 & & & 1 \\
\hline Total marine diatoms & 89 & 6 & 0 & 85 \\
\hline Unidentifiable & & 3 & & \\
\hline Centric sp. & 5 & 1 & & \\
\hline Denticula sp. & 2 & & & \\
\hline Nitzschia sp. small & 1 & & & \\
\hline Total unidentifiable & 8 & 4 & 1 & 8 \\
\hline Radiolarian fragment & 1 & & & \\
\hline Staurastrum sp. & & 1 & & \\
\hline Sponge spicules & 11 & 16 & & 20 \\
\hline Phytoliths & 10 & 297 & 105 & 708 \\
\hline
\end{tabular}


Table A6.8 Snow samples from Table Mountain, Mt. Feather and Mt. Crean

\begin{tabular}{|c|c|c|c|c|c|c|c|c|}
\hline & Table Mo & untain & & Mount $\mathrm{Fe}$ & ther & & Mt. Crear & \\
\hline Taxa & Control & Site One & Site Two & Control & Site One & Site Two & Blank & Site One \\
\hline Freshwater & & & & & & & & \\
\hline Achnanthes brevipes & & & 1 & & & & & \\
\hline Achnanthes c.f. delicatula & & & 1 & & & & & \\
\hline Asteronella formosa & 1 & 3 & & & & & & \\
\hline $\begin{array}{l}\text { Aulacosiera sp. } \\
\text { Aulacosiera distans }\end{array}$ & 9 & & & & $\begin{array}{c}48 \\
3\end{array}$ & 72 & & 21 \\
\hline Aulacosiera granulata & & & & & & 14 & & \\
\hline $\begin{array}{l}\text { Caloneis aff. sublineatis } \\
\text { Cocconeis costata }\end{array}$ & 1 & & 1 & & & & & \\
\hline $\begin{array}{l}\text { Cocconeis placentula var. tenui } \\
\text { Cocconeis sp. }\end{array}$ & 2 & & & & & & & 1 \\
\hline Cyclostephanos tholiformis & & & & & & 1 & & \\
\hline Fragilaria c.f. delicatissma & 1 & & & & & & & \\
\hline Fragilaria c.f. tenera & 1 & 1 & & & & & & \\
\hline $\begin{array}{l}\text { Fragilaria c.f. uina } \\
\text { Fragilaria sp. }\end{array}$ & 1 & & 1 & & & & & \\
\hline Hantzchia amphioxys & & & 1 & & & & & \\
\hline Navicula aff incertata & & & 1 & & & & & \\
\hline $\begin{array}{l}\text { Navicula muticopsis } \\
\text { Navicula tripunctata }\end{array}$ & & 1 & 1 & & & & & \\
\hline Navicula sp. & & 1 & 1 & & & & & \\
\hline Pinnularia sp. & & & 1 & & & & & \\
\hline Stauroneis anceps var. gracilis & & & & & & 1 & & \\
\hline Total freshwater diatoms & 16 & 5 & 8 & 0 & 51 & 88 & 0 & 22 \\
\hline Marine & & & & & & & & \\
\hline Marine & & & & & & & & \\
\hline Nitzschia curta & & & 3 & & & & & \\
\hline Nitzschia obliquecostata & & & 1 & & & & & \\
\hline Nitzschia turgiduloides & & & 1 & & & & & \\
\hline Nitzschia sublineata & & & 1 & & & & & \\
\hline Rhizosolenia spine & & & & & 1 & 1 & & \\
\hline $\begin{array}{l}\text { Stephanopyxis sp. } \\
\text { Centric fragments. }\end{array}$ & 1 & & 1 & & 1 & 1 & & \\
\hline & & & & & & & & \\
\hline Total marine diatoms & 1 & 0 & 7 & 0 & 2 & 1 & 0 & 0 \\
\hline Unidentified & & & 9 & 0 & 9 & 7 & & 1 \\
\hline Coccolith sp. & & & & & & 1 & & \\
\hline Pollen grain & 5 & & 4 & & 2 & 4 & & 3 \\
\hline Sponge spicules & & & 3 & & 1 & 1 & & \\
\hline Silicaflagellate & & & & & 1 & & & \\
\hline Phytoliths & 43 & 7 & 525 & 35 & 342 & 58 & & 12 \\
\hline
\end{tabular}


Table A6.9 New Zealand, South Island till

\begin{tabular}{|l|c|c|}
\hline & SI 1 (B) & SI 2 (G) \\
\hline Freshwater & & 2 \\
Amphora coffeaeformis & 1 & 4 \\
Caloneis bacillium & & 1 \\
Epithemia adnata & & 1 \\
Epithema sp & 1 & \\
Navicula c.f. perversa & & 1 \\
Nitzschia depilis & & 3 \\
Nitzschia c.f. sociabilis & 1 & 1 \\
Nitzschia sp. & & 1 \\
Pinnularia subcapitata & 4 & 199 \\
Pinnularia sp. & 7 & 214 \\
Rhophalodia rupestis & & 2 \\
Total freshwater diatoms & & 400 \\
Unidentifiable & & \\
Phytoliths & &
\end{tabular}

Table A6.10 Controls

Acidwashed Sand.

$\mathrm{Lg}$ numbers of phytoliths not removed from sand Diatoms

0

Blank mount

Diatoms

0

Phytoliths

5 


\section{APPENDIX 6.3}

Analysis for the possibility of diatoms in cracks in other rocks in Antarctica, not collected for this study, and for the possibility of contamination.

Table A6.11 Diatoms, phytoliths and sponge spicules from cracks in rocks from various sites in Antarctica stored in the VUW rock store.

\begin{tabular}{|c|c|c|c|c|c|c|c|}
\hline Sample & Marine & Fresh & Unid. & Total & Phytol. & Spo. Sp. & (grams) \\
\hline W1 & 4 & 9 & 8 & 21 & 237 & 2 & 0.65 \\
\hline W2 & 51 & 90 & 43 & 184 & 242 & 27 & 0.01 \\
\hline W2a & 13 & 121 & 39 & 173 & 877 & 37 & 0.11 \\
\hline W3 & - & - & - & - & 33 & - & 0.98 \\
\hline W4 & - & - & - & - & 80 & - & 2.19 \\
\hline W5 & - & - & - & - & 174 & - & 1.41 \\
\hline W6 & - & - & - & - & 236 & - & 0.52 \\
\hline W7 & - & 2 & - & 2 & 223 & - & 0.75 \\
\hline W8 & - & 1 & - & 1 & 628 & - & 0.85 \\
\hline W9 & - & - & - & - & 65 & - & 0.04 \\
\hline W10 & - & - & - & - & 140 & - & 0.35 \\
\hline Wi1 & - & - & - & - & 3 & - & 0 \\
\hline
\end{tabular}

W1 \#Petrified wood, Wellar Coal Measures, Allen Hills.

W2 ${ }^{\wedge}$ Dust from shelves in the rock store.

W3 ^Aztec Siltstone, Mt. Crean.

W4 $\wedge^{\wedge}$ Lashly Formation, Portal Mountain (Triassic).

W5 ^ Lashly Formation, Shapeless Mountain (Triassic).

$\mathrm{W} 6=\mathrm{W} 4$

$\mathrm{W} 7=\mathrm{W} 4$

W8 \#Wellar Coal Measures, Allen Hills.

W9 *Aztec Siltstone, Mt. Crean.

W10*Wellar Coal Measures, Mt. Feather.

W11 *Control

Amt. anal (grams) Amount of sediment processed to get the listed assemblage.

*collected by author

$\wedge$ from rock storage room

\# collected by Norman Smith, stored in office of Prof. Peter Barrett, vUW, 1995/1996. 


\section{APPENDIX 6.4}

The size of phytoliths and diatoms (whole and fragments) from Mt. Feather.

Table A6.12 Average and maximum size of diatoms and phytoliths (intermediate axis) from the Sirius Group at Mt. Feather.

\begin{tabular}{|l|c|c|c|}
\hline $\begin{array}{l}\text { Fossil } \\
\text { Flora }\end{array}$ & $\begin{array}{c}\text { Mean } \\
(\mu \mathrm{m})\end{array}$ & $\begin{array}{c}\text { Maximum } \\
(\mu \mathrm{m})\end{array}$ & $\begin{array}{c}\text { Number } \\
\text { counted }\end{array}$ \\
\hline Diatoms & 15 & 25 & 25 \\
Marine & 16 & 63 & 170 \\
Freshwater & 16 & 51 & 2000 \\
Phytoliths & 13 & \\
\hline
\end{tabular}

Table A6.13 The size of the intermediate axis of diatoms and phytoliths from selected Sirius Sites One and Two and from snow and regolith at Mt. Feather.

\begin{tabular}{|c|c|c|c|c|c|c|c|c|c|}
\hline \multicolumn{5}{|c|}{ Mt. Feather, Site One } & \multicolumn{5}{|c|}{ Mt. Feather, Site Two } \\
\hline \multirow[b]{2}{*}{ Depth } & \multirow{2}{*}{\begin{tabular}{|l|} 
Fossil \\
Flora
\end{tabular}} & \multicolumn{3}{|c|}{ Size $(\mu \mathrm{m})$} & \multirow[b]{2}{*}{ Depth } & \multirow{2}{*}{$\begin{array}{l}\text { Fossil } \\
\text { Flora }\end{array}$} & \multicolumn{3}{|c|}{ Size $(\mu \mathrm{m})$} \\
\hline & & Mean & s.d. & Max. & & & Mean & s.d. & Max. \\
\hline $0-2 \mathrm{~cm}$ & $\begin{array}{l}\text { Diatoms } \\
\text { Freshwate } \\
\text { Marine } \\
\text { Phytoliths }\end{array}$ & $\begin{array}{c}16.1 \\
17.6 \\
13 \\
\end{array}$ & $\begin{array}{r}- \\
\\
.8 \\
\end{array}$ & $\begin{array}{l}43 \\
25 \\
53 \\
\end{array}$ & $0-2 \mathrm{~cm}$ & $\begin{array}{l}\text { Diatoms } \\
\text { Freshwateı } \\
\text { Marine } \\
\text { Phytoliths }\end{array}$ & $\begin{array}{c}20.8 \\
14.5 \\
14 \\
\end{array}$ & $\begin{array}{r}- \\
6.9 \\
\end{array}$ & $\begin{array}{c}100 \\
20 \\
33 \\
\end{array}$ \\
\hline $7-17 \mathrm{~cm}$ & $\begin{array}{l}\text { Diatoms } \\
\text { Freshwate } \\
\text { Marine } \\
\text { Phytoliths }\end{array}$ & $\begin{array}{l}15.6 \\
10.3 \\
12.8 \\
\end{array}$ & $\begin{array}{c}- \\
5.8\end{array}$ & $\begin{array}{l}29 \\
12 \\
25\end{array}$ & $2-7 \mathrm{~cm}$ & $\begin{array}{l}\text { Diatoms } \\
\text { Freshwate } \\
\text { Marine } \\
\text { Phytoliths }\end{array}$ & $\begin{array}{c}24 \\
- \\
12.9\end{array}$ & $\begin{array}{c}- \\
5.5 \\
\end{array}$ & $\begin{array}{c}40 \\
- \\
33\end{array}$ \\
\hline $27-37 \mathrm{~cm}$ & $\begin{array}{l}\text { Diatoms } \\
\text { Freshwatel } \\
\text { Marine } \\
\text { Phytoliths } \\
\end{array}$ & $\begin{array}{c}13.4 \\
- \\
14.5 \\
\end{array}$ & $\begin{array}{c}- \\
- \\
4.7\end{array}$ & $\begin{array}{r}15 \\
- \\
26 \\
\end{array}$ & $7-17 \mathrm{~cm}$ & $\begin{array}{l}\text { Diatoms } \\
\text { Freshwate } \\
\text { Marine } \\
\text { Phytoliths } \\
\end{array}$ & $\begin{array}{c}11.5 \\
14 \\
12.8 \\
\end{array}$ & $\begin{array}{c}- \\
- \\
7.8 \\
\end{array}$ & $\begin{array}{l}18 \\
14 \\
25 \\
\end{array}$ \\
\hline Snow & $\begin{array}{l}\text { Diatoms } \\
\text { Freshwate } \\
\text { Marine } \\
\text { Phytoliths }\end{array}$ & $\begin{array}{c}13.4 \\
- \\
18.8\end{array}$ & $\begin{array}{c}4.3 \\
- \\
-\end{array}$ & $\begin{array}{c}28 \\
- \\
38\end{array}$ & Regolith & $\begin{array}{l}\text { Diatoms } \\
\text { Freshwater } \\
\text { Marine } \\
\text { Phytoliths }\end{array}$ & $\begin{array}{c}20 \\
- \\
20.2\end{array}$ & $\begin{array}{c}- \\
- \\
6.7\end{array}$ & $\begin{array}{c}30 \\
- \\
44\end{array}$ \\
\hline
\end{tabular}




\section{APPENDIX 6.5}

Species lists of diatom assemblages found by varoius people from within Sirius Group sediments , regolith and snow.

Table A6.14 Comparison of diatoms found by various authors significant to the debate. Compiled for the construction of matrix in Chapter Five.

\begin{tabular}{|c|c|c|c|c|c|c|c|c|c|}
\hline & $\operatorname{sir}(B I)$ & $\operatorname{Sir}(S)$ & $\operatorname{Sir}(H)$ & $\operatorname{sir}(K)$ & Reg(BI) & Reg(Bu) & \begin{tabular}{|l}
$\mathrm{Sn}(\mathrm{BI})$ \\
\end{tabular} & $\sin (K)$ & $\mathrm{Sn}(\mathrm{BU})$ \\
\hline 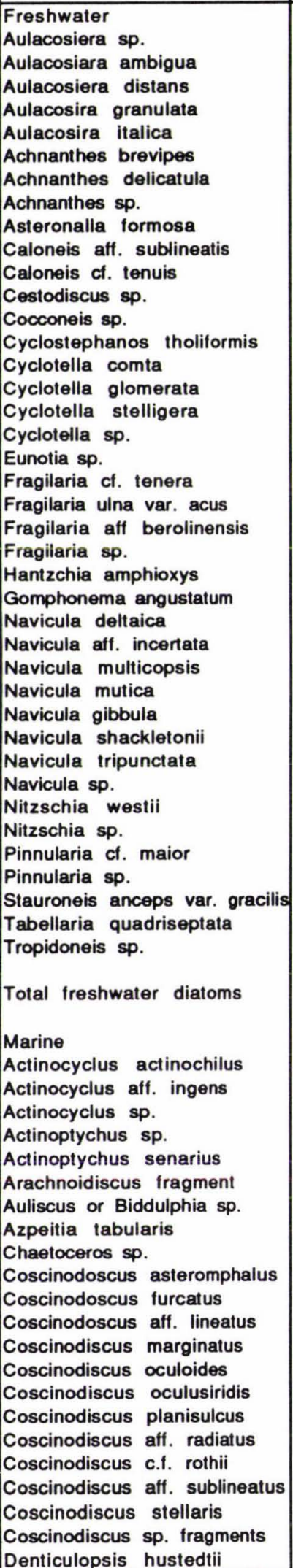 & $\begin{array}{l}4 \\
1 \\
2 \\
1 \\
2 \\
1\end{array}$ & $\begin{array}{l}3 \\
1 \\
\\
1 \\
1 \\
\\
4\end{array}$ & $\dot{:}$ & $\begin{array}{c}1 \\
1 \\
2 \\
32\end{array}$ & $\begin{array}{l}1 \\
2 \\
1\end{array}$ & : & $\begin{array}{c}120 \\
3 \\
14 \\
1 \\
1 \\
1 \\
1\end{array}$ & $\begin{array}{c}2 \\
17 \\
28\end{array}$ & $\begin{array}{l}\dot{ } \\
\dot{\cdot} \\
\dot{*}\end{array}$ \\
\hline
\end{tabular}


Table A6.14 continued

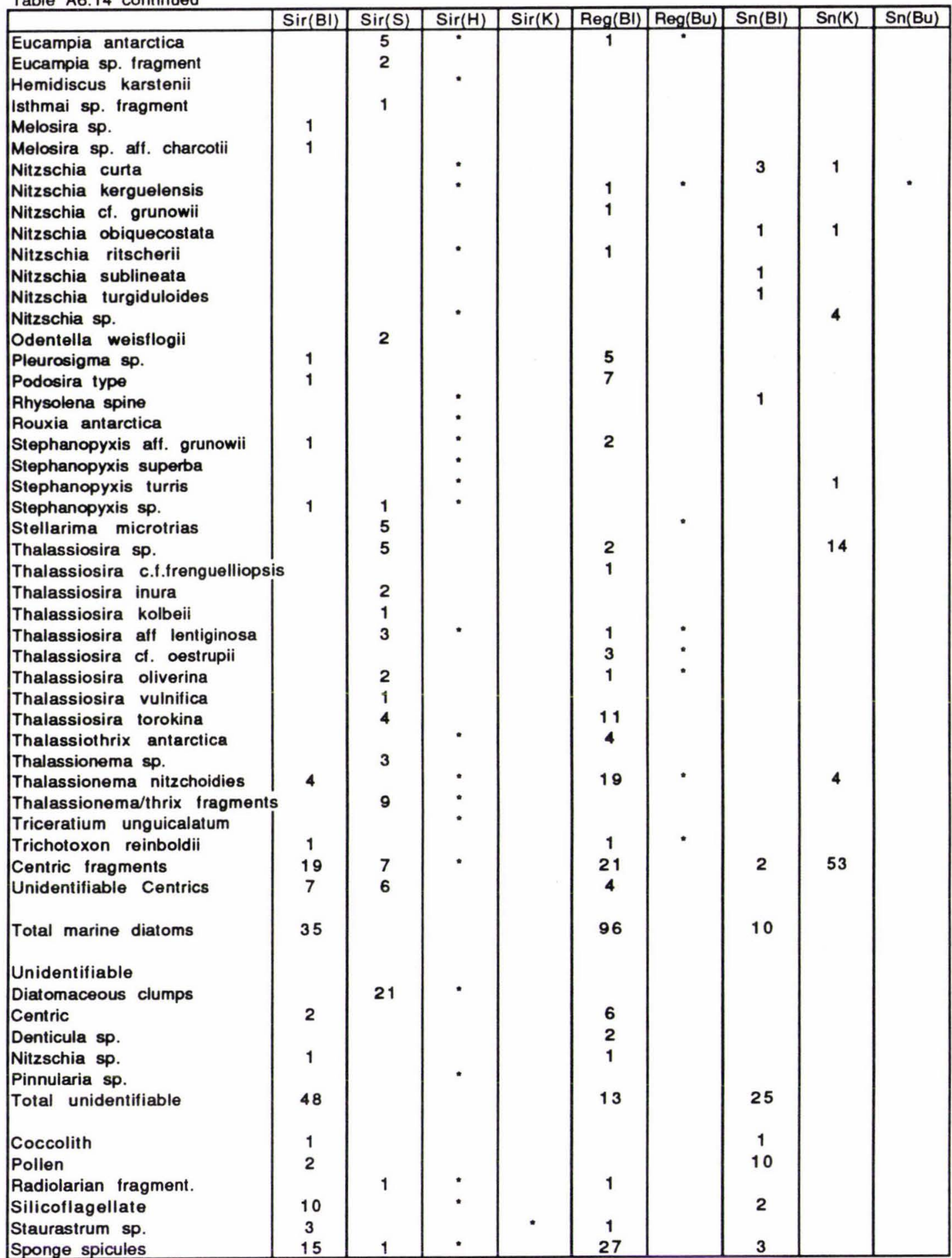

Key

$\operatorname{Sir}(B \mathrm{I})=$ combined Sirius Group samples from this thesis

$\operatorname{Sir}(\mathrm{S})=$ Diatoms found in the Sirius Group by Stroven at Mt. Fleming (1994)

$\operatorname{Sir}(H)=$ Diatoms found in the Sirius Group by Harwood at Mt. Fleming and Mt. Feather (1986)

$\operatorname{Sir}(K)=$ Diatoms found from the Sirius Group at Mt. Feather by Kellogg and Kellogg (1994).

Reg. $(\mathrm{BI})=$ combined regolith samples from this thesis, excluding Mt. Feather site two which could contain reworked "Sirius Group diatoms".

Reg(Bu) $=$ Crack Sediment Beacon Supergroup lgenous Rocks (1996).

$\mathrm{Sn}(\mathrm{BI})=$ combined snow samples from this thesis, excluding suspected contaminants

$\mathrm{Sn}(\mathrm{K})=$ Diatoms found in ice cores by Kellogg and Kellogg (1996)

$\mathrm{Sn}(\mathrm{Bu})=$ Diatoms found at Dome C by Burckle (1988). 
Table A6.15 Comparison of diatom abundance in regolith with surface and depth Sirius Group data from Bleakley and Stroeven.

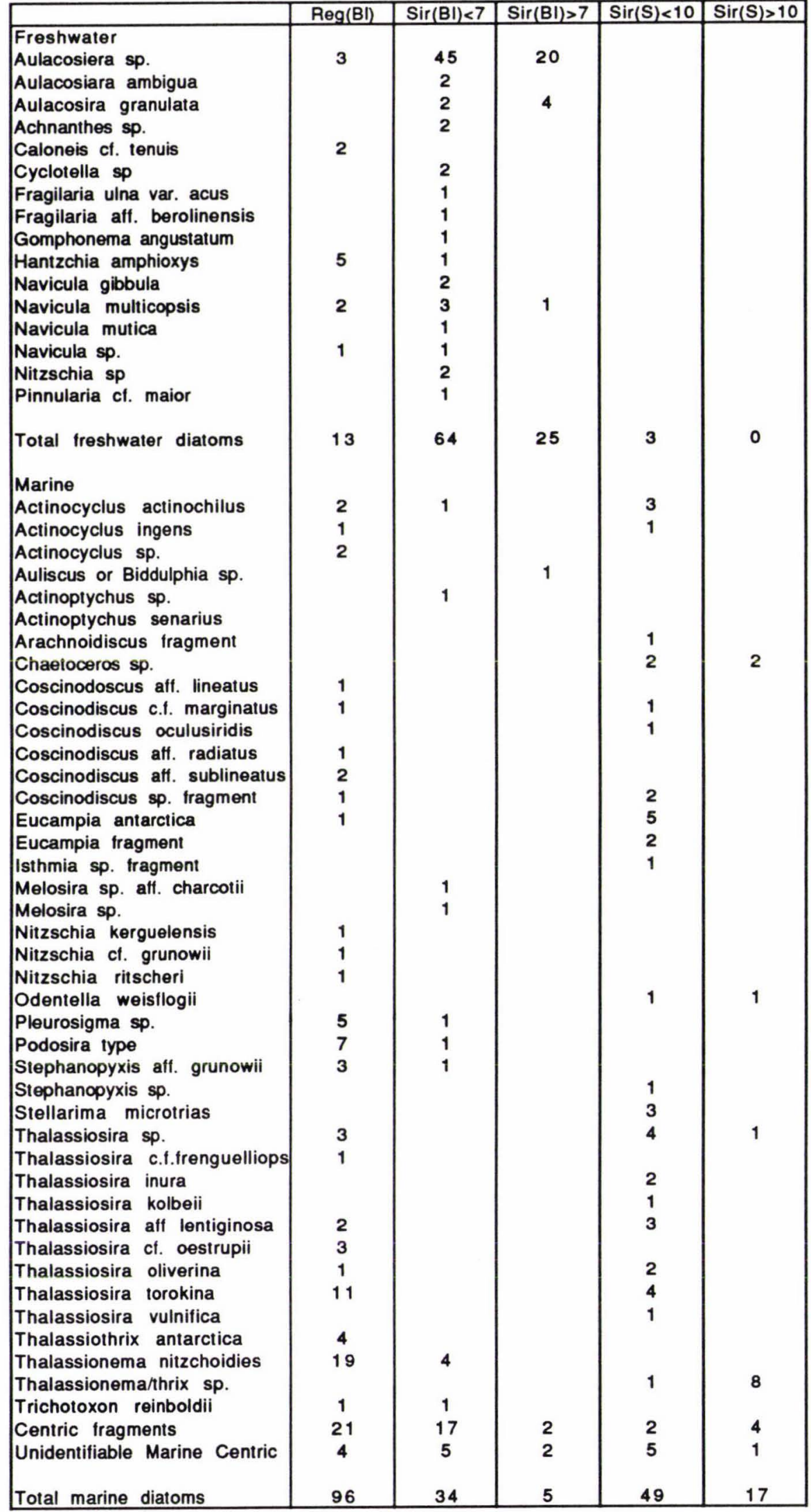

Continued over.... 
Table 6.15 continued

\begin{tabular}{|c|c|c|c|c|c|}
\hline 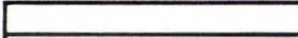 & Reg(BI) & $\operatorname{Sir}(B \mid)<7$ & $\operatorname{Sir}(B \mid)>7$ & $\operatorname{Sir}(S)<10$ & $\operatorname{Sir}(S)>10$ \\
\hline $\begin{array}{l}\text { Unidentifiable } \\
\text { Diatomaceous clumps } \\
\text { Centric diatom } \\
\text { Denticula sp. } \\
\text { Nitzschia sp. small }\end{array}$ & $\begin{array}{l}6 \\
2 \\
1\end{array}$ & 2 & & & 21 \\
\hline $\begin{array}{l}\text { Total unidentifiable } \\
\text { Coccolith } \\
\text { Pollen } \\
\text { Silicoflagellate } \\
\text { Radiolarian fragment } \\
\text { Staurastrum sp. } \\
\text { Sponge spicules }\end{array}$ & $\begin{array}{c}1 \\
1 \\
27\end{array}$ & $\begin{array}{c}27 \\
1 \\
2 \\
7 \\
3 \\
29\end{array}$ & 17 & 1 & \\
\hline
\end{tabular}

\section{Key}

Reg. $(\mathrm{Bl})=$ combined regolith samples from this thesis, excluding Mt. Feather Site Two which may contain reworked "Sirius Group diatoms".

$\operatorname{Sir}(\mathrm{Bl})<7=$ Diatoms from the surface $7 \mathrm{~cm}$ of the Sirius group tills at Mt. Feather from this study.

$\operatorname{Sir}(\mathrm{Bl})>7=$ Diatoms from greater than $7 \mathrm{~cm}$ in depth from the till at Mt. Feather in this study.

$\operatorname{Sir}(\mathrm{S})<10=$ Diatoms from the surface $10 \mathrm{~cm}$ in the Sirius group tills at Mt. Fleming from Stroeven (1994).

$\operatorname{Sir}(\mathrm{S})>10=$ Diatoms from greater than $10 \mathrm{~cm}$ in depth from the Sirius group tills at Mt. Fleming from Stroeven (1994). 


\section{APPENDIX 6.6}

Species lists and other important information on all diatoms found.

APPENDIX 6.6a

Table A6.16 Species list, and summary information on ages, environment, and the samples in which they were found.

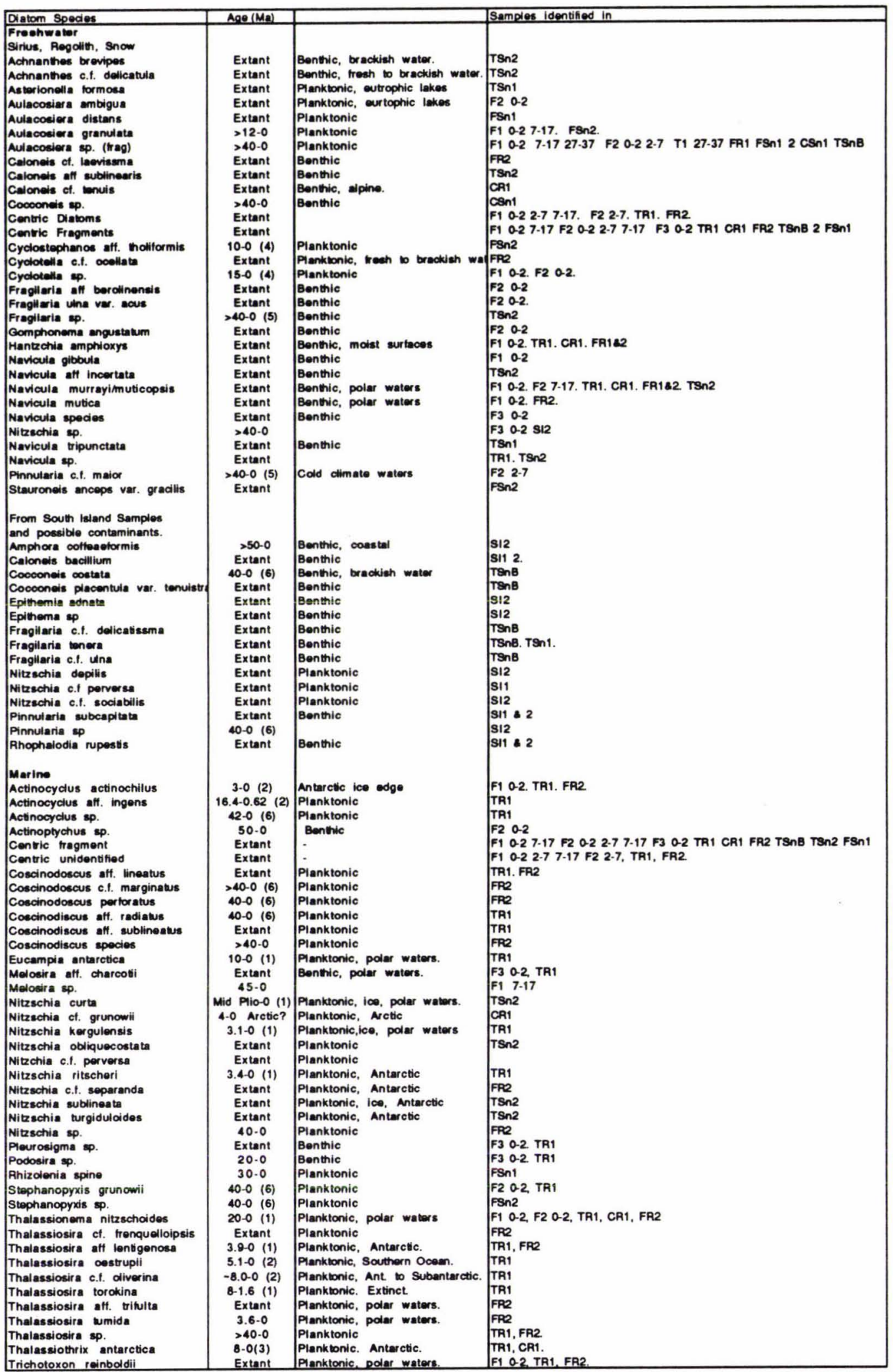

If distribution is not mentioned then the distribution is cosmopolitian.

References to ages

1.Harwood (1996 Pers. comm)

2.Harwood \& Maruyama (1992)

3. Temnsiskova-Topalova et al (1983)

4. Krebs et al.(1987)
5. Longman \& Andrews (1988)

6. In Oamaru Diatomite

Desikachary and Sreelatha, 1989

7. McCollum (1975) 


\section{APPENDIX 6.6b Comments, Systematics and Ecology of Taxa}

\section{A. Species from Sirius Group Till, snow and regolith samples}

Achnanthes brevipes Agardh
Sample - TSn2
Slide - 1
Co-ordinates- 25.0110 .5

Measurements- Size 17 x $5 \mu \mathrm{m} \quad$ Punctae $-10 / 10 \mu \mathrm{m}$

References - Hendey (1964), Krammer \& Lange-Bertalot (1991b).

Environment/Distribution - Brackish water, benthic. Cosmopolitan. < 25parts per thousand salt. Full marine conditions are 35 parts per thousand.

Age - Extant

Achnanthes delicatula (Kützing) Grunow

Sample- TSn2 Slide-1 Co-ordinates- 37.9107 .0

Measurements- $12 \times 4 \mu \mathrm{m}$ Striae $-18 / 10 \mu \mathrm{m}$

Discussion - slightly obscured specimen.

References - Krammer \& Lange-Bertalot (1991b).

Environment/Distribution -Freshwater to brackish, benthic, cosmopolitan

Age - Extant

Actinocyclus actinochilus (Ehrenberg) Simonsen.

[syn. Charcotia achinochilus]

$\begin{array}{llll}\text { Sample }- & \text { Slide }- & \text { Co-ordinates- } & \text { Size- } \\ \text { F1 0-2cm } & 7 & 27.9105 .2 & 20 \times 17 \mu \\ \text { FR2 } & 4 & 27.0105 .3,25.893 .8 & 15 \times 10 \mu, 16 \times 17 \mu\end{array}$

Other measurements - Areolae- $8 / 10 \mu$

Further description- Centric, Isolated radial rows.

References - Fryxell (1990). Harwood (1986) Plate 1, fig 11.

Environment/distribution- Marine planktonic, antarctic ice edge

Age- 3-0 Ma (Harwood, 1986, MSSTS-1 drillhole, Harwood Pers. Comm, 1996).

Actinocyclus aff.ingens Rattray

Sample- TR1 Slide - $3 \quad$ Co-ordinates - 31.0110 .2

Measurements- Fragment- $6 \times 9 \mu \mathrm{m}, 15 \times 17 \mu \mathrm{m} \quad$ Areolae $7-10 / 10 \mu$

Notes - Square to round areolae

References - Harwood and Maruyama (1992); Baldauf and Barron (1980).

Environment/Distribution - Marine plankton.

Age $-16.4-0.62 \mathrm{Ma}$, as above 
Actinocyclus sp.

Sample - TR1 Slide - $3 \quad$ Co-ordinates- 30.9106 .1

References - Round (1990) p.194

Environment/Distribution - Marine holoplankton, mainly epiphytic on seaweeds.

Age - Extant

Actinoptychus sp. Hassall

Sample- F2 0-2 Slide - 5

Measurements - $8 \times 10 \mu \mathrm{m}$

Diacussion - poor specimen

Environment/Distribution - Marine benthic.

Age - 50-0 ma

Asterionella formosa

Sample- TSn 1

Slide - 1

Co-ordinates-106.1

Measurements- $54 \times 3-4 \mu \mathrm{m}$ at the ends, middle $2 \mu \mathrm{m}$.

References - Hendey (1964), Krammer \& Lange-Bertalot (1991a) pg. 103

Environment/Distribution - Freshwater planktonic. Abundant in eutrophic lakes, cosmopolitian.

Age - Extant

Aulacosiera. Krebs. Widely recorded in the Early Miocene - Present.

Aulacoseira ambigua (Grunow) Simonsen

Sample- F2 0-2 Slide- $4 \quad$ Co-ordinates- 30.4112 .8

Measurements- 10x6 $\mu \mathrm{m}$

References - Krammer \& Lange-Bertalot (1991b).

Environment/Distribution - Freshwater planktonic, eutrophic lakes and rivers, cosmopolitian.

Age - Extant

Aulacoseira fragment.

Sample-F10-2 TSn2 FSn1 Slide-FSn1 4 Co-ordinates- 98.760 .5

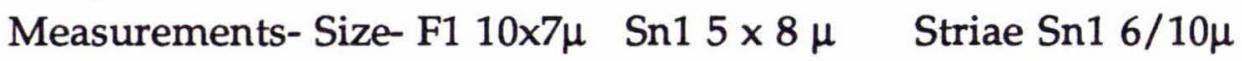

References - Krammer \& Lange-Bertalot (1991a).

Environment/Distribution - Freshwater planktonic

Age - Extant 
Aulacoseira distans (Ehrenberg) Simonsen [Melosira distans]

Sample- F2 2-7, FSn $1 \quad$ Slide - 1,7 Co-ordinates- 25.0102 .7

Measurements- $7 \times 6$ each (two joined) areolae $12 / 10 \mu \mathrm{m} \quad 20.2112 .8$

Discussion- In a clump of $35 \times 25 \mu \mathrm{m}$

References - Krammer \& Lange-Bertalot (1991a)

Environment/Distribution - Freshwater planktonic. Cosmopolitian. Fewer in recent material than in the past.

Aulacoseira granulata (Ehrenberg) Simonsen

$\begin{array}{lllll}\text { Sample- } & \text { Slide } & \text { Co-ordinates } & \text { Size } & \text { Punctae } \\ \text { F1 0-2 } & 2(3) & 29.4108,3 & 15 \times 10 \mu \text { valve full length } \\ \text { F1 7-17, } & 2 & & 12 \times 8 \mu \mathrm{m} \quad 8 / 10 \mu \mathrm{m} \\ & & & 12 \times 10 \mu \mathrm{m} & \\ \text { F2 7-17 } & 1 & & 12 \times 3 \mu \mathrm{m} & \\ & & & 4 \times 14 \times 10 \mu \mathrm{m} & 6 / 10 \mu \mathrm{m} \\ & & & 18 \times 12 \mu \mathrm{m} & 7 / 10 \mu \mathrm{m} \\ & & & 10 \times 8 \mu \mathrm{m} & \\ \text { T1 0-2 } & 51 & 34.895 .6 & 13 \times 5 \mu \mathrm{m} & 9 / 10 \mu \mathrm{m} \\ & & 31.6101 .5 & 23 \times 13 \mu \mathrm{m} & 6-7 / 10 \mu \mathrm{m} \\ \text { FR1 } & 4(2) & 28.7107 .8 & 20 \times 4 \mu \mathrm{m} & 6 / 10 \mu \mathrm{m}\end{array}$

FSn2

Description- can see central spine in some cases which is a characteristic of separation cells of this species.

References - Krammer \& Lange-Bertalot (1991a).

Environment/Distribution - Freshwater planktonic, eutrophic lakes and rivers.

Age - Early Miocene - 0

Most common freshwater species of all the taxa.

Biddulphia aff.turgida Wm Smith.

Also see Cerataulus turgidus (Ehrenberg) Ehrenberg

Sample- F1 7-17 Slide - 5

Measurements- Size- $23 \times 17 \mu \mathrm{m}$

Description- unlike either Eucampia species known today in polar waters.

References - Round (1990), Van Heurck, (1896).

Environment/Distribution - Marine, plankton.

Age - Late Eocene - 0 
Caloneis c.f. sublinearis (Grunow) Krammer

Sample- TSn2 Slide -4

Co-ordinates- 29.196 .1

Measurements - $22 \times 5 \mu \mathrm{m}$, striae $22 / 10 \mu \mathrm{m}$

References - Krammer \& Lange-Bertalot (1991)

Environment/Distribution - Freshwater. Cosmopolitan.

Age - Extant

Caloneis cf. tenuis (Gregory) Krammer

Sample- CR1 Slide- $2 \quad$ Co-ordinates- 28.9 98.3, 16.4 92.4.

Measurements- $11 \mu \mathrm{m} \times 4 \mu \mathrm{m}$ ( half length) $12 \times 4 \mu \mathrm{m} \quad$ Striae- 24-26/10 $\mu \mathrm{m}$

References - Krammer \& Lange-Bertalot (1986) 2/1 fig. 174: 11 pg 392

Environment/Distribution - Freshwater, cosmopolitan. Alpine.

Age - Extant

Centric Diatoms and pieces

Location Co-ordinates

F1 7-1

F1 0-2

F1 0-2

F1 17-27 5-20

F2 7-17.

F2 0-2

F3 $0-2$

Like small version of T.tumida

Areolae

Areolae 10/10 $\mu \mathrm{m}$

Areolae $4.5 / 10 \mu \mathrm{m}$

Punctae-5/10 $\mu \mathrm{m}$, hexagonal.

Punctae- 10/10 $\mathrm{m}$, hexagonal

Single separate aerolae

Striae- $16 / 10 \mu \mathrm{m}$

Punctae- 8-9/10

Outside operculate
Size

$8 \mu \mathrm{m}$

$7 \times 9 \mu \mathrm{m}$

frag, $8 \times 9 \mu \mathrm{m}$

$10 \times 12$

$14 \times 20 \mu \mathrm{m}$

$14 \mu \mathrm{m}$

$20 \times 35 \mu \mathrm{m}$

$13 \mu \mathrm{m}$

Two pieces in a clast

Cocconeis sp.

Sample- TSn1,CSn Slide - 1

Co-ordinates- 14.8104 .6

References - Krammer \& Lange-Bertalot (1991b)

Environment/Distribution - Freshwater Benthic

Age - Eocene-0

Coscinodiscus aff lineatus Ehrenberg

Sample-FR2, TR1

Slide -4

[syn. Thalassiosira leptopus]

Measurements- Diameter- $31 \mu \mathrm{m}$

edge $2 \mu \mathrm{m}$

Co-ordinates-25.8 94.6

striae at edge $8 / 10 \mu \mathrm{m}$, areolae $6 / 10 \mu \mathrm{m}$

Discussion - This specimen is smaller than lineatus.

References - Hendey, 1964.

Environment/Distribution - Marine planktonic

Age - Extant 
Coscinodiscus marginatus Ehrenberg
Sample- FR2
Slide - 4
Co-ordinates- 23.699 .9

Measurements- Punctae $4 / 10 \mu \mathrm{m}$

Discission - Stong highline margin, irregular areolae arrangemey, radial.

References - Hendy, 1964

Environment/Distribution - marine plankton.

Age - Upper Miocene in southern ocean, Late Eocene - 0 (Desikachary and Sreelath, 1989)

Coscinodiscus perforatus Hustedt

Sample- FR2 Slide - 4

Measurements- Areolae 2/10 $\mu$

References - Hustedt in Jensen (1985), Hendey (1964).

Environment/Distribution - marine plankton

Age - Late Eocene - 0 Omaru.

Coscinodiscus aff. sublineatus Grunow

Sample-TR1 Slide - $3 \quad$ Co-ordinates - 31.0111 .0

Measurements- $17 \times 15 \mu \mathrm{m}$,

References - Hustedt in Jensen (1985), Hendey (1964).

Environment/Distribution - marine planktonic

Coscinodiscus aff. radiatus Grunow

Sample-TR1 Slide-3 Co-ordinates- 35.0111 .3

Measurements- $15 \times 10 \mu \mathrm{m}$ Areolae 5/10 $\mu \mathrm{m}$

References - Hendey (1964)

Environment/Distribution - marine planktonic

Coscinodiscus sp.

Sample-TR1 Slide - $3 \quad$ Co-ordinates- $29.0106 .6,29.7106 .6,40.2106 .7$

Measurements - $6 \times 9 \mu \mathrm{m}$ Areolae-10/10 $\mu \mathrm{m}$.

Environment/Distribution - Planktonic

Cyclostephanos aff. tholiformis Stoermer, Håkansson \& Theriot

Sample- FSn2 Slide- 5 Co-ordinates-23.5 109.0

Measurements- $12 \mu \mathrm{m}$, radial striae, $13 / 10 \mu \mathrm{m}$

Discussion- could also be Cyclostephanos costatilimbus but is a little to large and has fewer striae per $10 \mu \mathrm{m}$

References - Krammer \& Lange-Bertalot (1991a) pg 364 fig 6: a\&b. 
Environment/Distribution - Freshwater planktonic, generally only in artificial lakes and in durty polluted waters.

Age - 10 - $0 \mathrm{Ma}(4)$

Cyclotella cf. ocellata Pantocsek

Sample- FR2 Slide - 4

Co-ordinates- 26.196 .8

Measurements- Diameter $8 \mu \mathrm{m} \quad$ Striae - 8-9/10 $\mu \mathrm{m}$

Notes - Slightly smaller than C. ocellata.

References - Krammer \& Lange-Bertalot (1991b)

Environment/Distribution - Freshwater-brackish planktonic, cosmopolitian.

Age - Extant

Cyclotella sp.

Sample - TR1, F2 0-2, F1 0-2 5-20

Slide-3 (5 other locations on this slide) Coordinates - 30.1106 .1

Measurements- fragments $6 \times 8 \mu \mathrm{m}$

References - Mainly freshwater, but some ar brackish to marine planktonic Age - 15 - $0 \mathrm{Ma}$ (4)

Denticula sp.

Sample- TR1 Slide - 3 Total of two identified. Co-ordinates- 28.5107 .9

Measurements- 7 × 10 $\mu \mathrm{m}$ Striae- $10 / 10 \mu \mathrm{m}$

References - Round (1990).

Environment/Distribution - Benthic marine and freshwater

Age - Extant

Eucampia antarctica (Castracane) Mangiun. [syn. Eucampia balustruim]

Sample- TR1 Slide-3 Co-ordinates- 39.6108 .4

Measurements-Diameter $17 \mu \mathrm{m}$ Punctae $8 / 10 \mu \mathrm{m}$

References - Medlin \& Priddle 1990

Environment/Distribution - Marine planktonic, Antarctic.

Age - 10 - $0 \mathrm{Ma}$ (Harwood and Maruyama, 1992)

Fragilaria aff. berolinensis (Lemmerman) Lange-Bertalot. [syn. Synedra berolenensis].

Sample - F2 0-2 Slide - 11A Co-ordinates- 30.0108 .3 or 27.3 106.3?

Measurements- $10.5 \times 3 \mu \mathrm{m} \quad$ Striae $-10 / 10 \mu \mathrm{m}$

References - Krammer \& Lange-Bertalot (1991a).

Environment/Distribution - Freshwater planktonic. Still to slow moving water.

Age - Extant 
Fragilaria tenera (W.Smith) Lange-Bertalot [Syn. Synedra tenera]

*In SI pot contaminatian, at Table Mt also.

Sample- TSn1 Slide- $1 \quad$ Co-ordinates- 14.6104 .2

Measurements- 40 × 2-3 $\mu \mathrm{m}$

Discussion- Very thin ends with small- slight thinckening at the very ends.

References - Krammer \& Lange-Bertalot pg 129, fig 114

Environment/Distribution - Freshwater, alpine regions, cosmopolitan.

Age - Extant

Fragilaria c.f. unla (Nitzsch) Lange-Bertalot [syn.Synedra ulna]

*in SI pot contamintion also

Sample - F2 0-2 Slide -

Co-ordinates-

Measurements- Size- 20x9 $\mu \mathrm{m}$ fragment. Striae- $9 / 10 \mu$

Diacussion - Striae come close to the centre, a very different form from the one described above, at maximum thickness, as described by Krammer \& LangeBertalot, 1991.

References - Krammer \& Lange-Bertalot, 1991, Plate 120, 1-5.

Environment/Distribution - Fresh to brackish water

Age - Extant

Fragilaria ulna var. acus (Kützing) Lange-Bertalot. [syn. Synedra ulna var. arcus]

F2 0-2 5-20 $\quad$ Slide-16. Co- ordinates- 36.9106 .4

Size- frag. $64 \times 4 \mu \quad$ Striae- $13 / 10 \mu$

Discussion - very long and thin, pin like.

Reference - Krammer \& Lange-Bertalot, 1991 pg 144 fig 122:13

Environment - Freshwater benthic.

Fragilaria sp.

Sample- TSn2, F2 0-2 Slide - 1

Measurements- $19 \times 4 \mu \mathrm{m} \quad$ Striae-10/10 $\mu \mathrm{m} \quad 2$ puntae/striae

Notes - very small type at F2

Environment/Distribution - Freshwater benthic, in sediment.

Age - $>40$ - $0 \mathrm{Ma}(5)$ 
Gomphonema angustatum (Kützing) Rabenhorst

Sample- F2 0-2 Slide - $6 \quad$ Co-ordinates- 41.2104 .4

Measurements- $27 \times 6 \mu \mathrm{m} \quad$ Striae $-10 / 10 \mu \mathrm{m}$

Discussion- Small, rostrate ends. Slightly radial striae from centre. One striea on each side of the central area appears slightly shorter.

References - Krammer \& Lange-Bertalot (1986)

Environment/Distribution - freshwater benthic

Age - Extant

Hantzschia amphioxys (Ehrenberg) Grunow

Sample- F1 0-2, Slide- 8 Co-ordinatesFR2 4

19.598 .9

$\begin{array}{ll}\text { TR1 } & 3 \\ \text { TSn2 } & 1 \\ \text { CR } & 1\end{array}$

Measurements

Striae length $37 \mu \mathrm{m}$, full $\sim 80 \mu \times 9 \mu \mathrm{m}, \sim 20 / 10 \mu \mathrm{m}$, Coarse punctae down side $\sim 7 / 10 \mu \mathrm{m}$

$45 \times 9 \mu \mathrm{m} \quad$ fine striae $\sim 21 / 10 \mu \quad$ Fibulae $\sim 4 / 10 \mu$

$25 \times 10 \mu \mathrm{m} \quad$ striae $10 / 10 \mu \quad$ Fibulae $6 / 10 \mu$

$\mathrm{Sn}-78 \times 11 \mu \mathrm{m} \quad$ striae $\sim 20 / 10 \mu \quad$ Fibulae $8 / 10 \mu$

References - Krammer \& Lange-Bertalot (1988), fig 128:3

Environment/Distribution - Freshwater benthic, aerophilic, cosmopoliton. Occurrs on material that can be dry for long periods and dampened occasionally. Known in Antarctica from Ross Island, South Victoria Land (Baker, 1967) and on the Prince Olav coast.

Age - Extant

Melosira aff. charcotii Peragallo

Sample- FR2 Slide - 4

F3 0-2

Co-ordinates- 18.5 102.5, 19.0102 .5 .

$32.5111 .0,30.6110 .6$.

Measurements - Diameter $10-13 \mu \mathrm{m}$

References - Scherer, 1987 Antarctic Journal of the United States 22, 35-37.

Environment/Distribution - Coastal Brackish-Freshwater Benthic, occurs in tidally influenced ice shelf conditions and other marine proximal, brackish water environments. Occur in meltpools on the McMurdo ice shelf today, especially near tidal cracks and in intertidal pools along the Antarctic Peninsula.

Age - At least Pleistocene to Present 
Melosira sp.

Sample- FR2

Slide -4

Co-ordinates- 27.8104 .0

Measurements- Diameter $9 \mu \mathrm{m}$

References -

Environment/Distribution - Freshwater and marine, often epibenthic.

Age - Extant

Navicula c.f. gibbula Cleve

Sample- F1 0-2, F1 0-2 5-20

Slide - 2,3 Co-ordinates- 29.4101 .4

Measurements- $42.5 \times 11 \mu \mathrm{m}, 44 \times 11 \mu \mathrm{m}$ Striae- 22/10, $16 / 10 \mu \mathrm{m}$ Punctae$\sim 25 / 10 \mu \mathrm{m}$

Notes - Slightly bulged at the centre.

References - Krammer \& Lange-Bertalot (1986) 235, fig 65, : 14\&15

Environment/Distribution - Freshwater-brackish benthic. Occurs in small lakes where there are high osmotic changes.

Age - Extant.

Navicula aff. incerta Lange-Bertalot

Sample- TSn2 Slide - $1 \quad$ Co-ordinates - 32.6110 .3

Measurements - $18 \times 6 \mu \mathrm{m}$ Striae - 14/10 $\mu \mathrm{m}$

Discussion - This specimen appears to have flatter sides than the reference.

References - Krammer \& Lange-Bertalot (1986) pg 111

Environment/Distribution - Benthic

Age - Extant

Navicula cf. laevissma

Sample - FR2 Slide -4

Measurements-> half $20 \times 10 \mu \mathrm{m}$ Striae- $\sim 22 / 10 \mu \mathrm{m}$ Punctae- 20/10 $\mu \mathrm{m}$

Descripton- Very rounded ends, striae slightly radial at centre.

References - Krammer \& Lange-Bertalot (1991).

Environment/Distribution -

Age - Extant. 
Navicula muticopsis Van Heurck orNavicula murrayi West

Sample Slide Co-ordinates Size Striae Punctae

$\begin{array}{llllll}\text { F1 0-2 } & 2 & 21.4104 .1,29.51 & 26 \times 9 \mu \mathrm{m} & 24 / 10 \mu \mathrm{m} & \\ \text { CR1 } & 4 & 26.994 .3 & 22 \times 8 \mu \mathrm{m} & 20 / 10 \mu \mathrm{m} & 2 \mathrm{~m} / 10 \mu \mathrm{m} \\ \text { TR1 } & 3 & & 25 \times 7 \mu \mathrm{m} & & \\ \text { F1 0-2 5-20s } & 3 & 27.398 .0 & 25 \times 9 \mu \mathrm{m} & 18 / 10 \mu \mathrm{m} & \\ \text { F2 7-17 } & 6 & 22.591 .4 & \text { Poor specimen } & \\ \text { F3 7-17 } & 6 & 19.8103 .5 & & \\ \text { TSn2 } & 1 & 20.2111 .7 & & \end{array}$

Description- Single pore or stigma in the central area, striae radiate throughout whole valve. The striae per $10 \mu$ differs slightly from the number out lined in Krammer \& Lange-Bertalot (1986) and West (1911). Crean specimen like Fig 61, 9-15.

References - Wassell, 1993. Wasell \& Hakansson,1992, pg 167 fig 38, Krammer \& Lange-Bertalot, 1986 fig 61: 13 and Hustedt, 1966 pg 610 fig 129, d \& e.

Environment/Distribution - Freshwater (also in some brackish environments) aerophil benthic, common in Antarctic water bodies (Wassell, 1993). One of the most common diatoms in the Antarctic and sub Antarctic (Kobayashi 1963) also in the arctic. West (1911) found species in penguin rookeries. This is also a common taxa on southern ocean islands such as Horseshoe Island (Wasell and Hakansson, 1992). In europe it is found in puddles after flooding (Krammer and Lange-Bertalot).

Age - Extant

Navicula muticopsis, mutica, murryi and cobnii all can be grouped togeather as one.

Navicula mutica Kützing

Sample- FR2, F1 0-2 5-20 Slide - 4,2 Co-ordinates- 29.5 x 100.4, 38.2111 .2

Measurements- Half $13 \times 8 \mu \mathrm{m}, 12 \times 7 \mu \mathrm{m}$, striae $21 / 10 \mu \mathrm{m}$

Discussion- Three short striae in central area.

References - Krammer \& Lange Bertalot (1986) pg 149, fig 61.7 
Environment/Distribution - Freshwater-brackish benthic, aerophil, found in gaps between stones. Occurrs in Antarctic lakes.

Age - Extant

Navicula paramutica Bock 1963

Sample- F1 0-2

Measurements- $15 \times 7 \mu \mathrm{m}$
Slide - 2
[Syn. N. mutica $v$. mutica]

Co-ordinates- 8.9106 .8

Description - Has two small punctae on the edge on the central area right side. Note - Does not have the single punctae, described. Striae radiate from the centre to half way to apices, then parallel. Has two punctae or short striae at the edge on one side of the valve.

References - Krammer \& Lange-Bertalot (1986) pg 140, fig 61:29 Similar shape to Hustedt, 1966 Navicula murrayi West pg 610, fig 129: f\&k.

Environment/Distribution - Freshwater benthic, aerophil, Occurs in unstable environments. Occurs in gaps between stones, and on "dry" surfaces where there is moisture in the air.

Age - Extant

Navicula tripunctata (O.F. Muller) Bory

Sample-TSn2 Slide - 1

Co-ordinates- 45.2100 .0

Measurements- $26 \times 6 \mu \mathrm{m} \quad$ Striae- $12 / 10 \mu \mathrm{m} \quad$ Punctae-21-27/10 $\mu \mathrm{m} \quad 2$ frustrules

References - German Plate 71 fig. 2, Patrick pg. 562)

Environment/Distribution - Fresh-brackish water benthic. Rare in Dry Valley lakes. Common in Canterbury Lakes New Zealand. Cosmopolitan

Age - Extant

Navicula sp.

Sample- TR1, Slide-3

TSn2, $\quad 3$

Co- ordinates - 38.8106 .4 ,

F3 0-2 5

39.9108 .0

22.1107 .5

Measurements - $26 \times 10 \mu \mathrm{m}$ full length $>40 \mu \mathrm{m} \quad$ Striae $24 / 10 \mu \mathrm{m} \quad$ c. $17 \times 4.5$

Nitzschia sp. Bory

Sample- F3 0-2 Slide - 5 Co-ordinates- 22.1 107.5,

F2 7-17

F1 17-27

27.991 .7

Measurements- Size $17 \times 4.5 \mu \mathrm{m}, 18 \times 7 \mu \mathrm{m}$, frag. $8 \times 4 \mu \mathrm{m} \quad$ Punctae- $-10 / 10 \mu \mathrm{m}$ 


\section{striae- $25 / 10 \mu \mathrm{m} \quad$ fibulae $11 / 10 \mu \mathrm{m}$}

Environment/Distribution - Freshwater-benthic, some also planktonic.

Age - Extant

Nitzschia curta (Van Heurck) Hasle [syn. Fragilariopsis curta]

Sample - TSn2 Slide-1 Co-ordinates-22.1 110.8

Measurements - $25 \times 6 \mu \mathrm{m} \quad$ Striae- $12-13 / 10 \mu \mathrm{m}$

References - Medlin \& Priddle, 1990

Environment/Distribution- Marine planktonic/ice, Antarctic.

Age - Mid Pliocene - 0 Ma (1) Upper Miocene/Pliocene - 0 Ma Harwood (1986).

Nitzschia debilis (Arnott) Grunow [syn. Nitzschia perversa,Tryblionella debilis]

Sample- SI. G (2) Slide - $1 \quad$ Co-ordinates- 26.9107 .8

Measurements- $14 \times 7 \mu \mathrm{m}$

References - Krammer and Lange-Bertalot (1988).

Environment/Distribution - Planktonic

Age - Extant

Nitzschia of grunowii (Cleve) Hasle [syn. Fragilariopsis c.f. grunowii]

Sample- CR Slide - 3

Co-ordinates-39.9 104.1

Measurements- $16 \times 5 \mu$ actual size $\sim 18 \mu \quad$ Striae $\sim 15 / 10 \mu \quad$ Punctae $\sim 18 / 10 \mu$.

Discussion- Very shabby looking, using size and measurements is closest to $N$. cylindrus or N. angulata, but it looks like neither of these, in shape and size is closest to N. grunowii which is an Arctic diatom.

References - Hasle and Medlin in Medlin and Priddle, 1990

Environment/Distribution - Marine plankton/ ice, Arctic.

Age - Extant

Nitzschia kergulensis (O'Meara) Hasle [syn. Fragilariopsis kerguelensis]

Sample-TR1 Slide-3 Co-ordinates-32.0 107.9

Measurements- $18 \times 7 \mu \mathrm{m}$, full length $>30$, striae $8 / 10 \mu \mathrm{m}$.

References - Medlin \& Priddle (1990)

Environment/Distribution - Marine planktonic /ice, Antarctic

Age - 3.1 - 0 Ma (Harwood and Maruyama, 1992) 2.7-0 (Donahue) 2.6-0 (McCullum, 1975). 
Nitzschia obliquecostata (Van Heurck) Hasle [syn. Fragilariopsis obliquecostata] Sample- TSn2

Slide - 1

Co-ordinates- 30.2105 .7

Measurements- $46 \times 8 \mu \mathrm{m}$ Striae $-7 / 10 \mu \mathrm{m} \quad$ Rows of punctae between striae

$-2$

References - Hasle \& Medlin (1990).

Environment/Distribution - Marine planktonic. Antarctic ice.

Age - Extant

Nitzschia ritscheri (Hustedt) Hasle [syn. Fragilariopsis ritscheri]

Sample- TR1 Slide - 3 Co-ordinates- 35.0111 .3

Measurements- $15 \times 8 \mu \mathrm{m}$ full length probably $\sim 50 \mu \mathrm{m}$. Fibulae $6 / 10 \mu \mathrm{m}$ Areolae 2-3 rows/between fibulae.

References - Hasle \& Medlin, in Medlin and Priddle, 1990 Environment/Distribution - Marine planktonic, Antarctic.

Age - 3.4 - $0 \mathrm{Ma}$ (Harwood and Maruyama, 1992).

Nitzschia c.f. separanda (Hustedt) Hasle

Sample -FR2 Slide- $4 \quad$ Co-ordinates-29.5 96.9

Measurements $20 \times 7 \mu \mathrm{m}$ Striae $10 / 10 \mu \mathrm{m}$

References- Hasle and Medlin, Medlin and Priddle (1990) pg 182.

Environment/ Distributuon- marine plankton, Antarctic.

Age - extant

Nitzschia sublineata Hasle

Sample- TSn2 Slide- $1 \quad$ Co-ordinates- 27.0 110.5

Measurements - $48 \times 6 \mu \mathrm{m} \quad$ Striae - $9 / 10 \mu \mathrm{m}$

References - Hasle \& Medlin in Medlin \& Priddle (1990).

Environment/Distribution - marine planktonic, ice, Antarctic .

Age - extant

Nitzschia turgiduloides Hasle [in sect, Pseudonitzschia]

Sample- TSn2 Slide - $4 \quad$ Co-ordinates- 32.0105 .5

Measurements- $40 \times 2 \mu \mathrm{m} \quad$ Str $16-18 / 10 \mu \mathrm{m}$

References - Medlin \& Priddle (1990).

Environment/Distribution - Marine, planktonic. Antarctic

Age - Extant 
Nitzschia sp or Denticula sp.

Buried in other material, hard to see.

Sample- aF2 0-2, Slide- $5 \quad$ Co-ordinates -b23.3 99.3,

Environment/Distribution - can be freshwater to marine, can also be aerophilic.

Age - extant

Pinnularia c.f. maior (Kützing) Rabenhorst

Sample- F2 2-7 Slide - $27 \quad$ Co-ordinates- 22.7105 .8

Measurements - $40 \times 12 \mu \mathrm{m}$

Curve on outside edge- straight to slightly curved.

References - Krammer \& Lange-Bertalot (1986) fig 196:1-4. Hustedt trans. in Jensen (1985) pg 737 fig 614.

Environment/Distribution - Freshwater, Antarctic lakes (Wassell, 1983), cosmopolitan, but dominantly Arcric and Antarctic waters.

Age - >40 - 0 (5)

Pinnularia sp.

Sample- F2 0-2, TSn2 Slide - 4

Measurements- Size-frag. $8 \times 9 \mu \mathrm{m} \quad$ Striae- $5 / 9 \mu \mathrm{m} \quad$ Punctae- $14 / 10 \mu \mathrm{m}$

Enverinment/distribution - Freshwater to marine.

Pleurosigma sp.

Sample- F3 0-2 Slide - 1

TR1 3 (4 on slide)

Co-ordinates- 36.5102 .1

31.2106 .4

Measurements - $14 \times 14 \mu \mathrm{m} \quad$ Punctae - 18/10 $\mu \mathrm{m}$

Environment/Distribution - Marine benthic

Age - Extant

Podosira sp.

Sample - TR1, F3 0-2 Slide - $3 \quad$ Co-ordinates - 33.4 110.6

Measurements- Diameter $19 \mu \mathrm{m}$

Environment/Distribution - Marine benthic

Age - 20-0 Ma Late Eocene.

Rhizosolenia spine Marine planktonic 
Stauroneis anceps var. gracilis (Ehrenberg) Cleve.

Sample FSn2 Slide - $1 \quad$ Co-ordinates - 45.9103 .9

Measurements - Size- $47 \times 10 \mu \mathrm{m} \quad$ Striae- $32 / 10 \mu \mathrm{m}$

Discussion - Striae curved.

References - Germain, 1981,pg 156, Plate 60:5 and Jensen pg 650, fig 1120:b. but has a more butterfly shaped stauros central area like that of $S$. agrestis.

Distribution- Freshwater, cosmopolitan. Widely spread in fossil deposits, found on stones in rivers.

Stephanopyxis aff. grunowii Grove \& Sturt.

Sample- TR1 Slide - 3 Co-ordinates- $31.1111 .9,36.3106 .6$

Measurements- Diameter $\sim 20 \mu \mathrm{m} \quad$ Areolae $4 / 10 \mu \mathrm{m}$

References - Harwood and maruyama (1992)

Environment/Distribution - Marine planktonic

Age - 40-0 Ma

Stephanopyxis sp.

Sample- FSn2 Slide - $4 \quad$ Co-ordinates-

Measurements- Areolae $7 / 10 \mu \mathrm{m}$

Diacussion - Unlike other Stephanopyxis species, it has two spines at the edge of the fustule, areolae round-hexagonal

References -

Environment/Distribution - Marine planktonic

Age - Cret - $0 \mathrm{Ma}$ (6)

Thalassionema nitzchiodes Grunow ex Hustedt.

$\begin{array}{lrll}\text { Sample- } & \text { Slide }- & \text { Co-ordinates- } & \text { Size } \\ \text { F1 0-2, } & 1 & 20.1100 .3 & 24 \times 4 \mu \mathrm{m} \\ \text { F1 0-2 } & 5 \text {-20sep. 1 } & 39.9102 .2 & 9 \times 3 \mu \mathrm{m} \\ \text { FR2 } & 4 & 26.2102 .8,29.796 .0, & 23 \times 4 \mu \mathrm{m}, 12 \times \\ \text { 14 } \mu \mathrm{m} & & 25.893 .8 & 20 \times 5 \mu \mathrm{m}, 20 \times \\ & & & \\ 5 \mu \mathrm{m} . & 2 & 23.7104 .4 & 15 \times 5 \mu \mathrm{m} . \\ \text { CR1 } & 3 & \text { Total of } 16 \text { on the slide } & 14 \times 4 \mu \mathrm{m} \\ \text { TR1 } & 6 & 39.9101 .6 & 15 \times 3 \mu \mathrm{m} \\ \text { F1 0-2 } & 5-20 \text { sep } 5 & 26.498 .4 & 19 \times 2 \mu \mathrm{m} \\ \text { F1 17- 27 } & 5 & \end{array}$

Measurements- Areolae- 9-14/10 $\mu \mathrm{m}$ 
References - Hendy (1964), Andrews (1986), Harwood pers comm.

Environment/Distribution - Marine planktonic, most abundant marine diatom recorded. Favours low salinity waters near shore (Pokras and Molfino, 1986.

Age - Miocene-0 (Harwood and Maruyama, 1992 \& 6)

Thalassiosira frenquelliopsis Fryxell and Johansen

Sample-FR2 Slide-4 Co-ordinates-19.697.3

Measurements $-22 \mu \mathrm{m}$ areolae $9 / 10 \mu \mathrm{m}$

References - Fryxell and Johansen (1990)

Envoronment/Distribution - Marine planktonic, subantarctic.

Age - Extant

Thalassiosira aff. lentiginosa (Janisch.) Fryxell [syn. Coscinodiscus lentiginosa]

Sample- FR2, TR1 Slide-4 Co-ordinates- 25.899 .8

Measurements- $20 \times 7 \mu \mathrm{m}$ Areolie $10 / 10 \mu \mathrm{m}$

References - Fryxell and Johansen in Medlin \& Priddle 1990

Environment/Distribution - Marine planktonic, Antarctic.

Age - 3.9 - $0 \mathrm{Ma}$.

Thalassiosira oestrupii (Ostenfeld) Hasle

Sample- TR1 Slide-3 Co-ordinates- 34.3111 .4

Measurements- full size $\sim 20 \mu \mathrm{m}+$

Discussion- Large eliptical areolae orented in different directions. Smooth surface.

References - Fryxell and Johansen in Medlin \& Priddle (1990).

Environment/Distribution - Marine planktonic. Cosmopolitan.

Age - 5.1(2) Pliocene - $0 \mathrm{Ma}(6)$.

Thalassiosira c.f. oliverana (O'Meara) Mak.

Sample-TR1 Slide-3 Co-ordinates- 24.1 95.9, 29.9 97.9

Measurements- $17 \times 20 \mu \mathrm{m}$, areolae $4 / 10 \mu \mu$

References - Fryxell and Johansen in Medlin \& Priddle (1990). Harwood pers com.

Environment/Distribution - Marine planktonic, Antarctic, subantartic Age - Extant 
Thalassiosira torokina Brady

Sample- TR1 Slide- $3 \quad$ Co-ordinates- 35.6111 .3

Measurements- $20 \times 12 \mu \mathrm{m}$, areolae $4 / 10 \mu \mathrm{m}$

Discussion- Areolae slightly irregular to linear hexagonal. Processes at edge and a fine process in the centre.

References - Harwood \& Maruyama, 1992. Harwood pers. com.

Environment/Distribution - Marine planktonic

Age - (8.6) 8-1.6 Ma.

Thalassiosira aff.trifulta Fryxell

Sample-FR2 Slide - 4

Measurements- $15 \times 18 \mu \mathrm{m}$

References - Fryxell and Johansen in Medlin and Priddle (1990).

Environment/Distribution - Marine planktonic

Age - Extant

Thalassiosira tumida (Janisch) Hasle

Sample- FR2 Slide - $4 \quad$ Co-ordinates- 27.895 .6

Measurements- $10 \times 16 \mu \mathrm{m}$ areolae $10 / 10 \mu \mathrm{m}$, small, linear, hexagonal.

Processes at margin and evenly all over.

References - Fryxell and Johansen in Medlin and Priddle (1990).

Environment/Distribution - Holoplankton

Age - Extant

Thalassiothrix antarctica Schimper

Sample- CR1 Slide - $1 \quad$ Co-ordinates-34.1 108.5

$\begin{array}{lll}\text { TR1 } & 3 & \text { Two further identifiedon this slide. } \\ \text { TSn2 } & 1 & \text { No spines }\end{array}$

Measurements- $3 \times 17 \mu \mathrm{m} 5 \times 19 \mu \mathrm{m} 29.2108 .2 \mu \mathrm{m} \quad$ Striae $-11-12 / 10 \mu \mathrm{m}$

References - Hasle, in Medlin and Priddle (1990).

Environment/Distribution - Holoplankton

Age - 8-0 Ma (3) 
Trichotoxon reinboldii (Van Heurck) Reid et Round.

[syn. Synedra reinboldii]

$\begin{array}{rrc}\text { Sample -F1 0-2cm, } & \text { Slide- } 9, & \text { Co-ordinates }-32.995 .8 . \\ \text { FR2 } & 4 & 32.2110 .1 \\ \text { TR1 } & 3 & \end{array}$

Size- piece $14 \times 5 \mu, 14 \times 6 \mu, 20 \times 4 \mu \quad$ Areolae- 8-9/10 $\mu$

Discussion - Areolae on centre of valve toward one end.

References - Hasle (1990) pg. 133.

Environment/Distribution - Marine planktonic

Age - Extant

Thalassiosira/Cyclosteph/Steph.

Sample - F2 2-7cm.

Measurements - Diameter $65 \mu \mathrm{m}$ Punctae- 24/10 $\mu \mathrm{m}$

\section{B. Species from South Island Samples and South Island Contaminants from the Control at Table Mountain.}

Amphora coffeaeformis (Agardh) Kutzing

Sample- SIG Slide - 1

Co-ordinates- $36.5109 .7,28.0$

108.4

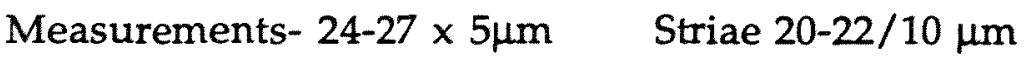

References - Hendey (1964). Krammer \& Lange- Bertalot (1986) pg. 347, fig 151 1-6:6.

Environment/Distribution - Brackish benthic

Age - Extant

Asterionella c.f. formosa Hassall [syn.Synedra c.f. formosa Hantzsch]

Sample- TSnB, TSn1 Slide - 1

Measurements - $54 \mu \mathrm{m} \times 2 \mu \mathrm{m}$, Apices spatulate, $3-4 \mu \mathrm{m}$

References - Hustedt trans. in Jensen (1985) p 215, Krammer and LangeBertalot (1991a) Table 103:7

Environment/Distribution - Marine benthic-littoral

Age - Extant 
Aulacoseira italica (Ehrenberg) Simonsen

[syn. Melosira italica (Ehrenberg)Kützing]

Sample - TSnB Slide - 5 Co-ordinates- 20.5107 .0

Measurements- $14 \times 8 \mu \mathrm{m}$ Striae- $16 / 10 \mu \mathrm{m}$

References - Krammer \& Lange-Bertalot (1991a) pg 29

Environment/Distribution - Freshwater planktonic. Eutrophic lakes and rivers. Cosmopolitan.

Age - Extant

Caloneis bacillum (Grunow) Cleve

Sample-SIG SIB Slide- 1 Co-ordinates- 34.5 109.6, 34.5 109.6, several others

Measurements- $25 \times 6 \mu \mathrm{m}$ Striae $24-28 / 10 \mu \mathrm{m}$

References - Krammer \& Lange-Bertalot (1986) pg 390

Environment/Distribution - Freshwater benthic. Cosmopolitan

Age - Extant

Cocconeis costata (Gregory)

Sample- TSnB Slide - $2 \quad$ Co-ordinates- 40.5106 .6

Measurements- $32 \times 12 \mu \mathrm{m} \quad$ Striae $-4 / 10 \mu \mathrm{m} \quad$ Punctae $10 / 10 \mu \mathrm{m}$

References - Hendy, 1964, Krammer and Lange-Bertalot 1991b.

Environment/Distribution - Marine, benthic, littoral

Age - Extant

Cocconeis placentula var. tenuistrata Geitler

Sample- TSnB Slide - $1,2 \quad$ Co-ordinats - 48.3106 .8

Measurements - Size- $21 \times 13 \mu \mathrm{m} \quad$ Striae $28 / 10 \mu \mathrm{m}$

References - Krammer and Lange \& Bertalot (1991b)

Environment/Distribution - Freshwater to brackish, benthic.

Age - Extant

Epithemia adnata (Kützing) Brébisson

Sample- SI.G Slide - $1 \quad$ Co-ordinates- 41.699 .8

Measurements-9 × 20 striae $12 / 10 \mu \mathrm{m}$

References - Krammer and Lange-Bertalot (1988)

Environment/Distribution - Fresh to brackish water. Still to slow moving water.

Age - Extant 
Epithemia sp.

Sample- S.I. G

Slide -1

Co-ordinates - 23.7106 .8

Measurements- $22 \times 6$

Environment/Distribution -Planktonic

Age - Extant

Fragilaria tenera (W. Smith) Lange-Bertalot

Sample- TSn1

Slide - 1

Co-ordinates- 14.6104 .2

Measurements- Size 50-100 $\mu \mathrm{m} \times 1-3 \mu \mathrm{m}$ Str - 16-19/10 $\mu \mathrm{m}$

References - Krammer and Lange-Bertalot (1991a) pg. 129, fig. 114

Environment/Distribution - Freshwater benthic, cosmopolitin, often occurs in alpine areas.

Age - Extant

Fragilaria c.f, unla (Nitzsch) Lange-Bertalot

[syn. Synedra ulna, Nitzsch]

Sample- TSn.B Slide - 2

Co-ordinates-

Measurements - Size - $5 \times 9 \mu \mathrm{m}$

Striae- $8 / 10 \mu \mathrm{m}$

References - Krammer and Lange-Bertalot 1991a

Environment/Distribution - Freshwater and benthic water. Cosmopolitan.

Age - Extant

Fragilaria c.f. delicatissma (W. Smith) Lange-Bertalot

Sample - TSnB Slide - 1

References - Krammer and Lange-Bertalot, pg 129, T114.

Environment/Distribution - Freshwater benthic.

Age - Extant

Nitzschia debilis (Arnott) Grunow

Sample- SI.B, SI.G Slide - 2, $1 \quad$ Co-ordinates- 28.8101 .1

Measurements- $14-23 \mu \mathrm{m} \times 7-10 \mu \mathrm{m} \quad$ Striae $-14-18 / 10 \mu \mathrm{m}$

References - Krammer \& Lange-Bertalot (1988) pg 39 fig 27: 6-7, 9-11 Krammer \& Lange-Bertalot $8-10 \mathrm{str} / 10 \mu \mathrm{m}$, this is $14 / 10 \mu \mathrm{m}$.

Environment/Distribution - Holoplankton, Mesohalobus, Cosmopoliton

Age - Extant 
Nitzschia cf. sociabilis Hustedt

Sample- SIG Slide $-1 \quad$ Co-ordinates- 28.0108 .4

Measurements- $26 \times 4 \mu \mathrm{m}$

References - Krammer \& Lange- Bertalot (1988),pg 119, fig 83: 1-8

Environment/Distribution - Freshwater. Slow moving to still standing. Cosmopolitan.

Age - Extant

Pinnularia subcapitata Gregory

Sample-SI. B, SI. G $\quad$ Slide - 2,1 Co-ordinates- $28.4106 .4,31.1107 .2$

Measurements- 26-33 x 5-6 $\mathrm{m} \quad$ Striae- $12-14 / 10 \mu \mathrm{m}$

References - Krammer \& Lange-Bertalot (1986) fig 193 pg 426. Shape like 14 centre like 17.

Environment/Distribution - Freshwater benthic. Cosmopolitan.

Age - Extant

Rhophalodia rupestis (W.Smith) Krammer

Sample-SI. G, SI. B Slide - 1,1 Large numbers

Measurements- $30-34 \mu \mathrm{m} \times 8-9 \mu \mathrm{m} \quad$ Striae - $15-17 / 10 \mu \mathrm{m}$

References - Krammer \& Lange-Bertalot (1988)

Environment/Distribution - Freshwater benthic, sub alpine.

Age - Extant 
APPENDE 6.7 Diatom Figures

APPENDIX 6.7.1 Diatoms from the Sirius Tills

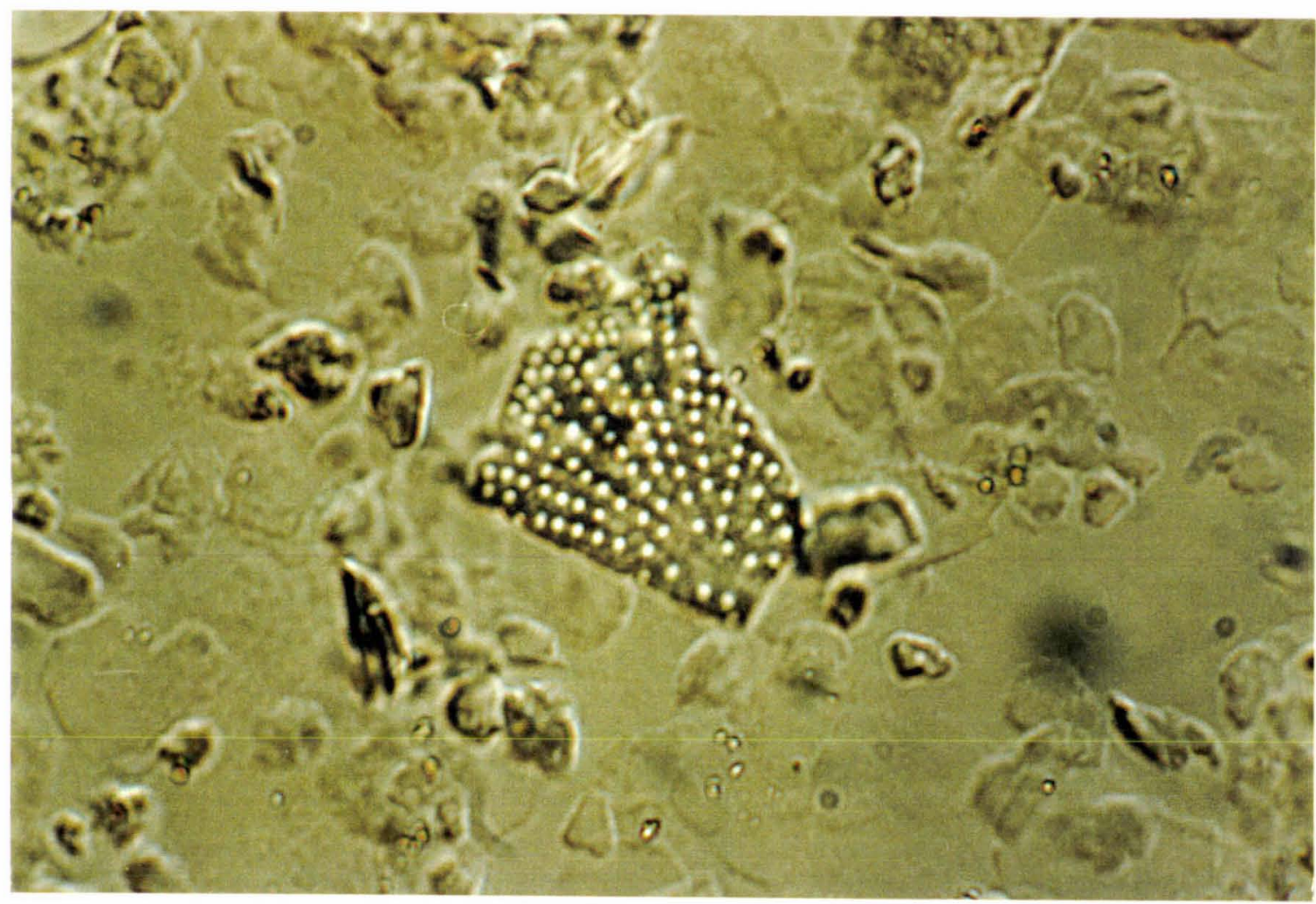

A. Actinocyclus actinochilus. Mt. Feather Site One $0-2 \mathrm{~cm} .20 \mathrm{~mm}=10 \mu \mathrm{m}$.

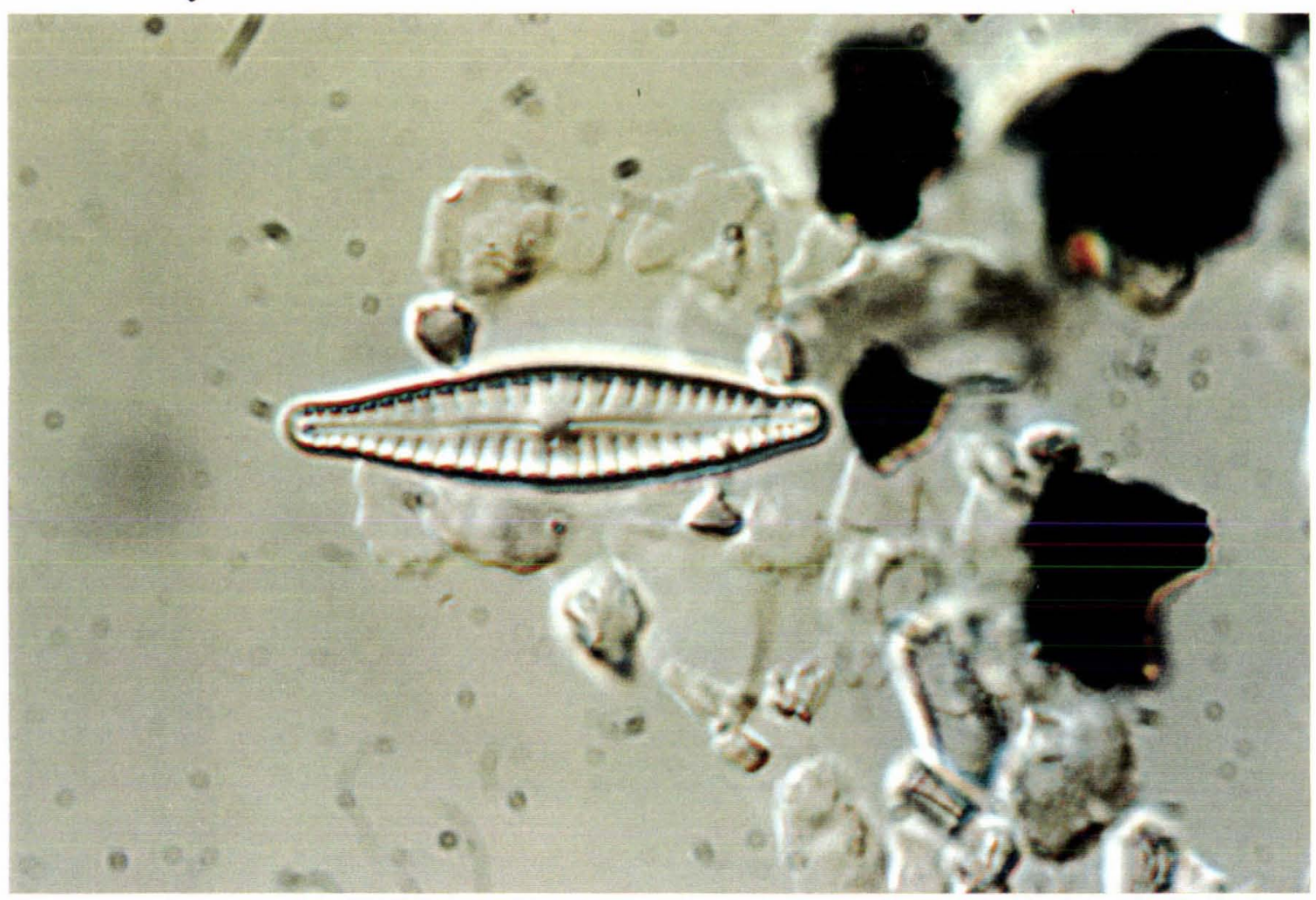

B. Gomphonema angustatum. Mt. Feather Site Two 0-2cm. Freshwater diatom. $23 \mathrm{~mm}=10 \mu \mathrm{m}$. 


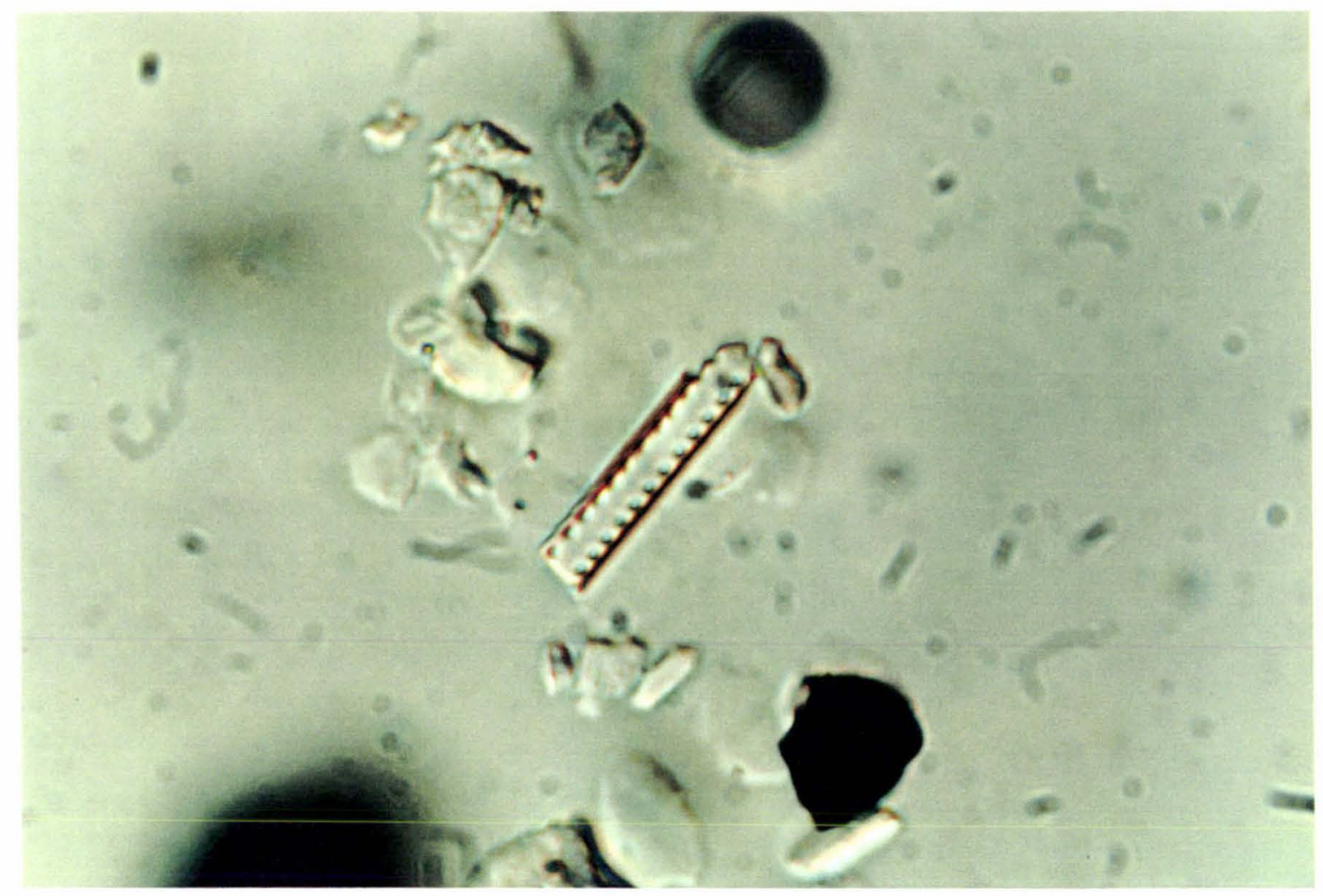

C. Thalassionema nitzschioides. Mt. Feather Site Two 0-2cm. Marine diatom. $15 \mathrm{~mm}=10 \mu \mathrm{m}$.

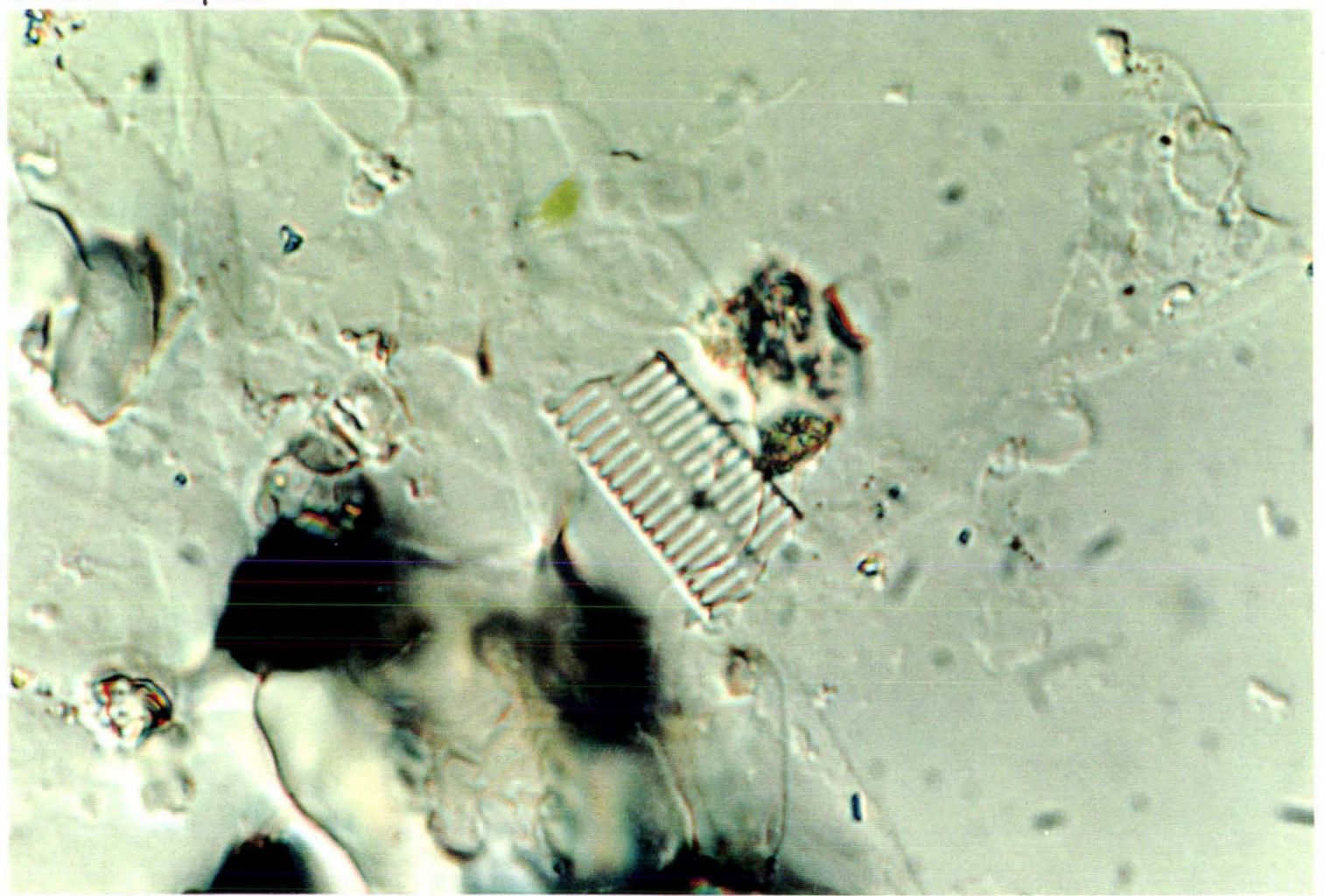

D. Unidentified piece of pennate diatom. Mt. Feather Site Two $0-2 \mathrm{~cm} .12 \mathrm{~mm}=$ $10 \mu \mathrm{m}$. 


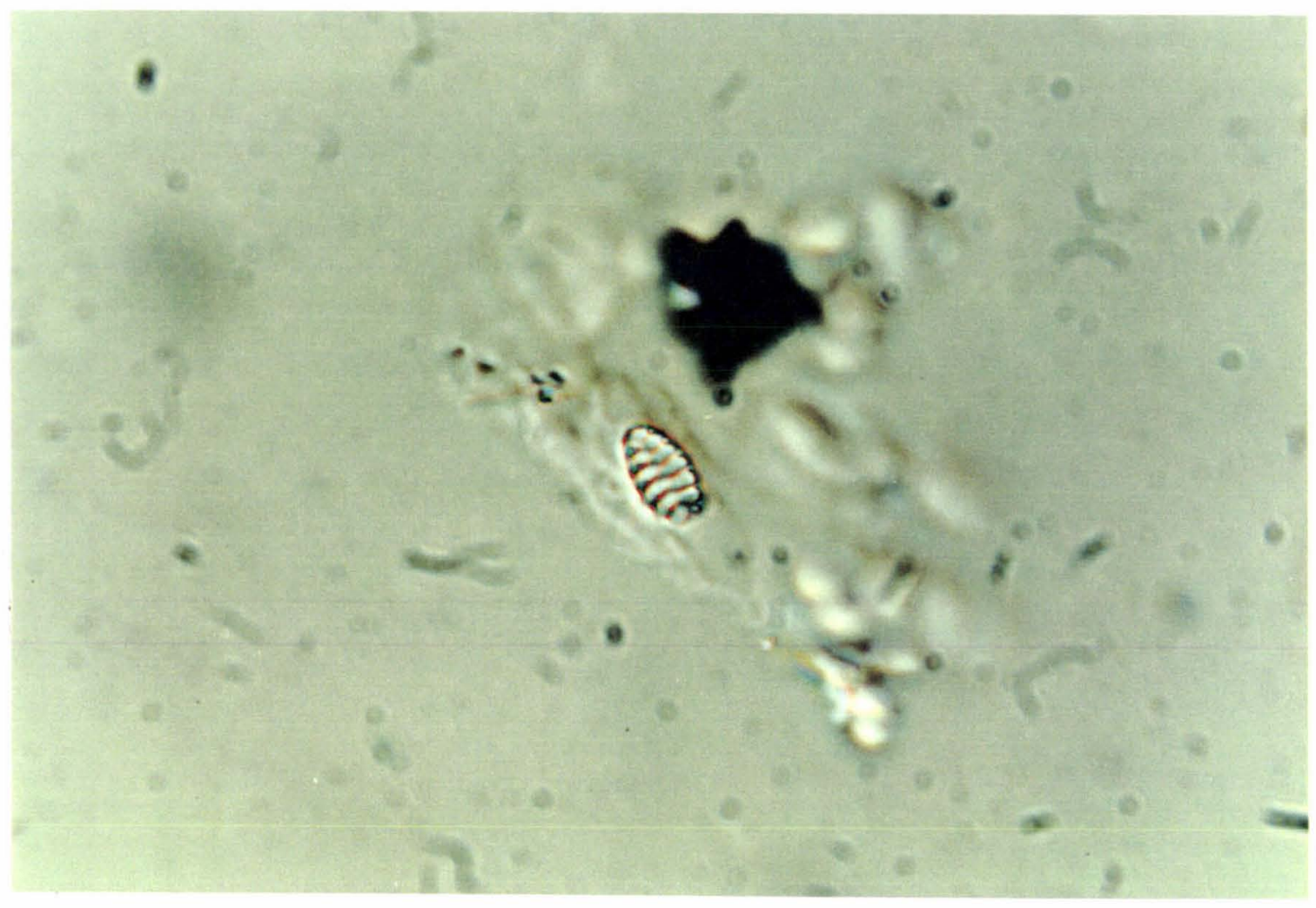

E. Fragilaria species. Mt. Feather Site Two $0-2 \mathrm{~cm}$. Freshwater diatom. $23 \mathrm{~mm}=$ $10 \mu \mathrm{m}$.

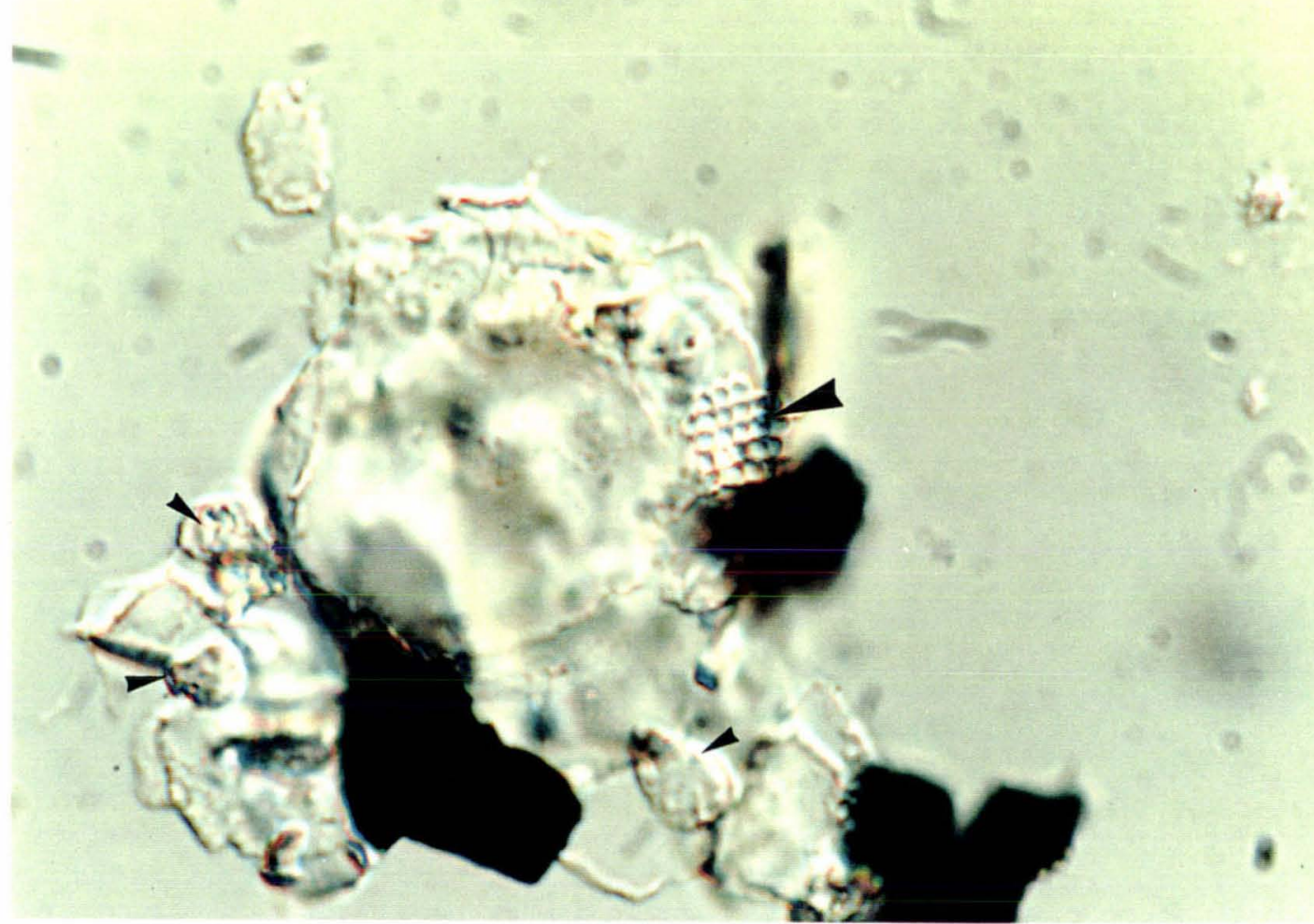

F. Piece of marine diatom (large arrow) in sediment clast with several phytoliths (small arrows). Mt. Feather Site Two $0-2 \mathrm{~cm} .9 \mathrm{~mm}=10 \mu \mathrm{m}$. 


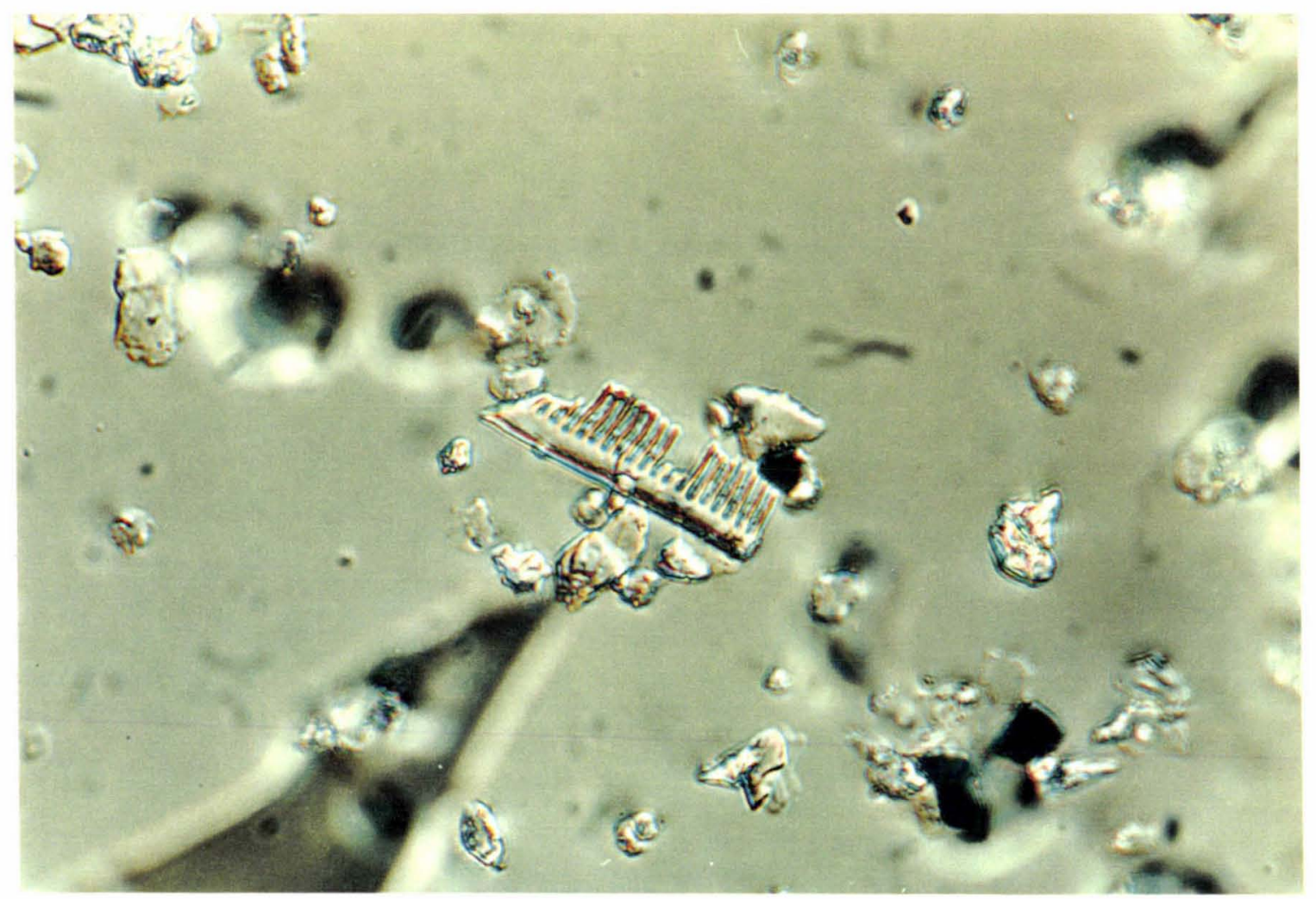

G. Pinnularia c.f. maior. Mt. Feather Site Two $2-7 \mathrm{~cm}$. Freshwater diatom. $10 \mathrm{~mm}=13 \mu \mathrm{m}$.

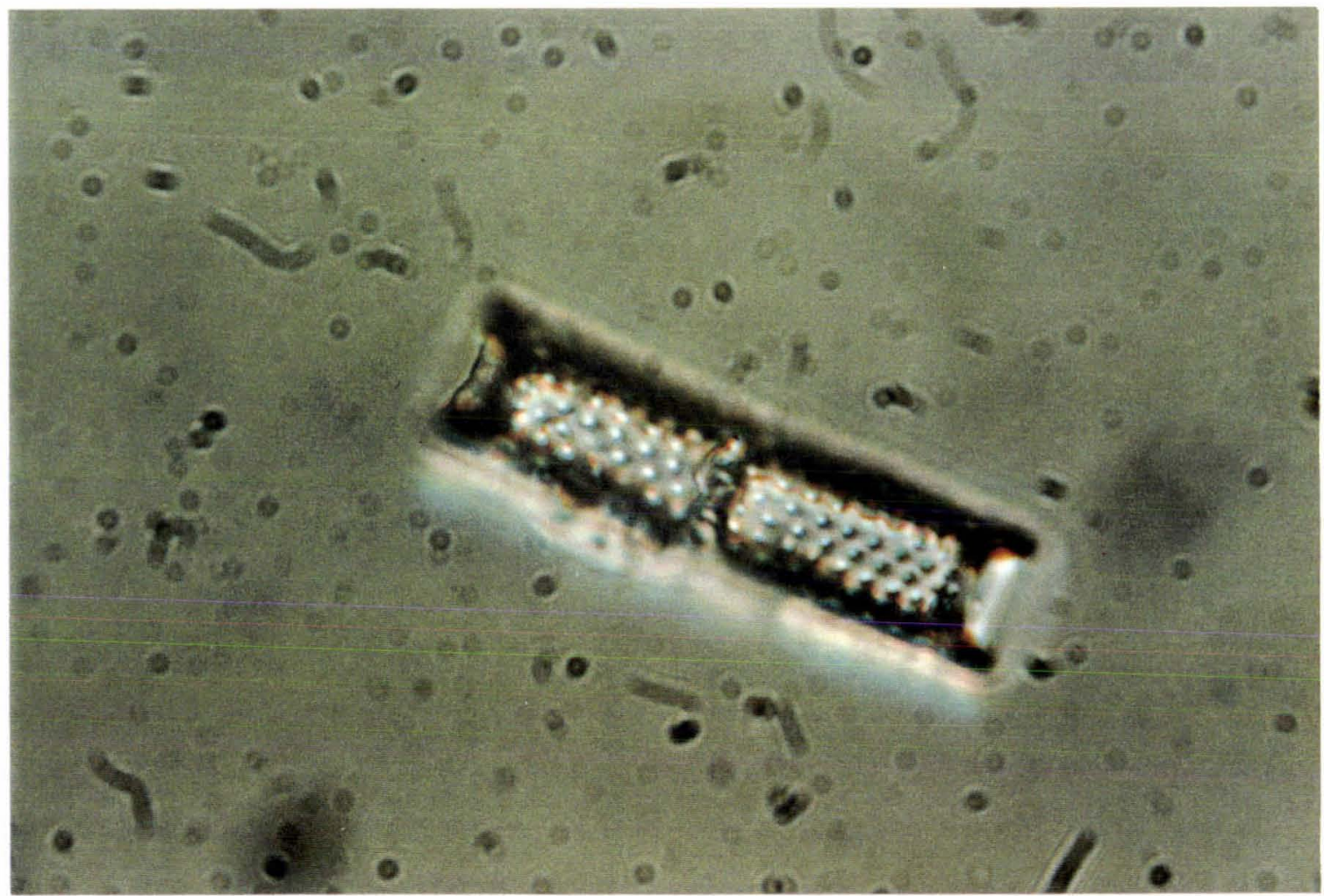

H. Aulacoseira Granulata. One of the most common freshwater diatoms found in the Sirius Group tills from Mt. Feather and Table Mountain. Freshwater diatom. Mt. Feather Site One $7-17 \mathrm{~cm} .22 \mathrm{~mm}=10 \mu \mathrm{m}$. 


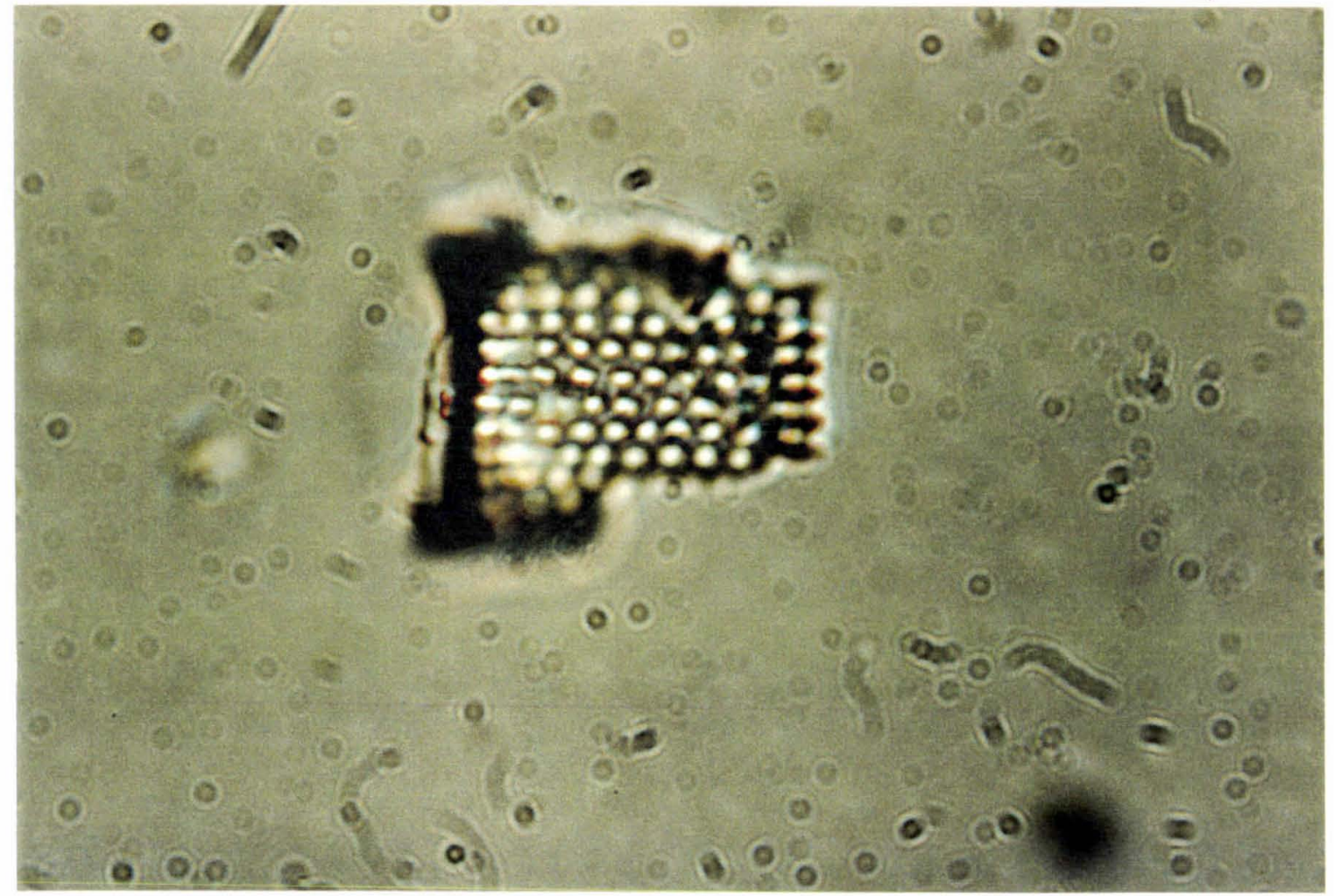

I. Aulacoseira Italica. Also a very common diatom fround in the Sirius Group tills. Freshwater diatom. Mt. Feather Site One $7-17 \mathrm{~cm} .20 \mathrm{~mm}=10 \mu \mathrm{m}$.

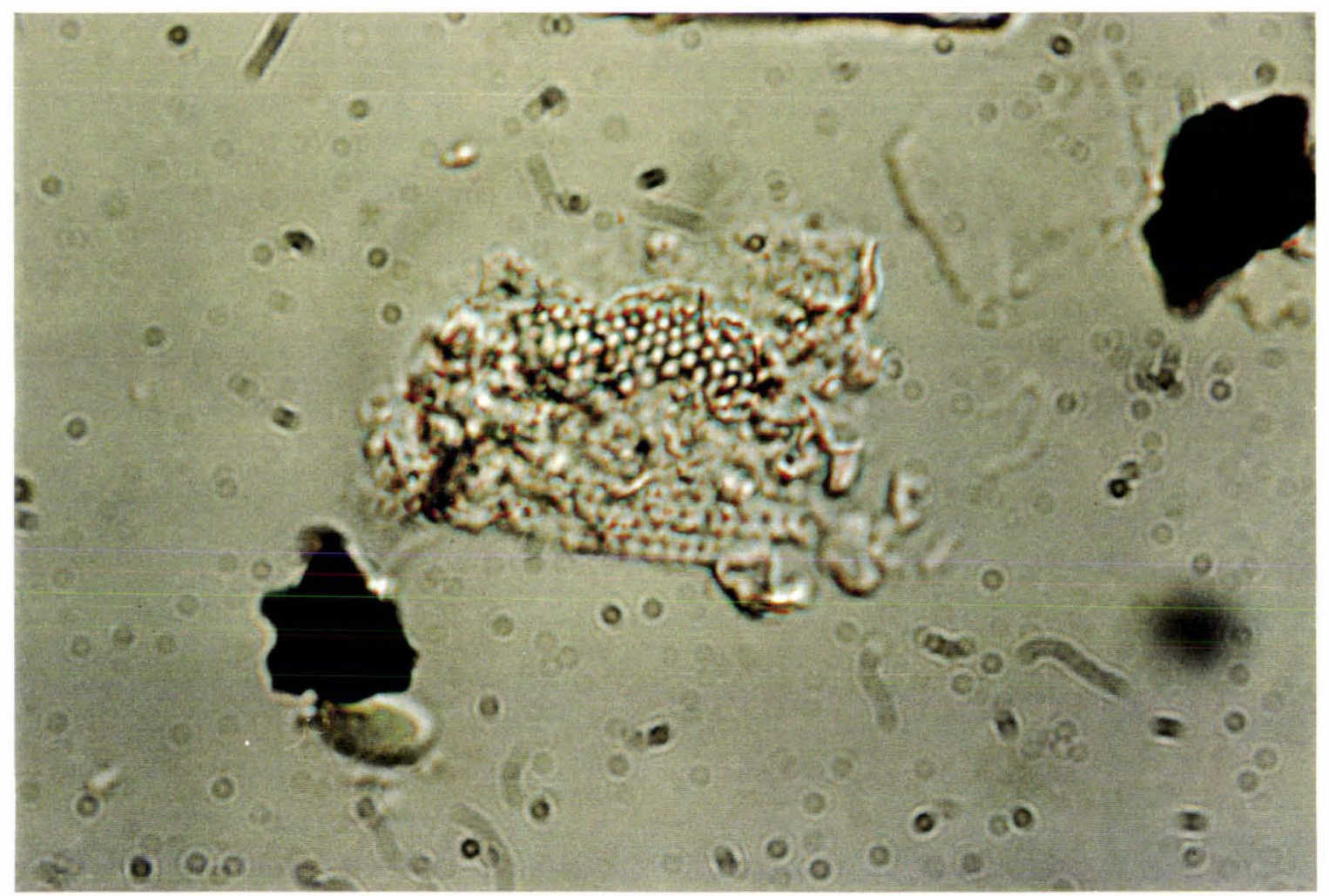

J. Microclast of marine diatom fragments. Mt. Feather Site One $2-7 \mathrm{~cm}, 23 \mathrm{~mm}=$ $10 \mu \mathrm{m}$. 


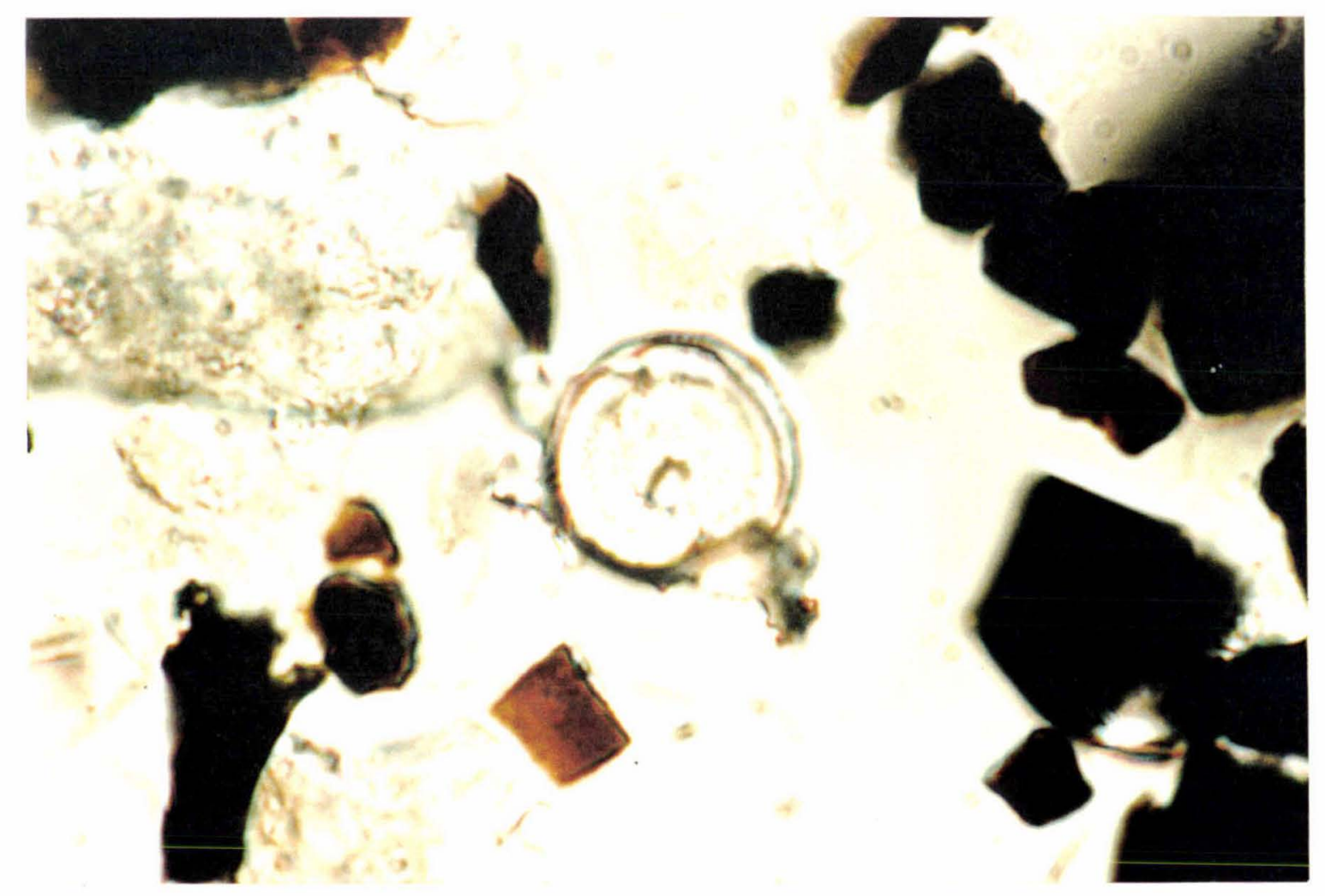

K. Unidentified marine diatom. Possibly Thalassiosira oliverina . Mt. Feather Site One $2-7 \mathrm{~cm} .14 \mathrm{~mm}=10 \mu \mathrm{m}$.

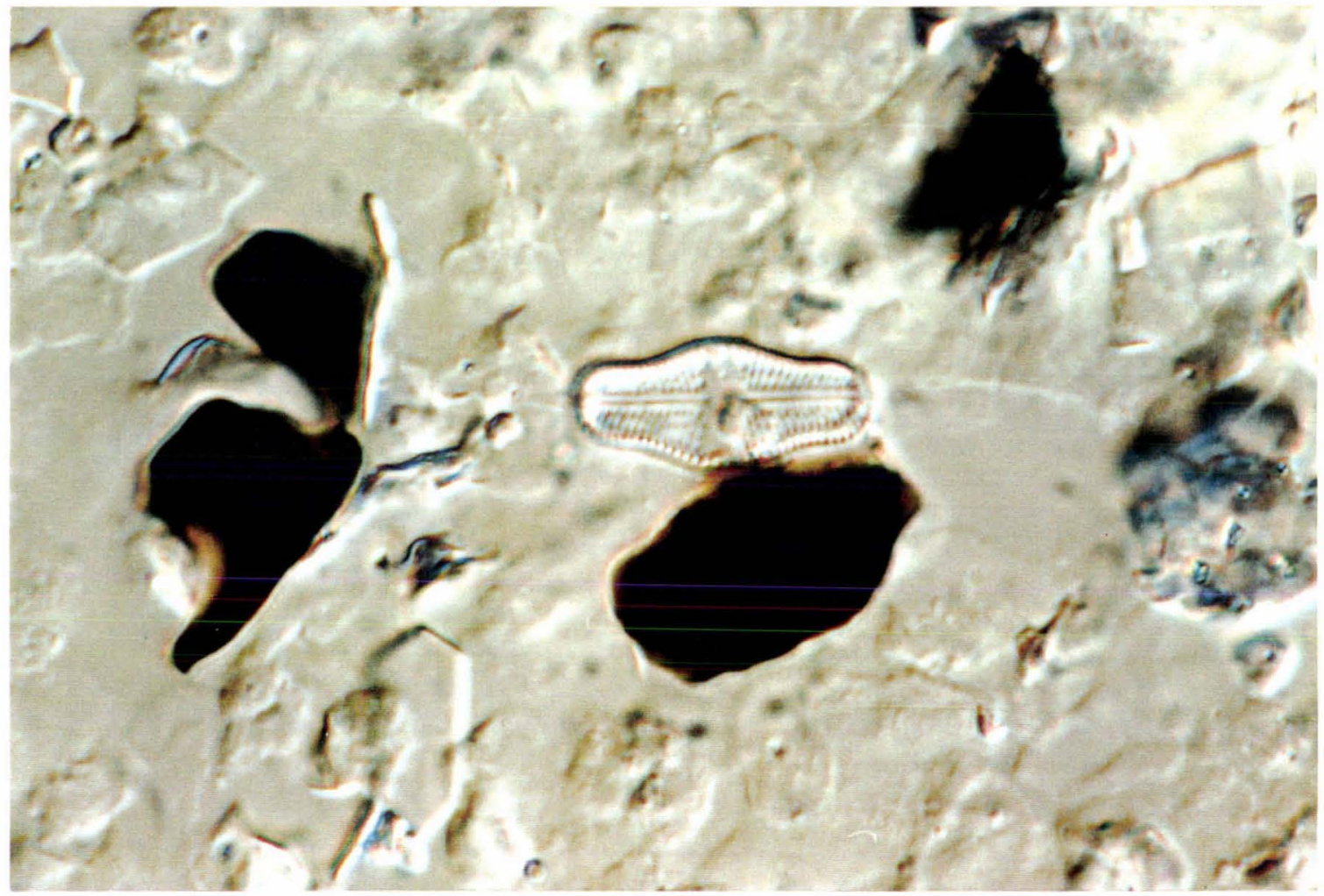

L. CalledAchnanthies species in this thesis, possibly actually Navicula mutica. Freshwater diatom. Mt. Feather Site One $0-2 \mathrm{~cm} .23 \mathrm{~mm}=10 \mu \mathrm{m}$. 


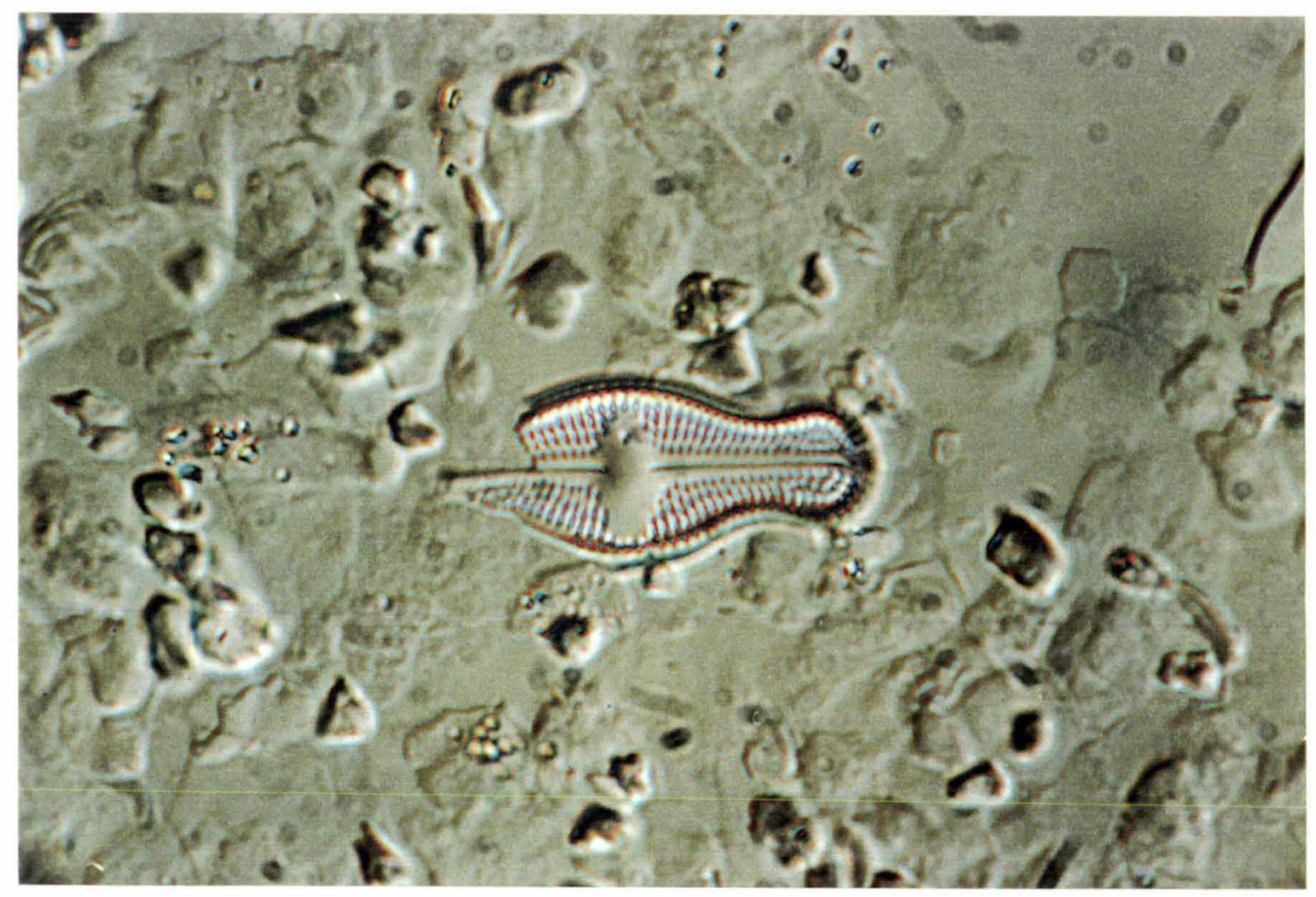

M. Navicula muticopsis. Common freshwater diatom found in Sirius Group tills. Mt. Feather Site One $0-2 \mathrm{~cm} .23 \mathrm{~mm}=10 \mu \mathrm{m}$

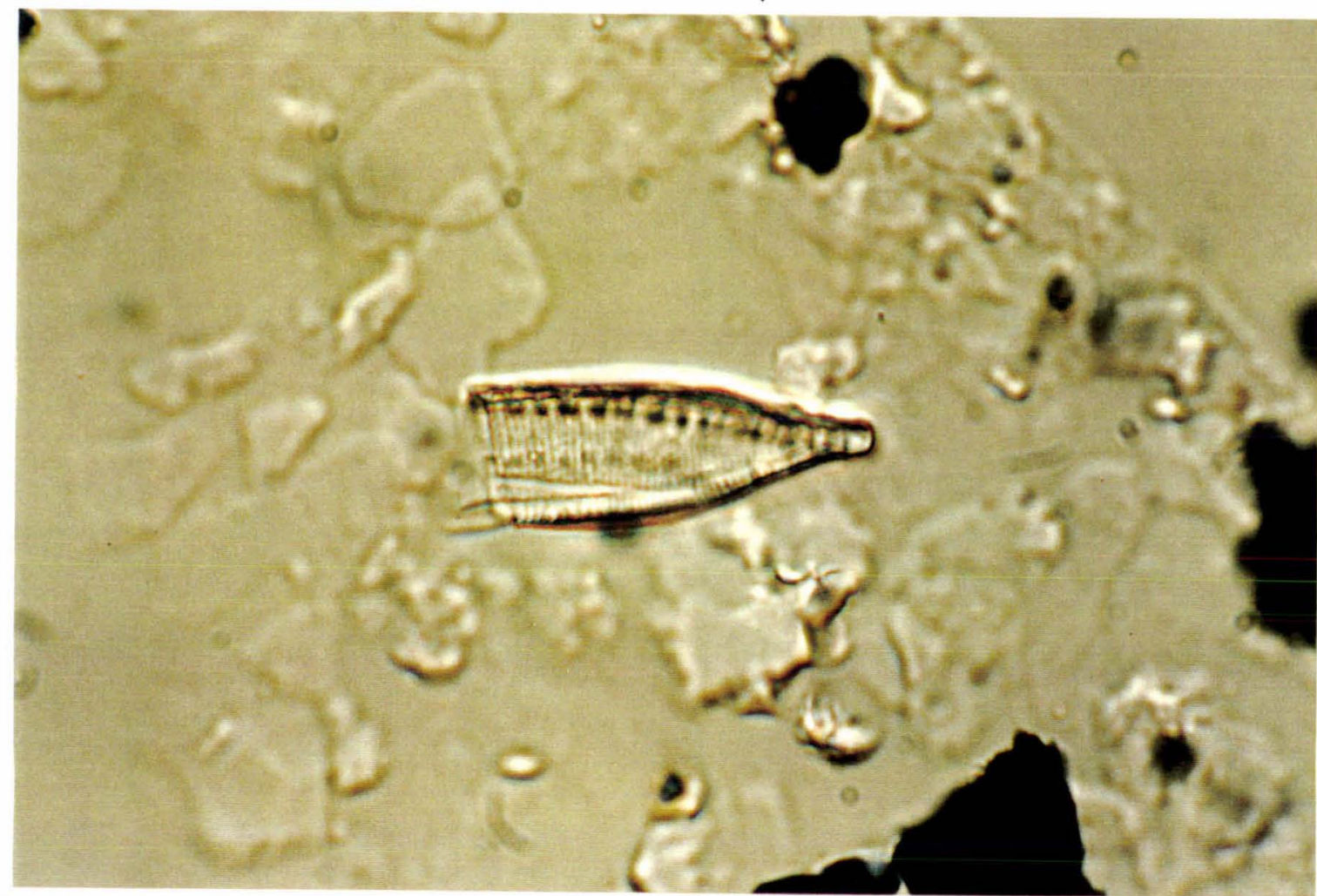

N. Hantzchia amphioxys. Mt. Feather Site One 0-2cm. Freshwater diatom common in the Sirius Group till, regolith and snow samples . $23 \mathrm{~mm}=10 \mu \mathrm{m}$ 


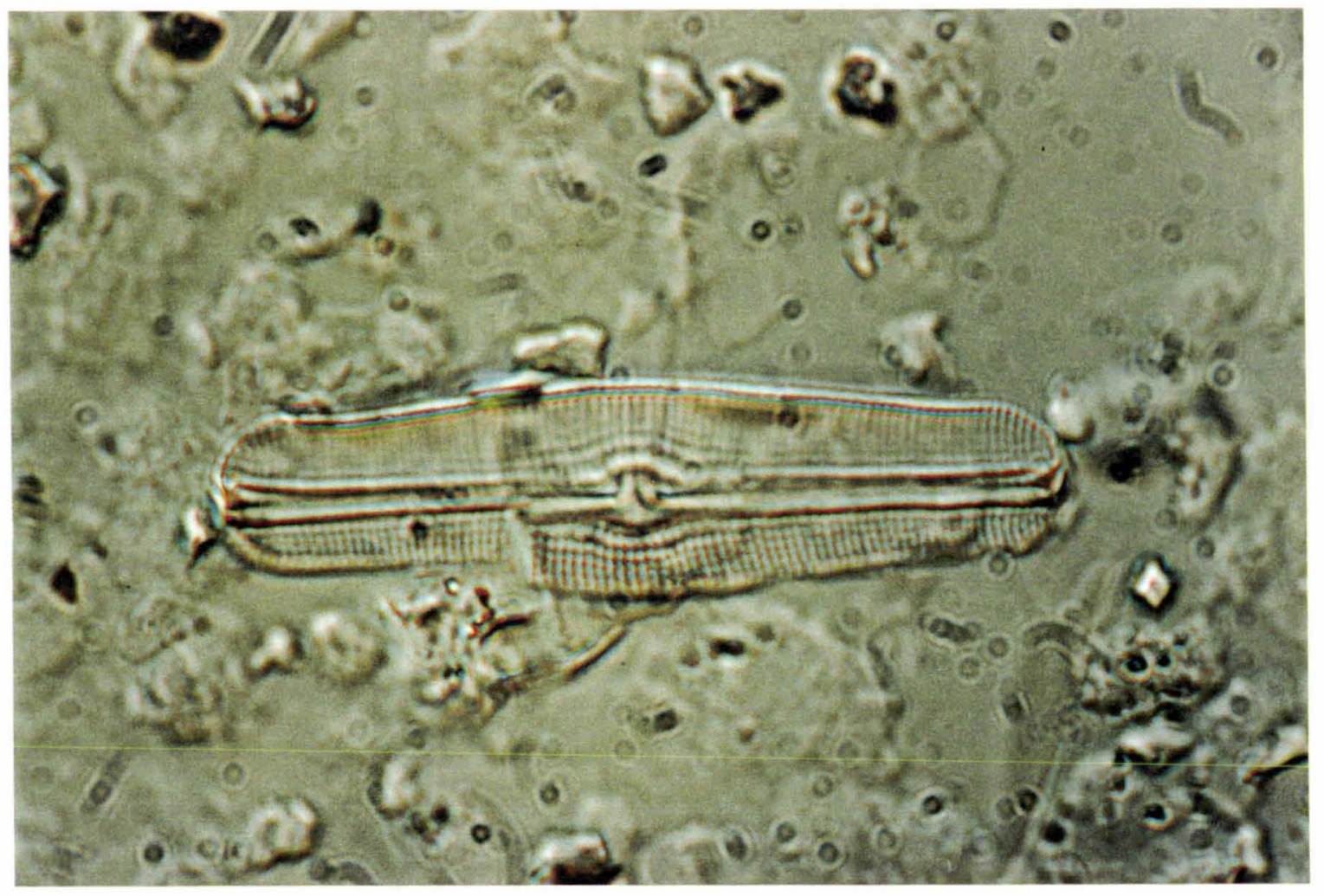

O. Navicula gibbula. Mt. Feather Site One 0-2cm. Freshwater diatom. $23 \mathrm{~mm}=$ $10 \mu \mathrm{m}$

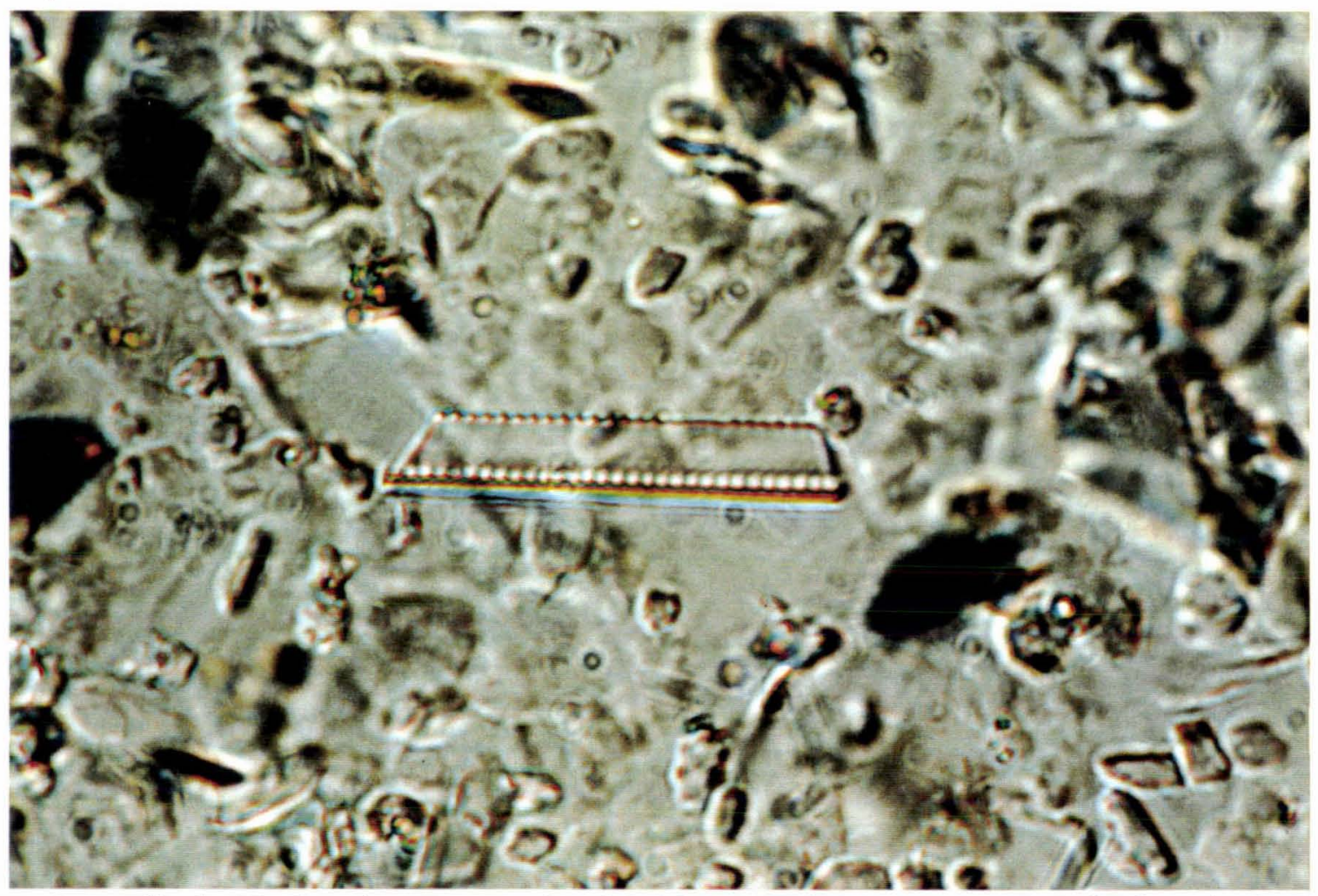

P. Is called Thalassionema nitzshioides in thesis, is now Thalassiothrix antarctica. Marine diatom. Mt. Feather Site One $0-2 \mathrm{~cm} .18 \mathrm{~mm}=10 \mu \mathrm{m}$ 


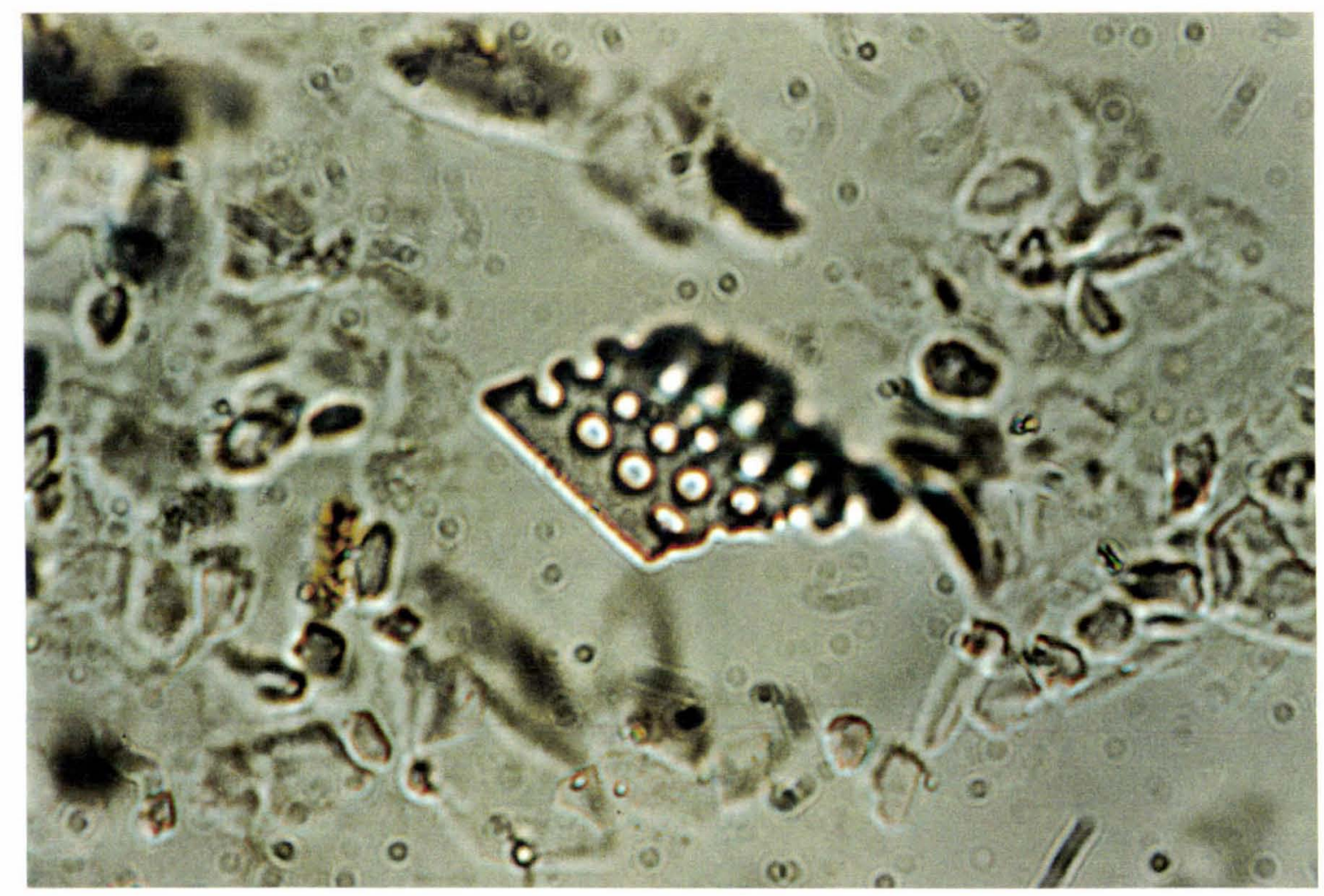

Q. Fragment of marine diatom, possibly of Eucampia antarctica. Mt. Feather Site One $0-2 \mathrm{~cm} .14 \mathrm{~mm}=10 \mu \mathrm{m}$.

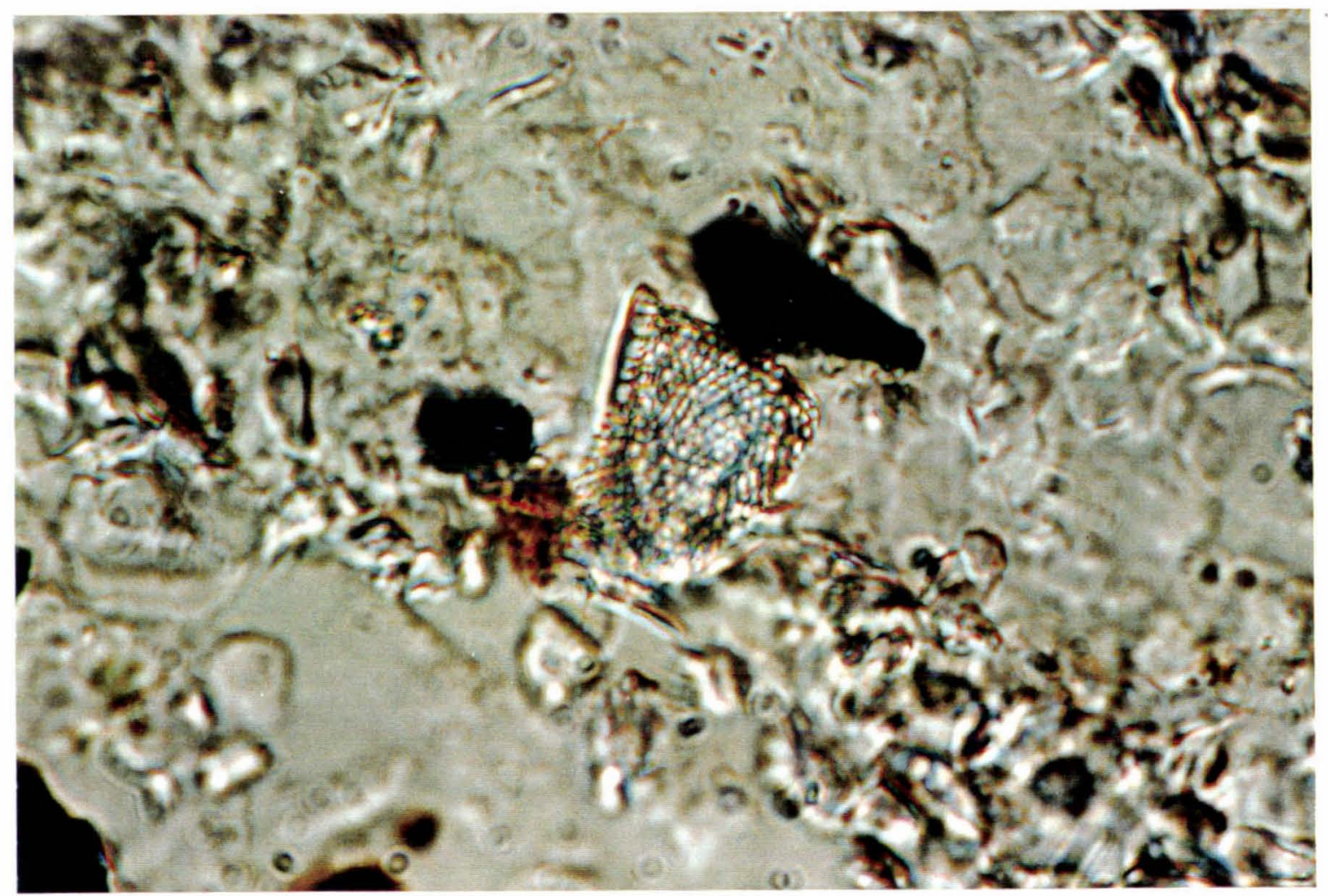

R. Marine diatom fragment. Mt. Feather Site One $0-2 \mathrm{~cm} .18 \mathrm{~mm}=10 \mu \mathrm{m}$ 
APPENDIX 6.7.2 Diatoms from the Regolith

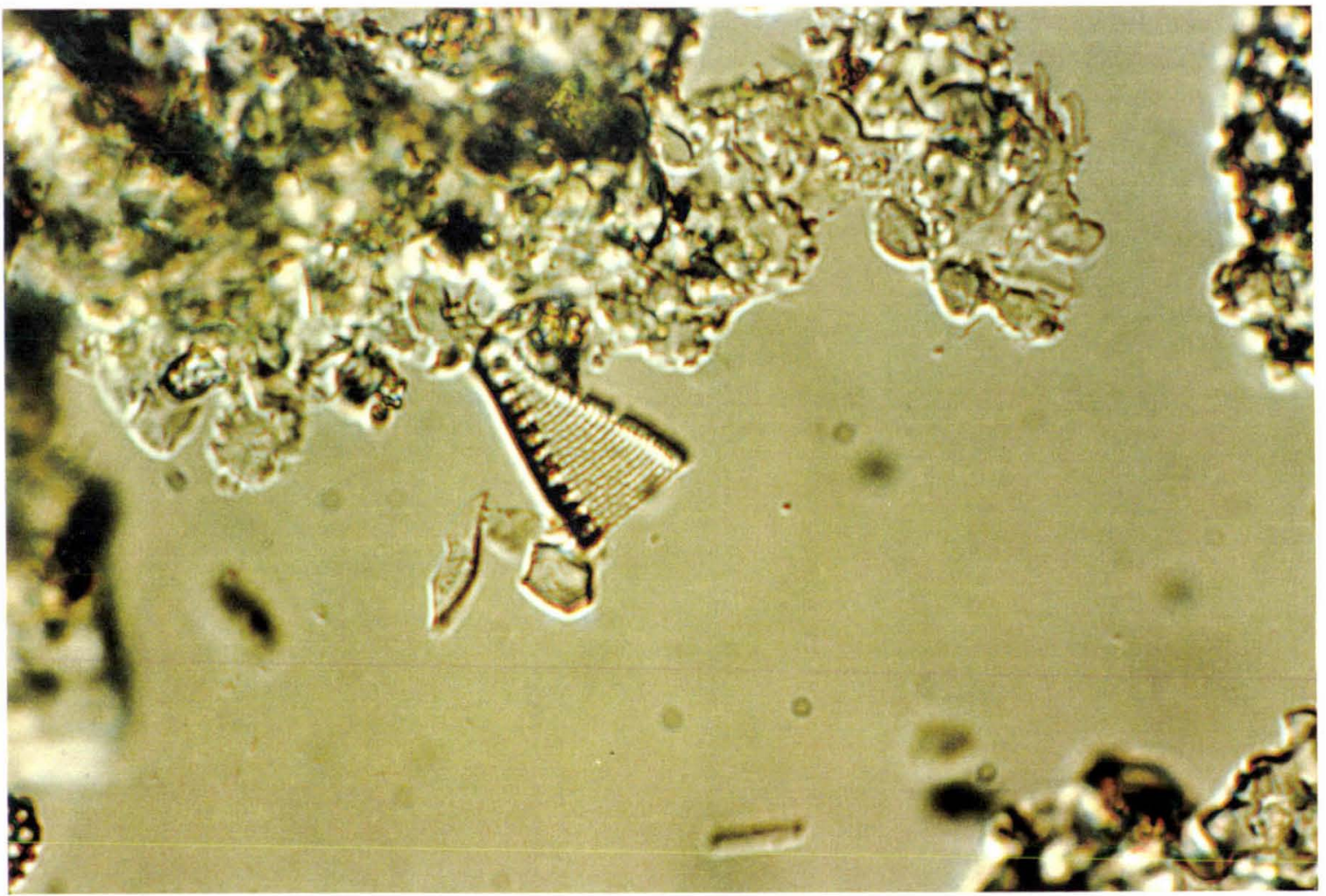

A. Hantzchia amphioxys. Table Mountain regolith. Widely distributed freshwater diatom in Antarctic. $23 \mathrm{~mm}=10 \mu \mathrm{m}$.

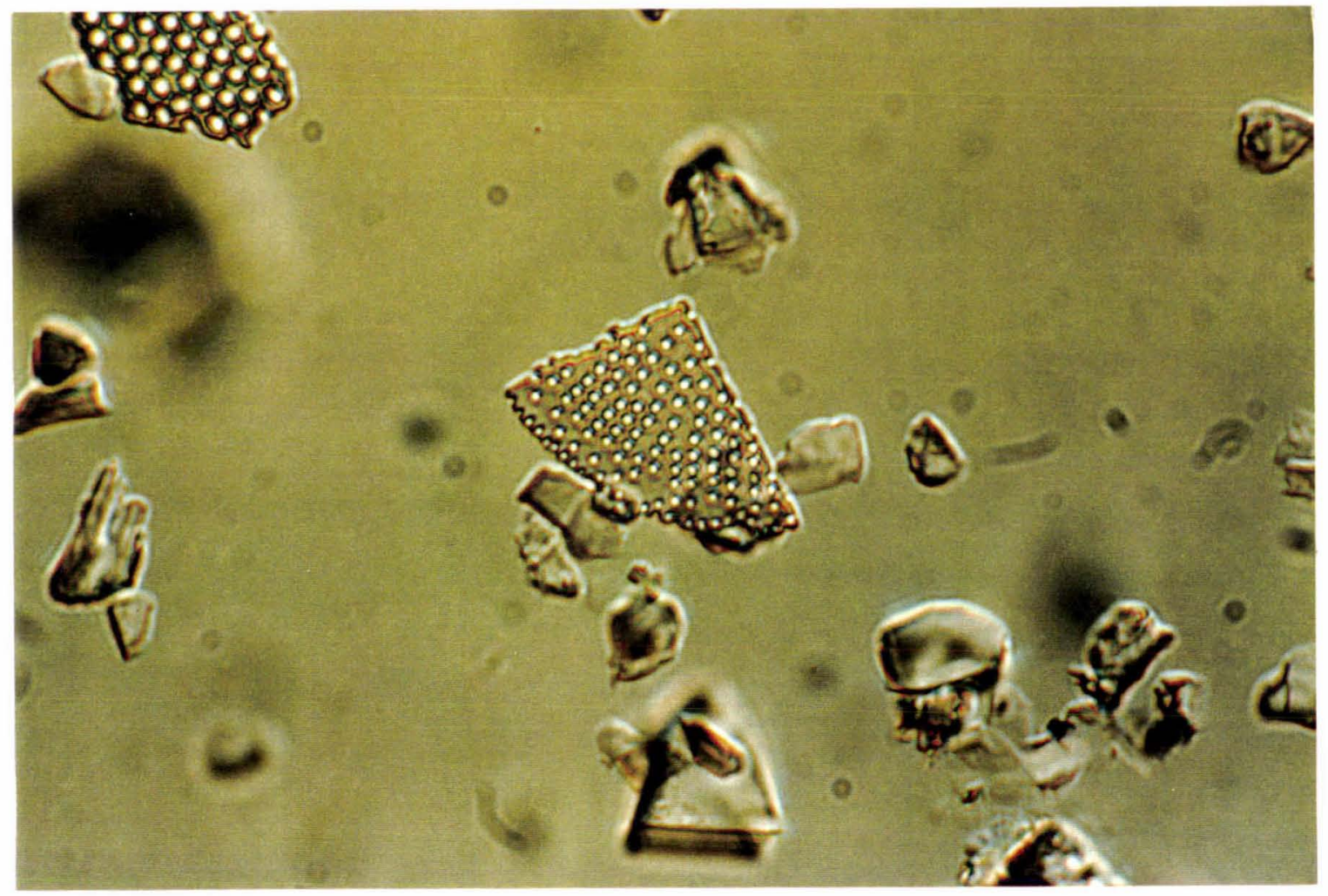

B. Actinocyclus actinochilus. Table Mountain regolith. Marine diatom. $23 \mathrm{~mm}$ $=10 \mu \mathrm{m}$ 


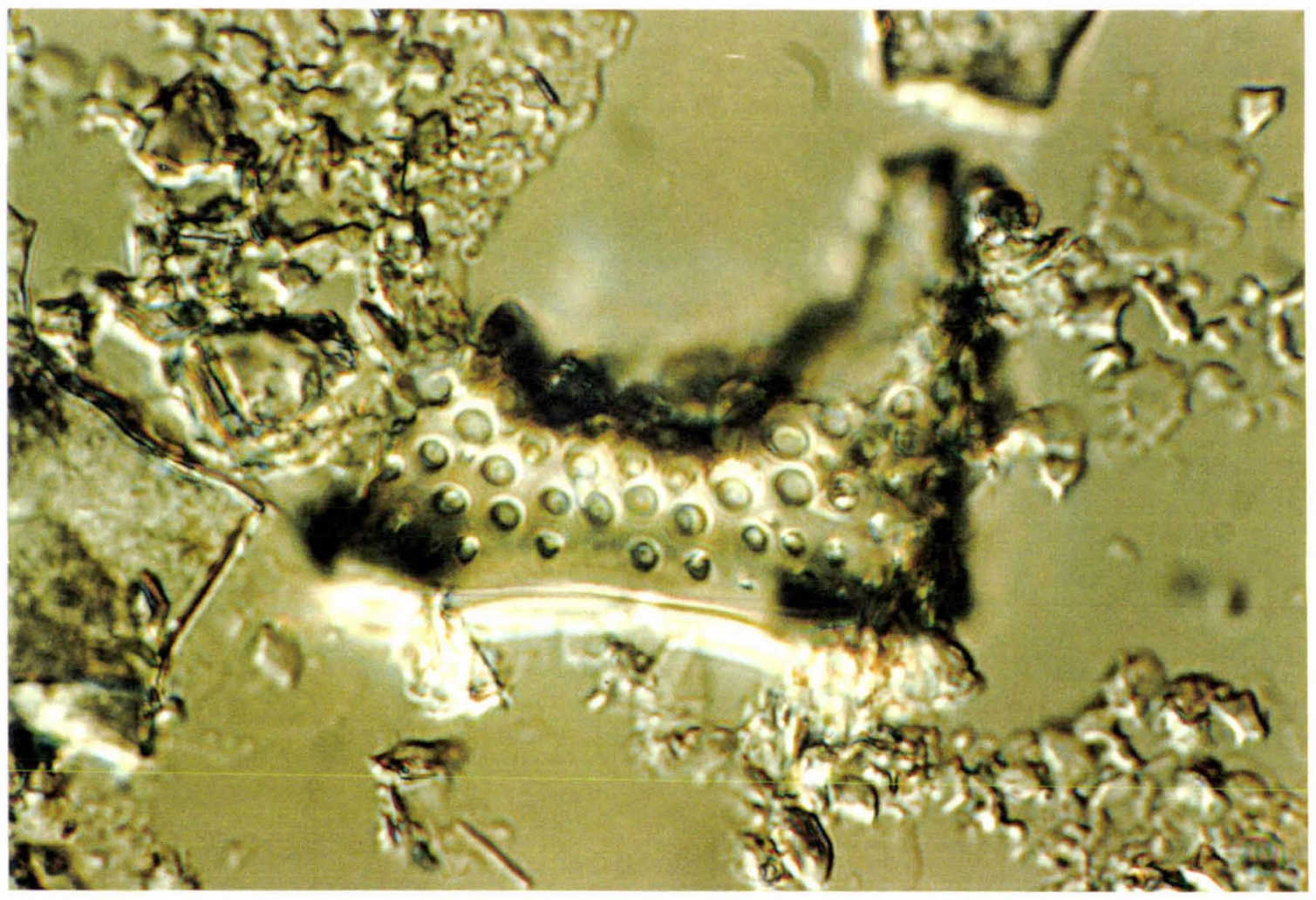

C. Eucampia antarctica. Table Mountain regolith. Marine diatom. $18 \mathrm{~mm}=$ $10 \mu \mathrm{m}$.

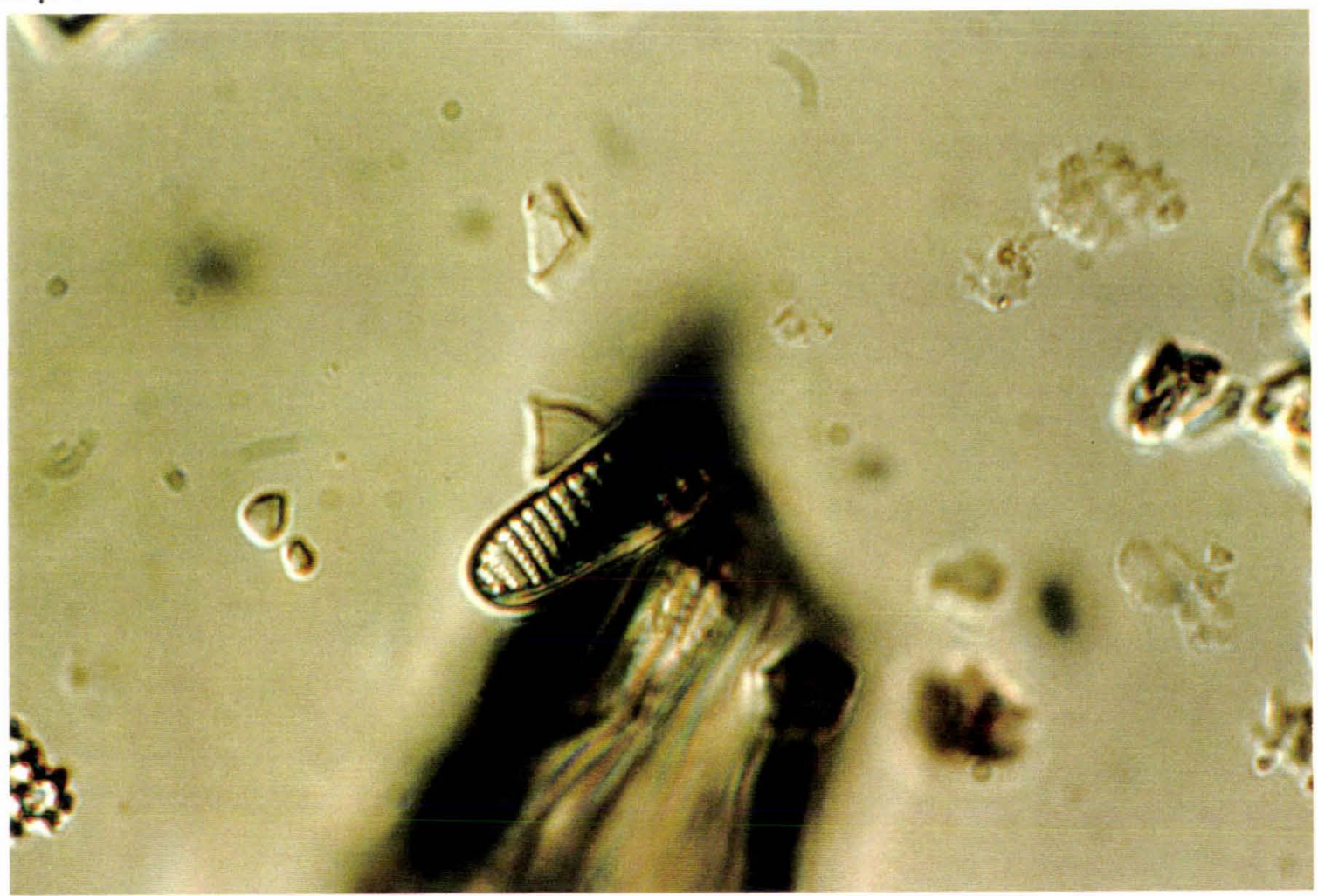

D. Nitzschia kergulensis. Table Mountain regolith. Marine diatom. $18 \mathrm{~mm}=$ $10 \mu \mathrm{m}$ 


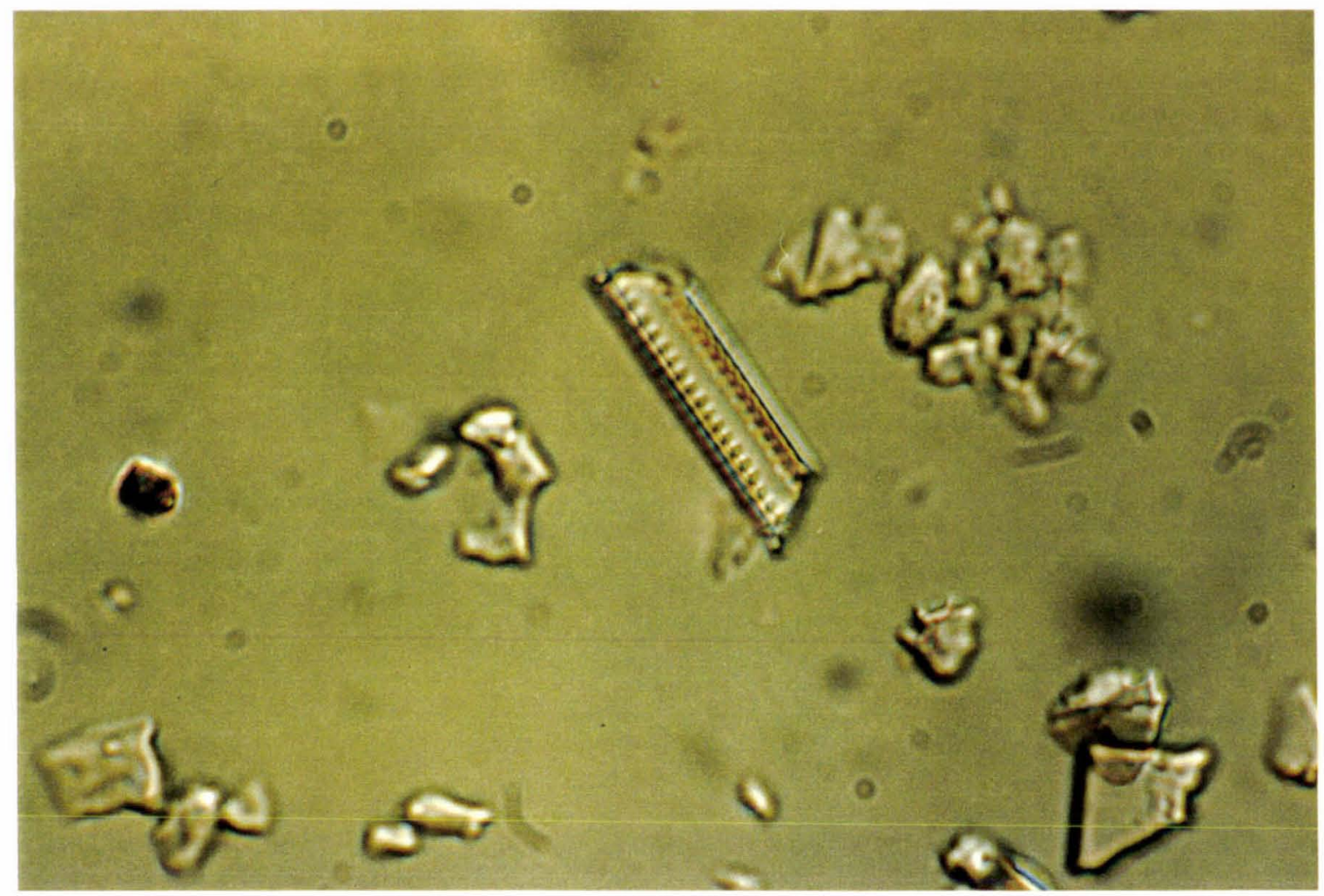

D. Thalassionema nitzschioidies. Table Mountain regolith. Marine diatom $18 \mathrm{~mm}=10 \mu \mathrm{m}$.

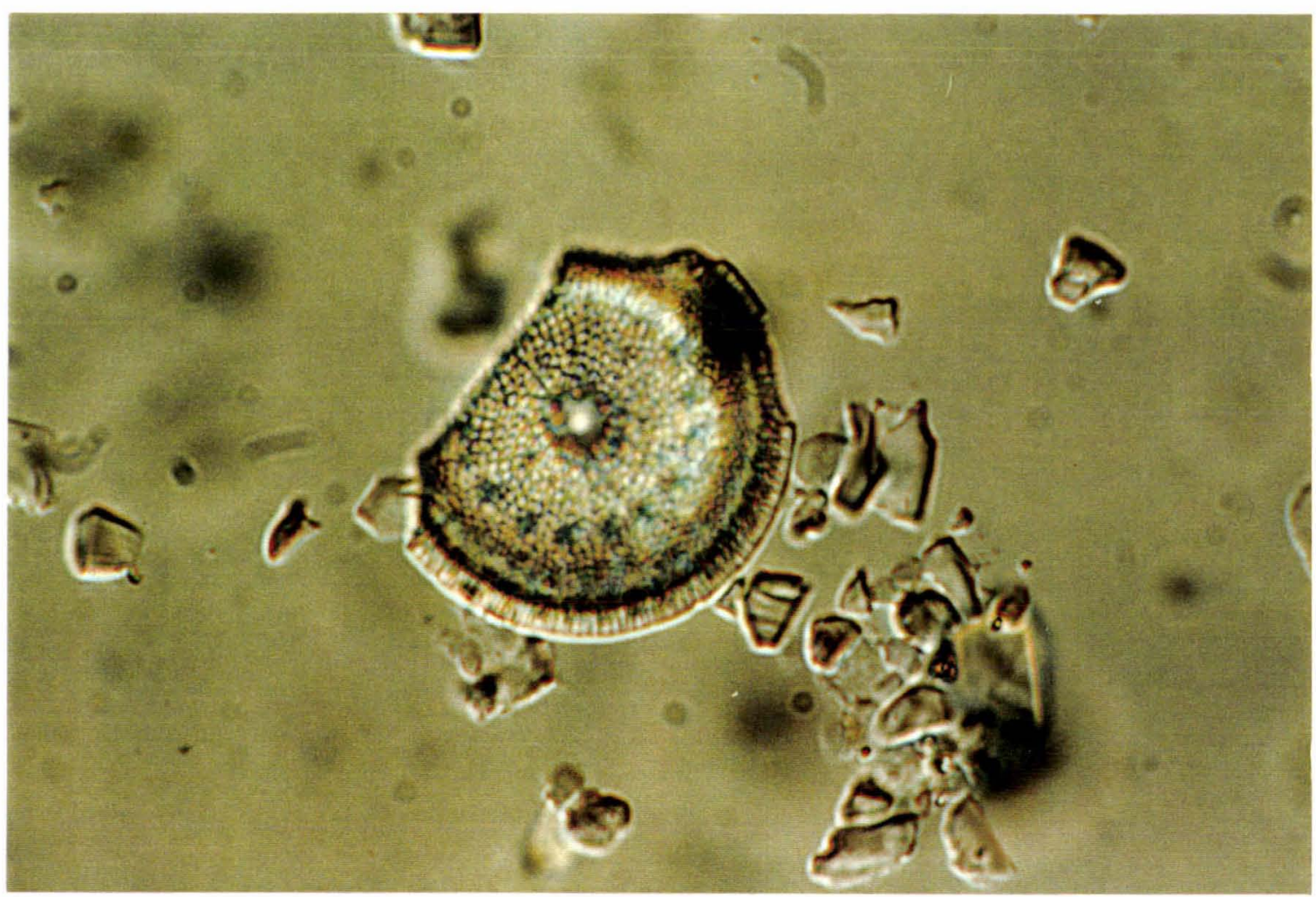

E. Thalassiosira complicata. Table Mountain regolith. Marine diatom, not recorded in thesis. $18 \mathrm{~mm}=10 \mu \mathrm{m}$ 


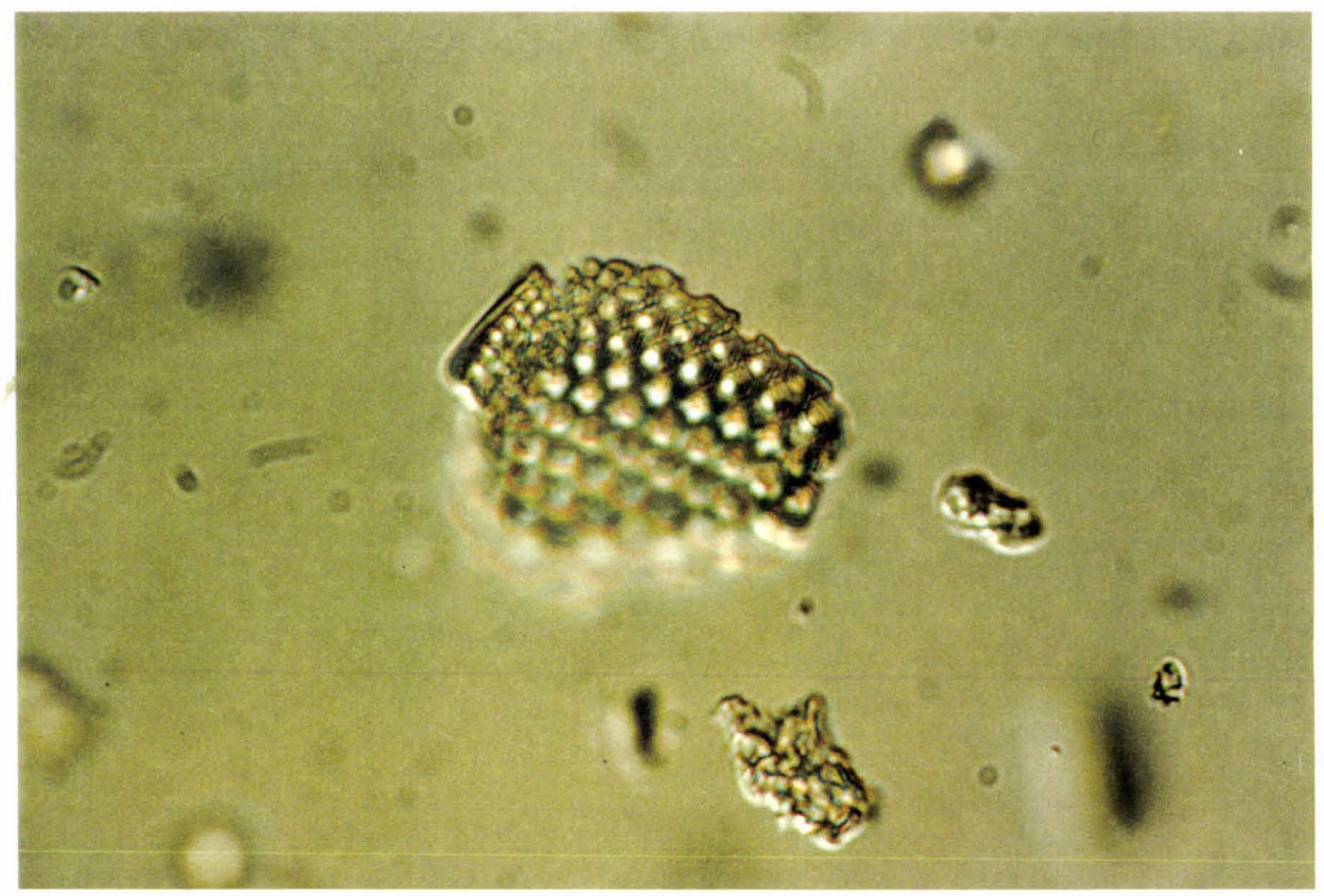

F.Thalassiosira c.f oliverina. Table Mountain regolith. Marine diatom not recorded in thesis. $18 \mathrm{~mm}=10 \mu \mathrm{m}$

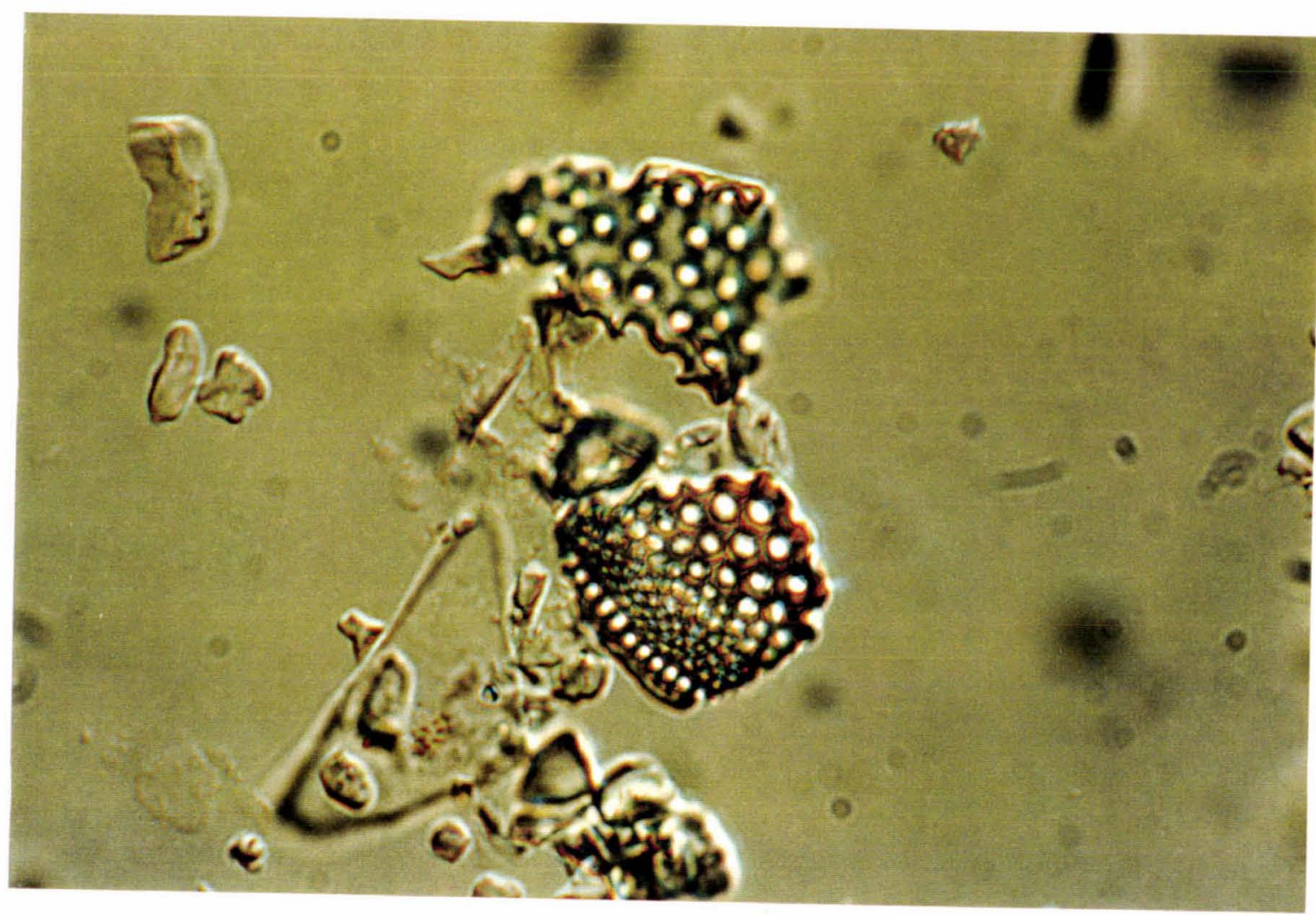

G. Thalassiosira torokina. Table Mountain regolith. Several found in this sample. Marine diatom. Biostratigraphic indicator $8-1.6 \mathrm{Ma} .18 \mathrm{~mm}=10 \mu \mathrm{m}$. 


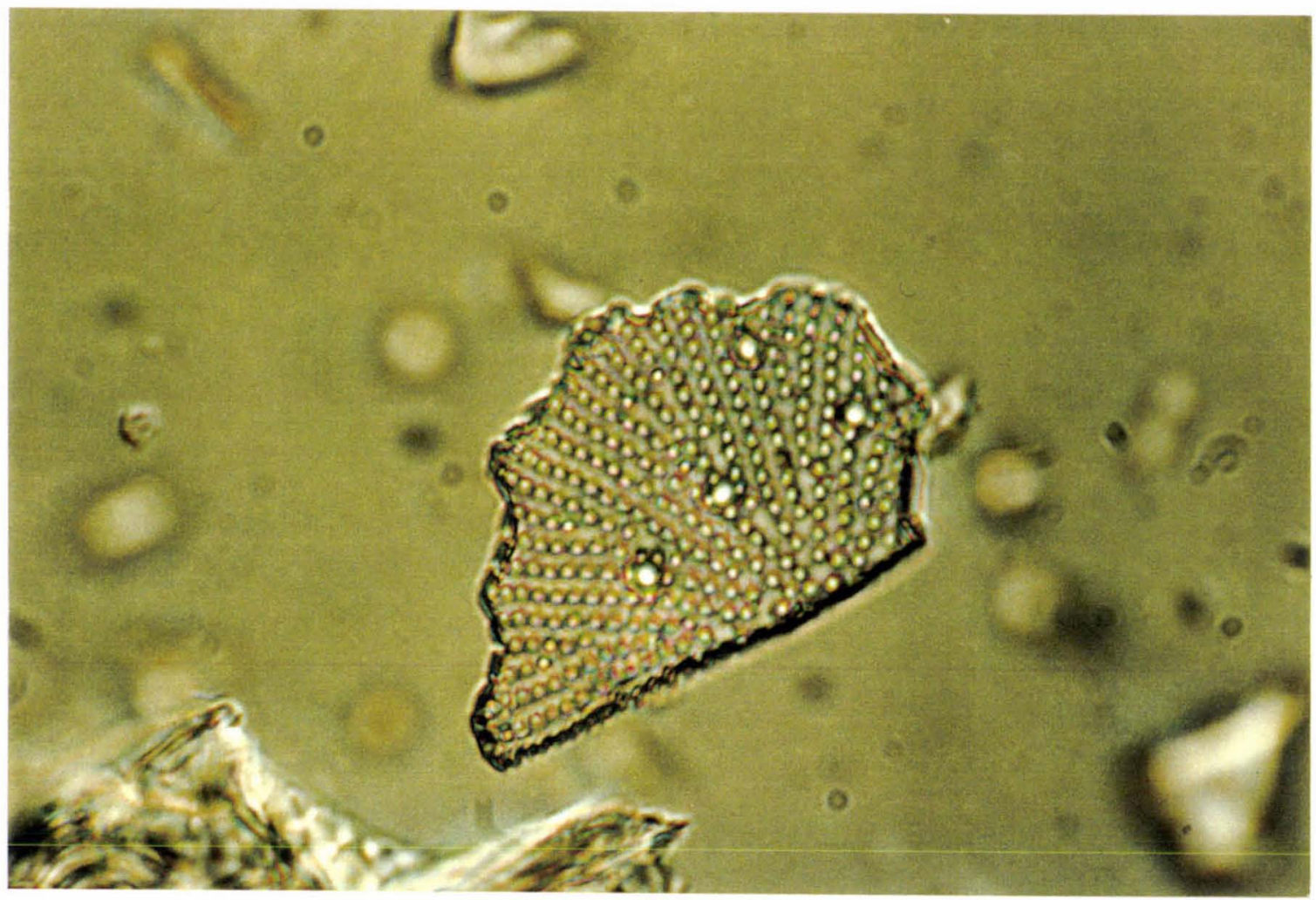

H. Thalassiosira c.f. vulnifica. Table Mountain regolith. Not recorded in thesis. Marine diatom. Biostratigraphic indicator to 3.1-2.2 Ma.

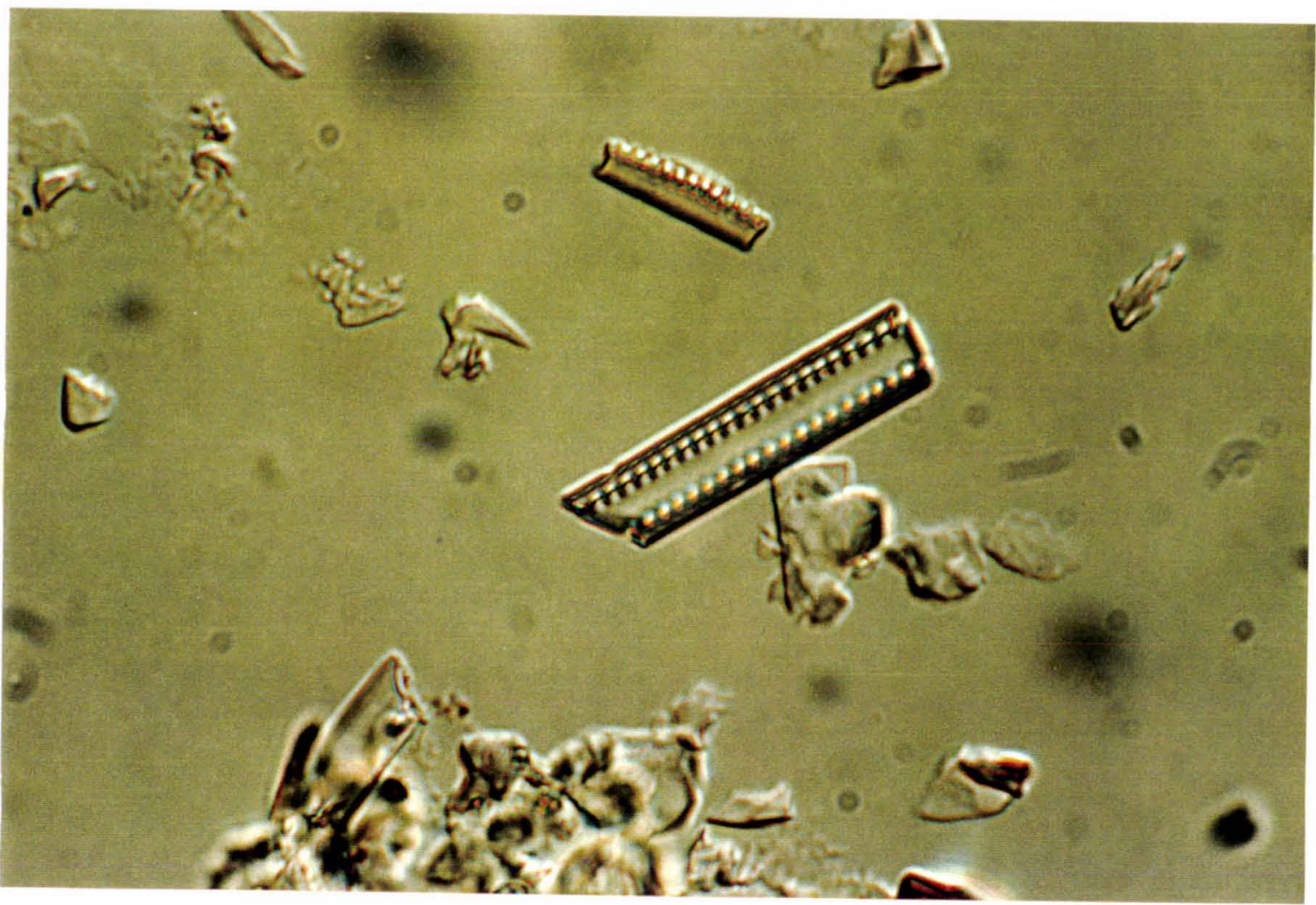

I. Thalassiothrix antarctica. Table Mountain regolith. marine diatom. $18 \mathrm{~mm}=$ $10 \mu \mathrm{m}$ 


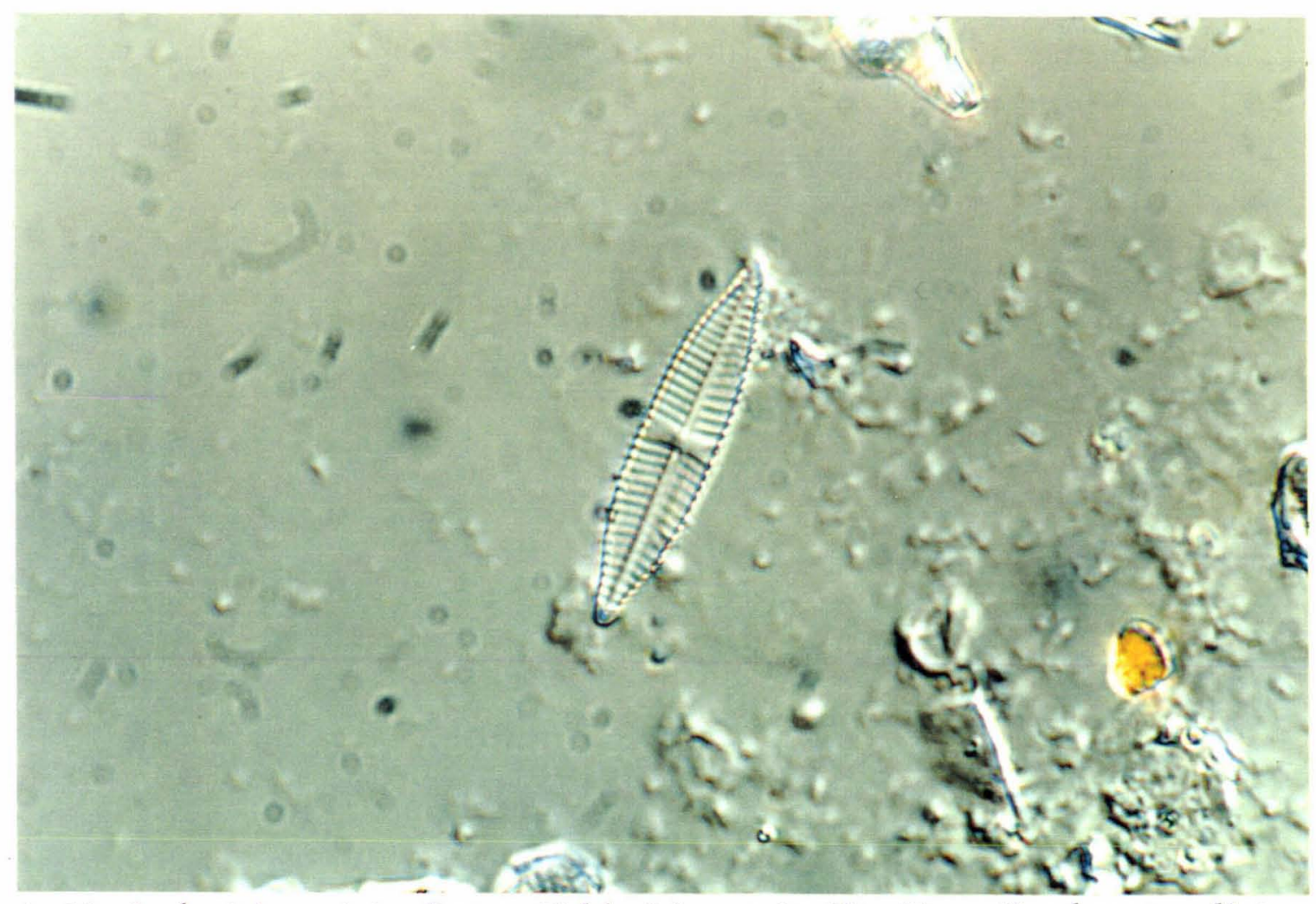

A. Navicula tripunctata. Snow, Table Mountain Site Two. Freshwater diatom. $15 \mathrm{~mm}=10 \mu \mathrm{m}$.

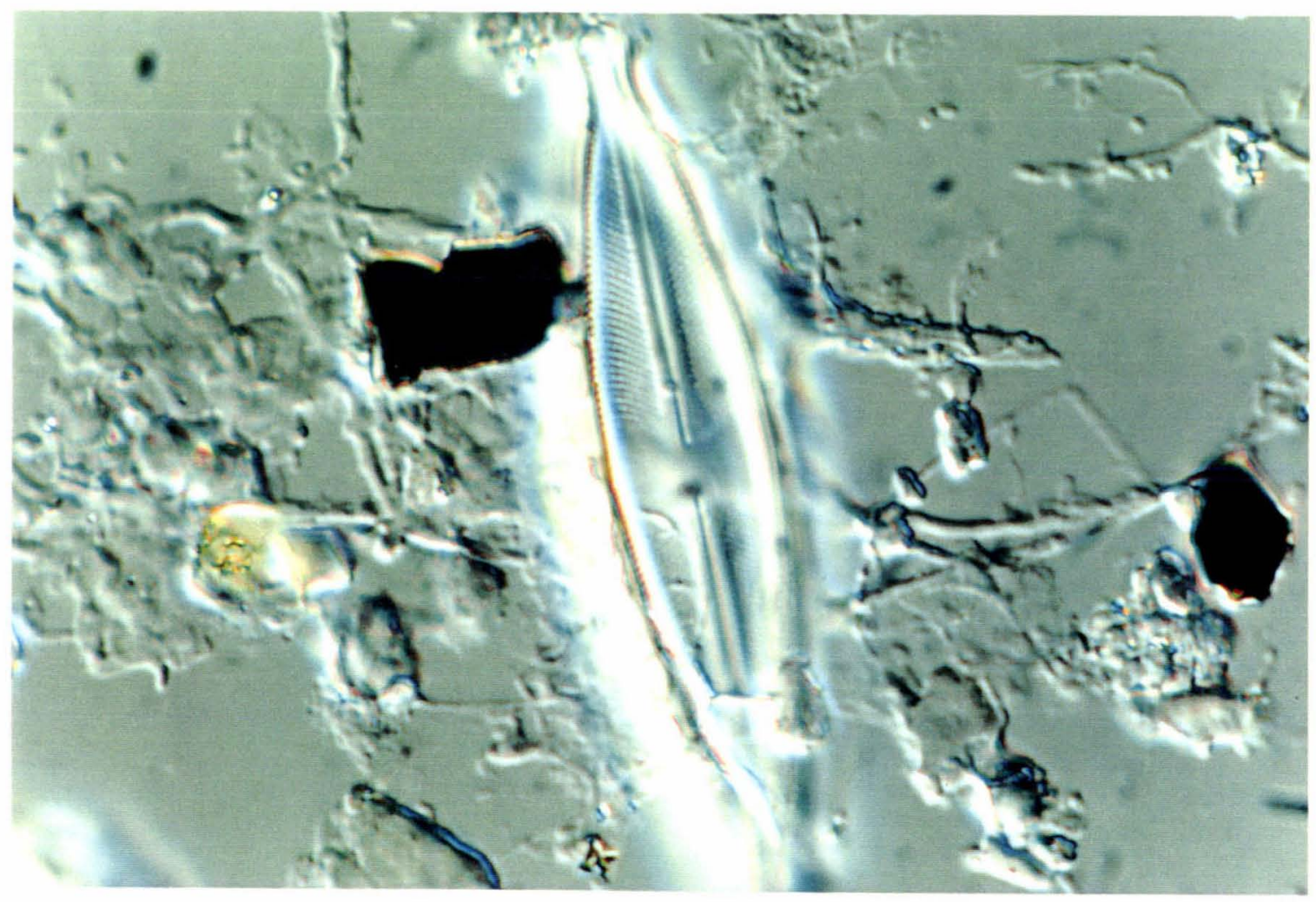

B. Stauroneis anceps var. gracilis. Freshwater diatom. Snow, Mt. Feather Site One. $23 \mathrm{~mm}=10 \mu \mathrm{m}$. 


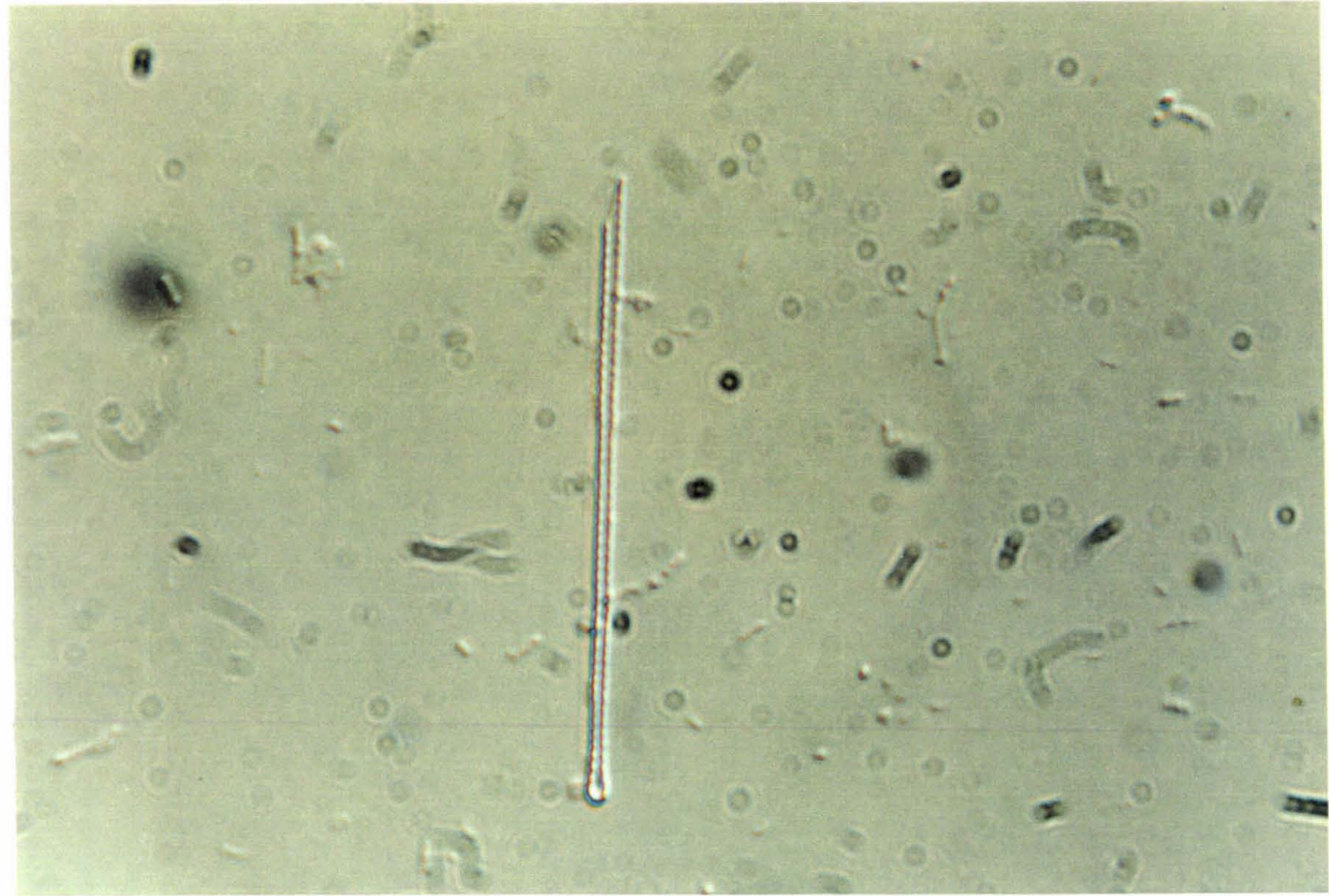

C. Fragilaria tenera. Snow, Table Mountain Site One. Freshwater diatom. $23 \mathrm{~mm}=10 \mu \mathrm{m}$.

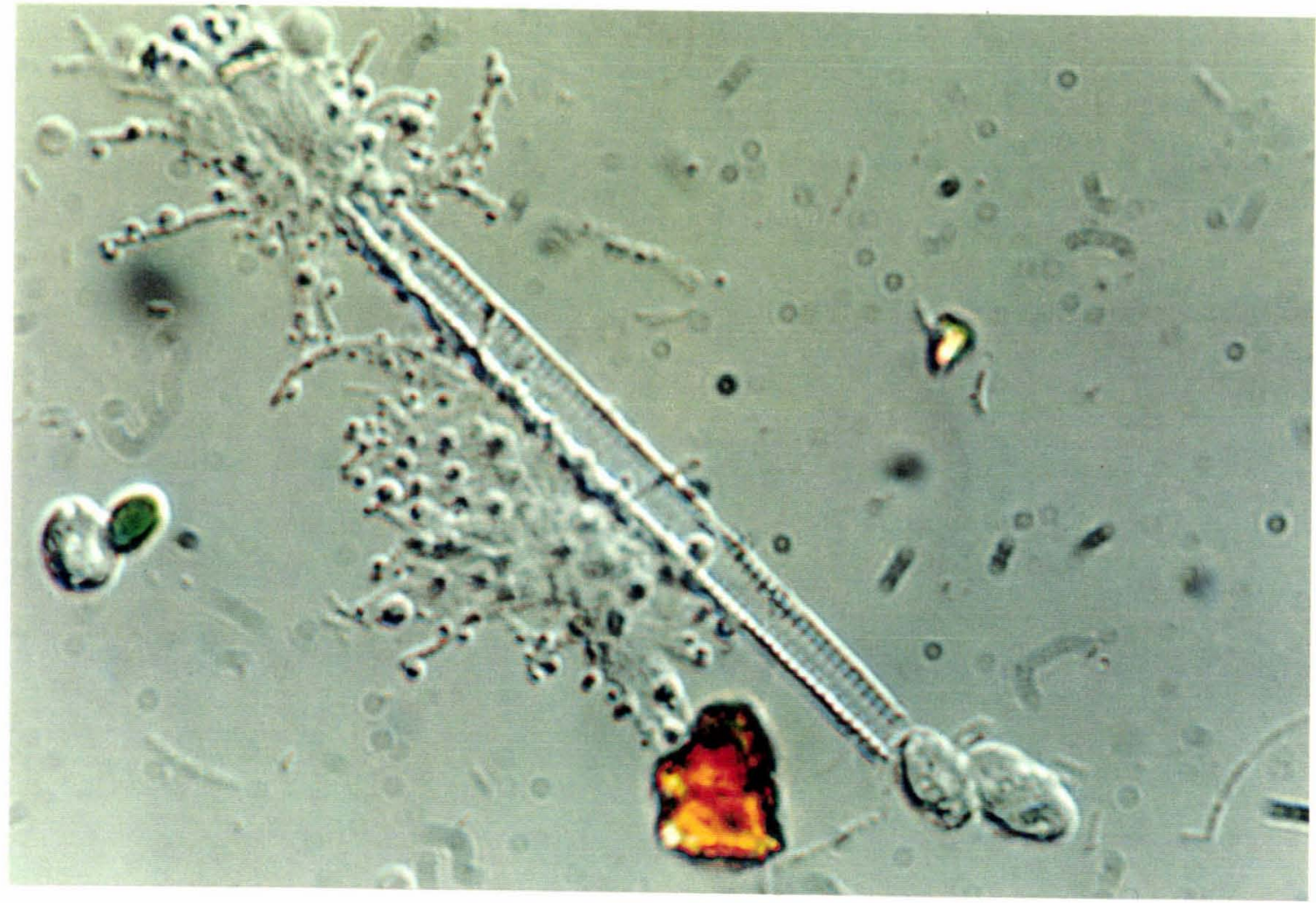

D. Asteronella formosa. Snow, Table Mountain Site One. Freshwater diatom. $23 \mathrm{~mm}=10 \mu \mathrm{m}$. 
APPENDIX 6.7.4 Diatoms from other locations.

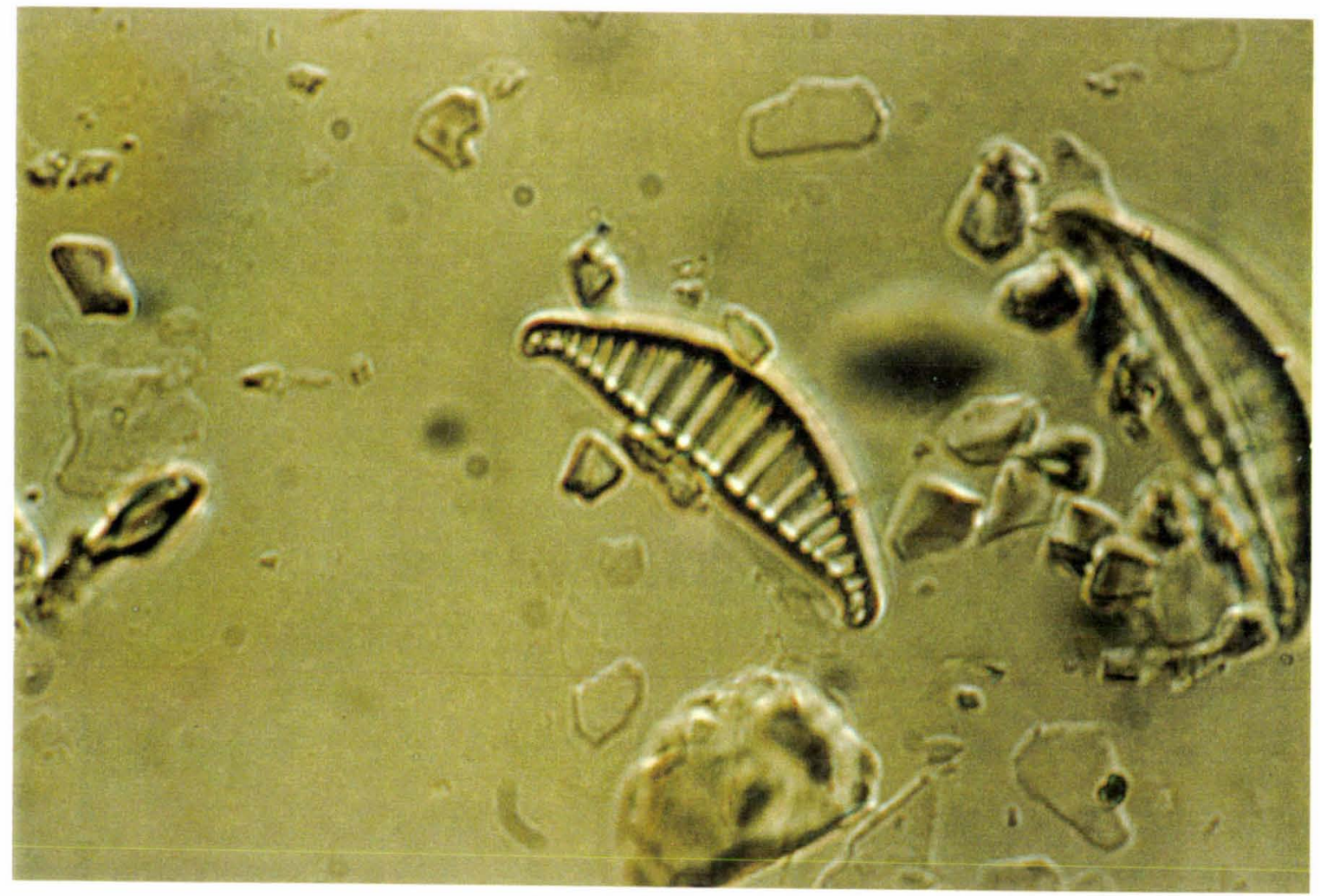

A. Rhophalodia rupestis. from South Island Sample $1(G)$. Is very common in this sample. Freshwater diatom. $18 \mathrm{~mm}=10 \mu \mathrm{m}$.

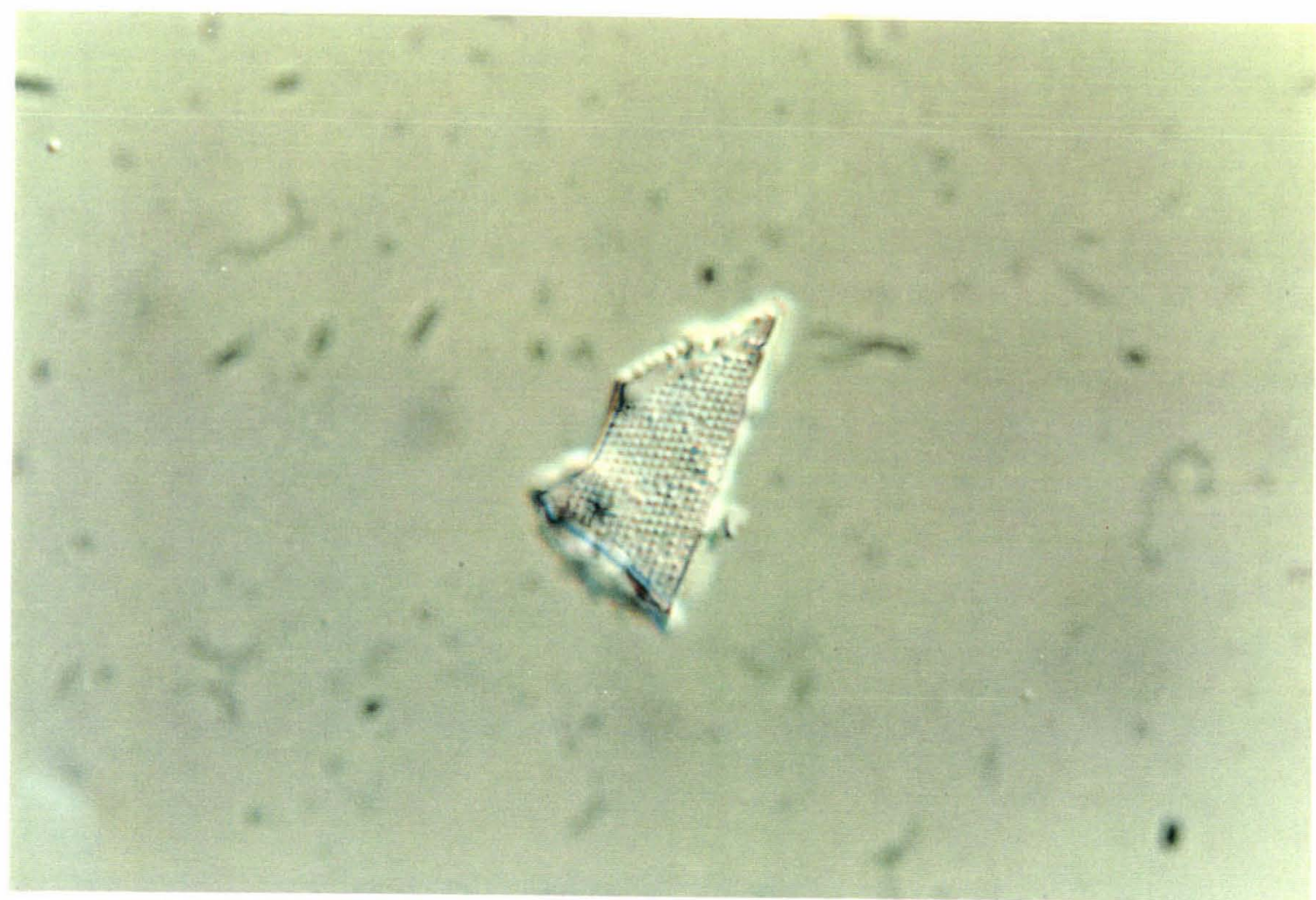

B. Piece of marine diatom found in crack sediment in petrified wood from the Weller Coal measures from Allen Hills. $23 \mathrm{~mm}=10 \mu \mathrm{m}$. 


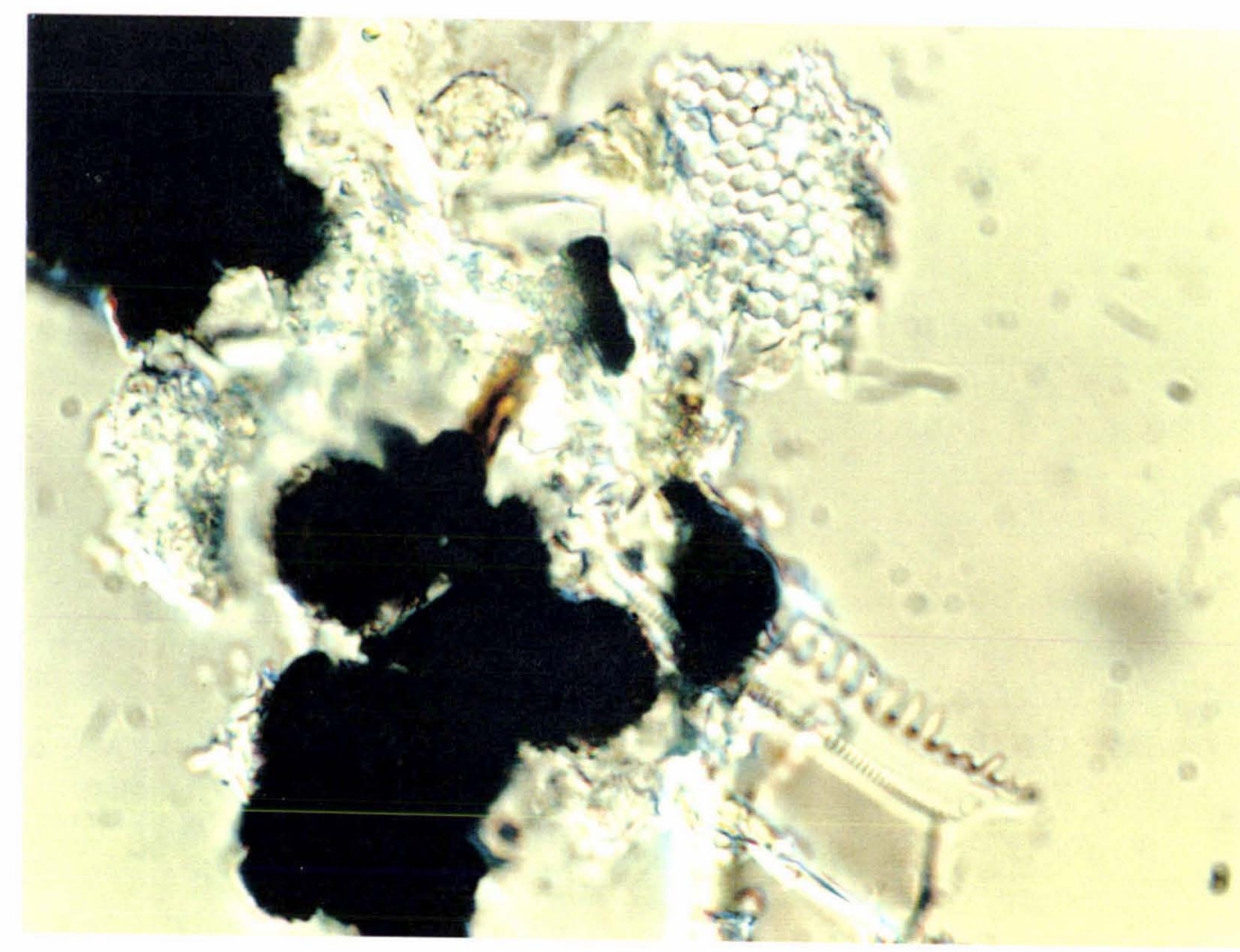

C. Fragments of marine diatoms. An example of material found in dust from the shelves from a typical rock store. $22 \mathrm{~mm}=10 \mu \mathrm{m}$. 


\section{APPENDIX SEVEN}

\section{Phytolith analysis}

Tables, diagrams and analysis of phytoliths.

APPENDIX 7.1 Classification and abbreviations of phytoliths identified.

Table A7.1A Phytolith class percentages for Sirius Group till samples at Mt. Feather.

Table A7.1B Phytolith class percentages for the Sirius tills at Table Mountain, in regolith and in South Island Samples.

Table A7.2A Phytolith class counts for Sirius Group till samples at Mt. Feather.

Table A7.2B Phytolith class counts fro Sirius Group till at Table Mountain, in regolith and, in South Island Samples.

Table A7.3 Percent of grass, tree and fern phytoliths per sample.

Table A7.4 Phytolith assemblage comparisions, using a statistical cluster analysis.

Figure A7.1 Percent of each phytolith class from Sirius Group tills at Mt. Feather and Table Mountain with depth, selected regolith samples and a South island till sample.

Figure A7.2 Phytolith Plates. 


\section{APPENDLX 7.1}

\section{CLASSIFICATION AND ABBREVLATIONS OF PHYTOLITHS IDENTIFIED.}

Phytolith classes from Kondo (1994) and Twiss et al. (1967) with some class modifications appropriate for this thesis.

\section{Grass Phytoliths}

Elongate (Ge)

Originate from long cells of leaves

Do not possess any subfamily or tribal characteristics

Present in graminaceous plants and other monocotyledons, ferns and some trees.

Have features which do allow some division.

Kondo et al. (1994), Twiss et al. (1967).

Hole form (Gh)

Separated in this analysis because of its large abundance it the samples, and its inability to fit into other classes.

Smooth, generally spherical to triangular, contains a hole or is hollow on the inside, has a thick outer margin.

Several forms

No grass of origin has been identified.

Quad shape (Goh)

Separated in this analysis because of its abundance in samples and inability to fit into other classes.

Square to Rectangular in shape. Generally straight sides suggesting not a Chionochloid form.

has a "hole" or "pore" in one corner.

No grass of origin has been identified.

Chionochloid (Gcn)

Spool and tower forms.

From short cells of some Arundinoideae.

Observed in sheaths and leaves of genus Chionochloa and Cortaderia in New Zealand.

Kondo et al. (1994); Pearsall and Trimble (1983); Pearsall (1989).

Shark tooth shape (Gst)

Separated in this analysis because of its repeated form, and inability to fit into other classes.

Lies closest to those of the point shape class yet is generally broader it also has a "double finn" at one end giving it its "shark tooth" form. 
Bambusoid (Gb)

Originate in epidermal "short" cells of Bambusoideae and some Arundinoideae.

Saddle shaped, similar to chloridoid phytoliths but longer.

Seldom detected in New Zealand Soils.

Kondo et al. (1994).

\section{Panicoid (Gpn)}

From epidermal cells (short cells) of Panicoideae, some Arundinoideae, and some Eragrostoideae. Commonly from warm climate grasses.

Dumb-bell, complex dumb-bell and cross shapes(Twiss et al. 1969).

In New Zealand detected in Panicoideae, in some Chionochloa, Cortaderia, and Rytidosperma.

Kondo et al. (1994).

Pendant shape (Gpd)

Pendant shaped epidermal "short" cell.

Ellipse shaped phytolith fatter at one end than the other.

Some forms have "chip marks" over the surface and/or around the edge.

Group was separated due to its abundance and inability to fit into other classes.

The classes they could be most associated with are fan shaped and/or festucoid classes.

\section{Short Cell (Gsc Unk)}

Unknown phytoliths that clearly originate from epidermal short cells.

Festucoid (Gf)

Originate from epidermal cells (short cells) of Pooideae and some Arundinoideae.

Described as "rectangular, elliptical, circular and oblong" by Twiss et al. (1969) and "trough" or boat-shaped by Parry and Smithson (1964).

Most exotic and pasture grasses (Poa, Festuca) in New Zealand. Commonly in Pooideae and a few Arundinoideae.

Kondo et al. (1994).

\section{Half Cell (Ghc)}

Phytoliths with a straight edge "base" with various shapes/forms on the other "sides". Most likely other forms split longways.

\section{Chloridoid (Gcl)}

From epidermal cells (short cells) of Eragrostoideae, Bambusoideae, and some Arundinoideae.

Described as "battle-axes" with a double edge" (Pratt 1936, 1948).

Seen in snow tussock and red tussock (genus Chionochloa) in New Zealand.

Kondo et al. (1994).

Triangular (Gtr)

Epidermal (Short) cells, triangular in shape.

Separated for this study. 
Fan shape (Gfn)

From bulliform (motor) cells.

Motor cells of Rytidosperma are a common source in this class (Zotov, 1963)

Rare in Pooideae and not seen in Chionochloa or Cortaderia.

Kondo et al. (1994).

Point shape (Gpt)

From prickle hairs of leaf epidermis most commonly in Pooideae and Sasa (Kondo \& Sase, 1986).

Kondo et al. (1994).

Stomata

Has a typical stomata shaped form.

Have a both grass and tree origin.

\section{Tree Phytoliths (includes those from shrubs)}

\section{Sclereid (Tsk)}

From vein-sheath parenchyma cells of leaves. Form along the minor veins of leaves and are generally smooth, long, slender rods that often taper to fine points at each end. Some are branched.

Rarely found in tropical species (Piperno, 1988).

Kondo et al. (1994).

Spherical smooth (Tss)

From the epidermis of leaves and from ray or parenchyma cells of twigs and wood.

Those from leaves arem smooth yet bear small protuberances originating from the centre of the cell and passing into sub-epidermal tissues. Most have a single small cavity.

Found in leaves of broad-leaved trees, but are seldom detected in New Zealand soils.

Found in beech (Nothofagus), kamahi, tawa, pohutukawa, rata, and their relatives in New Zealand. Also in black tree fern and wire rush.

Knodo et al. (1994).

Spherical verrucose (Tsv)

From the epidermis of leaves and from ray or parenchyma cells of twigs and wood.

Verrucose surface decoration.

Common from Nothofagus, other than silver beech, and in Rewarewa.

Kondo et al. (1994). 


\section{Spherical nodular (Tsn)}

From ray or parenchyma cells of twigs and wood.

Coarse aggregate surface resembling the dence head of a cauliflower (Ritcher, 1980)

Have also been described as "rosette forms" (Weatherhead, 1988) because of their outline as seen sometimes.

Kondo et al. (1994).

\section{Hair cell (Thc)}

From epidermal hair of leaves, most commonly from the epidermis of dicotyledon families.

Segmented (multi-cellular) hairs often have a v-shaped or hollow socket form with a number of distinct divisions across each phytolith.

Kondo et al. (1994).

Polyhedral (Tpg)

From epidermal cells of leaves.

Have from 4 to 8 sides and are square to rectangular in overall appearance.

Abundant in deciduous trees in USA and Japan (Wilding and Drees, 1973; Geis, 1973; Kondo and Pearson, 1981)

Kondo et al. (1994).

Tracheid $(\mathrm{Tt})$

From vascular tissues comprising thexylem and phloem of leaves.

The surfaces have a serrated, multi-faceted appearance.

Kondo et al. (1994).

\section{Fern Phytoliths}

Tabular (Ft)

Thick broad tabular phytoliths.

Carter (1995)

\section{Anticlinal (Fan)}

Derived from the epidermis of leaves.

Are anticlinal with sinuate margins.

Most common phytoliths from ferns.

Kondo et al. (1994).

Fern Elongate ( $\mathrm{Fe}$ )

Unknown origin.

Known to relate to the vascular system in ferns.

"Okra pod" form with surfaces characterised by small pits which are not corrosion features.

Can be recognised by their "gouda cheese" appearance.

Kondo et al. (1994). 
TABLE A7.1A PHYTOLITH CLASS PERCENTAGES FOR SIRIUS GROUP TILL SAMPLES AT MT. FEATHER

\begin{tabular}{|c|c|c|c|c|c|c|c|c|c|c|}
\hline & $F 1 \quad 0-2$ & Ft $2-7$ & F1 $7-17$ & F1 $17-27$ & F1 $27-37$ & F2 $0-2$ & F2 $2-7$ & F2 $7-17$ & F3 $0-2$ & F3 $7-17$ \\
\hline Ge & 20.81 & 16.81 & 10.55 & 27.48 & 7.00 & 16.75 & 5.00 & 17.00 & 24.39 & 34.48 \\
\hline Gn & 44.16 & & 67.84 & 3.82 & 54.50 & 29.95 & 80.50 & 62.00 & 14.63 & \\
\hline Gon & 1.02 & & 0.50 & 2.29 & 1.00 & 2.54 & & 1.50 & 4.88 & 17.24 \\
\hline Gen & 4.57 & 7.08 & 1.51 & 8.40 & 4.00 & 4.57 & 1.50 & 2.50 & & 13.79 \\
\hline Gst & 0.51 & 1.33 & 1.01 & 0.76 & & 1.02 & & & & 3.45 \\
\hline Gpn & 0.51 & 4.42 & 2.01 & 4.96 & 1.50 & 0.51 & & 1.50 & & \\
\hline Gpd (pen) & 2.54 & 13.27 & 0.50 & 4.58 & 1.00 & 2.03 & 1.50 & 1.50 & & 3.45 \\
\hline Gsc Unk. & 3.05 & 1.77 & 3.52 & 1.53 & 3.00 & 4.06 & & 2.50 & 2.44 & 3.45 \\
\hline Gf & 10.15 & 26.99 & 4.52 & 18.32 & 10.00 & 17.77 & 5.00 & 6.50 & 12.20 & 13.79 \\
\hline Go & & 0.88 & & & & & & & 2.44 & \\
\hline Ghc & 1.02 & & & & & & & & & \\
\hline $\mathrm{Gcl}$ & 0.51 & 0.88 & 0.50 & 0.76 & & 0.51 & & & 12.20 & \\
\hline Gtr & 0.51 & 2.65 & 0.50 & 3.44 & 0.50 & 1.02 & 0.50 & & 14.63 & 3.45 \\
\hline Gfn & 1.02 & 2.21 & 1.01 & 2.67 & 1.50 & 1.52 & 0.50 & 0.50 & 2.44 & \\
\hline Gpt & & 1.77 & & 3.82 & & 0.51 & 0.50 & & & \\
\hline Stomata & 0.51 & & & 0.76 & 1.00 & 0.51 & & & & \\
\hline Tsk & 4.06 & 11.95 & 2.51 & 5.34 & 1.00 & 5.58 & 2.00 & 2.50 & 7.32 & \\
\hline Tss & 2.54 & 2.21 & 1.51 & 0.38 & 6.50 & 4.06 & 1.00 & 0.50 & & \\
\hline Tsv & 1.02 & 1.77 & 1.01 & 2.29 & 1.50 & 2.03 & 0.50 & 1.00 & & \\
\hline The & 1.02 & 1.77 & & 7.25 & & 2.03 & 0.50 & 0.50 & 2.44 & 6.90 \\
\hline \multicolumn{11}{|l|}{ Tsn } \\
\hline \multicolumn{11}{|l|}{$\mathrm{Tpg}$} \\
\hline $\mathrm{Tt}$ & & 2.21 & & 1.15 & & 2.54 & 0.50 & & & \\
\hline & & & & & & & & & & \\
\hline $\mathrm{Ft}$ & 0.51 & & & & & & & & & \\
\hline Fan & & & 1.01 & & 5.50 & 0.51 & & & & \\
\hline $\mathrm{Fe}$ & & & & & 0.50 & & 0.50 & & & \\
\hline Sum & 100.00 & 100.00 & 100.00 & 100.00 & 100.00 & 100.00 & 100.00 & 100.00 & 100.00 & 100.00 \\
\hline
\end{tabular}

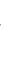


TABLE A7.1B

PHYTOLITH CLASS PERCENTAGES FOR SIRIUS GROUP TILLS AT TABLE MOUNTAIN, IN REGOLITH AND SOUTH ISLAND SAMPLES

\begin{tabular}{|c|c|c|c|c|c|c|c|c|}
\hline & T1 0.2 & $\mathrm{~T} 1>33$ & T2 0.2 & T2 $2-7$ & F. $\mathrm{A1}$ & F.R2 & C. $\mathrm{R}$. & S.I.B \\
\hline Ge & 21.50 & 20.00 & \begin{tabular}{r|}
24.86 \\
\end{tabular} & 11.65 & \begin{tabular}{|r|}
13.04 \\
\end{tabular} & 1.71 & \begin{tabular}{|r|}
22.51 \\
\end{tabular} & \begin{tabular}{|l|}
21.67 \\
\end{tabular} \\
\hline Gh & 7.50 & 3.50 & 8.47 & 0.49 & 55.07 & 96.25 & 4.19 & \\
\hline Gon & 2.50 & 2.50 & 0.56 & 1.94 & 4.35 & 0.68 & 4.19 & 10.00 \\
\hline Gon & 10.50 & 30.50 & 11.30 & 36.41 & 2.90 & 0.68 & 4.19 & 10.00 \\
\hline Gst & 1.50 & 1.00 & 4.52 & 3.88 & 1.45 & & 3.14 & 3.33 \\
\hline Gpn & 1.00 & 2.00 & & & 1.45 & & 0.52 & 3.33 \\
\hline Gpd (pen) & 2.00 & 1.50 & & 3.88 & 1.45 & & 0.52 & 5.00 \\
\hline Gsc Unk. & 4.00 & & & 0.49 & & 0.34 & 15.18 & 5.00 \\
\hline Gf & 26.00 & 15.00 & 18.08 & 14.56 & 10.14 & & 10.99 & 1.67 \\
\hline Go & & 1.50 & & 0.49 & 1.45 & & & 1.67 \\
\hline Ghe & & & & & & & 1.57 & 1.67 \\
\hline $\mathrm{Gcl}$ & 1.00 & 1.50 & 3.39 & 0.49 & & & & \\
\hline Gtr & & 2.50 & 1.13 & 3.88 & & & 12.57 & 5.00 \\
\hline Gin & 8.00 & 4.00 & 7.34 & 10.68 & & & 1.05 & 6.67 \\
\hline Gpt & 2.00 & 7.50 & 3.95 & 0.97 & 1.45 & & & 3.33 \\
\hline Stomata & & 1.50 & 1.13 & 0.49 & & & & \\
\hline & & & & & & & & \\
\hline Tsk & 2.50 & 4.00 & 4.52 & 4.85 & 4.35 & 0.34 & 1.57 & 1.67 \\
\hline Tss & & & & 0.49 & & & 1.57 & 1.67 \\
\hline Tsv & 2.50 & & 2.82 & 0.49 & 2.90 & & 14.14 & \\
\hline The & 4.00 & 1.00 & 7.34 & 2.91 & & & 1.05 & 16.67 \\
\hline Tsn & 1.50 & & & & & & 0.52 & 1.67 \\
\hline $\mathrm{Tpg}$ & & & & 0.49 & & & & \\
\hline $\mathrm{Tt}$ & 2.00 & 0.50 & 0.56 & & & & & \\
\hline & & & & & & & & \\
\hline $\mathrm{Ft}$ & & & & 0.49 & & & & \\
\hline Fan & & & & & & & & \\
\hline $\mathrm{Fe}$ & & & & & & & 0.52 & \\
\hline Sum & 100 & 100 & 100 & 100 & 100 & 100 & 100 & 100 \\
\hline
\end{tabular}




\begin{tabular}{|c|c|c|c|c|c|c|c|c|c|c|c|}
\hline & F1 $0-2$ & F1 $2-7$ & $\mathrm{~F} 1 \quad 7-17$ & $F 1 \quad 17-27$ & F1 $27-37$ & F2 $0-2$ & F2 2-7 & F2 $7-17$ & F3 $\quad 0-2$ & F3 $7-17$ & \\
\hline $\mathrm{Ge}$ & 41 & 38 & 21 & 72 & 14 & 33 & 10 & 34 & 10 & 10 & \\
\hline Gh & 87 & & 135 & 10 & 109 & 59 & 161 & 124 & 6 & & \\
\hline Goh & 2 & & 1 & 6 & 2 & 5 & & 3 & 2 & 5 & \\
\hline Gen & 9 & 16 & 3 & 22 & 8 & 9 & 3 & 5 & & 4 & \\
\hline Gst & 1 & 3 & 2 & 2 & & 2 & & & & 1 & \\
\hline Gpn & 1 & 10 & 4 & 13 & 3 & 1 & & 3 & & & \\
\hline Gpd (pen) & 5 & 30 & 1 & 12 & 2 & 4 & 3 & 3 & & 1 & \\
\hline Gsc Unk. & 6 & 4 & 7 & 4 & 6 & 8 & & 5 & 1 & 1 & \\
\hline Gf & 20 & 61 & 9 & 48 & 20 & 35 & 10 & 13 & 5 & 4 & \\
\hline Go & & 2 & & & & & & & 1 & & \\
\hline Ghe & 2 & & & & & & & & & & \\
\hline $\mathrm{Gcl}$ & 1 & 2 & 1 & 2 & & 1 & & & 5 & & \\
\hline Gtr & 1 & 6 & 1 & 9 & 1 & 2 & 1 & & 6 & 1 & \\
\hline Gin & 2 & 5 & 2 & 7 & 3 & 3 & 1 & 1 & 1 & & \\
\hline Gpt & & 4 & & 10 & & 1 & 1 & & & & \\
\hline Stomata & 1 & & & 2 & 2 & 1 & & & & & \\
\hline & & & & & & & & & & & \\
\hline Tsk & 8 & 27 & 5 & 14 & 2 & 11 & 4 & 5 & 3 & & \\
\hline Tss & 5 & 5 & 3 & 1 & 13 & 8 & 2 & 1 & & & \\
\hline Tsv & 2 & 4 & 2 & 6 & 3 & 4 & 1 & 2 & & & \\
\hline The & 2 & 4 & & 19 & & 4 & 1 & 1 & 1 & 2 & \\
\hline \multicolumn{12}{|l|}{ Tsn } \\
\hline \multicolumn{12}{|l|}{ Tpg } \\
\hline $\mathrm{Tt}$ & & 5 & & 3 & & 5 & 1 & & & & \\
\hline & & & & & & & & & & & \\
\hline $\mathrm{Ft}$ & 1 & & & & & & & & & & \\
\hline Fan & & & 2 & & 11 & 1 & & & & & \\
\hline $\mathrm{Fe}$ & & & & & 1 & & 1 & & & & \\
\hline Sum & 197 & 226 & 199 & 262 & 200 & 197 & 200 & 200 & 41 & 29 & \\
\hline
\end{tabular}


PHYTOLITH CLASS COUNTS FOR SIRIUS GROUP TILL AT TABLE MOUNTAIN, IN REGOLITH AND SOUTH ISLAND SAMPLES.

\begin{tabular}{|c|c|c|c|c|c|c|c|c|}
\hline & T1 $0-2$ & $\mathrm{~T} 1>33$ & T2 0.2 & T2 $2-7$ & F.R1 & F.P2 & C. $\mathrm{R}$. & S.I.B \\
\hline $\mathrm{Ge}$ & 43 & 40 & 44 & 24 & 9 & 5 & 43 & 13 \\
\hline Ch & 15 & 7 & 15 & 1 & 38 & 282 & 8 & \\
\hline Gon & 5 & 5 & 1 & 4 & 3 & 2 & 8 & 6 \\
\hline Gen & 21 & 61 & 20 & 75 & 2 & 2 & 8 & 6 \\
\hline Gst & 3 & 2 & 8 & 8 & 1 & & 6 & 2 \\
\hline Gpn & 2 & 4 & & & 1 & & 1 & 2 \\
\hline Gpd (pen) & 4 & 3 & & 8 & 1 & & 1 & 3 \\
\hline Gsc Unk. & 8 & & & 1 & & 1 & 29 & 3 \\
\hline Gf & 52 & 30 & 32 & 30 & 7 & & 21 & 1 \\
\hline Co & & 3 & & 1 & 1 & & & 1 \\
\hline Ghe & & & & & & & 3 & 1 \\
\hline $\mathrm{Gcl}$ & 2 & 3 & 6 & 1 & & & & \\
\hline Gtr & & 5 & 2 & 8 & & & 24 & 3 \\
\hline Gfn & 16 & 8 & 13 & 22 & & & 2 & 4 \\
\hline Gpt & 4 & 15 & 7 & 2 & 1 & & & 2 \\
\hline Stomata & & 3 & 2 & 1 & & & & \\
\hline Tsk & 5 & 8 & 0 & 10 & 0 & 9 & $?$ & 4 \\
\hline Tss & 3 & 0 & 0 & $\frac{10}{1}$ & 3 & 1 & $\frac{3}{3}$ & $\frac{1}{1}$ \\
\hline Tsv & 5 & & 5 & 1 & 2 & & 27 & \\
\hline The & 8 & 2 & 13 & 6 & & & 2 & 10 \\
\hline Tsn & 3 & & & & & & 1 & 1 \\
\hline Tpg & & & & 1 & & & & \\
\hline $\mathrm{Tt}$ & 4 & 1 & 1 & & & & & \\
\hline & & & & & & & & \\
\hline $\mathrm{Ft}$ & & & & 1 & & & & \\
\hline Fan & & & & & & & & \\
\hline $\mathrm{Fe}$ & & & & & & & 1 & \\
\hline Sum & 200 & 200 & 177 & 206 & 69 & 293 & 191 & 60 \\
\hline
\end{tabular}


TABLE A7.3

PERCENT OF GRASS, TREE AND FERN PHYTOLITHS PER SAMPLE

\begin{tabular}{|ll|c|c|c|}
\hline \multicolumn{2}{|c|}{ SAMPLE } & GRASS & TREE & FERN \\
\hline F1 & $0-2$ & 90.36 & 8.63 & 0.51 \\
F1 $2-7$ & 80.09 & 19.91 & \\
F1 $7-17$ & 93.97 & 5.03 & 1.01 \\
F1 $17-27$ & 82.82 & 16.41 & \\
F1 $27-37$ & 84.00 & 9.00 & 6 \\
\hline F2 $0-2$ & 82.74 & 16.24 & 0.51 \\
F2 $2-7$ & 95.00 & 4.50 & 0.5 \\
F2 $7-17$ & 95.50 & 4.50 & \\
\hline F3 $0-2$ & 90.24 & 9.76 & \\
F3 $7-17$ & 93.10 & 6.90 & \\
\hline T1 $0-2$ & 87.50 & 12.50 & \\
T1 $>33$ & 93.00 & 5.50 & \\
\hline T2 $0-2$ & 83.62 & 0.56 & \\
T2 $2-7$ & 89.81 & 9.22 & \\
\hline FR1 & 92.75 & 7.25 & \\
FR2 & 99.66 & & \\
CR & 80.63 & 18.85 & 0.52 \\
S.I.B & 78.33 & 11.67 & \\
\hline
\end{tabular}


TABLE A7.4

Phytolith Assemblage Comparisons using Statistical Clusrer Analysis.

1.00 is having most on common with the other - has little or nothing in common with the other assemblage 0.00 has the least in common.

* highest ratios in common with sample

\begin{tabular}{|c|c|c|c|c|c|c|c|c|c|c|c|c|c|c|c|c|c|c|}
\hline Sample & F1 $0-2$ & F1 2-7 & F1 $7-17$ & \begin{tabular}{|lll}
$F 1$ & $17-27$ \\
\end{tabular} & \begin{tabular}{|lll}
$F 1$ & 27 & -37 \\
\end{tabular} & $\begin{array}{lll}F 2 & 0-2 \\
\end{array}$ & F2 2-7 & F2 $7-17$ & $F 30-2$ & F3 7.17 & $\begin{array}{ll}T 1 & 0-2 \\
\end{array}$ & $T 1>33$ & $\begin{array}{ll}T 2 & 0.2 \\
\end{array}$ & T2 $2-7$ & FA1 & $F P 2$ & $C R$ & S.I.B \\
\hline $\begin{array}{lll}F 1 & 0-2 \\
\end{array}$ & & 0.25 & $0.95^{\circ}$ & 0.44 & 0.94 & $0.95^{\circ}$ & 0.92 & $0.98^{\circ}$ & 0.64 & 0.32 & 0.5 & 0.3 & 0.55 & 0.14 & $0.97^{\circ}$ & 0.89 & 0.35 & 0.17 \\
\hline F1 $2-7$ & 0.26 & & - & 0.82 & 0.05 & 0.48 & - & 0.08 & 0.49 & 0.58 & $0.82^{*}$ & 0.59 & 0.71 & 0.5 & 0.12 & - & 0.46 & 0.32 \\
\hline F1 $7-17$ & $0.95^{\prime \prime}$ & - & \% & 0.15 & $0.98^{\circ}$ & 0.84 & $0.99^{\circ}$ & $0.99^{\circ}$ & 0.45 & 0.03 & 0.24 & 0.08 & 0.28 & - & $0.98^{\circ}$ & $0.99^{\circ}$ & 0.14 & \\
\hline $\begin{array}{lll}\text { F1 } & 17-27 \\
\end{array}$ & 0.44 & $0.82^{\circ}$ & 0.15 & & 0.16 & 0.59 & 0.08 & 0.26 & $0.70^{\circ}$ & $0.86^{\circ}$ & $0.9^{*}$ & 0.72 & 0.93 & 0.53 & 0.27 & 0.01 & $0.66^{\circ}$ & 0.68 \\
\hline $\begin{array}{lll}F 1 & 27-37 \\
\end{array}$ & $0.94^{*}$ & 0.05 & $0.98^{\circ}$ & 0.16 & & 0.87 & $0.98^{\circ}$ & $0.97^{\circ}$ & 0.43 & 0.04 & 0.3 & 0.12 & 0.3 & 0.02 & 0.97 & $0.97^{\circ}$ & 0.14 & - \\
\hline $\begin{array}{lll}\text { F2 } & 0-2 \\
\end{array}$ & $0.95^{*}$ & 0.48 & 0.84 & 0.59 & 0.87 & \% & 0.81 & 0.89 & 0.68 & 0.42 & 0.69 & 0.41 & 0.68 & 0.24 & 0.9 & 0.77 & 0.45 & 0.19 \\
\hline F2 2-7 & $0.92^{\circ}$ & - & $0.99^{\circ}$ & 0.08 & $0.98^{*}$ & 0.81 & & $0.98^{\circ}$ & 0.4 & - & 0.19 & 0.05 & 0.23 & - & $0.98^{\circ}$ & 1 & 0.06 & - \\
\hline F2 $7-17$ & $0.98^{*}$ & 0.08 & $0.99^{\circ}$ & 0.26 & $0.97^{\circ}$ & $0.89^{*}$ & $0.98^{\circ}$ & & 0.53 & 0.15 & 0.34 & 0.17 & 0.38 & 0.02 & $0.99^{*}$ & $0.96^{\circ}$ & 0.22 & 0.05 \\
\hline F3 $0-2$ & 0.64 & 0.49 & 0.45 & 0.7 & 0.43 & 0.68 & 0.4 & 0.53 & & 0.61 & 0.62 & 0.39 & 0.7 & 0.18 & 0.52 & 0.35 & 0.64 & 0.43 \\
\hline F3 $7-17$ & 0.32 & 0.58 & 0.03 & 0.86 & 0.04 & 0.42 & - & 0.15 & 0.61 & & 0.74 & 0.7 & $0.78^{*}$ & 0.53 & 0.15 & - & $0.66^{\circ}$ & $0.81^{\circ}$ \\
\hline $\begin{array}{lll}\text { T1 } & 0-2\end{array}$ & 0.5 & $0.82^{\circ}$ & 0.24 & $0.9^{\circ}$ & 0.3 & 0.69 & 0.19 & 0.34 & 0.62 & 0.74 & & 0.73 & $0.93^{\circ}$ & 0.61 & 0.36 & 0.13 & 0.61 & 0.49 \\
\hline$T 1>33$ & 0.3 & 0.59 & 0.08 & 0.72 & 0.12 & 0.41 & 0.05 & 0.17 & 0.39 & 0.7 & 0.73 & & $0.77^{\circ}$ & $0.92^{\circ}$ & 0.18 & 0 & 0.4 & 0.52 \\
\hline$T 20-2$ & 0.55 & 0.71 & 0.28 & $0.93^{\circ}$ & 0.3 & 0.68 & 0.23 & 0.38 & $0.70^{\circ}$ & $0.78^{\circ}$ & $0.93^{*}$ & $0.77^{*}$ & & $0.62^{\circ}$ & 0.4 & 0.17 & 0.59 & 0.62 \\
\hline$T 2 \quad 2-7$ & 0.14 & 0.5 & - & 0.53 & 0.02 & 0.24 & - & 0.02 & 0.18 & 0.53 & 0.61 & $0.92^{\circ}$ & 0.62 & & 0.05 & - & 0.26 & 0.44 \\
\hline FRI & $0.97^{*}$ & 0.12 & $0.98^{*}$ & 0.27 & $0.97^{\circ}$ & $0.9^{*}$ & $0.98^{\circ}$ & $0.99^{\circ}$ & 0.52 & 0.15 & 0.36 & 0.18 & 0.4 & 0.04 & & $0.96^{\circ}$ & 0.2 & 0.01 \\
\hline FR2 & 0.89 & - & $0.99^{*}$ & 0.01 & $0.97^{*}$ & 0.77 & $1^{*}$ & $0.96^{\circ}$ & 0.35 & - & 0.13 & 0 & 0.17 & - & 0.96 & & 0.02 & - \\
\hline CA & 0.35 & 0.46 & 0.14 & 0.66 & 0.14 & 0.45 & 0.06 & 0.22 & 0.64 & 0.66 & 0.61 & 0.4 & 0.59 & 0.26 & 0.2 & 0.02 & & 0.48 \\
\hline$S .1 . \mathrm{B}$ & 0.17 & 0.32 & - & 0.68 & - & 0.19 & - & 0.05 & 0.43 & $0.81^{\circ}$ & 0.49 & 0.52 & 0.62 & 0.44 & 0.01 & - & 0.48 & \\
\hline
\end{tabular}




\section{Figure A7.1}

Percent of each phytolith class from Sirius Group tills Mt. Feather and Table Mountain with depth, selected regolith samples and a South Island till sample.

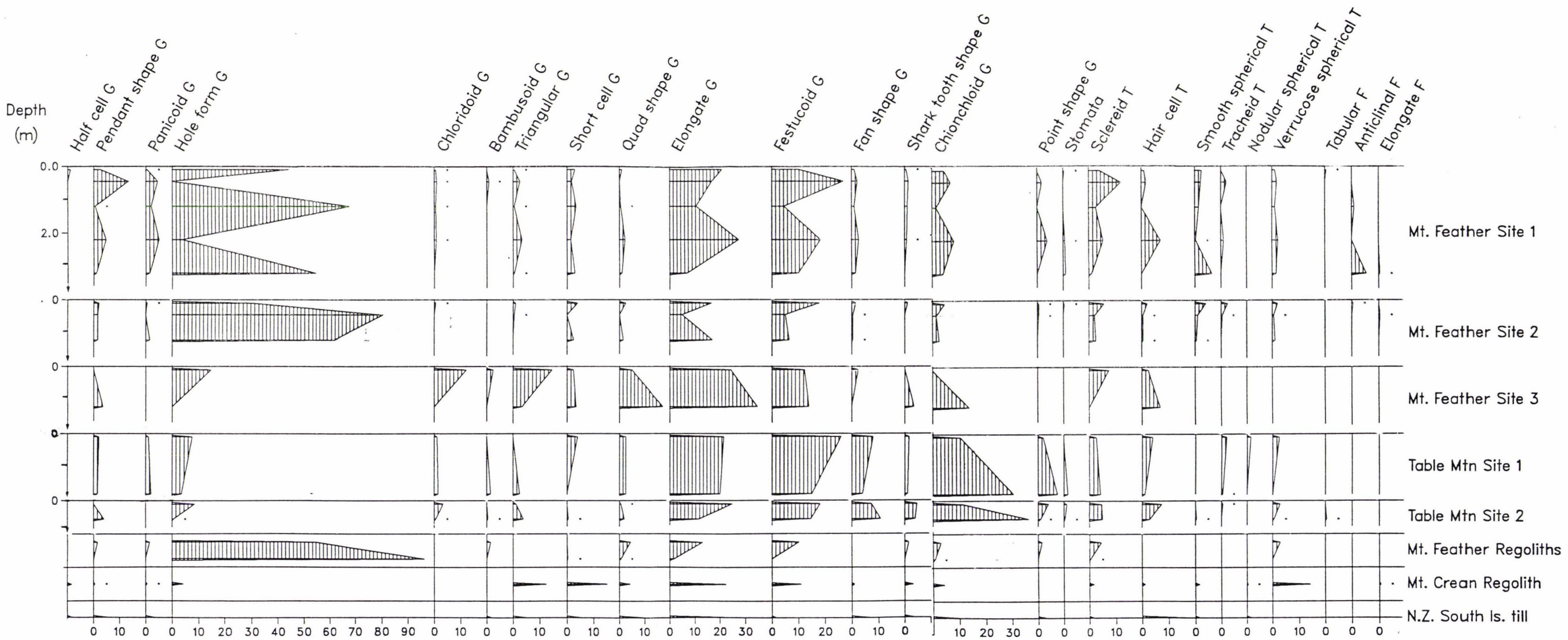

\% Total phytoliths 


\section{FIGURE A7.2 Phytolith Figures}

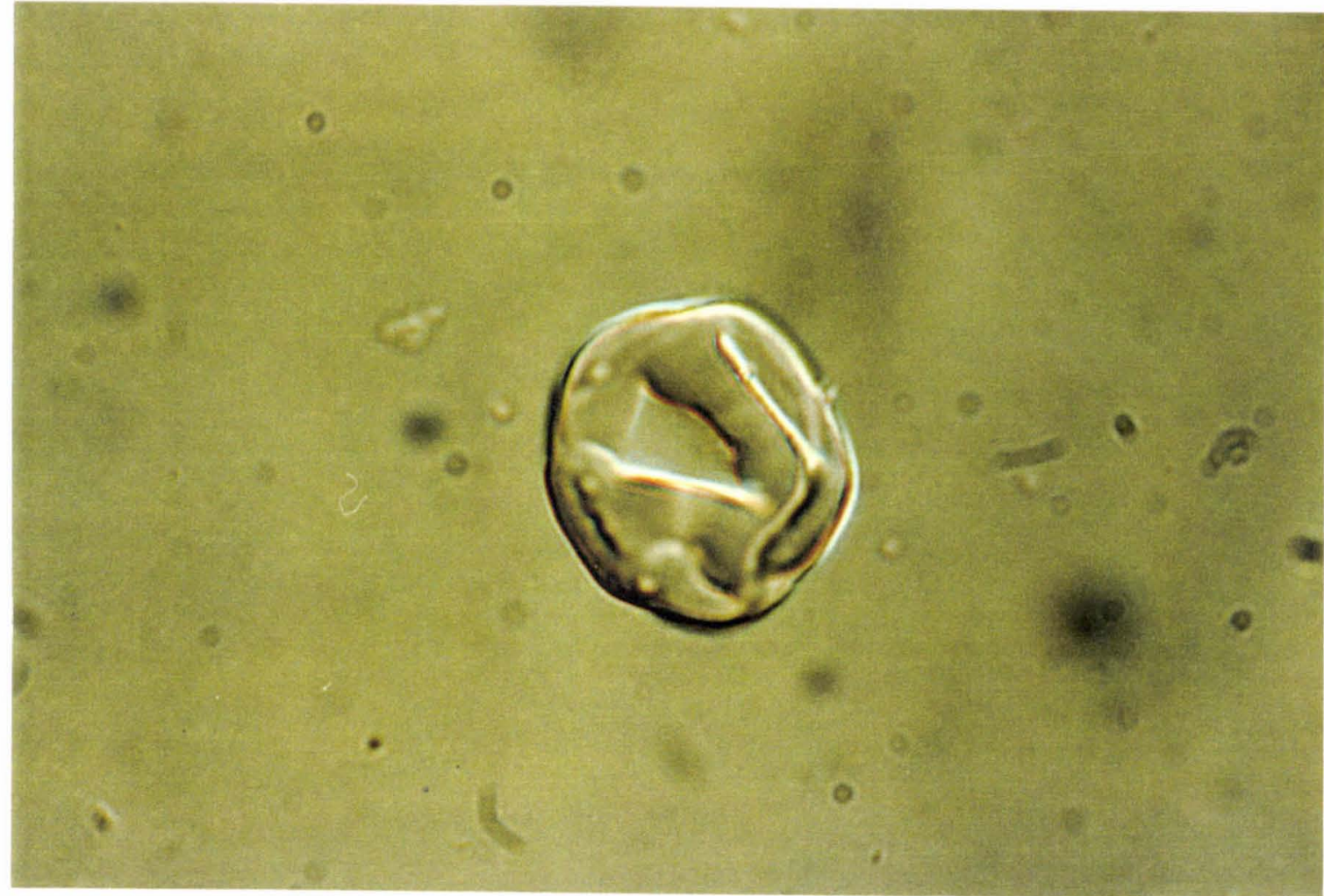

A. Grass phytolith of the "hole shape" class. From Mt. Feather Site One 0-2cm. $40 \mathrm{~mm}=10 \mu \mathrm{m}$.

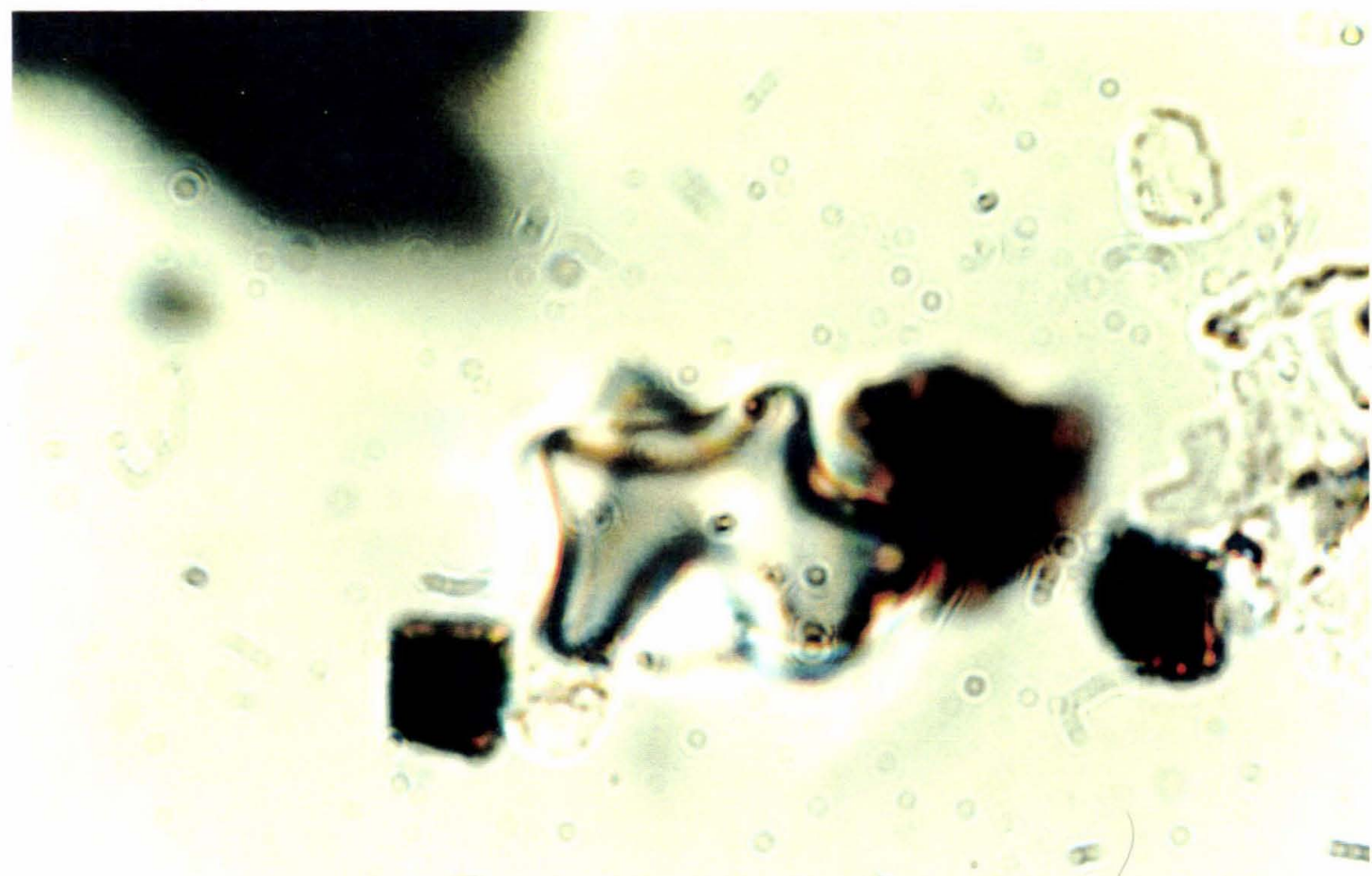

B. Fern phytolith of the anticlinal epidermal class. From, Mt. Feather Site One $7-17 \mathrm{~cm} 32 \mathrm{~mm}=10 \mu \mathrm{m}$. 


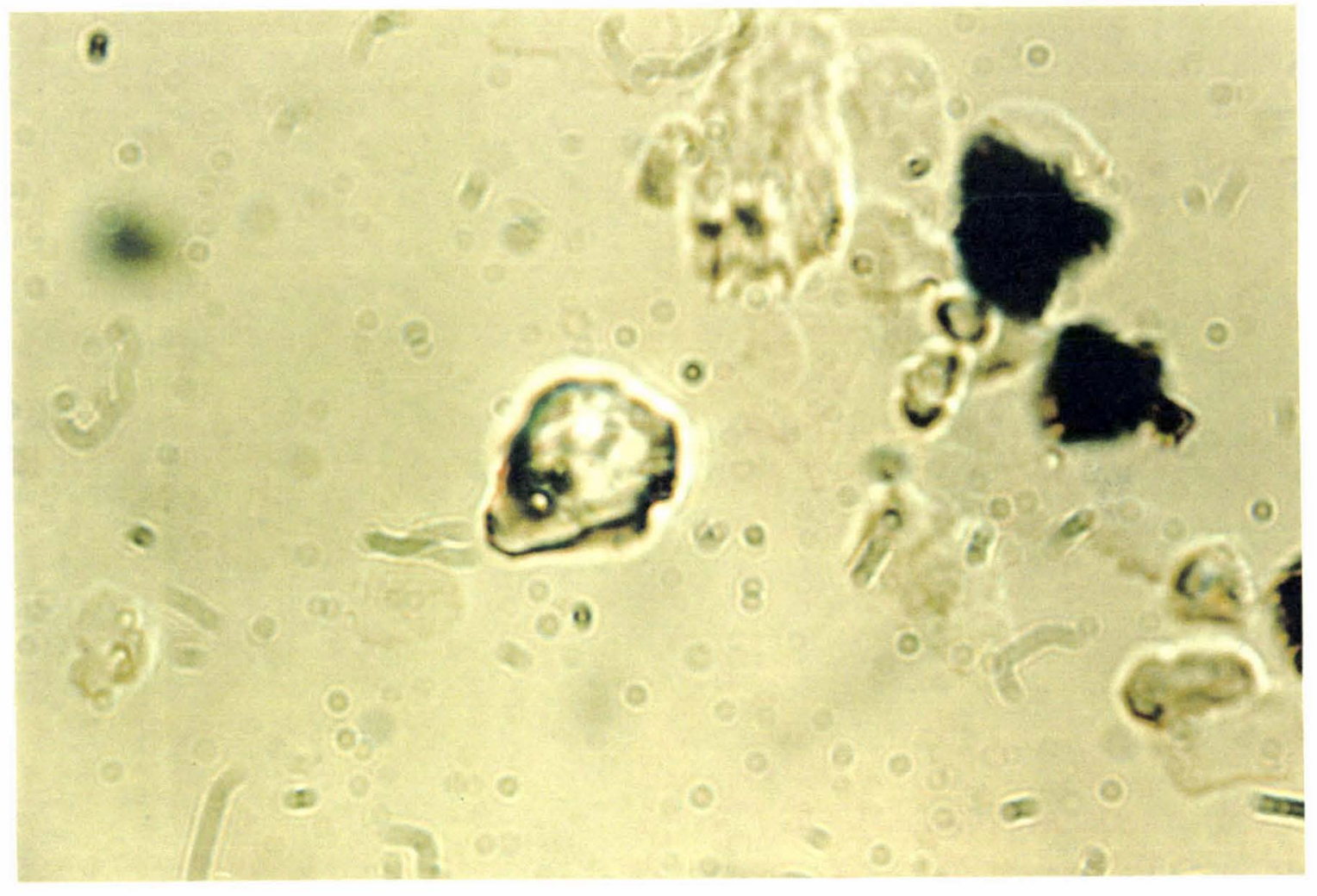

C. Grass phytolith of the fan shape class. Mt. Feather Site Two $7-17 \mathrm{~cm} .20 \mathrm{~mm}=$ $10 \mu \mathrm{m}$.

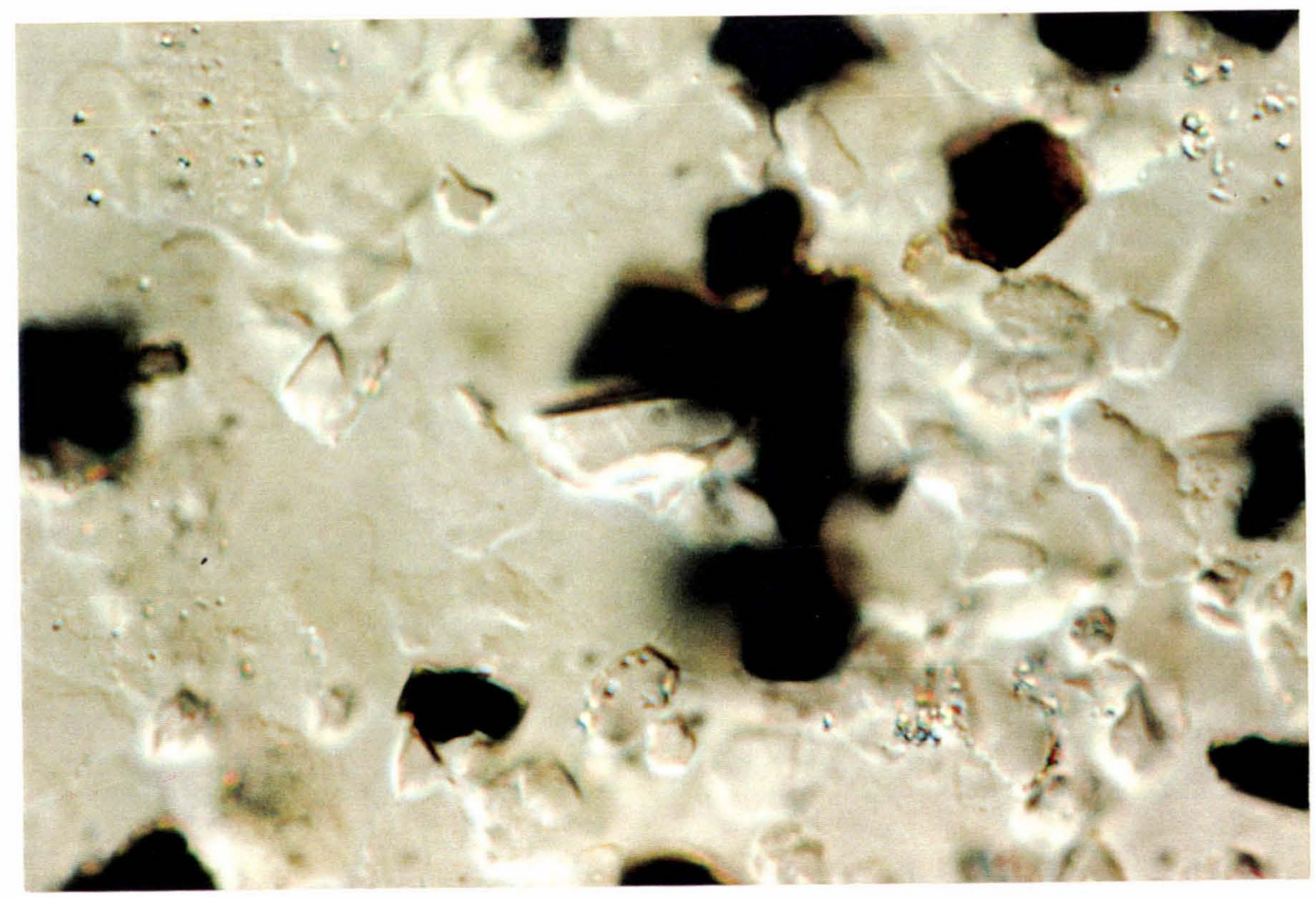

D. Grass phytolith of "saddle" form from Mt. Feather Site One $7-17 \mathrm{~cm} .20 \mathrm{~mm}$ $=10 \mu \mathrm{m}$. 


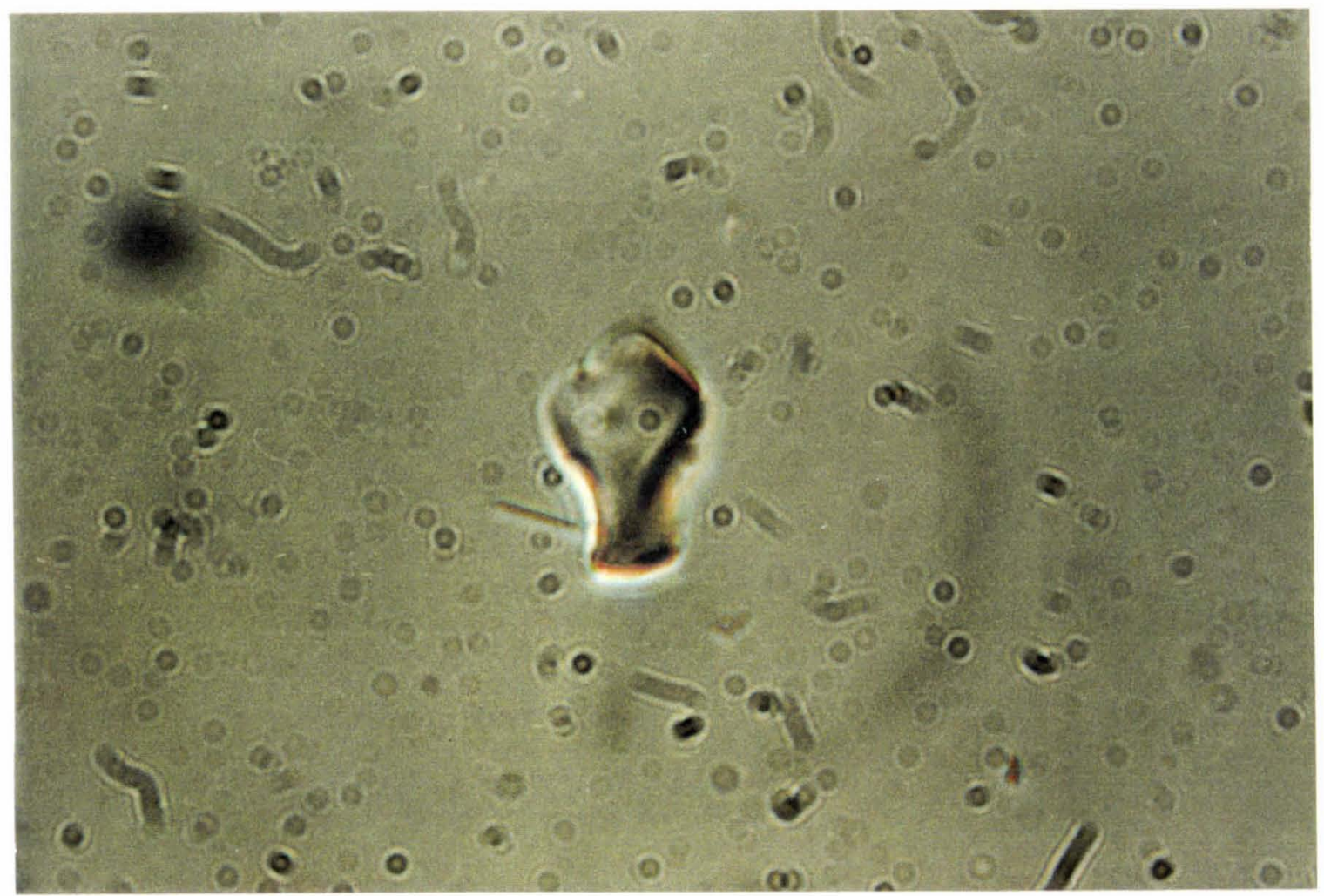

E. Grass phytolith of the fan shape class from $\mathrm{mt}$. Feather Site One $7-17 \mathrm{~cm}$. $20 \mathrm{~mm}=10 \mu \mathrm{m}$

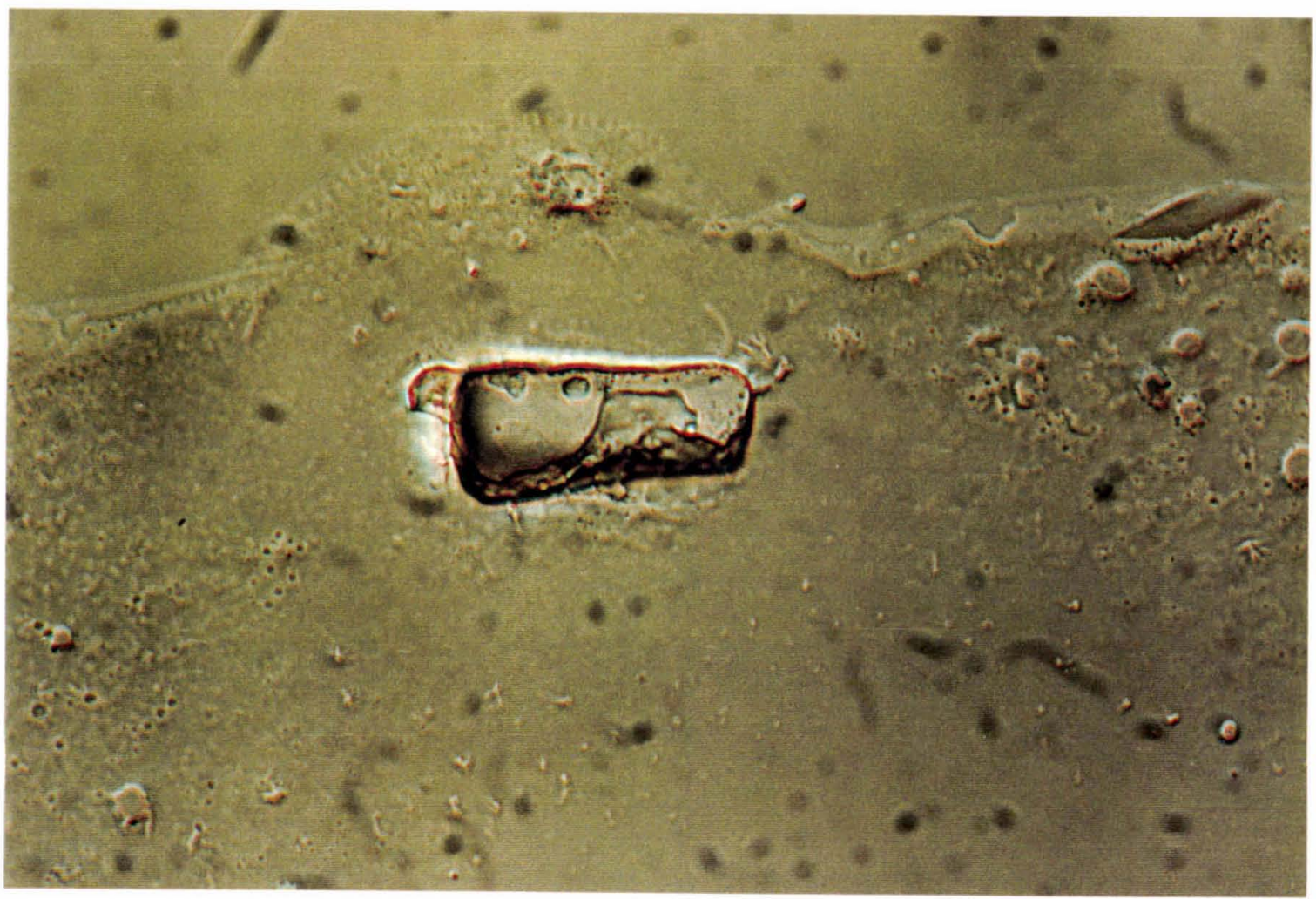

F. Grass phytolith of the elongate class from Mt. Feather Site One Site One 7$17 \mathrm{~cm} .30 \mathrm{~mm}=10 \mu \mathrm{m}$. 


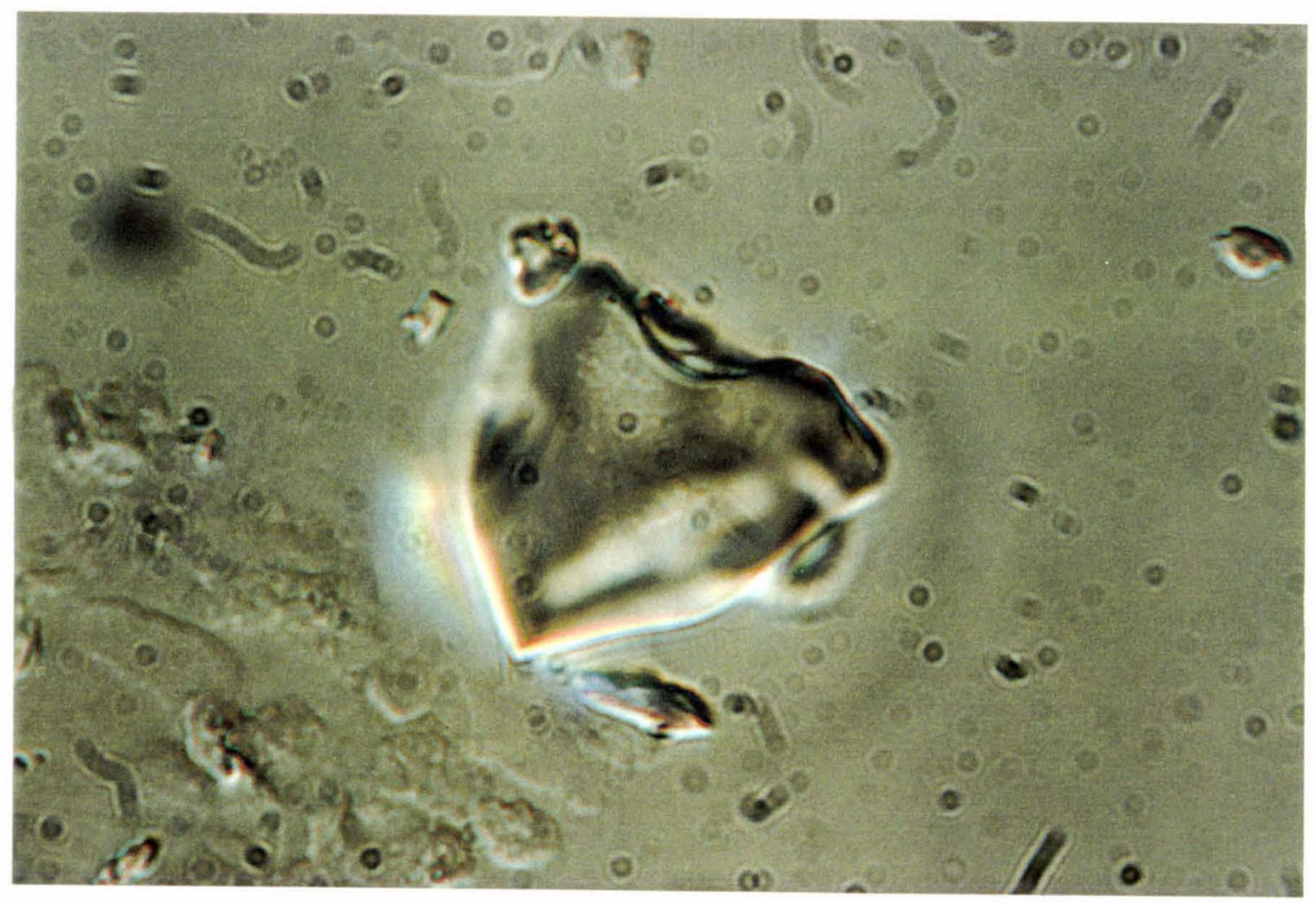

G. Grass phytolith of "arrow head" form classified into the shark tooth shape class for this study. Found in Mt. Feather Site One $0-2 \mathrm{~cm} .20 \mathrm{~mm}=10 \mu \mathrm{m}$.

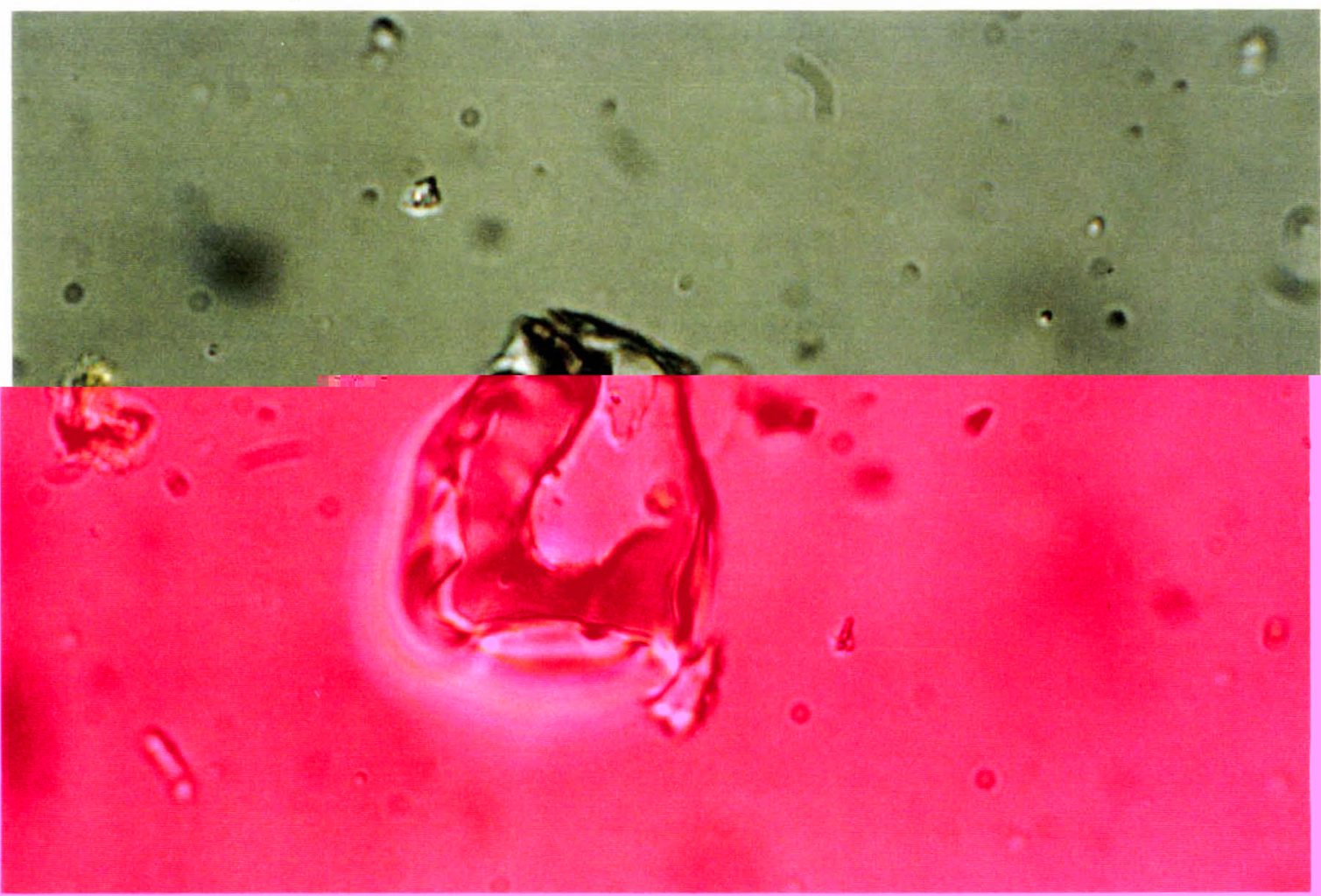

$\mathrm{H}$. Grass phytolith of the hole form class, from Mt. Feather Site One $27-37 \mathrm{~cm}$. $28 \mathrm{~mm}=10 \mu \mathrm{m}$. 


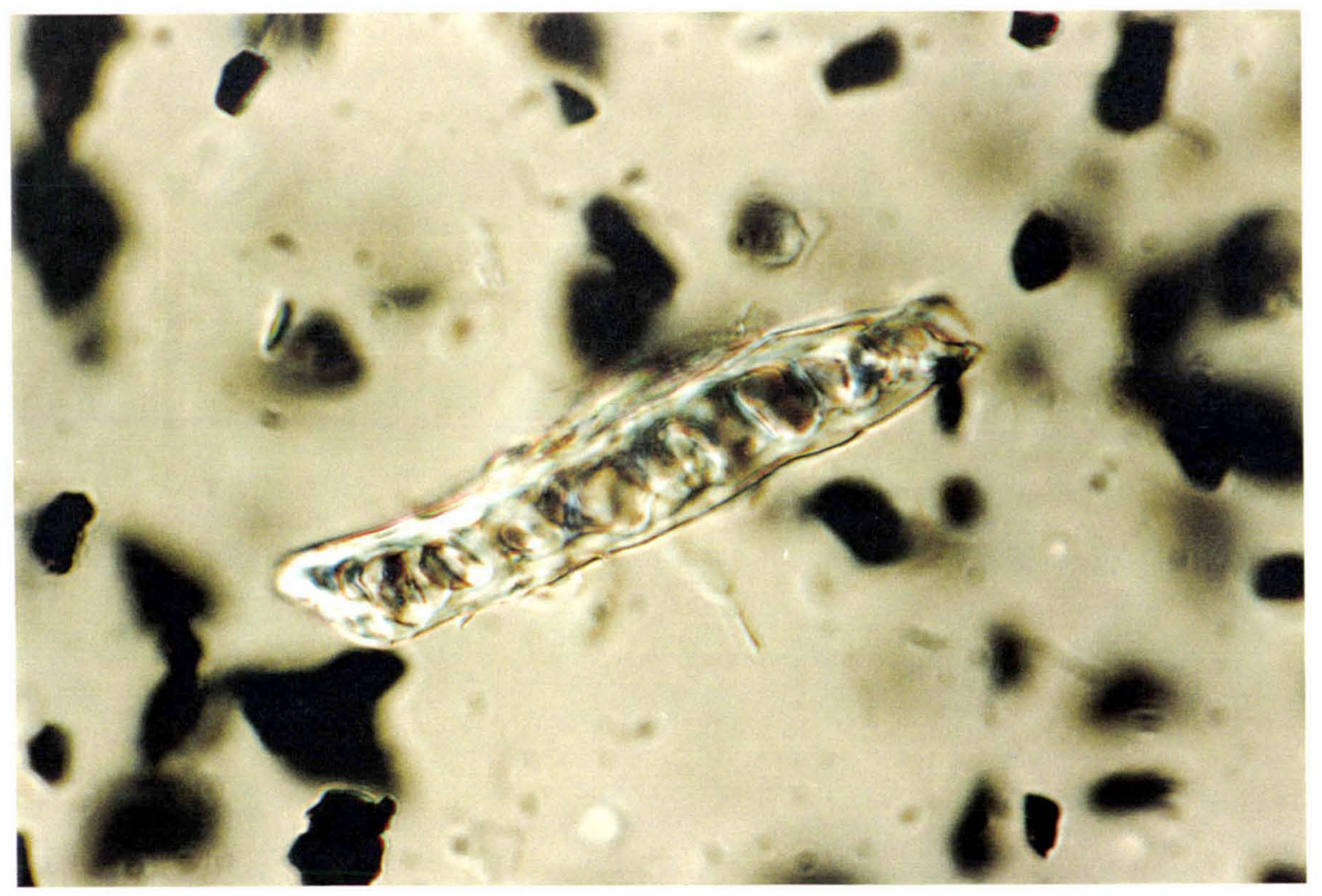

I. Pitted grass phytolith of the elongate class. From Mt. Feather Site One $2-7 \mathrm{~cm}$. $20 \mathrm{~mm}=10 \mu \mathrm{m}$.

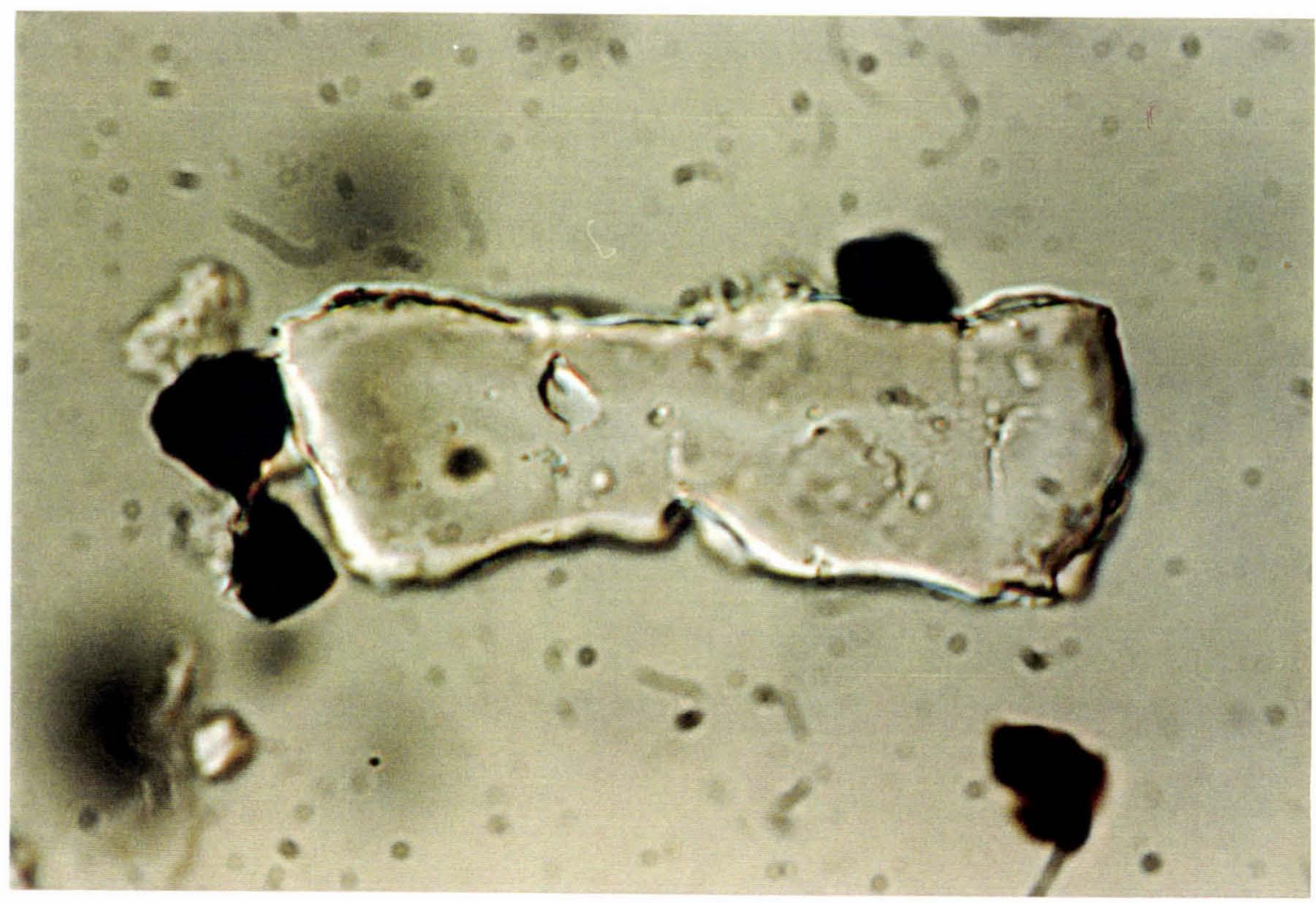

J. Weathered elongate grass phytolith, from Mt. Feather Site One $7-17 \mathrm{~cm}$. $20 \mathrm{~mm}=10 \mu \mathrm{m}$ 


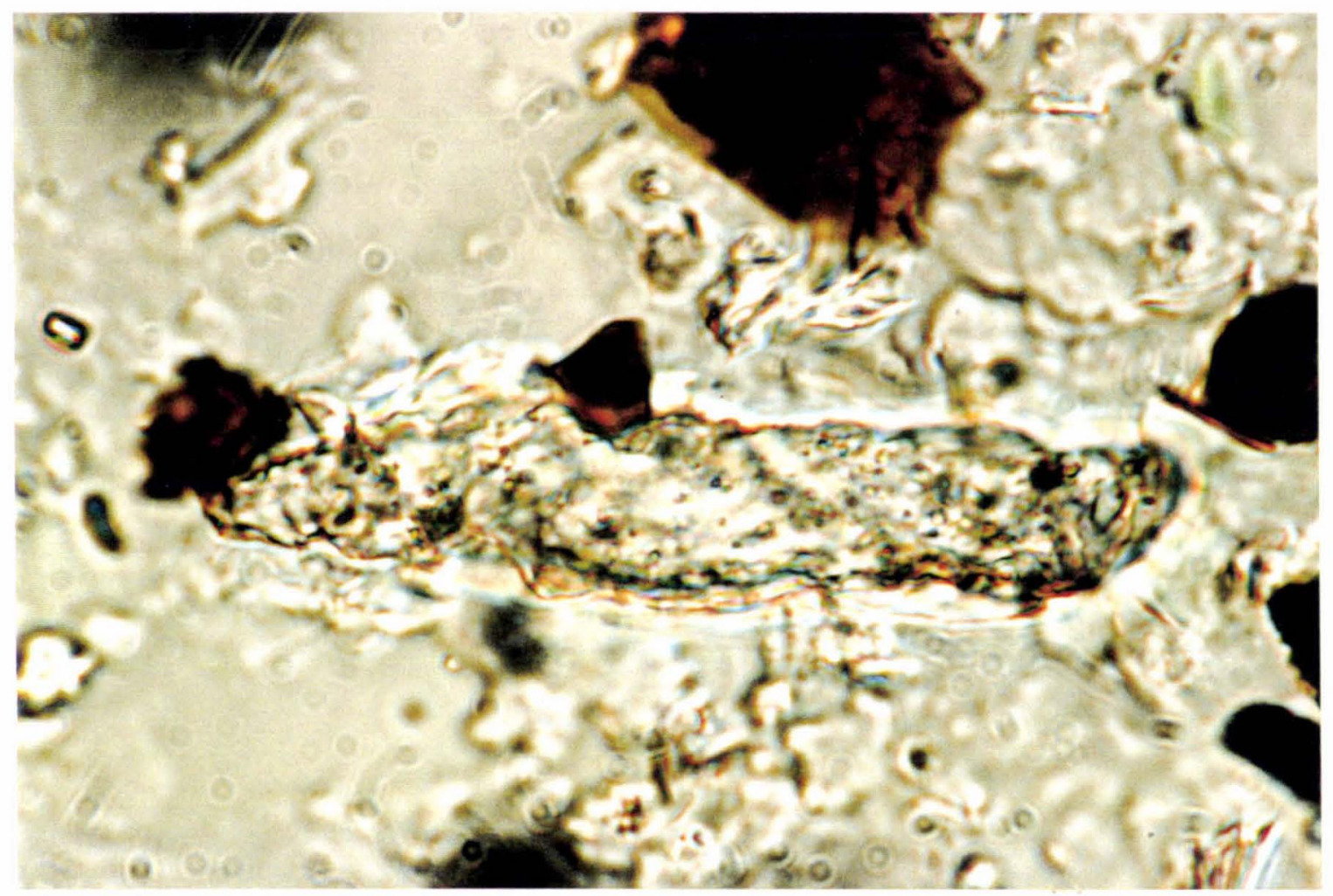

K. Textured elongate grass phytolith, from Mt. Feather Site One $0-2 \mathrm{~cm} .23 \mathrm{~mm}$ $=10 \mu \mathrm{m}$.

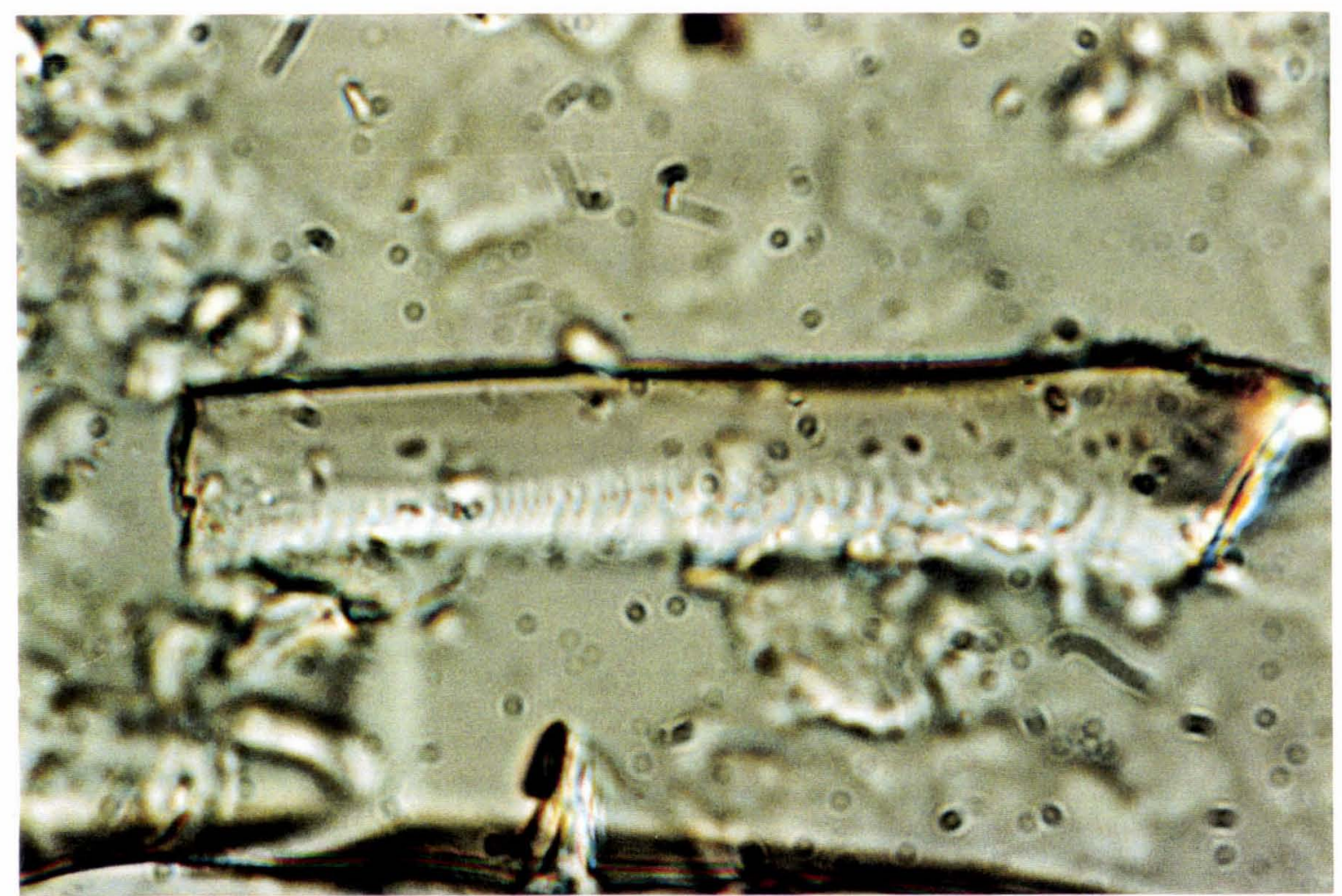

L. Elongate grass phytolith from Mt. Feather Site One $0-2 \mathrm{~cm} .12 \mathrm{~mm}=10 \mu \mathrm{m}$. 